\title{
Sequence stratigraphy, chronostratigraphy and zircon geochronology of the CIROS-1 drill core, Ross Sea, Antarctica: Implications for Cenozoic glacial and tectonic evolution
}

\author{
Evelien van de Ven
}

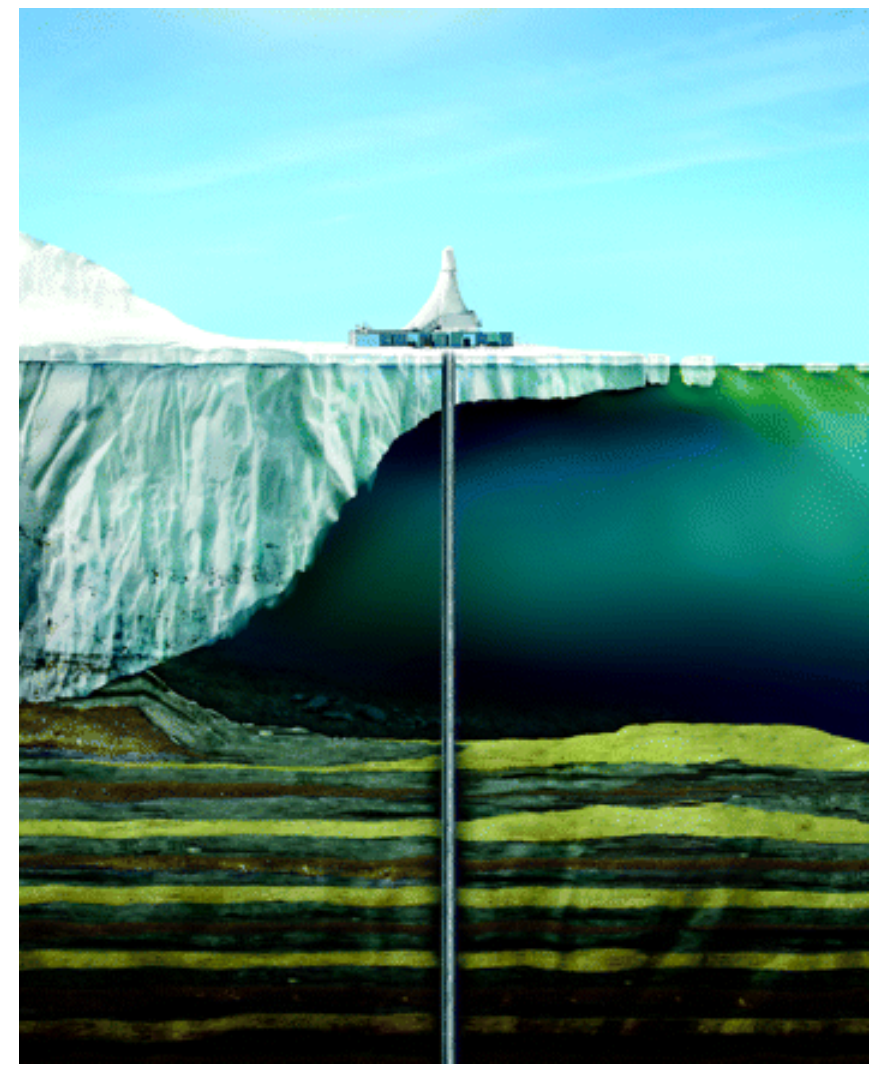

A thesis submitted to Victoria University of Wellington, in partial fulfilment of the requirements for the degree of Masters of Science in Geology

School of Geography, Environment and Earth Sciences

Victoria University of Wellington

November 2010 


\begin{abstract}
Antarctica plays a central role in the global climate system. Understanding the continent's past climate interactions is key to predicting its future response to, and influence on, global climate change. In recent decades, sediment cores drilled on the Antarctic continental margin have provided direct evidence of past climatic and tectonic events. Drilled in 1986 from sea ice in western McMurdo Sound, the pioneering 702 m-long CIROS-1 core extended back to the Late Eocene and provided some of the first evidence of the antiquity and history of the Antarctic ice sheets. The CIROS-1 drill core recovered a depositional history of the western margin of the Victoria Land Basin adjacent to the Trans-Antarctic Mountains. It was located directly offshore from where the Ferrar Glacier, which drains the East Antarctic Ice Sheet, discharges into the Ross Sea. Consequently CIROS-1 contains a record of both the glacial and tectonic Cenozoic evolution of the Antarctic margin.
\end{abstract}

This thesis provides a timely re-evaluation of the CIROS-1 core with new analysis techniques that enable further insights into the glacial and tectonic history of the western Ross Sea region, and includes three key objectives:

(1) Re-examine CIROS-1 sedimentology and stratigraphy and provide a new facies and sequence stratigraphic analysis using modern methods developed from recent drilling projects (e.g. CRP, ANDRILL).

(2) Develop a new integrated chronostratigraphic model through an assessment and compilation of previous studies, which provides a context for the interpretation of detrital zircon data, climate and tectonic history.

(3) Undertake a detailed examination of the provenance of CIROS-1 sediments using cutting edge in situ analysis techniques of detrital zircons $(\mathrm{U}-\mathrm{Pb}$ and trace element analysis using LA-ICP-MS).

Glaciomarine sequence stratigraphic analysis identifies 14 unconformity-bound sequences occurring in two distinctive stratigraphic motifs. The four sequences located beneath the $342 \mathrm{mbsf}$ unconformity contain relatively complete vertical facies succession. They were deposited in shallow marine, fluvio-deltaic conditions with distal glaciers terminating on land, and possibly calving into the ocean in adjacent valleys as evidenced by occasional ice-rafted debris. The ten sequences located above $\sim 342 \mathrm{mbsf}$ have a fundamentally different architecture. They are incomplete (top-truncated), contain subglacial and ice proximal facies grading upsequence into distal glaciomarine and shelf conditions. Top truncation of these sequences represents overriding of the CIROS-1 site by the paleo-Ferrar Glacier during glacial phases.

A revised age model for CIROS-1 is presented that utilises new calibrations for Antarctic diatom zones and compiles three previously published age models for different sections of the core (Roberts et al., 2003; Wilson et al., 1998; Hannah et al., 1997). The new age model allows correlation of Late Oligocene cycles with coeval cycles in CRP-2/2A, $80 \mathrm{~km}$ to the north. A fundamental orbital control on the dynamics of these East Antarctic Ice Sheet outlet glaciers is evident from this comparison. Both glacier systems respond in-phase to longer-period orbital components (e.g. eccentricity $100 \mathrm{kyr}$ and $400 \mathrm{kyr}$ ), but differ in their sensitivity to precession $(20 \mathrm{kyr})$. It appears that during the Late Oligocene the Ferrar catchment responded to $20 \mathrm{kyr}$ precession cycles, whilst the larger MacKay Glacier, which is more directly connected to the East Antarctic Ice Sheet, responded to longer duration $125 \mathrm{kyr}$ (eccentricity) forcing. 
CIROS-1 zircons group into four distinct geochemical suites. Zircons formed in felsic igneous environments dominate the CIROS-1 population, with $89 \%$ of zircons analysed showing geochemical characteristics inherent to granitic/rhyolitic zircons. Approximately $7 \%$ of CIROS-1 zircons have a highly trace element enriched igneous provenance and were most probably sourced from enriched enclaves in granitic/rhyolitic units or from pegmatites. Approximately $3 \%$ of CIROS-1 zircons show a metamorphic geochemical signature, and $\sim 1 \%$ formed in trace element depleted igneous environments. The zircons were sourced from the local basement (Koettlitz, Granite Harbour Groups), the Beacon Supergroup, and potentially, lithologies of the East Antarctic Craton located under the ice, or components of the Trans-Antarctic Mountains located under the current baseline of geologic exposure.

Large-scale, systematic temporal trends in zircon characteristics have been divided into three distinct climatic periods: Zone 1 (702-366 mbsf, Late Eocene), Zone 2 (366-250 mbsf, Late Oligocene) and Zone 3 (<250 mbsf, Late Oligocene and Early Miocene). Zircons deposited during these periods show unique properties. During Zone 1, Antarctica experienced a relatively warm temperate climate and alpine style glaciers flowed eastwards through the Trans-Antarctic Mountains. Zircons in this zone contain a subtle record of unroofing of geochemically zoned Granite Harbour and Koettlitz units located in the Ferrar Valley. During Zone 2 deposition, glaciers flowed though the Trans-Antarctic Mountains draining a large and ephemeral EAIS, which oscillated on orbital time scales. Zircons in this interval show variable properties, high numbers and were most probably deposited as the paleo-Ferrar Glacier deeply incised the Ferrar Fiord. In contrast, Zone 3 is characterised by a flux of McMurdo Volcanic Complex derived sediments, together with systematic changes in zircon characteristics. These patterns indicate a Late Oligocene shift in ice flow to the site (above $\sim 250 \mathrm{mbsf}$ ). Due to a cooling that culminated in the Mi-1 glaciation, ice flow to the site changed from an eastward to a northward flow, in response to an increased ice volume in the Ross embayment. 


\section{Acknowledgements}

First of all I would like to thank my supervisors Professors Tim Naish and Joel Baker, who have provided me with excellent guidance and a seemingly unending tap of expertise. Joel, thank you for being so patient when teaching me in the laboratory. Thank you for not blowing your top when the crystals turned out to be apatites. Tim, thank you for sharing with me your knowledge and enthusiasm for Antarctic science and for being so positive.

I would like to thank the institutions that have provided me with financial support, without which this endeavour would have been so much more challenging. This includes the Freemasons, the Dominion Post, ANDRILL, the Victoria University of Wellington Scholarships fund, the Taranaki Electricity Trust and the Antarctic Research Centre.

I would like to thank Chris Fielding for his contributions to the sedimentology and chronology of CIROS-1. I would like to thank Marc Alban-Millet for helping me in the laboratory and talking smack with me. I would like to thank Martin Schiller for being a very useful, if what sarcastic, lab mentor. I would like to thank Rob McKay, Alex Pyne, Peter Barrett, Mike Hannah and Warren Dickinson for giving me guidance and suggestions and always being open to helping me. I would like to thank Daniela Rubatto for helping me understand geochemical variations in zircons, Monica Handler for helping me see trends in data and Richard Wysoczanski for helping me in the initial stages of this thesis. Thank you Jim Connolly for helping me develop my dating methods. I would like to thank Tamsin Falconer and Michelle Dowe for being friendly faces and great go-to people. I would like to thank Shona De Sain for helping me and being supportive when I needed it most.

I would like thank my office buddies. Thank you Aidan Allan for helping and humouring me, Alexa Van Eaton, for being never endingly cheerful, Ian 'VOCWA' Schipper, for being fun and giving me a surf board and Netty Bolton or being so nice. Thank you Alex McKoy-West, Matt Stevens and Mellissa Rotella for sharing good times with me.

I would like to thank my friends, who have been an endless source of positivity and commiseration. Thank you Louise Odlin for being a great buddy. Thank you Anya Seward, Rosie Cody and Jess Johnson for all the brunches. Thank you Rachel Carne 
for being a good 'bestie', I miss you, you highflyer. Thanks to Jenny White for being on the outside but understanding and thanks Kim Owen for all your siftyness and going running with me. Thank you James Muirhead for giving me diagrams and funny rants. Thank you to Chelsea Tutt (from the Hutt) for being a great person to share late nights in the lab with. Thank you Andy Kolodododkjez for teaching me about the Red Socks and being my coffee date (go the Yankees!). Thanks to Katie Collins for editing and being a great co-tutor at Te Muna. Thanks Ramona for being such a funny and lovable lass. Thanks to Sophie Barton, Sarah Martin, Sarah Grain, Zara Rawlinson, Julia Bull, Dee Nimiss, Lloyd Pledger, Boot, Matt Ryan and the many others that have made my university experience great. Thank you to the person that invented coffee.

I would like to thank my family; my mom, Anita, my dad, Hans and my sister, Irene. Thanks mom and dad for being so generous with your time, love and money. You were always there for me and made sure I always had a home to go to and an ear to complain to. I will never forget and will always be grateful for the support you have given me. Thank you Irene for expertly filling the role of big sis and calming me down with your wisdom (and previous experience) whenever I was in a state. Too bad you smell like fish eggs.

Finally thank you to David Olson a.k.a the DEEES. You have been an exceptional boyfriend to me. You have been so patient and supportive to me when I needed it most and you have fine tuned cheering me up with your (strange) humour. I am very glad I met you. Here's to our thesis-free future. Whoop! 


\section{Table of Contents}

Abstract.....................................................................

Acknowledgements.......................................................

Table of Contents...........................................................vi

List of Figures.................................................................

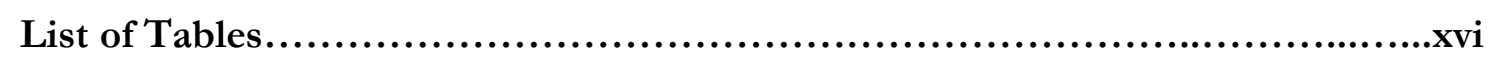

List of Equations.........................................................

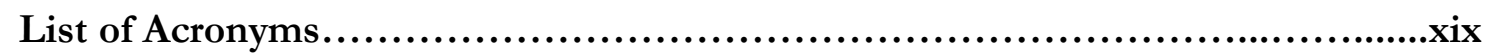

Chapter 1: Introduction..........................................................

1.1. Objectives of thesis...............................................4

1.2. Structure of thesis.................................................. 4

Chapter 2: Geological, glacial and climatic setting..............................6

2.1. Introduction. ..................................................6

2.2. Tectonic history of the West Antarctic Rift System and

the Trans-Antarctic Mountains..........................................

2.3. Geology of the Trans-Antarctic Mountains in South

Victoria Land..........................................................

2.4. Geology of the East Antarctic Craton.................................. 13

2.4.1. Geology of the Ross Sea sector of the East

Antarctic Craton.................................................13

2.5. Potential source units for CIROS-1 zircons.............................14

2.5.1. Descriptions of potential source lithologies for

CIROS-1 zircons................................................15

i. Direct sources.........................................15

ii. Recycled sources.........................................18

2.6. Climate and glacial influences on CIROS-1 deposition......................23

2.6.1. Cenozoic global ice volumes..............................23

2.6.2. Cenozoic Antarctic glaciology.............................27

2.7. Summary of conditions during CIROS-1 sedimentation....................30

Chapter 3: A re-evaluation of the Cenozoic record of East Antarctic glacial history from the CIROS-1 drill core: implications for Late Oligocene ice volume change.......................................................... 33 
3.1. Introduction. . .33

3.2. Geological and glaciological setting............................... 35

3.3. Previous stratigraphic and facies descriptions.........................37

3.4. Revised lithofacies analysis for the CIROS-1 core........................39

3.5. Sequence stratigraphy of sediments deposited on an open, wave-dominated glaciated continental margin..........................................44

3.6. New sequences stratigraphic analysis for the CIROS-1 core.................46

3.7. Previous chronostratigraphy for the CIROS-1 core $\ldots \ldots \ldots \ldots \ldots \ldots \ldots \ldots . \ldots 49$

3.8. Revised chronology for the CIROS-1 core............................53

3.9. Implications for Late Oligocene ice volume change and the Mi-1

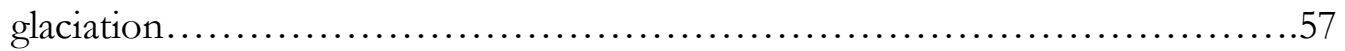

3.10. Conclusions..................................................61

Chapter 4: Zircons as indicators of sediment provenance.....................63

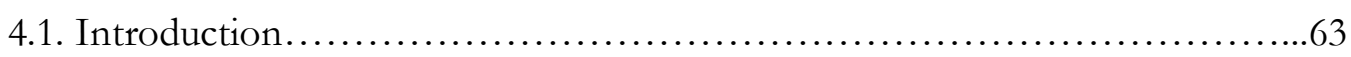

4.2. Properties of zircons.............................................63

4.3. Zircon formation environments.................................65

4.4. Trace elements and $\mathrm{U}-\mathrm{Pb}$ analytical methods........................66

4.5. Detrital zircon ages and their use for provenance analysis................67

4.5.1. Radiometric U-Th-Pb dating of zircons.......................67

i. Discordant vs. concordant zircons.............................68

4.5.2. Sediment provenance analysis using zircon ages..................69

4.6. Trace element constraints on zircon provenance.........................71

4.6.1. Rare Earth Elements in zircons..............................71

i. REE incorporation into zircons...............................71

ii. Total REE concentrations in zircons......................... 71

iii. Chondrite-normalised REE patterns.......................... 72

4.6.2. The Ti-in-zircon geothermometer.............................80

4.6.3. $\mathrm{Li}$ concentrations and zircon provenance.......................80

4.6.4. $\mathrm{Zr} / \mathrm{Hf}$ and Hf concentrations............................... 81

4.6.5. $\mathrm{U}$ and $\mathrm{Th}$ concentrations and the $\mathrm{Th} / \mathrm{U}$ ratio....................82

4.6.6. Resolution of felsic and mafic zircons using

elemental ratios................................................ 83

4.7. Internal zonation of trace elements: insights into zircon provenance..........84

4.7.1. Analysis of internal chemical zonation........................ 85

4.7.2. Igneous zircon cathodoluminescence characteristics...............85 


\section{Chapter 5: Geochemical analytical techniques, data reduction}

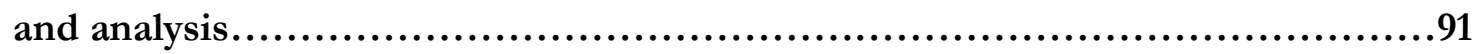

5.1. Introduction....................................................

5.2. Sample acquisition................................................ 91

5.3. Sample preparation................................................ 92

5.4. Sample imaging.................................................... 94

5.5. Geochemical analysis of zircon crystals..............................95

5.5.1. U-Pb geochronology using LA-ICP-MS......................96

i. Samples analysed for detrital fircon U-Pb ages.....................96

ii. Operational parameters...................................96

iii. Data reduction...............................................99

iv. Data analysis: Concordia plots and discordant zircons................101

v. Data analysis: Age probability diagrams........................102

vi. Data analysis: $U$ and $T h$ concentrations.......................102

vii. Validation of results.....................................103

5.5.2. Trace element analysis by LA-ICP-MS .......................105

i. Samples analysed for trace element content.......................105

ii. Operational parameters..................................105

iii. Data reduction ...........................................108

iv. Data presentation: Chondrite-normalised Rare Earth Element

diagrams.............................................. 108

v. Data analysis: Ti-in-zircon geothermometer.......................109

vi. Data analysis: Elemental concentrations and rations.................109

\section{Chapter 6: Geochemistry and geochronology of detrital zircons in the}

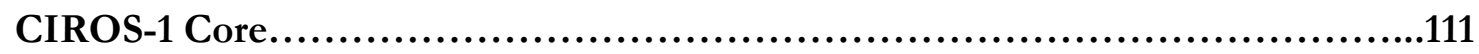

6.1. Introduction..................................................111

6.2. Results......................................................111

6.2.1. Zircon numbers and $\mathrm{U}-\mathrm{Pb}$ and $\mathrm{Pb}-\mathrm{Pb}$ ages....................111

6.2.2. Late Proterozoic-Early Palaeozoic (450-650 Ma) 'Ross'

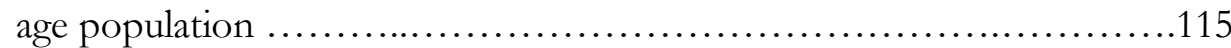

6.2.3. CIROS-1 cumulative age probability diagram..................116

6.2.4. Trace element chemistry of CIROS-1 zircons...................117 
i. Potential provenance of Group 1 irircons..........................118

ii. Potential provenance of Group 2 gircons.........................119

iii. Potential provenance of Group 3 gircons ......................120

iv. Potential provenance of Group 4 zircons........................123

6.2.5. Possible provenance of CIROS-1 zircon age populations..........124

6.3. Discussion.................................................... 127

6.3.1. Implication of age peaks in the cumulative age

probability diagram..........................................

6.3.2. Possible source units for CIROS-1 zircons.....................129

i. Summary of CIROS-1 detrital zircon provenance...................133

6.3.3. Temporal trends in zircon characteristics.......................134

i. Sub-250 mbsf section (Zones 1 and 2).......................138

ii. Above 250 mbsf (Zone 3)...............................138

6.4. Conclusions....................................................144

Chapter 7: Synthesis and suggestions for future work.........................146

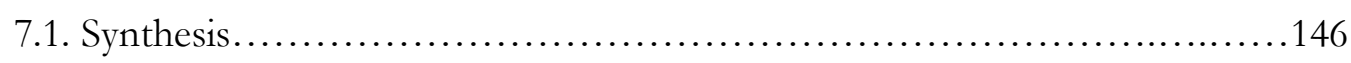

7.2. Suggestions for future work.....................................149

References..................................................................

Appendix 1: Sedimentological sample descriptions

Appendix 2: U-Pb data

Appendix 3: Trace element data

Appendix 4: Cathodoluminescence images 


\section{List of Figures}

\section{Frontispiece}

Courtesy of Angie Fox, Scientific Illustrator at the University of Nebraska State Museum.

\section{Chapter 1}

Figure 1.1: Benthic global temperature curve showing key climate events of the

Cenozoic. . .1

Figure 1.2: Tectonic setting of the Ross Sea and location of CIROS-1 ....................

\section{Chapter 2}

Figure 2.1: Cross-section of the Victoria Land Basin and Trans-Antarctic Mountains in

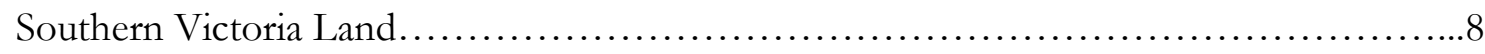

Figure 2.2: Geological map of Southern Victoria Land.............................10

Figure 2.3: Cross-section and time line of formation of units located in the Trans-Antarctic Mountains in South Victoria Land.............................................. 12

Figure 2.4: Cumulative zircon age probability diagram for modern sediments sourced from the Byrd Glacier and Ross Sea.............................................. 14

Figure 2.5: Trans-Antarctic Mountain and East Antarctic Craton geological map showing Last Glacial Maximum reconstructed ice flow lines.................................17

Figure 2.6: Zircon age probability diagrams for the Taylor Group at Sperm Bluff.

Figure 2.7: Zircon age probability diagrams for the Victoria Group in Queen Maud Land. .20

Figure 2.8: Zircon age probability diagrams for the Beardmore Group inboard assemblage..... 
Figure 2.9: Zircon age probability diagrams for the Beardmore Group outboard assemblage

Figure 2.10: The Cenozoic deep-sea benthic oxygen isotope record

Figure 2.11: Global temperature curve showing key climate events of the

Cenozoic.

Figure 2.12: Map of the McMurdo Sound showing the locations of sediment cores drilled in and near the Victoria Land Basin.

Figure 2.13: Glacial conditions in Victoria Land from the Mid-Oligocene to Early Miocene.

\section{Chapter 3}

Figure 3.1: Key geographical and structural features of the Victoria Land Basin .35

Figure 3.2: Cross-sectional view of the tectonic setting of the Victoria Land Basin .36

Figure 3.3: Glacial conditions of the Victoria Land coast from the Mid-Oligocene to Early Miocene. .36

Figure 3.4: Revised lithologic log for the CIROS-1 drill core.

Figure 3.5: Sequence stratigraphical model for glaciomarine deposition on a wave dominated coastline.

Figure 3.6: Typical glaciomarine sequence stratigraphic architecture 46

Figure 3.7: Composite sequence stratigraphic interpretation of CIROS-1 .48

Figure 3.8: Previous chronostratigraphic schemes for the CIROS-1 core... .51

Figure 3.9: An integrated chronological framework for CIROS-1 .55

Figure 3.10: Correlation of Late Oligocene sequences in the CIROS-1 core and 
age-equivalent sediments in CRP-2/2A to the astronomically-tuned benthic $\delta^{18} \mathrm{O}$ record....

\section{Chapter 4}

Figure 4.1: A zircon crystal under plain and cross-polarised light....

Figure 4.2: A U-Pb concordia diagram....

Figure 4.3: An example of age probability diagrams used in sediment provenance investigations...

Figure 4.4: Chondrite-normalised REE profiles for rare 'primary' mantle affinity zircons

Figure 4.5: Chondrite-normalised REE profiles for xenolithic mantle affinity zircons

Figure 4.6: Typical REE profiles for igneous zircons formed in the crust.... .75

Figure 4.7: REE profiles for high pressure metamorphic zircons. . .76

Figure 4.8: REE profiles of zircons with high pressure metamorphic rims and igneous cores.

Figure 4.9: Chondrite-normalised REE profiles for completely re-crystallised, low grade metamorphic zircons.

Figure 4.10: Chondrite-normalised REE profiles obtained from hydrothermal zircons

Figure 4.11: Elemental bivariate used to distinguish between zircons formed in the crust.

Figure 4.12: Oscillatory CL zoning in a granitic zircon showing local resorption.... .86

Figure 4.13: CL image of an igneous zircon displaying sector zoning. .86 
Figure 4.14: CL image of a kimberlitic zircon showing characteristic broad and weak oscillatory zoning

Figure 4.15: CL images of igneous zircons with xenocrystic cores.

Figure 4.16: CL image of high grade metamorphic zircons with xenocrystic cores....

Figure 4.17: CL image of metamorphic zircons showing irregular concentric zoning 88

Figure 4.18: CL image of a metamorphic zircon with homogenous trace element zones.

Figure 4.19: CL image displaying convoluted trace element zoning characteristic of hydrothermal zircon growth

Figure 4.20: CL image of a hydrothermal zircon with a patchy, trace element enriched texture.

Figure 4.21: BSE image of a hydrothermal zircon with a spongy, inclusion rich texture. .90

\section{Chapter 5}

Figure 5.1: CIROS-1 core log, sampling locations and sample names

Figure 5.2: Binocular microscope image of picked zircons prior to amount being made.

Figure 5.3: Binocular microscope image of a polished mount. .94

Figure 5.4: BSE image of CIROS-1 zircons .95

Figure 5.5: CL image of a CIROS-1 zircon. 95

Figure 5.6: Example of a U-Pb concordia diagram.... 101 
Figure 5.7: Example of an age probability diagram

Figure 5.8: Age probability diagram for initial 292-12 analysis .104

Figure 5.9: Age probability diagram for repeat 292-12 analysis

Figure 5.10: Chondrite-normalised REE profile for a group of CIROS-1

zircons 109

\section{Chapter 6}

Figure 6.1: Total zircon number, percentage of 450-650 Ma 'Ross' aged zircons and the occurrence of Devonian aged zircons per sample

Figure 6.2: Diagram showing zircon number and the amount of age populations in each sample 113

Figure 6.3: Age probability diagrams for each analysed sample.

Figure 6.4: Per sample average, minimum and maximum ages of zircons in the 450-650 Ma 'Ross' age population.

Figure 6.5: Cumulative age probability diagram for CIROS-1 zircons.

Figure 6.6: CL image showing the oscillatory zoning inherent to many Group 1 zircons.

Figure 6.7: CL images of Group 2 zircons.

Figure 6.8: Representative REE profile for Group 1 zircons.... 121

Figure 6.9: REE profile for Group 2 zircons.....

Figure 6.10: Representative REE profiles for Group 3 zircons.

Figure 6.11: REE profiles for zircons from Group 4.

Figure 6.12: Examples of CL zonation in Group 3 zircons. 
Figure 6.13: CL images of the two Group 4 zircons....

Figure 6.14: Age distribution of zircons sourced from orogenic granitoids and sedimentary samples from a range of globally-distributed locations

Figure 6.15: Cumulative age probability diagram for CIROS-1 zircons and the timing of orogenic episodes known to have occurred on the East Antarctic Craton.... .128

Figure 6.16: Age probability diagrams obtained from the Victoria Group in Marie Byrd Land. ...

Figure 6.17: Age probability diagrams for the Taylor Group at Sperm Bluff. 130

Figure 6.18: Average, minimum and maximum ages of zircons in the 'Ross' age population plotted against sample depositional age

Figure 6.19: Percentage (of total) 'Ross' aged zircons present in each sample plotted against depositional age of CIROS-1 strata...

Figure 6.20: The geology of the Ferrar Fiord and Taylor Glacier region with emphasis on Granite Harbour plutons.

Figure 6.21: Time scale of Granite Harbour intrusive emplacement 137

Figure 6.22: Ice flow lines for the western Ross Sea from $\sim 34 \mathrm{Ma}$ to present.... 140

Figure 6.23: Summary of the conditions present during CIROS-1 sedimentation. 


\section{List of Tables}

\section{Chapter 3}

Table 3.1: Lithofacies scheme developed for CIROS-1 core.

.40

Table 3.2: Chronostratigraphic datums used to construct the revised CIROS-1 age model. .56

Table 3.3: Magnetostratigraphical and chemical chronological datums used to construct the revised CIROS-1 age model.

\section{Chapter 4}

Table 4.1: Major and minor element chemistry of three zircon suites....

Table 4.2: Physical and optical characteristics of zircon. .64

Table 4.3: Tools for geochemical analysis of zircons. .67

\section{Chapter 5}

Table 5.1: Sample names, depositional ages and source units. .91

Table 5.2: Average ratios, 2 se errors and apparent ages for the 263 S-97-19 zircons analysed during this thesis.

.96

Table 5.3: Isotopes analysed (and their dwell times) during LA-ICP-MS U-Pb isotopic analysis of CIROS-1 zircons....

Table 5.4: Reference values for the U and Pb compositions of NIST 610 glass.

Table 5.5: Elements in zircon detectable above background by LA-ICP-MS

analysis .106

Table 5.6: Isotopes measured (and their dwell times) during LA-ICP-MS trace element analysis of CIROS-1 zircons. 


\section{Chapter 6}

Table 6.1: Zircon data per sample....

Table 6.2: Trace element compositions and ratios of the four geochemical populations identified in CIROS-1 zircons by LA-ICP-MS ....................................122

Table 6.3: Zircon provenance groups within each age peak on the cumulative age probability diagram 


\section{List of Equations}

\section{Chapter 4}

Equation 4.1: The Ti-in-zircon geothermometer................................. 80

\section{Chapter 5}

Equation 5.1: Standard error calculations to a two $\sigma$ level.............................100

Equation 5.2: The Ti-in-zircon geothermometer................................110 


\section{List of Acronyms}

ANDRILL Antarctic Geologic Drilling

BSE Back scattered electron

CIROS Cenozoic Investigations in western Ross Sea

CL Cathodoluminescence

CRP Cape Roberts Project

DSDP Deep Sea Drilling Project

DVDP Dry Valleys Drilling Project

EAC East Antarctic Craton

EAIS East Antarctic Ice Sheet

EAS East Antarctic Shield

EPMA Electron Probe Microanalyser

HREE Heavy Rare Earth Elements

KES Kukri Erosion Surface

LA-ICP-MS Laser Ablation-Inductively Coupled Plasma-Mass Spectrometry

LGM Last Glacial Maximum

LREE Light Rare Earth Elements

MREE Medium Rare Earth Elements

MSSTS McMurdo Sound Sediment and Tectonic Studies

MVG McMurdo Volcanic Group

OPD Ocean Drilling Project

REE Rare Earth Element

SVL Southern Victoria Land

TAM Trans-Antarctic Mountains

VLB Victoria Land Basin

WAIS West Antarctic Ice Sheet

WARS West Antarctic Rift System 


\section{Chapter 1: Introduction}

Since. the climatic optimum in the Eocene the Earth's climate has experienced regular orbitally-paced glacial-interglacial fluctuations around a progressively cooling mean temperature (Zachos et al., 2001a). Superimposed onto this, large and abrupt shifts to a cooler climate have occurred during the Eocene-Oligocene boundary ( 34 Ma; Kennett et al., 1975; DeConto and Pollard, 2003), the Oligocene-Miocene boundary ( 23 Ma; Naish et al., 2001a; Pekar et al., 2006) and the Middle-Late Miocene climate transition ( 13.8 Ma; Lewis et al., 2007) (Fig. 1.1). The marine oxygen isotope record from the deep ocean (Zachos et al., 2001a) arguably provides the most detailed and complete picture of the global cooling of Earth's climate during the Cenozoic and has allowed insights into past global ocean temperatures, ice volumes and sea water salinity.

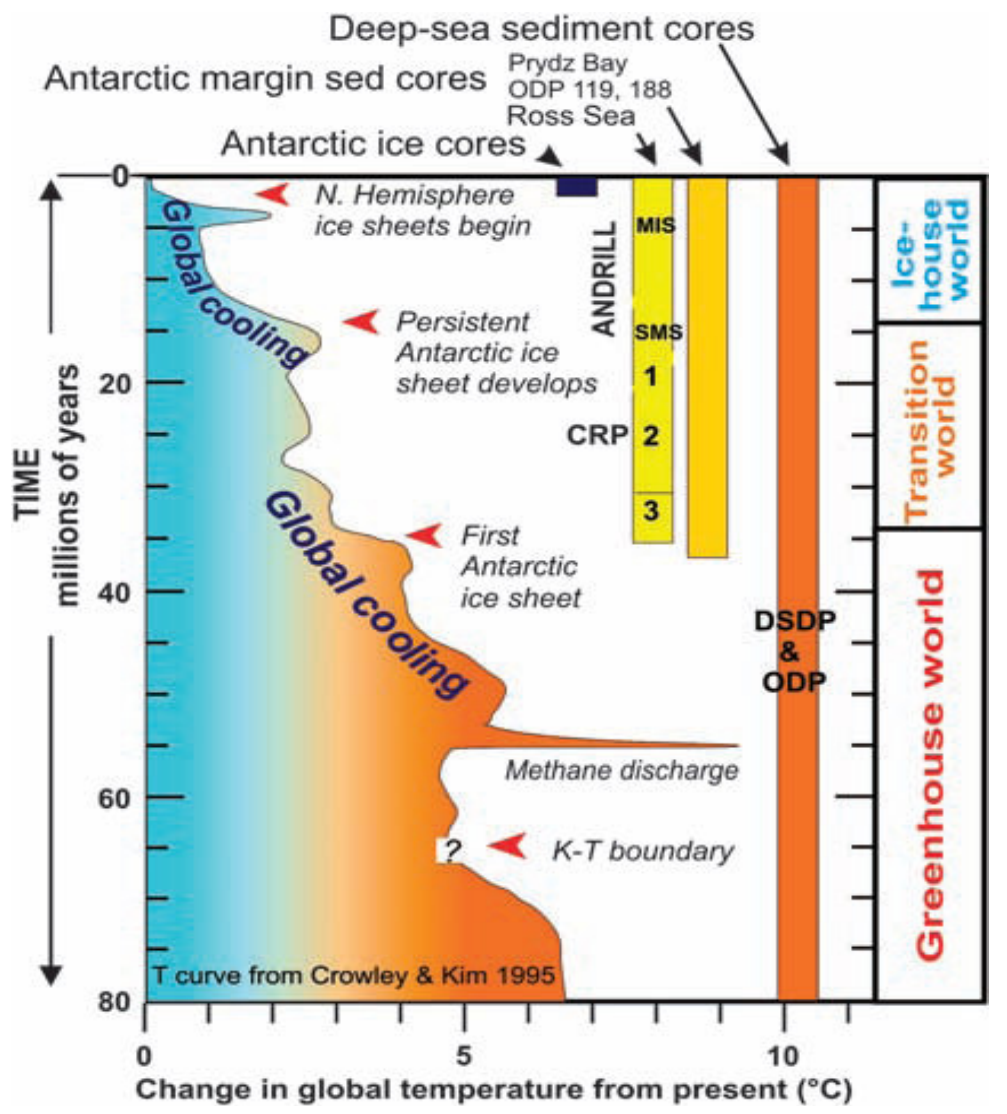

Figure 1.1: Global temperature curve constructed from the composite $\mathrm{CO}_{2}$ isotopic ratios of benthic foraminifera in deep ocean sediments. Key climate events of the Cenozoic are annotated (source: Barrett, 2009).

It is known that Antarctica has played a pivotal role in the global climate system since the Cenozoic. The continent influences the Earth's albedo and ocean circulation and the Antarctic cryosphere contains enough water to raise global sea 
levels by $\sim 65 \mathrm{~m}$ (IPCC, 2007). Nonetheless, there are still many questions regarding Antarctica's response to Cenozoic cooling (due to the continents remoteness and ice cover) and how the continents cryosphere may respond to the projected global warming from anthropogenic increases in atmospheric greenhouse gasses (IPPC, 2007; Naish et al., 2008a). In order to predict the future behaviour of the Antarctic cryosphere, it is first necessary to understand its past response to climate forcings.

A record of Antarctic's geological, tectonic, glaciological and climate past has been constructed in recent decades using a variety of ingenious sampling and modelling methods, possible despite the continent's extensive ice cover and isolation. These include integrated seismic and drill core basin analysis (e.g. Fielding et al., 2008) and analysis of the on-land geology (e.g. Siddoway and Fanning, 2009; Elliot and Fanning, 2008). Drilling continental shelf sediments eroded from the interior of the continent and deposited into sedimentary basins on the periphery provides direct evidence for the tectonic, climate and glaciological conditions present during sediment erosion and deposition.

The Victoria Land Basin (VLB) in the Ross Sea has been a hub of sediment drilling in the Antarctic over the last three decades. The basin is located adjacent to the Trans-Antarctic Mountains (TAM) in the West Antarctic Rift System (WARS) (Fig. 1.2) and has been the focus of extension in the WARS since the Late Eocene (or perhaps Cretaceous) (Fielding et al., 2008). The basin has accommodated an up to 10 $\mathrm{km}$ thickness of sediment supplied from the TAM and deposited by a variety of fluvial, glacial, volcanic and marine processes.

The McMurdo Sound area of the VLB (Fig. 1.2) has been the prime target for Antarctic sediment drilling over the last three decades for the following reasons (1) The high subsidence rates and high sediment accumulation rates means that, in this locality, the basin contains a fairly complete record of Antarctic climate and tectonism since the Late Eocene; (2) The location is proximal to pre-established bases and the McMurdo Station logistics hub; and (3) The region has the best understood sedimentary Cenozoic climate record in Antarctica (summarised in Barrett, 2009). Early sediment drilling in the VLB included the MSSTS-1 (late 1970's) and CIROS (1984 and 1986) projects (Barrett, 2009). Later, more advanced projects include the three-coring season Cape Roberts Project and, most recently, the two drill holes of the ANDRILL Project (Fig. 1.2). 


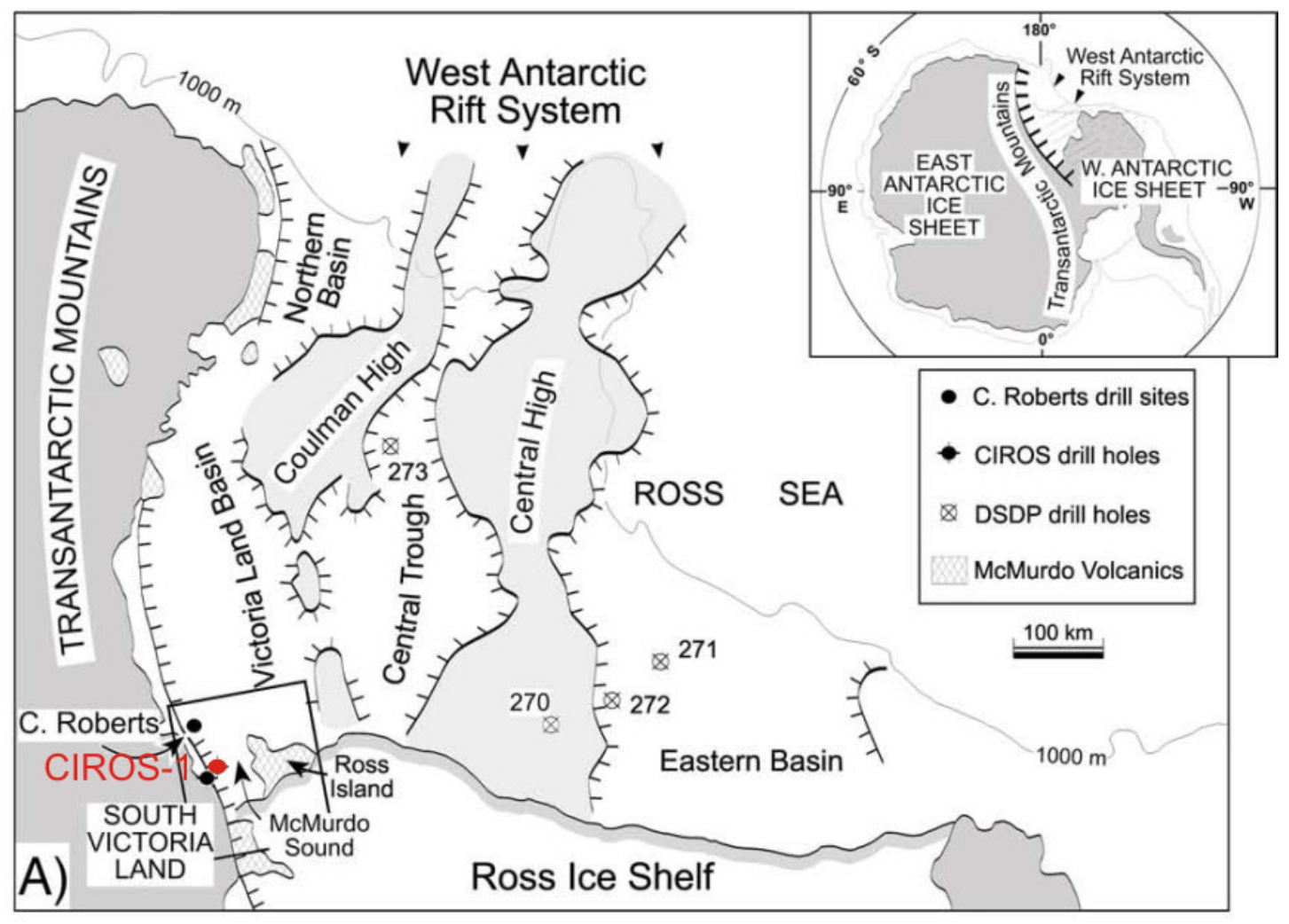

Figure 1.2: Inset: A simplified overview of the tectonic and glacial components of Antarctica. Main picture: The tectonic configuration of the WARS in the Ross Sea embayment. The VLB is located in this basin adjacent to the TAM. The location of CIROS-1 is shown in red (modified from Fielding et al., 2008).

There is a large cost associated with obtaining new drill cores from the Antarctic periphery. This high cost, the value and relative paucity of direct evidence for Antarctica's past behaviour and recent advances in our ability to construct glaciological and tectonic histories from Antarctic sediments cores (e.g. Fielding et al., 2008; Dunbar et al., 2008) make it timely and beneficial to re-evaluate the early records obtained using modern techniques.

The CIROS-1 drill core was drilled into the VLB (Fig. 1.2) to a depth of $702 \mathrm{mbsf}$ (Hambrey et al., 1989) and contains sediments of Late Eocene to Early Miocene age deposited as part of a glaciomarine deltaic complex fed from the Ferrar Valley (Barrett, 1989). The core contains a record of the Antarctic response to global climate events (e.g. the initiation of Antarctic glaciation and the Mi-1 glaciation) (Fig. 1.1) as well as a record of regionally-important tectonic events, such as the uplift of the TAM.

\subsection{Objectives of this thesis}


The objectives of this thesis are to re-evaluate the record of Antarctic climate and tectonism contained in the CIROS-1 core (Fig. 1.2). By analysing the core using modern techniques, fresh insights into the record contained in these sediments will be obtained.

More specifically, the two aims of this thesis are:

(1) Re-evaluate the sedimentology, lithofacies, sequence stratigraphy and chronology of CIROS-1 sediments using sediment analysis methods developed for the recent Antarctic drill cores (i.e. CRP and ANDRILL, e.g. Fielding et al., 2001; Dunbar et al., 2008; Naish et al., 2001b).

(2) Re-evaluate CIROS-1 sediment provenance (and any temporal variations therein) using modern in situ laser ablation inductively coupled (LA-ICP-MS) U-Pb and trace analysis of detrital zircons found in CIROS-1 sands. Such methods include those utilised and described by Chang et al. (2006); Kŏsler and Sylvester, (2003); and Veevers et al. (2008).

\subsection{Structure of this thesis}

This thesis comprises seven chapters and four appendices. The contents of these are as follows.

Chapter 2 describes the tectonic, climatic and glaciological history of the Antarctic continent with an emphasis on the depositional setting of CIROS-1 strata. This includes an overview of the zircon characteristics of known potential source units for CIROS-1 zircons.

Chapter 3 is a stand-alone paper that presents a revised sedimentology, lithofacies model, sequence stratigraphy and chronology for the CIROS-1 core. This paper is co-authored by Tim Naish, Chris Fielding and Mike Hannah and will be submitted to the journal Sedimentary Geology. Included in this paper are:

(1) A new stratigraphy of the CIROS-1 drill core, logged using the well-preserved, archived half of the core;

(2) A re-evaluated lithofacies scheme for the core, based on lithofacies models developed for CRP (Fielding et al., 1997; Fielding et al., 2001);

(3) A new composite sequence stratigraphic interpretation of CIROS-1 sediments based on recently developed sequence stratigraphic models for glaciomarine sedimentation on a wave-dominated coastline (Dunbar et al., 2008); and 
(4) A new chronology for CIROS-1 sedimentation constructed by splicing of historical data (e.g. Roberts et al., 2003; Wilson et al., 1998) and newly developed chronologies.

Chapter 4 is a review of the use of zircons as an indicator of sediment provenance and an overview of the methods used in this thesis.

In Chapter 5, the geochronological and geochemical analytical techniques and data reduction methods used to obtain CIROS-1 zircon U-Pb and trace element characteristics by LA-ICP-MS are outlined. This includes an outline of samples analysed, a review of the operational parameters used during analysis and an overview of the detrital zircon-based tools used for CIROS-1 sediment provenance analysis.

Chapter 6 outlines the results of the dating and geochemical analyses of CIROS-1 zircons conducted in this project and a discussion of the implications of these results. This includes an overview of the provenance of CIROS-1 zircons and a discussion of the temporal trends observed down-core. The implications of these results for the Cenozoic evolution of the East Antarctic Ice Sheet and older tectonic evolution of the Antarctic Craton are outlined.

Appendix 1 presents detailed sedimentological descriptions for each of the 18 samples analysed. Appendix 2 contains the U-Pb isotopic data and the calculated ages for all analysed zircons. Appendix 3 contains the trace element data of the three samples analysed for zircon trace element composition. Appendix 4 contains CL images for all CIROS-1 zircons analysed (Appendix 4 is located in a CD disc at the back of the thesis). 


\section{Chapter 2: Geological, glacial and climatic setting}

\subsection{Introduction}

Antarctica is a particularly challenging continent for which to construct a tectonic and geologic history due to its extensive ice-cover, cold climate and isolation. However, a tectonic and geologic record has been constructed using various sampling and modelling methods which include integrated seismic and drill core basin analysis (e.g. Fielding et al., 2008; Fielding et al., 2006) and both direct (e.g. Siddoway and Fanning, 2009; Elliot and Fanning, 2008) and indirect sediment sampling. Sampling of sediments eroded from the interior of the continent and deposited on the periphery provides direct evidence for the tectonic and glacial conditions present during their deposition. This method provides the basis for this study and has been the focus of much research in the Ross Sea and other peripheral locations around the Antarctic continent (e.g. Harwood et al., 2008; Veevers et al., 2008).

The sedimentary strata that comprise the CIROS-1 drill core are part of a glaciomarine deltaic complex fed from the Ferrar Valley (Barrett, 1989). From the Late Eocene-Early Miocene ( 38-21 Ma) these sediments were eroded from strata located in SVL (and potentially the EAC) and deposited into the VLB (Fig. 2.1). Sedimentation and deposition of detrital zircons at this site is influenced by three main factors; the geographical location of potential zircon source lithologies, tectonism during sediment deposition (e.g. exhumation of source lithologies and formation of accommodation space), and the climate and glacial dynamics during sediment deposition (e.g. erosional, depositional and sorting mechanisms). On the basis of these three factors, the present understanding of these depositional controls within the western Ross Sea are reviewed in this section, in order to provide a framework for CIROS-1 sedimentation dynamics discussed in later chapters. 


\subsection{Tectonic history of the West Antarctic Rift System and Trans- Antarctic Mountains}

The Ross Sea is located above the WARS. The Sea is bounded by the TAM and the EAC in the west and the rocks of West Antarctica in the east (Fig. 1.2).The WARS and the TAM are the dominant tectonic features of the Ross Sea. The WARS separates East and West Antarctica (Fig. 1.2) and extends below the Ross Sea, the Ross Ice Shelf and part of the WAIS (Fitzgerald, 2002). The rift system formed in response to initial rifting between East and West Antarctica during the breakup of Gondwana and has had a complex history (Winberry and Anandakrishnan, 2004), with the main phase of extension and crustal thinning occurred in the late Cretaceous (105-85 Ma).

The system comprises a series of asymmetric basement grabens, separated by basement highs. CIROS-1 sediments were deposited into one such graben; the VLB. The VLB has been the focus of WARS extension since the Late Eocene or perhaps even Cretaceous, when rapid subsidence occurred due to crustal thinning and extension (Fitzgerald, 2002; Barrett, 2009). Slower rates of subsidence of the VLB occurred in the Miocene, when thermally controlled subsidence became the main driving mechanism, a process that has continued to present day (Fielding et al., 2008). The VLB is $\sim 350 \mathrm{~km}$ long and has accumulated sediment thickness of up to $10 \mathrm{~km}$.

The TAM are located at the western edge of the WARS (and VLB) (Figs. 1.2 and 2.1) and define a fundamental lithospheric boundary between the EAC and the WARS. They are $3500 \mathrm{~km}$ long, typically $100-200 \mathrm{~km}$ wide and $<4500 \mathrm{~m}$ high (Fitzgerald, 2002). The TAM are divided by transverse structural features such as faults, grabens and accommodation zones through which major outlet glaciers typically run (Fitzgerald, 2002). The lithospheric boundary on which the TAM occurs has experienced numerous periods of exhumation, the most recent occurring in the Early Cenozoic. This episode caused the rock uplift associated with the formation of the TAM, which commenced $\sim 55 \mathrm{Ma}$ ago (Fitzgerald, 2002; Barrett, 2007). Average estimated exhumation rates for the TAM are relatively slow $(100 \mathrm{~m} / \mathrm{Myr})$, and are hypothesised to have been quicker in the first 10-15 Ma of TAM uplift (Fitzgerald, 2002). By c. $36 \mathrm{Ma}$, when deposition of CIROS-1 sediments into the VLB had commenced, $\sim 2 \mathrm{~km}$ of Ferrar and Beacon cover rocks had been eroded from the 
TAM, which were approximately their current height (Stern et al., 2005). By this time the basement and overlying Beacon Supergroup were extensively exposed in the TAM (Barrett, 1999) and were being actively eroded (these units are extensively detected in the CIROS-1 drill core) (Barrett, 1989).

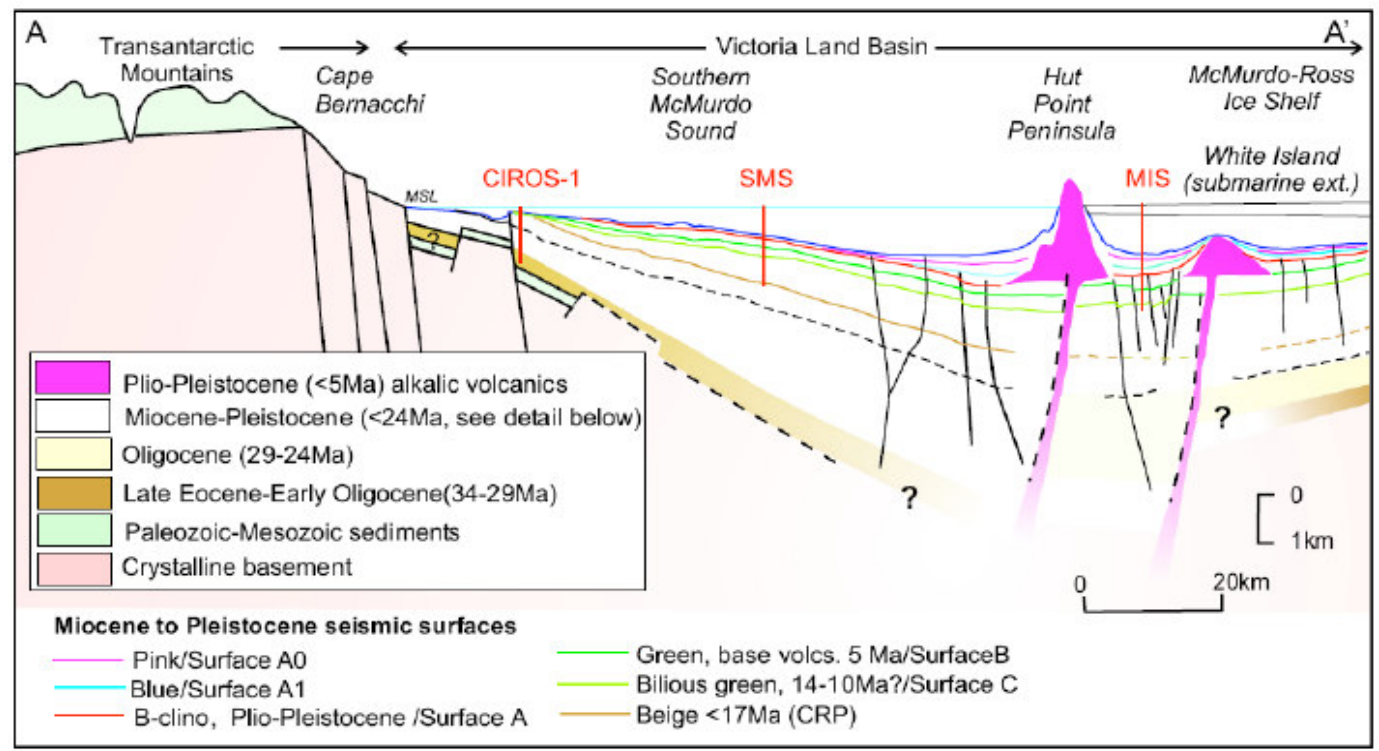

Figure 2.1: Cross-sectional view of the tectonic setting of the VLB, VLB stratigraphy and simplified geology of the TAM. Note the location of CIROS-1 proximal to the TAM and on the western margin of the Ross Sea and VLB (source: Naish et al., 2006). 


\subsection{Geology of the Trans-Antarctic Mountains in South Victoria}

\section{Land}

The geology of the TAM in SVL (Fig. 2.3) is a product of erosion, deposition and deformation of the geological units of the EAC margin. Many of the units in SVL formed in response to the Ross Orogeny, a series of events caused by collision of parts of West Gondwana along an internal suture (Tingey, 1991). This event caused widespread basement deformation, regional metamorphism, sedimentation of units and igneous intrusions and associated contact metamorphism. The orogeny may have started as early as $\sim 590 \mathrm{Ma}$ with the main period of Ross tectonism occurring post-Early Cambrian (Goodge et al., 2002).

The SVL basement consists of Proterozoic to Cambrian metamorphic and Cambrian-Ordovician intrusive units including granites formed during the Ross Orogeny (Granite Harbour Group) and metamorphic units (Skelton Group) (Fig. 2.2). The Granite Harbour intrusives are part of the numerous felsic plutons and smaller plugs and dykes (Allibone et al., 1993a) located along the length of the TAM. These (predominantly granite) plutons were intruded into a crystalline basement in two main phases between 590 and $455 \mathrm{Ma}$ (Allibone et al., 1993b). The crystalline basement in SVL consists of the metamorphic units of the Skelton Group which formed during the early stages of the Ross Orogeny, when the basement underwent widespread deformation and metamorphism $\left(700 \pm 50{ }^{\circ} \mathrm{C}\right.$ and $4-5 \pm 1$ kilo bar, upper amphibolite facies) (Allibone, 1992). The group includes multiply deformed marbles, calc-silicates, and pelitic, psammitic and amphibolitic schists (Grindely and Warren, 1964) that underwent variable episodes of deformation, metamorphism and intrusion of Ross granites. Denudation following the Ross Orogeny led to the formation of the Kukri Erosional Surface throughout the TAM in pre-Devonian times (Fitzgerald, 2002) (Fig. 2.3).

During the Devonian-Triassic, prior to rifting associated with the breakup of Gondwana, the Beacon Supergroup was deposited onto the Kukri Erosional Surface (Elliot and Fanning, 2008) (Fig. 2.2). During deposition of the Beacon Supergroup, an active magmatic arc was located at the paleo-Pacific boundary of the EAC. The Beacon Supergroup is divided into two units; the Taylor and Victoria Groups, separated by the Maya Erosional Surface. The Taylor Group, deposited on the Kukri Erosional Surface, is a voluminous (up to $1.4 \mathrm{~km}$ thick), dominantly sandstone unit, that outcrops predominantly in SVL (Elliot and Fanning, 2008). 


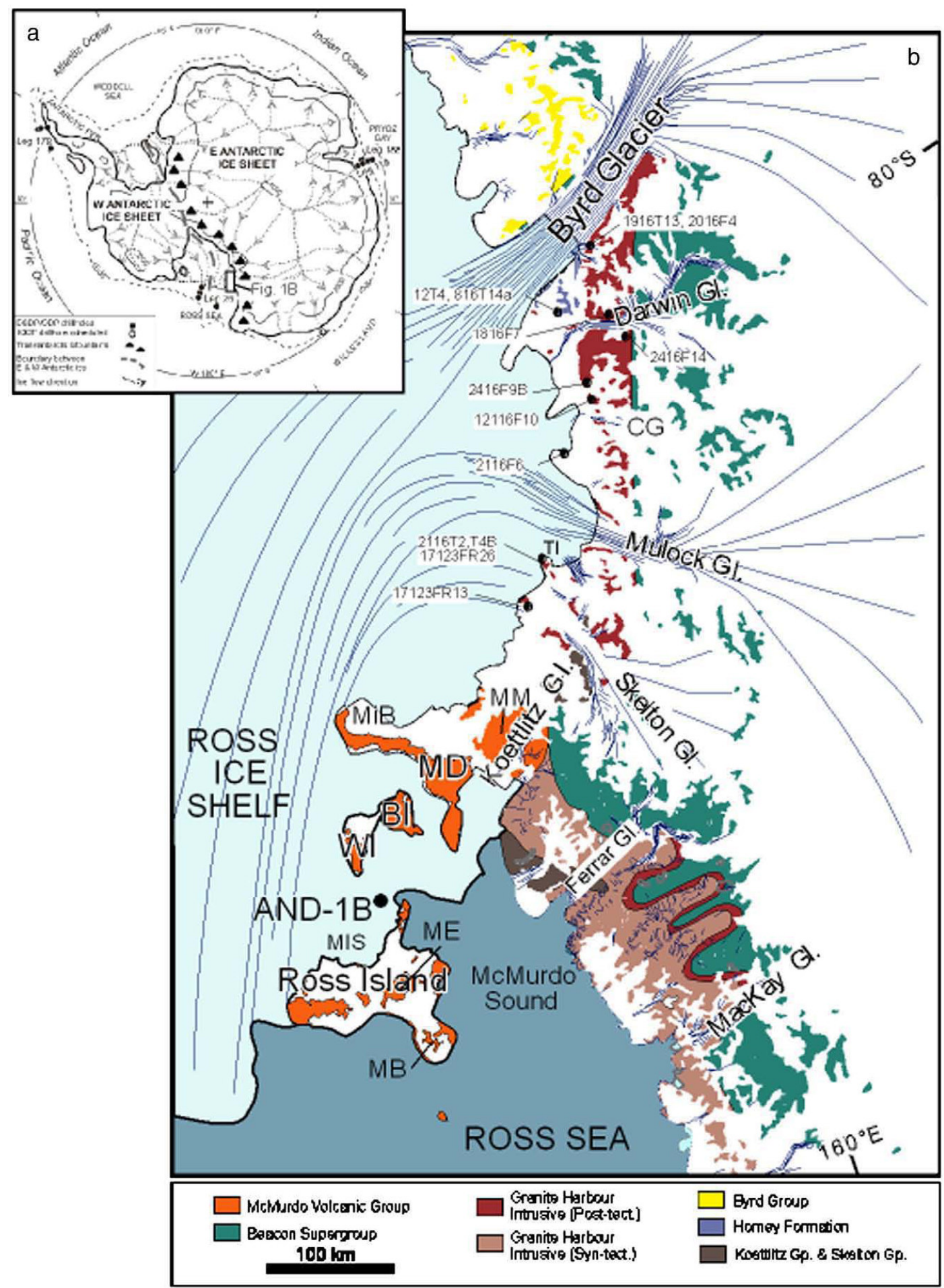

Figure 2.2: Geology of SVL. The Ferrar Fiord is located between the McKay and Koettlitz glaciers, due west of the AND-1B site. The CIROS-1 site is located at the mouth of the Ferrar Fiord, approximately $20 \mathrm{~km}$ offshore. The most seaward geological unit located in the Ferrar Fiord are the metamorphic units of the Koettlitz and Skelton Groups. The Ross-aged Granite Harbour Group and the Beacon Supergroup are located progressively more inland. Annotations (ME, MB, MD etc) are annotated of the names of MVG volcanoes (source: Talarico et al., 2009).

The Victoria Group, the Permian-Triassic section of the Beacon Supergroup, was deposited into intra-cratonic basins whilst a magmatic arc was present and contributing large amounts sediments to the unit (Elliot and Fanning, 2008). The 
group records the transition from a marine to terrestrial depositional environment, grading from marine sandstones to fluvial coal measures and then to Triassic flood plain sediments. Sedimentation of the Victoria Group ended in the Late Triassic (Savage, 2005; Elliot and Fanning, 2008).

The Ferrar Dolerite is a component of the Ferrar Large Igneous Province and was intruded into the Beacon Supergroup as a series of bedding-parallel, voluminous $\left(1.7 \times 10^{5} \mathrm{~km}^{3}\right)$ sills and dykes (Elliot and Fleming, 2008; Fleming et al., 1997) in response to rifting between East and West Gondwana (Elliot and Fanning, 2008; Encarnación et al., 1996). Rifting commenced in the Jurassic and was punctuated by the deposition of siliclastic volcanic sediments into the early rift (Elliot and Fleming, 2008: Ross et al., 2008), followed by plume related magmatism at $\sim 184 \mathrm{Ma}$ (Encarnación et al., 1996). The Ferrar Large Igneous Province includes the Ferrar Diorite (dolerite sills and dykes) and the Kirkpatrick Basalt (erupted as pyroclastic rocks and lava flows) (Elliot and Fanning, 2008).

There is a c. $160 \mathrm{Myr}$ gap in the stratigraphic record on land due to uplift and erosion of the rift margin (Fig. 2.3). Sediments have been deposited into the VLB since the Late Eocene, leaving an interval of time between 160-40 Myr unrepresented geologically in this part of Antarctica (Fig. 2.3). 


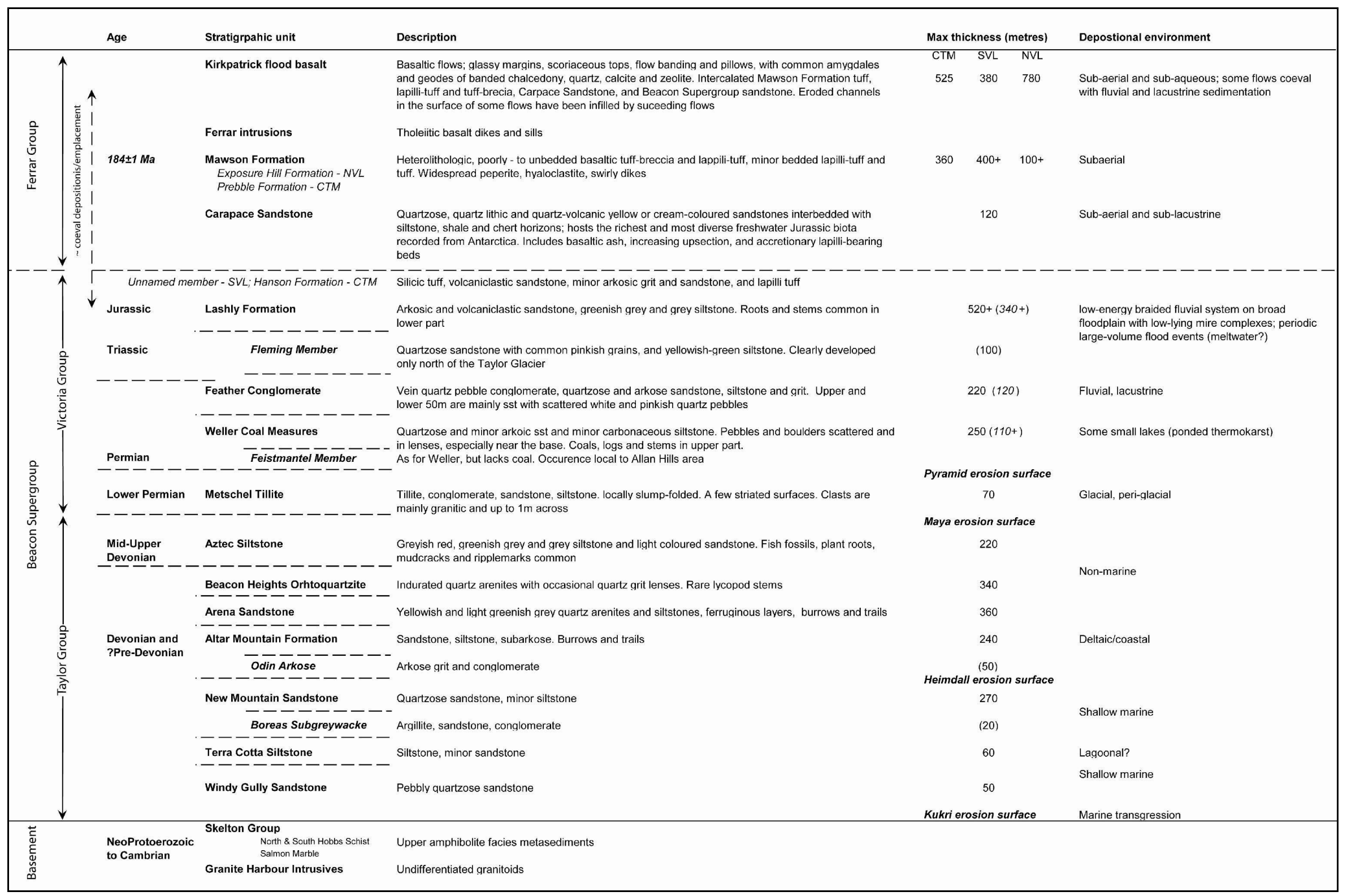

Figure 2.3: Summary of the geology of the TAM in SVL including the names of units, unit descriptions, thicknesses, depositional environments and ages (source: McClintock, 2001). 


\subsection{Geology of the East Antarctic Craton}

It is challenging to reconstruct the geology of the EAC due to extensive ice cover, poor petrological preservation, geochronological uncertainty due to isotopic resetting and debate over geological field relationships of exposed units (Goodge et al., 2001). However, it is understood that the geology of the Antarctic Shield is complex and composed of zones of mobile belts of Mid-Late Proterozoic metamorphic and igneous rocks that wrap around, separate and influence the edges of the older cratonic components (Tingey, 1991). The EAC is thought to be one of the oldest on Earth (Goodge et al., 2001) and includes Pan-African aged belts, Grenville aged provinces, Proterozoic domains and Archaean cratons (Fitzsimons, 2000; Harley, 2003). The growth of the EAC has been punctuated by a number of Archaean orogenic events including the Napier, (4.0 Ga), Rayner (3.5 Ga), Humboldt (3.0 Ga) and Insel (2.65 Ga) orogenies (Fitzsimons, 2000; Harley, 2003). The Proterozoic geological history of the EAC is dominated by three orogenic episodes, the Nimrod (1.73-1.72 Ga) (Goodge et al., 2001), Grenville (1.4-0.9 Ga), and Ross/Pan-African orogenies (600-400 Ma) (Fitzsimons, 2000; Laird, 1991).

\subsubsection{Geology of the Ross Sea sector of the East Antarctic Craton}

There are no outcrops of the EAC in the Ross Sea region and most insights into the composition of the EAC near the Ross Sea are from investigations of the composition of sediments eroded from the craton and deposited on the periphery. Palmer (2008) presented detrital zircon ages for a variety of modern sediments located in numerous locations in the Ross Sea and TAM (Fig. 2.4). From this, it appears that the sector of the EAC underlying the section of the EAIS that drains into the Ross Sea may consists of:

(1) 650-750 Ma Pan-African (?) units of igneous and metamorphic origin;

(2) 0.9-1.3 Ga aged Grenvillian provinces of igneous and metamorphic origin; and

(3) Numerous Archaean and Proterozoic igneous and metamorphic components. 


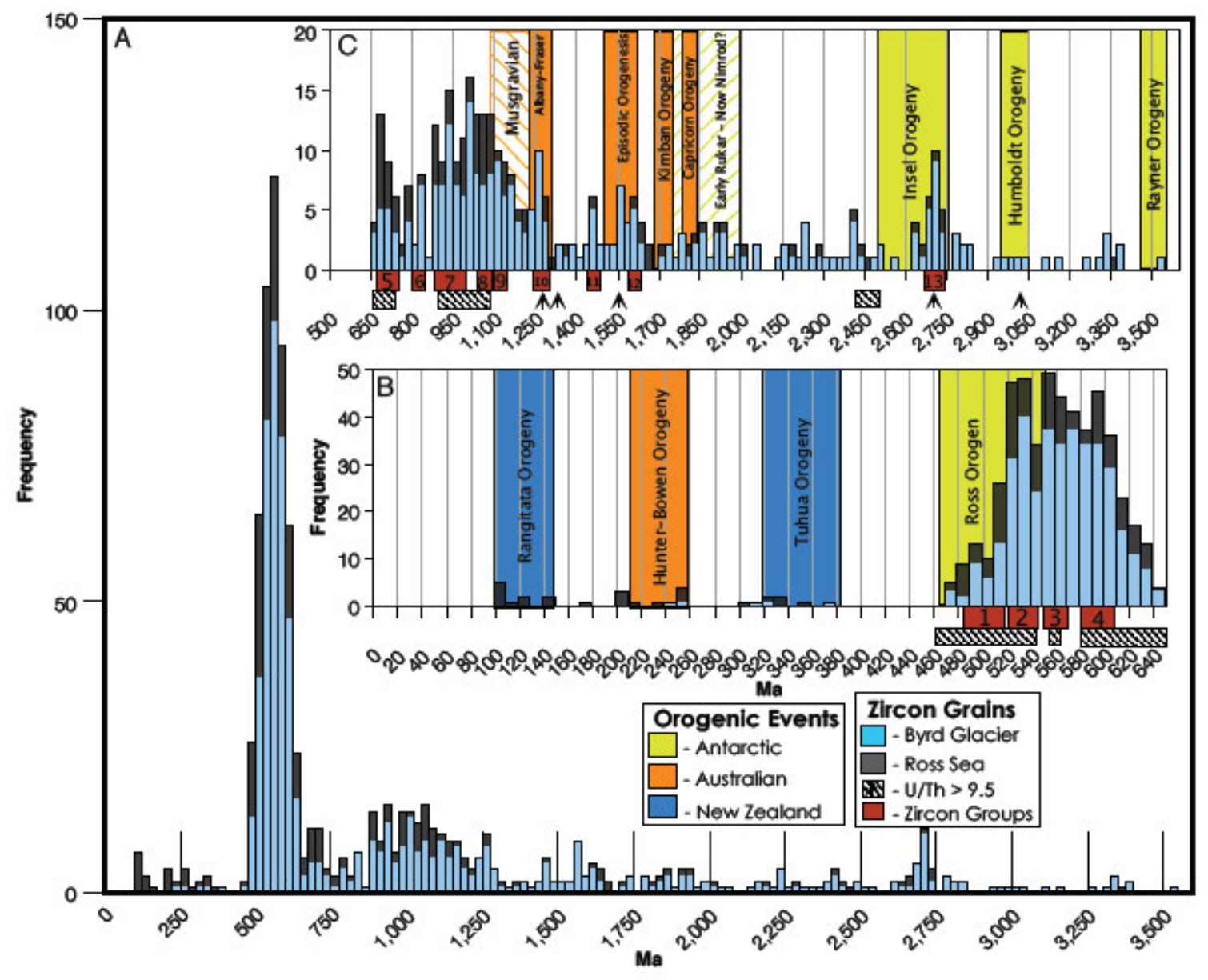

Figure 2.4: Cumulative age probability diagram of modern sediments sourced from tills deposited by the Byrd Glacier and sediment samples in the Ross Sea. The age peaks herein are indicative of the ages of components that comprise the Ross Sea sector of the EAC (source: Palmer, 2008).

\subsection{Potential source units for CIROS-1 zircons}

Initial work on CIROS-1 sand provenance (Roser and Pyne, 1989; George, 1989) concluded that sand source units were confined to the basement of the Ferrar Fiord (Skelton and Granite Harbour groups) and the Beacon Supergroup. No evidence for direct contribution from the EAC was reported. The more advanced techniques used in this study allow detection of subtle aspects of sand provenance, such as a very minor input of zircons from a more distal lithology, that may have been undetectable using previous methods. With this consideration the following section has been constructed. In this section, the characteristics of all potential source lithologies for zircons found in the CIROS-1 core are reviewed. This includes lithologies not assessed to be contributing to sediments by earlier workers and includes proximal lithologies (such as those in the Ferrar Fiord) as well as distal units deemed to be within depositional distance of the core. No West Antarctic lithologies are reviewed, as modern day and reconstructed glacial ice flow lines indicate no West Antarctic input of sediments into the McMurdo Sound (Licht et al., 2005; McKay, 2008). 
Potential lithologies reviewed in this section include both direct (igneous and metamorphic) and indirect (sedimentary) sources. Zircons with characteristics that cannot be tied to a known outcrop are assumed to be sourced from lithologies located under the ice or the current baseline of geologic exposure. To illustrate potential source lithologies and depositional pathways for CIROS-1 zircons, a map showing a generalised geology of the Ross Sea and paleo-ice flow lines for the LGM is included (Fig. 2.5).

\subsubsection{Descriptions of potential lithological sources for CIROS-1 zircons}

\subsection{1.i. Direct sources}

\section{A. Granite Harbour Group}

The Granite Harbour intrusive units are a dominant lithology in SVL and occur in the western Ross Sea border, the TAM, Dry Valleys and Ferrar Fiord. This group comprises the igneous units of the Ross Orogeny that formed through widespread intrusion of granites and numerous smaller plugs and dykes along the palaeo-Pacifc subduction zone of the EAC during the Ross Orogeny. These batholiths were emplaced during two periods: 589-490 $\mathrm{Ma}$ (syntectonic) and 486-477 Ma (post-tectonic). In the Dry Valleys, plutons are present in two forms. The older plutons are relatively undeformed, concordant, monzodiorite and granodiorite. They occur at deeper levels and were emplaced synchronously with the formation of the upper amphibolite facies Skelton Group. The younger plutons are discordant and consist of granodiorite and granite emplaced at higher crustal levels. The younger plutons formed in response to uplift and extension. Also present are younger mafic and felsic dykes (Allibone et al., 1993a).

\section{B. Skelton Group}

The Skelton Group occurs in the basement of SVL, and contains the oldest rocks in SVL. The group formed between 540-500 Ma, during metamorphism associated with the Ross Orogeny, and consists of regional and contact metamorphic units that formed from various protoliths. Units in the Skelton Group include metasediments, intercalated orthogneisses and pellitic schists, which experienced low pressure/high temperature deformation (700 $\pm 50{ }^{\circ} \mathrm{C}$ and $4-5 \pm 1 \mathrm{kbar}$, upper amphibolite facies) and underwent variable episodes of deformation and metamorphism and 
intrusion of Ross granites (Goodge et al., 2002; Rowell et al., 2001; Allibone, 1992; Allibone et al., 2003a and b; Findley et al., 1984).

\section{Cotton Plateau Gabbro}

The Cotton Plateau Gabbro is located within the Beardmore Group, a sedimentary unit located at the head of the Nimrod Glacier. It was emplaced $\sim 668 \mathrm{Ma}$ and consists of mafic metavolcanic units and includes greenschist facies pillow basalts, gabbro and plagiogranite. This unit produces zircons that yield concordant ages and are double prismatically terminated, equant to elongated in shape and contain abundant opaque inclusions (Goodge et al., 2002).

D. 1.4 Ga Granitic Unit

This unit was inferred to be located under the EAIS (Fig. 2.5) based on studies of detrital zircons deposited in sediments located under the Ross Sea. It has an emplacement age of $1.4 \mathrm{Ga}$ and a chemistry similar to A-type granites found in Laurentia. This unit is thought to be responsible for many of the detrital zircons of this age found around eastern Antarctica (Goodge et al., 2008).

\section{E. Nimrod Group}

This group is located near the Upper Nimrod Glacier. It consists of a heterogeneous assemblage of gneisses, schists and orthogneisses that formed during multiple orogenic events from variable protoliths of Archaean age. The units of the Nimrod Group produce zircons that have recorded multiple events. Ages of zircon growth zones include $3 \mathrm{Ga}, 2.9 \mathrm{Ga}, 2.5 \mathrm{Ga}, \sim 1.7 \mathrm{Ga}$ and $530 \mathrm{Ma}$ (Goodge et al., 2001; Goodge and Fanning, 1999; Grindley and McDougall, 1969; Grindley and Warren, 1964). 


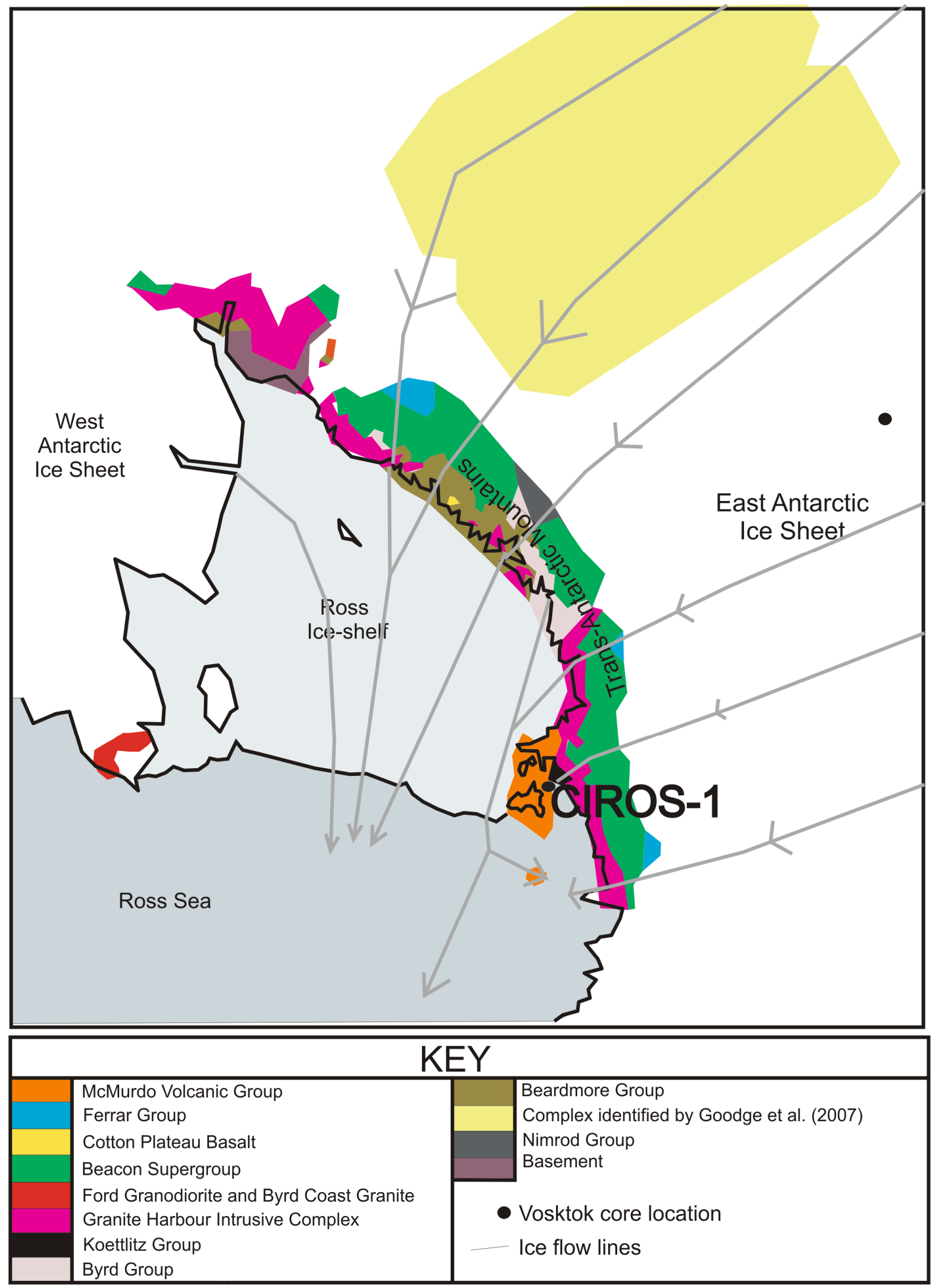

Figure 2.5: Geology of the TAM and inferred geology of the EAC combined with LGM reconstructed ice flow lines. Note the location of the CIROS-1 core, which is marked by the black oval. The Beacon Supergroup in the Ferrar Fiord consists of both Taylor and Victoria Groups. (Ice flow lines and TAM geology from Licht et al., 2005; Savage, 2005 and McKay, 2008. Vostok core location from Delmonte et al., 2004. Proterozoic granite complex located under the ice from Goodge et al., 2008). 


\subsection{1.ii Recycled sources}

Most siliclastic rocks in Antarctica contain large (but generally not dominant) populations of $\sim 1.8$ - to $1.6 \mathrm{Ga}$ detrital zircons in addition to relatively sparse Mesoproterozoic (1.2 to $0.9 \mathrm{Ga}$ ) and Archaean populations. These are generally assumed to be sourced from the EAC under the ice (Goodge et al., 2008), which indicates paleo-Proterozoic igneous and/or metamorphic rocks are a substantial crustal component within the composite EAC, as well as minor Archaean rocks.

A. Beacon Supergroup

The Beacon Supergroup is subdivided into two units, the older Taylor Group and younger Victoria Group.

The Taylor Group, which outcrops predominantly in SVL, was deposited onto the KES during the Devonian. It is a voluminous unit (up to $1.4 \mathrm{~km}$ thick) consisting mainly of well sorted sandstones that outcrop in the Sperm Bluff near the MacKay Glacier and on the southern side of the Ferrar Fiord (Elliot and Fanning, 2008; Savage, 2005). The zircons in the Taylor Group are dominated by a $\sim 500 \mathrm{Ma}$ age peak and older subordinate age peaks (Fig. 2.7). No age peaks younger than $\sim 450 \mathrm{Ma}$ have been reported in any Taylor Group localities.

The Late Proterozoic-Early Cambrian zircons (490-560 Ma) found in the Taylor Group are inferred to have a Granite Harbour Group provenance. Proterozoic and older grains ( $650-3300 \mathrm{Ma})$ are inferred to be sourced from either erosion of older units (e.g. Skelton Group or the units of the EAC) or from the inherited component of Granite Harbour igneous units (Bassett et al., 2009; Savage, 2005; Bradshaw and Harmsen, 2007). 

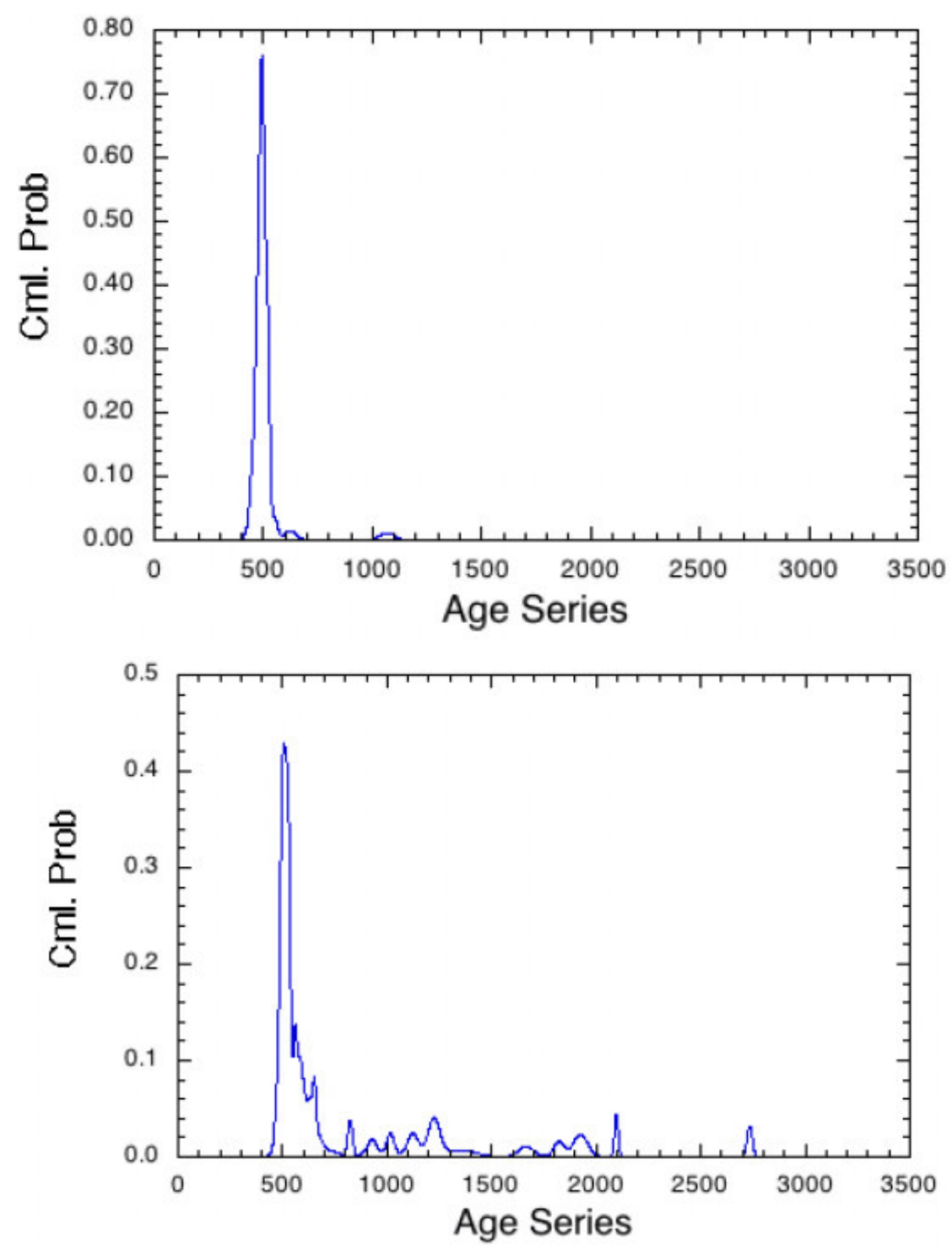

Figure 2.6: Examples of age probability diagrams for zircons obtained for the Taylor Group at Sperm Bluff, SVL. The top age probability, from a granulite conglomerate, is dominated by a $\sim 500 \mathrm{Ma}$ age peak. The bottom diagram is the age probability diagram constructed from a granulitic conglomerate at a different locality on Sperm Bluff. As with the top diagram, this shows a dominant age peak at $\sim 500 \mathrm{Ma}$ with additional subordinate peaks at $\sim 700-2200 \mathrm{Ma}$ and $\sim 3.3 \mathrm{Ga}$ (source: Savage, 2005).

The Victoria Group was deposited into intra-cratonic basins during the Permian and Triassic in association with a magmatic arc. The group records a transition from marine to terrestrial depositional settings from marine sandstones to fluvial coal measures to Triassic flood plain sediments. Victoria Group sediments were derived from both the EAC and volcaniclastic sandstones derived from this magmatic arc present during deposition. The characteristics of zircons in the Victoria Group are highly variable dependent on the spatial and temporal location of sampling (Fig. 2.7). 

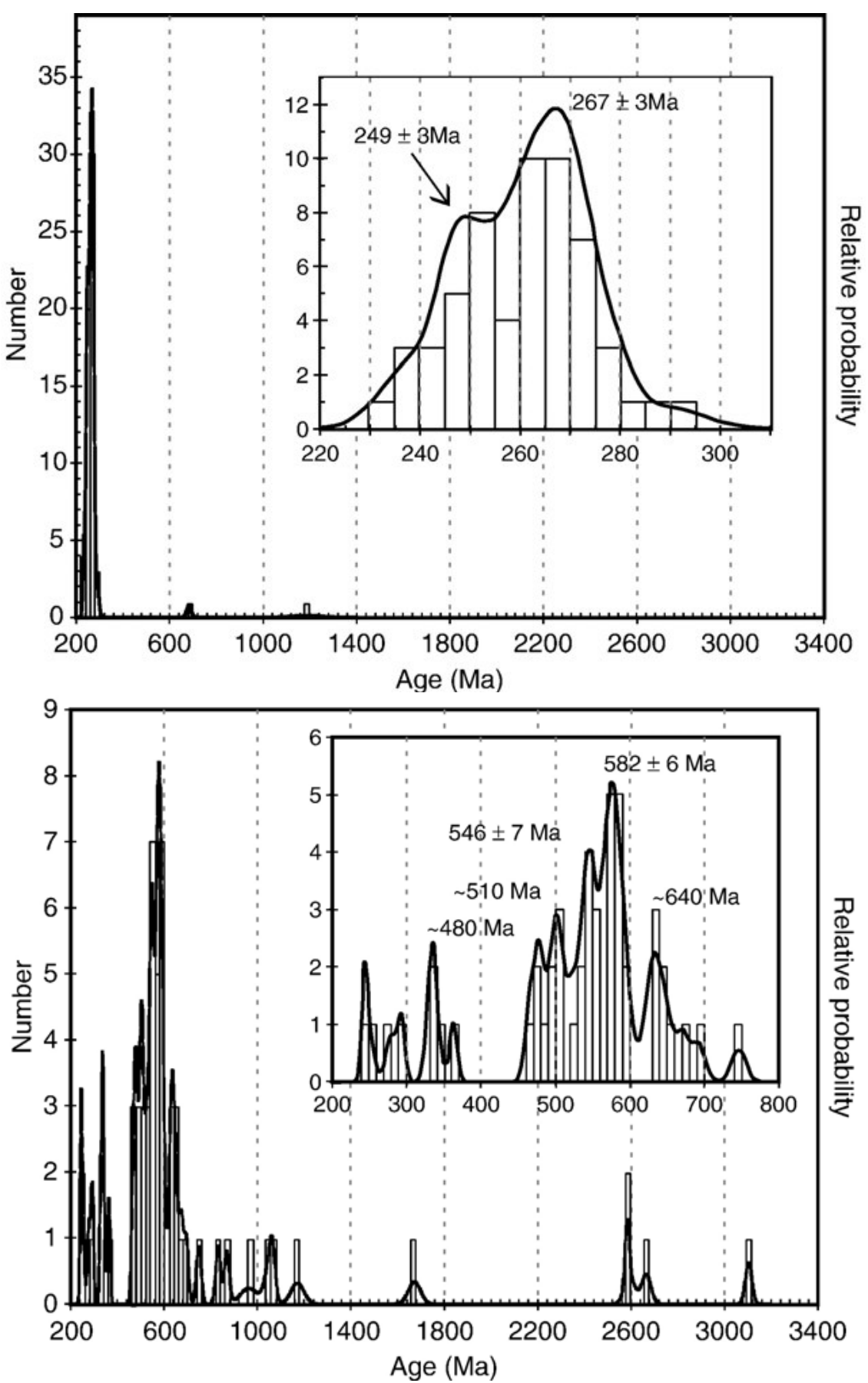

Figure 2.7: Examples of age probability diagrams constructed using detrital zircons from the Victoria Group of the Beacon Supergroup. Note the 200 Ma peak, the pronounced Early Cambrian peak and the older 'cratonic' component (source: Elliot and Fanning, 2008).

Late Permian $(267 \pm 3 \mathrm{Ma}$ and $249 \pm 3 \mathrm{Ma})$ zircons found in the Victoria Group are hypothesized to be from a magmatic source of Permian age, potentially the active magmatic arc present at the paleo-Pacific boundary of the EAC. Late Devonian zircons $(\sim 370 \mathrm{Ma})$ found in the group were potentially sourced from the Ford Granodiorite in Marie Byrd Land or 'from an uncertain extension of that belt eastward toward the Antarctic Peninsula' (Elliot and Fanning, 2008). The $\sim 460-510 \mathrm{Ma}$ zircons located in the Victoria Group were sourced from post-tectonic Ross granitoids, whilst Early 
Cambrian grains (560-510 Ma) were sourced from Ross or late Pan-African units. Late Neoproterozoic aged grains $(\sim 640 \mathrm{Ma})$ are inferred to be sourced from unknown early Pan-African units located in the EAC and Proterozoic and older grains from other unknown units in the EAC (Elliot and Fanning, 2008).

\section{B. Beardmore Group}

The Beardmore Group was deposited during the Late Precambrian, syntectonic with the Ross Orogeny. The group comprises pelitic schists, hornfels, metagreywackes, argillites and contains two assemblages, one which is located nearer the paleocoastline that the other.

The Beardmore Group inboard assemblage was deposited during the Late Proterozoic ( $\leq 670 \mathrm{Ma}$ ) in a platform to shoreline setting along an existing rift margin. The assemblage contains zircons from mixed cratonic sources that are dominated by $2.8 \mathrm{Ga}$ and 1.9 to $2.4 \mathrm{Ga}$ ages (Fig. 2.8). All zircons in this assemblage are thought to have been sourced from unknown units located under the ice in the EAC (Goodge et al., 2002).

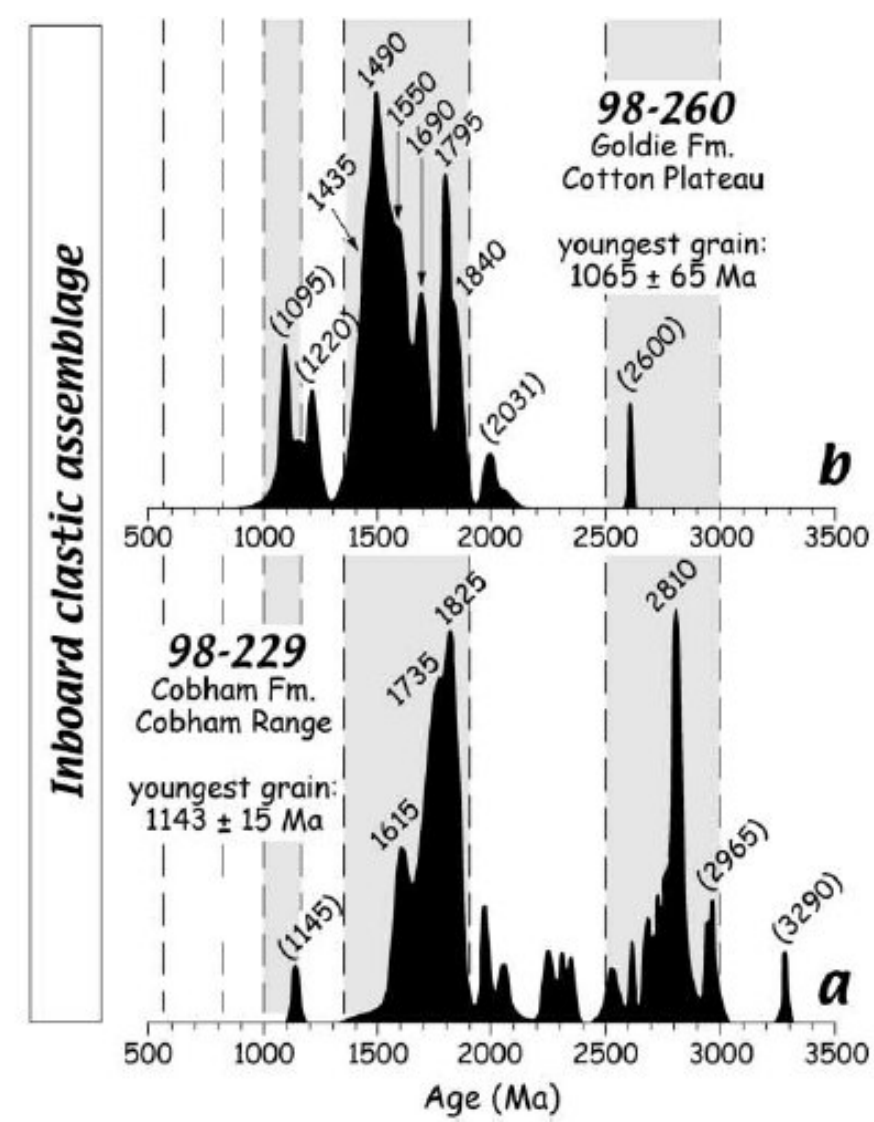

Figure 2.8: Age probability diagrams produced for zircons from the Beardmore Group inboard assemblage (source: Goodge et al., 2002). 
The volumetrically dominant outboard assemblage (Byrd Group) was deposited during the Early Cambrian $(\leq 520 \mathrm{Ma})$ in a continental margin volcanic arc setting. Detrital zircon ages in this group show a heavy dominance of Ross Orogeny aged strata $(\sim 500 \mathrm{Ma})$ and with minor $1.4 \mathrm{Ga}$, 1.1-0.94 Ga and $825 \mathrm{Ma}$ age peaks (Fig. 2.9).

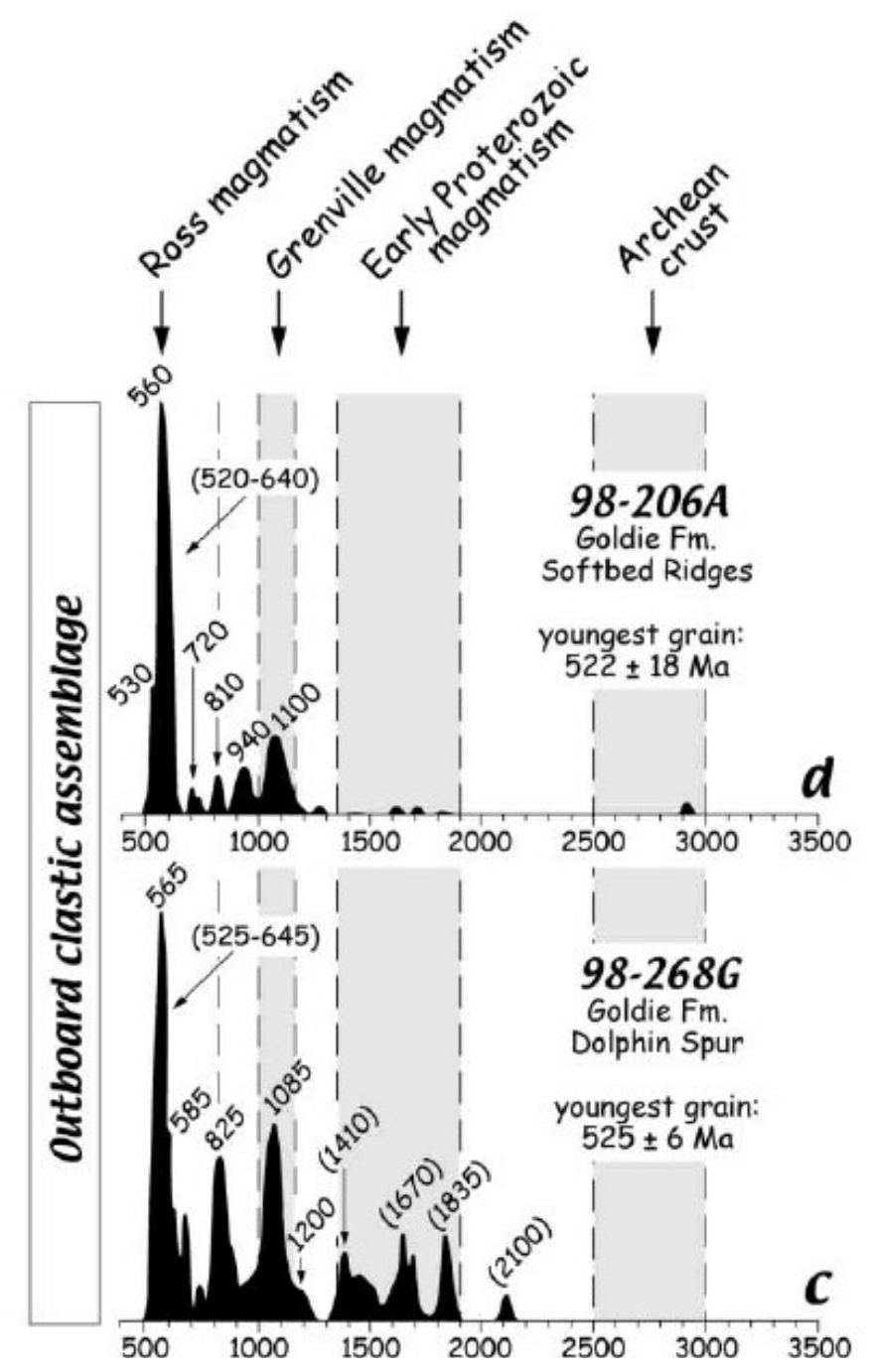

Figure 2.9: Detrital zircon age probability diagram for the Byrd Group. Note the presence of a Ross aged peak and the presence of various cratonic-sourced and Grenvillian-aged zircons (source: Goodge et al., 2002).

The Late Proterozoic-Early Cambrian (500-600 Ma) zircons located in the Byrd Group are thought to be sourced from the Ross granitoids in the TAM. Zircons of $\sim 668 \mathrm{Ma}$ in age are thought to be sourced from the Cotton Plateau Gabbro. Zircons in the Byrd Group 830 Ma and 1.1-1.2 Ma in age are thought to have been sourced from an unknown igneous source and asyet unknown Grenvillian aged belts. The zircons in the $\sim 1.4 \mathrm{Ga}$ age peak are hypothesised to be sourced from the igneous province inferred to be under 
the EAIS by Goodge et al. (2008), whist older grains (1.5-2.8 Ga) were sourced from unknown cratonic components (Goodge et al., 2002).

\subsection{Climatic and glacial influence on CIROS-1 deposition}

CIROS-1 sediments were deposited as part of a glaciomarine deltaic system fed by the Ferrar fiord (Barrett, 1989) between 38-22 Ma. The fluctuation of ice sheets and the dynamics of glaciers played a critical role in the erosion, transportation and deposition of sediments present in CIROS-1. In order to provide a framework for investigations into CIROS-1 sediments that occur in later chapters, the current knowledge of Antarctic and global climate conditions during CIROS-1 sedimentation are outlined in this section.

\subsubsection{Cenozoic global ice volumes}

The isotopic composition of oxygen in sea water changes in response to variances in global ice volume, local deep-sea temperature and salinity of seawater (Zachos et al., 2001a). $\delta^{18} \mathrm{O}$ of sea water increases during cold periods, whilst it decreases when global and/or local temperatures increase. Benthic foraminifera live on the sea floor. In some species, the $\delta^{18} \mathrm{O}$ composition of foraminifera tests directly reflects that of the seawater in which they lived. Thus, by measuring the $\delta^{18} \mathrm{O}$ of foraminifera tests, the global ice volume, sea water temperature and salinity in which it grew may be inferred. It is estimated that a $1 \%$ increase in $\delta^{18} \mathrm{O}$ is reflects a $110 \mathrm{~m}$ fall in sea level or $4{ }^{\circ} \mathrm{C}$ decrease in global temperature (Barrett, 1999; Kennett, 1982)

The Cenozoic ice volume and temperature record (Fig. 2.10) can be divided into 4 broad periods (Barrett, 1999; McKay et al., 2009; Barrett, 2009):

(1) 100-34 Ma; 'Greenhouse world'-preglacial times in Antarctica.

(2) 34-14 Ma; 'Transition world'- first occurrence of continental glaciation of Antarctica, ephemeral and large ice sheets that extended to the continental margin.

(3) 14-2.6 Ma; 'Icehouse world'- persistent ice sheets on Antarctica, the variability of size much debated.

(4) 2.6 Ma-present: 'Icehouse world'- current Antarctic regime with large and constant ice sheets.

The deep-sea benthic record shows an increase in $\delta^{18} \mathrm{O}$ of $5.4 \%$, reflecting a cooling trend during the Cenozoic (Zachos et al., 2001a). Approximately $3.1 \%$ of this is 
attributed to deep-sea cooling and $2.3 \%$ to increases in global ice volume $(\sim 1.2 \%$ in Antarctica and $\sim 1.1 \%$ in the Arctic) (Zachos et al., 2001a).

Long-term trends in the Cenozoic climate record include gradual warming during the Late Paleozoic ( $\sim 59 \mathrm{Ma}$ to $52 \mathrm{Ma}$ ) expressed as $\sim 1.5 \%$ decrease in benthic $\delta^{18} \mathrm{O}$. This warming culminated in the Eocene Climatic Optimum at $~ 52-50 \mathrm{Ma}$ (Fig. 2.11). Superimposed on the trend of this period is the aberration of the Late Palaeocene thermal maximum. During this event deep-sea temperatures increased by $5-6{ }^{\circ} \mathrm{C}$ (decrease in $\delta^{18} \mathrm{O}$ of $>1 \%$ ) in less than $10 \mathrm{kyr}$. The warming trend in the Eocene was followed by $\sim 17 \mathrm{Myr}$ of cooling (expressed as a $\sim 3 \%$ increase in $\delta^{18} \mathrm{O}$ ) and a 'transitional world' climatic state was entered into (Barrett, 1999) (Fig. 2.11). This cooling culminated with the Oi-1 glaciation, a large glaciation in Early Oligocene which lasted $\sim 400 \mathrm{kyr}$, during which benthic $\delta^{18} \mathrm{O}$ increased by $\sim 1 \%$ and bottom water temperatures decreased by $\sim 4{ }^{\circ} \mathrm{C}$. During the Oi-1 glaciation, Antarctic ice volume increased to present day volumes and permanent, yet dynamic ice sheets formed in Antarctica (Barrett, 2009; Zachos et al., 2001a; Pekar and Christie-Blick, 2008).

The cold conditions remained more or less constant until the Late Oligocene, when global oceans warmed and the extent of glaciation decreased. The records presented by Zachos et al. (2001a) show a significant drop in $\delta^{18} \mathrm{O}$ in the Late Oligocene, which was attributed to a marked increase in bottom water temperatures and a decrease in global ice volumes at this time. On the record presented by Zachos et al. (2001a), the warming of the Late Oligocene lasted 2-3 $\mathrm{Myr}$ and was followed by a period of cooling, represented by a $\delta^{18} \mathrm{O}$ decrease of $\sim 0.4 \%$. This relatively cool climate was argued to have lasted until $\sim 20 \mathrm{Ma}$, when temperatures increased again and culminated in the Mid-Miocene Climatic Optimum (Fig. 2.10).

The period of increased warmth during the Late Oligocene presented by Zachos et al. (2001a) is inconsistent with the findings from Antarctic margin sediment cores, such as CRP (Barrett, 2007). These direct proxies suggest a much smaller degree of warming during the Late Oligocene than was suggested by Zachos et al. (2001a). This inconsistency was accounted for by Pekar et al. (2006) who found that, during the period of $\delta^{18} \mathrm{O}$ decrease in the Late Oligocene presented by Zachos et al. (2001a), a splicing of two deep ocean records from vastly different latitudes had occurred. 
Thus the change in isotopic composition was strongly influenced by the meridional difference in deep ocean temperature between the equator and the polar regions.

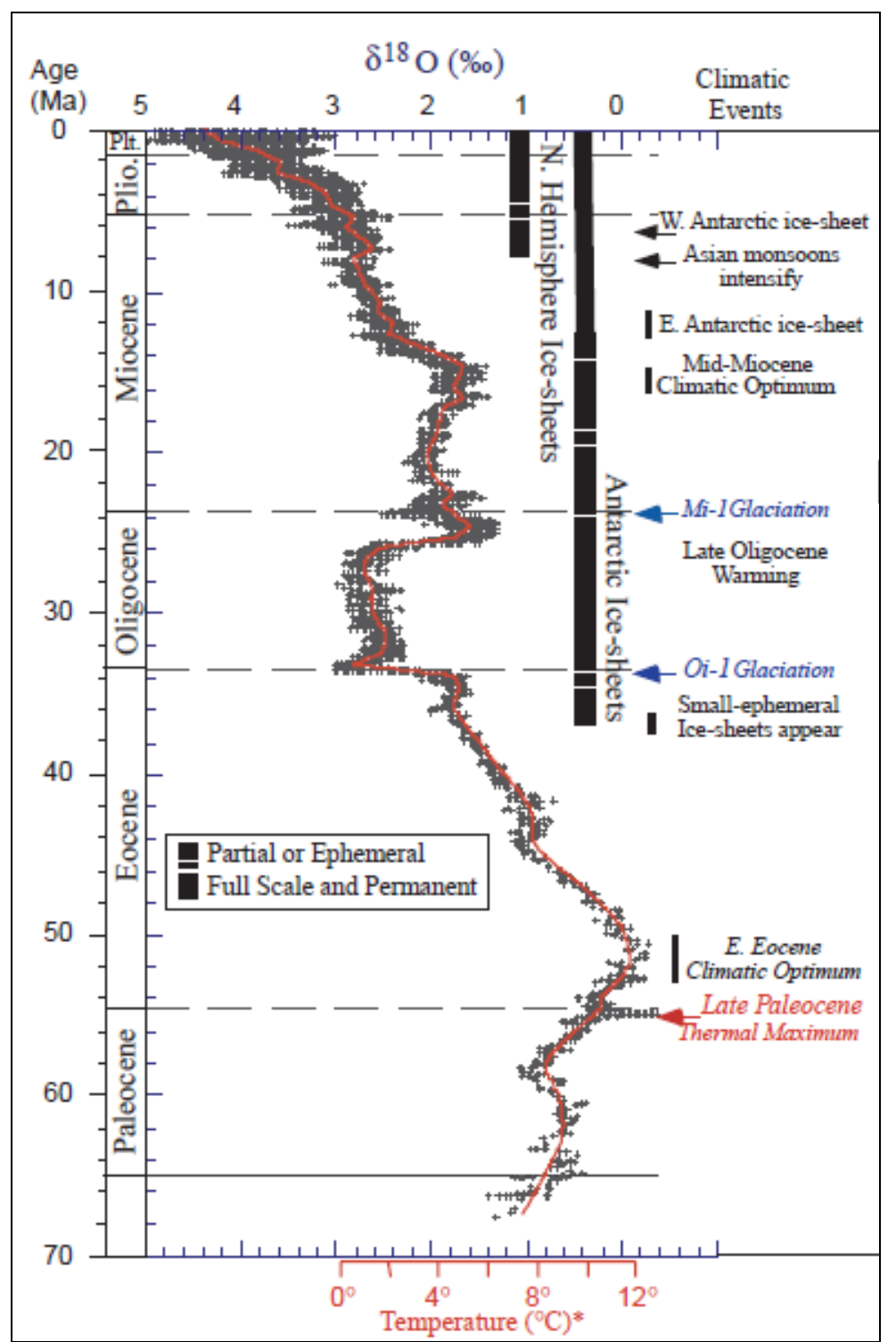

Figure 2.10: The deep sea benthic oxygen isotope record from Zachos et al. (2001a) showing both the accepted general cooling over the Eocene, abrupt cooling of the Oi-1 glaciation and the more contentious Late Oligocene warming and deglaciation.

In an attempt to constrain ice volume and extract temperature from the oxygen isotope record in the Late Oligocene, Pekar and Christie-Blick (2008) conducted backstripping of the New Jersey continental margin sea level record to constrain the size of eustatic change and thus the size of the Antarctic ice sheet during the Late Oligocene-Early Miocene. This investigation indicated that though a decrease in size of the EAIS occurred from the Late Oligocene to Early Miocene, warming was not as pronounced as appeared in the Zachos $\delta^{18} \mathrm{O}$ record (Fig. 2.10). Rather, this showed that during the Late Oligocene-Early Miocene the EAIS decreased in size from $\sim 30 \%$ greater than present to no less than $\sim 40 \%$ of its present size. 


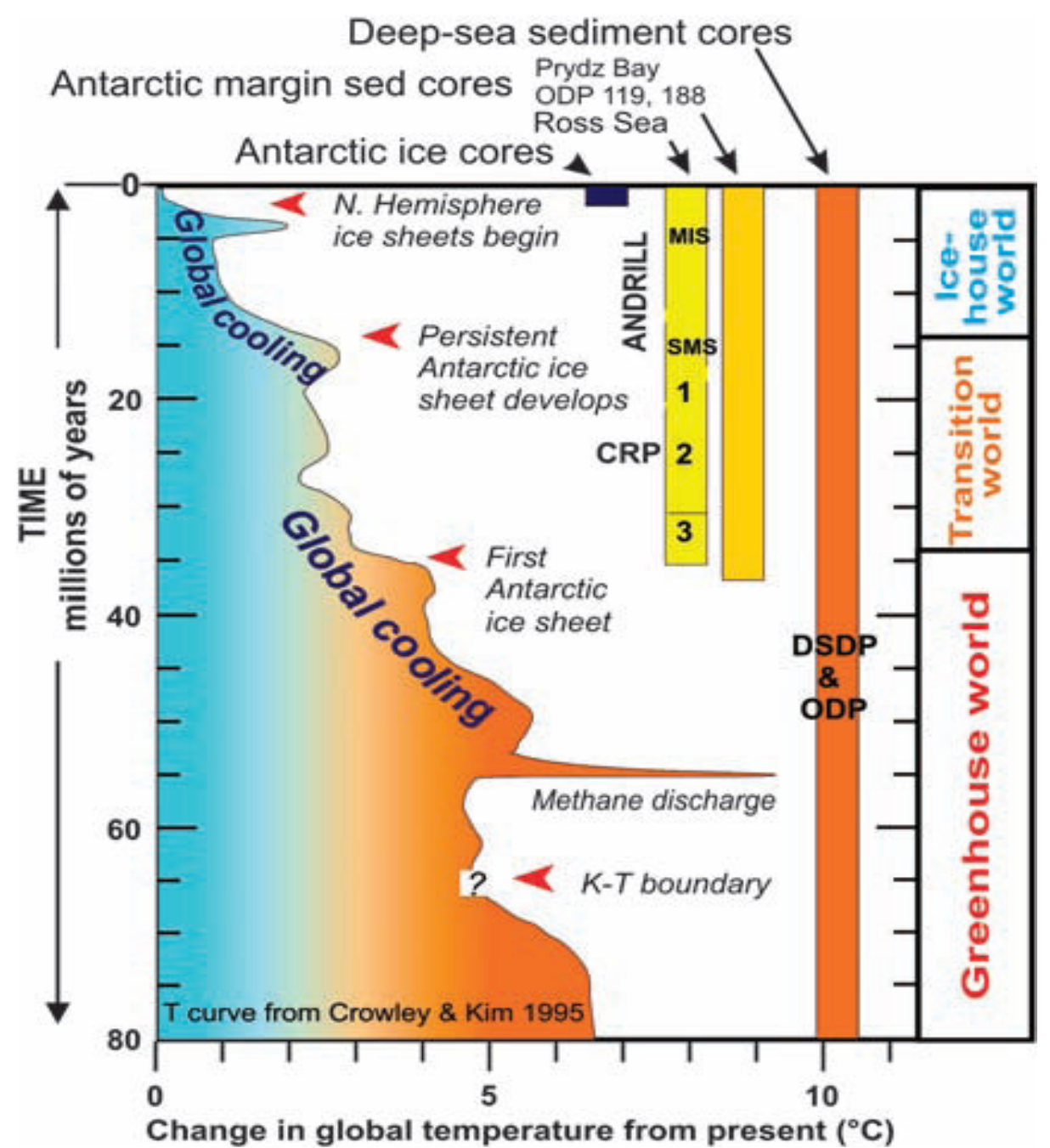

Figure 2.11: Global temperature curve constructed using oxygen isotopic concentrations of benthic foraminifera. Shown are key climate events that occurred in the Cenozoic (source: Barrett, 2009).

The Mi-1 glaciation, which occurred at the Oligocene-Miocene boundary ( $\sim 23 \mathrm{Ma}$ ), was a short-lived ( 200 kyr) but intense glacial event (Zachos et al., 2001a) during which the EAIS reached $\sim 120 \%$ of its current size (Naish et al., 2001a; Pekar et al., 2006). The Mi-1 glaciation was followed by warming that resulted in the MidMiocene Climatic Optimum (Fig. 2.10), the culmination of the trend of decreasing $\delta^{18} \mathrm{O}$ that had occurred since the Late Oligocene. The Mid-Miocene Climatic Optimum lasted $\sim 2 \mathrm{Myr}$ (from $\sim 17-15 \mathrm{Ma}$ ) and was followed by a gradual cooling (represented by an increase in $\delta^{18} \mathrm{O}$ of $\sim 2.6 \%$ ) during which an 'Icehouse world' state was entered (Barrett, 2009) (Figs. 2.10 and 2.11). This cooling has continued to the present day and was punctuated by the establishment of permanent ice sheets in Antarctica $(\sim 14 \mathrm{Ma})$ and the initiation of northern hemisphere ice sheets $(\sim 3 \mathrm{Ma})$ (Figs. 2.10 and 2.11). 
Though the benthic oxygen isotope record allows insights into global temperatures and ice volumes during the Cenozoic, it does not allow direct and unambiguous assessment of the glacial state of Antarctica during this interval. To construct the Cenozoic glacial history of Antarctica direct records of Antarctic glaciology must be used. These are discussed in the following section.

\subsubsection{Cenozoic Antarctic glaciology}

Drilling of Antarctic sediments located in peripheral basins started in the 1970's and includes deep sea drilling (ODP and DSDP), cores drilled on the sea ice and onshore cores (DVDP).

DSDP Leg 28 (1970-1973) initiated drilling of sediments, some of which were eroded from the Antarctic Continent. An aim of this leg was to obtain a climate and ocean record from the Southern Ocean and the Ross Sea continental shelf. This project produced the first record of Antarctic glaciation from the Quaternary to the Oligocene in the form of glacial marine debris (Barrett, 2009) and contained the first evidence of Antarctic glaciation as early as $30 \mathrm{Ma}$ and the presence of ice sheets since $14 \mathrm{Ma}$ (Barrett, 2009). This record demonstrated that the Antarctic ice sheet, first thought to have been only $3 \mathrm{Ma}$ old, had in fact been in existence since the Late Oligocene.

Subsequent $\delta^{18} \mathrm{O}$ studies of calcareous microfossils in the Southern Ocean (e.g. DSDP Leg 29) showed that the Cretaceous was warm and that the climate cooled and ice volume increased dramatically at the Eocene-Oligocene boundary and after the Mid-Miocene Climatic Optimum (Shackelton and Kennett, 1974). However, these records did not give direct evidence of Antarctica's glacial state during these times.

The DVDP project, initiated in 1973, yielded the first direct evidence of Antarctic glaciation from the terrestrial continental margin. These cores were drilled in various locations in the Dry Valleys (Fig. 2.12). Recovered strata contained glacial sediments and gave evidence for glaciation in this sector of Antarctic from the Late Miocene to present (Barrett, 2009). The first Antarctic offshore hole to be drilled on sea ice was DVDP-15, which was drilled into the sediments of the VLB (Fig. 2.12). Although this core only reached a depth of $62 \mathrm{mbsf}$, it proved the feasibility and scientific potential of drilling on sea ice and initiated a new era in Antarctic margin drilling. 
Following DVDP-15, the MSSTS project was developed in the late 1970's. MSSTS-1 hole (Fig. 2.12), drilled in 1979, reached a depth of $227 \mathrm{mbsf}$ and included Oligocene aged strata that contained cyclic packages of diamicts, sands and mud interpreted to reflect cycles of glacial advance and retreat. Further investigations (e.g. seismics) showed that these cycles of advance and retreat mainly occurred from the Oligocene onwards (Barrett, 2009).

Drilling for the CIROS project was initiated in 1984 with the aim to investigate the record of Antarctic glaciology and tectonism contained in sediments in the western margin of the VLB. Due to unforeseen circumstances, CIROS-2 was the first of these cores to be drilled in the Ferrar Fiord, $20 \mathrm{~km}$ inland from the future CIROS-1 site (Fig. 2.13). This core revealed Quaternary and Pliocene sediment cycles caused by: (1) The advance and retreat of inland ice in the Pliocene; and (2) Westward flow of the Ross Ice Shelf into the site during major Quaternary glacial events (Barrett, 2009).

Two years later, in 1986, CIROS-1 was drilled $20 \mathrm{~km}$ to the east of CIROS-2 (Fig. 2.13). This core reached a depth of $702 \mathrm{mbsf}$ (Late Eocene to Early Oligocene age), had a recovery of $98 \%$ (Hambrey et al., 1989) and gave the first direct evidence that the dynamic Antarctic ice sheet reached the Victoria Land coast from the Earliest Oligocene (Barrett, 1989; Barrett, 2009). It also gave direct evidence for the expansion and contraction of the EAIS during the Late Eocene to Early Miocene, which was found to be relatively synchronous with temperature fluctuations observed in the global deep sea $\delta^{18} \mathrm{O}$ record (e.g. Zachos et al., 2001a; Figs. 2.10 and 2.11).

DSDP Leg 113 and ODP Leg 119 were drilled to gain insights into the initiation of the East Antarctic Ice Sheet and history of glaciation in other sectors of Antarctica (Barrett, 2009). DSDP 113, drilled in the Weddell Sea, contained Palaeogene to Oligocene aged sediments that showed a cooling from the warmer Cretaceous to the Oligocene and the presence of some ice on land during the Oligocene (Barrett, 2009). ODP 119, drilled in Prydz Bay, recovered Cretaceous aged terrestrial sediments and thick Late Eocene-Early Oligocene aged diamicts. These diamicts gave the first evidence that 'continental scale ice sheets on Antarctica were delivering 
ice to the shelf edge beyond the limits of the modern ice sheet at least from Early Oligocene times' (Barrett, 2009).

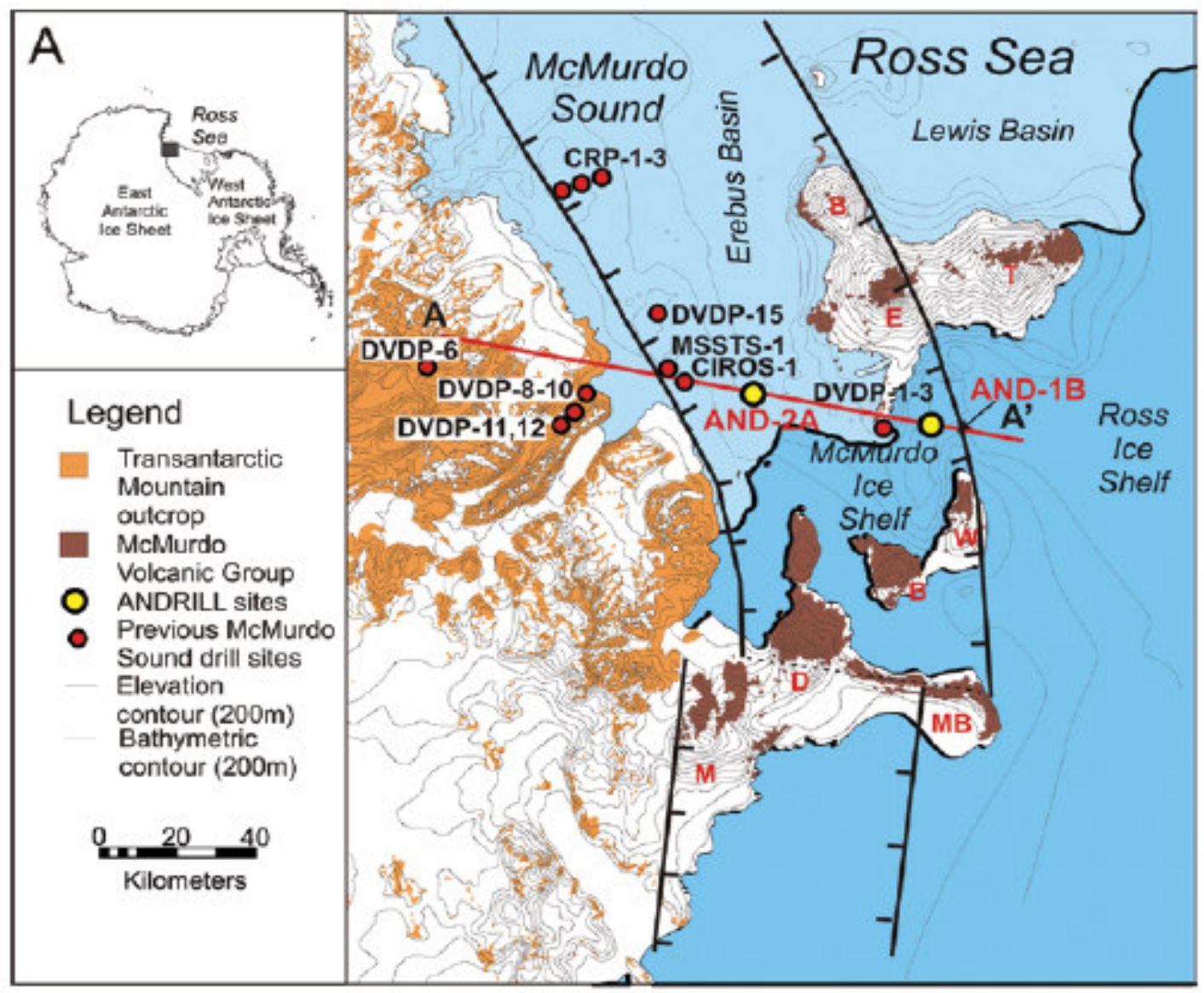

Figure 2.12: Map of the McMurdo Sound area showing the locations of various sediment cores drilled in and near the VLB (source: Naish et al., 2008a).

From 1997 to 1999, the CRP was drilled as three holes $70 \mathrm{~km}$ north of CIROS-1 (Fig. 2.12) (Barrett, 2007). These holes penetrated a near continuous sequence of VLB strata from Quaternary to Oligocene which terminated at the Beacon Supergroup basement. The CRP cores showed that continental ice reached beyond present ice limits in earliest Oligocene times, glaciers calved at sea level as early as 34 $\mathrm{Ma}$, and that grounded ice started extending into the Victoria Land Coast periodically from the $33 \mathrm{Ma}$ and continued to do so until the Early Miocene (Barrett, 2007). The cores yielded high resolution information on orbitally-forced fluctuations in ice volume and sea level from 34-17 Ma (Naish et al., 2001b; Barrett, 2009) however, no evidence to support extreme warming in the Late Oligocene, as hypothesised by Zachos et al. (2001a).

Most recently, the two cores of the ANDRILL program were drilled in Miocene and younger sediments of the VLB, to obtain information on the climate, volcanic and tectonic history of the Ross Sea region during the Neogene (Naish et al., 2008a; 
Harwood et al., 2008). In 2006, AND-1 (MIS) was drilled south of Ross Island on the Ross Ice Shelf to a depth of 1285 mbsf with a $95 \%$ core recovery (Fig. 2.12) (Naish et al., 2006; Krissek et al., 2007; Barrett, 2009). The core is located in the middle of the VLB and contains sediments of Late Neogene age that are a record of the Ross Ice Shelf and WAIS behaviour during the Neogene. A key finding of this core is the presence of a large diatomite unit between 350-460 mbsf (Scherer et al., 2007), indicating an extended period of open water in the Ross Embayment between 4.6-3.4 Ma (Barrett, 2009; Naish et al., 2008a).

AND-2/2A (SMS) was drilled in 2007 in the southern end of the McMurdo Sound (Fig. 2.12) to a depth of 1139 mbsf with a core recovery of $98 \%$. This core includes sediments of Early Miocene and younger age, a period long held as one of the fundamental time intervals in development of the modern Antarctic ice sheets. These strata hold the first physical evidence of the behaviour of the EAIS and the Ross Ice Shelf during the Mid-Miocene Climatic Optimum (Harwood et al., 2008) and Miocene sediments in the core show evidence of glacial advance and retreat. Palynomorphs from Mid-Miocene sediments in the SMS core show 'a sudden remarkably warm Antarctica' (Warney et al., 2009).

\subsection{Summary of conditions during CIROS-1 sedimentation}

During CIROS-1 sedimentation, the EAIS was dynamic, large and ice volume oscillated on orbital timescales (Fig. 2.12). The EAIS was wet-based for the entire duration of CIROS-1 sedimentation and had much more erosional power than the current EAIS, which has been cold-based for the past $\sim 14 \mathrm{Myr}$.

When CIROS-1 sedimentation initiated (Late Eocene, $37 \mathrm{Ma}$ ), the VLB was the focus of extension in the WARS and was rapidly subsiding in response to crustal thinning and extension (Fitzgerald, 2002; Barrett, 2009). The TAM, which had been exhumed since perhaps the Early Cretaceous, were approximately their current height, being uplifted at $\sim 100 \mathrm{~m} / \mathrm{Myr}$ (Fitzgerald, 2002) and had been eroded enough to expose the Granite Harbour Group (Barrett, 1989; Stern et al., 2005).

During early CIROS-1 sedimentation (Later Eocene and Early Oligocene), the EAIS was ephemeral, oscillated on orbital time scales and had a low ice volume. EAIS outlet glaciers flowed westward through the TAM and terminated on-land (Barrett, 2009). Late Eocene to Early Oligocene aged sediments occur below 366 mbsf in 
CIROS-1. These strata were deposited by glacial fluvial and shallow-marine depositional systems and include muds, sands and conglomerate and a minor iceberg rafted component. During this initial stage of CIROS-1 sedimentation, chemical weathering mechanisms were more significant that mechanical weathering, due to the warmer climate that prevailed (Barrett, 2007; Ehrmann, 1998).

Ice volume increased dramatically during the cooling of the Early Oligocene, during which the EAIS may have become $\sim 30 \%$ bigger than its present size (Zachos et al., 2001a). The $\sim 9$ Myr unconformity located at $~ 366$ mbsf in CIROS-1 (Roberts et al., 2003; Chapter 3, Fig 3.9), may have been caused by the overriding of the CIROS-1 site by an expanded EAIS. Ice volume remained high for the duration of the Oligocene and Early Miocene; with the EAIS no less than $\sim 40 \%$ of its current size (Pekar et al., 2006). During this time the ephemeral EAIS fluctuated on orbital time scales and flowed though outlet glaciers into the Ross Sea. CIROS-1 sediments deposited after the Early Oligocene cooling (above $~ 366$ mbsf) include diamicts, muds and sands, which are typically interspersed with drop stones, and record regular cycles of ice advance-retreat-readvance across the CIROS-1 drill site (as discussed in Chapter 3).

During the latest stages of CIROS-1 sedimentation (Latest Oligocene and Early Miocene), deposition of CIROS-1 strata was associated with proximal glaciers and glacial/fluvial systems (Fig. 2.13). During glacial times, an expanded ice sheet passed though the Ferrar Fiord and grounded on the continental shelf, whilst during interglacials, a reduced ice sheet with terrestrial margins caused sediments to be deposited by glacially fed fluvial systems (Barrett, 2007; Fig. 2.13). Due to the cooling of the climate from the Early Oligocene, mechanical weathering was the dominant erosional mechanism in the Late Oligocene and Early Miocene (Barrett, 2007; Ehrmann, 1998). By the Miocene, thermal subsidence became the dominant subsidence mechanism in the VLB and subsidence rates decreased to present day rates (Fielding et al., 2006). The EAIS increased in size significantly in response to the Mi-1 glaciation ( 22 Ma) (Naish et al., 2008a) during which the WAIS became established. Due to the increased volume of the EAIS and the presence of a WAIS, ice flow to the CIROS-1 site likely changed from an eastward (onshore-offshore) flow direction to a southern flow (e.g. as illustrated by McKay, 2008; Licht et al., 2005). 

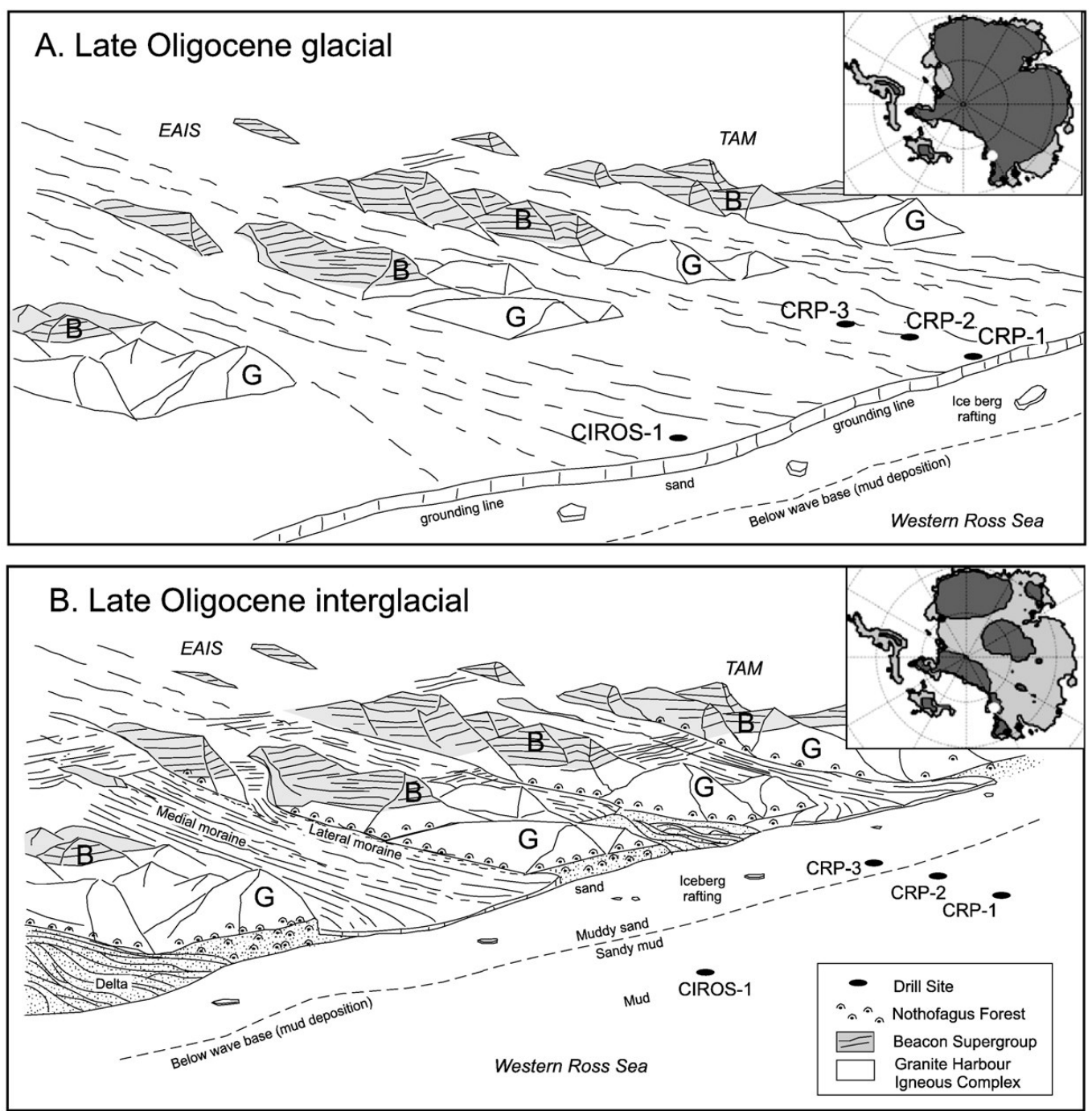

Figure 2.13: Glacial conditions of the Victoria Land coast from the Mid-Oligocene to Early Miocene. Estimated conditions during both glacial and interglacial periods are shown. This figure illustrates the types of depositional (and erosional) environments thought to have been present during CIROS-1 sediment deposition. During glacial times the EAIS overrode the site, most likely causing erosion of sediments and/or diamict deposition. During interglacial periods, sand, mud and conglomerate, interspersed with drop stones would have been deposited (source: Dunbar et al., 2008, modified from Barrett, 2007).

By 14 Ma, when CIROS-1 sedimentation had ceased, the EAIS was cold-based and non-erosive. This caused significant reduction in wet-based glacial reworking and may have lowered TAM exhumation rates. As a result, the landscape formed during the Eocene to Mid-Miocene from fluvial activity, uplift, escarpment retreat and fluvial down-cutting, has remained relatively unaltered for the past $\sim 14 \mathrm{Myr}$ (Fitzgerald, 2002). Tectonism that has altered the landscape since includes minor faulting, localised uplift and subsidence and formation of the MVG (Raymond, 1976). 


\title{
Chapter 3: A re-evaluation of the Cenozoic record of East Antarctic glacial history from the CIROS-1 drill core: implications for Late Oligocene ice volume change
}

\author{
Evelien van de Ven \\ Tim Naish \\ Chris Fielding \\ Mike Hannah
}

\subsection{Introduction}

The marine oxygen isotope records from the deep ocean (e.g. Zachos et al., 2001a), arguably provide the most detailed and complete picture of the stepwise global climate cooling during the Cenozoic. From an Eocene climatic optimum $(\sim 50 \mathrm{Ma})$, the Earth has experienced regular orbitally-paced glacial-interglacial fluctuations around a stepwise cooling climatic mean. The mean climate state has also experienced abrupt permanent shifts to cooler climates at:

(1) The Eocene-Oligocene boundary ( $34 \mathrm{Ma}$ ), when Earth cooled by $3-4{ }^{\circ} \mathrm{C}$ and the first large ice sheets are inferred to have developed on Antarctica (e.g. Kennett et al., 1975; DeConto and Pollard, 2003);

(2) The Oligocene-Miocene boundary ( $23 \mathrm{Ma})$ when a major transient glaciation is inferred to have grown the Antarctic ice sheet to $120 \%$ of its present day size (Naish et al., 2001; Pekar et al., 2006);

(3) The Middle-Late Miocene climate transition ( 13.8 Ma) when the East Antarctic Ice Sheet (EAIS) attained its present size and the West Antarctic Ice Sheet began to form (e.g. Lewis et al., 2007); and

(4) The Pliocene-Pleistocene boundary ( 2.6 Ma) when Earth experienced bi-polar glaciation with the development of a relatively stable cold polar WAIS (McKay et al., 2009) and a highly dynamic ice sheet on Northern Hemisphere continents (Maslin et al., 1999).

Owing to Antarctica's remoteness, its extensive sea ice apron and its extended ice sheet cover for the last $34 \mathrm{Myr}$, the Antarctic response to these Cenozoic climate changes inferred from deep-ocean sediment cores is only now being evaluated, through the recovery of well-constrained marine sedimentary records that directly sample past ice sheet oscillations from the Antarctic continental shelf. A drilling approach based on a closed-circulation, continuous wireline coring system used by the mineral industry has been applied from land and sea ice platforms in the 
McMurdo Sound region over the last $30 \mathrm{yrs}$. The first attempts at drilling from sea ice were made in the late 1970's with limited success and core recoveries of 50-60 \% (DVDP-15; Barrett and Treves, 1981; MSSTS-1; Barrett, 1986). During the 1980's and 1990's, progressively more sophisticated sea-riser technology was employed by the CIROS project (CIROS-1; Barrett, 1989) and CRP (CRST, 1999), which enabled the first deep Cenozoic records to be recovered (95-98\% core recovery). The results from sea ice-based drilling in the Ross Sea and McMurdo Sound have provided a framework for the Cenozoic (Late Eocene to Miocene) history of the Antarctic Ice Sheet.

CIROS-1 was drilled in the western margin of the VLB and recovered $702 \mathrm{~m}$ of glaciomarine strata (Figs. 3.1 and 3.2). Since the initial interpretation of the CIROS-1 core (Barrett et al., 1989) new evidence from both high-resolution deep-ocean climate proxies (e.g. Zachos et al., 1997; Pagani et al., 2005), and well-dated glaciomarine sedimentary cycles recovered by CRP (Naish et al., 2001, 2008a), $90 \mathrm{~km}$ north of CIROS-1 (Fig. 3.1), have revolutionised our understanding of Antarctic Ice Sheet behaviour during the Oligocene and Early Miocene. During this time, atmospheric carbon dioxide levels were as high as double pre-industrial levels (Pagani et al., 2005) and the Earth's average surface temperature was $3-4{ }^{\circ} \mathrm{C}$ warmer than present (Billups and Schrag, 2002). The Antarctic ice sheets were highly unstable, oscillating in response to orbital forcing (DeConto and Pollard, 2003; Naish et al., 2001) and driving global sea level change of up to $40 \mathrm{~m}$ amplitude (Naish et al., 2008a; Pekar et al., 2006). Moreover, the chronology of the CIROS-1 core has received a number of revisions as new-generation cryogenic magnetometers have enabled more detailed magnetostratigraphies to be developed (e.g. Wilson et al., 1998; Roberts et al., 2003) and high-latitude biochronologic schemes continue to improve (e.g. Hannah et al., 1997; Bohaty et al., 1998).

This paper presents a revised glaciomarine sequence stratigraphy for identifying ice advance and retreat cycles in the CIROS-1 drill core. This is based on approaches recently applied by Fielding et al. (2001) and Dunbar et al. (2008) to strata in the Cape Roberts core of similar age. The chronostratigraphic framework for the evaluation of Late Eocene to Early Miocene environmental changes in the core is revised by combining recently published improvements to the chronology and changes to the Geomagnetic Polarity Timescale (e.g. Gradstein et al., 2004). Finally, the new CIROS-1 chronostratigraphy is used to correlate orbitally-paced sequences 
of glacial advance and retreat during the Late Oligocene with the CRP-2A core and the global oxygen isotope record. This shows that both the Ferrar and McKay outlet glacier systems responded in phase to Milankovitch-scale climate cycles during cooling leading up to major ice expansion during the Mi-1 glaciation.

\subsection{Geological and glaciological setting}

CIROS-1 penetrated numerous unconformity-bound Late Eocene to Early Miocene sedimentary cycles (Barrett, 1986). These record the advance and retreat of a laterally-continuous ice margin across the western Ross Sea continental shelf. The strata accumulated some kilometres off the coast as part of a laterally-extensive seaward-thickening wedge in the VLB (Fig. 3.1); a structural half-graben, approximately $350 \mathrm{~km}$ long, hinged on its western side at the TAM front (Fig. 3.2). Major rifting in the VLB has occurred since the latest Eocene, perhaps having been initiated in the Cretaceous, and has accommodated up to $10 \mathrm{~km}$ of sediment (Cooper and Davey, 1985; Brancolini, 1995).

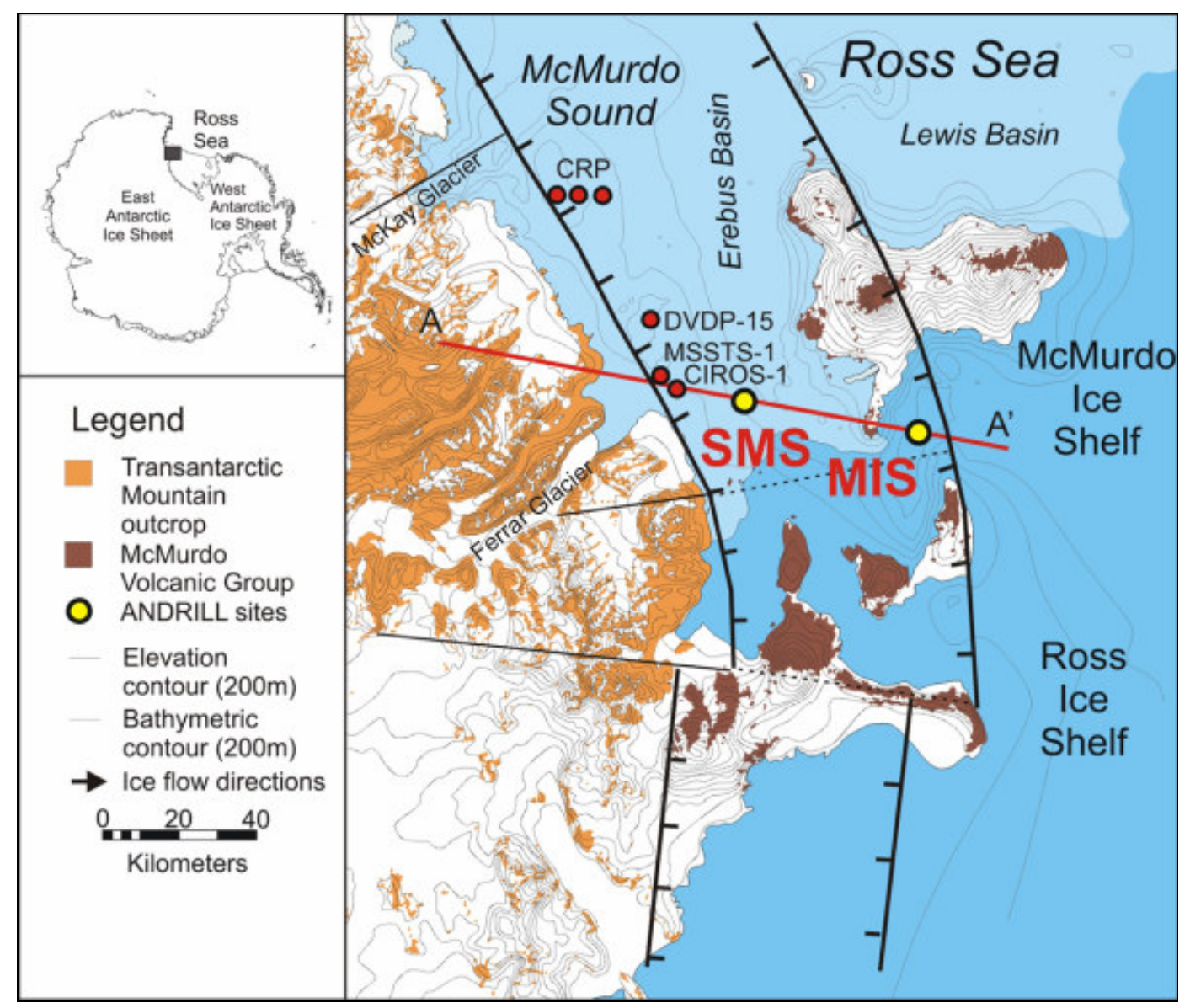

Figure 3.1: Key geographical and structural features of the VLB. CIROS-1 is located $20 \mathrm{~km}$ offshore at the mouth of the Ferrar Fiord. Note the location of the CRP drill cores off the McKay Glacier (source: Naish et al., 2006). 


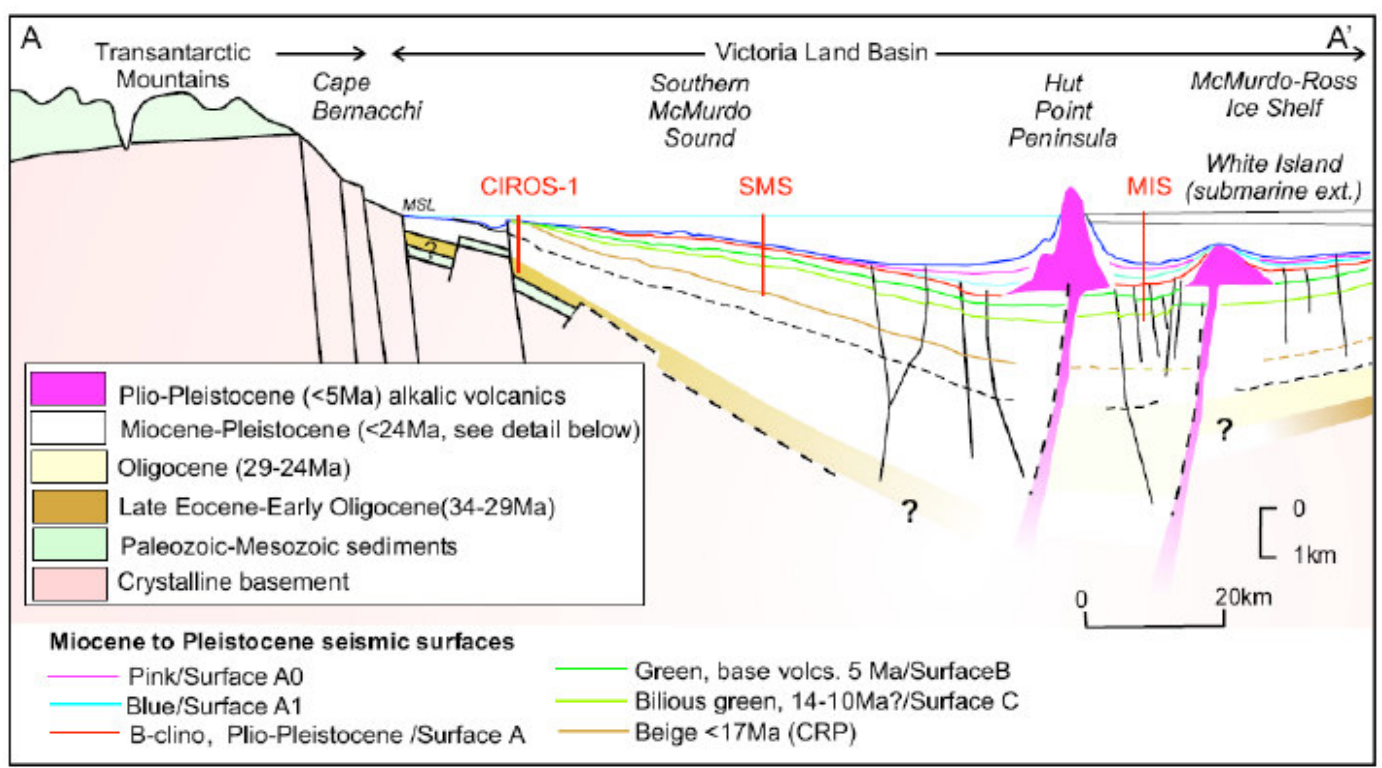

Figure 3.2: Cross-sectional view of the tectonic setting of the VLB, VLB stratigraphy and simplified geology of the TAM in SVL. Note the location of CIROS-1 proximal to the TAM and on the western margin of the Ross Sea and VLB (source: Naish et al., 2006).
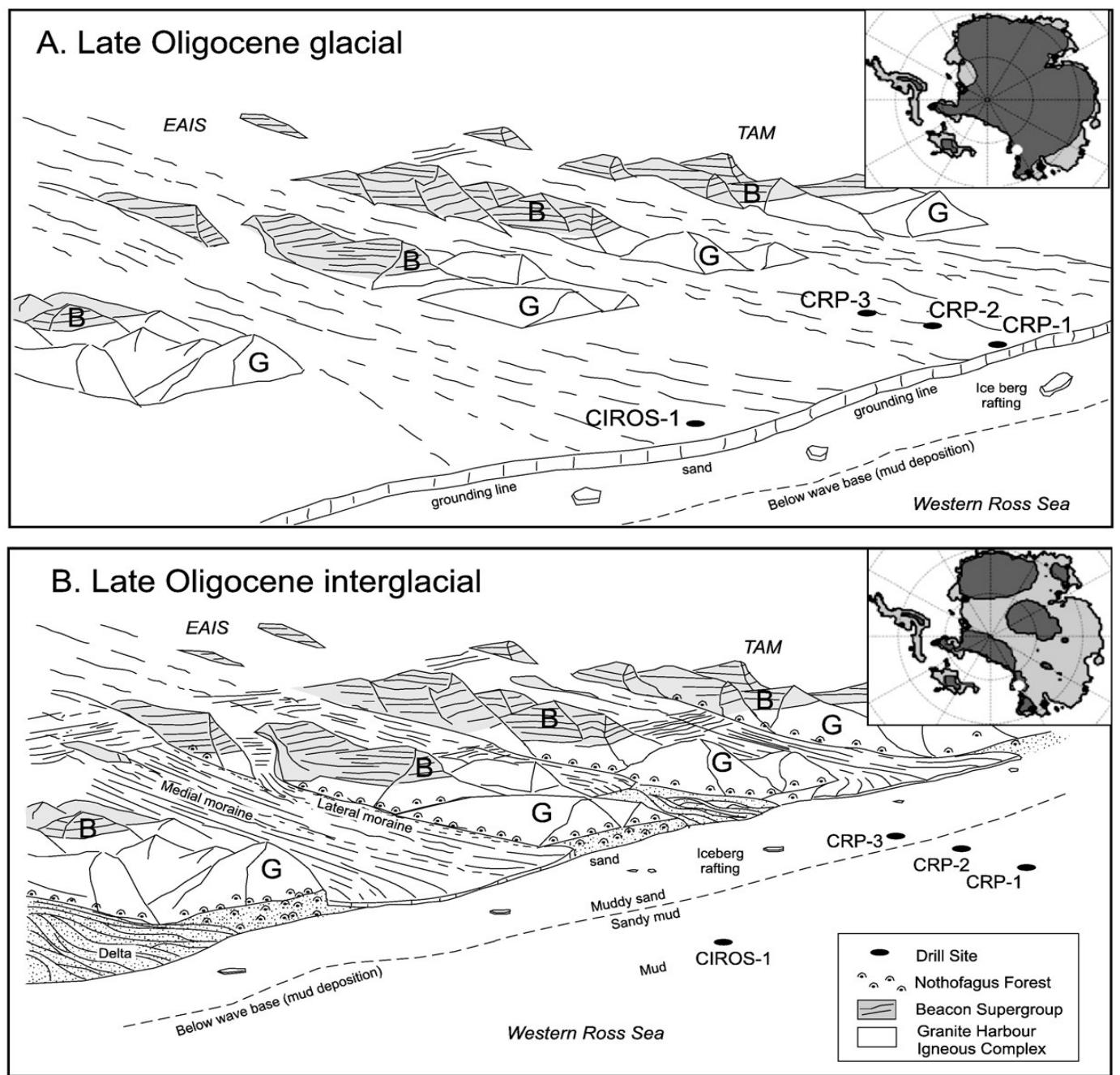

Figure 3.3: Glacial conditions of the Victoria Land coast from the Mid-Oligocene to Early Miocene. Estimated conditions during both glacial and interglacial periods are shown. This figure illustrates the types of depositional (and erosional) environments thought to have been present during CIROS-1 sediment deposition. During glacial times the EAIS overrode the TAM and terminated over the site, causing erosion of sediments and/or deposition of grounding-line proximal facies. During interglacial periods, sand, mud and conglomerates, interspersed with iceberg rafted drop stones were deposited (source: Dunbar et al. (2008) modified from Barrett, (2007)). 
The geometry of the strata is evident in seismic data (e.g. Fielding et al., 2006) oriented parallel to the coast (Fig. 3.2). During the Late Oligocene-Early Miocene periods of glacial advance, an interior ice sheet (the EAIS) fed through outlet glaciers to a laterally extensive ice terminus which extended well out onto the continental shelf east of the CIROS-1 drill site. In periods of ice retreat, the drill site lay off an open, wave-dominated, coast, with deposition of mud and occasional debris from floating ice (Fig. 3.3). Thus cycles of ice margin advance and retreat across the continental shelf have been viewed as cycles of expansion and contraction of the EAIS recorded as unconformity bound sequences (e.g. Dunbar et al., 2008).

\subsection{Previous stratigraphic and facies descriptions}

A variety of sedimentological, facies and environmental interpretations of the CIROS-1 core have been proposed since publication of the initial science report volume in 1989, which drew heavily on procedures established for previous and ice proximal drill holes in southern McMurdo Sound (MSSTS-1, Barrett, 1986; CIROS2, Pyne et al., 1985). Hambrey et al. (1989) presented a detailed sedimentological and stratigraphic description of the core, utilising Robinson's original descriptions (Barrett, 1989). The strata were considered to show a strongly cyclical glacial influence throughout. Conglomerates, diamictites, sandstones and mudstones were reported in varying amounts along the length of the core, and were interpreted to represent fluctuations in the relative proximity of the East Antarctic ice margin to the drill site. Most notably, diamicts, though more common in the upper section (Barrett, 1989), were reported through the entire length of the core, suggesting proximal continental glaciation for the entire duration of deposition (Hambrey et al., 1989). A number of unconformities underlay ice proximal diamictites, and were interpreted as the result of erosion by an advancing glacier or ice sheet terminus, with a major unconformity identified at 366 mbsf (Hambrey et al., 1989), that may have resulted from both glacial and longer term tectonic influences.

Fourteen lithofacies were recognised in the CIROS-1 core (Hambrey et al., 1989) including massive, weakly- and well-stratified diamicts, sandstones, mudstones, conglomerates and breccias, associated with a spectrum of glaciomarine environments from ice contact/grounding line proximal to open marine. In addition, the ice proximity and water depth during deposition were constrained using both the facies analysis and grainsize characteristics of a wave-graded shelf (Barrett, 1989). 
The latter was only appropriate when glaciers were terminating on land during interglacial times and the coastline and shelf were wave-dominated.

There is a marked unconformity located at $\sim 366$ mbsf. The presence of breccias and diamicts representing regular advances of the grounding line over the drill site in the sediments above this unconformity, and their lesser occurrence below $366 \mathrm{mbsf}$, led Fielding et al. (1997) to hypothesise that this unconformity represented a major shift in depositional environment, associated with a fundamental change involving climate cooling and an increase in the size of the EAIS. However, the presence of icebergrafted debris though the entire length of the core implied that coastal outlet glaciers (e.g. paleo-Ferrar or adjacent fjiordal glaciers) were calving at the coastline throughout deposition of the core. The deposition of the sub-366 mbsf section was reported to have occurred in relatively deep water setting (mid to outer shelf), whilst the water depth during deposition of the upper section was variable (shelf to emergent; Barrett, 1989). This implied that a major shoaling of the basin occurred across the (then) Mid-Oligocene unconformity due to tectonic, glacial and/or eustatic influences. While glaciomarine sediments dominated above 366 mbsf, sediment gravity flow sediments were inferred to have been deposited directly from coastal fan-deltas during the sedimentation of the lower interval of the section with significantly less ice-proximal influence.

Fielding et al. (1997) re-logged the CIROS-1 strata using the heavily degraded and sampled working half of the core. This in part may explain the considerable reduction in the number of diamicts identified above the 366 mbsf unconformity, and the absence of diamicts reported beneath it. Rather, these sections were logged as (potentially) fluvially-derived conglomerates or mudstones and sandstones with dropstones. Fielding et al. (1997) removed all breccias below 366 mbsf and reported the occurrence of these exclusively above 366 mbsf. The revised facies model for CIROS-1 core presented by Fielding et al. (1997) consisted of seven lithofacies and four facies associations. These included sandstone, siltstone, mudstone, breccia, diamict and conglomerate facies. Lithofacies were interpreted in terms of deposition in a range of environments from coastal fluvial plain, delta, wave-dominated coastline and shelf, with significantly less influence from glaciomarine, groundingline-proximal deposition. The sedimentary characteristics of the strata show that changes in lithofacies-stacking patterns through time primarily reflect the proximity of the ice sheet grounding zone and changes in relative sea level driven by associated mass changes in the EAIS. 
Based on these lithofacies-stacking relationships, the associations and cycle-bounding unconformities, Fielding et al. (1997) undertook the first sequence stratigraphic analysis of the core. Sequence boundaries were identified by abrupt facies dislocations. At least six cycles were recognised in the upper section of the core (<366 mbsf). These sequences consisted of inconsistent but prevalent groupings of diamict, breccia and conglomerate deposited in ice proximal and ice contact glaciomarine environments during advance and withdrawal of the grounding line over the drill site. Mud-dominated facies represent deposition in more ice-distal marine environments during interglacial ice minima. Sharp erosional surfaces at the base of diamictites truncating underlying shelf facies were termed glacial surfaces of erosion, and represented erosion by the glacier entering the marine environment. Diamictite, conglomerate and breccia facies overlying the glacial surface of erosion represented ice contact (lodgement till) or grounding zone deposition. Typically facies successions fined upwards into interstratified sandstones and siltsones with iceberg rafting and massive biotrubated mudstones as the grounding line progressively retreated from the drill site. These fining upwards and progressively less ice influenced cycles were considered to represent retreat of the grounding-line in concert with rising eustatic sea level. Periods of glacial advance are generally marked by glacial surfaces of erosion and occasionally, a shallowing-upwards regressive facies succession is preserved below the overlying glacial surface of erosion. The latter represents shallowing from shelf to shoreline water depths and relative sea level fall prior to glacial over-riding during the next advance. Only two sequences were recognised by Fielding et al. (1997) in the sub-366 mbsf section of the core. These consist of packages of conglomerate and mudstone, the conglomerate having been deposited during glacial advances as outwash from a relatively distal, land-terminating glacier.

Below we present a revised stratigraphy and facies model for the CIROS-1 drill core, based on a redescription of the better preserved archived half of the core stored at the Florida State University Antarctic Core Repository.

\subsection{Revised lithofacies analysis of the CIROS-1 Core}

Facies analysis of CIROS-1 strata was conducted using the facies scheme developed for CRP-3 (Fielding et al., 2001) which was based on previous schemes used for CRP 1 (CRST, 1998) and CRP2/2A (CRST, 1999). The facies scheme, including lithological description and interpretation, is summarised in Table 1, and more details 
of facies and inferred deposition environments are available in the above references.

In this revised scheme, seven facies are identified. They are numbered in an order that spans a 'deepest water and/or most ice-distal' to 'shallowest water and/or most ice-proximal' depositional spectrum. The vertical occurrence of the lithofacies in the

CIROS-1 core is shown in Figure 3.4.

Table 3.1: Lithofacies scheme developed for CIROS-1 core glaciomarine sediments and their interpreted depositional processes and environments (modified after Fielding et al., 1997 and Fielding et al., 2001).

\begin{tabular}{|c|c|c|c|}
\hline Facies & Lithology & Facies characteristics & Interpretation \\
\hline 1 & $\begin{array}{l}\text { Fine-grained siltstone, } \\
\text { locally interlaminated } \\
\text { with very fine- to fine- } \\
\text { grained sandstone }\end{array}$ & $\begin{array}{l}\text { Horizontal stratification, } \\
\text { sparse-to-common } \\
\text { bioturbation, sedimentary } \\
\text { intrusions, invertebrate shells, } \\
\text { dispersed gravel }\end{array}$ & $\begin{array}{l}\text { Offshore marine to } \\
\text { glaciomarine (shelfal, } \\
\text { below storm wave } \\
\text { base) }\end{array}$ \\
\hline 2 & Sandy siltstone & $\begin{array}{l}\text { Rare stratification, abundant } \\
\text { bioturbation, sedimentary } \\
\text { intrusions, invertebrate shells, } \\
\text { dispersed gravel }\end{array}$ & $\begin{array}{l}\text { Offshore transition } \\
\text { (between storm and } \\
\text { fair-weather wave } \\
\text { base), with iceberg } \\
\text { and/or sea ice } \\
\text { rafting }\end{array}$ \\
\hline 3 & $\begin{array}{l}\text { Muddy (interstratified), } \\
\text { very fine to fine-grained } \\
\text { sandstone }\end{array}$ & $\begin{array}{l}\text { Rare-to-common stratification } \\
\text { (flat and low-angle lamination, } \\
\text { hummocky cross-stratification, } \\
\text { ripple cross-lamination), } \\
\text { abundant bioturbation, soft- } \\
\text { sediment deformation, } \\
\text { invertebrate shells, dispersed } \\
\text { gravel }\end{array}$ & $\begin{array}{l}\text { Distal lower } \\
\text { shoreface, with } \\
\text { iceberg and/or sea } \\
\text { ice rafting }\end{array}$ \\
\hline 4 & $\begin{array}{l}\text { Well-sorted, stratified } \\
\text { sandstone }\end{array}$ & $\begin{array}{l}\text { Pervasive stratification (flat } \\
\text { lamination, cross-bedding, } \\
\text { ripple cross-lamination), } \\
\text { bioturbation absent-to-sparse, } \\
\text { invertebrate shells, dispersed } \\
\text { or layers of gravel }\end{array}$ & $\begin{array}{l}\text { Middle to upper } \\
\text { shoreface, possibly } \\
\text { on delta fronts, } \\
\text { minimal iceberg } \\
\text { and/or sea ice } \\
\text { influence }\end{array}$ \\
\hline 5 & $\begin{array}{l}\text { Sandy conglomerate } \\
\text { and clast-rich sandstone }\end{array}$ & As for Facies 4 & $\begin{array}{l}\text { As for Facies } 4 \text {, plus } \\
\text { possible delta } \\
\text { platform }\end{array}$ \\
\hline 6 & $\begin{array}{l}\text { Intraformational } \\
\text { mudstone clast breccia }\end{array}$ & $\begin{array}{l}\text { Sparse stratification, } \\
\text { sedimentary intrusions, no } \\
\text { bioturbation, sparse shell } \\
\text { debris }\end{array}$ & $\begin{array}{l}\text { Sedimentary gravity } \\
\text { flow deposits } \\
\text { triggered by seafloor } \\
\text { failures }\end{array}$ \\
\hline 7 & Diamictite & $\begin{array}{l}\text { Weak (particularly in fine- } \\
\text { grained partings) stratification } \\
\text { to massive, soft-sediment } \\
\text { deformation, sedimentary } \\
\text { intrusions, dropstone textures, } \\
\text { sparse shell debris }\end{array}$ & $\begin{array}{l}\text { Grounding zone to } \\
\text { subglacial associated } \\
\text { with tidewater } \\
\text { glaciers }\end{array}$ \\
\hline
\end{tabular}




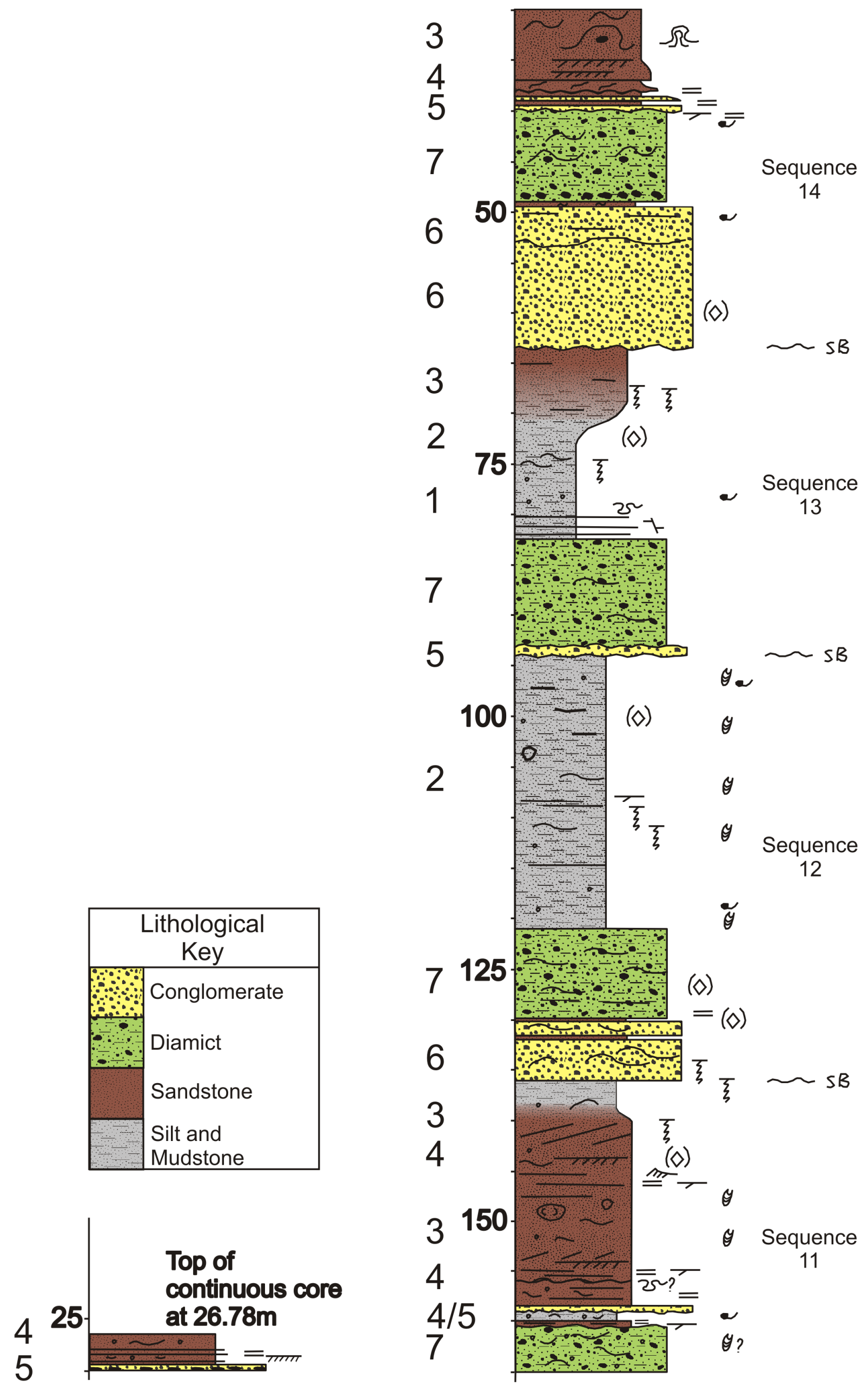




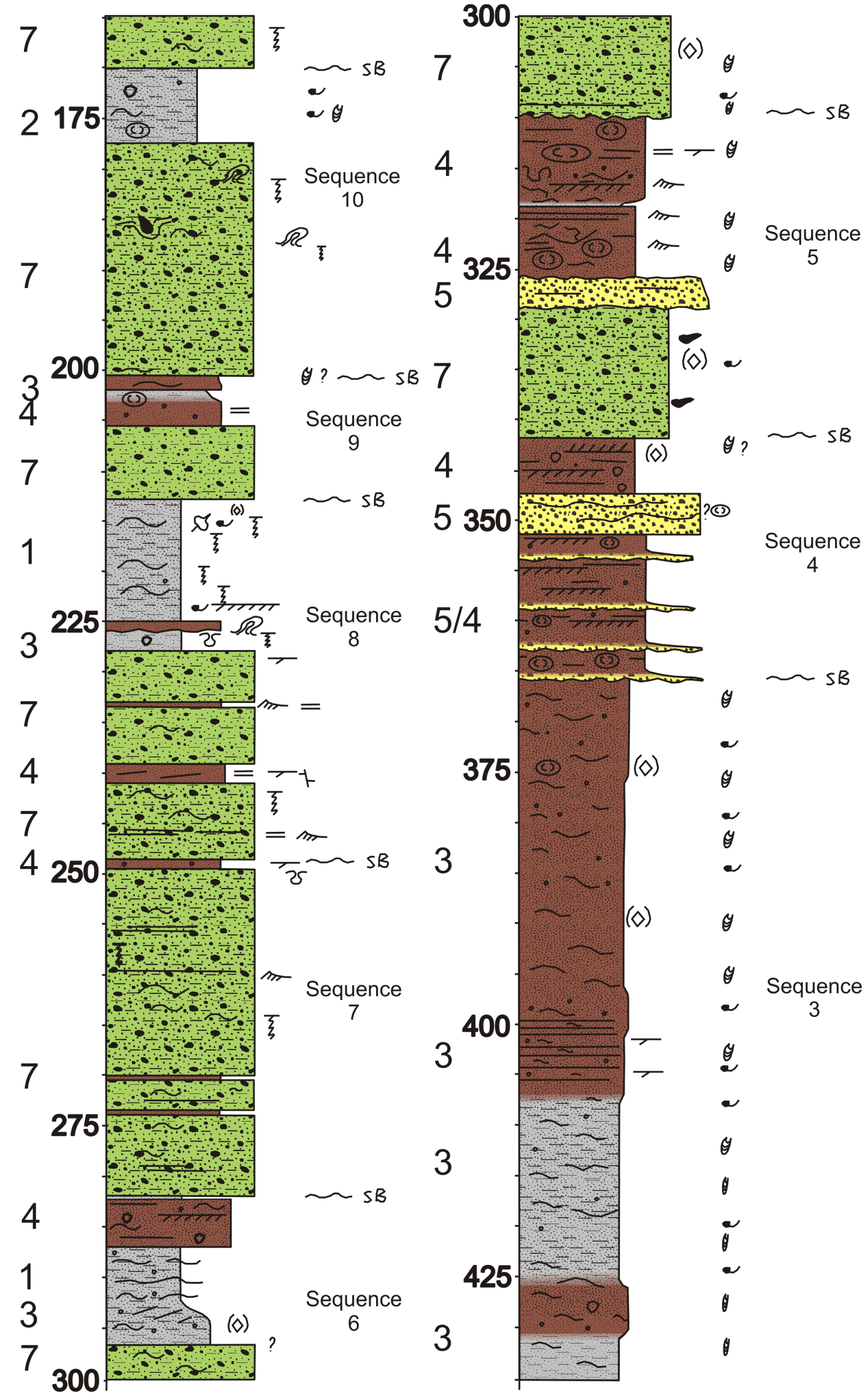




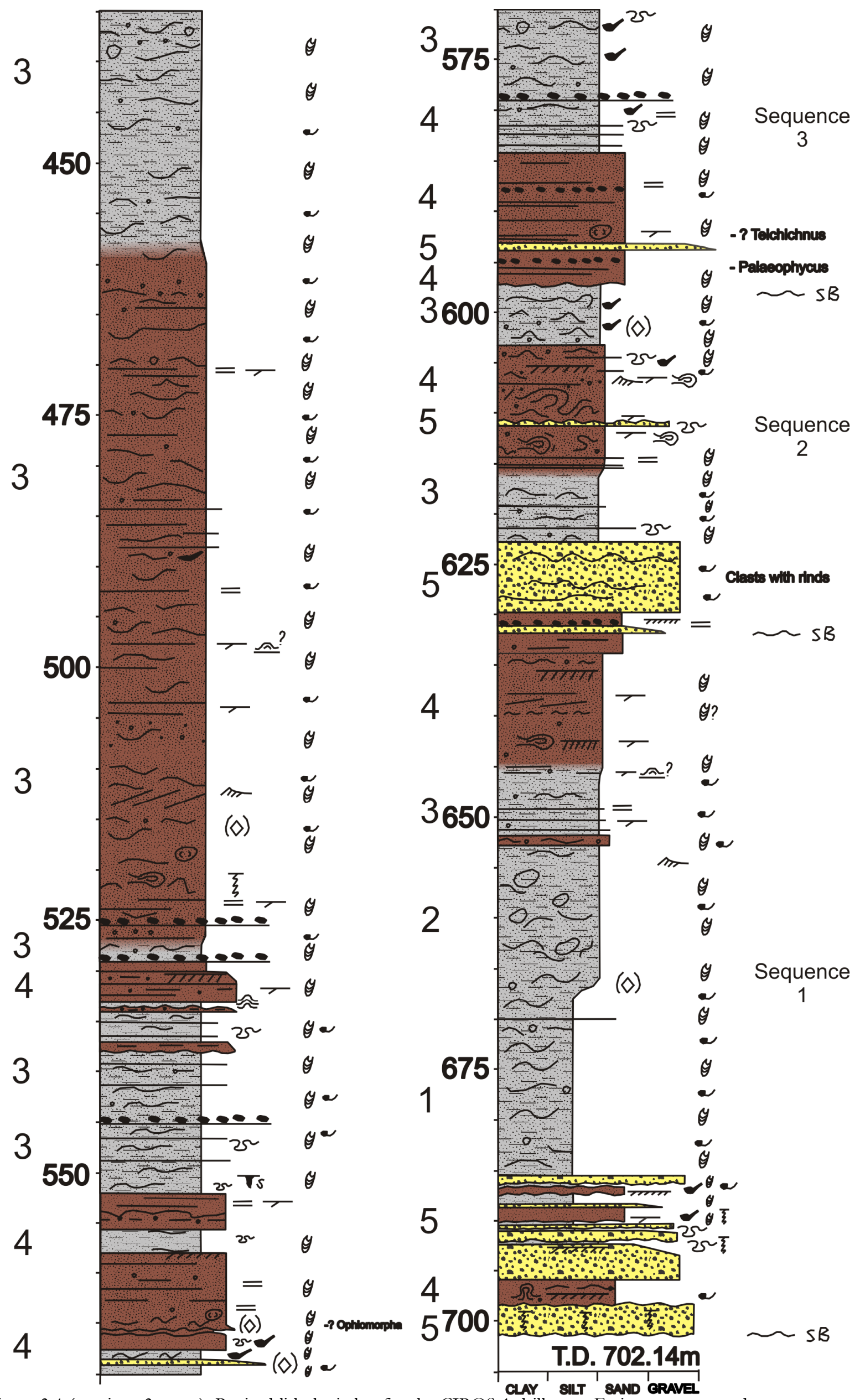

Figure 3.4 (previous 3 pages): Revised lithologic log for the CIROS-1 drill core. Facies are annotated using numbers from Table 3.1. Sequence boundaries (SB) predominantly representing glacial surfaces of erosion (GSE), bound facies cycles of ice advance retreat and readvance across the drill site in concert with eustatic sea level fluctuations. Sequences are noted. 


\subsection{Sequence stratigraphy of sediments deposited on an open, wave-dominated glaciated continental margin}

Dunbar et al. (2008) presented a sequence stratigraphic model for sediments deposited on a glaciated continental margin (Fig. 3.5), based on an analysis of the CPR cores, which is applied here to stratigraphic interpretation of the CIROS-1 lithofacies. A complete and idealised motif for a cycle of glacial advance and retreat and coupled sea level rise and fall is given in Figure 3.6 (Motif A). It contains repetitive and predictable facies successions that are stacked vertically and bounded by unconformities (Fielding et al., 2001). At the base is the sequence boundary, the glacial surface of erosion (GSE), which forms as the glacier advances over the site (Fig. 3.5D and E; Fig. 3.6). Above the GSE, stratified and massive diamicts are deposited in association with graded conglomerates and interstratified mudstone and sandstone in ice-proximal and grounding zone environments. As the glacier retreats and sea level rises, progressively finer-grained sediments are deposited in this glacial transgressive systems tract (Fig. 3.5A and B; Fig. 3.6). At the sea level maximum and interglacial ice volume minima, the glacial highstand systems tract is deposited, consisting of sandstones and mudstones and condensed shell beds with the lowest abundance of ice-rafted debris (Fig. 3.5 C; Fig. 3.6). During glacial periods, relative sea level falls, the glacier terminus advances and a progressively coarsening-upwards regressive, wave-influenced shelf-to-shoreline facies succession is deposited as a glacial regressive systems tract (Figs. 3.5 and 3.6). Superposed onto this, the GSE marks erosional truncation of underlying regressive and highstand facies during ice advance, with deposition of sub-glacial diamictite immediately overlying the GSE (Figs. 3.5 E and 3.6 Motif A). The idealised sequence described above is not always fully preserved. Preservation is dependent on rate of subsidence, sediment supply, glacial erosion and base-level change. Additionally, the stratigraphic architecture of a glaciomarine sequence is strongly controlled by the environment in which the glacier terminates. For example the above architecture represents deposition by a marineterminating ice sheet (Fig. 3.6 Motif A). For glaciomarine sequences influenced by a land-terminating glacier feeding a fluvial deltaic system, the resulting facies succession is different. Such sequences are dominated by fluvially-derived conglomerates and shallow-marine sandstones (with or without ice rafting) deposited during glacial periods, and shallow shelf sandstones and sandy-mudstones deposited during interglacial periods. Sequence boundaries are controlled by wave-base erosion due to base-level changes rather than by the proximity of the grounding line (Fig. 3.6 Motif B). 
A

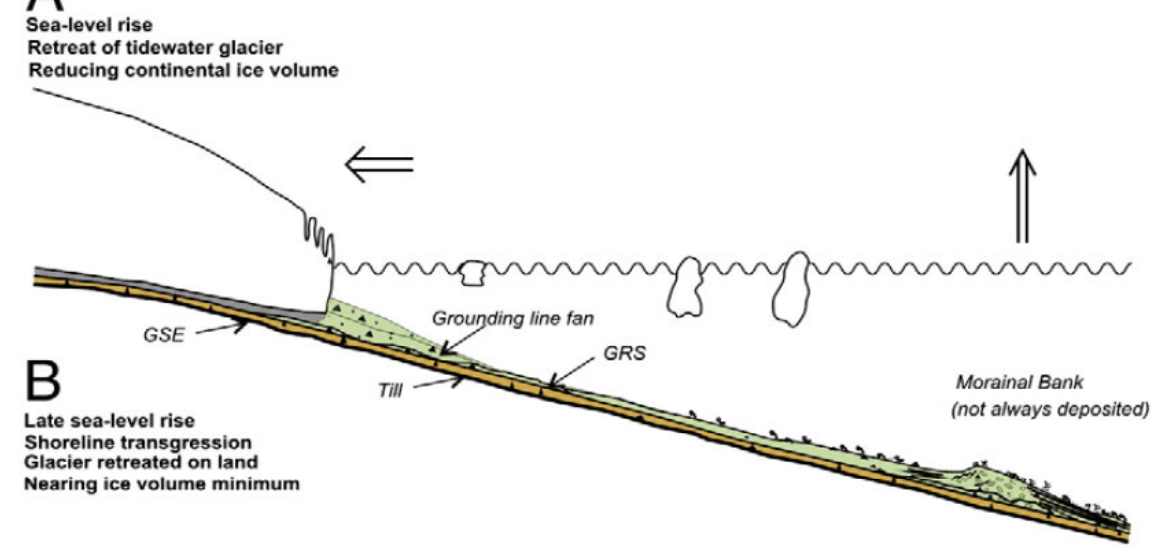

S Retrogradational grounding line fan

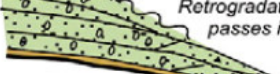

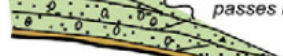

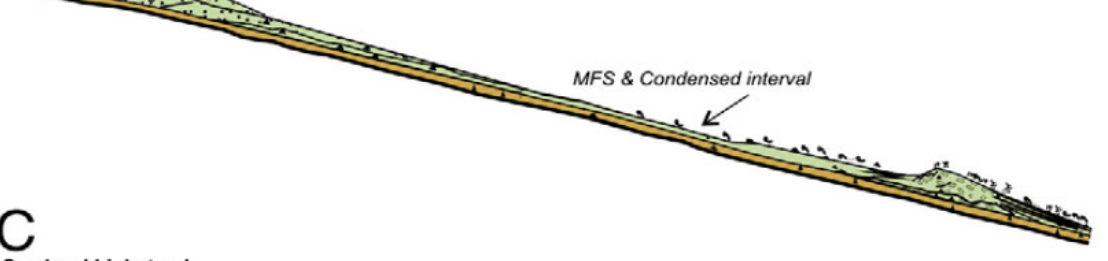
Sea-level highstand
Early shoreline regression
Interglacial ice volume minimum Fluvial plain Wave influenced delta/coastline

o d onn

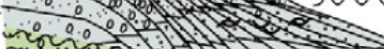

in
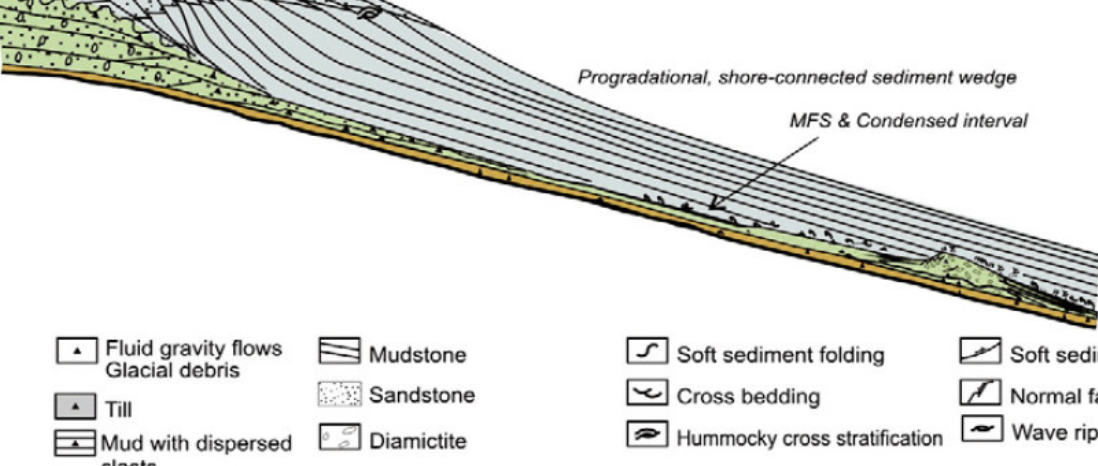

[S Soft sediment folding

Soft sediment thrusting

1 Till Mud with
clasts
D

Seat-evel tail

Increasing continental ice volum

$\gamma$
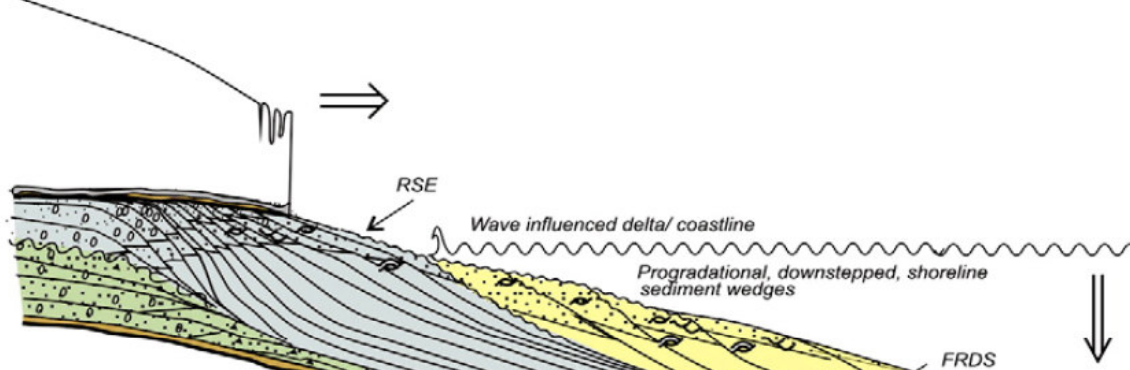

E

Approaching sea-level lowstand Advancing tidewater glacier

Nearing ice vo
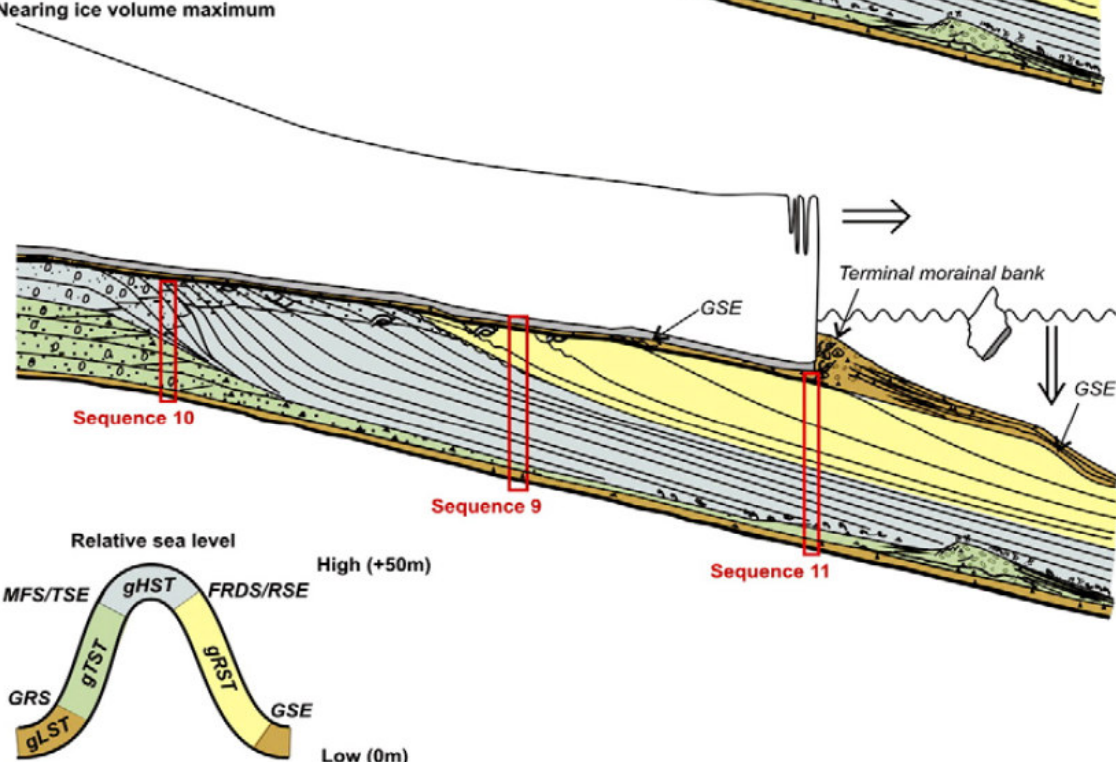

Low $(0 \mathrm{~m})$

Benthic life $\square$ Lowstand systems $\square$ Transgressive systems $\quad \square$ Highstand systems tract $\quad \square$ Regressive systems 


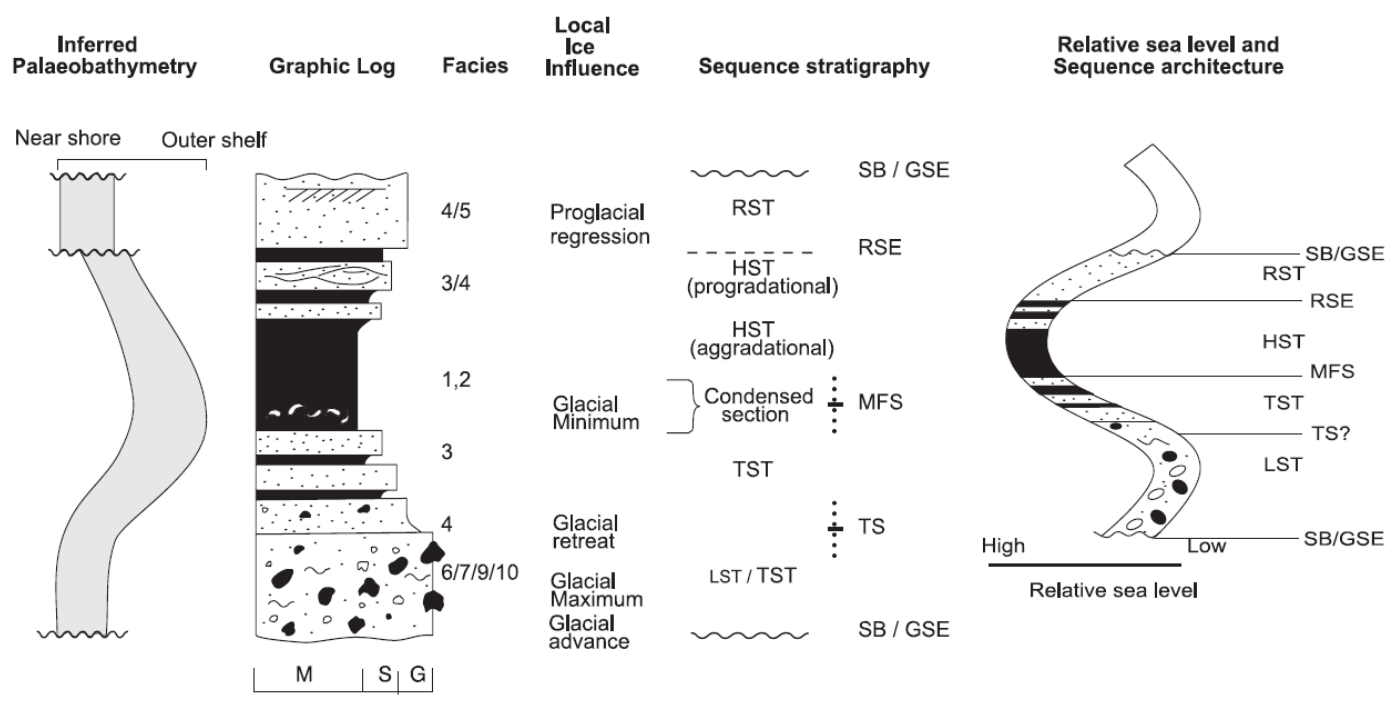

IDEALISED SEQUENCE MOTIF B

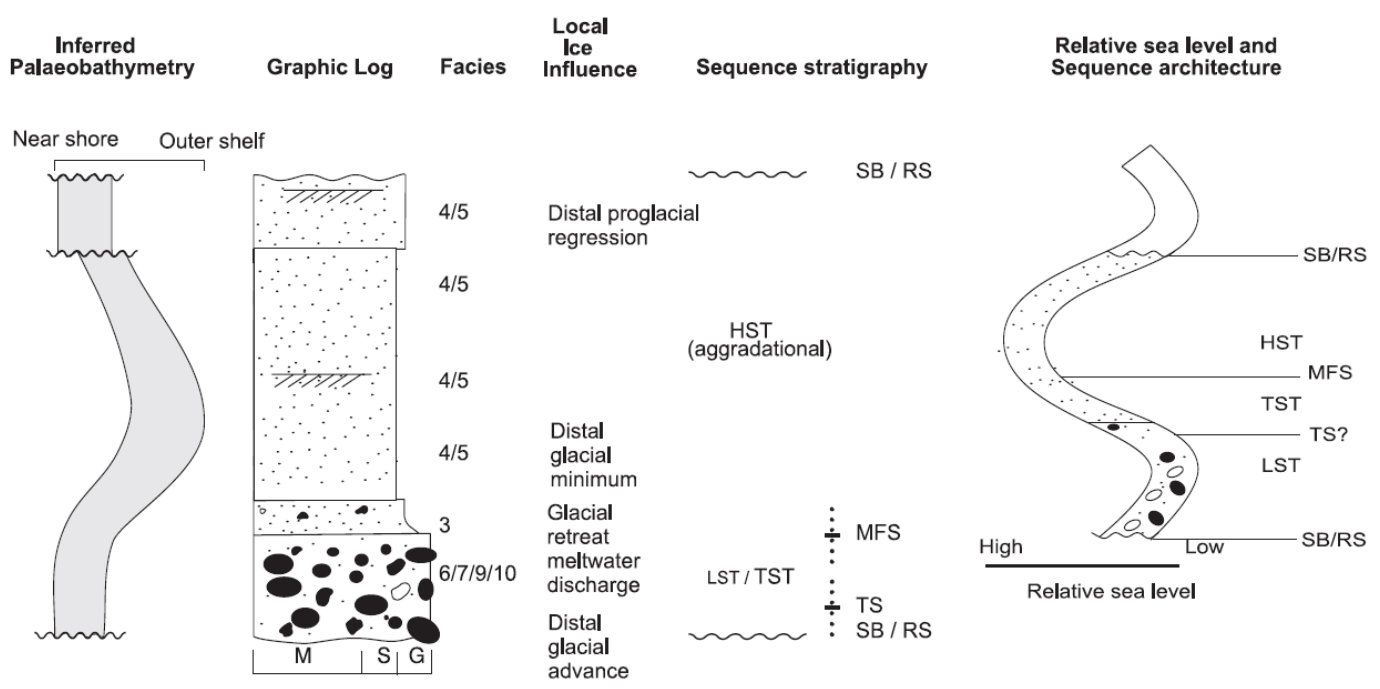

Figure 3.6: Typical glaciomarine sequence stratigraphic architecture shown with respect to a cycle of relative sea level and local ice influence. In Motif A the grounding line advances into the marine environment and passes across the drill site producing a GSE at the sequence boundary. In Motif B the grounding line remains on land and issues sub-glacial sediment into a fluvio-deltaic system. The sequence boundary represents subaerial exposure during base-level fall and/or wave base erosion during ensuing transgression of the shoreline (source: Fielding et al., 2001).

\subsection{New sequence stratigraphic analysis of the CIROS-1 core}

The revised sequence stratigraphy of the CIROS-1 drillhole is based on a redescription of the better-preserved archived half of the core, and utilises the facies scheme in Table 3.1 and the glaciomarine sequence stratigraphic model of Dunbar et al. (2008) (Fig. 3.5). The succession has been divided into 14 sequences (Fig. 3.7). There are two major "motifs" or sequence styles represented in the core, with sequences 1-4 (below $342 \mathrm{mbsf}$ ) showing a fundamentally different style from 
sequences 5-14 (above $342 \mathrm{mbsf}$ ). It is therefore possible that the fundamental discontinuity in the core may not be at 366 but at 342 mbsf.

Sequences 1-4 are relatively complete (in terms of systems tracts), containing both fining-upward and overlying coarsening-upward facies successions. These sequences are typically thick and bounded by packages of well-washed sandy conglomerates deposited as distal outwash and displaying no direct evidence of ice contact (Figs 3.4 and 3.7). For this reason, we do not use the term "Glacial Surface of Erosion" to describe sequence boundaries in this part of the core. Rather, such sequence boundaries represent erosion during base level changes associated with subaerial exposure and/or transgressive wave base erosion. These sequences resemble aspects of Motif B sequences in CRP-3 (Fig. 3.6), in that they preserve well-developed regressive shoreline facies assemblages in their upper parts. They also preserve abundant bioturbation and shell fossils

Sequences 5-14 are incomplete, strongly top-truncated, thin, and contain finingupward trends but not overlying coarsening-upward trends (Fig. 3.7). These sequences are bounded by diamictites representing ice-proximal proglacial to possibly subglacial settings and show direct evidence of glacial influence. Sequences 5-14 resemble those in CRP-2 and-1 (Fig. 3.6 Motif A) and do not preserve a regressive shoreline facies assemblage, only intermittently preserve bioturbation, and have sparse shell fossils. 
Relative Sea- Facies and interpretation level
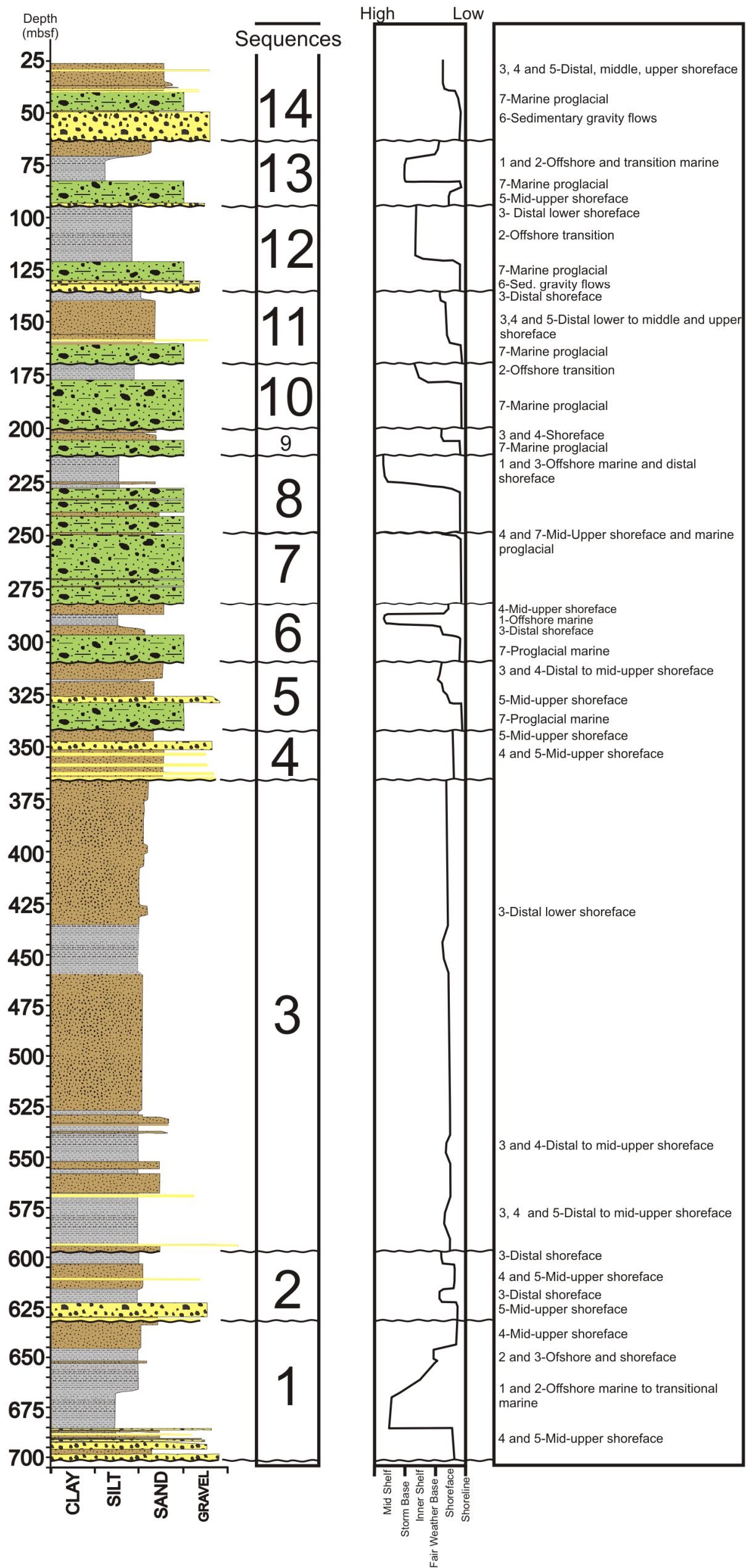

Figure 3.7: Composite sequence stratigraphic interpretation of the CIROS-1 log showing sequence boundaries, facies and interpretations. Fluctuations in relative sea level inferred from these are shown. 


\subsection{Previous chronostratigraphy for the CIROS-1 Core}

The original chronostratigraphic analysis of CIROS-1 core inferred that the sediments were deposited during the Early Oligocene to the Early Miocene (Fig. 3.8). The age of the sub-366 mbsf section of the core has been problematic due to generally poorly-preserved fossils, their generally low abundance and diversity and the presence of older reworked fossils. Harwood (1989) used siliceous (diatom) microfossils to constrain the depositional age, and reported an Early Oligocene age for the base of the core, whilst the top was at least Middle Miocene. Above 502 mbsf, the presence of well-preserved and rich Oligocene and Miocene species made the age determination relatively robust for sections therein.

However, between 702-502 mbsf the siliceous microfossils were particularly poorlypreserved due to diagenetic dissolution of the diatoms. Both Eocene and Oligocene siliceous microfossils were found in this section, and as no age-diagnostic Eocene species were found, an Early Oligocene age was attributed and a hiatus of $4 \mathrm{Myr}$ was estimated for the 366 mbsf unconformity.

Webb (1989) used benthic foraminifera to constrain the age of the core. Like Harwood (1989), Webb (1989) concluded a Late Oligocene-Early Miocene age for the upper half of the core. An Early Oligocene age was assigned to the section below $366 \mathrm{mbsf}$, despite the presence of Eocene foraminifera, which were assumed to be reworked. Terrestrial (Mildenhall, 1989) and marine palynology (Wilson, 1989) both showed low recovery and diversity of taxa, with a high degree of reworking. Wilson (1989) found many dinoflagellate cysts of Eocene age below $366 \mathrm{mbsf}$ of the core, which were attributed to reworking. Thus an Early Oligocene age was assigned to the lower section which was consistent with ${ }^{87} \mathrm{Sr} /{ }^{86} \mathrm{Sr}$ ages from mollusca providing a minimum age of earliest Oligocene for the very lowest section of the core (679 mbsf) (Barrera, 1989).

Edwards and Waghorn (1989) used calcareous nannofossils to constrain the core's chronology. Similarly to previous studies, a low species occurrence and diversity was noted. Based on the presence of potentially in situ Eocene-age species in the lower section of the core, a Late-Middle Eocene age was assigned to the sub-366 mbsf section, and an Early Miocene age was inferred for the upper section. In addition, the shift from diamict-poor sediments to diamict-dominant sediments at $366 \mathrm{mbsf}$ was attributed to abrupt cooling associated with growth of the EAIS across the 
Eocene-Oligocene boundary. Rieck (1989) constructed an initial magnetic polarity zonation for the core. A number of processes were reported to have masked the detrital magnetisation and thus a partial polarity zonation was constructed. As with Hambrey et al. (1989), Rieck (1989) assigned an Early Oligocene-Early Miocene chronology to the core, producing a magnetostratigraphic interpretation that was consistent with the available biostratigraphic data.

Owing to the considerable amount of ambiguity associated with the early chronology of CIROS-1, a substantial amount of effort has been invested to further constrain the core's chronology. Wei (1992) used calcareous nannofossils to constrain the age model for the sub-366 mbsf section of the core. As the assemblages were of similar composition to other 'presumed coeval assemblages of ODP legs 113 and 119' and 'consistent with other Southern Ocean sites' (Watkins, 2007), Wei (1992) concluded the nannofossils were not reworked and assigned a Late Eocene age to the studied interval.

Hannah (1994) presented a chronology with similar ages to those assigned by previous workers to the upper 366 mbsf. A Mid-Eocene age was assigned to the very bottom section. Hannah (1994) put the Eocene-Oligocene boundary at 500 mbsf, with a section of Early Oligocene strata below the $366 \mathrm{mbsf}$ unconformity.

In 1997, a volume on new studies conducted on CIROS-1 was published in the journal Terra Antarctica. In it, Hannah et al. (1997) further developed the dinoflagellate-based chronology of Hannah (1994) with a focus on the sub-366 mbsf section. In this section dinoflagellates are moderately diverse and abundant and are of Eocene and Oligocene age. Originally, the presence of Eocene dinoflagellates was attributed to reworking (Wilson, 1989). However, a strong relationship between glacial proximity and melt-water influence, and the distribution of dinoflagellate assemblages, led Hannah et al. (1997) to consider the Eocene microfossils as in situ. A Late Eocene age was assigned to the lower section of the core, and an Early Oligocene age was reported for the sediments directly below the $366 \mathrm{mbsf}$ unconformity. The Eocene-Oligocene (E-O) boundary was reported to be located at $\sim 460$ mbsf (Figs. 3.8 and 3.9). 


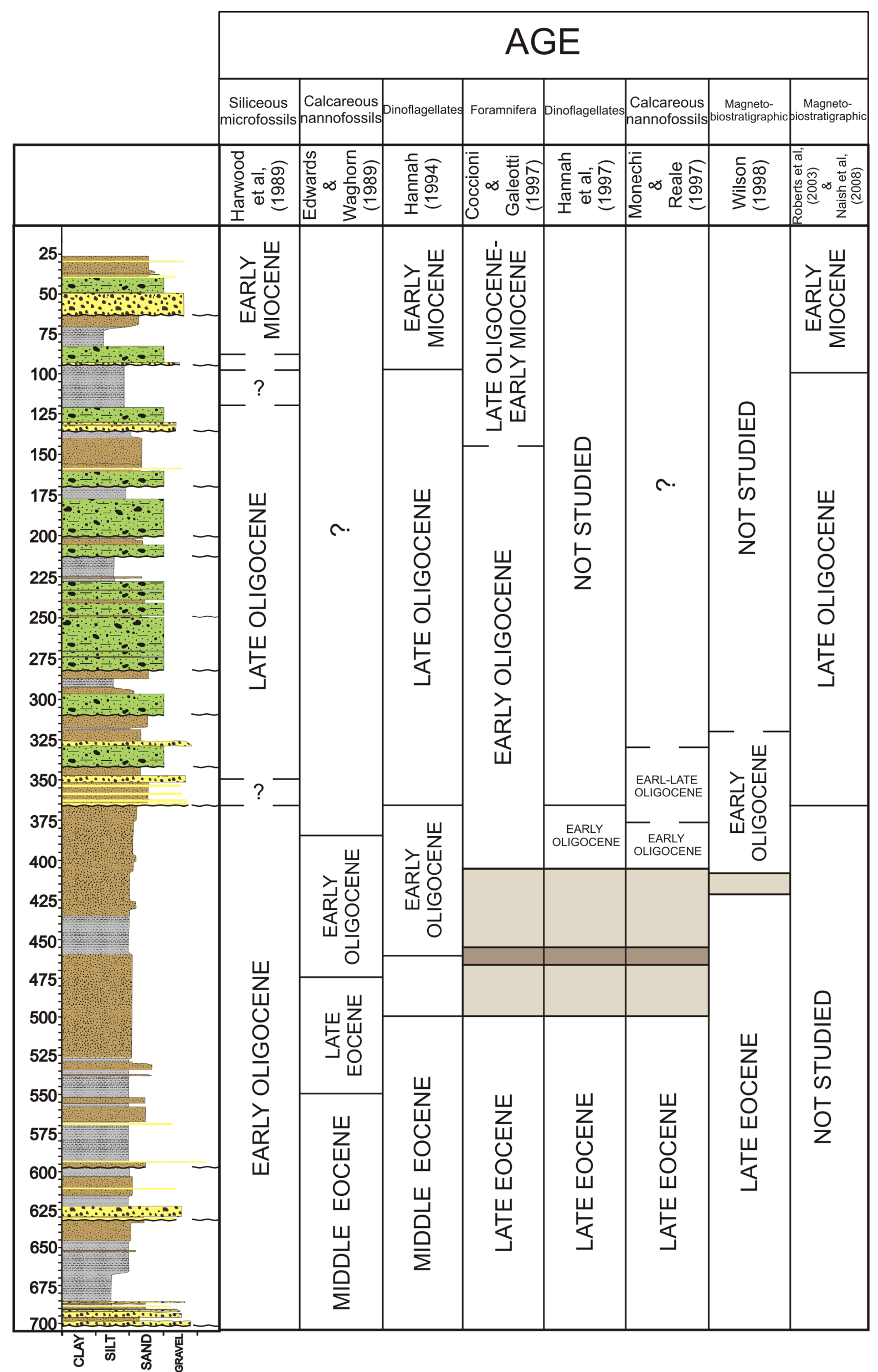

Figure 3.8: A summary of previous chronostratigraphic schemes for the CIROS-1 core. 
In the same volume, Monechi and Reale (1997) used calcareous nannofossils too constrain depositional age and assigned a Late Eocene age to the lowermost section of the core. Similarly to Hannah et al. (1997), Monechi and Reale (1997) estimated the Eocene-Oligocene boundary as lying between $468-455$ mbsf (Fig. 3.8). Coccioni and Galeotti (1997) re-evaluated the foraminiferal content of CIROS-1 and produced a revised chronology and, like the above workers, found that the lowermost section of the core was of late Eocene age and that the Eocene-Oligocene boundary was located between 468-455 mbsf. Above the Eocene-Oligocene boundary an Early Oligocene age was assigned, and the Miocene-Oligocene boundary was placed at $\sim 150$ mbsf (Fig. 3.8). Coccioni and Galeotti (1997) estimated that the unconformity at 366 mbsf encompassed about $4 \mathrm{Myr}$.

The magnetobiostratigraphic chronology of the section below 366 mbsf was revised by Wilson et al. (1998) (Figs. 3.8 and 3.9), who analysed paleomagnetic samples taken every 1-2 $\mathrm{m}$, and made a new correlation to the geomagnetic polarity timescale (Cande and Kent, 1995). The results of this were combined with previously established biostratigraphic horizons and Sr isotope age data. Wilson et al. (1998) assigned an age of Early-Late Eocene $(\sim 36.5 \mathrm{Ma})$ to the base of the core, whilst an Earliest Oligocene $(\sim 33 \mathrm{Ma})$ age was assigned to the sediments directly below the 366 mbsf unconformity. Wilson et al. (1998) inferred the Eocene-Oligocene boundary to be located between 410-420 mbsf, within a sandy mudstone and not incidental with an unconformity. This was established by combining the age models presented in Reick (1989) and Harwood (1989) and the chronology established for the sub-366 mbsf section presented in Wilson et al. (1998). As Rieck (1989) and Harwood (1989) assigned an Early-Late Oligocene age (ca. $28 \mathrm{Ma}$ ) to the sediments directly above the 366 mbsf unconformity, and Wilson et al. (1998) dated the sediments directly below as Earliest Eocene (ca. 33 Ma), Wilson et al. (1998) estimated the 366 mbsf unconformity to cover $4 \mathrm{Myr}$ and suggested this time may have been distributed amongst the suite of unconformities located between $~ 366$ 250 mbsf.

Roberts et al. (2003) re-evaluated the magnetostratigraphy of the uppermost section of the core. Roberts et al. (2003) analysed 231 samples at $\sim 0.5-1 \mathrm{~m}$ intervals for their magnetic polarity stratigraphy. These were plotted relative to the geomagnetic polarity time scale from Cande and Kent (1995). In addition to these new data, Roberts et al. (2003) re-evaluated published diatom biostratigraphic data for the 
upper section of the core. These zones were correlated to a high-precision age model constructed for CRP 2/2A based on the biostratigraphic zonation scheme of Scherer et al. (2000), which was calibrated by Wilson et al. (2002) using two ${ }^{40} \mathrm{Ar} /{ }^{39} \mathrm{Ar}$ ages for two ash horizons near the Oligocene-Miocene boundary in the CRP2/2A core. The results differ significantly from the original paleomagnetic work done by Rieck (1989) (Fig. 3.8), being much simpler and with fewer polarity intervals. This, combined with the updated diatom zonation created for CRP 2/2A, enabled Roberts et al. (2003) to significantly revise the chronology for the uppermost $366 \mathrm{mbsf}$ of the core (Figs. 3.8 and 3.9). The $24.3 \mathrm{Ma}$ age for the sediments directly above the 366 mbsf unconformity reported by Wilson et al. (2002) is significantly younger than the initial age of $\sim 29$ Ma presented by Rieck (1989) and Harwood (1989). As such, Roberts et al. (2003) concluded that the time lost in the 366 mbsf unconformity is $\sim 9 \mathrm{Myr}$, rather than the $4 \mathrm{Myr}$ originally believed. Roberts et al. (2003), report that the Miocene-Oligocene boundary is located in an unconformity in sediments at 249 mbsf. A Lower Miocene age of $\sim 23.7 \mathrm{Ma}$ was assigned to sediments at $80 \mathrm{mbsf}$.

In spite of burgeoning amounts of chronostratigraphic data, Watkins (2007) reported strong doubts about an Eocene age for the sub-366 mbsf section of the core. Watkins (2007) argued that many of the Eocene ages for this section were derived from potentially reworked nannofossils that were reported by the authors as being in situ. It was argued that, as global proxies (such as deep-ocean sediment cores) imply no significant glaciation in Antarctica until the earliest Oligocene, the Eocene age assigned to the sub-366 mbsf section of the CIROS-1 drill core must be incorrect, as sediments in the section show signs of significant glaciation (e.g. diamicts and the presence of ice-rafted debris reported in Hambrey et al, 1989). Consequently, Watkins (2007) assigned an Early Oligocene age to sub-366 mbsf section.

\subsection{Revised chronology for the CIROS-1 core}

The composite age model for CIROS-1 (Fig. 3.9) presented here, was constructed by re-evaluating the historical data and selectively splicing previously published and newly-developed chronologies for different sections of the core (Tables 3.2 and 3.3). The age for the section down to $100 \mathrm{mbsf}$ is based on the integrated biomagnetostratigraphy developed by Roberts et al. (2003). The chronology for the section between 100-366 mbsf has been revised based on Roberts et al. (2003), following the recalibration of diatom zones in correlative strata in the CRP-2/2A core by Naish et al. (2008b). Two ${ }^{40} \mathrm{Ar} /{ }^{39} \mathrm{Ar}$ ages on ash layers in the CRP-2/2A core 
(e.g. Wilson et al., 2002) allow detailed correlation of the Hemiaulus sp. $A$ and Pterotheca reticulata diatom zones to short-lived subchrons within Chron C7, consistent with the astronomically-tuned timescale of Billups et al. (2004). This recalibration constrains the Oligocene-Miocene boundary at $\sim 100$ mbsf in the CIROS-1 core (Fig. 3.9). A consequence of this is that the beech leaf identified by Hill (1989) sits in Late Oligocene strata. It is not possible, with the available chronostratigraphic data, to determine what percentage of the $\sim 9$ Myr time interval between 35 and $26 \mathrm{Ma}$ is lost at the 366 mbsf or 342 mbsf unconformities, as illustrated by the error boxes (in light yellow, Fig. 3.9). The chronology for the lower section reflects two main options from published work.

A strength of the Wilson et al. (1998) chronology is that it is based on correlation of a revised magnetostratigraphy to the magnetic polarity timescale and is supported by the available biostratigraphic data. Moreover, the accumulation rate of $100 \mathrm{~m} / \mathrm{Myr}$ implied by the slope of the curve on the age depth plot in Figure 3.9 is consistent with typical rates of glaciomarine successions on the western margin of the VLB. To this end, a third option for the age of sediments between 366-425 mbsf is offered which is consistent with the biostratigraphic data and the accumulation rates of Wilson et al. (1998). In this model (coloured red in Fig. 3.9), this normal-polarity stratigraphic interval has been correlated with C15n instead of C13n. A Late Eocene age for the sediments in the lower section of the core is consistent with the higher occurrence of clay minerals, such as smectite, associated with relatively more chemical weathering and a warmer, wetter climate regime than that of the earliest Oligocene (Ehrmann, 1998). 


\section{Age (Ma)}

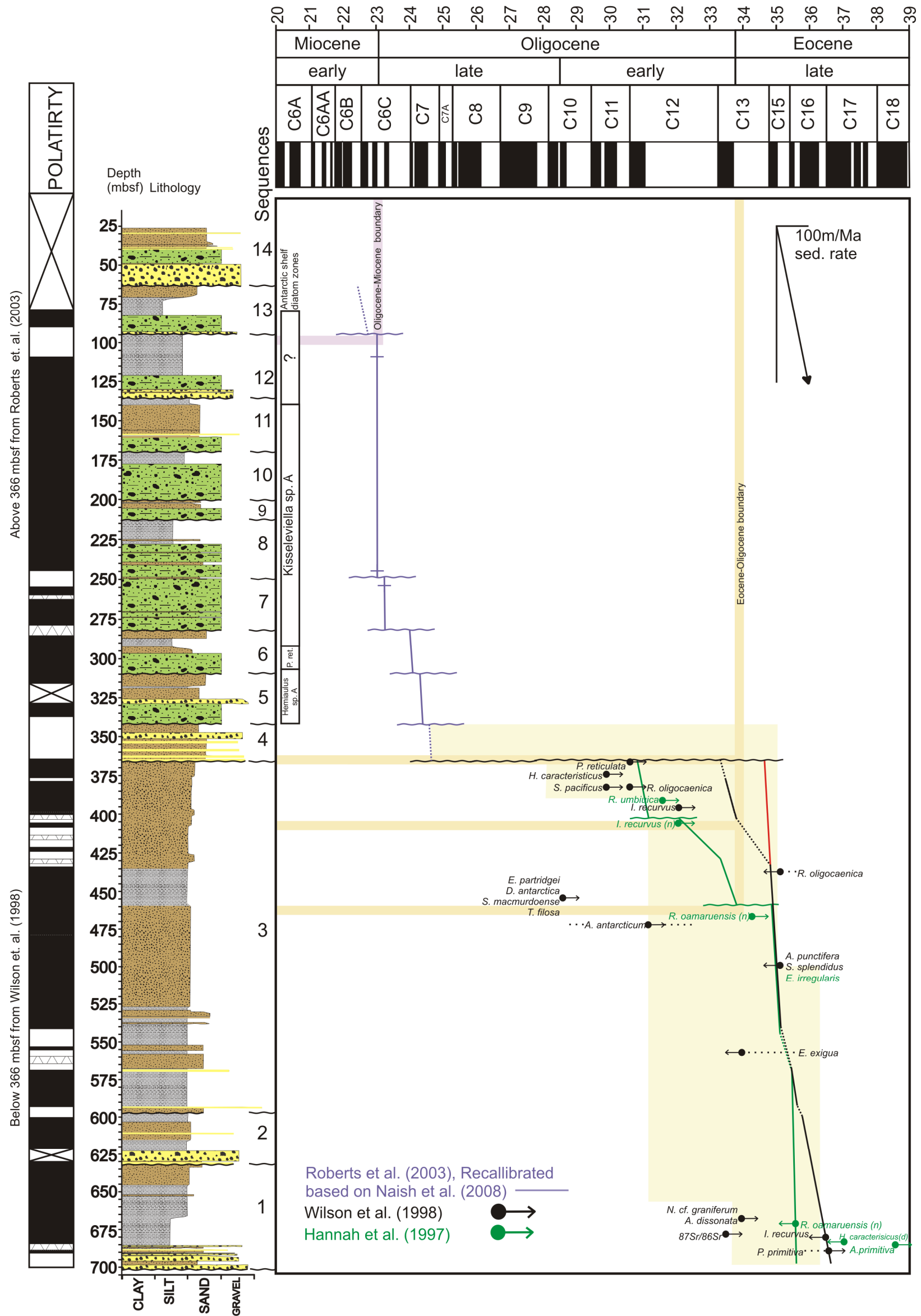

Figure 3.9: An integrated chronological framework for the CIROS-1 core. Above 366 mbsf the chronology is based on Roberts et al. (2003) which has been recalibrated using Naish et al. (2008b). Three possible chronologies have been given for the sub-366 mbsf section of the core (Wilson et al., 1998; Hannah et al., 1997). An alternative chronology for the upper part of the sub-366 mbsf section of the core, suggested in this work, is shown in red. The light yellow zone indicates the uncertainty associated with the chronology of the sub-366 mbsf section and shows that the time missing in the $\sim 9$ Myr hiatus (traditionally thought to be located at $\sim 366 \mathrm{mbsf}$ ), may be partially of wholly distributed at the unconformity located at 342 mbsf. The magnetochronology used is based on Gradstein et al. (2004). For definitions of biostratigraphic datums and paleomagnetic chrons used refer to Tables 3.2 and 3.3. 
Table 3.2: Chronostratigraphic datums used to construct the revised CIROS-1 age model (Fig. 3.9).

\begin{tabular}{|c|c|c|c|c|c|c|}
\hline \multicolumn{7}{|c|}{ Roberts et al. (2003) (Above 366 mbsf) } \\
\hline \multirow[t]{2}{*}{ Datum } & \multicolumn{2}{|c|}{ Occurrence (mbsf) } & \multicolumn{2}{|c|}{ Paleo chronology } & \multicolumn{2}{|c|}{ References } \\
\hline & Base & Top & Base & Top & Occurrence & Chronology \\
\hline Kisseleviella sp. A & 145.21-139.35 & 296.68-290.78 & C7n.1n & C6Cn.2n & $\begin{array}{l}\text { Harwood (1989) presented in } \\
\text { Roberts et al. (2003) }\end{array}$ & $\begin{array}{l}\text { Scherer et al. (2000) calibrated } \\
\text { by Wilson et al, (2002) }\end{array}$ \\
\hline Pterotheca reticulata & 296.68-290.78 & $309.38-304.95$ & C7n.1n & C7n.1n & “ & $\begin{array}{l}\text { Scherer et al. (2000) recalibrated based on } \\
\text { Naish et al. (2008) }\end{array}$ \\
\hline Hemiaulus sp. A & 309.38-304.95 & $\sim 342$ & C $7 n .2 n$ & C7n.2n & “ & " \\
\hline \multicolumn{7}{|c|}{ Wilson et al, (1998) (Below 366 mbsf) } \\
\hline \multirow[t]{2}{*}{ Datum } & $\begin{array}{l}\text { First Occurrence I } \\
\text { Last Occurrence }\end{array}$ & Occurrence (mbsf) & \multirow{2}{*}{\multicolumn{2}{|c|}{ Paleo chronology }} & \multicolumn{2}{|c|}{ References } \\
\hline & & & & & Occurrence & Chronology \\
\hline \multicolumn{7}{|l|}{ Diamtoms } \\
\hline Consistent Pyxilla reticulata & LO & 367 & & & $\begin{array}{l}\text { Harwood and Maruyama (1992) } \\
\text { presented in Wilson et al. (1998) }\end{array}$ & $\begin{array}{c}\text { Harwood and Maruyama (1992) } \\
\text { callibrated based on Berggren et al. }\end{array}$ \\
\hline Hemiaulus caracterusticus & LO & 375 & & า. $2 n$ & " & (1995) presented in_Wilson et al. (1998) \\
\hline Sphynctolethus pacificus & LO & 383 & & ר. $2 n$ & " & . \\
\hline Rhizosolenia oligocaenica & LO & 383 & & $2 n$ & “ & . \\
\hline Rhizosolenia oligocaenica & FO & 438 & $\mathrm{C} 13 \mathrm{r} / \mathrm{C} 1$ & n or older & $"$ & " \\
\hline Stephanopyxis splendidus & FO & 500 & $\mathrm{C} 13$ & C15.n & $"$ & " \\
\hline Asterolampra punctifera & FO & 438 & $\mathrm{C} 13$ & C15.n & $"$ & “ \\
\hline \multicolumn{7}{|l|}{ Foramnifera } \\
\hline Epistominella exigua & FO & 558 & & & $\begin{array}{l}\text { Coccioni and Monechi (1996, pers coms), } \\
\text { presenteded in Whison et ail. (1998) }\end{array}$ & $\begin{array}{l}\text { Webb (1996, Pers comms) presented in Wilson } \\
\text { et al. (1998) }\end{array}$ \\
\hline Nonion cf. graniferum & LO & 669 & $C 13 r$ & rolder & $\begin{array}{l}\text { Webb (1989), presented in Wilson } \\
\text { et al (1998) }\end{array}$ & $\begin{array}{l}\text { Webb (1989) presented in Wilson } \\
\text { et al (1998) }\end{array}$ \\
\hline Alabamina dissonata & LO & 669 & $C 13 r$ & r older & et al. (1998) & et al. (1998) \\
\hline Pseudogloboquadrina & LO & 690 & C16r or po & ibly younger & " & $\begin{array}{l}\text { Couch and Hollis (1996) and Evitt and Pierce } \\
\text { (1975) presented in Wilson (1998) }\end{array}$ \\
\hline \multicolumn{7}{|l|}{ Calcareous nannofossils } \\
\hline Isthmolithus recurvus & LO & 392 & & & Wei (1992) presented in Wilson et al. (1998) & $\begin{array}{l}\text { Wei (1992), callibrated using Cande and Kent } \\
(1992,1995) \text { and Berggren et al. (1995) }\end{array}$ \\
\hline Isthmolithus recurvus & FO & 681 & & ר. $2 n$ & " & “ \\
\hline \multicolumn{7}{|l|}{ Marine Palynomorphs } \\
\hline Enneadocysta partridgei & LO & 455 & & & \begin{tabular}{|l|} 
Wilson (1989) presented in Wilson et al. \\
$(1998)$
\end{tabular} & $\begin{array}{l}\text { Stover and Williams (1995), presented in } \\
\text { Wilson et al. (1998). }\end{array}$ \\
\hline Deflandrea antarctica & LO & 455 & & & “ & Mohr (1990), presented in Wilson \\
\hline Spinidinium macmurdoense & LO & 455 & & & “ & $\begin{array}{l}\text { Wilson (1967) presented in Wilson et al. } \\
\text { (1998) }\end{array}$ \\
\hline Tubiosphaera filosa & LO & 455 & & & “ & $\begin{array}{l}\text { Couch and Hollis (1996) and Evitt and Pierce } \\
\text { (1975) presented in Wilson et al. (1998) }\end{array}$ \\
\hline Arachnodinium anarcticum & LO & 473 & & $\mathrm{C} 12$ & $\begin{array}{c}\text { Harwood et al. (1989) and references } \\
\text { there-in, presented in Wilson et al. (1998) }\end{array}$ & $\begin{array}{l}\text { Harwood et al. (1989) and references } \\
\text { therein, presented in Wilson et al. (1998) }\end{array}$ \\
\hline \multicolumn{7}{|c|}{ Hannah et al, (1997) (Below 366 mbsf) } \\
\hline \multicolumn{7}{|c|}{ W } \\
\hline Pyxilla reticulata & LO & 367 & & & \begin{tabular}{|l} 
Harwood (1989) presented in Hannah \\
et al. (1997)
\end{tabular} & \begin{tabular}{|l|} 
Harwood (pers comm.) presented in \\
Hannah et al. (1997)
\end{tabular} \\
\hline Sphynctolethus pacificus & LO & 383 & & n. $2 n$ & " & $\begin{array}{l}\text { Wilson et al. (1998) presented in Hannah } \\
\text { et al. (1997) }\end{array}$ \\
\hline Rhizosolenia oligocaenica & LO & 383 & & & “ & $\ln (1)$ \\
\hline Rhizosolenia oligocaenica & $\mathrm{FO}$ & 438 & & & “ & $\begin{array}{l}\text { Harwood and Maruyama (1992) presented in } \\
\text { Hannah et al. (1997) }\end{array}$ \\
\hline Stephanopyxis splendidus & $\mathrm{FO}$ & 500 & & & " & $\begin{array}{l}\text { Wilson et al, (1998) presented in Hannah } \\
\text { et al. (1997) }\end{array}$ \\
\hline Asterolampra punctifera & $\mathrm{FO}$ & 500 & & & " & 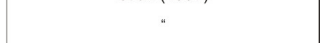 \\
\hline E. irregularis & FO & 438 & & & " & . \\
\hline Hemiaulus caracterusticus & LO & 375 & & า. $2 n$ & “ & . \\
\hline Hemiaulus caracterusticus & $\mathrm{FO}$ & 684 & & n. $1 \mathrm{n}$ & " & “ \\
\hline \multicolumn{7}{|l|}{ Foramnifera } \\
\hline A. primitiva & LO & 558 & & own & $\begin{array}{l}\text { Coccioni and Galeotti (1997), } \\
\text { presented in Hannah et al. (1997) }\end{array}$ & N/A \\
\hline A. primitiva & FO & 686 & & $18 n$ & $\begin{array}{l}\text { Webb (1989) presented in Hannah } \\
\text { et al. (1997) }\end{array}$ & $\begin{array}{l}\text { Berggren et al. (1995) presented in } \\
\text { Hatrluati tel all. (1997) }\end{array}$ \\
\hline \multicolumn{7}{|l|}{ Calcareous nannofossils } \\
\hline R. umbilica & LO & 392 & & $c 12 r$ & $\mid$ Wei (1992) presented in Hannah et al. & $\begin{array}{l}\text { Berggren et al. (1995) presented in } \\
\text { Hannah et al. (1997) }\end{array}$ \\
\hline Isthmolithus recurvus & LO & 407 & Mid-I & e C12r & \begin{tabular}{|c|} 
Wei (1992), Monechi and Reale (19977), presented \\
in Hannah et al. (1997)
\end{tabular} & “ \\
\hline Isthmolithus recurvus & FO & 681 & & n. $2 n$ & Wei (1992), presented in Hannah et al, (1997) & " \\
\hline O. oamaruensis & LO & 468 & & $\mathrm{C} 13 \mathrm{r}$ & \begin{tabular}{|c|} 
Monechi and Reale (1997) presented in \\
Hannahe et al. (1997)
\end{tabular} & “ \\
\hline O. oamaruensis & FO & 673 & Late & $16 n .1 n$ & " & “ \\
\hline
\end{tabular}


Table 3.3: Magnetostratigraphical and chemical chronological datums used to construct the revised CIROS-1 age model (Fig. 3.9).

\begin{tabular}{|c|c|c|c|}
\hline \multirow[t]{2}{*}{ Chron } & \multicolumn{2}{|c|}{ Depth (mbsf) } & \multirow[t]{2}{*}{ Reference } \\
\hline & Base & Top & \\
\hline \multicolumn{4}{|c|}{ Magnetostratigraphic } \\
\hline C6Cn.2n & 92 & 27 & Roberts et al, (2003) recallibrated \\
\hline C6Cn.2r & 111 & 92 & based on Naish et al, (2008) \\
\hline C6Cn.3n & 244 & 111 & “ \\
\hline C6Cn.3r & 254 & 244 & “ \\
\hline C7n.2n (+ C7n1n?) & 338 & 254 & “ \\
\hline $\mathrm{C} 6 \mathrm{Cr}$ & $366 ? ?$ & 338 & “ \\
\hline C13n & 405 & 366 & Wilson et al, (1998) \\
\hline $\mathrm{C} 13 \mathrm{r}$ & 435 & 405 & “ \\
\hline C15n & 543 & 435 & “ \\
\hline C15r & 570 & 543 & “ \\
\hline C16n.1n & 595 & 570 & “ \\
\hline C16n.1r & 602 & 595 & “ \\
\hline C16n.2n & 692 & 602 & “ \\
\hline \multicolumn{4}{|c|}{ Strontium isotope ratio } \\
\hline $\begin{array}{c}{ }^{87} \mathrm{Sr} /^{86} \mathrm{Sr}=0.707764 \pm 20 \\
(\text { NBS-987) }\end{array}$ & 679 & $13 n$ or older & $\begin{array}{c}\text { Barrera (1989), Harwood et al, (1989) } \\
\text { presented in Wilson et al, (1998) }\end{array}$ \\
\hline
\end{tabular}

\subsection{Implications for Late Oligocene ice volume change and the Mi-1 Glaciation}

In Figure 3.10B, Late Oligocene sedimentary cycles of grounding-line advance and retreat along the Victoria Land coastline of Western Ross Sea are correlated with the astronomically-tuned benthic $\delta^{18} \mathrm{O}$ record. This has been done using the new chronostratigraphy for the CIROS-1 drill core. Figure 3.10A shows a similar correlation for age-equivalent sedimentary cycles to that of the CRP-2/2A drill core, $80 \mathrm{~km}$ to the north, as reported in previous studies (Naish et al., 2008b; Naish et al., 2001). The chronostratigraphic constraints on both drill cores allow one-to-one correlation between sedimentary cycles and the $\delta^{18} \mathrm{O}$ cycles. This implies an orbital control on Late Oligocene EAIS volume changes. A noteworthy point is that the new chronostratigraphy allows the orbital response of two different EAIS outlet glaciers, the McKay and the Ferrar, to be evaluated and compared prior to and during a major cooling event that culminated in the Mi-1 glaciation at the OligoceneMiocene boundary.

Ice-volume estimates for the Late Oligocene and Early Miocene have been determined by Pekar and DeConto (2006) and Pekar et al. (2006) by applying $\delta^{18} \mathrm{O}$ - 
to-sea level calibrations to the high-resolution $\delta^{18} \mathrm{O}$ record from ODP Site 1090

(Billups et al., 2004). These calibrations are based on reconstructions of "apparent sea level" (eustasy + water loading effects on the crust) fluctuations recorded in the

New Jersey Shelf margin using a two-dimensional flexural backstripping approach

(Pekar, et al., 2002).

A

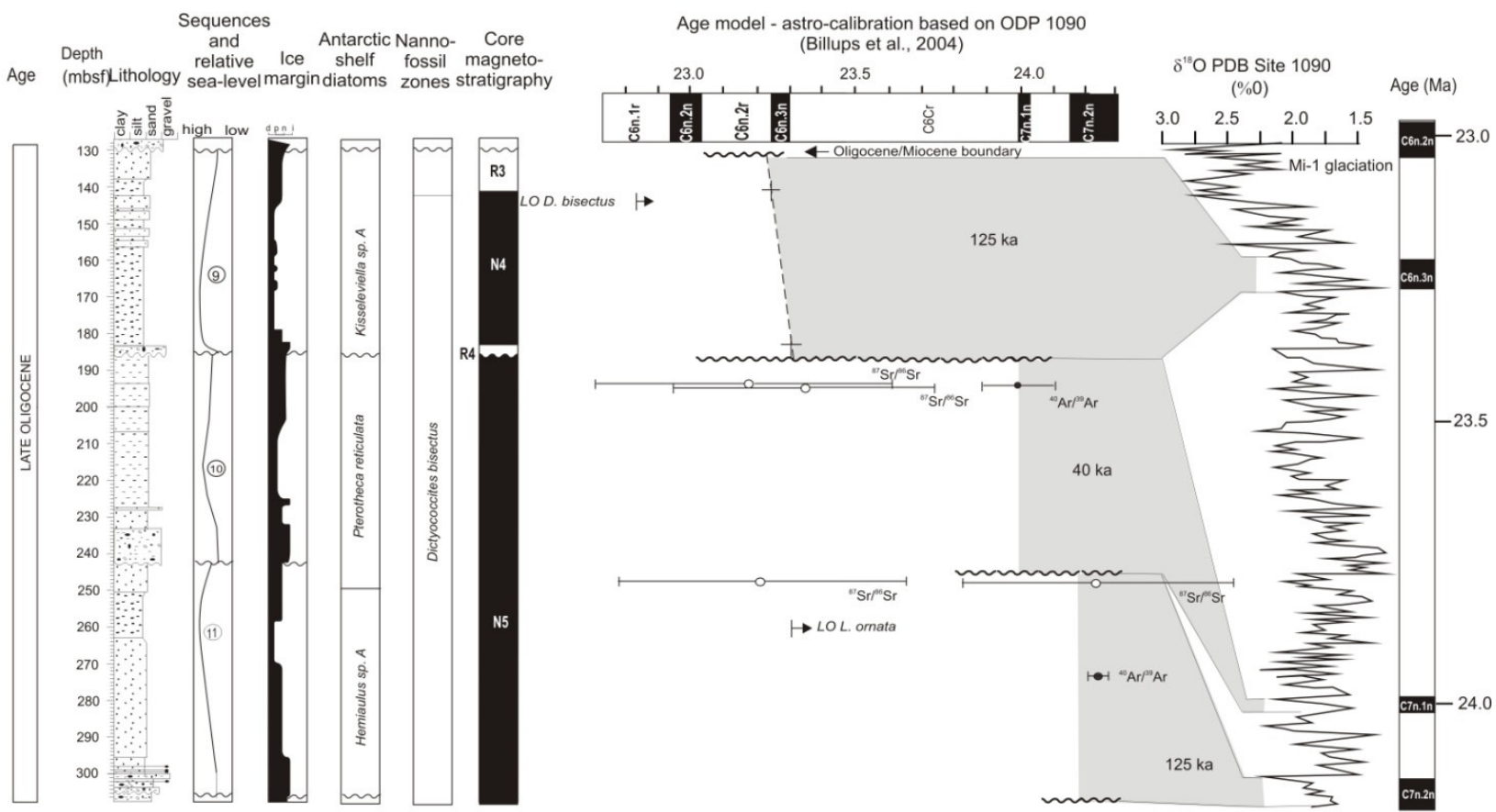

B
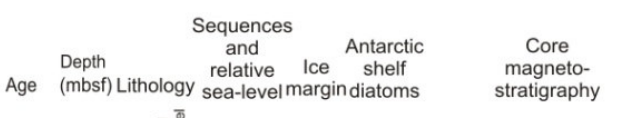

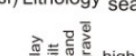
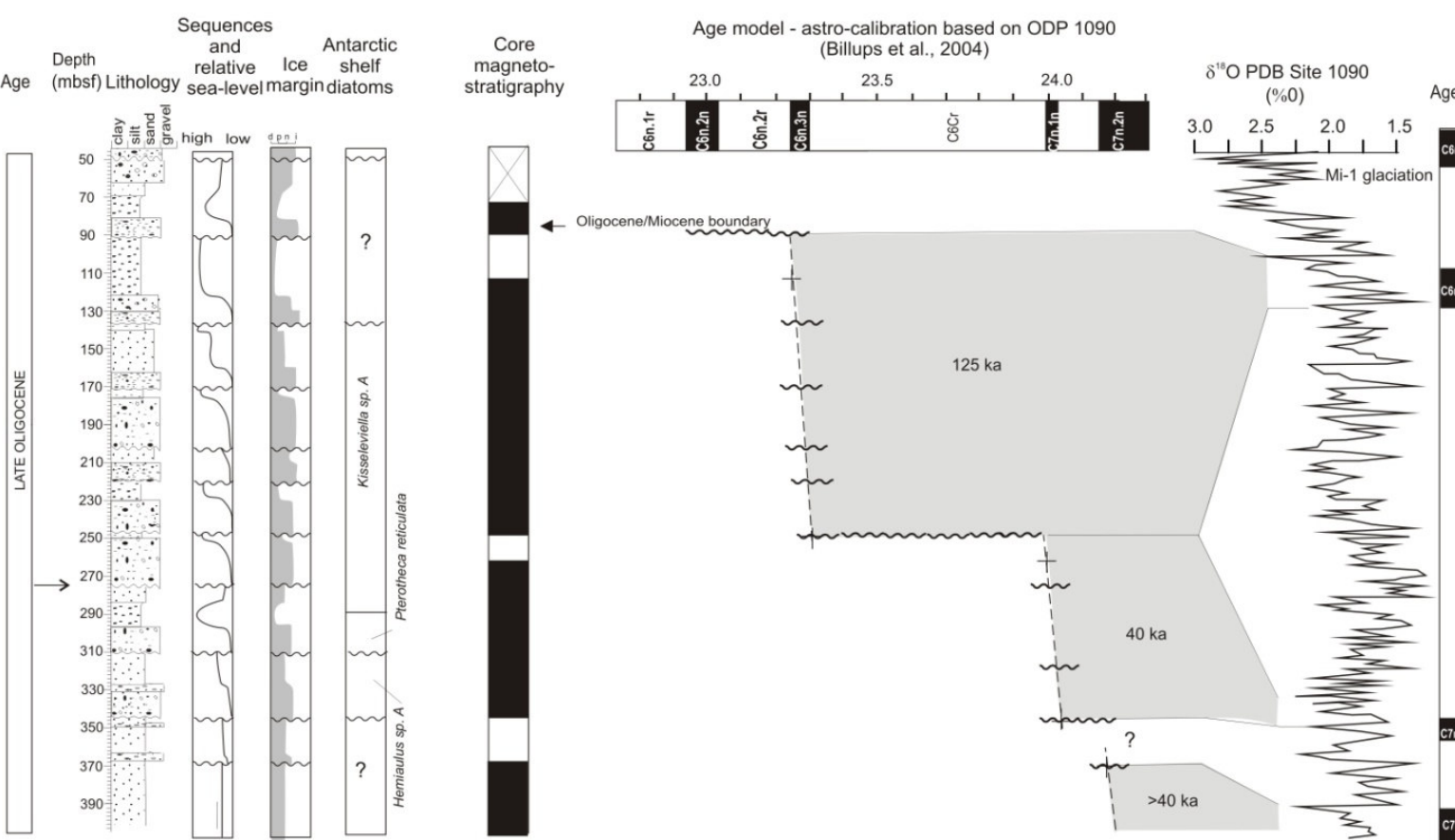

Age (Ma)
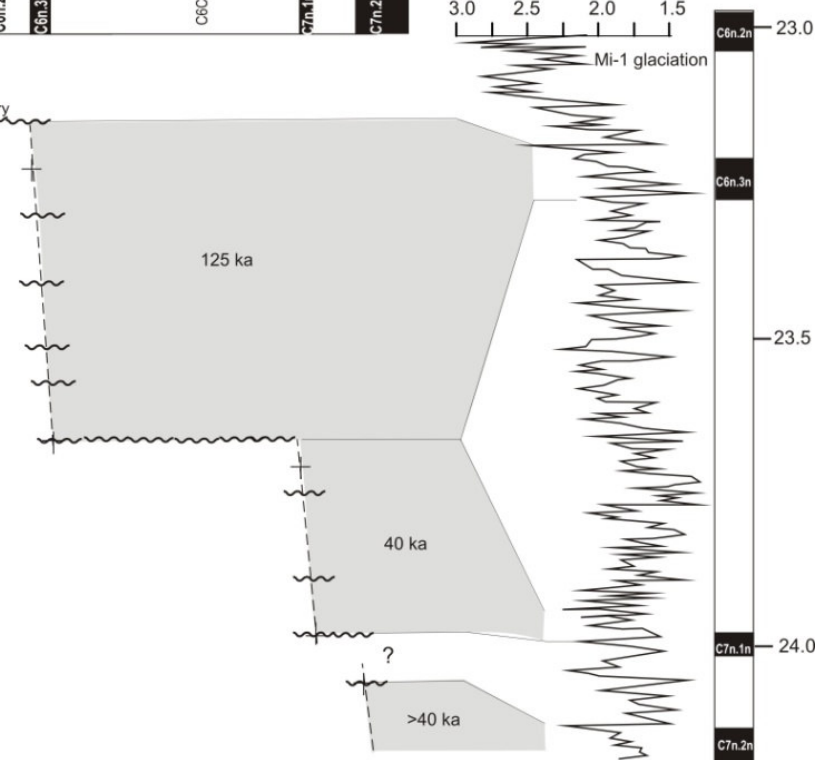

Figure 3.10: Correlation of Late Oligocene sequences in the CIROS-1 core (B) and age-equivalent sediments in CRP$2 / 2 \mathrm{~A}$ (A) to the astronomically-tuned benthic $\delta^{18} \mathrm{O}$ record (A is from Naish et al., 2008a).

These calibrated records indicate that ice volume ranged between $50 \%$ and $125 \%$ of

the present day EAIS during the Late Oligocene and most of the Early Miocene (23- 
$17 \mathrm{Ma}$ ). Maximum ice volume occurred at the Early Miocene Mi-1 event (125\% of the present day ice sheet), and implies a glaciated WAIS, with grounding-lines well beyond their present day position and an ice extent similar to that of Late Quaternary glacial periods (EAIS 15-20\% greater than present) (Denton and Hughes, 2002; Huybrechts, 2002). Using this approach, individual 41 kyr- and 100 $\operatorname{kyr} \delta^{18} \mathrm{O}$ ice volume cycles during the Late Oligocene and Early Miocene are inferred to represent global eustatic fluctuations of $10-30 \mathrm{~m}$ with a minimum sea level of -50 $\mathrm{m}$ at the peak of the Mi-1 glaciation.

Naish et al. (2008a) attempted to measure a direct record of eustatic sea level from the Antarctic continental shelf sedimentary sequences in the CRP-2/2A core utilising a grainsize-derived paleobathymetry curve (Dunbar et al., 2008). This approach estimated the eustatic sea level contribution to the paleobathymetry curve by placing constraints on total subsidence, decompacted sediment accumulation and glacioisostasy. In close agreement with Pekar et al. (2006), these authors showed that eustatic sea level fluctuated at orbital frequencies by between $10 \mathrm{~m}$ and $40 \mathrm{~m}$. These fluctuations represented ice volume variances involving $15 \%$ to $60 \%$ of the present day Antarctic Ice Sheet. The estimates of Naish et al. (2008a) for the Mi-1 glacial excursion support a significant expansion of ice on Antarctica, perhaps equivalent to $120 \%$ of the present day EAIS, with an attendant fall in global sea level of $\sim 50 \mathrm{~m}$.

This and other major glacial events (Mi and Oi events) have been attributed to times of comparatively-rare orbital congruence between 400 kyr-duration eccentricity and obliquity minima (e.g. Zachos et al., 2001b). These anomalies, which consist of lowamplitude variance in obliquity (a node) and a minimum in eccentricity, produce extended periods (200 kyr) of low-seasonality orbits favourable to ice sheet expansion (Palike et al., 2006). The record from CIROS-1 for this time interval provides further insights into the dynamics of the TAM outlet glaciers through which the EAIS discharged. Three short-lived Oligocene diatom zones Hemiaulus sp. $A$, Pterotheca reticulata and Kisseleviella $s p A$. are recognised in both drill core records. The fortuitous occurrence of two silicic volcanic ashes with high-precision ${ }^{39} \mathrm{Ar} /{ }^{40} \mathrm{Ar}$ numeric ages occurring within short-duration normal polarity zones in Late Oligocene sequences 10 and 11 in CRP-2/2A has allowed the diatom zones and sequences to be accurately correlated with the astronomically-tuned timescale (Fig. 3.10A). Recognition of the same diatom zones associated within normal polarity 
Subchrons C7n.2n, C7n.1n C6Cn.2n in the CIROS-1 drill core allows direct comparison of the cycles of glacial advance and retreat.

The first observation of note is that both drill core records preserve sequences of similar age and have similar times of erosion during the Late Oligocene. This implies a first-order regional response of the EAIS outlet glaciers to orbital climate cycles. However, there are significant differences between the records in terms of the detailed response to orbital influences. While the paleo-McKay Glacier (CRP) experiences a single eccentricity-paced $\sim 125$ kyr-duration cycle of advance-retreatreadvance spanning Subchron C6Cn.2n, the grounding-line of the paleo-Ferrar Glacier oscillated 5 times across the CIROS-1 drill site at $\sim 20$ kyr-duration. Correlation with the oxygen isotope record shows a prominent eccentricity cycle modulating five precession cycles at this time. Moreover the paleo-Ferrar appears to oscillate at a $\sim 20 \mathrm{kyr}$ frequency during subchrons C7n.1n and C7n.2n, whereas the paleo-McKay cycles correlate with the longer-period obliquity components.

The differing orbital responses may reflect major differences in the glaciology of these quite different outlet glacier systems. Today the McKay Glacier is one of the major outlet glaciers along the TAM - third-largest after the Byrd and Beardmore glaciers. Moreover it has the most direct connection to the EAIS, discharging through a wide gap in the TAM. In contrast, the Ferrar Glacier is a more restricted, steeper-gradient glacier incised deeply within the TAM, and fed from Taylor Dome at the edge of the EAIS. During the Late Oligocene, prior to the Mi-1 glaciation, sea level-calibrated oxygen isotope records imply a significantly smaller ice sheet on East Antarctica - $50 \%$ of present day (Pekar et al., 2006) during the warmest climate Earth had experienced since the Eocene (Zachos et al., 2001a).

It is proposed here that under such climatic conditions, the paleo-Ferrar Glacier behaved in a similar manner to the Alpine-style temperate glaciers of Patagonia or New Zealand. Numerical ice sheet models show the occurrence of an isolated ice cap on the TAM during warmer climates when ice volume was half that of present day (DeConto and Pollard, 2003). Its mass-balance would have been fundamentally sensitive to surface ablation controlled by local insolation; over long timescales the intensity of summer insolation, and thus the number of positive-degree-days, is controlled by precession. In contrast, the paleo-McKay glacier's mass-balance would 
have reflected the overall behaviour of the EAIS, given its direct connection to the interior ice sheet which is maintained at $50 \%$ present day volume (DeConto and Pollard, 2003). It is proposed that the continental EAIS remained colder because of its higher elevation and height-mass balance feedbacks and may have been less sensitive to seasonal insolation. Rather, it may have only responded during times of extremely favourable orbital geometries for ice ablation or accumulation. For example, times when high eccentricity coincided with extremes in precession or obliquity values. This might explain the sensitivity of the paleo-McKay Glacier to the longer-period orbital components. Notwithstanding the apparently different behaviours of these glacier systems to orbital forcing, they both displayed in-phase behaviour during major longer-duration periods of ice advance and retreat, such as the Mi-1 glaciation, which is recorded as a major unconformity of regional extent, presumably associated with widespread expansion of the EAIS into Ross Embayment.

\subsection{Conclusions}

(1) CIROS-1 sediments occur as seven facies, including muds, sands, conglomerates and diamicts.

(2) A revised stratigraphy for the CIROS-1 core, based on descriptions of the wellpreserved archived half, contains no diamicts beneath 366 mbsf. Rather, large clasts are deposited as conglomerates or by ice rafting.

(3) Sequence stratigraphic analysis of the CIROS-1 core shows two fundamentally different sequence motifs are preserved in CIROS-1. Sequences 1-4 (702-342 mbsf) are reasonably complete and were deposited during advance and retreat of fairly distal glaciers that terminated on land. Sequences 5-14 (342-25 mbsf) are incomplete, top-truncated and were deposited in glacial proximal conditions.

(4) CIROS-1 sediments were deposited between the Late Eocene-Early Miocene. Strata below 366 mbsf were deposited during the Latest Eocene. Strata between 342 and 100 mbsf are of Late Oligocene age and strata above $100 \mathrm{mbsf}$ were deposited during the Early Miocene. The age of the strata between 366-342 mbsf may be between 31-22 Ma. The $\sim 9$ Myr hiatus in the core may be wholly or partially distributed in the 342 mbsf unconformity in addition to the 366 mbsf unconformity. 
(5) The revision of CIROS-1 facies and chronology has enabled a correlation between CIROS-1 and CRP-2/2A for the sedimentary cycles spanning the Late Oligocene-Miocene and the high-resolution oxygen isotope curve. The chronostratigraphic constraints of both drill cores allow one-to-one correlation between sedimentary cycles and the $\delta^{18} \mathrm{O}$ cycles, and imply an orbital control on Late Oligocene EAIS volume changes. The new chronostratigraphy allows the orbital response of two different EAIS outlet glaciers, the McKay and the Ferrar, to be evaluated and compared prior to and during a major cooling event that culminated in the Mi-1 glaciation at the Oligocene-Miocene boundary. While the paleo-McKay Glacier experiences a single eccentricity paced $\sim 125$ kyr-duration cycle of advanceretreat-readvance spanning Subchron C6Cn.2n in the Late Oligocene, the groundingline of the paleo-Ferrar Glacier oscillated five times across the drill site at $\sim 20 \mathrm{kyr}-$ duration during this same interval. This contrasting style of behaviour represents a fundamentally different sensitivity to orbital forcing between the two glacier systems. 


\section{Chapter 4: Zircons as indicators of sediment provenance}

\subsection{Introduction}

The properties of zircons that make them useful tracers of sediment provenance are reviewed in this chapter, which provides a framework for the methods used in this thesis to constrain CIROS-1 zircon provenance. The major element chemistry, physical characteristics and formation environments of zircons are reviewed first. This is followed by: (1) An overview of tools currently used to investigate zircon compositions and the advantages and shortfalls of each; (2) An outline of the systematics of U-Th- $\mathrm{Pb}$ zircon dating and applications of detrital zircon geochronology in sediment provenance studies; and (3) An outline of other tools used to constrain detrital zircon provenance, including minor and trace element compositions and internal zonation.

\subsection{Properties of zircons}

Zircon has an orthosilicate structure and a general formula of $\mathrm{ATO}_{4}$ (Finch and Hanchar, 2003). It is comprised of silicon atoms which are surrounded by a tetragonal group of four oxygen atoms (distance $1.61 \AA$ ) and a zirconium atom located between two groups of four oxygen atoms (distance $2.15 \AA$ and $2.29 \AA$, respectively) (Deer et al., 1997). To this end, the principle structure of this mineral is a chain of alternating edge and corner sharing $\mathrm{SiO}_{4}$ tetrahedra and $\mathrm{ZrO}_{8}$ triangular dodecahedra extending parallel to the $z$ axis (Deer et al., 1997). The average major element chemistry of three zircon is outlined in Table 4.1. 
Table 4.1: Major and minor element chemistry of three zircon suites: (1) Dark red-brown zircons, North Burgess, Ontario, Canada; (2) Zircon, China; and (3) Greyish green to brown zircon from pegmatite, Japan (source: Deer et al., 1997).

\begin{tabular}{|llll|}
\hline & 1 & 2 & 3 \\
\hline $\mathrm{SiO}_{2}$ & 32.51 & 31.45 & 27.13 \\
$\mathrm{ZrO}_{2}$ & 67.02 & 64.03 & 51.68 \\
& & & \\
$\mathrm{HfO}_{2}$ & -- & -- & 1.18 \\
$\mathrm{TiO}_{2}$ & -- & 0.04 & tr \\
$\mathrm{AlO}_{2}$ & 0.21 & 1.36 & 0.48 \\
$\mathrm{Fe}_{2} \mathrm{O}_{3}$ & 0.08 & 0.09 & 0.45 \\
$\mathrm{REE}_{2} \mathrm{O}_{3}$ & 0.04 & 1.18 & 10.51 \\
$\mathrm{MgO}$ & 0.01 & 0.04 & tr \\
$\mathrm{CaO}$ & 0.22 & 0.13 & tr \\
$\mathrm{ThO}^{2}$ & -- & 0.01 & 1.03 \\
$\mathrm{P}_{2} \mathrm{O}_{5}$ & -- & -- & 3.37 \\
$\mathrm{H}_{2} \mathrm{O}^{+}$ & 0.03 & -- & 3.12 \\
$\mathrm{H}_{2} \mathrm{O}^{-}$ & -- & 0.17 & 0.32 \\
& & & \\
$\mathrm{Total}$ & 100.12 & 99.81 & 99.84 \\
\hline
\end{tabular}

Zircon is part of the zircon group minerals. The only naturally occurring polymorph of zircon is the high-pressure reidite, found in shocked zircons formed during meteorite impacts or high pressure metamorphic events (Glass and Lui, 2001; Glass et al., 2002). The physical properties of a zircon grain are governed by its chemistry and the degree of metamictisation it has experienced (Speer, 1982a; Deer et al, 1997). Distinguishing features of zircon crystals include straight extinction, high refractive indices and birefringence, and common prismatic habit (Fig. 4.1; Table 4.2) (Deer et al., 1997).

Table 4.2: Physical and optical characteristics of zircon (source: Deer et al., 1997).

\begin{tabular}{|ll}
\hline Optical character & Tetragonal positive \\
Dispersion & Very strong (nearly equal to diamond) \\
$\mathrm{D}^{*}$ & $4.6-4.7$ \\
$\mathrm{H}$ & 7.5 \\
Twinning & Rare \\
Colour & Reddish brown, yellow, grey green, \\
& colourless. In thin section colourless \\
& to pale brown. \\
Pleochroism & Very weak \\
$*$ These values are for fresh materials. Metamict materials may have values outside these ranges.
\end{tabular}


Generally, zircon major element chemistry allows few insights into its provenance (i.e. Table 4.1) and trace element chemistry and isotope ratios must be analysed to constrain its formation history. The small voids between the tetrahedra and dodecahedra and open channels parallel to cause the zircon structure to be relatively open and prone to trace element incorporation (Finch and Hanchar, 2003). Trace elements are substituted into the zircon lattice in either the $\mathrm{Zr}^{4+}$ or $\mathrm{Si}^{4+}$ sites via reactions governed by the ionic radii and charge of the substituting cation relative to the one it is replacing. Trace elements incorporated into the zircon lattice generally have high closure temperatures $\left(\sim 900^{\circ} \mathrm{C}\right)$ (Pettke et al., 2005).

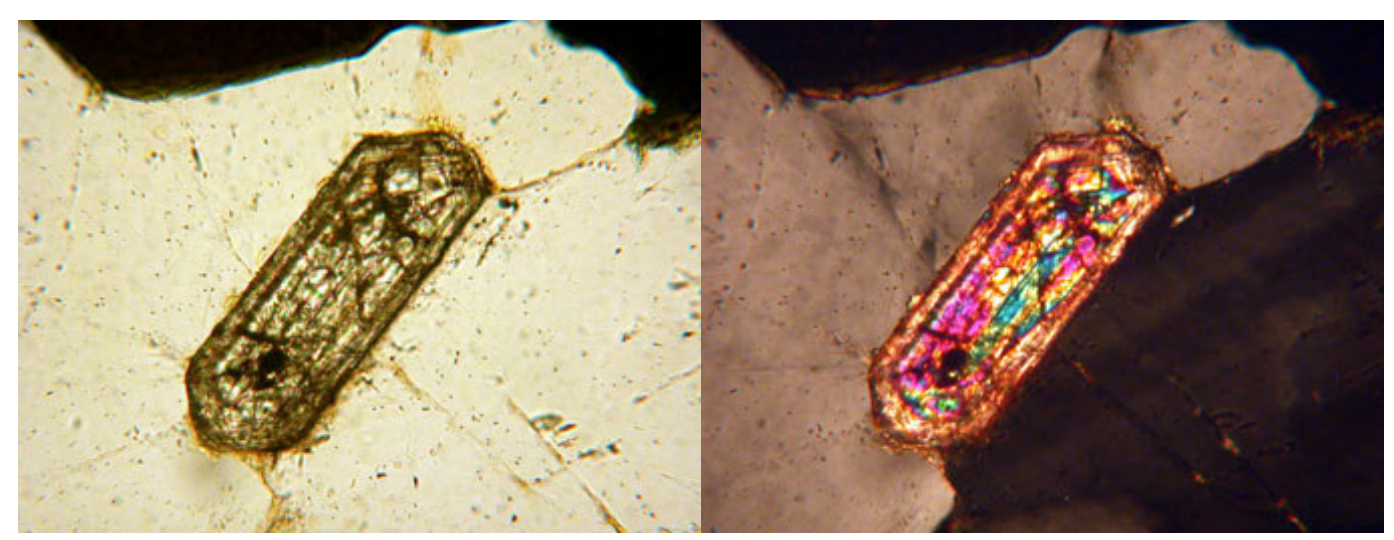

Figure 4.1: A zircon crystal under plain (left) and cross-polarised (right) light. These photomicrographs show common double terminated prismatic habit, high relief and high order interference colours (source: http://www.ucl.ac.uk/ ucfbrxs/PLM/zircon.html).

\subsection{Zircon formation environments}

The environments in which zircons can form are many and varied and there is considerable ambiguity as to the boundaries that separate their classification. Zircon crystallisation environments require silicate melts (or aqueous fluids) with intermediate to high degrees of zirconium saturation. Zirconium saturation may be caused by high initial whole rock zirconium concentrations and saturation due to differentiation, the introduction of zirconium-saturated fluids and the dissolution of zirconium-rich sources.

Most commonly, zircon forms in intermediate to felsic igneous units (Hoskin and Schaltegger, 2003) and low grade metamorphic rocks. Zircons occur in lesser abundances in high grade metamorphic rocks and mafic (ophiolites), mantle affinity igneous units (kimberlites, carbonatites) and rocks that formed by hydrothermal processes (Grimes et al., 2009). It has been suggested that zircons can form from 
authigenic processes (Hoskin and Schaltegger, 2003 and references therein). Due to the overlap in many of these environments, there may be considerable ambiguity regarding the identification of detrital zircon provenance. For example, should a zircon that formed in a late-stage, aqueous fluid-rich magma be classified as magmatic or a hydrothermal? And should a zircon formed in a closed system metamorphic environment in the presence of metamorphic aqueous fluids be classified as metamorphic or hydrothermal?

\subsection{Trace element and $\mathrm{U}-\mathrm{Pb}$ analytical methods}

The techniques used to investigate zircon elemental and isotopic compositions are outlined in Table 4.3.

For this study, a LA-ICP-MS was utilised. This tool allows rapid, relatively high precision (to $\sim 0.5 \%, 1 \sigma$ ) in situ analyses, but it has the advantage that instrumentation is much cheaper. LA-ICP-MS uses a laser to ablate the zircon, after which elements and isotopes are ionised in an inductively coupled plasma source. These are then analysed by mass in a mass spectrometer (Davis et al., 2003).

The characteristics of LA-ICP-MS make it an ideal tool for zircon-based sediment provenance studies. The lesser degree of precision offered by LA-ICP-MS is, if mitigated properly, offset by the advantages of the high sample throughput offered by this technique.

Table 4.3: Tools for geochemical analysis of zircons (sources: Stern and Amelin, 2003; Davis et al., 2003; Dickin, 2003; Bernet et al., 2004).

\begin{tabular}{|c|l|c|c|}
\hline $\begin{array}{c}\text { Method } \\
\text { name }\end{array}$ & Method overview & Precision & $\begin{array}{c}\text { Sample } \\
\text { through-put }\end{array}$ \\
\hline
\end{tabular}




\begin{tabular}{|c|c|c|c|}
\hline ID-TIMS & $\begin{array}{l}\text { Isotope dilution-thermal ionisation mass spectrometry- } \\
\text { one of the most accurate and precise methods of obtaining } \\
\text { isotopic and concentrations, however this method requires } \\
\text { a large amount of preparation work and is largely } \\
\text { restricted to bulk analysis }\end{array}$ & $\begin{array}{c}<1 \% \\
(2 \mathrm{se})\end{array}$ & Low \\
\hline SIMS & $\begin{array}{l}\text { Secondary ionisation mass spectrometry- } \\
\text { SIMS uses a high energy ion beam to transport the } \\
\text { sample to a mass spectrometer. Allows for in situ isotopic } \\
\text { measurements of zircon zones. High cost of instrumentation. }\end{array}$ & $\begin{array}{c}\sim 1 \% \\
(1 \mathrm{se})\end{array}$ & Intermediate \\
\hline $\begin{array}{l}\text { MC-ICP- } \\
\text { MS }\end{array}$ & $\begin{array}{l}\text { Multi-collector inductively coupled mass spectrometry- } \\
\text { utilises a double focusing mechanism to obtain isotopic } \\
\text { compositions and is the most precise MS method. } \\
\text { Cost of instrumentation is high. }\end{array}$ & $\begin{array}{c}\sim 1 \% \\
(1 \mathrm{se})\end{array}$ & Intermediate \\
\hline $\begin{array}{l}\text { LA-ICP- } \\
\text { MS }\end{array}$ & $\begin{array}{l}\text { Laser ablation inductively coupled mass spectrometry- } \\
\text { offers less precision and accuracy } \\
\text { than double focusing ICP-MS. However, the instrumentation } \\
\text { is cheap, sample through-put is high and sample preparation } \\
\text { is short. This method allows in situ analysis of zones } \\
\text { by the attachment of a laser for sample introduction. }\end{array}$ & $\begin{array}{c}>1 \% \\
(2 \mathrm{se})\end{array}$ & High \\
\hline $\begin{array}{l}\text { Fission } \\
\text { Track }\end{array}$ & $\begin{array}{l}\text { Often a complementary method to U-Pb dating- fission } \\
\text { track allows for insights into sediment provenance and } \\
\text { by investigating the length of fission tracks. } \\
\text { These are the results of radioactive (primarily } \alpha \text { decay) } \\
\text { of }{ }^{235} \mathrm{U},{ }^{238} \mathrm{U} \text { and }{ }^{232} \mathrm{Th} \text {. }\end{array}$ & $\mathrm{N} / \mathrm{A}$ & Low \\
\hline
\end{tabular}

\subsection{Detrital zircon ages and their use for provenance analysis}

The analysis of sediment provenance using detrital zircon ages includes two steps:

(1) Individual zircons are radiometrically dated (by LA-ICP-MS).

(2) Suites of zircon ages from a sample are analysed for age populations which are tied to potential known sources of appropriate ages.

\subsubsection{Radiometric U-Th-Pb dating of zircons using LA-ICP-MS}

Radiometric zircon age dating is the cornerstone for many zircon provenance studies. It is based on the long-lived radioisotopes of $\mathrm{U}$ and the $\mathrm{U}-\mathrm{Th}-\mathrm{Pb}$ decay scheme. Tetravalent $\mathrm{U}^{4+}$ and $\mathrm{Th}^{4+}$ are incorporated into the zircon lattice by simple substitution for $\mathrm{Zr}^{4+}$ (i.e. $\mathrm{Th}^{4+}=\mathrm{Zr}^{4+}$ ). As this reaction does not require additional substitutions for charge balance, $\mathrm{U}$ and Th occur in zircons (Grimes et al., 2007; 
Hoskin and Schaltegger, 2003; Belousova et al., 2002) (Table 4.1). Pb is the daughter isotope of $\mathrm{U}$ and Th. It is too large to be readily substituted for $\mathrm{Hf}^{4+}$ or $\mathrm{Si}^{4+}$ during zircon formation or alteration thus, any $\mathrm{Pb}$ measured in zircons is presumed to have formed as a result of radioactive decay of $\mathrm{U}^{4+}$ or $\mathrm{Th}^{4+}$. Assuming no lead loss, an age of the last time the zircon was above the closure temperature of this system can be calculated.

\subsection{1.i. Discordant versus concordant zircons}

$\mathrm{U}-\mathrm{Pb}$ dating comprises two U-Pb decay chains, ${ }^{235} \mathrm{U} \rightarrow{ }^{207} \mathrm{~Pb}\left(\mathrm{t}_{1 / 2} 704 \mathrm{Ma}\right)$ and, ${ }^{238} \mathrm{U} \rightarrow{ }^{206} \mathrm{~Pb}\left(\mathrm{t}_{1 / 2} 4.47 \mathrm{Ga}\right)$. The presence of two distinct dating schemes allows two U-Pb-based ages to be obtained for a single grain (or spot on a crystal). These ages can be plotted against one another on a concordia diagram (Fig. 4.2) which is used to the assessment of the robustness of ages obtained from individual ratios.

On the $\mathrm{y}$-axis of a concordia diagram, the ${ }^{238} \mathrm{U} /{ }^{206} \mathrm{~Pb}$ ratio is plotted and on the $\mathrm{x}$-axis is the ${ }^{235} \mathrm{U} /{ }^{207} \mathrm{~Pb}$. The concordia line represents the shift in respective ratios with changing zircon age. If data from both schemes plot as a point on this line, the zircon is concordant. This concordancy means that the zircon has remained pristine since its formation and that the ages obtained from it are robust. If the data from the two dating systems do not fall on the concordancy line, the zircon is discordant. Discordancy is mainly caused by lead loss from the zircon, which may be catalysed by metamorphic events and radiation damage and discordant zircons are often discounted from further age analysis (e.g. are not used in age probability diagrams). However, discordant zircons can allow valuable insights into a zircon's history. Discordant zircons from an individual suite may plot on a straight line, their position on this reflecting their initial uranium content. The upper intersect of this line and the concordia line indicates the age of initial crystallisation of the suite, the lower intercept represents the age of the event that caused discordancy. Thus, although significantly discordant zircons are not be used to construct age probability diagrams, they can yield insights into the events that formed them. 


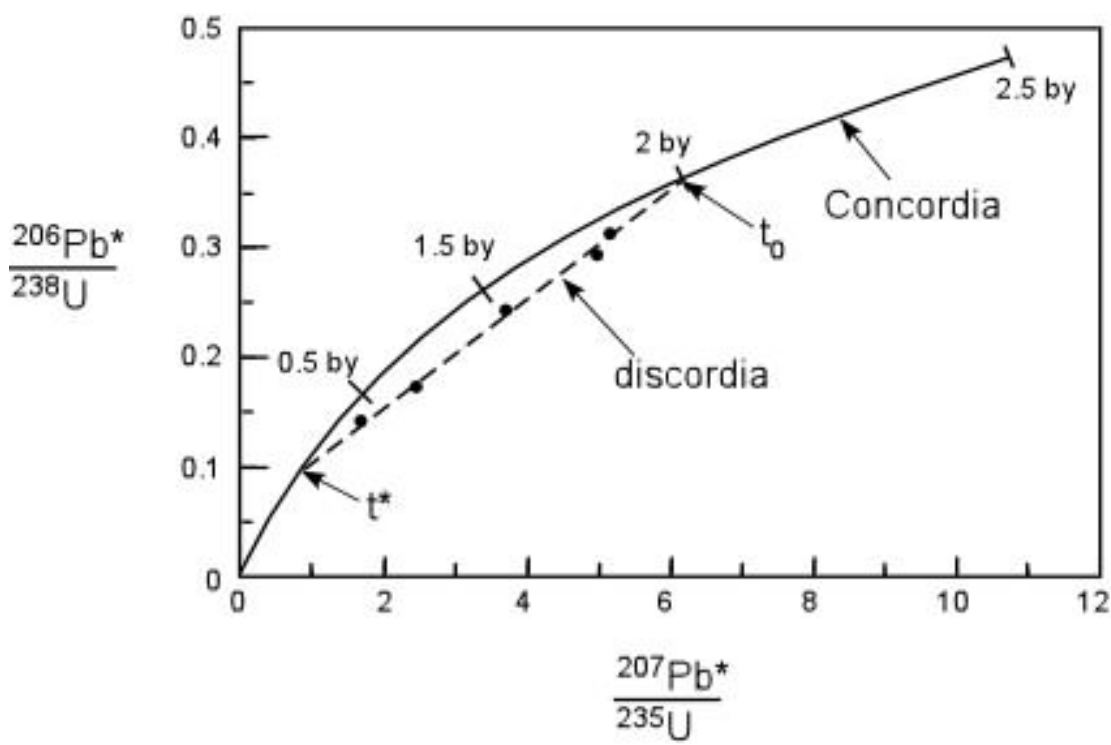

Figure 4.2: $\mathrm{U}-\mathrm{Pb}$ concordia diagram. Note the differing decay schemes on the $\mathrm{x}$ and $\mathrm{y}$-axes and the curved concordia line. Concordant samples will fall within error of the concordia line. Discordant samples (black dots) are those that are not within error of the concordia line. If these are from the same suite and fall in a straight line, the lower intersect of this discordancy line with the concordia line indicates timing of the event which caused discordancy (most often a metamorphic episode), whilst the upper intersect indicates the time of crystallisation (source: http://www.tulane.edu/ sanelson/images/Discordia Pbleakage .jpg).

\subsubsection{Sediment provenance analysis using zircon ages}

The focus of detrital zircon-based sediment provenance studies is to gain insights into the ages (and compositions) and relative input of lithologies that contributed to the sediment. To do this, clusters of radiometric ages of zircon found in the sediment are analysed. Age probability diagrams (Fig. 4.3) are an effective way to present age data obtained from detrital zircons of a single sediment sample. They allow easy interpretation of the age range of lithologies contributing to the sediment and their relative importance. By linking the age peaks to known lithologies (using age data and other provenance information), inferences about the conditions in past sedimentary systems, minimum deposition age of the sediment and the timing and relative importance of geological events may be made. Data representation on an age probability diagram is often two-fold; the numbers of zircons that have ages within certain age bins are plotted as a bar graph (Fig. 4.3) and an age probability line is calculated to account for the errors associated with each age. These lines, calculated using Gaussian kernels that vary with each individual age (Fedo et al., 2003), depict a probability distribution of the ages of detrital zircon populations found in the sediment. 


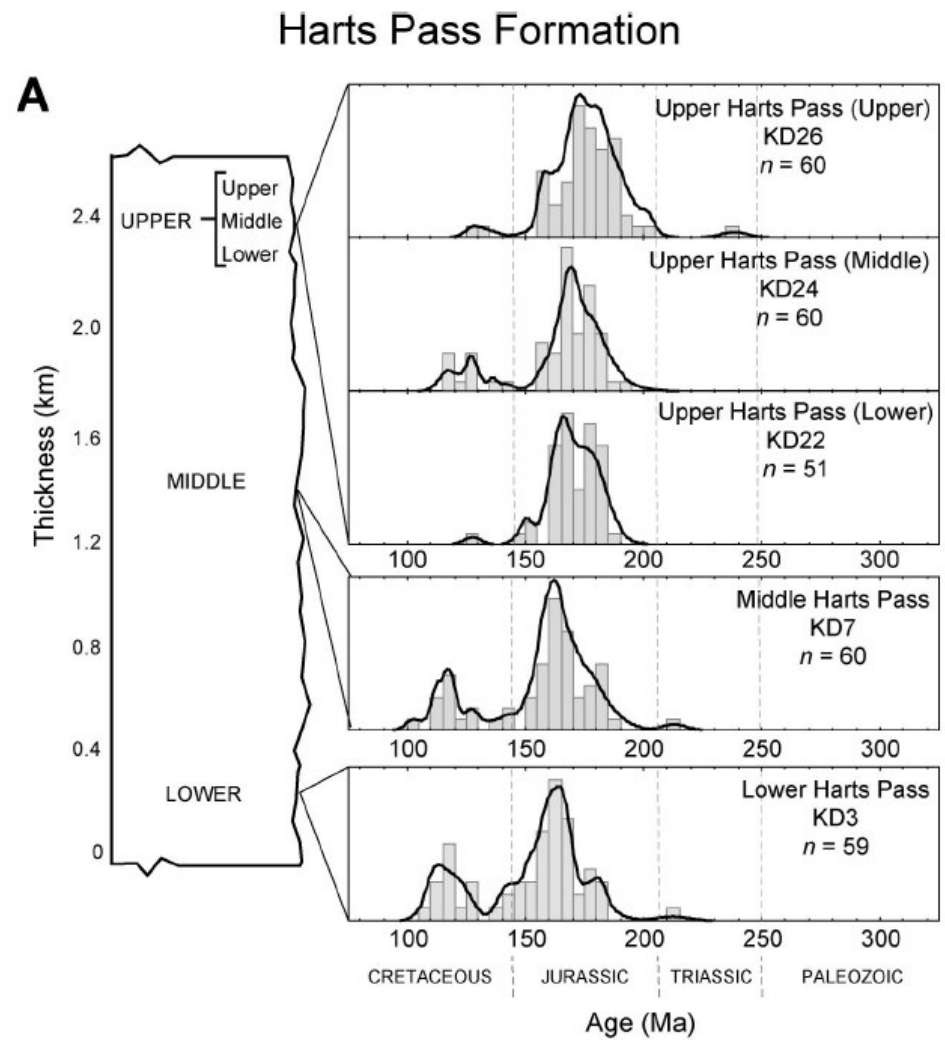

Figure 4.3: Combined age probability diagrams and age distribution histograms for sediments from a range of ages. These show variations in sediment source which may allow interpretations into the conditions present during sediment deposition (source: DeGraaf-Surpless et al., 2003).

The amount of zircons (n) needed to construct a robust age probability diagram was investigated by Dodson et al. (1988) who found that in a typical case of a provenance component comprising of 1 in 20 of the total sediment, there is a $95 \%$ probability that all provenance sources are includes if 59 grains are analysed (Dodson et al., 1988; Fedo et al., 2003).

Analysis of sediment provenance using age probability diagrams is often two-fold. Potential source lithologies for a sediment sample are constrained by comparison of age peaks in the sediment to those of known potential source lithologies. This is made easier and more reliable with the use of complementary trace element and morphological information, as discussed later in this chapter. Also, changes in the system that deposited the sediments may be quantified by comparison of age probability diagrams of spatially and/or temporally proximal samples (e.g. Veevers et al., 2008). 


\subsection{Trace element based constraints on zircon provenance}

In situ trace element analysis of detrital zircons is often successfully used in conjunction with radiometric dating to discern sediment provenance (e.g. Veevers et al., 2008). This dual approach to constraining detrital zircon provenance was used in this research and the chemistry-based provenancing tools used in this study are outlined in this section.

\subsubsection{Rare earth elements in zircon}

A zircon's REE composition reflects that of its formation environment. Zircons are resistant to chemical and physical weathering and REE are essentially immobile in zircons under most geologic conditions (Cherniak et al., 1997). Thus, REE in zircons form a unique archive of the environment within which the zircon formed (Hanchar and van Westrenen, 2007).

\subsection{1.i. REE incorporation into zircons}

Rare earth elements are trivalent cations that have relatively large ionic radii, high charge and are commonly substituted into a zircon crystal lattice for $\mathrm{Zr}^{4+}$ (Hanchar and van Westrenen, 2007). The incorporation of REE into the zircon lattice is governed by REE size relative to $\mathrm{Zr}^{4+}(0.84 \AA)$ and the pressure, temperature and composition of their growth environment (Hanchar and van Westrenen, 2007). Thus the zircon lattice can better accommodate ions of decreasing size and REE profiles in zircons are generally depleted in LREE relative to smaller HREE (Whitehouse, 2003).

\subsection{1.ii. Total REE concentrations in zircons}

A zircons total REE concentration ( $\mathrm{REE}$ ) reflects the $\Sigma$ REE of its formation environment. Belousova et al. (2002) found it is possible to constrain the composition of the melt in which an igneous zircon formed based on its $\Sigma$ REE with higher total concentrations occurring in zircons formed in evolved melts. Zircons formed in pegmatites and granitoids were found to have $\Sigma$ REE $<1.5-2 \mathrm{wt} \%$. Kimberlitic and carbonatitic zircons were found to have $\Sigma$ REE $\sim 90-480$ ppm and mantle affinity zircons had $\Sigma$ REE of $<50$ ppm (Belousova et al., 2002). 


\subsection{1.iii. Chondrite-normalised REE patterns}

Chondrite-normalised REE profiles are used to distinguish zircons from a variety of formation environments. To construct a REE profile, the concentration of rare earth elements in a zircon are divided by chondritic REE values (McDonough, 2000) and plotted adjacent to one another in ascending atomic mass on the $\mathrm{x}$-axis (Fig. 4.4).

It is difficult to pin-point the formation environment for a single detrital zircon based on its REE profile alone. However, it is possible to distinguish between REE profiles from zircons formed in distinctly different environments. At present, based solely on chondrite-normalised REE patterns, it is possible to resolve between:

(1) Igneous zircons formed in the crust;

(2) Igneous zircons formed in the mantle;

(3) Zircons formed in high pressure metamorphic environments;

(4) Zircons formed in low pressure metamorphic environments; and

(5) Hydrothermal zircons.

It is not yet possible to resolve finer scale variation in sources for zircons (e.g. the resolution of different granite sources) based on REE profiles alone (Rubbato, pers. comm., 2009).

\section{Chondrite-normalised REE profiles for igneous zircons}

Two broad groups of igneous zircons are distinguishable based on chondritenormalised REE plots alone:

(1) Mantle affinity (carbonatite and kimberlite).

(2) Crustal affinity (e.g. gabbro, granite).

As some ambiguity remains regarding the role of fluids during the formation of zircons in pegmatites and the mantle (van Lichtervelde et al., 2009; Schaltegger, 2007), zircons from such environments may be arguably classified as hydrothermal.

Zircons are a common minor mineral in kimberlites, carbonatite, peridotites and pyroxenites. Two types of mantle affinity zircons are known to exist, those that are xenolithic and those that crystallised in the mantle. Zircons that formed in situ in the mantle are very rare. Such zircons are commonly 
very depleted in trace elements, have steep chondrite-normalised REE profiles, have variable degrees of enrichment and concavity of HREE and have positive Ce anomalies and no Eu anomalies (Fig. 4.4) (e.g. Siebel et al., 2009; Schmidberger et al., 2005; Belousova et al., 1998).

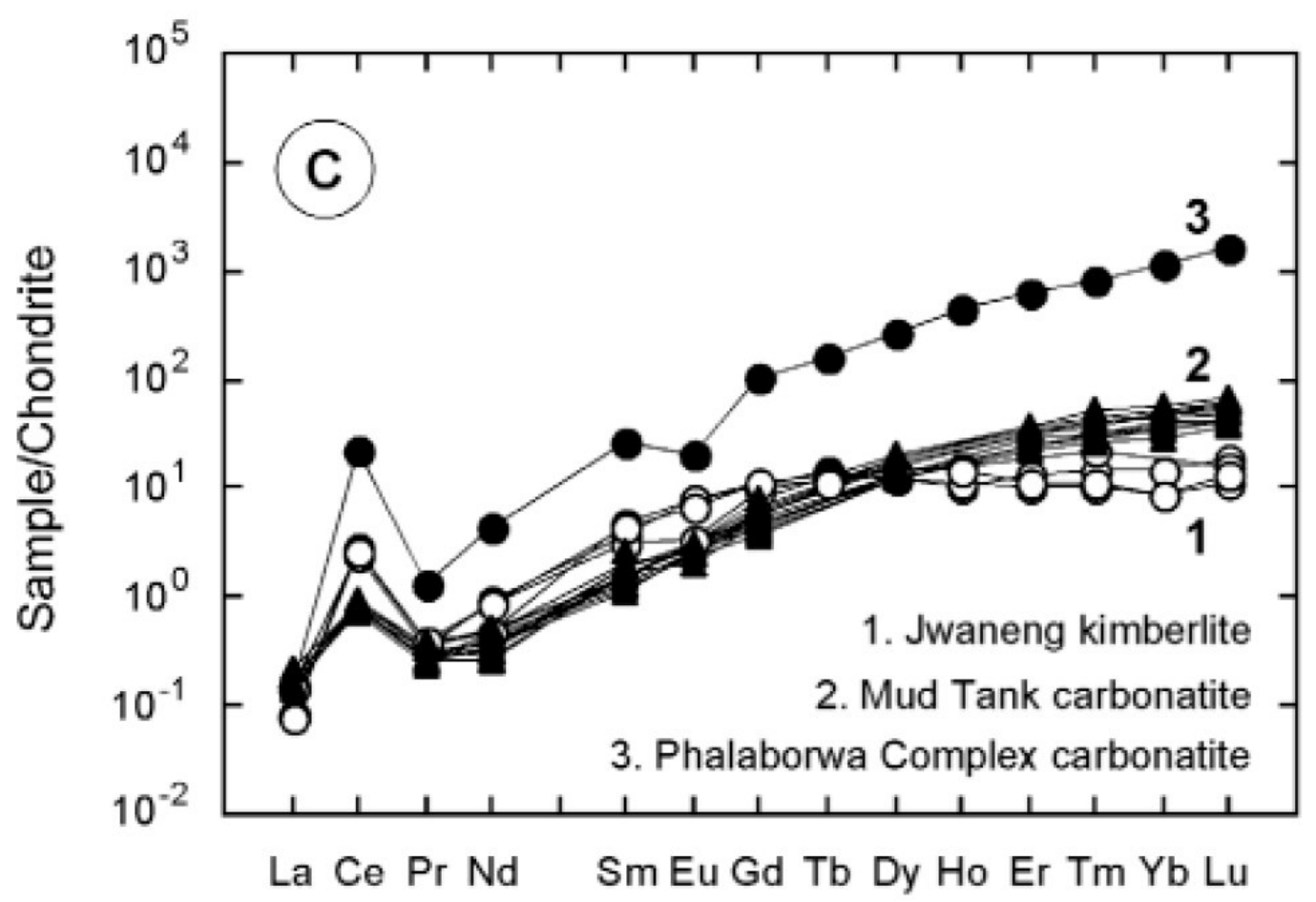

Figure 4.4: Chondrite-normalised REE profiles for rare 'primary' mantle affinity zircons, hypothesised to have crystallised in the mantle. Note the variable amplitude $\mathrm{Eu}$ and $\mathrm{Ce}$ anomalies and the relatively depleted concentrations of HREE (source: Hoskin and Schaltegger, 2003).

The REE profiles of mantle xenolith zircons are commonly a result of partial overprinting of inherited REE signatures whilst the crystal resided in the mantle. To this end, mantle xenolith zircons are generally more trace element enriched than those that formed in situ in the mantle and show variable REE profiles (Fig. 4.5). REE profiles may include a lack of Eu anomalies, a pronounced Ce anomaly and high HREE concentrations (Fig. 4.5; Siebel et al., 2009). 


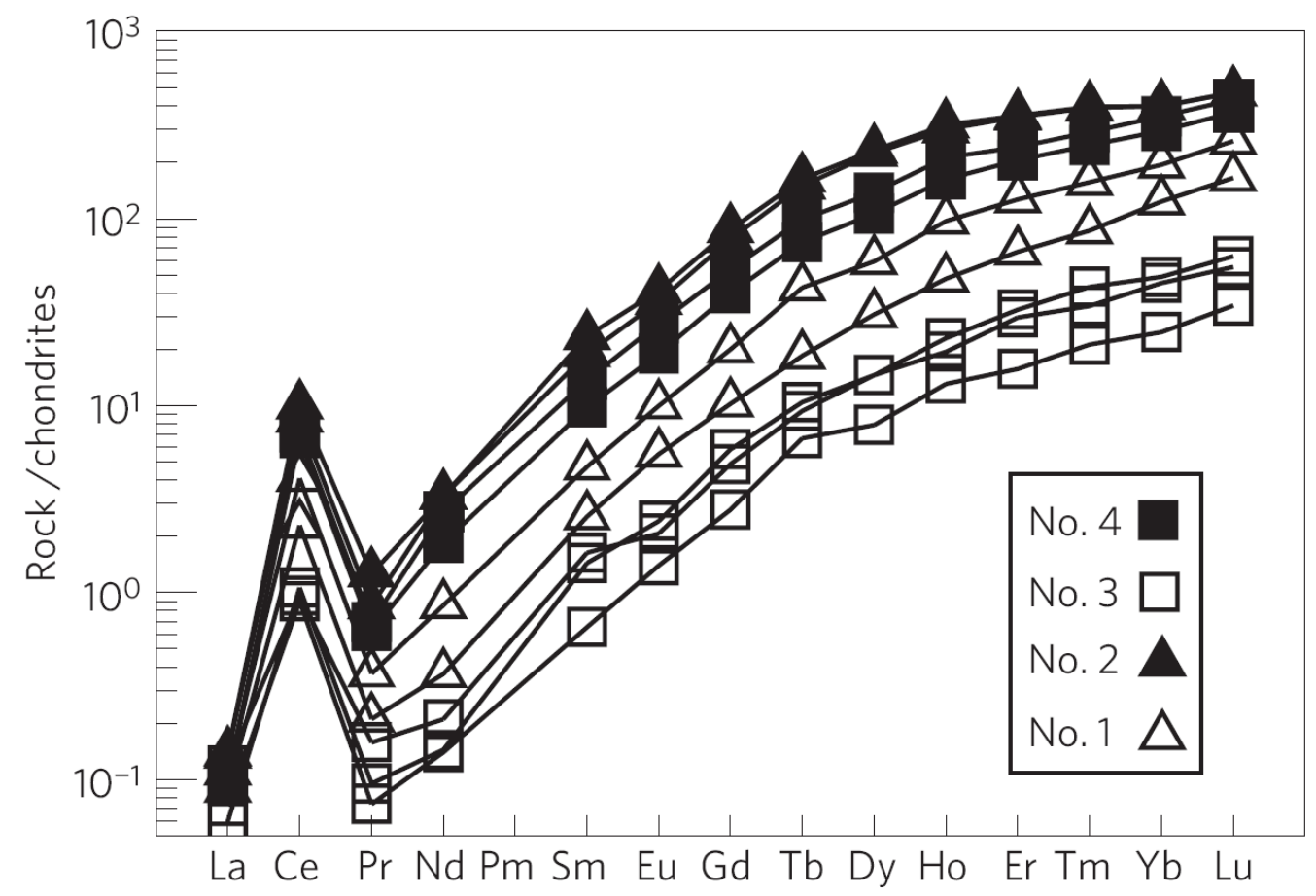

Figure 4.5: Chondrite-normalised REE profiles for xenolithic mantle affinity zircons. Note the characteristically high HREE and the pronounced Ce anomaly discussed in the text (source: Siebel et al., 2009).

A crustal formation environment is most common for zircons. Crustal affinity zircons display large intra- and inter- crystal chemical heterogeneity (e.g. Gagnevin et al., 2010), which reflects the high degree of chemical variability present in the crust. Zircons formed in crustal igneous environments generally have overlapping REE profiles (Fig. 4.6) and it is not possible to distinguish between different crustal sources for zircons based on chondrite-normalised REE profiles alone (Grimes et al., 2009). Zircons formed in crustal igneous environments have REE profiles that are distinct from those formed in mantle, metamorphic and hydrothermal environments. To this end it is possible to constrain a crustal igneous province for a detrital zircon based on its REE profile alone.

Typical crustal affinity igneous zircon have REE profiles with steep positive slopes (HREE enrichment) and a pervasive prominent positive Ce and negative Eu anomalies (Fig. 4.6) (Whitehouse, 2003). Steep positive trends from LREE to HREE are caused by the increasing ability of zircon lattice to incorporate the elements as their atomic radii decreases with increasing atomic number (the lanthanide contraction effect) (Whitehouse, 2003). The 
negative Eu anomaly can be accounted for due to the presence of coexisting feldspars that crystalised before the zircon, which have strong positive Eu anomalies (Rubatto and Herman, 2007). The magnitude of the Ce anomaly reflects variations in redox state during zircon growth. The total concentrations of REE in crustal affinity zircons is caused by the enrichments of the source units (increases with increasing differentiation, as discussed above) and the distribution coefficients during crystallisation.

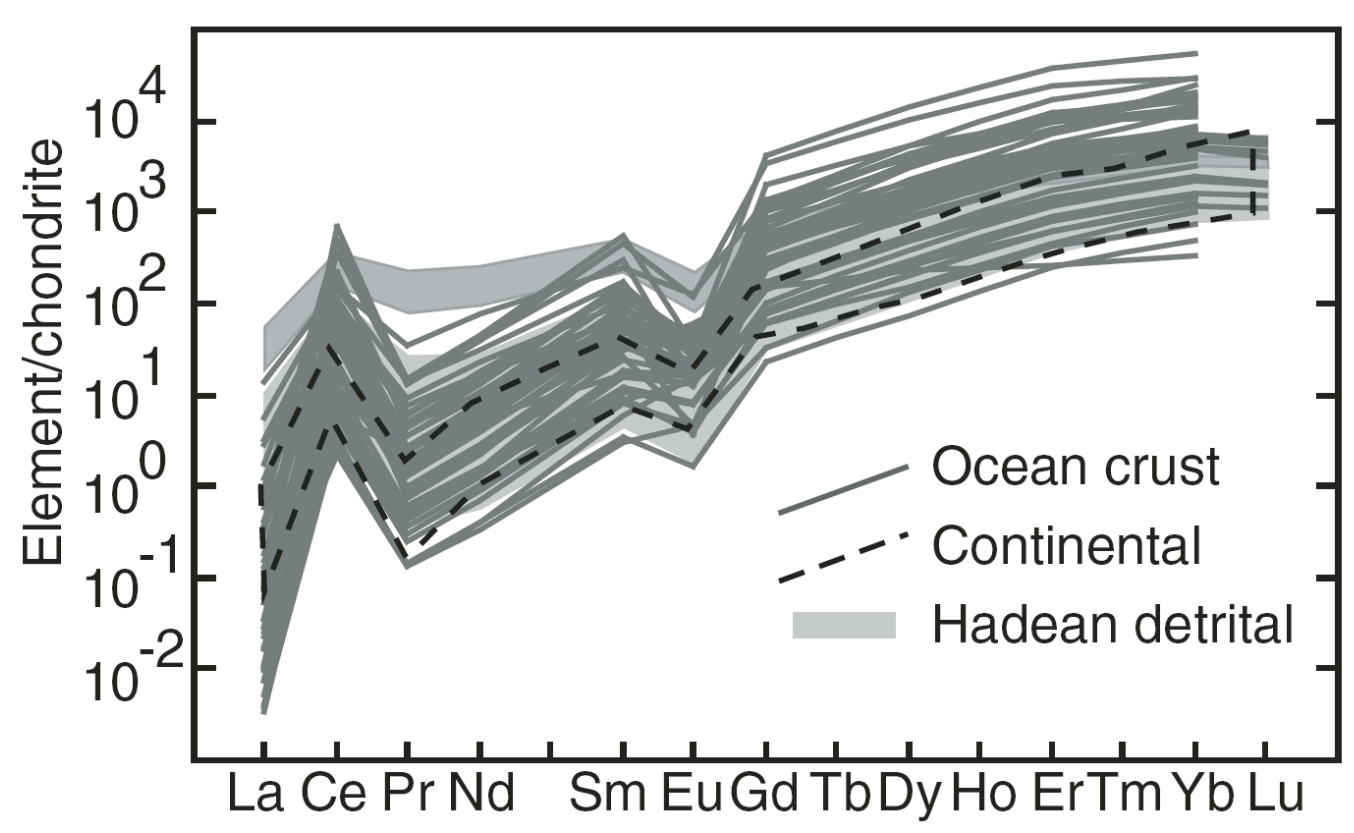

Figure 4.6: Typical REE profiles from crustal affinity zircons which are reasonably reproducible and therefore easily distinguishable from those from other broad formation groups. However, inter- and intra- grain chemical heterogeneity within this group of zircons is large making it challenging to distinguish between zircons from within this group based on REE profiles alone (source: Grimes et al., 2007).

\section{Chondrite-normalised REE profiles of metamorphic zircons}

Based on a zircon's chondrite-normalised REE profile, two broad metamorphic environments are distinguishable:

(1) Low pressure metamorphic environments (e.g. greenschists).

(2) High pressure metamorphic environments (e.g. eclogites and granulites).

High grade metamorphic zircons are known to occur in eclogites and granulites, but are generally quite rare. If such a zircon forms in equilibrium with an anatectic melt its trace element composition and REE profile will be very similar to that of igneous zircon (Figs. 4.7 and 4.8). However, if the zircon grows in subsolidus conditions in equilibrium with garnet it will have a distinctive trace element composition and REE profile (Figs. 4.7 and 4.8). 


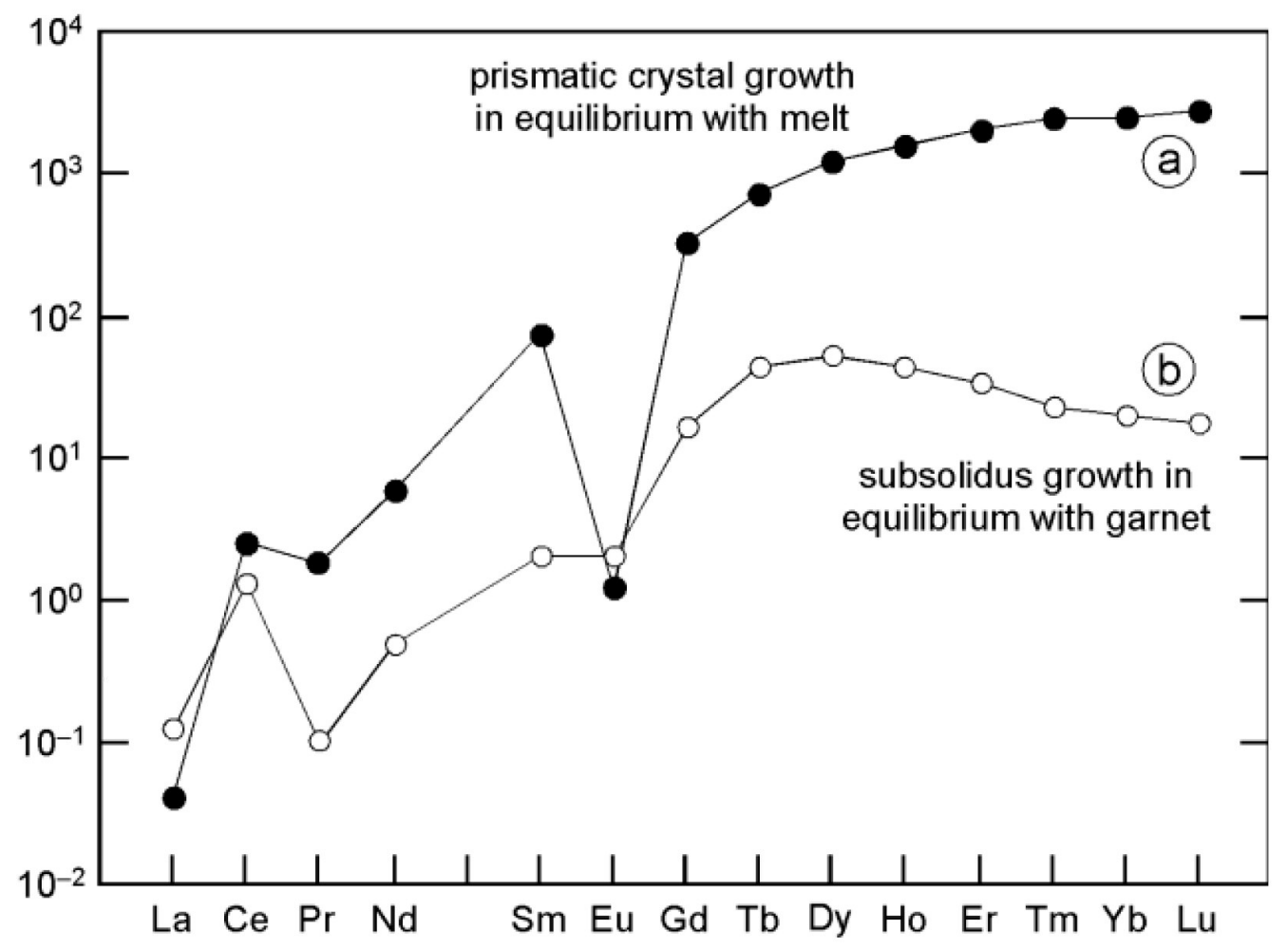

Figure 4.7: REE profiles for high pressure metamorphic zircons. Crystals formed in equilibrium with an anatectic melt (black dots) have REE profiles comparable to those of crustal affinity igneous zircon (e.g. igneous cores in Figure 4.8). Zircons formed in subsolidus conditions in a high grade metamorphic rock (white dots) have distinctive REE profiles, which may be distinguishable from those of other broad formation groups (source: Hoskin and Schaltegger, 2003).

High grade metamorphic zircons that formed in subsolidus conditions have extremely variable REE profiles which may include: (1) Depletion of HREE relative to Mid REE (MREE) or flat HREE slopes (Figs. 4.7 and 4.8). This pervasive trait is due to the co-crystallisation of garnet (Rubatto and Hermann, 2007); (2) Weak Eu anomalies, which is due to the zircons crystallising prior to feldspars in high grade metamorphic rocks (Rubatto and Hermann, 2007); and (3) Variable Ce anomalies, the cause of which are poorly understood (perhaps oxidation states). 


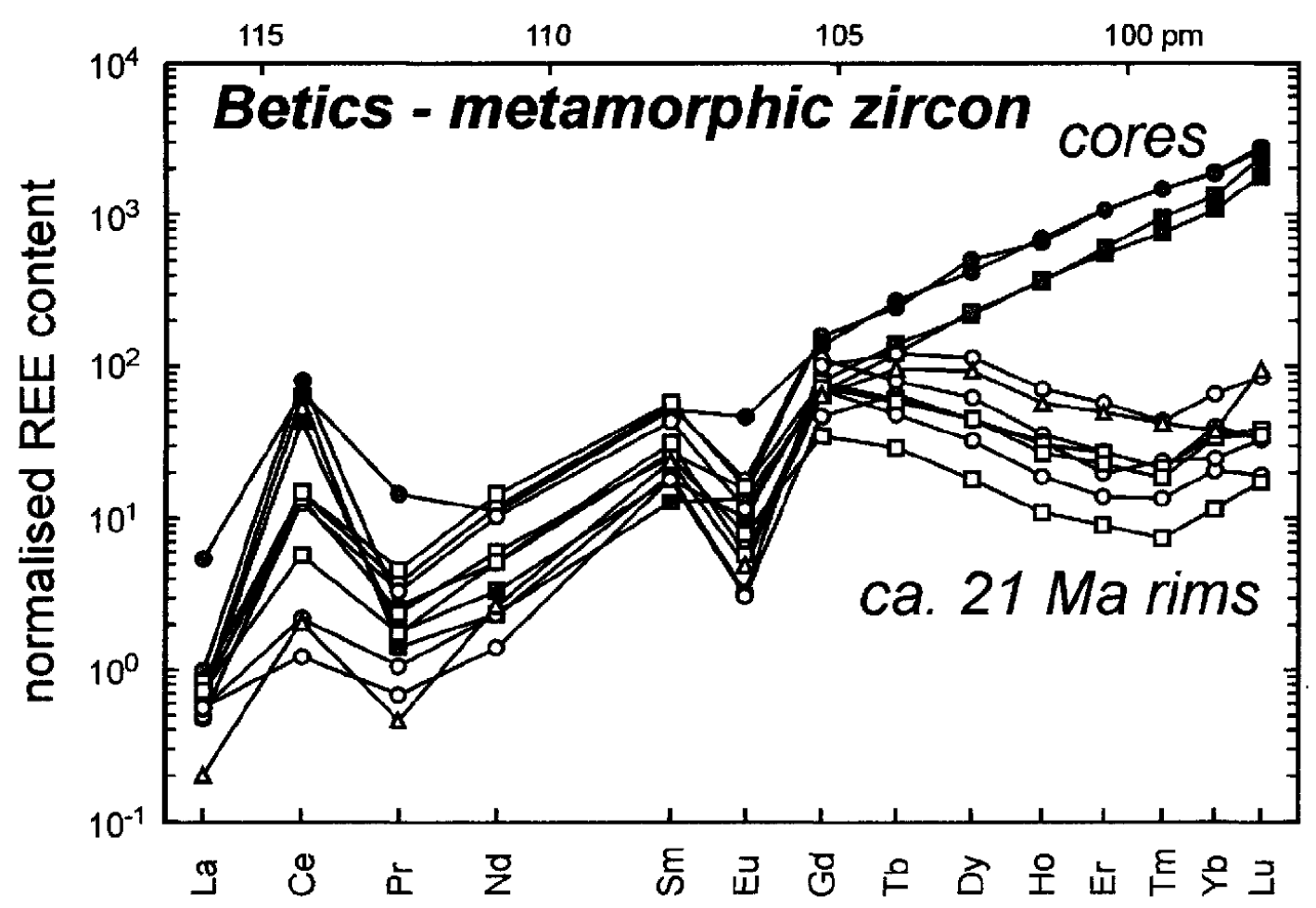

Figure 4.8: REE profiles of high pressure metamorphic zircon (granulite grade rims) and igneous cores. The HREE depletion in the metamorphic zircon is due to the presence of garnet during crystallisation (Rubatto and Herman, 2007). Note the similarity between the REE profiles of the igneous cores and that of the zircon formed in equilibrium with a melt (black dots) in Figure 4.7. (source: Whitehouse, 2003).

Zircons formed in low grade metamorphic environments have REE profiles distinct from those formed in high grade metamorphic, igneous and hydrothermal environments (Fig. 4.9). Fluids expelled during metamorphic reactions may cause hydrothermal growth or alteration of pre-existing zircons. However, as these fluids are usually expelled in a closed system, such zircons may generally be classified as metamorphic.

In low grade metamorphic environments new zircon growth is rare and zircons are commonly formed from the recrystallisation of protolith zircons. Thus the chemical compositions of low-grade metamorphic zircons are often a result of the partial overprinting of the protolith zircon in the metamorphic environment. Though sections that retain the characteristics of the protolith zircons will be chemically indistinguishable from the protolith, sections of zircons formed from the complete recrystallising of the protolith will show distinct REE patterns (Fig. 4.9). 


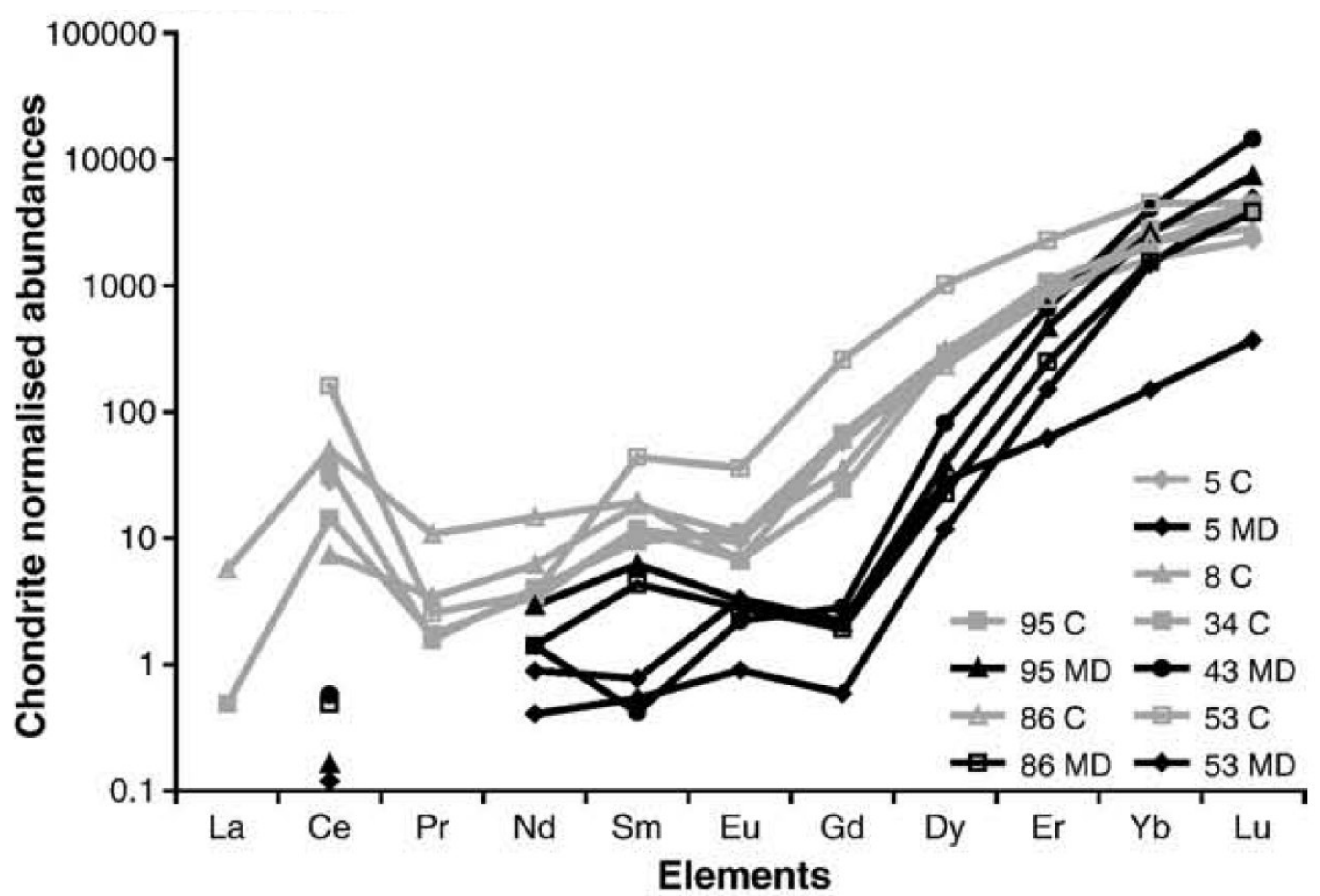

Figure 4.9: Completely re-crystallised, low grade metamorphic zircon REE profiles (black) for zircons found in a metapelite. Inherited igneous core REE profiles (shown in grey) are significantly different. Note the exceedingly low MREE and LREE concentrations found in the metamorphic overgrowths (source: Martin et al., 2008).

During complete recrystallisation of a protolith zircon in a low pressure metamorphic environment, cations with ionic radii significantly larger than $\mathrm{Si}, \mathrm{Zr}$ and $\mathrm{Hf}$ are expelled. As a result, entirely recrystallised protolith zircons will show depletions in LREE and MREE, as these are larger than HREE (Fig. 4.9). Low grade metamorphic zircons commonly show variable Eu and Ce anomalies.

Chondrite-normalised REE profiles of zircons formed in association with aqueous fluids

Due to the large amount of overlap in zircon formation environments, it is ambiguous whether hydrothermal zircons are a distinct group or whether they should be classified as igneous and/or metamorphic (Schaltegger, 2007). Recently, much research has been conducted into hydrothermal zircon characteristics (e.g. Pelleter et al., 2007) that suggest hydrothermal REE (and other trace element) characteristics are often distinct from those formed in other environments (e.g. Grimes et al., 2009). Thus, for completeness, the current understanding of the REE characteristics of hydrothermal zircon is briefly reviewed. 
It is difficult constrain the shape of hydrothermal zircon REE profiles (and trace element concentrations) due to the extreme variability of the composition of hydrothermal zircons (e.g. Pettke et al., 2005), which reflects the high degree of chemical heterogeneity in hydrothermal environments. The geochemical characteristics of zircons formed from or altered by fluids are controlled by an interplay of the crystallisation sequence of accessory minerals (Schaltegger, 2007), the composition of the aqueous fluid, the redox state in which the zircon formed, and the composition of the pre-exiting, altered zircon (Pelleter et al., 2007).
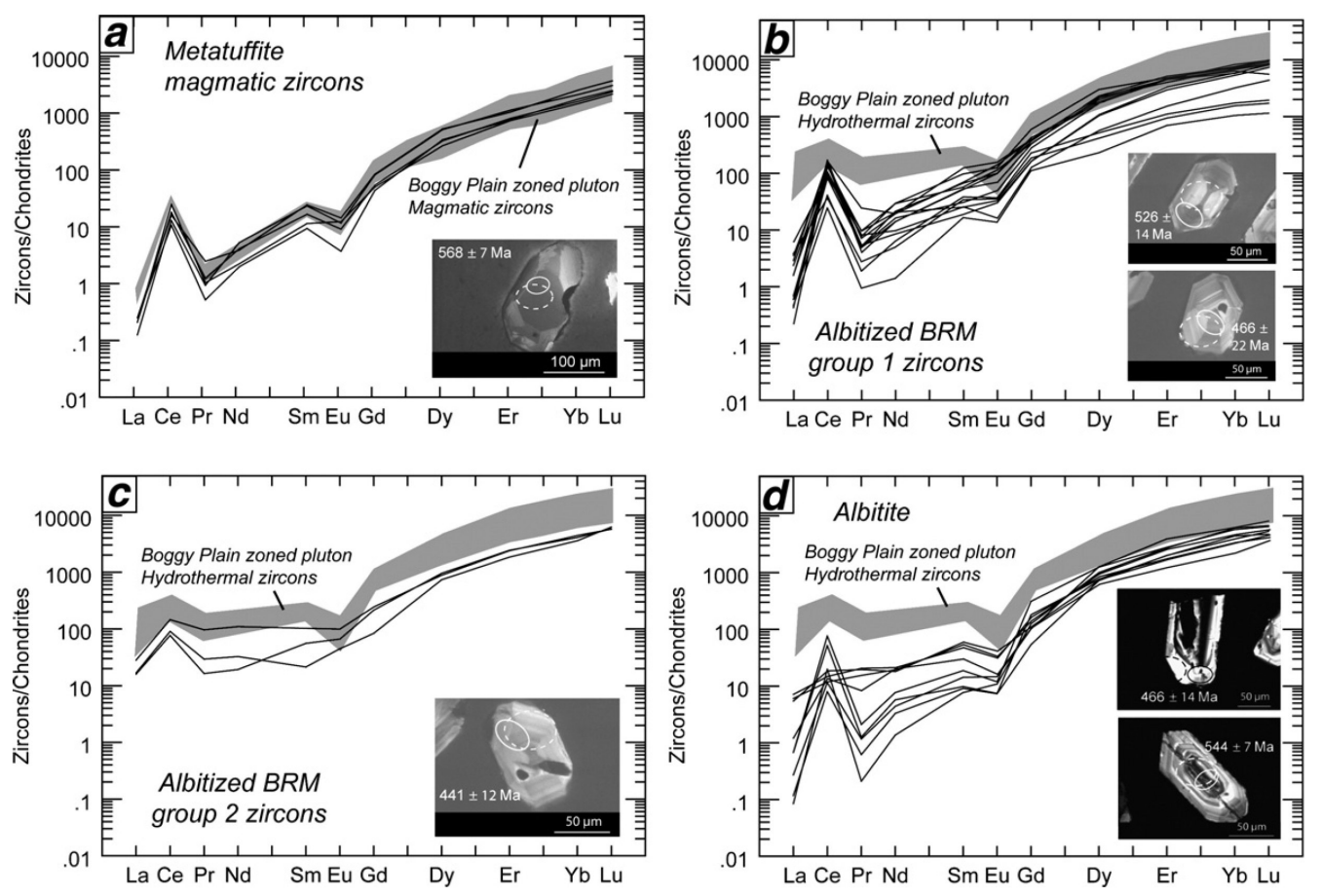

Figure 4.10: Variable REE compositions obtained from hydrothermal zircons from a single source. The variability is attributed to a number of factors including: the evolution of fluid composition (from Eu enriched to depleted, causing variations in $\mathrm{Eu}$ anomalies) and variations in altered magmatic zircon composition and redox state. This illustrates how variable zircon chemistry from a single suite can be if fluid interaction occurs (source: Pelleter et al., 2007).

A pervasive characteristic of hydrothermal zircons is an enrichment in REE (and other trace elements) relative to magmatic zircons from the same rock (Fig. 4.10) (Hoskin, 2004; Pettke et al., 2005) which reflects the elemental enrichment common in many hydrothermal fluids. Other reported characteristics include elevated LREE, hypothesised to be a product of zircon interaction with saline aqueous fluids (Hoskin, 2004; Grimes et al., 2009). Depletion of LREE in hydrothermal zircons has also been reported 
(Schaltegger, 2007). Coupled variation in Eu and Ce anomalies have also been reported for hydrothermal zircons (Pelleter et al., 2007), with a strong positive correlation between the magnitudes of negative $\mathrm{Eu}$ anomalies and positive Ce anomalies.

\subsubsection{The Ti-in-zircon geothermometer}

Ti-in-zircon saturation geothermometry allows Ti concentration-based zircon formation temperatures to be estimated. This system has been widely applied to rocks from a variety of genesis (e.g. Watson and Harrison, 2005) but recently it has been found that this system may not be as reliable as initially thought and may be influenced by a variety of factors, such as the presence of co-crystallising $\mathrm{Ti}$ incorporating phases (Fu et al., 2008). It appears the formation temperatures for zircons formed in a variety of host rocks are generally considerably lower than expected and it is understood that Ti-in-zircon temperatures alone are not sufficient to identify parental melt compositions (Fu et al., 2008).

The premise of this system is the increased ability of $\mathrm{Ti}^{4+}$ to replace $\mathrm{Zr}^{4+}$ and $\mathrm{Si}^{4+}$ in the zircon lattice with increased temperature. The dominant substitution in this reaction is $\mathrm{Ti}^{4+}=\mathrm{Si}^{4+}$ or $\mathrm{Zr}^{4+}$, which is isovalent and relatively insensitive to pressure. This replacement relationship (Equation 4.1) is logarithmic with concentrations of 0.3-50 ppm yielding temperatures between $\sim 600-1,450{ }^{\circ} \mathrm{C}$ (Watson et al., 2006).

$\log \left(\mathrm{Ti}_{\text {zircon }}\right)=(6.01 \pm 0.03)-((5080 \pm 30) /(\mathrm{T}(\mathrm{K})))$

Equation 4.1: Ti-in-zircon geothermometer (source: Watson et al., 2006).

The geothermometer assumes $\mathrm{Ti}$ saturation in a host rock. For in situ zircons saturation may be confirmed by the co-existence of a Ti-bearing accessory phase. However, as this cannot be confirmed for detrital zircons, Ti-in-zircon values for detrital zircons are minimum formation temperatures.

\subsubsection{Li concentrations and zircon provenance}

The lithium concentration of a zircon may give information on the Li content of its parent rock, the degree of surface material incorporated into the parent rock, and the amount and duration of heating the zircon experienced since its formation. High Li 
concentrations within zircons indicate highly evolved magmatic sources or contamination by surface material (Cherniak and Watson, 2010). Lower concentrations indicate no surficial contamination and/or low degrees of magma differentiation. As such, mantle derived zircons have Li concentrations of the order of parts per billion, whilst evolved melts such as granites and pegmatites, and pelitic metasediments have Li concentrations up to 250 ppm (Ushikubo et al., 2008).

Ushikubo et al. (2008) measured the lithium concentrations of Jack Hills (Australia) zircons, to constrain the amount of surficial contamination and/or differentiation in the parent melt. It was assumed that, similarly to other elements, Li diffusion in zircon was slow and that Li concentrations in a zircon were generally unaltered since formation. The Jack Hills zircons were found to have high Li concentrations (10-60 ppm) which was hypothesised to indicate a low temperature interaction of the Jack Hills zircon parental melt with liquid water.

More recently, Cherniak and Watson (2010) found diffusion of $\mathrm{Li}$ in zircon is relatively rapid and requires lower activation energy than other trace elements (such as $\mathrm{U}$, Th and REE). It was calculated that the Li concentrations from the centre of a $100 \mu \mathrm{m}$ grain are lost in $2000 \mathrm{yr}$ if a temperature of $750{ }^{\circ} \mathrm{C}$ is sustained and are lost in $60 \mathrm{Myr}$ if the zircon is heated to $500{ }^{\circ} \mathrm{C}$. To this end, the closure temperature for $\mathrm{Li}$ in zircon is much lower than those for other trace elements (e.g. Pb; Cherniak and Watson, 2000). This indicates that a xenolith zircon that experienced high temperature metamorphic conditions would experience a decoupling of its elemental compositions; the zircon's $\mathrm{Li}$ concentrations would be reset and whilst concentrations of other element with higher activation energies would be maintained.

Thus, a decoupling of $\mathrm{Li}$ and other trace elements may be observed if a detrital zircon was once a xenolith in high grade metamorphic, mafic igneous and/or mantle environment. However, this decoupling is less likely to occur in zircons that were once xenoliths in lower grade metamorphic or felsic igneous environments.

\subsection{4. $\mathrm{Zr} / \mathrm{Hf}$ and $\mathrm{Hf}$ concentrations}

Zircon $\mathrm{Zr} / \mathrm{Hf}$ ratios allow insights into the amount of differentiation of the parental melt, regardless of the temperature at which the zircons formed. Zircon is the prime 
reservoir for both $\mathrm{Zr}$ and $\mathrm{Hf}$ (Grimes et al., 2009), which are substituted into the zircon lattice for $\mathrm{Si}^{4+}$ by a reaction that requires no charge compensation (Grimes et al., 2007). Due to its slightly smaller size, $\mathrm{Zr}$ is slightly more compatible than $\mathrm{Hf}^{4+}$ in zircon (Grimes et al., 2007; Hoskin and Schaltegger, 2003). Thus, when zircon crystallisation occurs, the $\mathrm{Zr} / \mathrm{Hf}$ of the melt will decrease as $\mathrm{Zr}$ is preferentially incorporated into the crystal. Subsequent zircon crystallised from this melt have lower $\mathrm{Zr} / \mathrm{Hf}$ ratios and their crystallisation will serve to further lower $\mathrm{Zr} / \mathrm{Hf}$ in the residual melt. Thus, high Hf concentrations (low $\mathrm{Zr} / \mathrm{Hf}$ ratios) indicate highly differentiated formation environments, whereas low $\mathrm{Hf}$ concentrations (high $\mathrm{Zr} / \mathrm{Hf}$ ratios) indicate a lesser degree of differentiation has occurred.

As their incorporation characteristics are so similar, any appreciable variances in $\mathrm{Hf}$ and $\mathrm{Zr}$ concentrations in zircons requires a high degree of melt differentiation. Most crustal rocks maintain near chondritic whole rock ratios with only rhyolitic and granitic melts displaying whole rock $\mathrm{Zr} / \mathrm{Hf}$ that deviate significantly from chondritic values (Grimes et al., 2009). Generally $\mathrm{Zr} / \mathrm{Hf}$ ratios in calc-alkaline rocks decrease from 60 for mafic, early formed rocks, such as gabbros to about 30-40 for granites (Gulson, 1969). This well established trend in $\mathrm{Zr} / \mathrm{Hf}$ ratios allows large-scale investigations into the amount of differentiation an igneous rock has experienced However, it does not allow more detailed insights into the degrees of differentiation experienced (e.g. it is not possible to distinguish between granites with variable amounts of differentiation based solely on Zr/Hf ratios) (Grimes et al., 2009).

\subsection{5. $\mathrm{U}$ and $\mathrm{Th}$ compositions and the $\mathrm{Th} / \mathrm{U}$ ratio}

$\mathrm{U}$ and Th concentrations in zircon reflect parental melt enrichment. Crustal zircons are generally most enriched in $\mathrm{U}$ and $\mathrm{Th}$ and have concentrations on the order of tens to thousands of ppm (Hoskin and Schaltegger, 2003). Kimberlitic zircons show much lower $\mathrm{U}$ and $\mathrm{Th}$ concentrations (e.g. 10.9 and $3.3 \mathrm{ppm}$, respectively) (Belousova et al., 1998) and zircons sourced from eclogites and hydrothermal units show intermediate concentrations (U $\sim 100$ ppm and Th $\sim 100-400$ ppm) (Rubatto and Hermann, 2003; Pelleter et al., 2007). Considerable ambiguity may be present when constraining detrital zircon formation environment based on $U$ and Th concentrations alone, due to the heterogeneous intracrystalline distribution of these elements (Hoskin and Schaltegger, 2003). 
This heterogeneity is less when considering zircon Th/U ratios which allow an igneous versus metamorphic provenance for detrital zircons to be discerned. Igneous zircons have average Th/ $<1$ (ratios as high as 10,000 have been reported in highly Th enriched rocks such as pegmatites and carbonatites) (Belousova et al., 2002). Metamorphic zircon $\mathrm{Th} / \mathrm{U}$ ratios are generally less than 0.1 due to the preferential expelling of Th cations during protolith recrystallisation (Hoskin and Schaltegger, 2003).

\subsubsection{Resolution of felsic and mafic igneous zircons using elemental ratios}

Though not necessarily differentiable using REE profiles alone, detrital zircons sourced from a number of crustal affinity (as well as mantle affinity) sources, may be distinguished from one another using a number of elemental ratios.

$\mathrm{U} / \mathrm{Yb}$ ratios and their relationship to $\mathrm{Hf}$ and $\mathrm{Y}, \mathrm{P}$ and HREE may help distinguish zircons from different crustal affinity igneous sources. $\mathrm{U}$ and $\mathrm{Yb}$ have very similar mineral/melt partitioning coefficients and near equivalent compatibility in zircon (Grimes et al., 2007; Grimes et al., 2009). Given this, U/Yb ratios in zircon will exactly reflect the whole rock $\mathrm{U} / \mathrm{Yb}$ ratio of the melt from which they formed. In magmatic systems, $\mathrm{U}$ and $\mathrm{Yb}$ exhibit variable behaviours; with increasing differentiation $\mathrm{U}$ becomes enriched whilst $\mathrm{Yb}$ becomes depleted. As zircon $\mathrm{U} / \mathrm{Yb}$ ratios replicate those of the host material, this results in low $\mathrm{U} / \mathrm{Yb}$ ratios for mafic igneous zircons (around 0.2), higher values of $\sim 1$ for continental igneous zircons, and the highest values for kimberlitic zircons (2.1). The exact replication of host $\mathrm{U} / \mathrm{Yb}$ found in zircons means it is possible to resolve between groups of zircons from continental and oceanic crust when plotted against Hf, Y, P or HREE (Fig. 4.11) (as illustrated in Grimes et al., 2007; Grimes et al., 2009). 

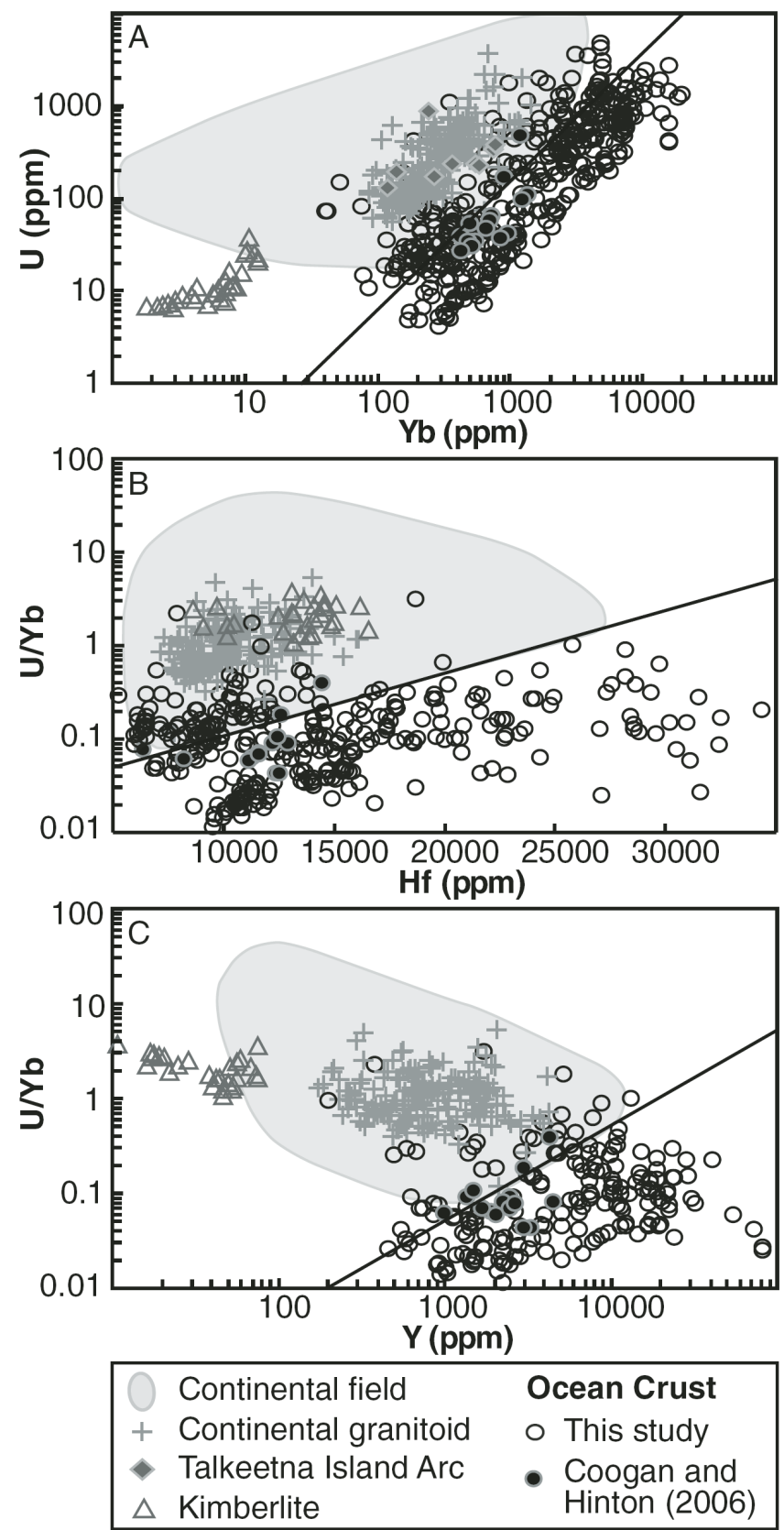

Figure 4.11: Elemental bivariate plots used to distinguish between crustal-affinity zircons. When plotted on bivariate plots, zircons from continental vs. mantel sources show inherently difference characteristics. This Study refers to the source paper of this image (source: Grimes at al., 2007).

\subsection{Internal zonation of trace elements: Insights into zircon provenance}

The relative insolubility of zircon in crustal melts and fluids, as well as their general resistance to physical and chemical weathering means several generations of geochemical information are often preserved in a single grain (Cherniak and Watson, 2003). Preserved zonation within a crystal is a record of thermal and geochemical 
evolution which can be investigated using in situ geochemical analysis techniques. Zoning in zircons can form from slight fluctuations in source chemistry, erosion of zircon during transportation on the Earth's surface or the absorption of pre-existing zircon. Sharp compositional zones are prevalent in zircon crystals and are occasionally on an extremely fine scale ( $\mu \mathrm{m}$ to sub- $\mu \mathrm{m})$ (Cherniak et al., 1997). Due to the slow diffusivity rates of trace elements in zircons, sharp compositional zones have been proven to be long lasting, (a $1 \mu \mathrm{m}$ zone will be destroyed over $100 \mathrm{Myr}$ and lost over $1 \mathrm{Gyr}$ if consistently at $800{ }^{\circ} \mathrm{C}$ ) (Cherniak et al., 1997).

\subsubsection{Analysis of internal zonation}

An electron probe micro-analyser (EPMA) can be used to investigate internal geochemical zonation with a zircon crystal by back scattered electron (BSE) and cathodoluminescence (CL) imaging. BSE images are created when X-rays emitted by the EPMA hit the sample and cause electrons to become dislodged. The brighter the BSE image returned, the higher the atomic mass of the crystal. Thus BSE analysis is a sound way to distinguish between zircons and other crystals with lower atomic masses. CL images are created when X-rays hit a crystal causing trace elements within it to emit visible light (CL), the brightness of which correlates positively with Hf, Y, P REE, U and Th concentrations (Siebel et al., 2009; Corfu et al., 2003; Cherniak et al., 1997). The most prominent known CL characteristics for zircon from variable formation environments and how these may be used to infer zircon genesis are outlined below.

\subsubsection{Igneous zircon cathodoluminescence characteristics}

There are a number of zoning characteristics inherent to igneous zircons the most pervasive being oscillatory growth zones (Fig. 4.12). Oscillatory zones are created in response to episodic growth of the crystal and the amount of trace elements available in the host rock (Corfu et al., 2003). Sector zoning (Fig. 4.13) occasionally occurs in igneous zircons, although the cause of this is still debated (Corfu et al., 2003). Occasionally, igneous zircons display very weak, faint, broad zoning (Fig. 4.14) which may represent zonation on a finer scale than is resolvable using current imaging techniques. This lack of zoning if often observed in mantle affinity zircons, such as those from carbonatites and kimberlites, due to hig temperatures and subsequent diffusion and homogenisation of trace elements (Belousova et al., 1998; Corfu et al., 2003). In such samples, the absence of zonation may be caused by prolonged 
residence in the mantle. Mantle zircons often show other, more complex zoning features, such as mosaic textures. Xenocrystic cores are common in igneous zircons and their internal zoning is often corroded, truncated and overgrown by igneous rims (Fig. 4.15) (Corfu et al., 2003). If zirconium undersaturation has occurred within the growth environment, dissolution and reprecipitation textures may cut primary growth zones (Geisler et al., 2007).

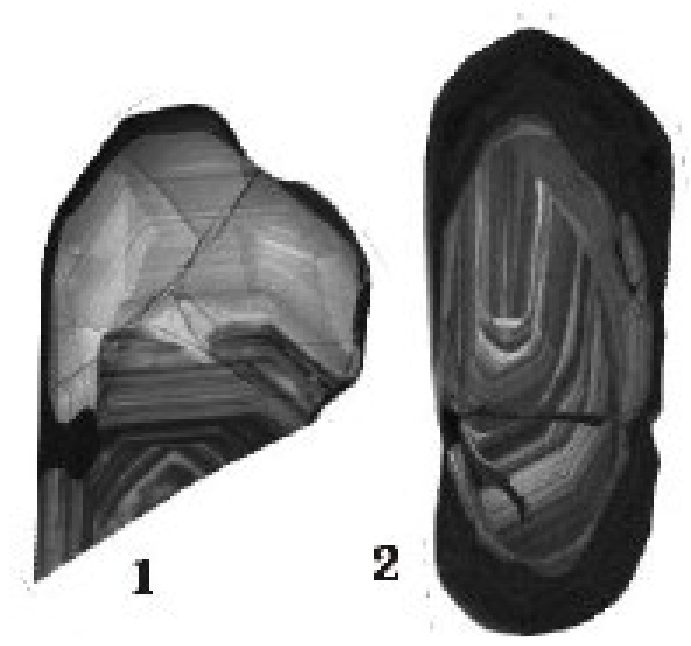

Figure 4.12: Oscillatory zoning in a granitic zircon with local resorption (source: Corfu et al., 2003).

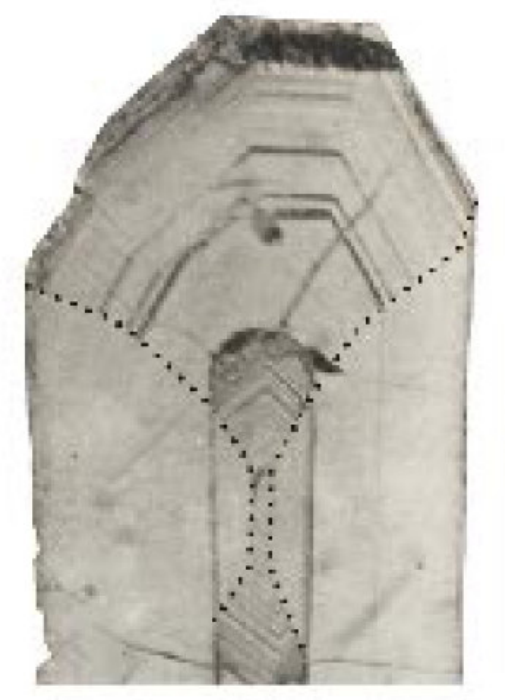

Figure 4.13: A zircon showing sector zoning, as indicated by the dashed lines (source: Corfu et al., 2003). 


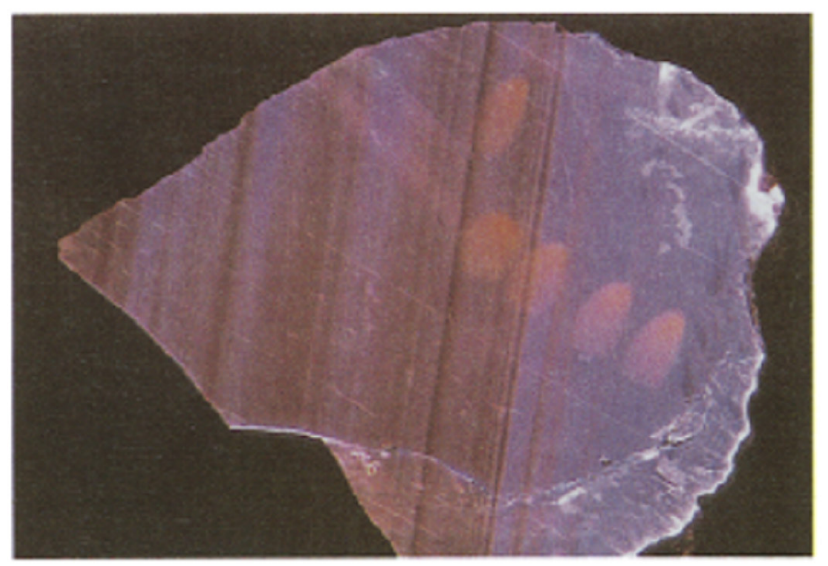

Figure 4.14: Broad weak oscillatory zoning characteristic of kimberlitic zircon (source: Belousova et al., 1998).
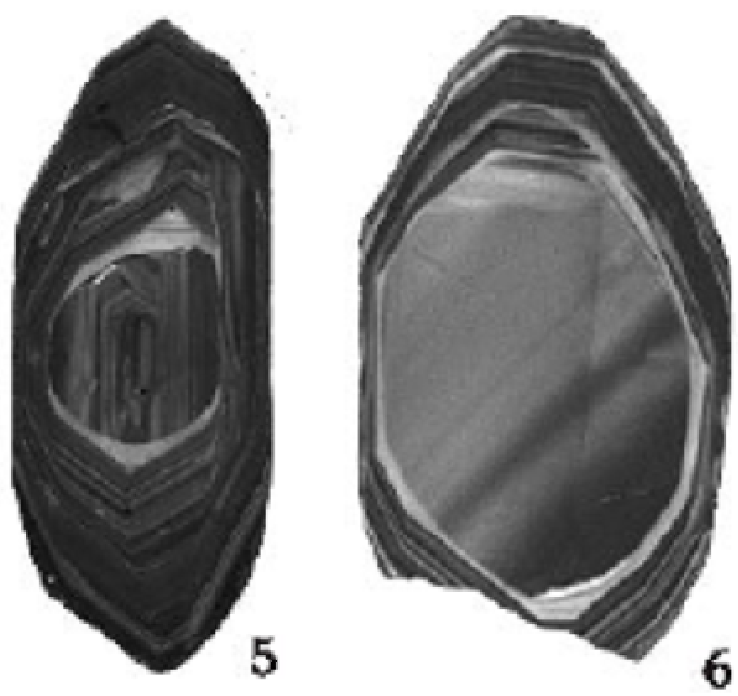

Figure 4.15: Igneous zircons with xenocrystic cores (source: Corfu et al., 2003).

\subsubsection{Metamorphic zircon cathodoluminescence characteristics}

Zircons found in metamorphic rocks have highly variable, complex and chaotic internal zonation patterns that reflect the highly changeable parameters present during metamorphic zircon formation/recrystallisation. Variables that influence metamorphic zircon internal zonation include the physio-chemical conditions during crystallisation, the duration of each metamorphic event, the pre-existing structures in the protolith zircon, and the overgrowth of new zircon (Corfu et al., 2003). Internal zonation found in metamorphic zircons include: protolith cores that preserve original growth zoning (Fig. 4.16) (predominantly in low-grade metamorphic rocks), chaotic textures that combine growth patterns, flow structures and overgrowths (Fig. 4.17), variants of sector zoning that are caused by variances in growth rates and homogeneous zones (Fig. 4.18). 

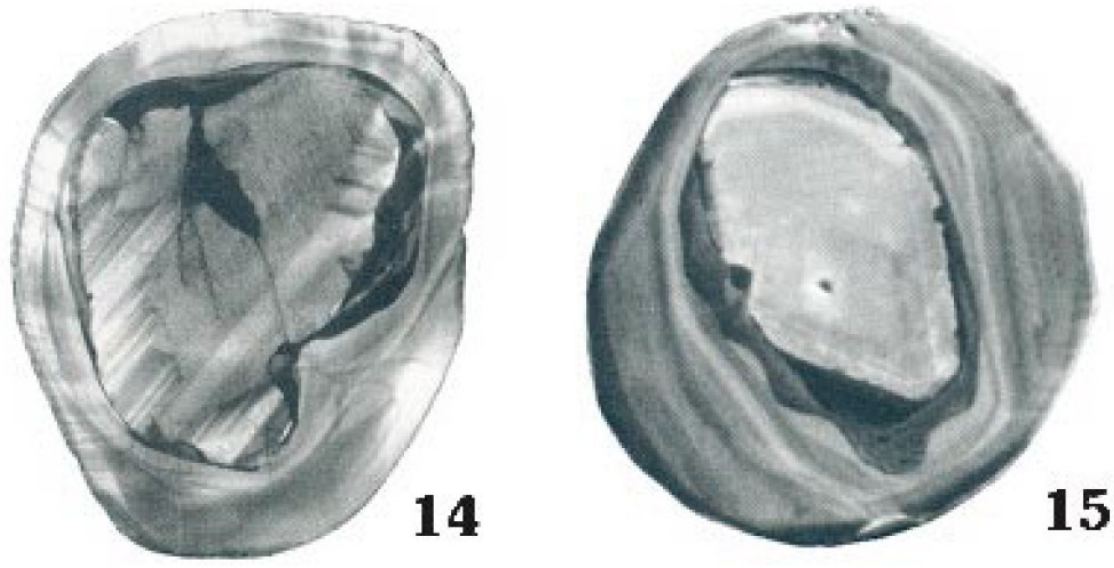

Figure 4.16: High grade metamorphic zircons with xenocrystic cores that have preserved original (oscillatory) growth zones (source: Corfu et al., 2003).
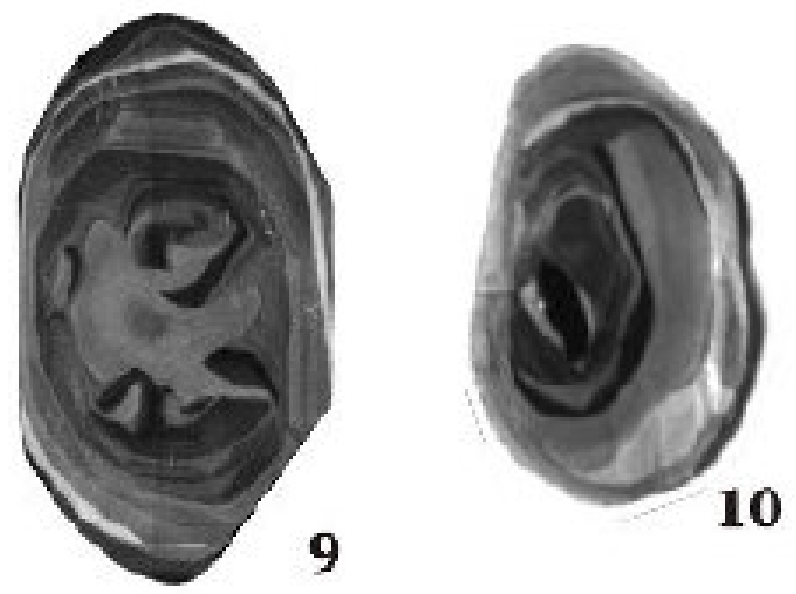

Figure 4.17: Zircons with irregular concentric zoning with overgrowths on zircons of a metamorphic origin (source: Corfu et al., 2003).
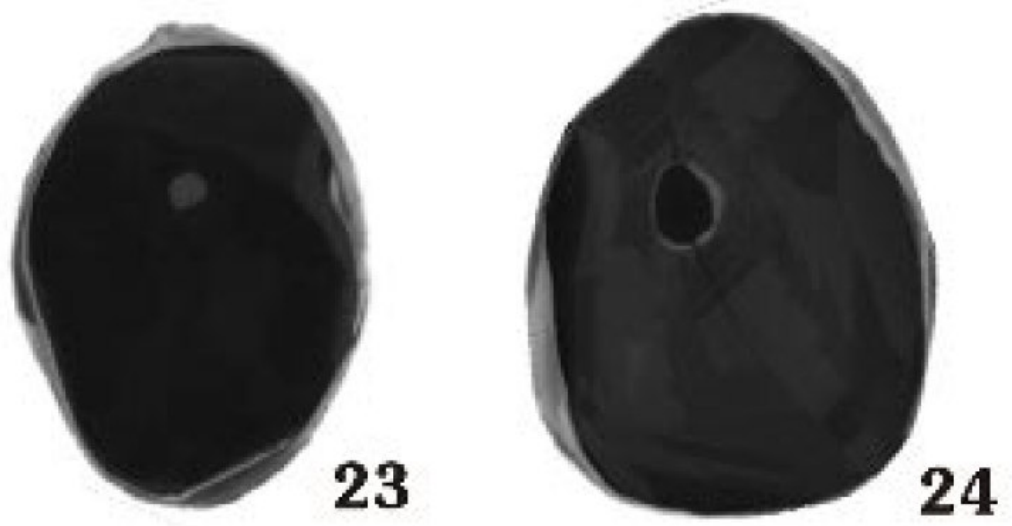

Figure 4.18: Homogenous zones of a metamorphic origin (source: Corfu et al., 2003). 


\subsubsection{Hydrothermal zircon cathodoluminescence characteristics}

Hydrothermal zircon may form by growth of new crystals (including overgrowths) or from fluid alteration of pre-existing zircons, which often occurs in close association with metamorphic and igneous environments. Similarly to the chemical characteristics of hydrothermal zircons, the internal growth zones of this group are highly heterogeneous, reflecting the numerous variables involved during hydrothermal zircon alteration and/or growth. Zircons formed or re-crystallised in association with fluids may display convolute zoning (Fig. 4.19) and zones of enrichment of high field strength elements, REE and non-radiogenic lead (Fig. 4.20). Other zoning characteristics potentially displayed by hydrothermal zircons include secondary domains cutting primary growth zones and open, spongy, inclusion-rich textures (hydrothermal environment primary zircon growth) (Fig. 4.21).

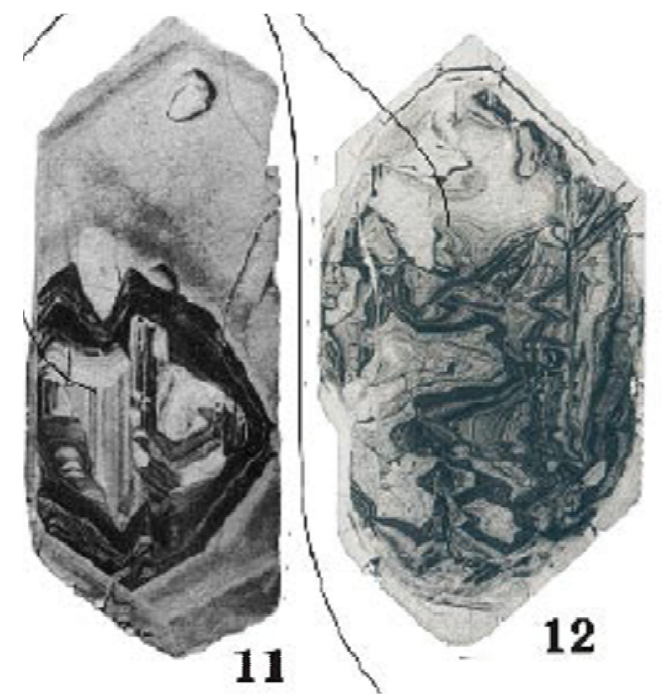

Figure 4.19: Convoluted zoning characteristic of hydrothermal overgrowths/recrystallisation (source: Corfu et al., 2003).

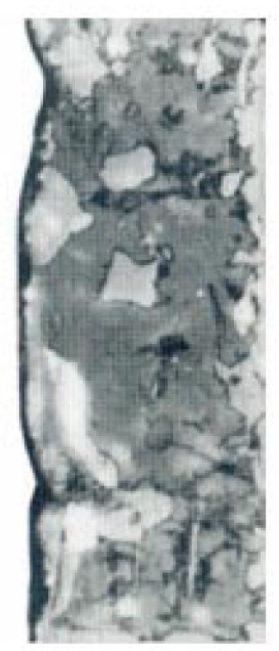

Figure 4.20: Trace element enriched zircon patchy texture showing metasomatic replacement of low U domains by high U domains (bright areas) (source: Corfu et al., 2003). 


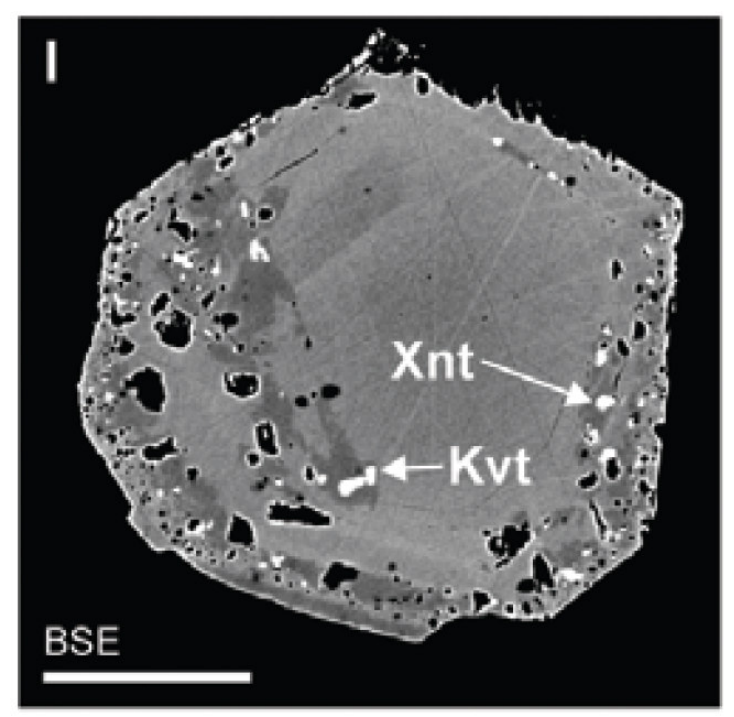

Figure 4.21: BSE image of a zircon with a spongy, inclusion rich texture characteristic of zircon growth in a hydrothermal environment (source: Geisler et al., 2007). 


\section{Chapter 5: Geochronological and geochemical analytical techniques, data reduction and analysis}

\subsection{Introduction}

The analytical work for this thesis was conducted using the Victoria University of Wellington Geochemical Laboratory. Facilities used include the EPMA and LA-ICPMS. For ease of explanation, this chapter has been structured in the chronological order in which the methods were conducted.

\subsection{Sample acquisition}

Eighteen hand-sized sample were taken from the working half of the CIROS-1 drill core at intervals of $\sim 50 \mathrm{~m}$ (Fig. 5.1; Table 5.1). Sand-sized lithologies were targeted as zircons big enough to allow in situ geochemical analysis most commonly occur in these lithologies. On two occasions, samples were taken within $\sim 5 \mathrm{~m}$ of one another. This was done to allow comparison of zircon content from temporally proximal samples that were deposited by different processes during orbitally forced variations in depositional environments (e.g. sand from the matrix of a diamict and its overlying sand unit). Thus, any potential fine-scale variation in the lithologies contributing sediments to the core would not be missed.

Table 5.1: The names, locations, depositional ages and source units of the samples analysed in this thesis.

\begin{tabular}{|c|c|c|c|}
\hline $\begin{array}{l}\text { Sample } \\
\text { name }\end{array}$ & $\begin{array}{l}\text { Location } \\
\text { (mbsf) }\end{array}$ & Depositional Age & Source unit \\
\hline $28-21$ & 28 & Early Miocene & Poorly sorted coarse/very coarse sandstone \\
\hline $78-18$ & 78 & Early Miocene & Fine sandstone/mudstone \\
\hline $91-17$ & 91 & $\begin{array}{l}\text { Early Miocene-Late } \\
\text { Oligocene? }\end{array}$ & Sandstone matrix of a diamict \\
\hline $148-16$ & 148 & Late Oligocene & Medium/coarse sandstone \\
\hline $205-15$ & 205 & Late Oligocene & Medium sandstone \\
\hline $249-14$ & 249 & Late Oligocene & Sandstone matrix of a diamict \\
\hline $292-13$ & 292 & Late Oligocene & Fine sandstone/mudstone \\
\hline 295-12 & 295 & Late Oligocene & Fine/medium sandstone \\
\hline $362-11$ & 362 & Late Oligocene & Coarse sandstone \\
\hline $403-10$ & 403 & Late Oligocene-Late Eocene? & Medium/coarse bedded sandstone \\
\hline $462-7$ & 462 & Late Oligocene-Late Eocene? & Medium/coarse sandstone \\
\hline $465-8$ & 465 & Late Oligocene-Late Eocene? & Medium/coarse sandstone \\
\hline $507-6$ & 507 & Late Eocene & Medium/coarse sandstone \\
\hline $560-5$ & 560 & Late Eocene & Medium sandstone \\
\hline $610-4$ & 610 & Late Eocene & Medium sandstone \\
\hline $652-3$ & 652 & Late Eocene & Medium sandstone \\
\hline $687-1$ & 687 & Late Eocene & Sandstone matrix of a conglomerate \\
\hline $693-2$ & 693 & Late Eocene & Sandstone matrix of a conglomerate \\
\hline
\end{tabular}




\subsection{Sample preparation}

Approximately half of each sample was disaggregated and the mud fraction was removed using water-based density separation. This was repeated for particularly muddy or aggregated samples. Once dry, the samples were sieved into $<53 \mu \mathrm{m}$, 53$150 \mu \mathrm{m}, 150-250 \mu \mathrm{m}, 250-300 \mu \mathrm{m}$ and $>300 \mu \mathrm{m}$ fractions. The $<53 \mu \mathrm{m}$ and $>300$ $\mu \mathrm{m}$ fractions were stored and not used. Although the most likely size fraction for zircons is $\sim 53-150 \mu \mathrm{m}$, the two larger fractions were also processed to ensure no analysable zircons were missed. Per sample, the three size fractions were magnetically separated using the VUW Franz and from each a magnetic and non-magnetic fraction was obtained. Each non-magnetic fraction was density separated using sodium polytungstate (specific gravity $=2.9 \mathrm{~g} / \mathrm{cm}^{3}$ ).

Approximately 100 zircon grains were picked from the heavier portions of each sample. There was a $\sim 99 \%$ occurrence of zircons within the $53-150 \mu \mathrm{m}$ fraction, with an occurrence of $<10$ individual 150-300 $\mu \mathrm{m}$ zircons. Zircons were placed on double sided cellotape in groups according to their size. Once sufficient zircons were picked the proto-mount was photographed under a binocular microscope to enable later investigations of zircon morphology and colour (Fig. 5.2). Prior to mounting in epoxy $\sim$ three, $1 \mathrm{~mm}$ shards of NIST 610 (an internal standard) were added to the tape. Round epoxy mounts were made and hardened on a hot plate. Mounts were polished using polishing paper and grinding lap until the widest sections of the zircon crystals were exposed. 


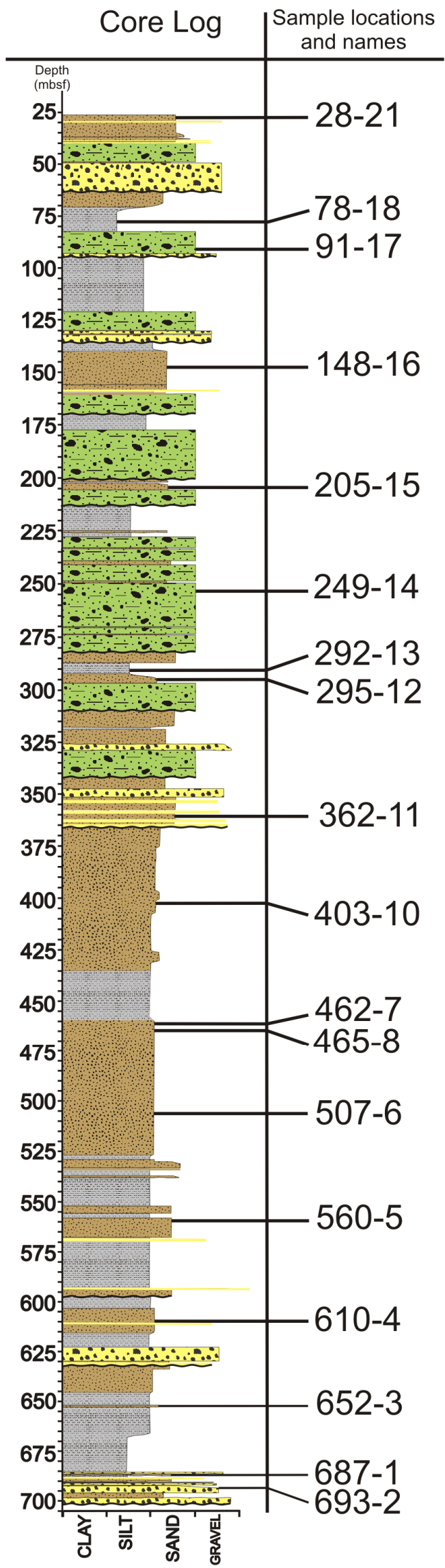

Figure 5.1: CIROS-1 core log, sampling locations and sample names. Sample names first state the depth of the sample. The second number represents when it was sampled in the sampling process. 


\subsection{Sample imaging}

Imaging methods used are similar to those utilised by Kitajima et al. (2008). Each polished mount was photographed using a binocular microscope to aid navigation during sample analysis (Fig. 5.3). The VUW JEOL 733 Electron Microprobe was used to conduct BSE and CL imaging of the zircons. During all imaging a current of $120 \mathrm{nA}$ and a voltage of $15 \mathrm{keV}$ was maintained. BSE images (e.g. Fig. 5.4) were used to distinguish between zircons and other minerals with lower atomic masses. Zircon grains were individually imaged (occasionally in groups of $\sim 5$ ) for internal zonation by CL (e.g. Fig. 5.5).

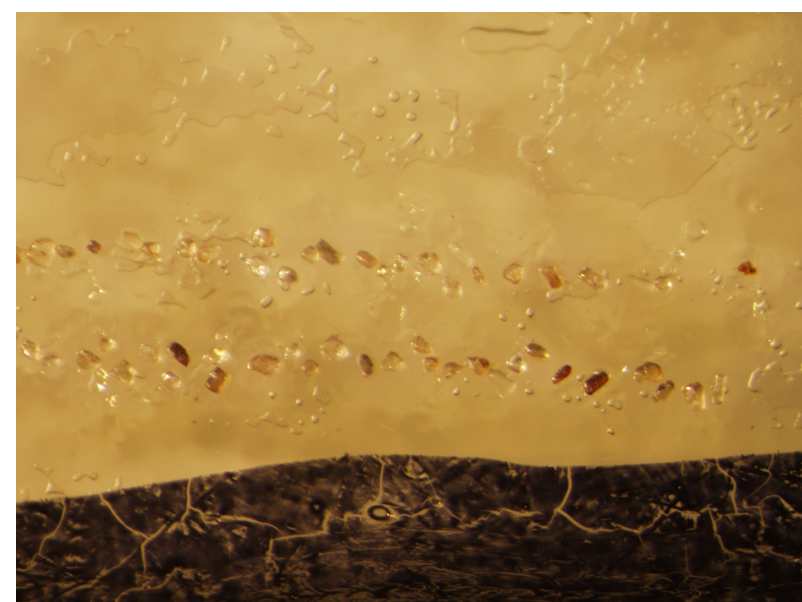

Figure 5.2: Binocular microscope image of zircons from the 53-150 $\mu \mathrm{m}$ fraction of sample 91-17 prior to the mount being made. This imaging was done to allow later investigations into zircon morphology and colour.

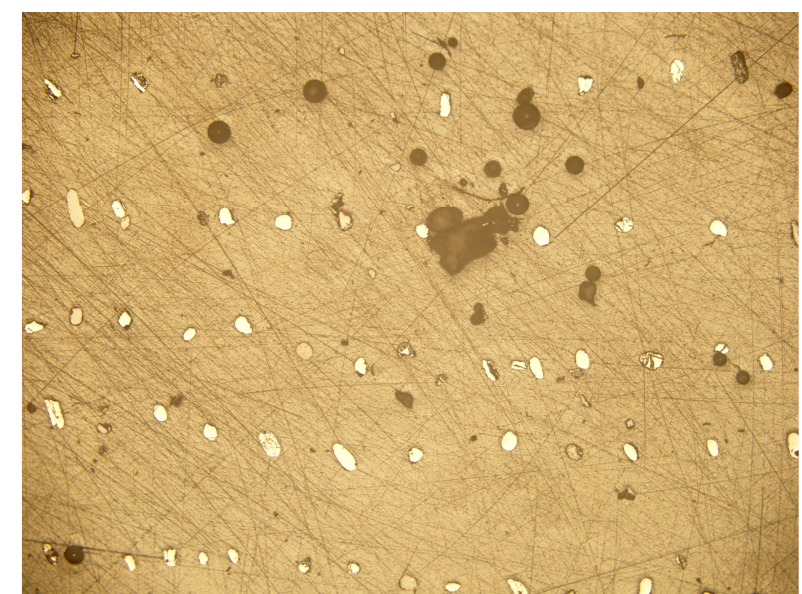

Figure 5.3: Binocular microscope image of 53-150 $\mu \mathrm{m}$ zircons in a polished mount (249-14) used for navigational purposes when conducting EPMA and LA-ICP-MS analysis. Additionally, such images aided in the picking of appropriate spot locations at which to conduct LA-ICP-MS analysis. 


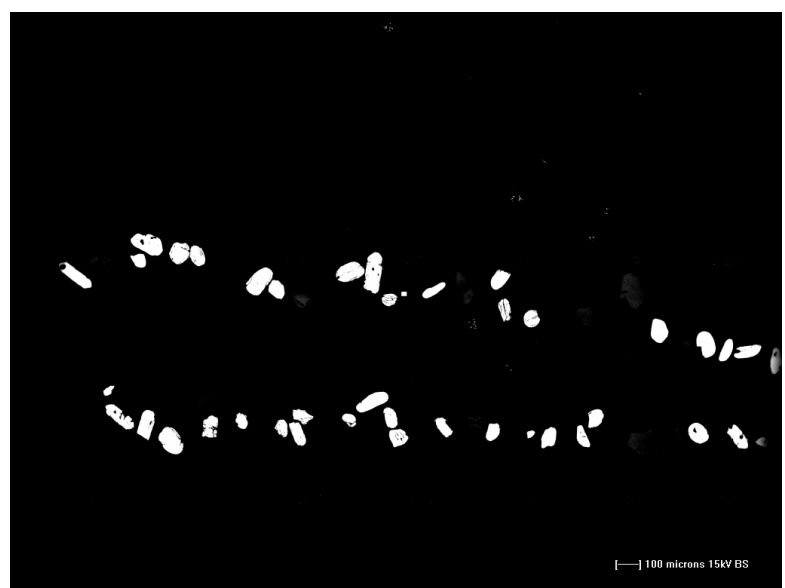

Figure 5.4: BSE image of 53-150 $\mu \mathrm{m}$ zircons in sample 292-13. Bright grains are zircons whereas less bright or invisible grains are other minerals with lower atomic masses.

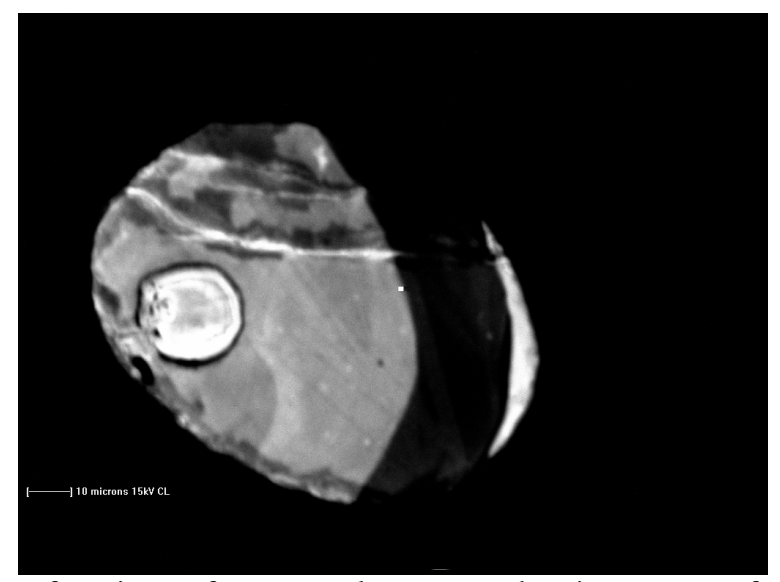

Figure 5.5: CL image of a zircon from sample 292-13 showing zones of variable trace element composition (CL zones). A $25 \mu \mathrm{m}$ diameter ablation pit is visible in the relatively homogeneous zone on the left of the zircon. Note the high-U (bright) zone on the right of the grain and the bright crack, both of which are avoided when conducting LA-ICP-MS analysis of zircons.

\subsection{Geochronological and geochemical analysis of zircon crystals}

Spot locations for analysis were picked based on binocular microscope, CL and BSE images. If a zircon was not deemed to be in a relatively pristing condition, it was not analysed. CL imaging was used to find well defined zones, such as cores and rims, which were targeted for analysis. Inclusion-rich areas, identified using the binocular microscope and BSE imaging, as well cracks were avoided. Zones of excessive U concentrations, identified as very bright zones in CL images, were avoided as these indicate a degree of open system behaviour in the zircon which might yield unreliable results. Analysis of zircon spots was conducted using the VUW Agilent 7500 cs ICP-MS coupled to a NewWave $193 \mu$ m solid-state Nd-YAG laser. Samples were thoroughly washed in methanol and Milli-Q water and dried in a $40{ }^{\circ} \mathrm{C}$ oven for $\sim 4 \mathrm{hr}$ prior to being analysed or at any time after being handled to remove surficial contamination. 


\subsubsection{U-Pb geochronology using LA-ICP-MS}

In recent years, LA-ICP-MS has been established as an accurate, fast and relatively cheap way to obtain radiometric ages of zircons (and other minerals) (Chang et al., 2006; Cocherie and Robert, 2008). The manner in which this method was applied in this research is outlined below.

\subsection{1.i. Samples analysed for detrital zircon U-Pb ages}

Zircons from all 18 samples were analysed for their U-Pb compositions. Many zircons were analysed in multiple locations to allow detailed insights into their growth histories and therefore possible provenance. Other sampling strategies used will be discussed later in this section.

\subsection{1.ii. Operational parameters}

The operational parameters to obtain $\mathrm{U}-\mathrm{Pb}$ and $\mathrm{Pb}-\mathrm{Pb}$ ages for CIROS-1 zircons were developed and tested using the S-97-19 granitic zircon standard. The TIMS age for this standard is $1089 \pm 1 \mathrm{Ma}$ (1se) (James Connolly, pers. comm., 2007). S-97-19 zircons were also used as an external standard. One to two runs comprising 12 S-97-17 zircon analyses were conducted before and after analysis of each CIROS-1 sample. The average ratios and apparent ages obtained for this standard over the duration of this project are given in Table $5.2(\mathrm{n}=263)$.

Table 5.2: Average ratios, 2se errors and apparent ages for the 263 S-97-19 zircons analysed during sample analysis and method development. The TIMS age for this standard zircon is $1089 \pm 1 \mathrm{Ma}$ (1se) (J. Connolly, pers. comm., 2007).

$$
\begin{array}{cccccccc}
\multicolumn{8}{c}{\text { Average ratio }} \\
{ }_{0}{ }^{207} \mathrm{~Pb} /{ }^{206} \mathrm{~Pb} & 2 \text { se } & { }^{238} \mathrm{U} /{ }^{206} \mathrm{~Pb} & 2 \text { se } & { }^{235} \mathrm{U} /{ }^{207} \mathrm{~Pb} & 2 \text { se } \\
0.0763 & 0.0014 & 5.3950 & 0.1300 & 0.04502 & 0.0568 \\
\multicolumn{8}{c}{\text { Average apparent age }(\mathrm{Ma})} \\
{ }^{207} \mathrm{~Pb} /{ }^{206} \mathrm{~Pb} & 2 \text { se } & { }^{238} \mathrm{U} /{ }^{206} \mathrm{~Pb} & 2 \mathrm{se} & { }^{235} \mathrm{U} /{ }^{207} \mathrm{~Pb} & 2 \text { se } & \text { Concordia } & 2 \text { se } \\
1103 & 35 & 1097 & 24 & 1089 & 18 & 1083 & 82
\end{array}
$$

The internal standard used during age analysis was the National Institute of Standards and Technology (NIST) Standard Reference Material (SRM) 610 glass. This glass has concentrations of $\sim 450$ ppm for many elements; 
including $\mathrm{U}$ concentrations of $461.5 \mathrm{ppm}$ and $\mathrm{Pb}$ concentrations of $426 \mathrm{ppm}$ (GeoReM preferred values).

Individual runs (of both CIROS-1 and S-97-19 zircons) were set up as: one internal standard (NIST 610) spot, six unknown zircon spots, one NIST 610 spot, six unknown zircon spots, one NIST 610. Many analyses included multiple spots on a single zircon (e.g. cores and rims or repeats of zones in different runs to examine reproducibility). For each sample, approximately 48 runs of 12 unknown zircons were conducted. On completion of a sample, 1-2 runs of S-97-19 zircons were conducted to validate the age being obtained for the sample zircons.

Spot locations were pre-ablated prior to analysis. Pre-ablation (20 pulses of the laser) parameters were: $50 \mu \mathrm{m}$ spot size, $75 \%$ power, $10 \mathrm{~Hz}$ frequency. Pre-ablation served a number of purposes:

(1) Clean the surface of the zircons (e.g. clear away any residual anthropogenic lead);

(2) Confirm the quality of spot locations (e.g. there were no cracks and/or inclusions present that were not yet identified). If a zircon was not in a relatively pristince condition it was not analysed; and

(3) Confirm the grain being analysed was a zircon. This was done by running the ICP-MS during pre-ablation and monitoring the ${ }^{90} \mathrm{Zr}$ peak. If the peak was less that $100,000-1,000,000 \mathrm{cps}$ the grain was assumed not to be a zircon and excluded from further analysis.

Prior to each analysis session, the laser was warmed up (fired for $\sim 20 \mathrm{~min}$ with shutter closed, $100 \%$ power, $100 \mu \mathrm{m}$ spot size, $10 \mathrm{~Hz}$ frequency). It was auto-tuned 1-3 times preceding every run and was operated with an irradiance of $\sim 2-4 \mathrm{Gw} / \mathrm{cm}^{2}$ and a fluence of $\sim 5-7 \mathrm{~J} / \mathrm{cm}^{2}$. Runs were conducted with a laser power of $75 \%$ and a frequency of $5 \mathrm{~Hz}$. Spot sizes for zircons were $25 \mu \mathrm{m}$ and $35 \mu \mathrm{m}$ for NIST 610 spots. Smaller spot sizes for the samples allowed multiple analyses on many zircon grains. During each analysis active focusing, involving progressive raising of the stage, was used to reduce $\mathrm{U}-\mathrm{Pb}$ fractionation and increase counts (Cocherie and Robert, 2008; Hirata and Nesbit, 1995). Ablation times were set at $60 \mathrm{~s}$ with $\sim 100$ - 
$120 \mathrm{~s}$ wash-out intervals between analyses (as outlined in Kŏsler and Sylvester, 2003).

Prior to each analytical session the ICP-MS was stabilised for $~ 30 \mathrm{~min}$. Once stabilised and after every sample change, the ICP-MS was tuned using NIST 610 shards in the mounts. Tuning was conducted by monitoring signal intensity and stability of a range of isotopes on the ICP-MS and reducing their RSD errors to $<5 \%$. Parameters changed during tuning were predominantly carrier (Ar) and optional $(\mathrm{He})$ gases. The carrier gas was usually set to between $0.80-0.90 \mathrm{~L} / \mathrm{min}$ and the optional gas was usually about $80-91 \%$ flow. Additionally parameters that were less commonly altered during tuning include: RF power (never set to less than $1000 \mathrm{~W}$ ), RF matching, torch position and ion extract lenses.

Isotopes used for tuning include ${ }^{206} \mathrm{~Pb},{ }^{207} \mathrm{~Pb},{ }^{208} \mathrm{~Pb},{ }^{232} \mathrm{Th}$ and ${ }^{238} \mathrm{U}$, which were tuned to RSD's of $<5 \%$. Typically cps when the ICP-MS was optimally tuned included $\sim 15,000$ for ${ }^{206} \mathrm{~Pb}, \sim 40,000$ for ${ }^{232} \mathrm{Th}$ and $\sim 55,000$ for ${ }^{238} \mathrm{U}$. During tuning, the ${ }^{248} \mathrm{ThO}^{+} /{ }^{232} \mathrm{Th}$ was reduced to $<2 \%$, mainly by reducing the flow of carrier gas. If this was not possible more time was needed to flush the chamber and tuning was delayed for $\sim 10 \mathrm{~min}$. Additionally, the ${ }^{232} \mathrm{Th} /{ }^{238} \mathrm{U}$ was measured during tuning. As both these isotopes occur in roughly equivalent amounts in the NIST 610 glass, tuning was conducted so that this ratio was $1.0 \pm 0.1$. This was done to ensure no excessive fractionation between $\mathrm{U}$ and $\mathrm{Th}$ was occurring at the given settings to which the machine was tuned. During tuning, wash out times were evaluated and an appropriate washout delay was set (most commonly all isotopes washed out in $\sim 45-60 \mathrm{~s}$ and wash out delays of $\sim 100-120 \mathrm{~s}$ were set).

Runs of 12 unknown zircons and three NIST 610 shards usually took $\sim 40$ min. The isotopes measured during sample analysis and their dwell times are listed in Table 5.3. A $10 \mathrm{~ms}$ dwell time was chosen for the more abundant isotopes that occur in zircons whilst $30 \mathrm{~ms}$ was used for ${ }^{204} \mathrm{~Pb}$ and ${ }^{207} \mathrm{~Pb}$, which occur in very small quantities in zircons. ${ }^{235} \mathrm{U}$ concentrations were calculated from ${ }^{238} \mathrm{U}$ cps and ${ }^{235} \mathrm{U} /{ }^{238} \mathrm{U}=1 / 137.88$. 
Table 5.3: Isotopes and dwell times used during LA-ICP-MS zircon U-Pb isotopic analysis.

\begin{tabular}{|c|c|}
\hline Isotope & Dwell time (ms) \\
\hline${ }^{204} \mathrm{~Pb}$ & 30 \\
\hline${ }^{206} \mathrm{~Pb}$ & 10 \\
\hline${ }^{207} \mathrm{~Pb}$ & 30 \\
\hline${ }^{208} \mathrm{~Pb}$ & 10 \\
\hline${ }^{232} \mathrm{Th}$ & 10 \\
\hline${ }^{238} \mathrm{U}$ & 10 \\
\hline
\end{tabular}

\subsection{1.iii. Data reduction}

Raw ICP-MS data was produced as .csv files that contained cps data for the selected isotopes measured through the duration of the run (Table 5.3). These files were cut and pasted into a Microsoft Excel data reduction spreadsheet used to obtain background and internal standard corrected isotopic ratios. Firstly, all the data were background corrected by removing the average background counts for the $\sim 20$ s prior to the laser firing. Then outliers were removed using a time sequence graphical representation of the data. ${ }^{207} \mathrm{~Pb} /{ }^{206} \mathrm{~Pb},{ }^{238} \mathrm{U} /{ }^{206} \mathrm{~Pb},{ }^{235} \mathrm{U} /{ }^{207} \mathrm{~Pb},{ }^{232} \mathrm{Th} /{ }^{208} \mathrm{~Pb}$ ratios were calculated for both NIST and zircon spots. As $\mathrm{U}$ and $\mathrm{Pb}$ fractionation is known to increase with increased ablation time (e.g. Hirata and Nesbitt, 1995), only the first $30 \mathrm{~s}$ of data were used for $\mathrm{U} / \mathrm{Pb}$ and $\mathrm{U} / \mathrm{Th}$ ratios whereas $\sim 60 \mathrm{~s}$ worth of data was used for ${ }^{207} \mathrm{~Pb} /{ }^{206} \mathrm{~Pb}$ ratios (to reduce $2 \sigma$ errors). Correction factors to correct instrument drift or bias were calculated using the ratios obtained for NIST 610 spots and their published values (Table 5.4).

Table 5.4: Reference values for $\mathrm{U}$ and $\mathrm{Pb}$ isotopes in NIST 610 glass. ${ }^{207} \mathrm{~Pb} /{ }^{206} \mathrm{~Pb}$ isotopes were obtained using MC-ICP-MS. ${ }^{238} \mathrm{U} /{ }^{206} \mathrm{~Pb}$ reference value was obtained by TIMS. ${ }^{235} \mathrm{U} /{ }^{207} \mathrm{~Pb}$ reference value was calculated from the ${ }^{238 \mathrm{U} / 206 \mathrm{~Pb} \text { value. }}$

\begin{tabular}{|c|c|c|}
\hline Ratio & Reference Value & Source \\
\hline${ }^{207} \mathrm{~Pb} / 206 \mathrm{~Pb}$ & $0.9099 \pm 0.003$ & Baker et al. (2004) \\
\hline${ }^{238} \mathrm{U} / 206 \mathrm{~Pb}$ & $3.9984 \pm 2.4 \%$ & Bea et al. (2006) \\
\hline${ }^{235} \mathrm{U} /{ }^{207} \mathrm{~Pb}$ & $0.0315 \pm 2.4 \%$ & From ${ }^{238} \mathrm{U} /{ }^{206} \mathrm{~Pb}$ \\
\hline
\end{tabular}

Correction values based on these known and the measured NIST ratios were applied to all sample ratios. Two $\sigma$ errors were calculated for all ratios using the formula showed in Equation 5.1. U-Pb age calculations using LA-ICPMS typically does not require large common lead corrections (Kŏsler and 
Sylvester, 2003). As such, ${ }^{204} \mathrm{~Pb}$ counts were observed and if the average background corrected ${ }^{204} \mathrm{~Pb}$ counts were above $\sim 100 \mathrm{cps}$, the analysis was discounted.

$$
2 \sigma=(2 * \mathrm{sd}) /(\sqrt{\mathrm{n}})
$$

Equation 5.1: Standard error calculations to a two $\sigma$ level. sd is the standard deviation within the populations and $\mathrm{n}$ is the number in the population.

Ages were calculated in a separate spreadsheet from background and internal standard corrected ratios. $\mathrm{U}-\mathrm{Pb}$ ages were calculated and $\mathrm{Pb}-\mathrm{Pb}$ ages were iteratively obtained using decay constants from Jaffey et al. (1971). Concordia ages, errors and MSWD's were calculated from rho values, U-Pb ages and errors using Isoplot 3.7 (Ludwig, 2003). Two $\sigma$ errors were first converted to percentage errors and there after to years.

Once the ages for the zircons were calculated, the most reliable age for each was assessed (for use in age probability diagrams etc). ${ }^{207} \mathrm{~Pb} /{ }^{206} \mathrm{~Pb}$ ages are not reliable under an age of $\sim 0.5-1 \mathrm{Ga}$ (Hirata and Nesbit, 1995) as the percentage error in age increase significantly with decreasing age (Mattinson, 1987). As such, a cut off of $700 \mathrm{Ma}$ was chosen below which $\mathrm{U}-\mathrm{Pb}$ ages were only used. For zircons of age $>700 \mathrm{Ma} \mathrm{Pb}-\mathrm{Pb}$ ages were used, as this system is the most reliable way to date older zircons. If a zircon of age $<700 \mathrm{Ma}$ was discordant, it was discounted from age probability diagrams. This step may cause biasing of the ages as it may cause cutting out of zircons less that $750 \mathrm{Ma}$, formed by an event that caused discordant zircons. If it was concordant, the ${ }^{238} \mathrm{U} /{ }^{206} \mathrm{~Pb}$ age was used, as the isotopes that make up this ratio are the most abundant and therefore yield the most reliable and precise ages. No post-analysis CL imaging of spot locations was conducted to ensure zones were co-analysed.

\subsection{1.iv. Data analysis: Concordia plots and discordant zircons}

In addition to calculating concordia ages and age probability diagrams, Isoplot 3.7 was used to construct concordia diagrams (Fedo et al., 2003). As discussed above, if zircons were concordant (and less than $\sim 700 \mathrm{Ma}$ in age) the age obtained was deemed reliable and used in construction of age probability diagrams. The age of concordant zircons is reflected by their location upon the concordia line on concordia diagrams (Fig. 5.6). 
Discordant zircons will not fall within error of the concordia line. Discordant zircons with ages $<700 \mathrm{Ma}$ were not used in age probability diagrams as their age was deemed unreliable. Though not useful in age probability diagrams, discordant zircons can yield useful provenance information. Discordant zircons from the same suite within a sediment sample may fall on a straight line, their location there on reflecting their initial $U$ content. If these discordant zircons fall on a straight line and are confirmed to be of the same suite, the upper intersect of this line will represent the timing of zircon crystallisation and the lower intersect will indicate the timing of the event that caused lead loss and subsequent discordance. Discordant zircons were plotted on concordia diagrams and any linear trends observed were used to discern whether they came from the same suite, their formation age and the age at which they underwent lead loss.

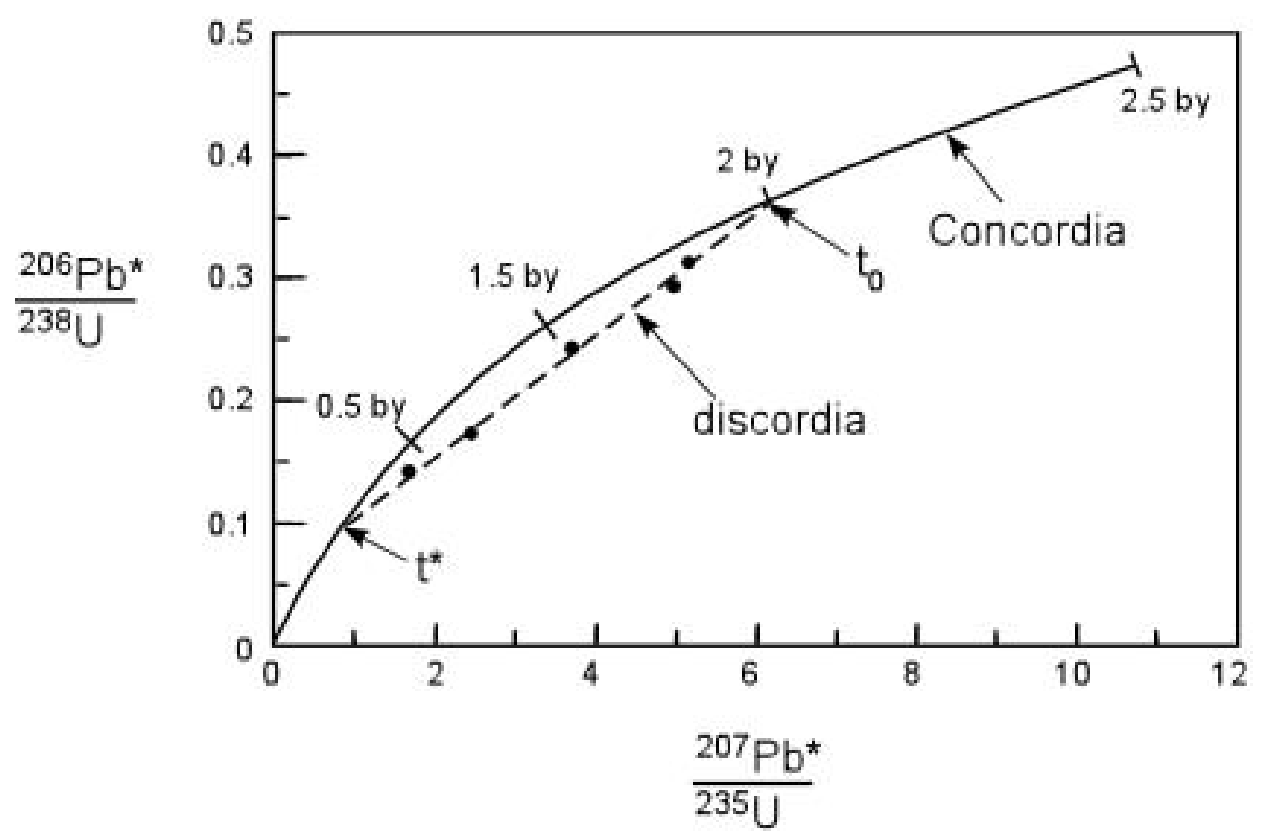

Figure 5.6: U-Pb concordia diagram. Note the differing decay schemes on the $\mathrm{x}$ and $\mathrm{y}$-axes and the curved concordia line. Concordant samples will fall within error of the concordia line. Discordant samples (black dots) are those that are not within error of the concordia line (source: http://www.tulane.edu / sanelson/images/discordiapbleakage.jpg).

\subsection{1.v. Data analysis: Age probability diagrams}

Once the appropriate ages were selected for each zircon an age probability diagram was created for each sample (Fedo et al., 2003). If a zircon's core and rim had been analysed, the rim age was included in the age probability diagram (as this yields information on the latest event that formed the zircon, thus making it easier to constrain provenance). If a zone in a zircon had 
received multiple analyses that were within error of one another, an average age of the ages was used in the age probability diagram. Age probability diagrams were constructed using Isoplot 3.7 (e.g. Fig. 5.7).

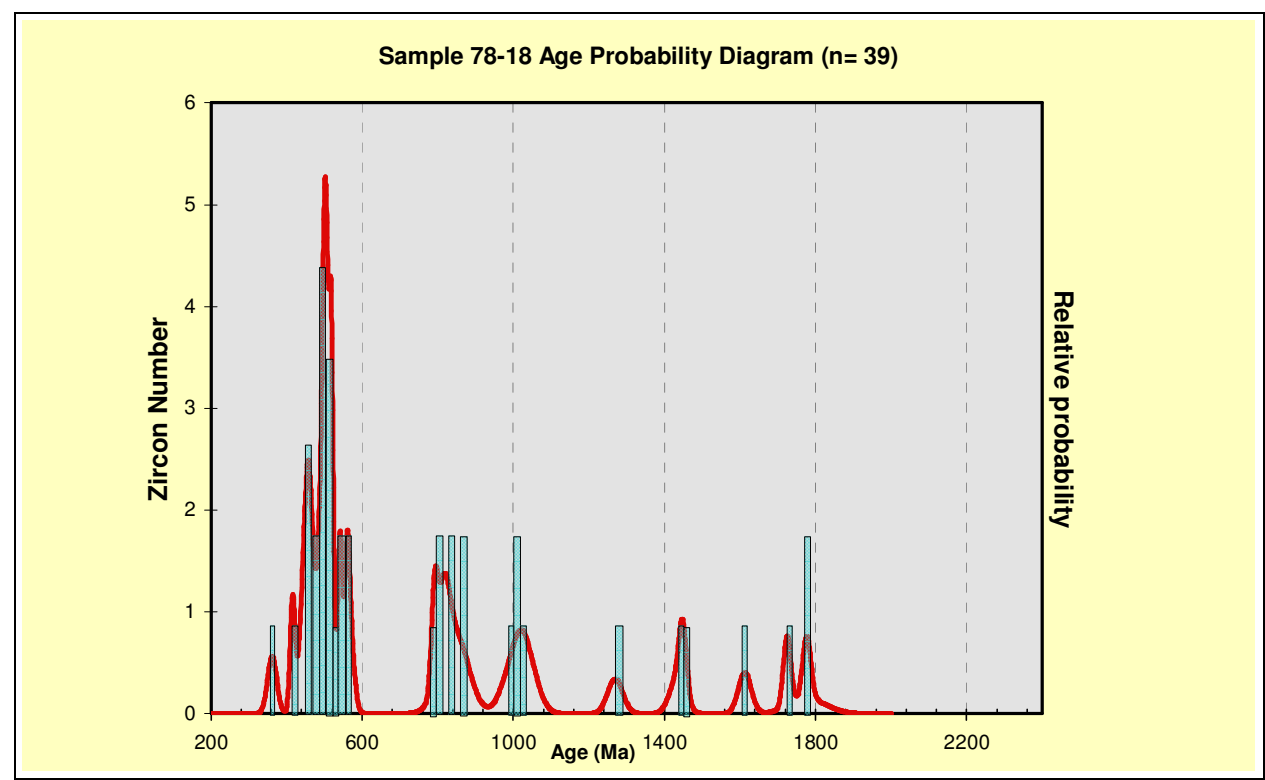

Figure 5.7: An age probability diagram for sample 78-18, constructed from the most reliable ages obtained for zircons from this sample. The diagram was constructed from zircon age and 2 se error data using Isoplot 3.7. Note the red line which represents the age probability, which was calculated using both ages and errors. The blue bars represent the number of zircons whose age falls within a given age bin.

\subsection{1.vi. Data analysis: $U$ and $T h$ concentrations}

$\mathrm{U}$ and Th concentrations for each zircon analysed were calculated. This was done using the known $\mathrm{U}$ (or Th) concentration $(\mu \mathrm{g} / \mathrm{g})$ in NIST 610 (461.5 ppm (GeoReM preferred value)) and the cps of $U$ (or Th) measured in the NIST glass. By dividing NIST 610 counts per second by its known concentration, a 'conversion factor' was obtained. This was used to convert the $\mathrm{U}$ (or Th) cps in the zircon to $\mathrm{U}$ (or Th) concentration. The cps obtained for the zircon was divided by the cps obtained for the NIST glass. This value was multiplied by the 'conversion factor' giving the $\mathrm{U}$ (or Th) ppm concentration in the zircon.

$\mathrm{U}$ and Th concentrations were used to calculate the $\mathrm{Th} / \mathrm{U}$ ratios of all zircons. This ratio is indicative of an igneous or metamorphic origin for zircons (Hoskin and Schaltegger, 2003), with a low Th/U ratio $<0.1$ 
indicating a metamorphic origin and a high ratio of $>0.1$ indicating an igneous origin (for more details refer to Chapter 4).

\subsection{1.vii. Validation of results}

To validate the age probability diagrams and zircon numbers (n) obtained for each sample, two samples were completely re-analysed. This included obtaining a new aliquot of the sediment sample and conducting sample crushing, sieving and magnetic and density separations. From the zircon concentrate zircons were picked and mounted. The new mounts were imaged using EMPA and their ages determined by LA-ICP-MS.

The first sample for which the entire process of obtaining age data was repeated was sample 295-12. During initial processing this sample yielded high zircon numbers and thus a reliable age probability diagram. It was repeated to assess the repeatability of its age probability diagram and the degree to which the variable number of zircons analysed influences its shape. The results from this (Figs. 5.8 and 5.9) show a distinct overlap between the age probability diagram obtained from the original processing and those created from the reprocessed sample. For example, both show a wide 500 Ma peak and overlapping Palaeozoic peaks. The repeat of sample 295 has a smaller zircon number (due to time limitations involved with picking), which is reflected when the age probability diagrams are compared. For example, the repeated sample shows a reduced number of zircons with ages older than Palaeozoic. The reduced number of age peaks observed in the reprocessed sample (which had lower $\mathrm{n}$ ) displays the expected correlation between the number of zircons analysed and the reduced numbers of age peaks. 


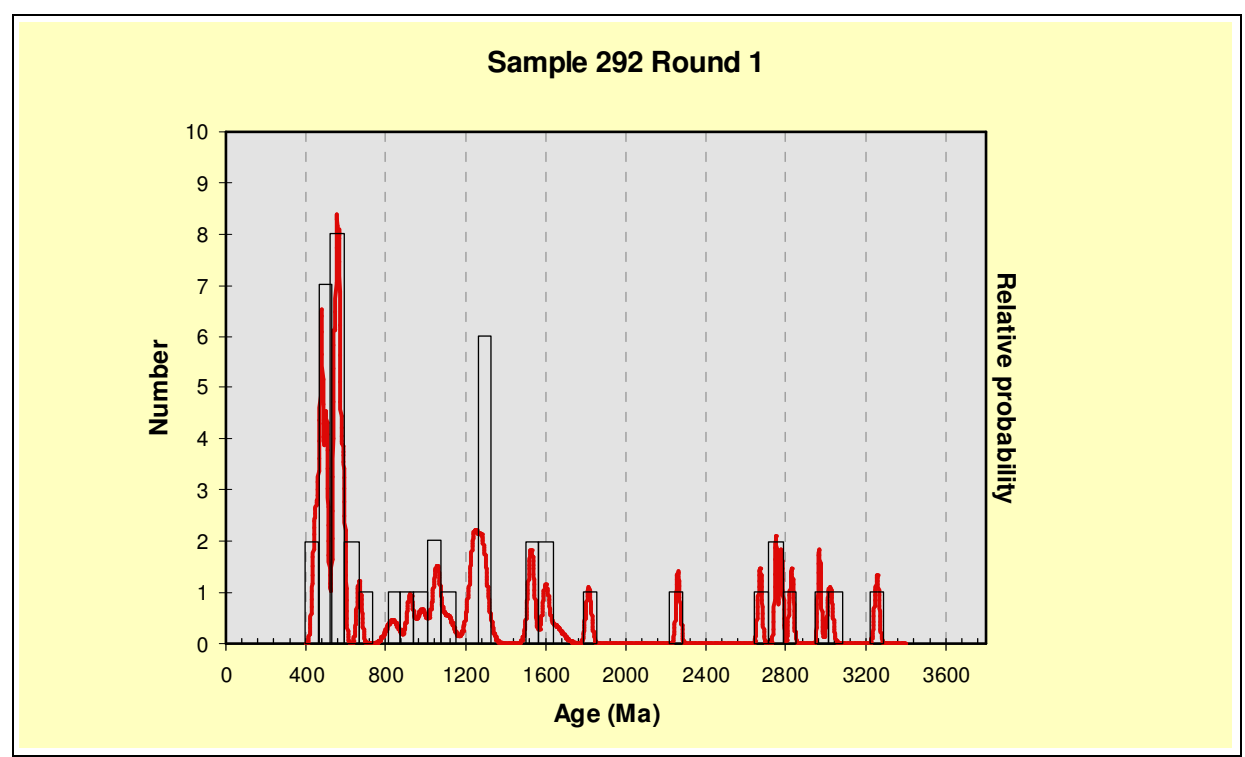

Figure 5.8: Age probability diagram for initial 292-12 analysis. $\mathrm{n}=45$.

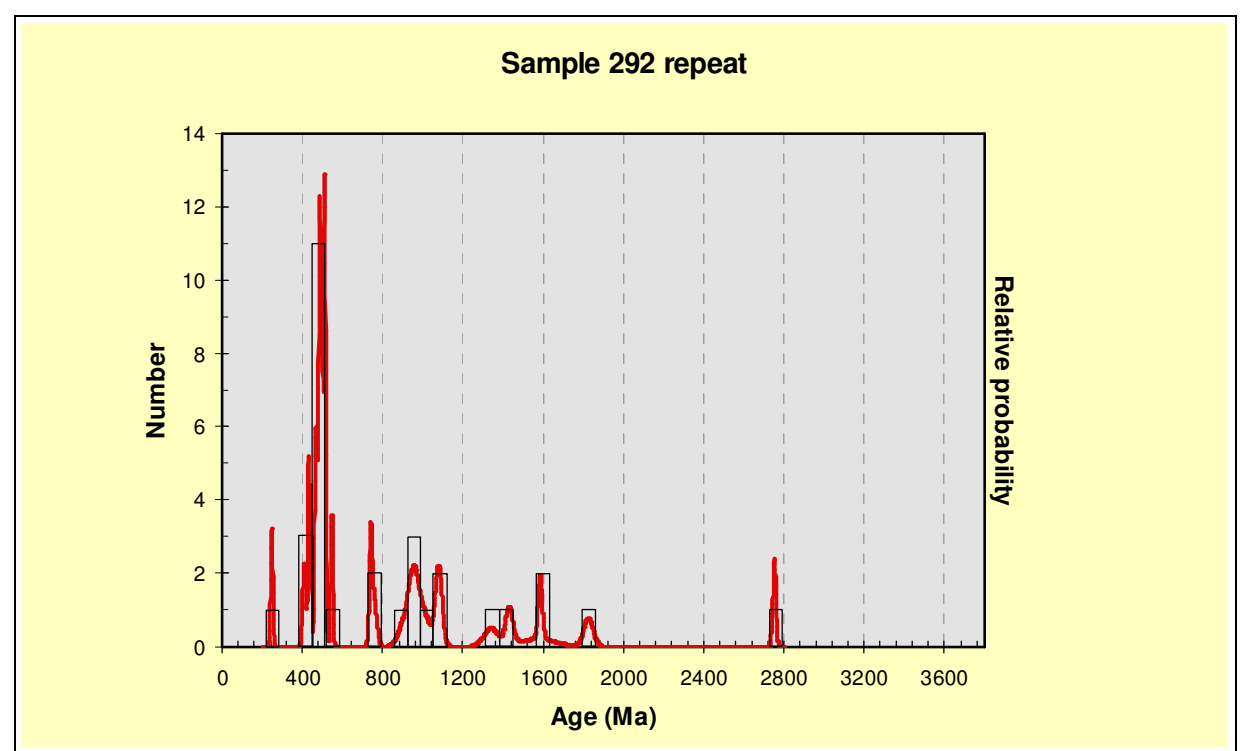

Figure 5.9: Age probability diagram constructed for the repeat of sample 292-12. $n=31$.

The second repeated sample was 148-16. During initial processing relatively few zircons were obtained, thus it was re-processed to confirm it was indeed zircon poor or if the zircons had been lost during the initial processing. The similarly low number of zircons obtained during reprocessing proved that low (or high) zircon counts in given samples were inherent to the sample, and not a function of sample preparation. 


\subsubsection{Trace element analysis by LA-ICP-MS}

Trace element analysis allows insights into detrital zircon provenance. Thus, age and chemical data for a detrital zircon allows a two fold approach to investigating provenance as both age and zircon chemistry can be used to match the zircon to source lithologies. As such, geochemical investigations of zircons were conducted on a number of samples as outlined in the following section.

\subsection{2.i. Samples analysed for trace element content}

Trace element analysis was conducted on zircons obtained from three samples, 205-15, 462-7 and 652-3, which were chosen for the following reasons:

(1) The sample depths (205, 462 and 652 mbsf) were evenly spaced throughout the core;

(2) Each sample contained a high number of zircons, meaning a large number of zircons would have matching age and chemistry data; and

(3) Most importantly, the combined age probability diagrams of these three samples covers the entire spectra of ages populations observed in the CIROS-1 core, thus chemistry data for all age populations in the core was obtained by analysing three samples (assuming all age populations in the core were sourced from the same lithology).

\subsection{2.ii. Operational parameters}

This section will outline those methods used to conduct elemental analysis of zircons in samples 205-15, 462-7 and 652-3. Isotopes of elements selected for analysis needed to fit the following criteria:

(1) Concentrations in zircons must be high enough to yield signals above detection limits of LA-ICP-MS;

(2) Isotopes used must not have interferences from other elements; and

(3) Each element must give insights into the conditions present during zircon formation/alteration.

To test which isotopes yielded signals above background, a range of isotopes were initially tested using S-97-19 standard zircon. The results of this are given in Table 5.5. Of those isotopes that yielded signals detectable by LAICP-MS, only those that did not have interferences from other elements were 
used. For example, ${ }^{181} \mathrm{~W}$ may have an interference from ${ }^{165} \mathrm{Ho}$ and ${ }^{16} \mathrm{O}$, whereas a false signal may be generated for ${ }^{137} \mathrm{Ba}$ due to a combination of ${ }^{90} \mathrm{Zr}$ and ${ }^{47} \mathrm{Ti}$.

The measured isotopes and analytical dwell times are listed in Table 5.6. The following isotopes were selected for the reasons outlined below:

(1) Both ${ }^{88} \mathrm{Sr}$ and ${ }^{86} \mathrm{Sr}$ were analysed as although ${ }^{88} \mathrm{Sr}$ is the larger isotope (so would yield more reliable data) it has a number of potential interferences. Thus the smaller and interference-free ${ }^{86} \mathrm{Sr}$ was also measured as a control;

(2) ${ }^{91} \mathrm{Zr}$ was analysed as it is a minor $\mathrm{Zr}$ isotope (thus the detectors would not be swamped during zircon analysis); and

(3) ${ }^{7} \mathrm{Li}$ was analysed as recent research has shown interesting results in $\mathrm{Li}$ variation from zircon from variable sources (Cherniak and Watson, 2010; Ushikubo et al., 2008; Chapter 4), and Li concentrations within zircons was found to be well above the detection limit of the LA-ICP-MS.

Table 5.5: Elements analysed using LA-ICP-MS and S-97-19 standard zircon to ascertain which elements were detectable above background.

\begin{tabular}{|c|c|c|c|c|c|}
\hline Mass & Element & $\begin{array}{l}\text { Detectable } \\
(\mathrm{Y} / \mathrm{N})\end{array}$ & Mass & Element & $\begin{array}{l}\text { Detectable } \\
(\mathrm{Y} / \mathrm{N})\end{array}$ \\
\hline 7 & $\mathrm{Li}$ & $\mathrm{Y}$ & 95 & Mo & $\mathrm{Y}$ \\
\hline 11 & B & $\mathrm{N}$ & 133 & Cs & Y \\
\hline 24 & $\mathrm{Mg}$ & $\mathrm{N}$ & 137 & $\mathrm{Ba}$ & Y \\
\hline 27 & $\mathrm{Al}$ & $\mathrm{N}$ & 139 & $\mathrm{La}$ & Y \\
\hline 29 & $\mathrm{Si}$ & Y & 140 & $\mathrm{Ce}$ & Y \\
\hline 31 & $\mathrm{P}$ & Y & 141 & $\operatorname{Pr}$ & Y \\
\hline 34 & S & $\mathrm{N}$ & 146 & $\mathrm{Nd}$ & Y \\
\hline 44 & $\mathrm{Ca}$ & $\mathrm{N}$ & 147 & $\mathrm{Sm}$ & Y \\
\hline 45 & Sc & $\mathrm{Y}$ & 153 & $\mathrm{Eu}$ & $\mathrm{Y}$ \\
\hline 47 & $\mathrm{Ti}$ & $\mathrm{Y}$ & 157 & $\mathrm{Gd}$ & Y \\
\hline 51 & V & $\mathrm{N}$ & 159 & $\mathrm{~Tb}$ & Y \\
\hline 52 & $\mathrm{Cr}$ & $\mathrm{N}$ & 163 & Dy & $\mathrm{Y}$ \\
\hline 55 & $\mathrm{Mn}$ & $\mathrm{N}$ & 165 & Ho & Y \\
\hline 59 & Co & $\mathrm{N}$ & 166 & Er & Y \\
\hline 60 & $\mathrm{~N}$ & $\mathrm{~N}$ & 169 & $\mathrm{Tm}$ & Y \\
\hline 63 & $\mathrm{Cu}$ & $\mathrm{N}$ & 172 & $\mathrm{Yb}$ & Y \\
\hline 66 & $\mathrm{Zn}$ & $\mathrm{N}$ & 174 & $\mathrm{Lu}$ & Y \\
\hline 69 & Ga & $\mathrm{N}$ & 175 & $\mathrm{Hf}$ & Y \\
\hline 72 & $\mathrm{Ge}$ & $\mathrm{N}$ & 181 & $\mathrm{Ta}$ & $\mathrm{Y}$ \\
\hline 75 & As & $\mathrm{N}$ & 182 & W & $\mathrm{N}$ \\
\hline 85 & $\mathrm{Rb}$ & $\mathrm{N}$ & 185 & $\operatorname{Re}$ & $\mathrm{N}$ \\
\hline 86 & $\mathrm{Sr}$ & Y & 189 & Os & $\mathrm{N}$ \\
\hline 88 & $\mathrm{Sr}$ & Y & 205 & Th & $\mathrm{Y}$ \\
\hline 89 & Y & Y & 209 & $\mathrm{Bi}$ & $\mathrm{N}$ \\
\hline 93 & $\mathrm{Nb}$ & Y & & & \\
\hline
\end{tabular}


Spot locations on zircons were within the same growth zones (identified using CL images) in which $\mathrm{U}-\mathrm{Pb}$ age dating had been conducted. Runs were set up as: one NIST 612 spot, six zircons, one NIST 612, six zircons, one NIST 612. Spot sizes for NIST 612 was $35 \mu \mathrm{m}$ and $25 \mu \mathrm{m}$ for zircons.

The laser ablation parameters used for trace element analysis were similar to those used for $\mathrm{U}-\mathrm{Pb}$ isotopic analysis. The laser was warmed up by running it with the shutter closed for $15 \mathrm{~min}(100 \%$ power, $10 \mathrm{~Hz}, 100 \mu \mathrm{m}$ spot size). The laser was tuned 1-3 times prior to each run and was run with an irradiance of $\sim 2-4 \mathrm{Gw} / \mathrm{cm}^{2}$ and a fluence of $\sim 5-7 \mathrm{~J} / \mathrm{cm}^{2}$. Pre-ablation (four times five bursts at $50 \mu \mathrm{m}$ spot size, $75 \%$ power, and $10 \mathrm{~Hz}$ frequency) was conducted at each spot location. Spots were run at a spot size of $35 \mu \mathrm{m}$, $5 \mathrm{~Hz}$ and $75 \%$ power. Analytical times were $80 \mathrm{~s}$ and washout delays varied between 80-120 s (dependent on the washout time measured during tuning).

Table 5.6: Isotopes measured and their dwell times during LA-ICP-MS trace element analysis.

\begin{tabular}{|ccc|ccc|}
\hline Mass & Element & Dwell time (s) & Mass & Element & Dwell time (s) \\
\hline 7 & $\mathrm{Li}$ & 0.01 & 157 & $\mathrm{Gd}$ & 0.02 \\
29 & $\mathrm{Si}$ & 0.01 & 159 & $\mathrm{~Tb}$ & 0.02 \\
31 & $\mathrm{P}$ & 0.01 & 163 & $\mathrm{Dy}$ & 0.02 \\
49 & $\mathrm{Ti}$ & 0.01 & 165 & $\mathrm{Ho}$ & 0.02 \\
86 & $\mathrm{Sr}$ & 0.01 & 166 & $\mathrm{Er}$ & 0.01 \\
88 & $\mathrm{Sr}$ & 0.03 & 169 & $\mathrm{Tm}$ & 0.02 \\
89 & $\mathrm{Y}$ & 0.01 & 172 & $\mathrm{Yb}$ & 0.01 \\
91 & $\mathrm{Zr}$ & 0.01 & 175 & $\mathrm{Lu}$ & 0.02 \\
93 & $\mathrm{Nb}$ & 0.03 & 178 & $\mathrm{Hf}$ & 0.01 \\
139 & $\mathrm{Ca}$ & 0.03 & 181 & $\mathrm{Ta}$ & 0.03 \\
140 & $\mathrm{Ce}$ & 0.02 & 183 & $\mathrm{~W}$ & 0.02 \\
141 & $\mathrm{Pr}$ & 0.03 & 184 & $\mathrm{~W}$ & 0.02 \\
146 & $\mathrm{Nd}$ & 0.03 & 232 & $\mathrm{Th}$ & 0.01 \\
147 & $\mathrm{Sm}$ & 0.03 & 238 & $\mathrm{U}$ & 0.01 \\
153 & $\mathrm{Eu}$ & 0.03 & & & \\
\hline
\end{tabular}

The ICP-MS was stabilised for $\sim 30$ min after being turned on. At the start of every run the ICP-MS was tuned using NIST 610. Isotopes used for tuning covered the spectrum of masses measured during each run, including ${ }^{7} \mathrm{Li}$, ${ }^{47} \mathrm{Ti},{ }^{93} \mathrm{Zr},{ }^{140} \mathrm{Ce}{ }^{147} \mathrm{Sm}{ }^{165} \mathrm{Ho}{ }^{181} \mathrm{Ta}$ and ${ }^{238} \mathrm{U}$. Additionally, ${ }^{248} \mathrm{ThO}^{+} /{ }^{232} \mathrm{Th}$ was monitored to assess the oxide in production. As tuning was conducted on such a range of masses, the ICP-MS was tuned to RSD's of $<10 \%$. 
After tuning, washout delays to be used were assessed. The amount of time it took for all elements to wash out was usually $\sim 45-75 \mathrm{~s}$ and washout delays of $\sim 80-120$ s were set. Prior to running sample zircons, pulse-analogue factors for those elements likely to have $>1,000,000 \mathrm{cps}$ were assessed. This was done so that PA corrections could be applied to these elements. Pulse analogue factors were analysed by lasering a sample zircon that was not used for analysis. Pulse analogue corrections were applied to ${ }^{29} \mathrm{Si},{ }^{91} \mathrm{Zr}$ and ${ }^{178} \mathrm{Hf}$.

\subsection{2.iii. Data reduction}

Raw trace element data was in a .csv format containing cps data. For each zircon, the raw data was cut and pasted into an individual MS Excel spreadsheet. Data reductions methods followed those outlined by Allen et al. (2008). To obtain trace element compositions, a minor isotope of a major element in zircon was used. $\left({ }^{29} \mathrm{Si}\right)$. Previous studies have shown Si concentrations in zircon to be $\sim 30 \mathrm{wt} \%$ (300,000 ppm) and this known value was used for normalisation (Deer et al. 1997). NIST 612 was used as an internal standard with known concentrations of ${ }^{29} \mathrm{Si}$ (GeoReM preferred values). For each zircon, background corrections were applied based on the average background count of the element for the $45 \mathrm{~s}$ prior to the laser starting. Thereafter, all scans were normalised to mean $\mathrm{Si}$ values (average $\mathrm{Si}$ composition of $\sim 30 \%$ ) (as outlined in Allen et al., 2008). Following this, outliers were identified using time resolved analysis and removed. These data were scrutinised using the methods outlined below.

\subsection{2.iv. Data presentation: Chondrite-normalised REE plots}

Processes that occur in the Earth's crust and mantle cause a deviation from REE chondritic values. REE characteristics of a zircon will be influenced by the REE composition of their parental rock and the partitioning coefficients between the parental rock and the zircon (Belousova et al., 2002; Whitehouse, 2003). As such, by comparing a zircon's REE concentration to that of chondrites, insights into the processes that formed the zircon may be gained. This can be done using chondrite-normalised REE plots (Fig. 5.10; Chapter 4). 


\section{Group 1 representative REE profiles}

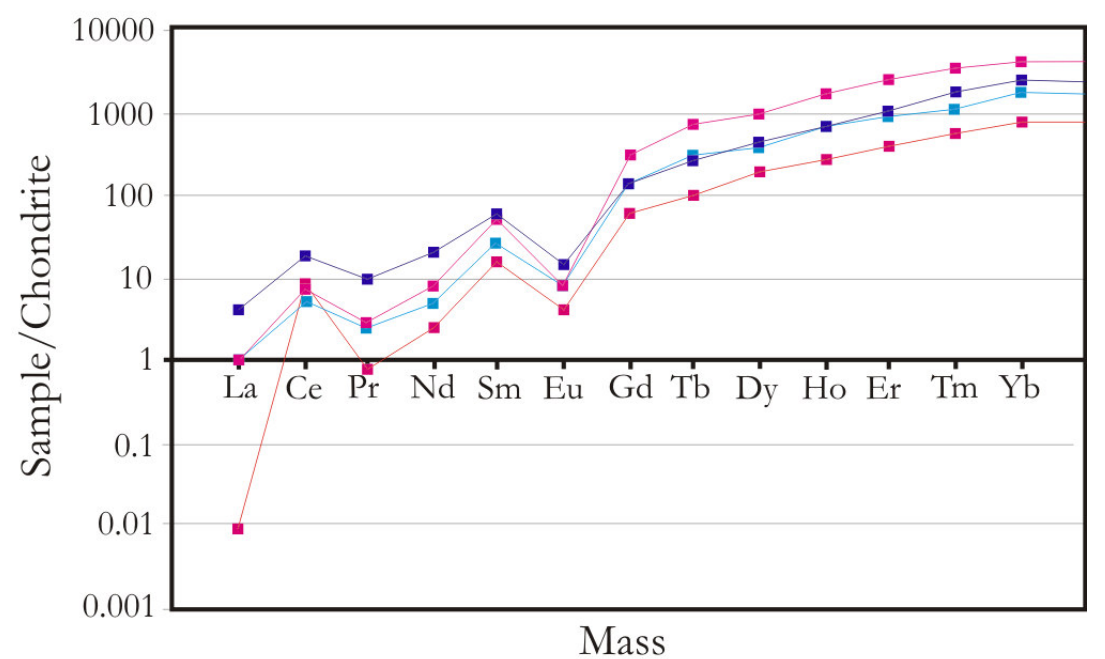

Figure 5.10: Chondrite-normalised REE profile for a group of CIROS-1 zircons.

To construct chondrite-normalised REE plots using the REE concentrations obtained the following steps were taken:

(1) Chondritic REE values were obtained from McDonough (2000);

(2) Zircon/chondrite ratios were calculated for REE from each zircon; and

(3) These ratios were plotted to form a chondrite-normalised plot (Fig. 5.10).

\subsection{2.v. Data analysis: Ti-in-zircon geothermometer}

Ti-in-zircon saturation geothermometry allows $\mathrm{Ti}$ concentration-based formation temperatures to be calculated for zircons. When applied to detrital zircons, this formula will give a minimum formation temperature. This system and recent investigations as to the robustness of the Ti-in-zircon geothermometer (e.g. Fu et al., 2008) are outlined in Chapter 4. The equation used to calculate Ti-in-zircon temperatures is given below. Ti-in-zircon geothermometry was conducted for all zircons analysed for their trace (and minor) element composition.

$\log \left(\mathrm{Ti}_{\text {zircon }}\right)=(6.01 \pm 0.03)-((5080 \pm 30) /(\mathrm{T}(\mathrm{K})))$

Equation 5.2: Ti-in-zircon geothermometer (source: Watson et al., 2006).

\subsection{2.vi. Data analysis: Elemental concentrations and ratios}

Elemental ratios are a key tool to gain insights into the conditions present during zircon formation and/or zircon provenance. Thus, ratios and 
concentrations that may yield useful information were calculated and used to help constrain the detrital zircons formation environment. Ratios and concentrations analysed include: Li concentration, $\mathrm{Zr}$ and $\mathrm{Hf}$ concentrations and the $\mathrm{Zr} / \mathrm{Hf}$ ratio, $\mathrm{U}$ and $\mathrm{Th}$ concentrations and the $\mathrm{U} / \mathrm{Th}$ ratio, $\mathrm{U} / \mathrm{Yb}$, $\mathrm{Ce} / \mathrm{Ce}^{*}, \mathrm{Eu} / \mathrm{Eu}^{*}, \mathrm{Sm} / \mathrm{Pr}$ and $\mathrm{U} / \mathrm{Th}$ (for more information refer to Chapter 4). 


\section{Chapter 6: Geochronology and geochemistry of detrital zircons in the CIROS-1 core}

\subsection{Introduction}

This chapter reviews the results of the LA-ICP-MS geochemical and geochronological investigations of CIROS-1 conducted in this study. The associated implications of these results for our understanding of the record of Antarctic climate change and tectonism contained in CIROS-1 are also reviewed.

This chapter reviews the following results:

(1) Zircon $\mathrm{U}-\mathrm{Pb}$ age results for the 18 samples analysed and inter-sample variations therein;

(2) The cumulative age probability diagrams constructed using U-Pb ages of all of the analysed CIROS-1 zircons;

(3) The results of trace element analysis conducted to constrain the provenance of CIROS-1 zircons; and

(4) The geochemical characteristics of zircons within each age population in the cumulative age probability diagram.

The second half of this chapter reviews the implications of these results. This includes a discussion of the record of zircon growth events contained in CIROS-1, an overview of source lithologies for CIROS-1 zircons, and a review of potential causes for the temporal variations of zircon characteristics observed in the core.

\subsection{Results}

\subsubsection{Zircon numbers and $\mathrm{U}-\mathrm{Pb}$ and $\mathrm{Pb}-\mathrm{Pb}$ ages}

In this research, 18 sand-sized samples from various stratigraphic levels of the $702 \mathrm{~m}$ long CIROS-1 core were taken. Sample nomenclature was based on stratigraphic depth and the order in which samples were taken (e.g. Sample 292-14 was the $14^{\text {th }}$ sample taken and came from $292 \mathrm{mbsf}$ ). In total 854 zircons were analysed for $\mathrm{U}-\mathrm{Pb}$ ages and 119 were analysed for trace element chemistry. The range of zircon numbers analysed per sample (n) was 18 to 77 with a per sample average of 46 zircons. 
Zircon numbers per sample vary systematically down core; zircon numbers increases steadily down core from 28 mbsf to 148 mbsf ( $\mathrm{n}=55$ and 19, respectively). Below this depth, zircon numbers increase to a depth of $292 \mathrm{mbsf}$ (sample 292-13; n = 77) and decrease steadily to the lowermost sample at $693 \mathrm{mbsf}(\mathrm{n}=\sim 20)$ (Table 6.1; Fig. $6.1)$.

A cumulative probability diagram was created using the ages of all zircons analysed in addition to the construction of age probably diagrams for each sample. The number of age peaks (age populations) in each individual probability diagram was counted, the results of which are shown in Figure 6.2. Seventeen of the 18 samples analysed show a positive correlation between number of age populations $\left(\mathrm{N}_{\text {age }}\right)$ and total zircon numbers $\left(\mathrm{N}_{\text {zirc }}\right)$ (Fig. 6.2; Table 1).

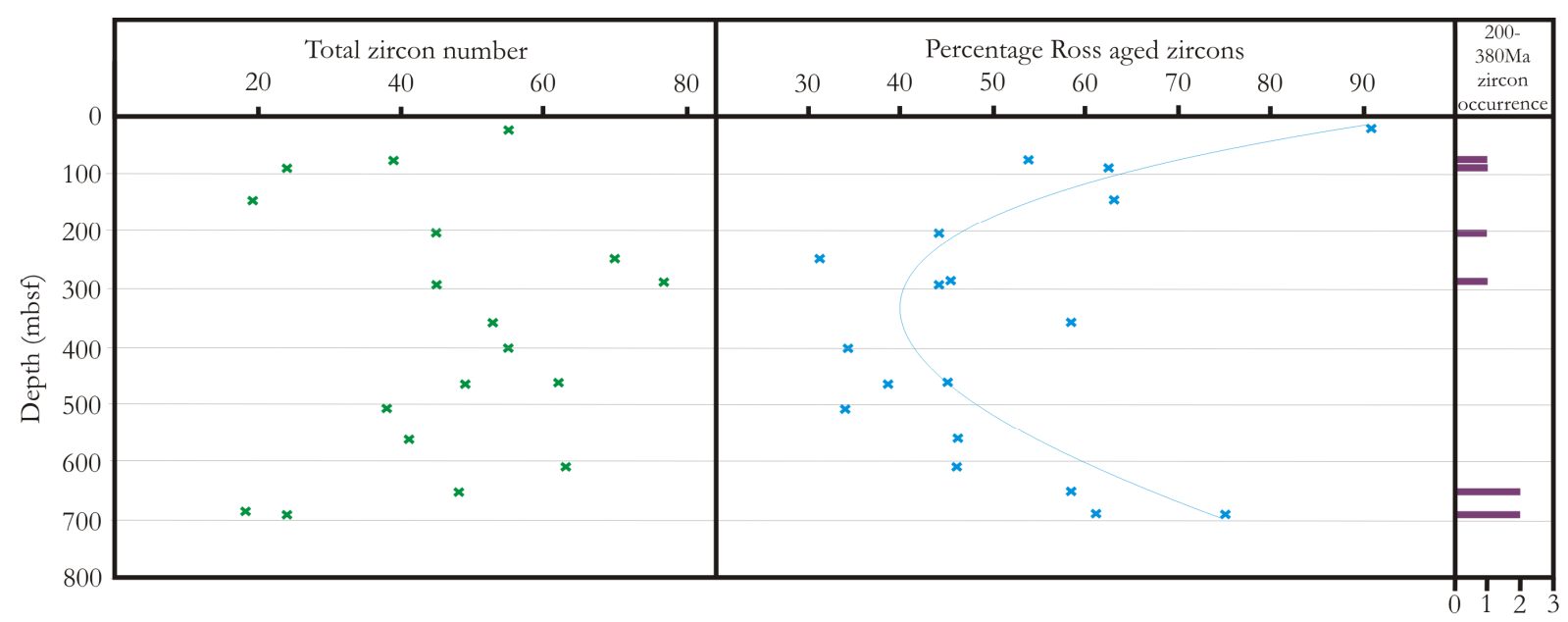

Figure 6.1: Combined diagram of total zircon number per sample (n), percentage of 450-650 Ma 'Ross' age population and the occurrence of Devonian aged zircons. The blue line is a graphical trend line drawn through the data.

Sample 292-13 had the largest zircon population $(n=77)$ and the largest spread of ages ( 19 individual age peaks) (Figs. 6.2 and 6.3; Table 1). The most prominent feature in this sample's age probability diagram is the large peak at $\sim 450-700 \mathrm{Ma}$. Lesser but distinct age peaks also occur at 800-1000 Ma and 1000-1200 Ma (Fig. 6.3) and additional smaller peaks are present (e.g. 210 Ma, $1200 \mathrm{Ma}, 1350 \mathrm{Ma}, \sim 1900$ Ma, $3300 \mathrm{Ma}$ ). The smallest zircon population was found in sample 687-1 (687 mbsf; $\mathrm{n}=18$ ) which also had the smallest spread of ages, containing only six zircon age populations (Fig. 6.3). Similarly to sample 292-13, sample 687-1 had its most prominent age peak at 400-600 Ma with a smaller but distinct peak at 900-1200 Ma. Additional smaller age peaks occurred only between 2200-2800 Ma (Fig. 6.3). 
Sample 28-21, the uppermost sample analysed (28 mbsf), did not show a trend of increasing $\mathrm{N}_{\text {zirc }}=$ increasing $\mathrm{N}_{\text {age }}$ (Fig. 6.1; outlier on bottom right of graph). This sample has a relatively high total zircon number $(n=55)$ and an abnormally small spread of ages $\left(\mathrm{N}_{\text {age }}=6\right.$ ) (Fig. 6.3). Forty nine of its 55 zircons have ages between 449-551 Ma with only six older grains. There is also a distinct lack of a peak at 900$1200 \mathrm{Ma}$, which occurs in all other samples (Fig. 6.3).

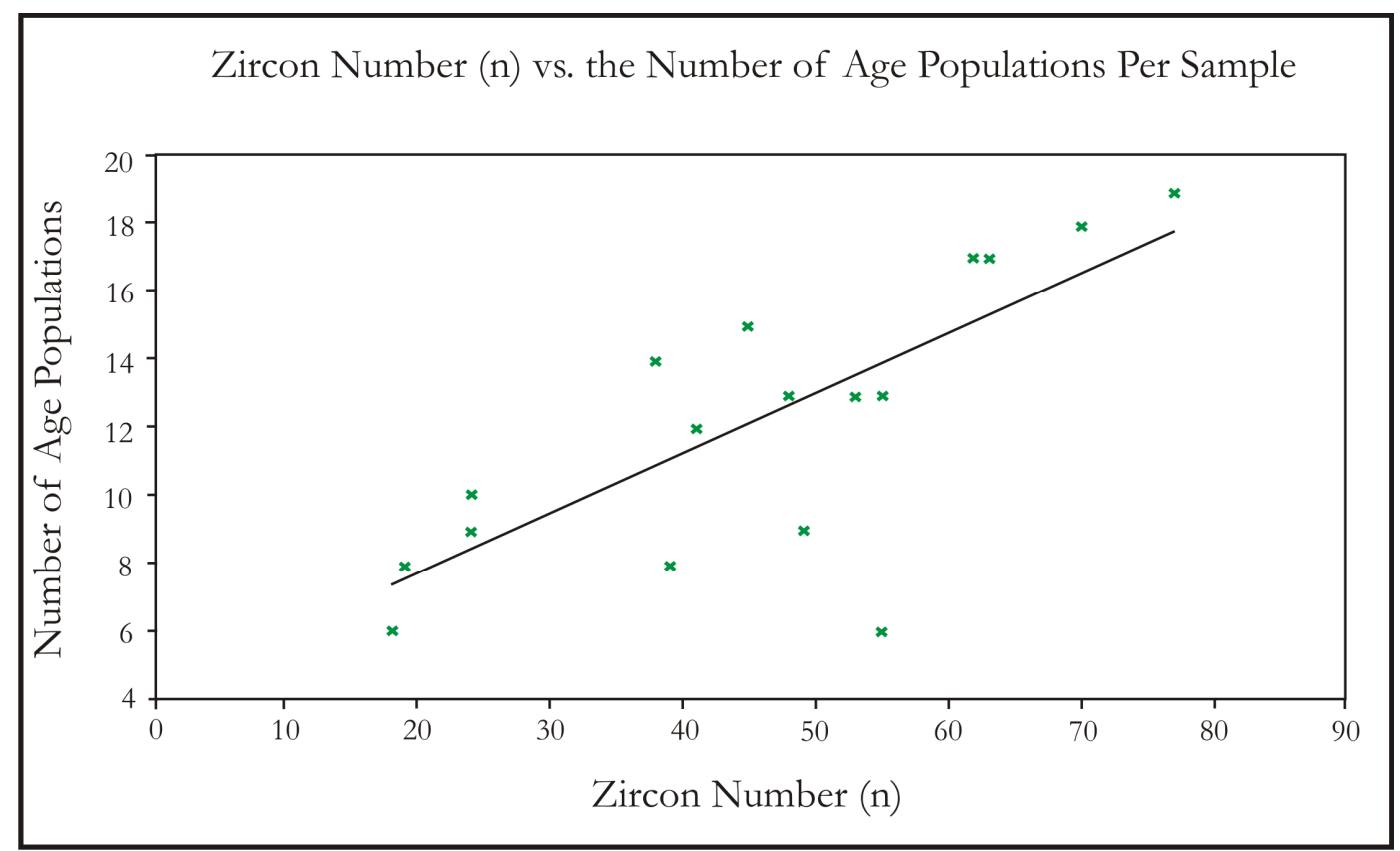

Figure 6.2: Graph displaying the number of zircons and the number of age populations in each sample. This shows a trend of increasing number of age populations per sample with increasing number of zircons analysed, as defined by the trend line. 

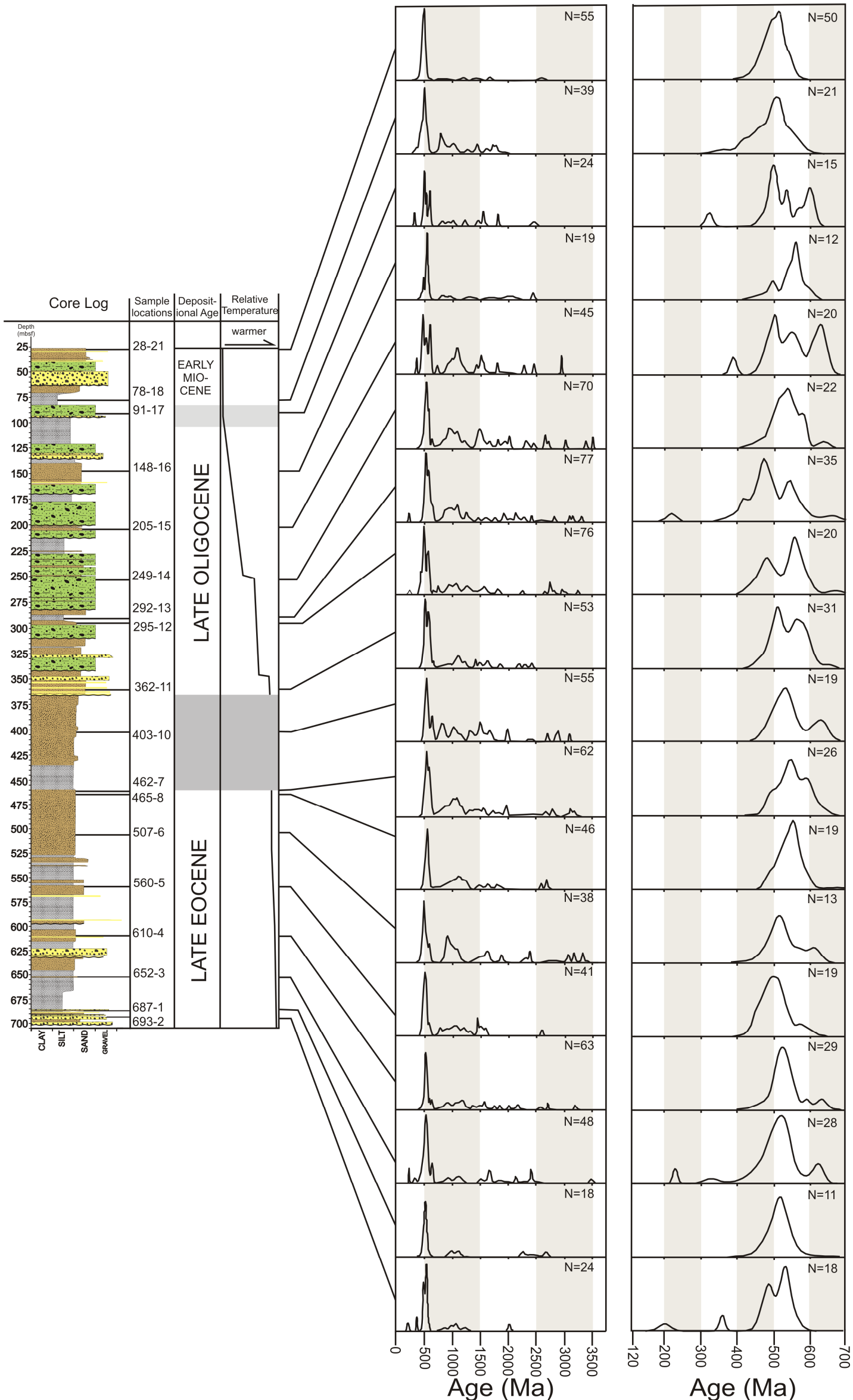

Figure 6.3: Summary of age probability diagrams obtained for each of the 18 samples analysed for U-Pb. The column headed 'Cumulative age probability diagram' depicts the age probability diagram for all the zircons obtained for a single sample. The column named 'Age probability 120-700 Ma' shows the probability over 120-700 Ma. This has been included to allow detailed examination of the 450-650 Ma age peak, which is the dominant peak on all age probability diagrams. Note the sample names, depositional ages and relative climate during sedimentation, shown to the right of the core log. 


\subsubsection{Late Proterozoic-Early Palaeozoic (450-650 Ma) 'Ross' age population}

The 450-650 Ma age population is dominant in all samples (Fig. 6.3). Due to the dominance of this age peak, zircons of this age are numerous enough to allow statistically sound investigations of any variances within this population (as discussed below). The majority of zircons in this population fall within the ages of the Ross Orogeny (Allibone et al., 1993a) and are referred to a 'Ross' aged zircons in much of this work.

The percentage of total zircon numbers ( $\mathrm{n}$ ) that comprises of 450-650 Ma 'Ross' aged grains is plotted per sample in Figure 6.1. This variable is defined by a bellshaped curve with a general decrease in the percentage of 450-650 Ma grains between samples 28 and $\sim 300$ mbsf (from $\sim 90-30 \%$ ). From $\sim 300$ mbsf to the base of the core, the percentage of 'Ross' aged zircons increases again from $\sim 30$ to $\sim 80$ $\%$ (Fig. 6.1).

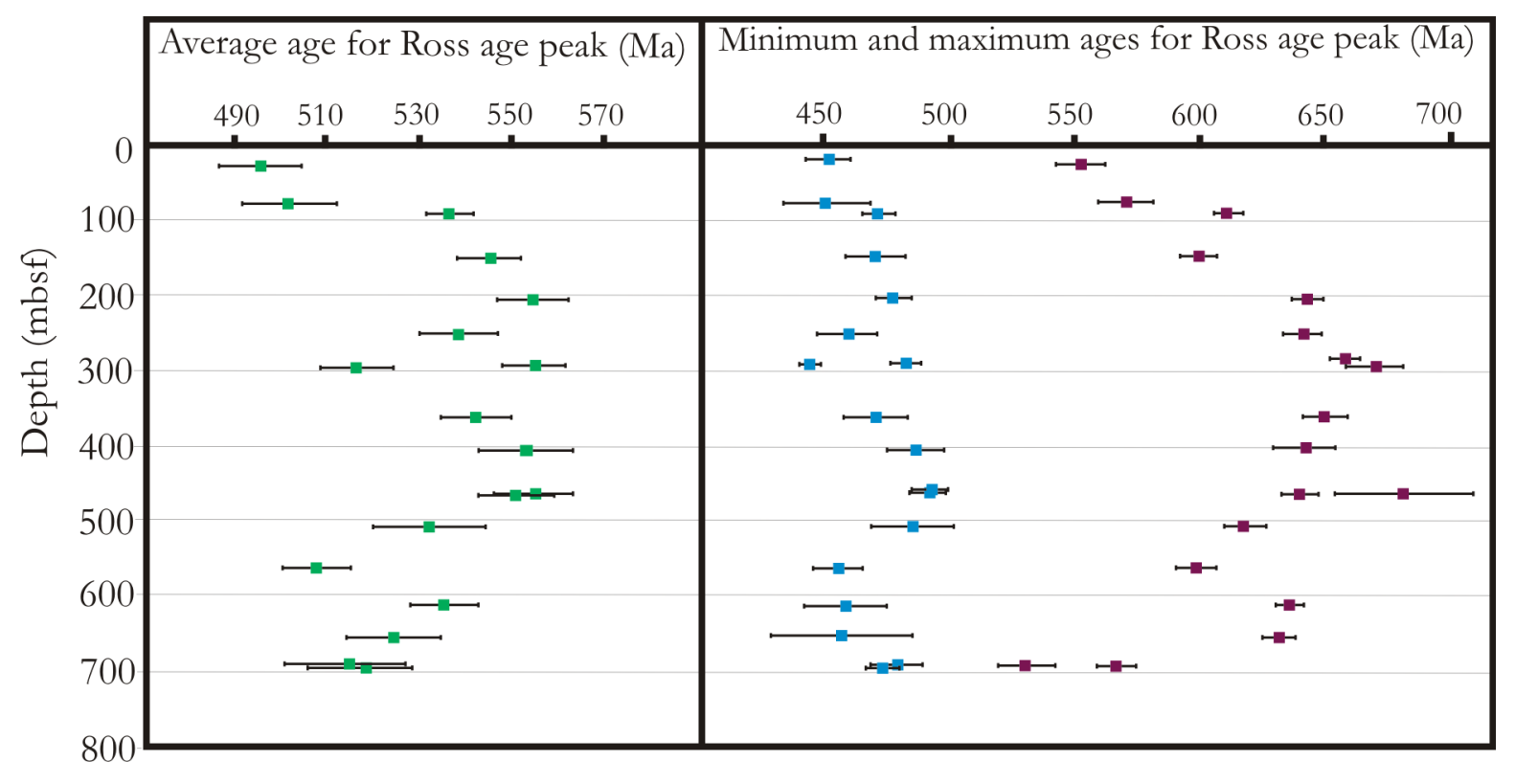

Figure 6.4: Average, minimum and maximum ages of zircons 450-650 Ma 'Ross' age population zircons per sample. The error bars depict one standard deviation errors on the ages.

The average, minimum and maximum ages for zircons in the 450-650 Ma 'Ross' age population are plotted in Figure 6.4. The maximum ages of 'Ross' aged zircons in each sample (Fig. 6.4; red squares) define a bell shape down core; ages systematically increase between 28-295 mbsf (from $\sim 550-660 \mathrm{Ma}$ ) and thereafter decrease to a minimum of $\sim 535 \mathrm{Ma}$ at 693 mbsf. The minimum ages of the 'Ross' age population show a different trend (Fig. 6.4; blue squares). These ages remain more or less constant for the entire length of the core (between $\sim 440-490 \mathrm{Ma}$ ). The average age of the 'Ross' aged zircons in each sample is shown in green. The trends follow those 
observed in the maximum ages, but are not as distinct due to a lack in relative variation. At the very top of the core the average age is very low $\sim 500 \mathrm{Ma}$. This age increases to $\sim 550 \mathrm{Ma}$ between $100-480 \mathrm{mbsf}$ and decreases again to $\sim 510 \mathrm{Ma}$ at the base of the core (Fig. 6.4).

Table 6.1: Zircon data per sample. Data includes total zircon numbers (n), the number of age populations in each age probability diagram and the proportion of 450-650 Ma grains in each sample. Also shown are the minimum, maximum and average ages for zircons in the 450-650 Ma 'Ross' age population per sample.

\begin{tabular}{|c|c|c|c|c|c|c|}
\hline Sample & $\begin{array}{c}\mathrm{N} \\
\text { zircons }\end{array}$ & $\begin{array}{c}\mathrm{N} \text { age } \\
\text { populations }\end{array}$ & $\begin{array}{c}\% \\
\text { (Total) } \\
450- \\
650 \mathrm{Ma} \\
\text { grains }\end{array}$ & $\begin{array}{c}\text { Youngest } \\
450-650 \\
\mathrm{Ma} \\
\text { grains }\end{array}$ & $\begin{array}{c}\text { Oldest } \\
450- \\
650 \mathrm{Ma} \\
\text { grains }\end{array}$ & $\begin{array}{c}\text { Average } \\
\text { age } \\
450-650 \\
\mathrm{Ma} \\
\text { grains }\end{array}$ \\
\hline $28-21$ & 55 & 6 & 91 & 449 & 551 & 496 \\
\hline $78-18$ & 39 & 8 & 54 & 449 & 569 & 502 \\
\hline $91-17$ & 24 & 10 & 63 & 469 & 610 & 537 \\
\hline $148-16$ & 19 & 8 & 63 & 469 & 596 & 545 \\
\hline 205-15 & 45 & 15 & 44 & 475 & 642 & 554 \\
\hline 249-14 & 70 & 18 & 31 & 457 & 640 & 538 \\
\hline 292-13 & 77 & 19 & 45 & 481 & 657 & 555 \\
\hline 295-12 & 45 & 15 & 44 & 442 & 669 & 521 \\
\hline $362-11$ & 53 & 13 & 58 & 468 & 649 & 542 \\
\hline 403-10 & 55 & 13 & 35 & 484 & 641 & 553 \\
\hline $462-7$ & 62 & 17 & 45 & 490 & 639 & 554 \\
\hline $465-8$ & 49 & 9 & 39 & 489 & 681 & 550 \\
\hline $507-6$ & 38 & 14 & 34 & 483 & 617 & 532 \\
\hline $560-5$ & 41 & 12 & 46 & 453 & 597 & 508 \\
\hline 610-4 & 63 & 17 & 46 & 456 & 635 & 535 \\
\hline $653-3$ & 48 & 13 & 58 & 455 & 630 & 524 \\
\hline $687-1$ & 18 & 6 & 61 & 477 & 529 & 514 \\
\hline 693-2 & 24 & 9 & 75 & 470 & 565 & 518 \\
\hline
\end{tabular}

\subsubsection{CIROS-1 cumulative age probability diagram}

The cumulative age probability diagram (Fig. 6.5) was constructed by combining the ages of all zircons analysed into a single age probability diagram $(\mathrm{n}=854)$. The black line bars represent the number of zircon ages that fall within each $40 \mathrm{Myr}$ age bin. The relative probability of a zircon sourced from CIROS-1 being of a certain age is shown as the red line. This has been calculated using the ages and associated (two standard error) errors for each zircon analysed. It must be noted that this diagram shows an artificial bias towards younger ages as the rims of many zircons were preferentially analysed. This was done as rim analyses yield insights into the most recent processes that influenced the zircons. 


\section{CUMULATIVE AGE PROBABILITY CIROS-1 DRILL CORE}

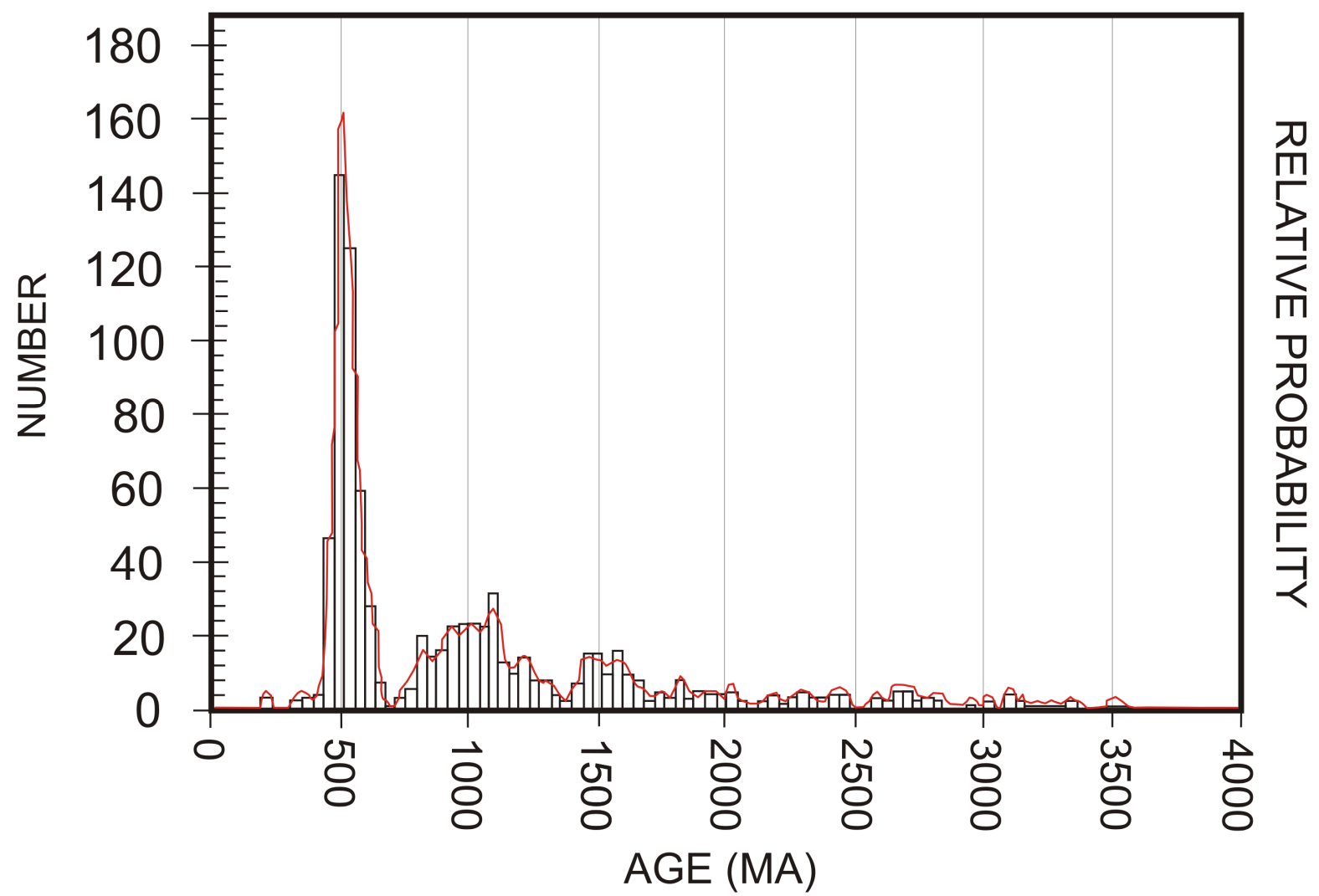

Figure 6.5: Cumulative age probability diagram for the entire suite of CIROS-1 zircons $(n=854)$. The histograms reflect the counts of zircon ages that fall within $40 \mathrm{Myr}$ age bins. The red line reflects the probability of a CIROS-1 zircon being a certain age and was calculated from zircon counts, individual zircon ages and two sigma errors.

Peaks at 450-650 Ma, 900-1250 Ma and 1400-1650 Ma are clearly distinguishable on the diagram. Smaller, less discernable peaks occur at 200-250 Ma, 320-390 Ma, 810$870 \mathrm{Ma}, 1800-2050 \mathrm{Ma}$ (Fig. 6.5).

\subsubsection{Trace element chemistry of CIROS-1 zircons}

Trace element analysis was conducted on 119 zircons from three samples located at 205, 462 and 652 mbsf. Combined, these zircons fall in all of the age peaks in the cumulative age probability diagram (Fig. 6.5). Examination of zircon trace element data shows that four chemically distinct groups of zircons are present in CIROS-1. The geochemical characteristics that define these groups from one-another and potential provenance of these groups are discussed in this section and are summarised in Table 6.2 and Figures 6.8-6.11. 


\subsection{4.i. Suggested provenance of Group 1 zircons}

With 106 of the 119 zircons falling within this category, Group 1 zircons were by far the most common zircons analysed. The geochemical characteristics that define zircons in Group 1 are discussed below. Zircons of this Group showed the greatest spread of trace element concentrations with large ranges of Ce/Ce*, Eu/Eu*, HREE/LREE, HREE/MREE, Ti-inzircon formation temperatures and $\mathrm{Li}$ concentrations (Table 6.2). All but three zircons within this population have Th/U ratios above 0.1. Although highly variable in absolute concentrations, the chondrite-normalised REE profiles obtained from these zircons share many common features including typically steep positive slopes (i.e. $\mathrm{Nd} / \mathrm{Yb}$ average is 258 and $\mathrm{Lu} / \mathrm{Gd}$ average is 2.74) and an enrichment in HREE (average $\mathrm{Lu}_{\text {zircon }} / \mathrm{Lu}_{\text {chondrite }}$ in this population is 2240) (Fig. 6.8).

Zircons in this group have pervasive and large Ce anomalies, with a $\mathrm{Ce} / \mathrm{Ce}$ * of 2-2635 and an average Ce/Ce* of 176. Negative Eu anomalies are also ubiquitous, with $\mathrm{Eu} / \mathrm{Eu}^{*}$ ranging between 0.01-0.83 and averaging 0.21 (Fig. 6.8). The chemistry of Group 1 zircons suggests they are of a crustal-affinity igneous provenance given that:

(1) The high degree of chemical variability seen within the trace elements is similar to the high degree of chemical variability known to be present in igneous bodies within the crust and in zircons that form therein (Hoskin and Schaltegger, 2003);

(2) The Th/U ratio is generally $>0.1$ is suggestive of an igneous origin (Hoskin and Schaltegger, 2003);

(3) The range of $\mathrm{Zr} / \mathrm{Hf}$ ratios between 35-73 (all but three Group 1 zircons yielded $\mathrm{Zr} / \mathrm{Hf}>60$ and the group yielded an average $\mathrm{Zr} / \mathrm{Hf}$ of 46) are indicative of a crustal igneous origin where $\mathrm{Zr} / \mathrm{Hf}$ ratios are know to vary between $\sim 60$ for mafic, early formed rocks such as gabbros and diorites and 30-40 for granites (Gulson, 1969; Clairborne et al., 2006);

3. Average apparent minimum Ti-in-zircon formation temperatures between $545^{\circ} \mathrm{C}$ and $1611^{\circ} \mathrm{C}$ (with only three temperatures above $1000^{\circ} \mathrm{C}$ and an average formation temperature of $737^{\circ} \mathrm{C}$ ) are consistent with formation temperature of known zircons of a crustal origin (Watson et al., 2006);

(4) The features on chondrite-normalised REE profiles obtained from Group 1 zircons are consistent with those obtained from zircons of known crustal 
igneous origin (Fig. 6.8). The steep positive slopes on chondrite-normalised REE patterns, HREE enrichments and pervasive Ce and Eu anomalies are all features known to occur in crustal-affinity igneous zircon REE profiles (Whitehouse, 2003); and

(5) The oscillatory zonation patterns inherent to many Group 1 zircons (examples Fig. 6.6) are consistent with known CL patterns of igneous zircons (Corfu et al., 2003).

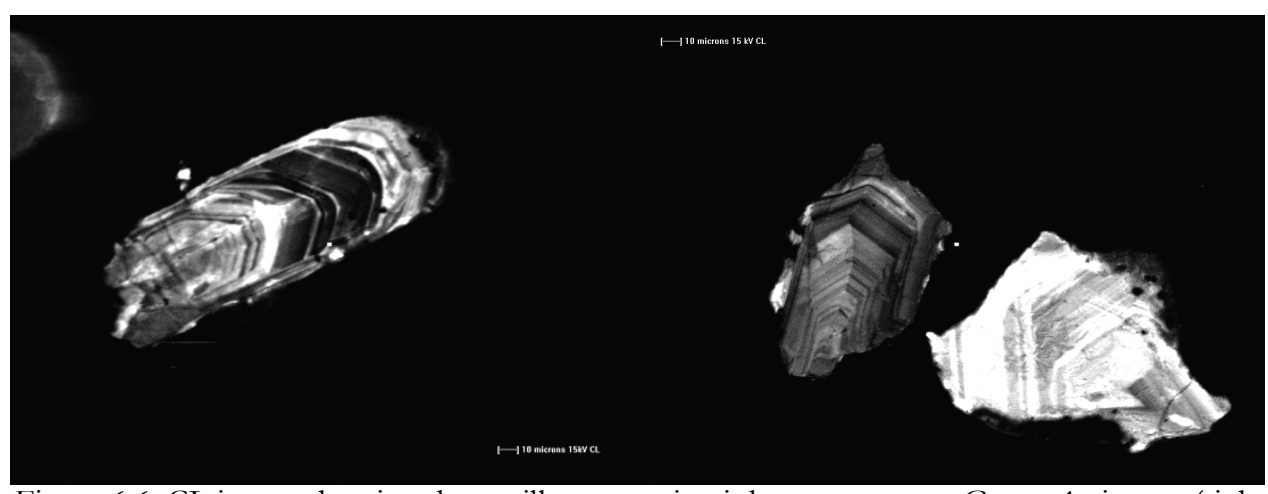

Figure 6.6: CL image showing the oscillatory zoning inherent to many Group 1 zircons (right picture shows zircons 16 and 17 from Sample 205-15 and left picture is zircon 49 from Sample 462-7).

\subsection{4.ii. Suggested provenance of Group 2 zircons}

This group only comprises three zircons that have $\mathrm{Th} / \mathrm{U}<0.13$, particularly large $\mathrm{Ce}$ and $\mathrm{Eu}$ anomalies (average $\mathrm{Eu} / \mathrm{Eu}^{*}=0.3$ and average $\mathrm{Ce} / \mathrm{Ce}^{*}=$ 19) and are relatively depleted in REE (average $\Sigma$ REE $=190 \mathrm{ppm}$ ). These zircons have steep positive slopes between the LREE and MREE on a chondrite-normalised REE profile (Fig. 6.9) (average $\mathrm{Nd} / \mathrm{Yb}=12.3$ ) but are depleted in HREE with average $\mathrm{Lu}_{\text {zircon }} / \mathrm{Lu}_{\text {chondrite }}$ of 90 and average $\mathrm{Nd} / \mathrm{Yb}$ of 0.07 . The average apparent minimum formation temperature for this group is $729^{\circ} \mathrm{C}$. The CL characteristics of Group 2 zircons are dominated by broad homogeneous zones (Fig. 6.7). The chemical characteristics of Group 2 zircons indicate a high-grade metamorphic provenance. Low Th/U (usually $<0.1)$ values are known to be inherent to zircons with a metamorphic petrogenesis and the characteristics seen on chondrite-normalised REE profiles for these zircons (Fig. 6.9), such as large Eu and Ce anomalies and are similar to those produced by zircons with known metamorphic origins (Hoskin and Schaltegger, 2003). The depletion of HREE relative to MREE is known to be a common feature in zircons that formed in high grade metamorphic environments (Rubatto and Herman, 2007). The homogeneous 
zones seen in the CL images of these zircons (Fig. 6.7) are a feature inherent to zircons formed in metamorphic environments (Corfu et al., 2003).

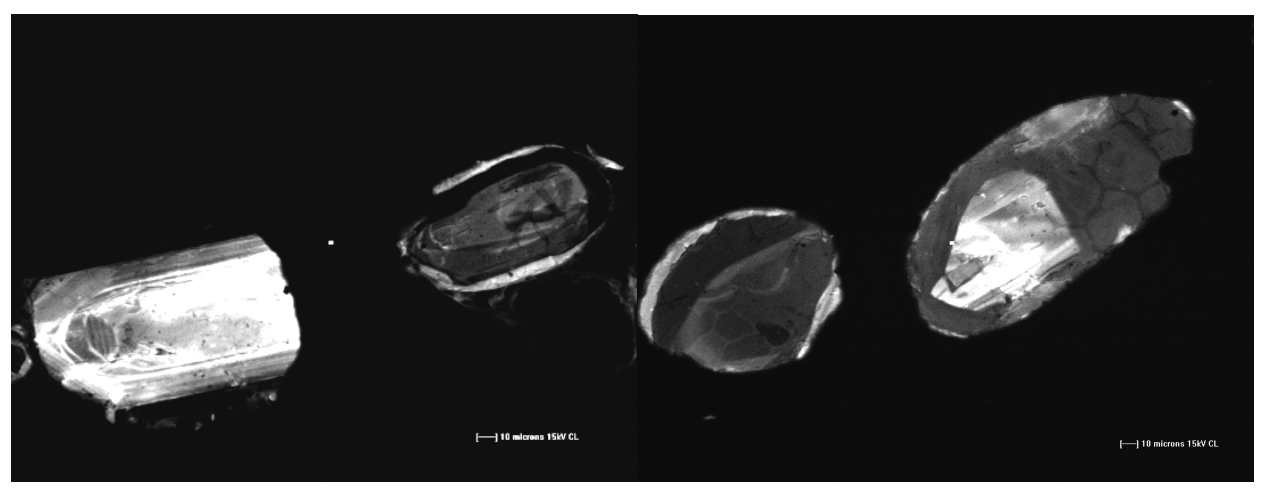

Figure 6.7: CL images of Group 2 zircons. These include zircon 60, from sample 462-7 (right picture, left hand grain) and zircon 16, from sample 462-7 (left hand picture, grain on the right). Both show homogeneous and trace element depleted (dark) zones that are characteristic of metamorphic zircons (Corfu et al., 2003).

\subsection{4.iii. Suggested provenance of Group 3 zircons}

The nine zircons within Group 3 which are characterised by:

(1) Very high total REE concentrations, with an average $\Sigma$ REE of 1102 ppm (Table 6.2);

(2) Exceptionally high LREE and MREE concentrations. Group 3 zircons have an average $\mathrm{Pr}_{\text {rcon }} / \mathrm{Pr}_{\text {chondrite }}$ of 18 (other groups all had values $<2.2$ ) and average $\mathrm{Sm}_{\text {rcon }} / \mathrm{Sm}_{\text {chondrite }}$ values of 147 (other groups all had values $<33$ );

(3) Very small Eu anomalies; average $\mathrm{Eu} / \mathrm{Eu}^{*}$ in this Group is 0.59 . Ce anomalies were moderate, averaging a $\mathrm{Ce} / \mathrm{Ce} *$ of 23 ;

(4) Mid-range concentrations of $U$ and Th; zircons in this group had average $\mathrm{U}$ and Th concentrations of 285 and $240 \mathrm{ppm}$, respectively;

(5) High $\mathrm{Th} / \mathrm{U}$ ratios, with an average $\mathrm{Th} / \mathrm{U}$ of 1.12 and relatively high $\mathrm{Zr} / \mathrm{Hf}$ (average $\mathrm{Zr} / \mathrm{Hf}=52$ );

(6) Low Li concentrations that were $\sim 1.3$ ppm average; and

(7). Chondrite normalised REE profiles that show steep positive slopes and pervasive Ce and Eu anomalies (Fig. 6.10). 
Group 1 representative REE profiles

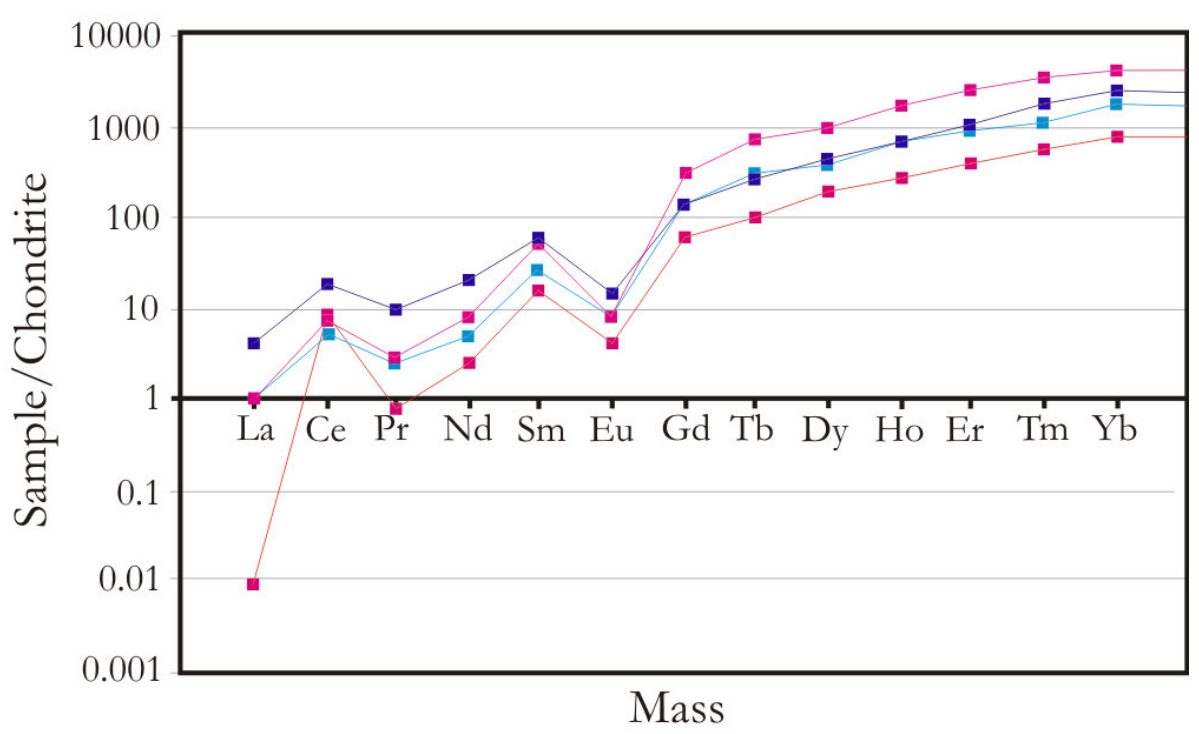

Figure 6.8: Representative REE profile for Group 1 zircons.

Group 2 REE profiles

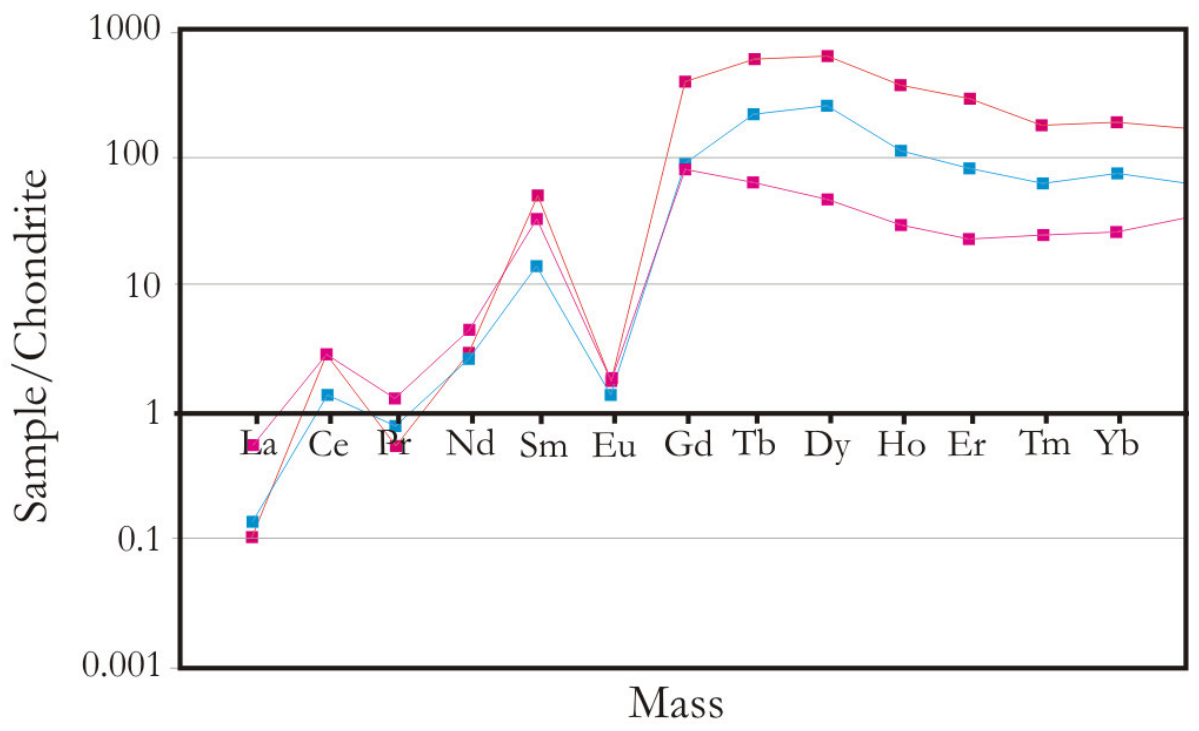

Figure 6.9: REE profile for Group 2 zircons. 
Group 3 representative REE profiles

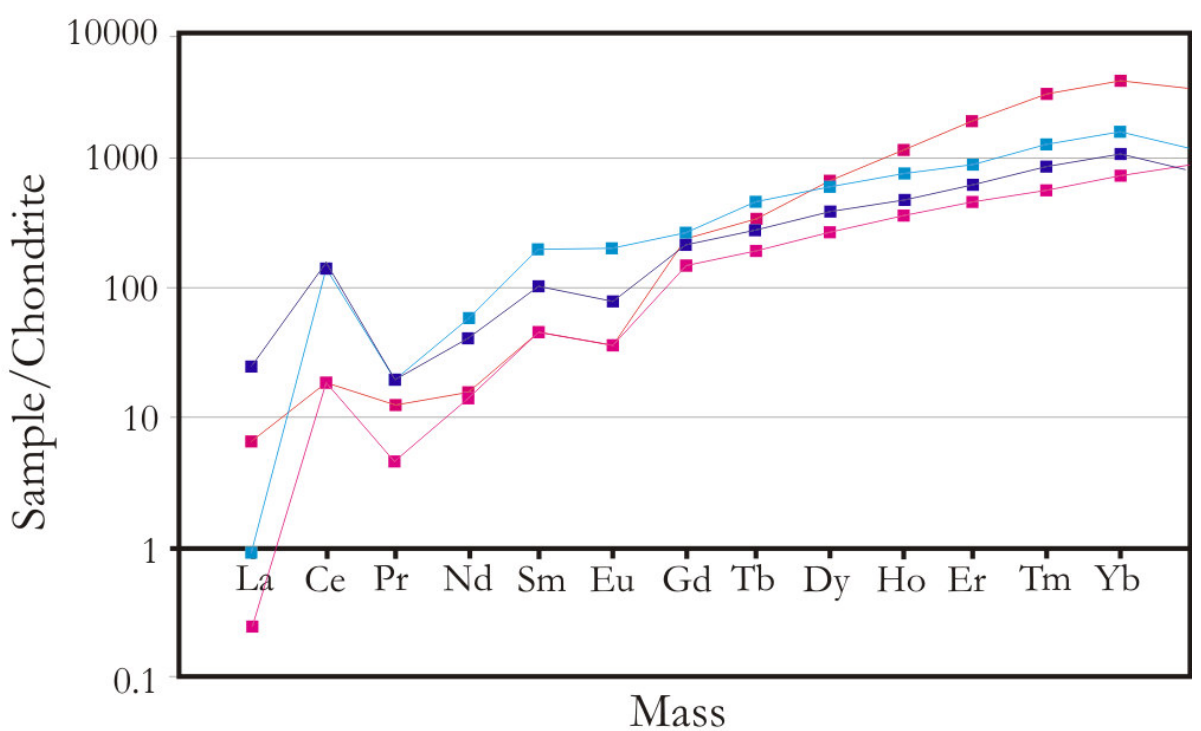

Figure 6.10: Representative REE profiles for Group 3 zircons

\section{Group 4 REE profiles}

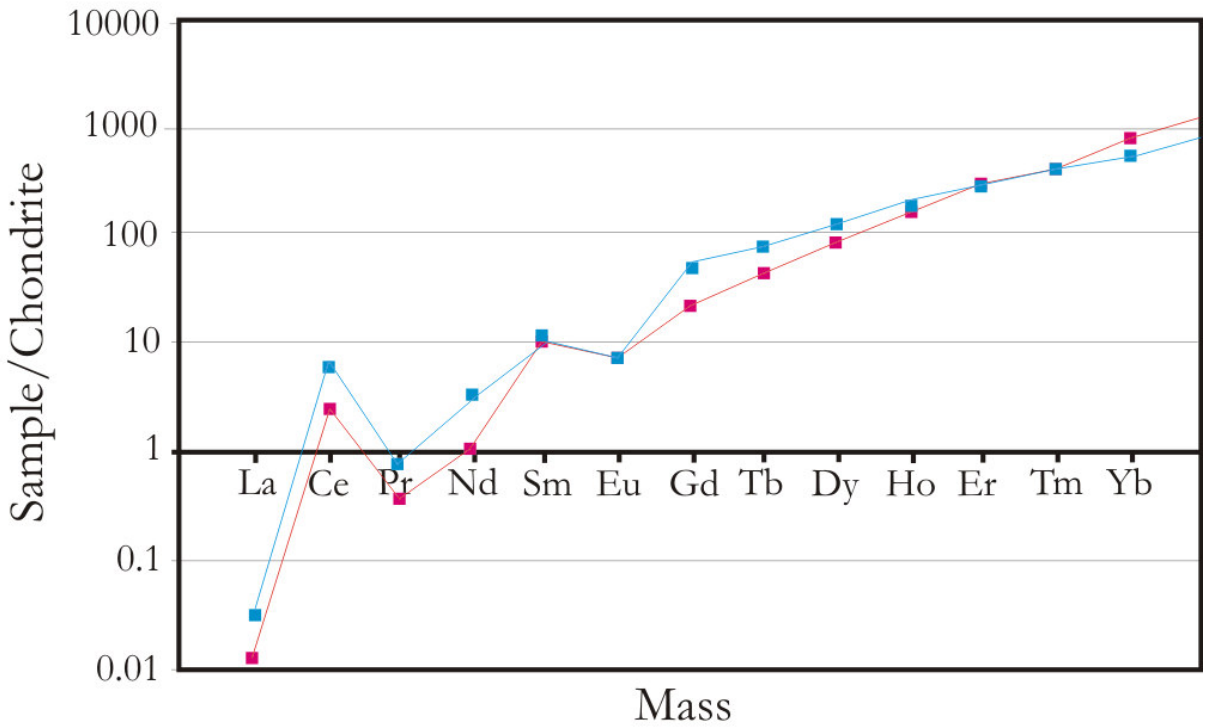

Figure 6.11: REE profiles for zircons from Group 4.

Table 6.2: Trace element compositions and ratios of the four zircon populations identified in CIROS-1 using LA-ICP-MS.

\begin{tabular}{|c|c|c|c|c|c|c|c|c|c|c|c|c|c|c|c|c|c|c|c|}
\hline $\mathrm{TE}$ group & $\mathrm{n}$ & $\mathrm{Eu} / \mathrm{Eu}^{*}$ & & $\mathrm{Ce} / \mathrm{Ce}^{*}$ & & $\mathrm{Nb} / \mathrm{Yd}$ & & $\mathrm{Lu} / \mathrm{Gd}$ & & $\mathrm{U} / \mathrm{Th}$ & & $\mathrm{Zr} / \mathrm{Hf}$ & & Ti-in-zirc & $\left({ }^{\circ} \mathrm{C}\right)$ & $\mathrm{Li}(\mathrm{ppm})$ & & $\sum \mathrm{REE}$ & \\
\hline & & Range & Average & Range & Average & Range & Average & Range & Average & Range & Average & Range & Average & Range & Average & Range & Average & Range & Average \\
\hline Group 1 & 105 & $0.01-0.83$ & 0.21 & $2.63-26.35$ & 175.92 & $12.25-2129.07$ & 257.77 & $0.24-10.29$ & 2.74 & $0.05-7.41$ & 0.70 & $32.58-72.47$ & 45.83 & $545-1611$ & 737 & $0-37.02$ & 4.95 & $2124-116$ & 778.71 \\
\hline Group 2 & 3 & $0.01-0.04$ & 0.03 & $3.62-47.66$ & 18.68 & 2.14-22.9 & 12.28 & $0.05-0.09$ & 0.07 & $0.05-0.13$ & 0.09 & 25.0434 .43 & 30.84 & 713-756 & 729 & $1.28-12.44$ & 7.50 & $52-375$ & 190.37 \\
\hline Group 3 & 9 & $0.28-1.02$ & 0.59 & $2.27-76.10$ & 22.81 & $9.28-96.47$ & 26.86 & $0.35-3.45$ & 1.06 & 0.242 .66 & 1.12 & $40.74-65.2$ & 51.77 & 701-857 & 780 & $0-5.02$ & 1.34 & $387-1801$ & 1101.71 \\
\hline Group 4 & 2 & $0.28-0.46$ & 0.37 & 161.94 & 161.94 & $56.25-228.72$ & 142.49 & $2.10-6.23$ & 4. 17 & 0.340 .58 & 0.46 & $46.44-59.8$ & 53.12 & $528-726$ & 627 & $0.88-1.19$ & 1.03 & $223-240$ & 231.61 \\
\hline
\end{tabular}




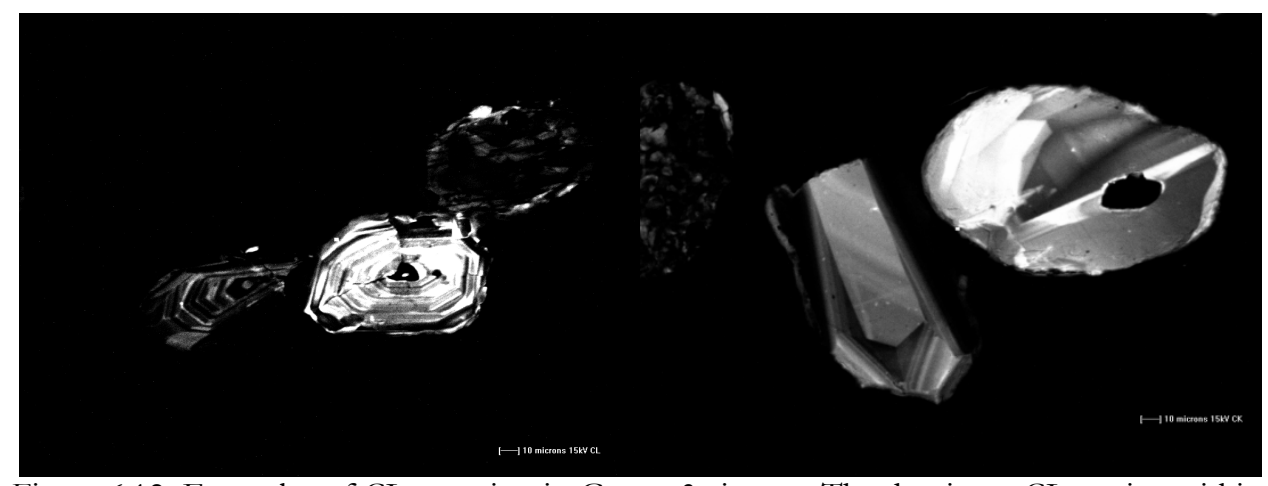

Figure 6.12: Examples of CL zonation in Group 3 zircons. The dominant CL zoning within this group is oscillatory. Oscillatory zoned Group 3 zircons include zircon 41 (right hand image, middle zircon) from sample 462-7 and zircon 3 from sample 652-3 (right hand image, middle grain).

The high Th/U ratios suggest an igneous source (Hoskin and Schaltegger, 2003) and the high amount of total REE of zircons in this group suggests that they formed from an enriched source(Schluz et al., 2006). This igneous provenance is supported by oscillatory CL zonation patterns observed within these zircons (Fig. 6.12) and the shape of their chondrite normalised REE profiles (Fig. 6.10) which show characteristics similar to those produced by known igneous zircons (Hoskin and Schaltegger, 2003). The average apparent (minimum) formation temperatures for these zircons $\left(\sim 780^{\circ} \mathrm{C}\right)$ as well as their chemical and zonation characteristics is suggestive of an enriched igneous environment such as a granite or a pegmatite.

\subsection{4.iv. Suggested provenance of Group 4 zircons}

Group 4 contains two zircons that are relatively depleted in REE (average $\Sigma$ REE $=232 \mathrm{ppm}$ ), and have comparatively steep REE slopes (Fig. 6.11) with an average $\mathrm{Nd} / \mathrm{Yb}$ of 143 and an average Lu/Gd of 4.2 (Table 6.2). Group 4 zircons have low Th and U concentrations (average $126 \mathrm{ppm}$ and $48 \mathrm{ppm}$ respectively) and an average $\mathrm{Th} / \mathrm{U}$ of 0.46 . The average formation temperature for Group 4 zircons is a relatively low $627^{\circ} \mathrm{C}$. These zircons have the highest $\mathrm{Zr} / \mathrm{Hf}$ of all the populations (averaging 53) and the lowest Li concentrations with an average of $1.0 \mathrm{ppm}$ (Table 6.2).

Given the limited and ambiguous data available for these zircons it is difficult to constrain their provenance. From the total REE it is evident that their source(s) were depleted in trace elements (Belousova et al., 2002). The steep slope between LREE and HREE on chondrite-normalised REE profiles suggests that this source/these sources may have been igneous (Fig. 6.11) (Hoskin and Schaltegger, 2003). This hypothesis is supported by the 
oscillatory growth zones seen in the CL images (Fig. 6.13) (Corfu et al., 2003). A depleted igneous source would usually be a mafic one, such as a gabbro or basalt (Hoskin and Schaltegger, 2003). This provenance seems plausible considering the high average $\mathrm{Zr} / \mathrm{Hr}$, however, the low average formation temperature does not fit with a mafic igneous provenance as these units often form at high temperatures $\left(\sim 1000-1400{ }^{\circ} \mathrm{C}\right)$ (e.g. Wendlandt, 1982). Recent studies have outlined that the Ti-in-zircon geothermometer may yield formation temperatures for mafic zircons considerable lower than expected (Fu et al., 2008). Consequently, all that can be concluded about these zircons is that they formed in a trace element depleted, possibly mafic igneous, source such as a gabbro or potentially a kimberlite.

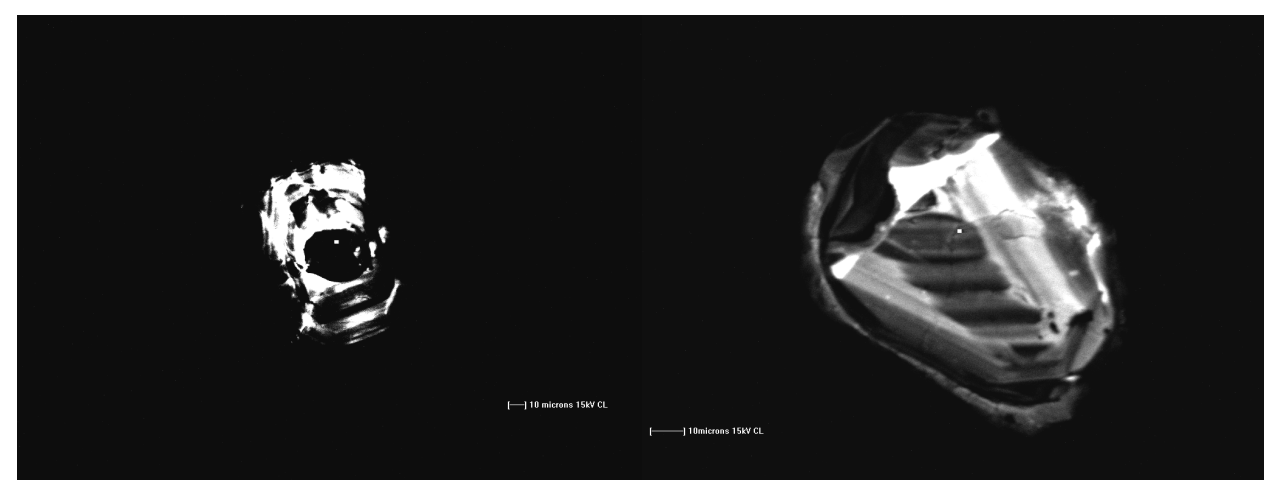

Figure 6.13: CL images of the two Group 4 zircons showing oscillatory growth zones. Zircon 4 is shown in the left hand image and zircon 12 is on the right. Both Group 4 zircons are sourced from sample 652-3.

\subsubsection{Possible provenance of CIROS-1 zircon age populations}

This section reviews the possible provenance of zircons that fall within the age peaks on the cumulative age probability diagram (Fig. 6.5) in order to gain insights into the units contributing zircons to CIROS-1. This has been summarised in Table 6.3 and is discussed below.

The dominance of Group 1 igneous zircons implies the main contributing units of CIROS-1 zircons were relatively enriched and differentiated/crustal igneous units such as granites or rhyolites of a range of ages. The occurrence of Group 2, 3 and 4 zircons suggests both highly enriched and depleted (probably igneous) units and metamorphic units of various ages contributed sediments to the core.

The only zircon analysed for trace element compositions with an age in the 200-250 Ma age has a 'Group 1' igneous chemistry (Table 6.3). This suggests CIROS-1 zircons of this age were sourced from a granitic or rhyolitic unit. Both grains with 
ages in the 320-390 $\mathrm{Ma}$ age range were of Group 1 igneous origin (Table 6.3), implying CIROS-1 zircons of this age were sourced from a relatively enriched (rhyolitic or granitic) igneous source.

Table 6.3: Overview of the provenance groups within each age peak visible on the cumulative age probability diagram (Fig. 6.5). This includes the amount of zircons per age peak that fall within a provenance group.

\begin{tabular}{|c|cc|}
\hline \multicolumn{3}{|c|}{ Provenance of Zircons per Age Peak } \\
\hline Age Peak & N & Provenance \\
Zircons & Group \\
\hline $200-250 \mathrm{Ma}$ & 1 & Group 1 \\
$320-390 \mathrm{Ma}$ & 2 & Group 1 \\
$450-650 \mathrm{Ma}$ & 49 & Group 1 \\
& 1 & Group 2 \\
& 4 & Group 3 \\
& 2 & Group 4 \\
$810-870 \mathrm{Ma}$ & 2 & Group 1 \\
& 1 & Group 3 \\
$900-1250 \mathrm{Ma}$ & 25 & Group 1 \\
& 1 & Group 2 \\
& 2 & Group 3 \\
$1400-1650 \mathrm{Ma}$ & 11 & Group 1 \\
$\sim 1750 \mathrm{Ma}$ & 2 & Group 1 \\
$\sim 1814 \mathrm{Ma}$ & 1 & Group 1 \\
$\sim 1950 \mathrm{Ma}$ & 1 & Group 1 \\
& 1 & Group 2 \\
$2460-3350 \mathrm{Ma}$ & 6 & Group 1 \\
& 1 & Group 3 \\
\hline
\end{tabular}

The 450-650 Ma age peak is dominant on the cumulative age probability diagram (Fig. 6.5) and 56 of the 119 zircons analysed for trace elements have ages within this range. Zircons in this population fall within all four geochemical groups. Group 1 zircons are dominant within this age population (49 zircons are Group 1). The only two Group 4 zircons are 440-460 Ma old, making them the youngest grains in this age population. Their characteristics indicates a $\sim 440-460 \mathrm{Ma}$ old, REE depleted, possibly igneous source contributed sediments to the core. Four, Group 3 REE enriched igneous zircons of various ages and one Group 2 metamorphic grain (age $624 \mathrm{Ma}$ ) fall within this age population. The dominance of Group 1 igneous zircons implies that granitic/rhyolitic units were the dominant source of 450-650 Ma zircons in the CIROS-1 core. The presence of zircons with Group 2, 3 and 4 chemistry in this age range indicates metamorphic units in addition to enriched and depleted igneous units also contributed a minor proportions zircons of this age to the CIROS1 core. 
Three grains occur within the relatively minor $810-870 \mathrm{Ma}$ age population (Fig. 6.5). Two of these are Group 1 igneous whilst one is Group 3. This suggests that a unit or units of this age contributed sediments to the core and it/they were igneous in origin and enriched to very enriched in trace elements.

Twenty-eight analysed zircons fall within the 900-1250 Ma age population, which is the second most distinct on the cumulative age probability diagram (Fig. 6.5). All but three of these all within Group 1, with two Group 3 zircons and one Group 2 zircon. This implies that the units contributing zircons of this age to the core were predominantly enriched igneous units such as granites but also consisted of much enriched, possibly igneous units and metamorphic units.

Eleven analysed zircons fall within the 1400-1650 Ma age peak seen on the cumulative age probability diagram (Fig. 6.5). All of these are Group 1 igneous zircons, suggesting that a granitic/rhyolitic igneous source contributed MidProterozoic aged zircons to CIROS-1.

It is challenging to discern any distinct age groups on the cumulative age probability diagram for older zircons (Fig. 6.5). Thus, the trace element characteristics of zircons older than $\sim 1.7 \mathrm{Ga}$ will be discussed for individual zircons or for zircons with ages that fall within error of one another (Table 6.3). Two zircons with ages $\sim 1750 \mathrm{Ma}$ have Group 1 chemical characteristics. This indicates that a $\sim 1.7 \mathrm{Ga}$ felsic igneous unit contributed zircons of this age to the core. One zircon of $1814 \mathrm{Ma}$ was likewise Group 1, suggesting a granitic/rhyolitic unit contributed $\sim 1.8$ Ga old zircons to CIROS-1. Two zircons analysed for their trace element compositions had an age of $\sim 1950 \mathrm{Ma}$. One had a chemical signature that fell within the Group 1 category and the other showed characteristics of a Group 2 zircon. This indicates that two units of similar age but different provenance (one granitic/rhyolitic, one metamorphic) contributed sediments of this age to the core.

The seven oldest zircons analysed for their trace-element compositions have ages that do not fall within error of one another (age range 2.46-3.35 Ga), signifying a range of units contributed the oldest zircons contained in CIROS-1. All but one of these zircons have chemistries that fall within Group 1 (the 2.73 Ga old zircon fell within Group 3) (Table 6.3). This indicated that the Late Proterozoic and Archaean units contribution zircons to the core were enriched to highly igneous units such as granites and pegmatites. 


\subsection{Discussion}

\subsubsection{Implication of age peaks in the cumulative age probability diagram}

It is well established that peaks in global zircon ages broadly correlate to periods of supercontinent assembly and that during periods of supercontinent stasis and breakup, global zircon numbers of that age are low (Condie and Aster, 2010) (Fig. 6.14).

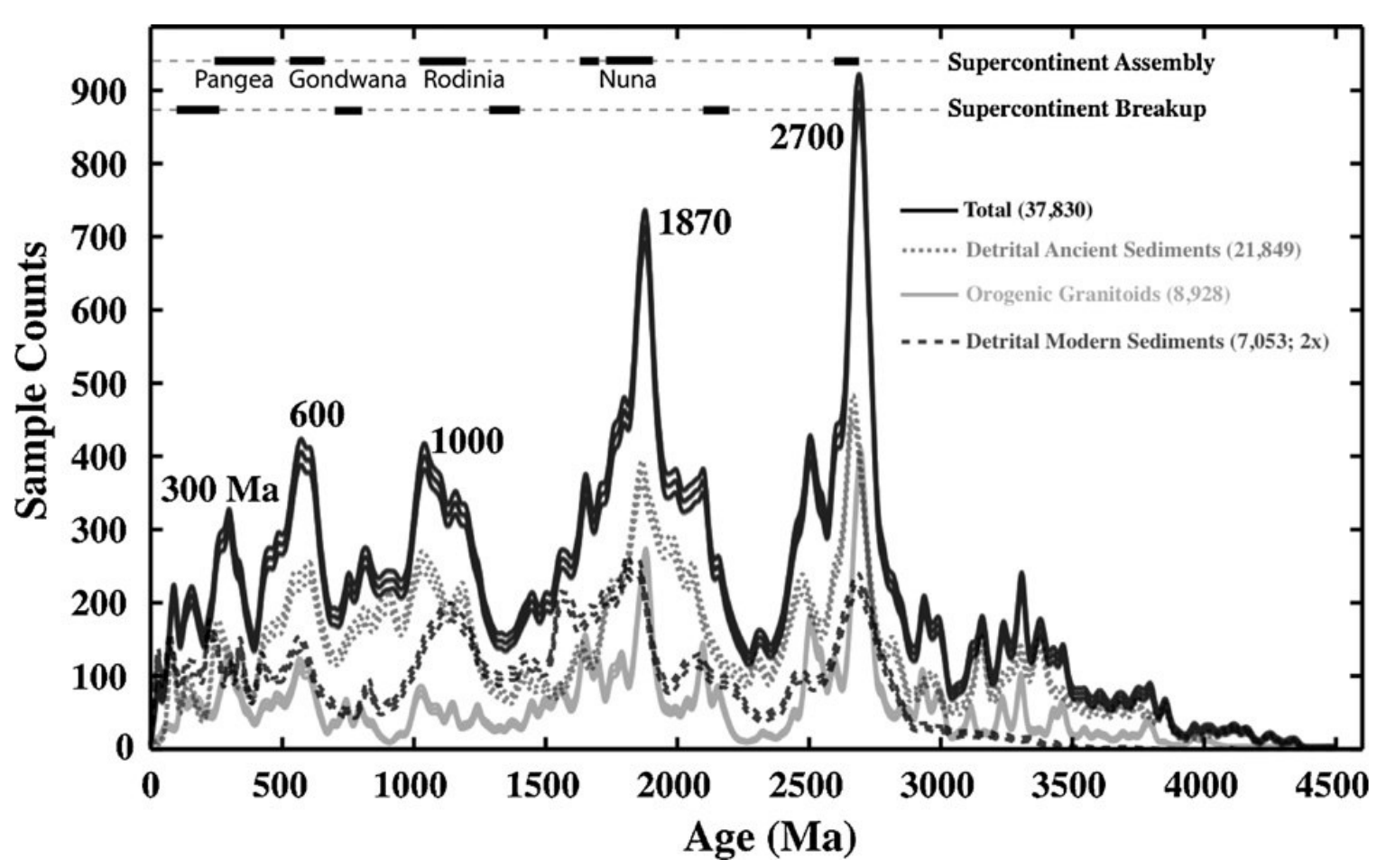

Figure 6.14: Age distribution of zircons sourced from orogenic granitoids and sedimentary samples from a range of globally-distributed locations. In the upper section, known periods of supercontinent assembly and breakup are given. Note the correlation of zircon age peaks and periods of supercontinent formation and zircon minima and supercontinent breakup and/or stasis (source: Condie and Aster, 2010).

The cumulative age probability diagram constructed for CIROS-1 (Fig. 6.15) contains peaks that correlate to periods of known supercontinent formation (Fig. 6.14) (Condie and Aster, 2010). These include the pronounced age peaks at $\sim 600 \mathrm{Ma}$ and $1000 \mathrm{Ma}$ and to a lesser degree the age peaks at $1870 \mathrm{Ma}$ and $3000 \mathrm{Ma}$. There is also limited correlation with zircon minima on the CIROS-1 cumulative age probability diagram and periods of known continental breakup or stasis. This includes minima at 650-750 Ma and $<200 \mathrm{Ma}$. This means that CIROS-1 zircons hold a partial record of global supercontinent history (Fig. 6.14). 


\section{CUMULATIVE AGE PROBABILITY CIROS-1 DRILL CORE}

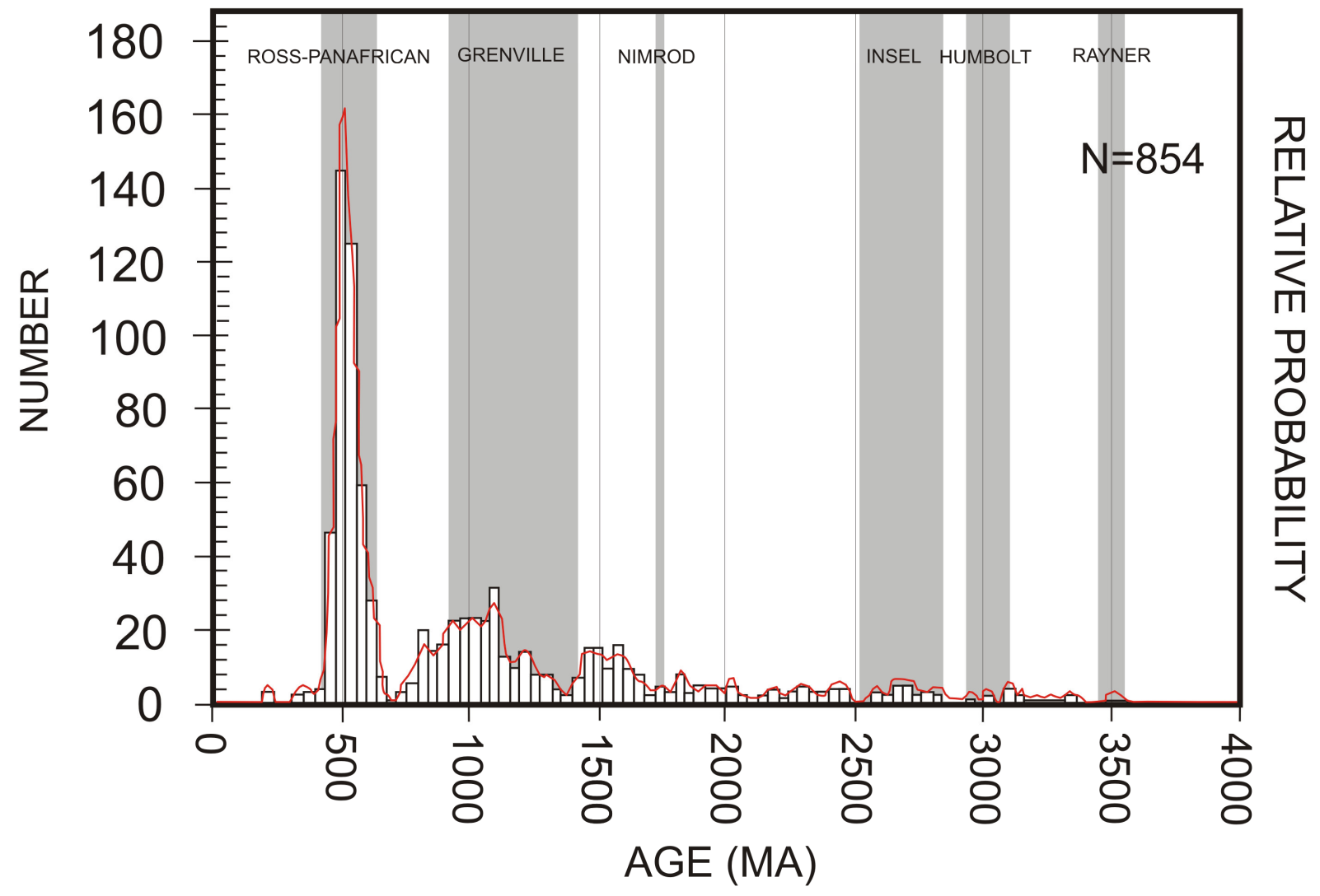

Figure 6.15: Cumulative age probability diagram for the 854 zircon grains analysed in this study. Zircon numbers for each $40 \mathrm{Myr}$ age bin are given in the bar graphs and the relative probability is shown as the red line. Orogenic episodes known to have occurred on the EAC are shown in the grey bars (sources: Tingey, 1991; Fitzsimons, 2000; Goodge et al., 2001).

More specific to Antarctic history, the age probability diagram shows a broad correlation between age peaks and orogenic episodes known to have occurred on the continent (Fig. 6.15). There is a strong correlation between the Ross/Pan-African Orogeny and the dominant 450-650 Ma age peak indicating that zircons formed during the Ross and Pan-African orogenies were a dominant source of zircons in CIROS-1 sediments. There is limited correlation between the distinct 0.8-1.3 Ga age population and the timing of the Grenville Orogeny, with the CIROS-1 age peak containing zircons that are overlapping and slightly younger than the age of this orogeny (Fig. 6.15). If CIROS-1 zircons in the 0.8-1.3 Ga age population were definitely sourced from Grenvillian units, the offset in the age peak and the timing of the Grenville Orogeny may indicate that: (1) Zircons of this age formed in the very latest stages of the Grenville Orogeny; or (2) The Grenville Orogeny in this sector occurred later. Alternatively, zircons in this age peak may have been sourced from granitic/metamorphic units that formed during an as yet unknown event. This would imply that an orogenic event younger than and partially coeval with the Grenville Orogeny occurred in the Ross Sea Sector of the EAC. 
A lesser degree of correlation is present between the older orogenies that occurred in the EAC and CIROS-1 zircon age peaks (Fig. 6.15). This lack of correlation may be due a number of factors, including: (1) The orogenic episodes did not have a large impact on the Ross Sea Sector of the EAC; (2) Zircons formed during these events are not well preserved, perhaps due to overprinting of subsequent orogenic events (e.g. Goodge et al., 2001); or (3) An artificial bias on the cumulative diagram towards younger ages caused by the preferential use of rim over core analyses in zoned zircons.

\subsubsection{Potential source units for CIROS-1 zircons}

The youngest age peak on the cumulative probability diagram consists of zircons the few zircons of age between 200-250 Ma (Fig. 6.5). This age peak occurs in many detrital samples in the Ross Sea region (e.g. Palmer, 2008; Elliot and Fanning, 2008). From trace element evidence of this study it appears these zircons were, in part at least, sourced from a 200-250 Ma, intermediate-felsic igneous unit. The Victoria Group, the younger of the two members of the Beacon Supergroup, occurs in the upper reaches of the Ferrar Fiord (Barrett, 2010, per. comm.; Elliot and Fanning, 2008; Licht et al., 2005). In Queen Maud Land it is known to contain zircons of 200$250 \mathrm{Ma}$ age, that are inferred to have an igneous provenance (Elliot and Fanning, 2008) (Fig. 6.16).

The Victoria Group also contains a silicic tuff that has zircons (Elliot and Fleming, 2008) and has an unconstrained Triassic or Jurassic age (Ross et al., 2008). This tuff outcrops between SVL (Coombs-Alan Hills area) and the Queen Alexander Range in the TAM (Elliot and Fleming, 2008; Ross et al., 2008). Thus, the 200-250 Ma age peak observed in the CIROS-1 zircon population may have been sourced from the erosion of the Victoria Group with the silicic tuff being a minor contributor due to its limited volume (Elliot and Fleming, 2008). 

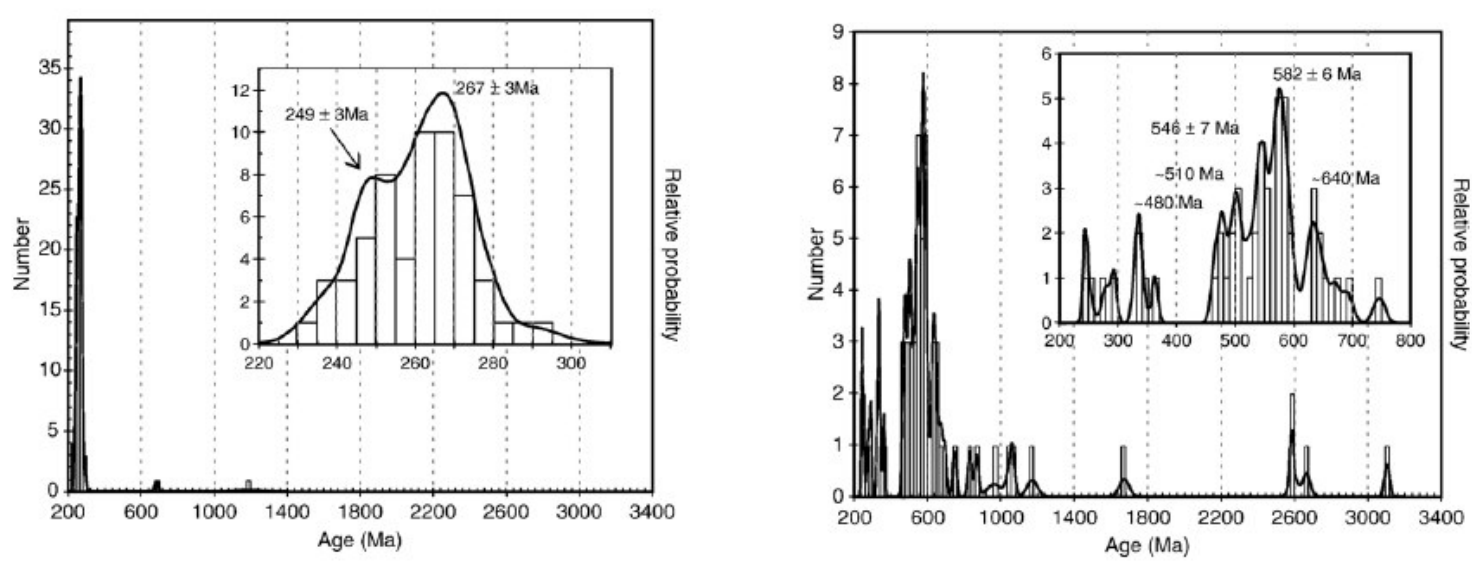

Figure 6.16: Age probability diagrams obtained from outcrops of the Victoria Group in Marie Byrd Land. Note the presence of relatively young (Triassic-Devonian) ages, thought to be from zircons formed in an active magmatic arc during subduction of the Antarctic palaeo-Pacifc margin (source: Elliot and Fanning, 2008).

Zircons in the weak 320-390 Ma age peak in Figure 6.5 were partially or wholly sourced from an intermediate-felsic igneous unit. Elliot and Fanning (2008) found a Devonian age peak in the zircons from the Victoria Group in Queen Maud Land (Fig. 6.16). The source unit for these zircons was igneous and hypothesised to potentially be the Ford Granodiorite in Marie Byrd Land or 'an uncertain extension of that belt eastward toward the Antarctic Peninsula' (Elliot and Fanning, 2008). From this it appears the Devonian age population in CIROS-1 zircons (Fig. 6.5) may have been sourced from the erosion of the Victoria Group, located in the Upper Ferrar Fiord (Barrett, 2010, pers. comm.; Elliot and Fanning, 2008; Licht et al., 2005).
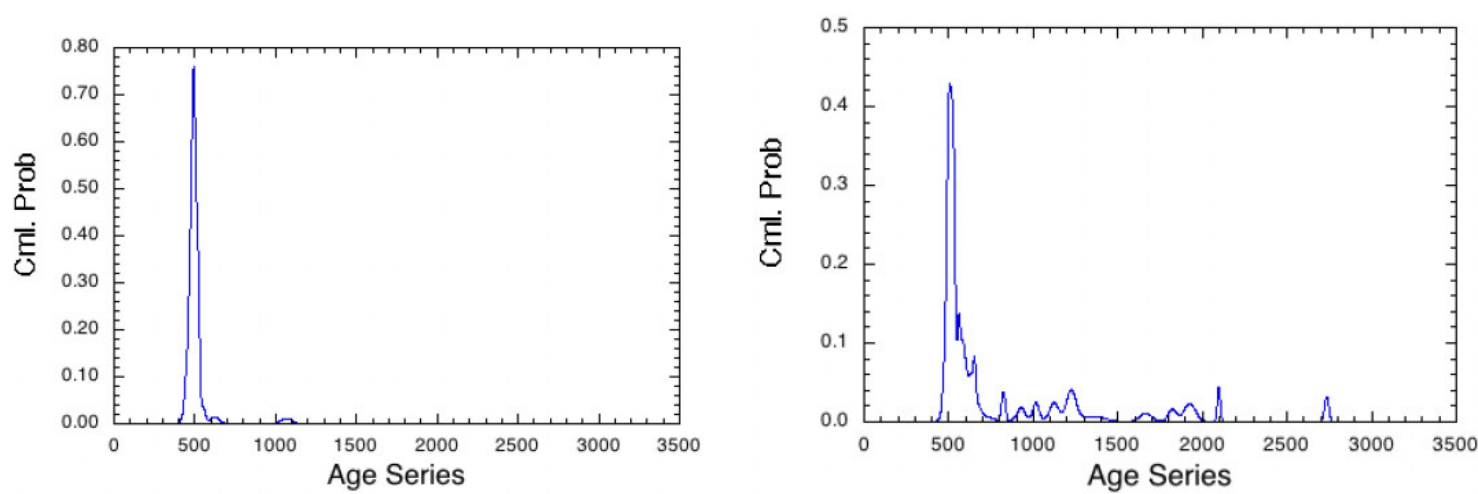

Figure 6.17: Age probability diagrams obtained for the Taylor Group at Sperm Bluff, South Victoria Land. The left hand image shows the age probability diagram for a granulite conglomerate, that is dominated by a $\sim 500 \mathrm{Ma}$ age peak. The right hand image shows the age probability diagram constructed from a granulitic conglomerate at a different locality on Sperm Bluff. As with the left hand image, this age probability diagram shows a dominant age peak at $\sim 500 \mathrm{Ma}$ with additional subordinate peaks at $\sim 700-2200 \mathrm{Ma}$ and $\sim 3.3 \mathrm{Ga}$ (source: Savage, 2005).

The 450-650 Ma age peak observed in the CIROS-1 zircons (Fig. 6.5) contains zircons of variable trace element chemistry. Zircons of this age were sourced from a number of temporally overlapping but distinctly different provenances. The most likely source for Group 1, 3 and 4 zircons within this age peak are the Granite 
Harbour units. These units occur throughout the TAM in SVL and are present in the Ferrar Fiord (Allibone et al., 1993a). The highly variable chemistries of these batholiths and the dykes (Allibone et al., 1993b) implies that Group 3 and 4 zircons of this age may have been sourced from chemically enriched and depleted enclaves within the Granite Harbour units. The youngest zircons in the 450-650 Ma age peak were possibly sourced from the youngest units of the Granite Harbour intrusives (post-tectonic Ross Granitoids which are of 460-510 Ma in age) (Allibone et al., 1993a) and older zircons from the syntectonic older batholiths (which are $\sim 490-590$ Ma in age) (Allibone et al., 1993a). The oldest zircons within this age group may have been sourced from the regional basement, which includes orthogneisses of the Skelton Group which have formation ages < 590 Ma (Allibone et al., 1993a). The Group 2 metamorphic grains that occur within this age peak (age 624 Ma) was likely sourced from the metamorphic Skelton Group. This group formed during the early stages of the Ross Orogeny and is the basement of the TAM and Ferrar Fiord (Allibone et al., 1993a; Rowell et al., 2001). Although direct deposition from erosion of the Granite Harbour Group seems most likely for zircon in this age group (due to the proximity of Granite Harbour batholiths to the CIROS-1 site and dominance of zircons source from these in CIROS-1), some contribution may have occurred from the Beacon Supergroup, which is known to contain a large amount of zircons sourced from the Granite Harbour Intrusives (Figs. 6.16 and 6.17).

CIROS-1 zircons with ages $>650 \mathrm{Ma}$ can not be tied to any outcrops in the region. Rather they may have originated from one of the following:

(1) Recycled sources containing mature sediments. This may include the Beacon Supergroup which outcrops throughout the TAM and in the Ferrar Fiord (Elliot and Fanning, 2008), or unknown sedimentary units located under the ice;

(2) Direct but unknown sources located under the ice of under the current baseline of geologic exposure. This may include the cratonic components of the EAC or older units located under the ice in the TAM; and

(3) The inherited components in zircons sourced from the Granite Harbour Intrusives (e.g. Savage, 2005).

Due to considerable gaps in our knowledge of Antarctic geology, it is challenging to constrain sources of detrital zircons if there are no known outcrops (e.g. Elliot and Fanning, 2008; Goodge et al., 2002). Nonetheless, possible sources for $>650 \mathrm{Ma}$ 
zircons found in CIROS-1 have been investigated using the information obtained during this research, as outlined below.

Three 808-854 Ma old grains of felsic igneous provenance were found in CIROS-1. The source of these grains is likely an unknown igneous body located under the ice (perhaps a component of the EAS) which may be similar to the $\sim 830 \mathrm{Ma}$ igneous source identified for the zircon in the Byrd Group by Goodge et al. (2002). It is not possible to determine if these zircons were directly eroded from their source unit or from the Beacon Supergroup.

Zircons with ages $900-1200 \mathrm{Ma}$ form a distinct peak on the age probability diagram (Fig. 6.5). Zircons of this age are very common in sediments of the region (e.g. Goodge et al., 2008; Palmer, 2008; Licht et al., 2005), however no known units of this age outcrop in the Ross Sea sector. Thus a likely source for these grains are units that formed during the Grenville Orogeny and are located under the ice and/or the current baseline of geologic exposure in the TAM. Direct erosion of these units may have resulted in the deposition of Grenvillian-aged zircons or they may have been sourced from the erosion of sedimentary units such as the Beacon Supergroup, that contain zircons of this age. The presence of a Grenvillian-aged metamorphic grain in the CIROS-1 core indicates both igneous and metamorphic units of this age are located under the ice and either directly or indirectly contributed sediment to the core.

The zircons of the 1400-1600 Ma age population appear to be wholly of an igneous origin. Sources for these zircons are most likely the cratonic components of the EAC located under the ice. One such unit may be the $\sim 1.4 \mathrm{Ga}$ granitic unit identified by Goodge et al. (2008) (Fig. 2.6). It is not possible to constrain whether sediments from these units were directly eroded from the EAC or if they were sourced from sedimentary units containing cratonic components, such as the Taylor Group (Fig. 6.17).

Zircons older than $\sim 1.6 \mathrm{Ga}$ are common in many sediments around the Ross Sea region (e.g. Palmer, 2009; Savage, 2005). It is likely such zircons are sourced from unknown igneous and to a lesser degree, metamorphic components of the EAC. It is not possible to constrain if they were directly eroded from these units or source from recycled units more proximal to the CIROS-1 site. 


\subsection{2.i. Summary of CIROS-1 detrital zircon provenance}

Zircons found in CIROS-1 were likely sourced from:

(1) The regional basement, which includes the Skelton Group and the Skelton Metamorphic and Granite Harbour Intrusive units;

(2) The Beacon Supergroup (Victoria and Taylor Groups); and

(3) Direct erosion of unknown units located under the EAIS in the EAC and below the current levels of geologic exposure in the TAM.

George (1989) used sand mineralogy to constrain CIROS-1 sand provenance and found that sands in the core were sourced from four units: (1) The regional basement (including the Skelton and Granite Harbour Groups); (2). The MVG; (3) The Ferrar Dolerite; and (4) The Beacon Supergroup. The dominant sediment sources were found to be the basement units and the Beacon Supergroup and their relative contributions were estimated to be 3:1 (George, 1989; Roser and Pyne, 1989). The results of this research agrees with this previous work as the Beacon Supergroup and basement units were both identified to be major contributors for sediment provenance in each study.

The fact that zircons sourced from the MVG were not detected in this research indicates it is not a zircon producing lithology. The Ferrar Dolerite is known to produce zircons with ages $\sim 183.6 \pm 1.8 \mathrm{Ma}$ (Encarnación et al., 1996). Zircons of this age were not observed in this study. It is challenging to speculate why zircons sourced from the Ferrar units were not observed in this research whilst it does appear the Ferrar is a contributor of CIROS-1 sands (George, 1989, Roser and Pyne, 1989). A cause may be that the Ferrar Dolerite does not contain many zircons, which seems likely given the general zirconium-undersaturated nature of many mafic rocks (Hoskin and Schaltegger, 2003).

When assessing CIROS-1 sand provenance, George (1989) and Roser and Pyne (1989), did not attribute any CIROS-1 sedimentation to direct erosion of the EAC. It may be impossible to constrain whether the $>650 \mathrm{Ma}$ zircons found in this study were sourced directly by erosion of the EAC or recycled through erosion of the sedimentary lithologies such as the Beacon Supergroup. 


\subsubsection{Temporal trends in zircon characteristics}

Temporal trends in zircon characteristic observed in CIROS-1 include:

(1) A bell shaped old-young-old trend in the maximum and average ages of the 450-

650 Ma population down core (Fig. 6.4);

(2) A bell shape curve that defines the percentage (of total zircon number) of 450-

$650 \mathrm{Ma}$ aged zircons (Fig. 6.2); and

(3) A bell shaped increasing trend of zircon number towards the midsection of the core followed by a progressive decrease in zircon numbers to the top of the drill core (Fig. 6.2).

The bell shaped curve in the maximum, and to a lesser degree average, ages of the 'Ross' aged zircons shows that from near the base of the core to $\sim 250 \mathrm{mbsf}$, the oldest 'Ross' aged units being eroded increase in age from $\sim 525 \mathrm{Ma}$ to $\sim 660 \mathrm{Ma}$. Above $\sim 250$ mbsf the age of the oldest 'Ross' aged zircon in each sample decreases from $\sim 660 \mathrm{Ma}$ to $\sim 550 \mathrm{Ma}$ (Fig. 6.4).

At the base of the core, 'Ross' aged zircons comprise $\sim 70 \%$ of the total zircons per sample. This decreases to $\sim 30 \%$ at $\sim 250 \mathrm{mbsf}$ and increases again to the top of the core, where 'Ross' aged zircons consist of $\sim 90 \%$ of total (Fig. 6.2). Figure 6.18 shows the same zircon trends in Figure 6.2, but plotted against sediment depositional age (between 40 and $20 \mathrm{Ma}$ ). Data gaps represent times of erosion and or nondeposition due to short-duration glacial processes and/or longer duration tectonic processes (see Fig. 3.9). The CIROS-1 core can be subdivided into three time zones/groups of strata representing quite different climatic regimes. In ascending stratigraphic order these zones are:

Zone 1: this is the red band on Figure 6.18 and 6.19 and consists of strata between $\sim 700$ and 366 mbsf, of late Late Eocene (37-34 Ma) age (Fig. 3.9; the sub-366 mbsf red-line chronology was used for this discussion). These units represent fluvio-deltaic deposition under generally warm temperate (Zachos et al., 2001a) ice free conditions with local alpine-style glaciers in the Trans-Antarctic Mountains. As discussed in Chapter 3, any or all of the $\sim 9$ Ma time interval missing in the CIROS-1 core may be distributed at the $342 \mathrm{mbsf}$ unconformity, in additional to the unconformity located at 366 mbsf. However, for the purposes of the discussion in this thesis, the $366 \mathrm{mbsf}$ datum has captured the 9 Ma unconformity. 
Zone 2: Strata from 366 to 250 mbsf that were deposited during the Late Oligocene $(\sim 25$ to $23.5 \mathrm{Ma}$ ) (green zone in Figs. 6.18 and 6.19). They are grounding line proximal glaciomarine sediments produced during cooler, sub-polar climate conditions. During this interval, an ephemeral EAIS regularly expanded onto the Ross Sea continental shelf (CIROS-1 drill site) via outlet glaciers through the TAM (including the Ferrar Fiord) during orbital-scale glaciations.

Zone 3: Comprises strata between $\sim 250-20$ mbsf deposited between $\sim 23.5$ to $22 \mathrm{Ma}$ (Fig. 3.9 and blue zone on Figs. 6.18 and 6.19). These sediments represent regular oscillations in the grounding line of the Ferrar Glacier (interbedded diamictites and glaciomarine sands and muds) during progressively cooler climate conditions as the ice sheet progressively expanded during the cooling that culminated with the Mi-1 glaciation at $\sim 23 \mathrm{Ma}$ (Zachos et al., 2001a). A 600 kyr-long major erosional hiatus from 23.2 $\mathrm{Ma}$ is recorded in both CRP-2/2A and CIROS-1 (see Fig 3.9) and corresponds to widespread ice sheet expansion in western Ross Sea during the Mi-1 glaciation (Pekar et al., 2006; Naish et al., 2001a).

'Ross' aged zircon characteristics vs. depositional age

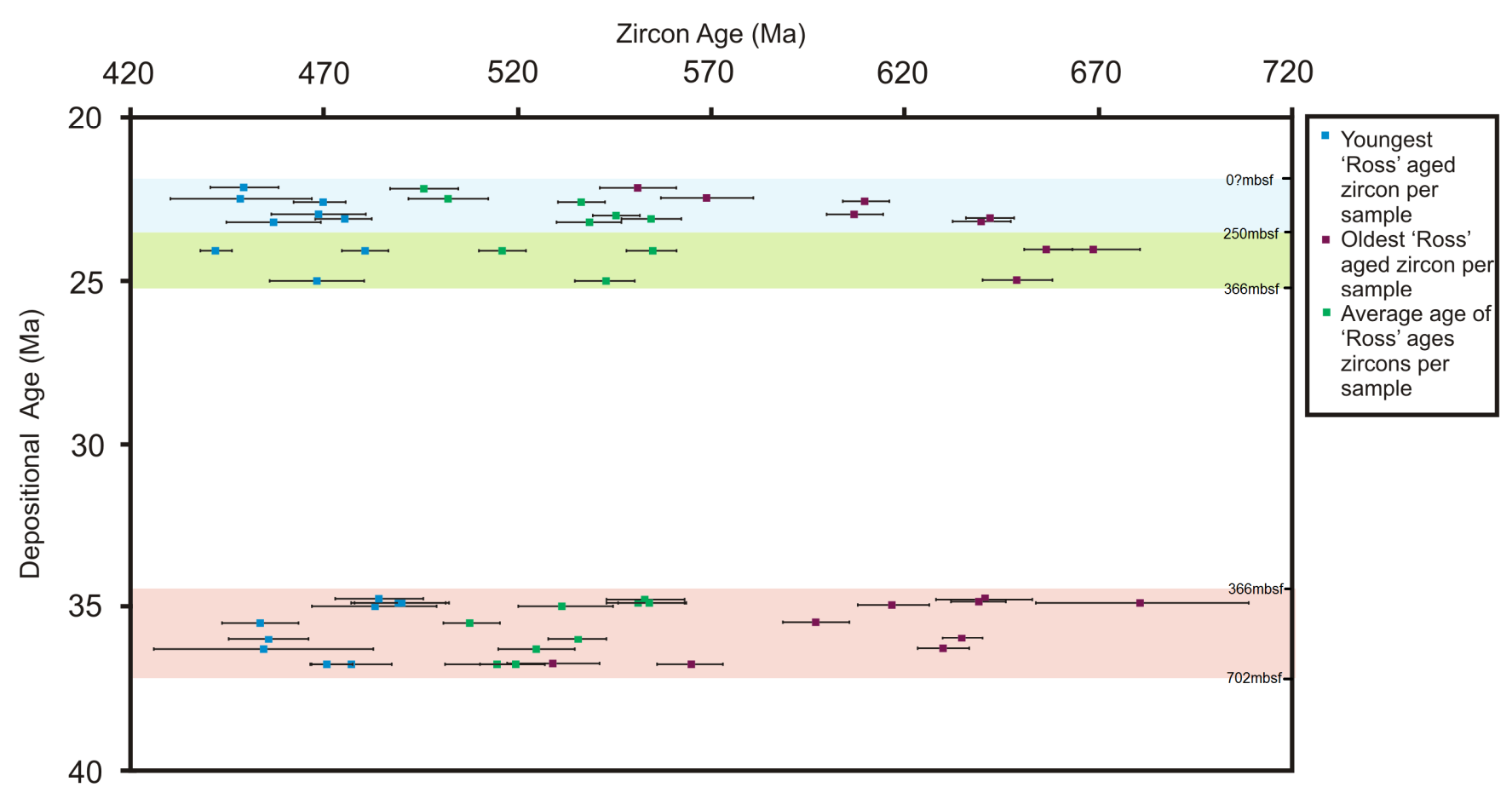

Figure 6.18: Average, minimum and maximum ages of zircons in the 'Ross' age population plotted against sample depositional age. The three zones discussed in the text are indicated by the coloured bands (red is Zone 1, green is Zone 2 and blue is Zone 3). The top and bottom depths of these zones are given. Note the trends of increasing maximum and average ages with decreasing depositional age in Zone 1 and the decreasing average and maximum ages observed up core in Zone 3. Zircons derived from Zone 2 show no distinct trends. 
Percentage 'Ross' aged zircon vs. depositional age

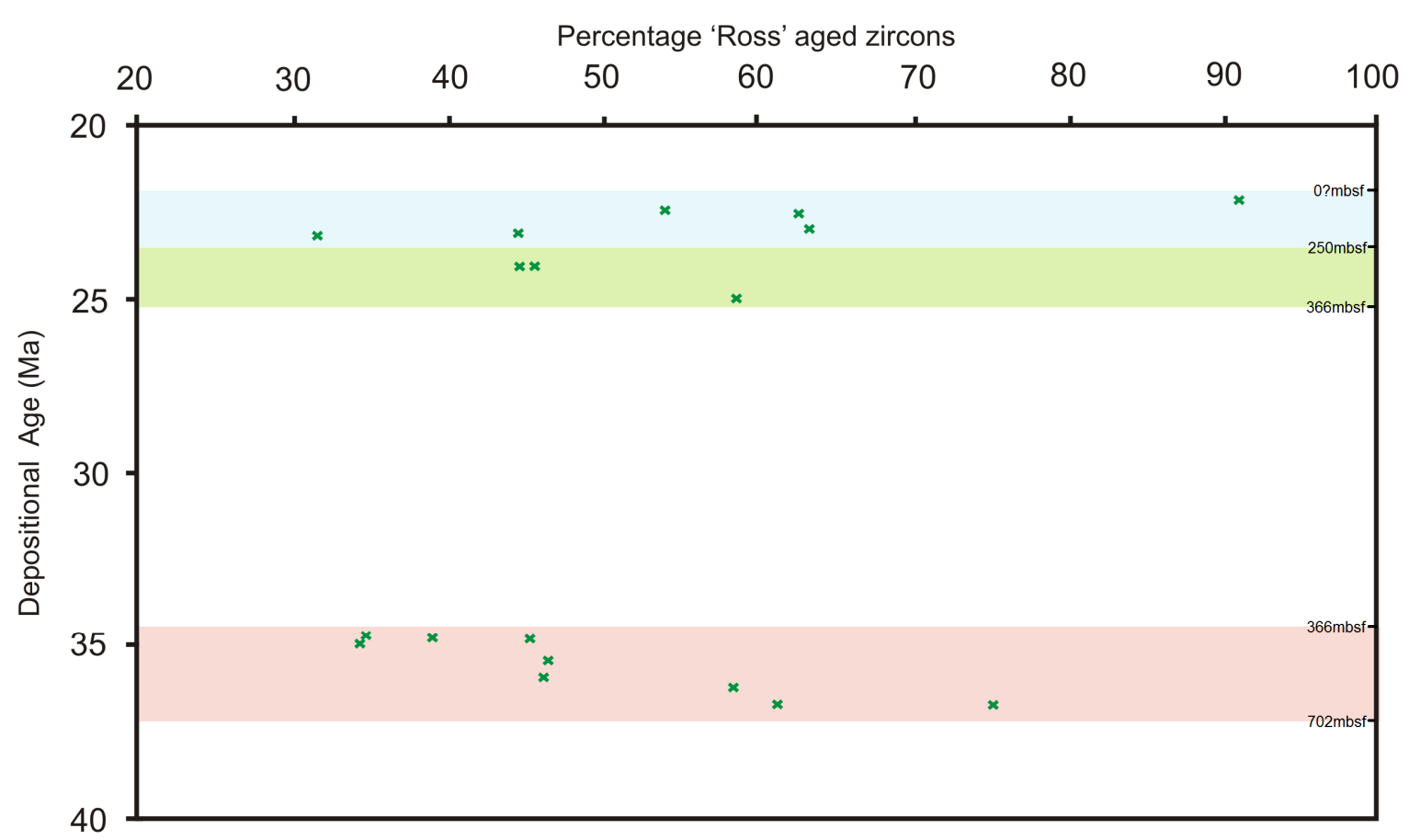

Figure 6.19: Percentage (of total) 'Ross' aged zircons present in each sample. The three zones noted in the text are indicated by the red (Zone 1), green (Zone 2) and blue (Zone 3) bands. The top and bottom depths of these zones are given. There is a correlation between decreasing depositional age and decreasing amounts of 'Ross' aged zircons in Zone 1 and the trend of increasing 'Ross' aged zircons with decreasing depositional age present in Zone 3. Zircons derived from Zone 2 show no distinct trend.

The Granite Harbour Intrusives in SVL were intruded in two stages: between 589$490 \mathrm{Ma}$ (syntectonic) and 486-477 Ma (post-tectonic) (Allibone et al., 1993a; Cox et al., 2000). The older batholiths were emplaced synchronously with the Skelton Group in response to subduction of a palaeo-Pacifc cratonic margin. The younger granodiorite and granite plutons were emplaced at higher crustal levels. They formed in response to uplift and extension (Allibone et al., 1993a). All Granite Harbour plutons are known to contain high numbers of zircons. In Ferrar Fiord the oldest identified Granite Harbour pluton is the Bonney Pluton which is $\sim 100 \mathrm{~km}$ long, 25 $\mathrm{km}$ wide and $\sim 590 \mathrm{Ma}$ old (Figs. 6.20 and 6.21). The smaller Catspaw Pluton, which at $\sim 490-590 \mathrm{Ma}$ is slightly younger than the Bonney, also outcrops in the Ferrar Fiord. These two plutons both belong to the lower-level, syntectonic group of plutons (Allibone et al., 1993a). Post-tectonic plutons in the Fiord include the Hedley, Rhone, Pearse and Mt. Falconer plutons which are 490 Ma old (Smillie, 1992; Allibone et al., 1993a) (Figs. 6.20 and 6.21). The oldest identified igneous units in the Ferrar Fiord are orthogneiss units which occur below and around the Granite Harbour plutons and are > $590 \mathrm{Ma}$ in age (Fig. 6.20; Allibone et al., 1993a). 
It does not appear that the spatial chemical zonation within Ross Harbour granitoids has been investigated in detail. However, research into chemical zonation within granitic plutons shows that 'compositional zoning of granitic plutons is a common feature' (Hecht et al., 1997; Arniaud et al., 1984). This chemical zonation may be complex and involve younging of crystals both towards and away from the centre of the pluton. Thus erosion of granitic plutons may cause the exposure of zircons with systematically changing ages.

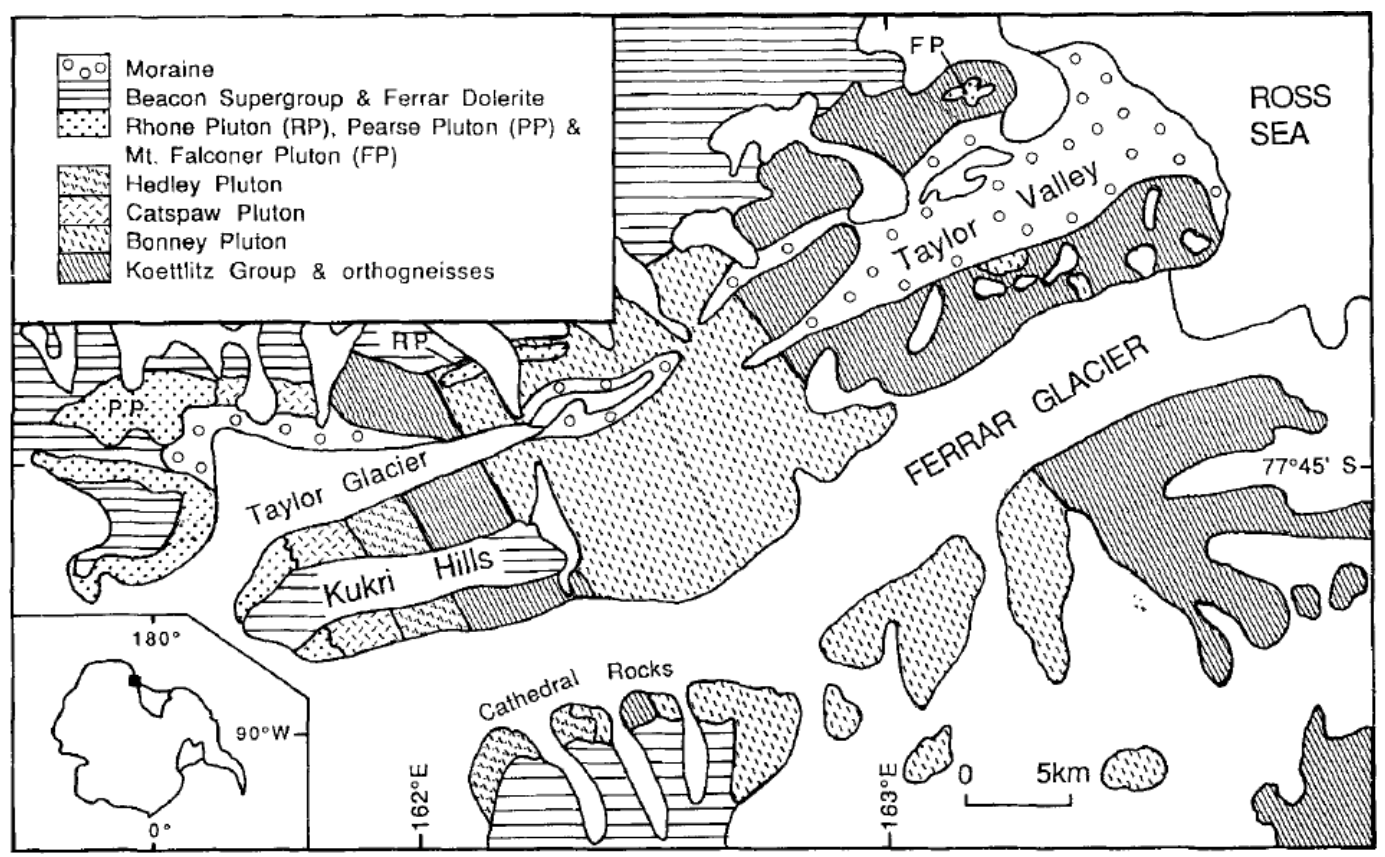

Figure 6.20: The geology of the Ferrar Fiord and Taylor Glacier region showing Granite Harbour plutons, regional basement and recent sediments (source: Smillie, 1992).

\begin{tabular}{|c|c|c|}
\hline - Isoclinal folding $\quad \frac{\text { upright folding about }}{\text { NNW trending axes }}$ & \multicolumn{2}{|c|}{ KOETTLITZ GROUP } \\
\hline hornblende-biotite & \multicolumn{2}{|c|}{$\begin{array}{l}\text { DRY VALLEYS 1a } \\
\text { (DV1a) SUITE }\end{array}$} \\
\hline 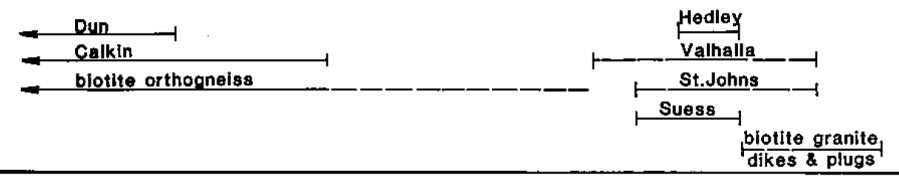 & \multicolumn{2}{|c|}{$\begin{array}{l}\text { DRY VALLEYS 1b } \\
\text { (DV1b) SUITE }\end{array}$} \\
\hline \multicolumn{3}{|l|}{ VANDA MAFIC DIKES } \\
\hline . & Orestes & Brownworth \\
\hline STRONG DRY VALLEYS 2 CHARACTER & 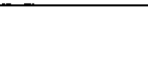 & Swinford, \\
\hline $\begin{array}{l}\text { DRY VALLEYS } 2 \\
\text { (DV2) SUITE }\end{array}$ & qutz monzonite & $\underset{\text { Nibelungen }}{\stackrel{\text { Perse }}{\longmapsto}}$ \\
\hline 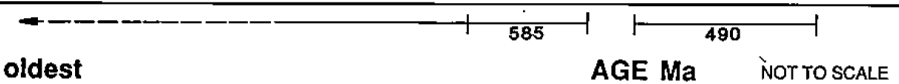 & $\vdash 486-1$ & 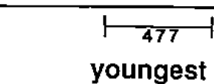 \\
\hline
\end{tabular}

Figure 6.21: Timescale of Granite Harbour intrusive emplacement and formation and deformation of the basement (incl. Skelton Group) (source: Allibone et al., 1993a). 
For ease of discussion the temporal distribution in zircon number and the characteristics of 450-650 Ma 'Ross' age peaks can be divided into two sections: below $250 \mathrm{mbsf}$ (Zones 1 and 2), and above $250 \mathrm{mbsf}$ (Zone 3).

\subsection{3.i. Sub-250 mbsf section (Zones 1 and 2)}

Original work on the provenance of sands in CIROS-1 found that a simple unroofing history of the TAM was not recorded in CIROS-1 (George, 1989; Roser and Pyne, 1989). The dominant provenance for sands was found to be the Granite Harbour Intrusive units which and sediments sources from these were intermixed with irregular influxes of Beacon Supergroup derived sands (George, 1989; Roser and Pyne, 1989). This study uses different techniques, which are able to detect more subtle changes in sediment provenance than the techniques available for previous work. In the zircon data presented in this thesis a degree of subtle unroofing may be recorded between $\sim 366-700$ mbsf. Sediments in this interval were deposited during the Late Eocene (Zone 1) (Figs. 6.18 and 6.19). Late Eocene erosion was primarily influenced by localised temperate alpine-style glaciation and fluvial outwash systems. The dominant ice flow direction was from the west, through the Ferrar Fiord (Fig. 22D). Thus we infer that in Zone 1, a gradual unroofing of the highly heterogeneous and differentiated units of the Granite Harbour and Skelton Groups in the Ferrar Fiord is recorded.

For the entire deposition of Zone 1 strata, the upper-level, post-tectonic Granite Harbour units (such as the Hedley Pluton) were being eroded, as evidenced by the continual presence of $\sim 470 \mathrm{Ma}$ zircons in the youngest age of the Ross population (Fig. 6.18). The age of the oldest 'Ross' aged zircons shows that first the oldest zircons in this population were sourced from the older, syntectonic Ross Granitoids (Bonney and/or Catspaw Plutons). At $\sim 36 \mathrm{Ma}$ (depositional age in CIROS-1) the oldest 'Ross' aged zircons become older than the ages of the Granite Harbour Plutons in the Fiord (Figs. 6.18 and 6.21). Thus, at this stage, the older orthogneisses located in the Ferrar Fiord were eroded (Figs. 6.20 and 6.21). It is not possible to constrain whether this change is due to the exposure of the older orthogneisses due to down cutting though Granite Harbour units, or if changes in ice dynamics caused erosion of pre-exposed but previously uneroded basement orthogneisses. 
The termination of the unroofing history recorded in Zone 1 strata occurs at $\sim 366 \mathrm{mbsf}$ - the level of the unconformity that spans $\sim 9 \mathrm{Myr}$ at the EoceneOligocene boundary (Figs. 6.18 and 3.9). Though it is not possible to confirm with any certainty, the gradual but marked increases in the average and maximum ages of the zircons from the 'Ross' age population may be due to the erosion of chemically and temporally zoned granitic and orthogneiss units, a concept which requires further investigation.

Strata deposited in Zone 2 were eroded in a dynamic yet regionally-extensive glacial regime where ice sheets reached continental scale during glacial periods but may have retreated to $50 \%$ of their present day size during interglacials. This style of glaciation was variably sub-polar to temperate and would have caused significant localised valley erosion in the TAM which were being uplifted isostatically as glaciers incised (Stern et al., 2005). Thus, it is inferred that during deposition of Zone 2 strata, the main direction of ice flow was from the west through the TAM/Ferrar Fiord (Fig. 6.22C). This interval (Zone 2 ) corresponds to a $\sim 40-60 \%$ proportion and relatively high age range for 'Ross' aged zircons (Figs. 6.19 and 6.20) and a high total amount of zircons per sample (Fig. 6.2), and may reflect the quite localised spatially-restricted erosion in steeply incised valley glaciers systems.

\subsection{3.ii. Above 250 mbsf (Zone 3)}

At approximately $250 \mathrm{mbsf}$ in the core the trends in total zircon number and 450-650 Ma population change. The age of the oldest 450-650 Ma zircon in each age population starts decreasing (Fig. 6.19) and the percentage of 450$650 \mathrm{Ma}$ zircons starts to increase (Fig. 6.20). As the age of the youngest zircon in the 450-650 Ma population remains more or less steady (Fig. 6.19), it appears that post-tectonic Ross granitoids were eroded during this entire interval. However, the decrease in the maximum (and average) ages for the 450-650 Ma population (from $\sim 660$ to $550 \mathrm{Ma}$ ) and increase in the percentage of 'Ross' aged zircons suggests that erosional, transportational and depositional dynamics changed. 


\section{Paleoglaciological Reconstruction for McMurdo Sound \\ Present day- LGM \\ Mi-1 Glaciation- 23Ma- Zone 3}
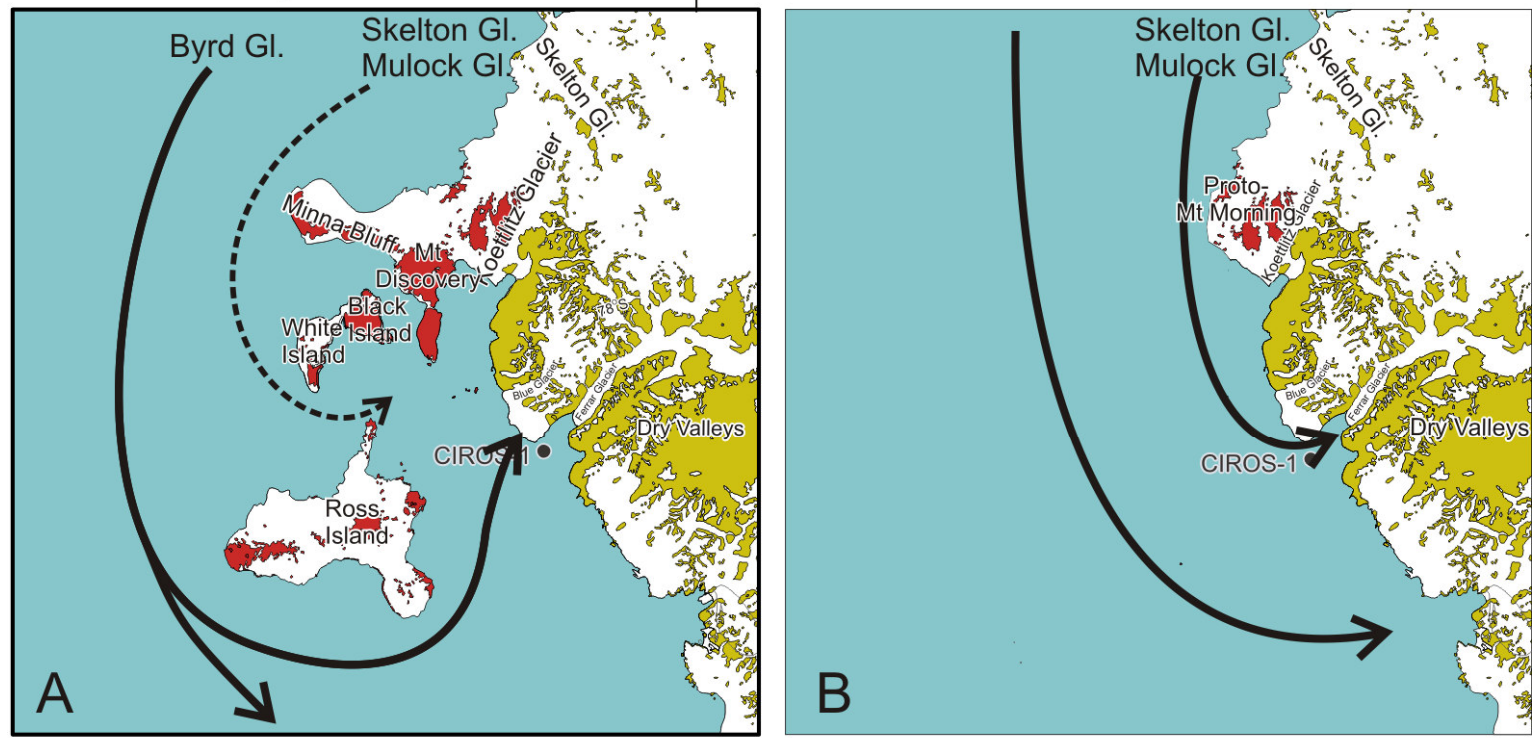

25-23.5 Ma- Zone 2

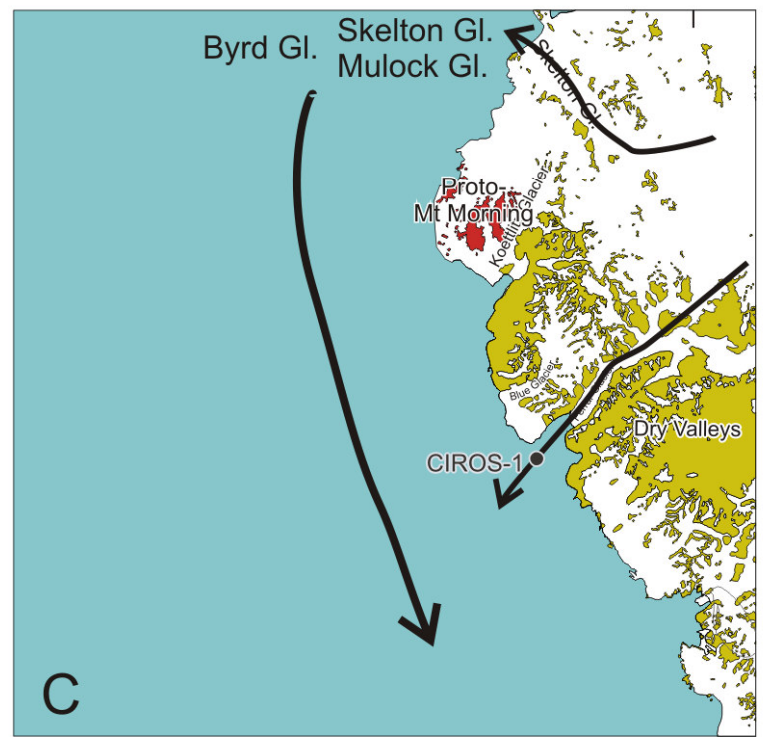

235-37 Ma- Zone 1

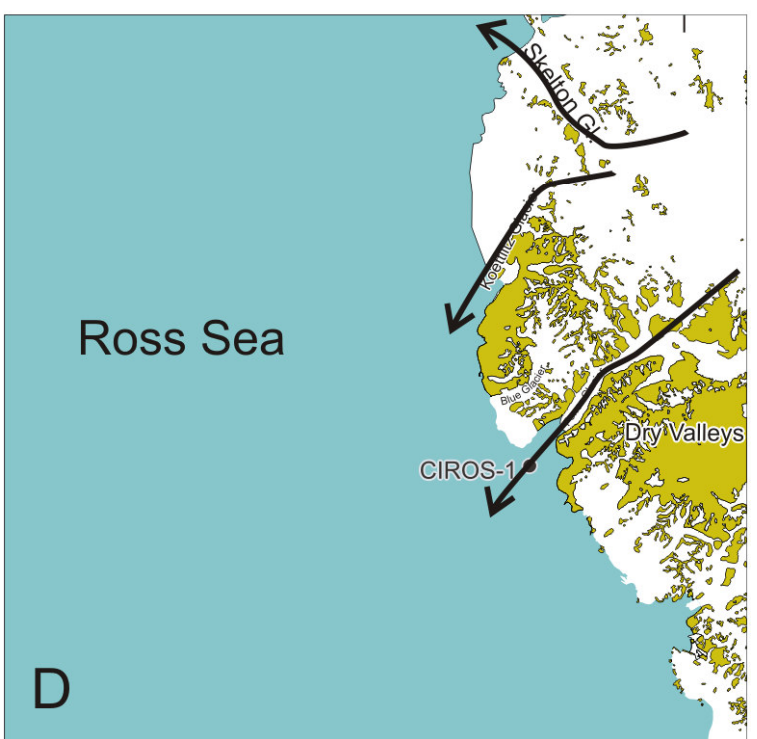

Figure 6.22: Ice flow lines for the western Ross Sea from $\sim 34$ Ma to present, partially reconstructed based clast lithologies in tills from the ANDRILL drill cores. The general climatic trend between $\sim 34 \mathrm{Ma}$ to present is one of cooling (Barrett, 2007). Between 37- 34 Ma (Fig. D), the WAIS was reduced or absent and ice flux from southern TAM outlet glaciers was reduced. The dominant ice flow direction to the CIROS-1 site would have been westwards through the Ferrar Fiord into the Ross Sea. It must be noted that during the Late Eocene the ice extent onland was considerably less than that is depicted in Fig. D. At $\sim 25-23.5 \mathrm{Ma}$ (Fig. C) the increased size of the EAIS meant that ice flowed from the south but the dominant ice flow direction to the CIROS-1 site was from the west, through the Ferrar Fiord. As the climate cooled, the flow of grounded ice in western Ross Embayment became from the south due to the confining influence of a large WAIS and increased flux from southern TAM outlet glaciers. Thus during this period the ice flow to the CIROS-1 site was from the south, was most probably from the Skelton and Mulock Glaciers (Fig. B), which is fairly similar to LGM configurations (Fig A) (modified from: McKay, 2008).

One possible interpretation is that the old orthogneisses in the Ferrar Fiord ceased contributing sediments and syntectonic aged batholiths became the oldest units contributing to the 450-650 Ma population. The uppermost sample analysed (28 mbsf) shows a marked dominance of 450-650 Ma aged zircons (Fig. 6.3), indicating that when CIROS-1 sedimentation ceased, a 
single (most probably syntectonic) Ross-aged granitoid was supplying the majority of zircons to the core.

In Zone 3, sediments between $\sim 100-250$ mbsf were deposited during the Latest Oligocene $(\sim 23.9-23 \mathrm{Ma})$ and sediments above $\sim 100 \mathrm{mbsf}$ were deposited in the Earliest Miocene. This stratigraphic interval spans a climatic cooling and ice sheet expansion leading into and spanning the Mi-1 glaciation (see Chapter 3 discussion and Fig. 3.9). The Mi-1 glaciation represents the largest ice volume on Antarctica since the initial glaciation (Oi-1) at the Eocene-Oligocene boundary. The ice volume of the EAIS may have been up to $\sim 120 \%$ of present (Naish et al., 2001; Pekar et al., 2006) causing the ice sheet to ground well out onto the Ross Sea continental shelf. Moreover, an ice sheet is inferred to have developed on West Antarctica (WAIS). This had major implications for regional glacial flow dynamics (Fig. 22 B).

Reconstructions for ice flow in western Ross Sea during the LGM provides a good analogue for the Mi-1 glaciation, and shows that the combined volume of WAIS and EAIS ice flow into Ross Sea results in grounded ice, sourced from the southern TAM outlet glaciers (e.g. the Mulock and Skelton glaciers), flowed south and west into McMurdo Sound (e.g. McKay, 2008; Licht et al., 2005) (Figs. 6.22A and B). Moreover, Naish et al. (2009) showed that such a glacial ice flow configuration has happened during numerous glacial periods over the last $14 \mathrm{Ma}$ when the WAIS has been fully expanded confining the increased discharge of EAIS glaciers into western Ross Sea. Figure 6.22 shows a schematic paleo-glaciological evolution for the last $34 \mathrm{Ma}$. It is proposed here that the Mi-1 glaciation at $23 \mathrm{Ma}$ would have had a glacial configuration similar to the LGM (Fig. 6.22B and A, respectively) and that during the latest Oligocene and earliest Miocene ice flow to the CIROS-1 site changed from west ward to the south. Thus, in this interval, zircons may have been sourced in tills from the Skelton and Mulock Glaciers rather than directly from the Ferrar Glacier catchment.

The Mt. Morning Volcanic Complex commenced eruption to the south of the CIROS-1 site around > 18.7 Ma (Martin, 2009). When conducting whole rock geochemical analysis of CIROS-1, Roser and Pyne (1989) noted an influx of MVG-type material above $\sim 250$ mbsf. As Mt. Morning is the 
earliest known MVG volcano, Roser and Pyne (1989) indicated the observed influx may have been sourced from this volcano. The influx seen occurs at 23.5 Ma, which is older than the oldest known outcrop of Mt Morning, suggesting that either Mt. Morning formed earlier than is currently known from radiometric dating of lavas, or that there was older now eroded volcano in a similar location. This line of evidence is supported by the occurrence of two pumiceous phonolitic tephra between 24 and $22 \mathrm{Ma}$ in the CRP-2/2A core (Naish et al., 2001b; Wilson et al., 2002).

The change in zircon characteristics and the influx of MGV-type material noted by Roser and Pyne (1989) that occurs above 250 mbsf may have been caused by cooling and ice sheet expansion associated with the Mi-1 glaciation. This caused a change in ice flow to the CIROS-1 site, due to the increased amount of ice entering western Ross embayment from WAIS and southern TAM outlet glaciers (Talarico et al., 2009; McKay, 2008). This means that rather than a localised source from the west for sediments (as seen beneath $\sim 250 \mathrm{mbsf}$ ), the source for sediments above $\sim 250$ mbsf may have come from the south, from the Skelton and Mulock Glaciers (Fig. 6.22B) which flow though fiords that contain Skelton and Granite Harbour units (Cottle and Cooper, 2006; Cook and Craw, 2002). This would have resulted in the coincident influx of MVG/Mt. Morning material noted by Roser and Pyne (1989) which was brought from the Mt. Morning site to the north by the ice. 


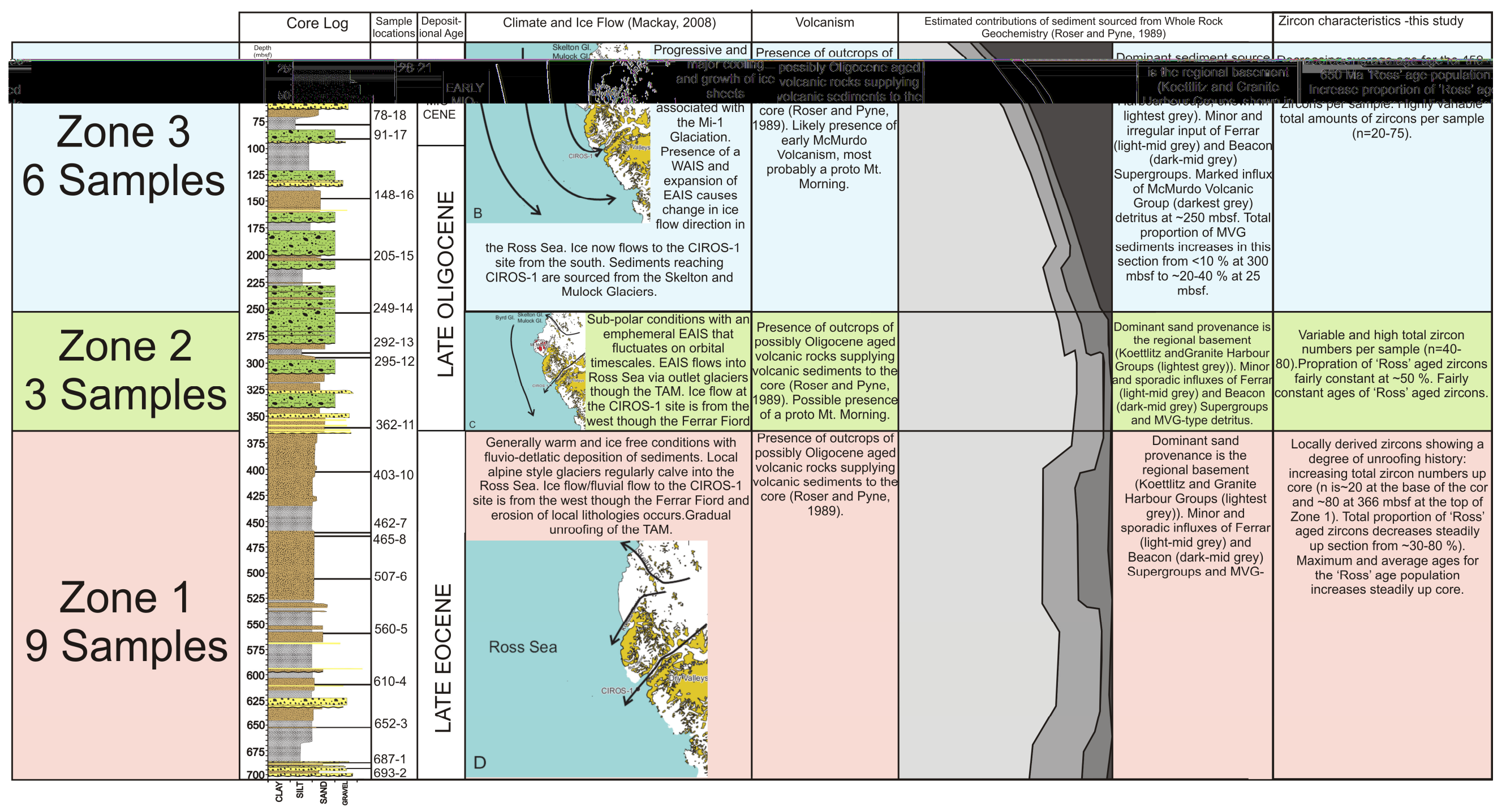

Figure 6.23: Summary of the conditions present above and below $\sim 250 \mathrm{mbsf}$ in the CIROS-1 core. This includes the relative climate and subsequent possible ice flow pathways (after McKay et al., 2008) and the timing/characteristics of volcanism. The zircon characteristics obtained for this research and the whole rock geochemical characteristics obtained by Roser and Pyne (1989) are outlined. Age model and sedimentology from Chapter 3 . 


\subsection{Conclusions}

LA-ICP-MS U-Pb and trace element studies of zircons in the CIROS-1 drill core have provided three key insights into the record of Antarctic tectonism and climate contained in the core:

(1) The cumulative age probability diagram of zircons in the CIROS-1 core reflects the orogenic episodes known to have occurred in the EAC. The relatively young ages for 'Grenvillian' aged zircons suggests that this orogeny occurred later in this sector or, alternatively, that these zircons were formed by a distinct event partially coeval with the Grenville Orogeny.

(2) The majority of ages and geochemical characteristics of zircons observed in the CIROS-1 drill core can be explained by a variable input of the basement (Skelton and Granite Harbour Groups), Beacon Supergroup (Taylor and Victoria Groups), and potentially the units located under the EAIS or current baseline of geologic exposure. More specifically, units that contributed zircons to the CIROS-1 drill core include granitic batholiths that formed post- and syn-tectonic to the Ross Orogeny (Granite Harbour Group), the metamorphic Skelton Group, the Victoria and Taylor Groups of the Beacon Supergroup and potentially currently unexposed EAC/TAM units. The latter may include early Pan-African units, a $\sim 830 \mathrm{Ma}$ igneous unit, $\sim 1.0$ 1.3 Ga Grenvillian units, 1.4-1.6 Ga aged unknown cratonic components.

(3) Zircon characteristics, particularly within the 450-650 Ma age group, show systematic temporal variations throughout the core. Combined with knowledge from previous whole rock geochemistry and sand provenance work, these trends indicate a major shift in erosional, depositional and transportational mechanisms at $\sim 250 \mathrm{mbsf}$ $(\sim 23.5 \mathrm{Ma})$. This shift is reflected by progressive changes in zircon numbers and ages up core and by an influx of volcanogenic (possible early MVG-related) sediments at $\sim 250$ mbsf.

The sub-250 mbsf section of the core was deposited during the Late Eocene (Zone 1, 37-34 Ma). During this relatively warm period, alpine-style glaciers flowed westward though the TAM and sediments were deposited at CIROS-1 via fluviomarine systems fed by land terminating glaciers in Ferrar Fiord. It is proposed that the sub-250 mbsf section of core contains a subtle unroofing history of the units in the Ferrar Fiord, with increasing ages of the 450-650 Ma 'Ross' population up core. 
This likely reflects an analytical advantage over the earlier studies of George (1989) and Roser and Pyne (1989), which were unable to distinguish a consistent temporal trend recorded in these sediments.

Above $\sim 250$ mbsf two distinct climatic periods are recorded (Zones 2 and 3). During the deposition of Zone $2(\sim 25-23.5 \mathrm{Ma})$ ice flow to the CIROS-1 site was from the west and CIROS-1 sediments were sourced from the Ferrar Fiord. The EAIS was ephemeral and oscillating on orbital timescales, and outlet glaciers were wet based and highly erosive. In this zone the proportion of 'Ross' aged zircons is highly variable and the total zircon number high.

The strata of Zone 3 were deposited between $\sim 23.2-22 \mathrm{Ma}$, when the climate was rapidly cooling toward the Mi-1 glaciation, the ice volume of EAIS was increasing and the WAIS was establishing. During this period 'Ross' population ages decrease systematically up core and the proportion of 'Ross' aged grains increases significantly. Marked changes in CIROS-1 sediment provenance above $250 \mathrm{mbsf}$ were also noted by Roser and Pyne (1989), who reported a large increase of MVGtype material in the core from $\sim 250$ mbsf upwards. Additionally, MVG-type tephras were found at 24 and $22 \mathrm{Ma}$ in CRP 2/2A (Naish et al., 2001; Wilson et al., 2002). These changes in sand and zircon provenance at $\sim 23.5 \mathrm{Ma}$ are proposed to result from a shift in ice flow direction from west to south, as a response to ice growth of the EAIS and WAIS in the lead up to the Mi-1 glaciation (McKay, 2008; Talarico et al., 2009). 


\section{Chapter 7: Synthesis and suggestions for future work}

\subsection{Synthesis}

The marine oxygen isotope record (e.g. Zachos et al., 2001a), provides a picture of the stepwise global cooling of the Cenozoic which has occurred since the climatic optimum in the Eocene. Antarctic margin sediment drill cores contain compelling proxy evidence for Antarctic climate during the Cenozoic and allow evaluation of Antarctica's response to global cooling events recorded in the global benthic oxygen isotope record. Drilled in 1986, the CIROS-1 drill core contains sediments deposited by Trans-Antarctic Mountain outlet glaciers (e.g. Ferrar, Mulock and Skelton glaciers) draining the EAIS during the Late Eocene-Early Miocene. Sediment deposition occurred during key global cooling climatic events associated with stepwise development of the Antarctic Ice Sheets between 20-40 Ma (including the EoceneOligocene boundary and the Mi-1 glaciation). Since the CIROS-1 core was recovered, new and advanced techniques for drill core and sediment analysis have been developed.

The primary aim of this thesis is to re-evaluate the record of Cenozoic Antarctic history contained in CIROS-1 using cutting-edge analytical techniques. New techniques utilised are based on revisions of sequence stratigraphic models (e.g. Dunbar et al., 2008) and facies schemes (e.g. Fielding et al., 2001) for sediments deposited on a glaciated continental margin. In Addition, new and re-evaluated chronological constraints on Antarctic sediment deposition (e.g. Naish et al., 2008b; Scherer et al., 2000) are used. CIROS-1 sediment provenance and broad scale temporal variances therein is investigated using advanced methods for geochemical analysis and detrital zircon dating (e.g. Veevers et al., 2008; DeGraaf-Surpless et al., 2003), not yet developed when the core was originally analysed.

In summary, two main research objectives of this thesis are to: (1) Re-evaluate CIROS-1 sedimentology, lithofacies, sequence stratigraphy and chronology using methods developed for the Cape Roberts and ANDRILL cores (e.g. Fielding et al., 1997; Fielding et al., 2001; Dunbar et al., 2008; Naish et al., 2008a); and (2) Re-assess the provenance of CIROS-1 sands and any temporal variances there-in using in situ LA-ICP-MS analysis techniques. 
Key findings of this investigation include:

(1) CIROS-1 glaciomarine sequence stratigraphy shows that 14 sequences, occurring in two distinctive stratigraphic motifs, are present in CIROS-1 (Figs. 3.6 and 3.7). Four sequences, located beneath the 342 mbsf unconformity, are relatively complete in terms of systems tracts. They were deposited in shallow marine, fluvio-deltaic conditions with distal glaciers terminating on land and possibly calving into the ocean in adjacent valley glacier systems, as evidenced by occasional ice-rafted debris. Nine sequences are located above $\sim 342$ mbsf and have a fundamentally different architecture. They are incomplete (top-truncated), contain diamicts and were deposited under proximal glaciomarine conditions. Top truncation of these sequences represents overriding of the CIROS-1 site by the paleo-Ferrar Glacier during glacial phases (which occurred at least nine times during the Late OligoceneEarly Miocene).

(2) The new CIROS-1 chronology, developed using recently published improvements in the Geomagnetic Polarity Timescale (Gradstein et al., 2004), recent calibrations for Antarctic diatom zones (Naish et al, 2008a; Wilson et al., 2002) and the compilation of previous work (Roberts et al., 2003; Wilson et al., 1998; Hannah et al., 1997), shows CIROS-1 sediments were deposited $\sim 37-22 \mathrm{Ma}$, between the Late Eocene-Early Miocene (Fig. 3.9). Sediments between 702-366/342 mbsf were deposited during the Late Eocene. The new age model provides equivocal ages to sediments between 366-342 mbsf, which may be between 31 to $22 \mathrm{Ma}$ in age. Strata located between this depth interval and $\sim 100$ mbsf were deposited during the Latest Oligocene and those above $\sim 100$ mbsf are Early Miocene in age. Sediments above $\sim 250$ mbsf were deposited in an increasingly cool climate that culminated in the Mi1 glaciation at Oligocene-Miocene boundary ( $\sim 100 \mathrm{mbsf})$. In this new chronology, the $9 \mathrm{Myr}$ hiatus historically thought to be exclusively located at an unconformity at 366 mbsf (e.g. Harwood et al., 1989; Roberts et al., 2003), may be wholly or partially distributed on this unconformity and another located at $\sim 342$ mbsf.

(3) The new CIROS-1 chronology allows direct comparison of Late Oligocene orbitally-paced sedimentary cycles in CIROS-1 with those in CRP-2/2A, and shows a fundamental orbital control on the dynamics of these EAIS outlet glaciers. Both glacier systems respond in-phase to longer period orbital components (e.g. Eccentricity, $100 \mathrm{kyr}$ and $400 \mathrm{kyr}$ cycles), but differ in their sensitivity to precession (20 kyr). Precession provides a first order influence on the long term intensity of 
summer insolation and thus higher temperature $\left(>0^{\circ} \mathrm{C}\right)$ days when surface ablation can occur. Over a $\sim 125 \mathrm{kyr}$ period (in Chron 6n.3n) the paleo-Ferrar Glacier experienced five oscillations of glacial advance and retreat whilst the paleo-McKay Glacier experienced only one cycle of advance-retreat-readvance (Fig. 3.10). It appears that during the Late Oligocene, the Ferrar catchment responded to $20 \mathrm{kyr}$ precession cycles, whilst the larger MacKay Glacier, which is more directly connected to the EAIS, responded to longer duration eccentricity (125 kyr) forcings. The Ferrar may have behaved more like a mid-latitude (New Zealand and Patagonian) glacier during past "warmer than present" climate. These respond directly to local seasonal insolation modulated by precession over longer timescales. In contrast the paleoMacKay outlet glacier may have displayed a pattern of behaviour more related to the interior East Antarctic Ice Sheet, which is high, large, cold, more inert, and therefore may only have melted in response to thresholds in orbital geometry modulated by the longer-duration components.

(4) CIROS-1 zircons fall within four geochemical groups. Zircons formed in felsic igneous environments dominate the CIROS-1 population, with $89 \%$ percent of zircons analysed showing geochemical characteristics inherent to granitic/rhyolitic zircons (Hoskin and Schaltegger, 2003). Approximately $7 \%$ of CIROS-1 zircons have a highly trace element enriched igneous provenance and were most probably sourced from trace element enriched enclaves in granitic/rhyolitic units or from pegmatites. Approximately $3 \%$ of CIROS-1 zircons have a metamorphic origin and $\sim 1 \%$ formed in trace element depleted igneous environments.

(5) CIROS-1 zircons were sourced from: the local basement (Skelton and Granite Harbour Groups), the Beacon Supergroup and, potentially, lithologies of the East Antarctic Craton or Trans-Antarctic Mountains located under the ice or below the current baseline of geologic exposure.

(6) Large-scale, systematic temporal trends in zircon characteristics are present in CIROS-1. The core can be divided during three distinct climatic periods: Zone 1 (702-366 mbsf, Late Eocene), Zone 2 (366-250 mbsf, Late Oligocene) and Zone 3 $(<250$ mbsf, Late Oligocene and Early Miocene). Zircons deposited during these periods exhibit distinct properties:

Zone 1: Antarctica experienced a relatively warm climate and alpine style glaciers flowed eastwards through the Trans-Antarctic Mountains. Zircons in this zone 
record a subtle unroofing history of the units located in Ferrar Fiord, with the age of the 450-650 Ma age-range populations steadily increasing up core, coupled with a decrease in the abundance of this population. These trends may reflect the unroofing of geochemically zoned Granite Harbour and Skelton units (located in the Ferrar Fiord) by widespread glacial and fluvial erosion.

Zone 2: Glaciers flowing through the Trans-Antarctic Mountains drained the large and ephemeral East Antarctic Ice Sheet which oscillated on orbital time scales. Zircons in this interval show variable properties and high numbers, and were likely deposited as the paleo-Ferrar Glacier deeply incised the Ferrar Fiord. This downcutting caused dynamic topographic response, further localising valley glacier incision.

Zone 3: The Antarctic climate was cooling markedly, culminating in the Mi-1 glaciation at the Oligocene-Miocene boundary ( $23 \mathrm{Ma}$ ) (Zachos et al., 2001a). At the base of Zone 3, previous workers noted a marked influx of McMurdo Volcanic Group-type detritus (Roser and Pyne, 1989; George, 1989), which was potentially sourced from the erosion of a paleo-Mt. Morning volcano, located to the south of the CIROS-1 site. This influx, together with systematic changes in zircon characteristics recorded in this zone (up core increase in the number of 450-650 Ma aged zircons and a coupled decrease of the average age of this population), indicates a change in ice flow to the site. During periods of cold climate, when a West Antarctic Ice Sheet is present (e.g. during the Last Glacial Maximum) ice flow to the CIROS-1 site is from the south from the Skelton and Mulock glaciers (McKay, 2008; Licht et al., 2005). During relatively warmer periods (such as the Late EoceneOligocene), ice flow is from the west through the Trans-Antarctic Mountains (Fig. 6.22). Thus Zone 3 zircons may record a change in ice flow direction to the CIROS1 site from west to south due to climatic cooling.

\subsection{Suggestions for future work}

\section{Analysis of temporal variations in CIROS-1 clasts}

Talarico et al. (2009) petrographically analysed clasts in the ANDRILL-1B core and found that source units for the clasts changed during glacial and interglacial periods. In contrast, CIROS-1 zircons did not show intra-sequence variations in provenance, but do show broader scale shifts. Analysis of CIROS-1 clasts (particularly in the 
upper section of the core) would complement the data presented in this thesis by revealing short-scale variations in sediment source units not resolvable in zirconspecific work.

\section{Investigate chemical zonation in Granite Harbour Intrusive Group batholiths}

Granitic plutons commonly exhibit compositional zones (Hecht et al., 1997). This zonation may be reverse or normal and include temporal variances in the crystallisation times of constituent crystals. Naturally, erosion of these batholiths would create sedimentary deposits with systematically varying chemistries and/or ages following the pattern of unroofing. The spatio-chemical zonation of batholiths in the Trans-Antarctic Mountains has not yet been studied in detail, and would establish a more reliable framework for determining sediment provenance in the region.

\section{Conduct fission track analysis on CIROS-1 zircons}

Fission track dating of zircons, apatites or titanites gives insight into the thermochronological history of the grains, with the potential to clarify exhumation processes and the cooling of metamorphic and igneous rocks (Kŏsler and Sylvester, 2003). Furthermore, dual fission track and U-Pb analysis of zircon can determine both the formation and cooling ages of grains, constraining depositional ages and the orogenic evolution of source terrains (Reiners et al., 2005). The benefits of conducting fission track analysis of the grains analysed for this thesis would be twofold. First, it would allow easier identification of potential sources of detrital zircons. Secondly, it would shed light on the unroofing and thermal history of the TransAntarctic Mountains during the Late Eocene-Early Miocene.

\section{Conduct zircon analysis on temporally correlative sedimentary cores in the $V L B$}

The analysis of zircon populations in sedimentary cores drilled in the Victoria Land Basin that were deposited during the same time intervals as CIROS-1 strata will allow the results of this research to be validated and compared. For example, if Oligocene-aged sediments found in CRP were analysed for zircon content, the systematic temporal trends observed in CRIOS-1 could be compared to those in CRP cores. Additionally, the sources for zircons in both cores could be compared and contrasted. This would allow a more robust and complete picture of zircon depositional dynamics in the McMurdo Sound area over the Eocene-Miocene to be constructed. This, in turn, would provide greater insights into the mechanisms 
responsible for sand deposition into the Victoria Land Basin, the response of the Antarctic cryosphere to climatic forcings and the tectonic state of the region over this time interval. 


\section{References}

Allen, S. R. A., Baker, J. A., Carter, L., Wysoczanksi, R. J. (2008). Reconstructing the Quaternary evolution of the world's most active silicic volcanic system: Insights from an $\sim 1.65 \mathrm{Ma}$ deep ocean tephra record sourced from Taupo Volcanic Zone, New Zealand. Quaternary Science Reviews, 27: 2341-2360.

Allibone, A. H. (1992). Low pressure/high temperature metamorphism of Keottlitz Group schists, Taylor Valley and upper Ferrar Glacier area, South Victoria Land, Antarctica. New Zealand Journal of Geology and Geophysics, 35: 115-127.

Allibone, A. H., Cox, S. C., Graham, I. J., Smillie, R. W., Johnstone, R. D., Ellery, S. G. and Palmer, K. (1993a). Granitoids of the Dry Valleys area, southern Victoria Land, Antarctica: Plutons, field relationships, and isotopic dating. New Zealand Journal of Geology and Geophysics, 36: 281-297.

Allibone, A. H., Cox, S. C. and Smillie, R. W. (1993b). Granitoids of the Dry Valleys area, southern Victoria Land: Geochemistry and evolution along the Early Paleozoic Craton margin. New Zealand Journal of Geology and Geophysics, 36: 299-316.

Arniaud, D., Dupuy, C. and Dostal, J. (1984). Geochemistry of Auriat Granite (Massif Central, France). Chemical Geology, 45: 263-277.

Baker, J., Peate, D., Waight, T. and Meyzen, C. (2004). Pb isotopic analysis of standards and samples using a ${ }^{207} \mathrm{~Pb}-{ }^{204} \mathrm{~Pb}$ double spike and thallium to correct for mass bias with a double-focusing MC-ICP-MS. Chemical Geology, 211(3): 275-303.

Barrera, E. (1989). Strontium isotope ages. DSIR Bulletin, 245: 151-152.

Barrett, P. J. (1986). Antarctic Cenozoic history from the MSSTS-1 drill hole, McMurdo Sound. DSIR Bulletin, 237: 174.

Barrett, P. J. (1989). Sediment texture. DSIR Bulletin, 245: 49-58.

Barrett, P. J. (1999). Antarctic climate history over the last 100 million years. Terra Antarctica, 3: 53-72.

Barrett, P. J. (2007). Cenozoic climate and sea level history from glacimarine strata off the Victoria Land coast, Cape Roberts Project, Antarctica. In: Hambrey, M. J., Christoffersen, P., Glasser, N. F. and Hubbart, B. (eds.) Glacial Processes and Products. International Association of Sedimentologists Special Publication (in press), $39 \mathrm{pp}$.

Barrett, P. J. (2009). A history of Antarctic Cenozoic glaciation - view from the margin. In: Florindo, F. and Siegert, M. (eds.) Antarctic Climate Evolution, Developments in Earth and Environmental Sciences, 8, pp 33-82.

Barrett, P. J. and Treves, S. B. (1981). Sedimentology and petrology of DVDP-15, McMurdo Sound. In: McGinnis, L. D. (ed.) Dry Valley Drilling Project, Antarctic Research Series. AGU, Washington, DC, 81, pp 1-5. 
Bassett, K., Palin, J., Gilmer, G., Savage, J., O’Toole, T., Bradshaw, M. and Bradshaw, J. (2009). Provenance of the Devonian Taylor Group, Lower Beacon Supergroup, Antarctica. New Zealand Geological Society Conference (Abstract).

Bea, F., Montero, P., Talavera, C. and Zinger, T. (2006). A Revised Ordovician Age for the Miranda Do Douro Orthogeneiss, Portugal. Zircon U-Pb Ionmicroprobe and LA-ICP-MS dating. Geologica Acta: An International Earth Science Journal, 4: 395-401.

Belousova, E. A., Griffin, W. L. and Pearson, N. J. (1998). Trace element composition and cathodoluminescence properties of southern African kimberlitic zircons. Mineralogical Magazine, 62: 355-366.

Belousova, E. A., Griffin, W. L., O'Reilly, S. Y. and Fisher, N. I. (2002). Igneous zircon: Trace element composition as an indicator of source rock type. Contributions to Mineralogy and Petrology, 143: 602-622.

Bernet, M., Brandom, M. T., Garver, J. I. and Molitor, B. R. (2004). Fundamentals of detrital zircon fission-track for provenance and exhumation studies with examples from the European Alps. Geological Society of America Special Paper, 238: $25-36$.

Billups, K. and Schrag, D. P. (2002). Paleotemperatures and ice volume of the past $27 \mathrm{Myr}$ revisited with paired $\mathrm{Mg} / \mathrm{Ca}$ and $18 \mathrm{O} / 16 \mathrm{O}$ measurements on benthic foraminifera. Paleoceanography, 17: 11.

Billups, K., Pälike, H., Channell, J. E. T., Zachos, J. C. and Shackleton, N. J. (2004). Astronomic calibration of the Late Oligocene through Early Miocene geomagnetic polarity time scale. Earth and Planetary Science Letters, 224: 33 44.

Bohaty, S. M., Scherer, R. P. and Harwood, D. M. (1998). Quaternary diatom biostratigraphy and paleo-environments of the CRP-1 drill core, Ross Sea, Antarctica. Terra Antarctica, 5: 431-453.

Bradshaw, M. A. and Harmsen, F. J. (2007). The paleoenvironmental significance of trace fossils in Devonian sediments (Taylor Group), Darwin Mountains to the Dry Valleys, southern Victoria Land. U. S. Geological Survey and the National Academies, USGS OF-2007-1047 (Extended Abstract 133).

Brancolini, G. (1995). Descriptive text for the seismic stratigraphic atlas of the Ross Sea, Antarctica. Geology and Seismic Stratigraphy of the Antarctic Margin. In: Cooper, A. K., Barker, P. F. and Brancolini, G. (eds.) Antarctic Research Series, 68, American Geophysical Union, Washington, D.C, pp 271-286.

Breggeren, W. A., Kent, D. V., Swisher, C. C. and Aubrey, M. P. (1995). A revised Cenozoic geochronology and biostratigraphy. In: Breggeren, W. A., Kent, D. V., Aubrey, M. P and Hardenbol, J. (eds.) Geochronology, timescales and stratigraphic correlation framework for an historical geology. SEPM (Society for Sedimentary Geologists) Special Publication, 54, pp 129-212. 
Cande, S. C. and Kent, D. V. (1992). A new geomagnetic polarity timescale for the Late Cretaceous and Cenozoic. Journal of Geophysical Research, 97: 1391713951.

Cande, S. C. and Kent, D. V. (1995). Revised calibration of the geomagnetic polarity time scale for the Late Cretaceous and Cenozoic. Journal of Geophysical Research, 100: 6093-6095.

Cape Roberts Science team (1998). Initial Report of CRP-1, Cape Roberts Project, Antarctica. Terra Antarctica, 5: 1-187.

Cape Roberts Science team (1999). Initial Report of CRP-2/2A, Cape Roberts Project, Antarctica. Terra Antarctica, 6: 1-173.

Chang, Z., Vervoort, J. D., McClelland, W. C. and Knaack, C. (2006). U-Pb dating of zircon by LA-ICP-MS. Geochemistry, Geophysics, Geosystems, 7: 1-14.

Cherniak, D. J. and Watson, E. B. (2000). Pb diffusion in zircon. Chemical Geology, 172: 5-24.

Cherniak, D. J. and Watson, E. B. (2003). Diffusion in zircon. Reviews in Mineralogy and Geochemistry, 53: 113-143.

Cherniak, D. J. and Watson, E. B. (2010). Li diffusion in zircon. Contributions to Mineralogy and Petrology, 45: 413-430.

Cherniak, D. J., Hanchar, J. M. and Watson, E. B. (1997). Rare-earth element diffusion in zircon. Chemical Geology, 134: 289-301.

Clairborne, L. L., Miller, C. F., Walker, B. A., Wooden, J. L., Mazdab, F. K. and Bea, F. (2006). Tracking magmatic processes through $\mathrm{Zr} / \mathrm{Hf}$ ratios in rocks and Hf and Ti zoning in zircons: An example from the Spirit Mountain Batholith, Nevada. Mineralogical Magazine, 70: 517-542.

Coccioni, R. and Galeotti, S. (1997). Calcareous nannofossil assemblage of the CIROS-1 core (Ross Sea): Further assessment of age. Terra Antarctica, 4: 89102.

Cocherie, A. and Robert, M. (2008). Laser ablation coupled with ICP-MS applied to $\mathrm{U}-\mathrm{Pb}$ zircon geochronology: A review of recent advances. Gondwana Research, 14: 597-608.

Condie, K. C. and Aster, R. C. (2010). Episodic zircon age spectra of orogenic granitoids: The supercontinent connection and continental growth. Precambrian Research, 180: 227-236.

Cook, Y. A. and Craw, D. (2002). Neoproterozoic structural slices in the Ross Orogen, Skelton Glacier area, South Victoria Land, Antarctica. New Zealand Journal of Geology and Geophysics, 45: 133-143.

Cooper, A. K., and Davey, F. J. (1985). Episodic rifting of the Phanerozoic rocks of the Victoria Land Basin, Western Ross Sea, Antarctica. Science, 229: 10851087. 
Corfu, F., Hanchar, J. M., Hoskin, P. W. O. and Kinny, P. (2003). Atlas of zircon textures. Reviews in Mineralogy and Geochemistry, 53: 468-500.

Cottle, J. M. and Cooper, A. F. (2006). Geology, geochemistry, and geochronology of an A-type granite in the Mulock Glacier area, southern Victoria Land, Antarctica. New Zealand Journal of Geology and Geophysics, 49: 191-202.

Couch, E. M. and Hollis, C. J. (1996). Paleogene palynomorphs and radiolarian biostratigraphy of DSDP Leg 29, Sites 280 and 281, South Tasman Rise. Institute of Geological and Nuclear Sciences Science Report, 96(19), Wellington, New Zealand, 46 pp.

Cox, S. C., Parkinson, D. L., Allibone A. H. and Cooper, A. F. (2000). Isotopic character of Cambro-Ordovician plutonism, southern Victoria Land, Antarctica. New Zealand Journal of Geology and Geophysics, 43: 501-520.

Davis, D. W., Williams, I. S. and Krough, T. E. (2003). Historical development of zircon geochronology. Reviews in Mineralogy and Geochemistry, 53: 145-181.

DeConto, R. M. and Pollard, D. (2003). Rapid Cenozoic glaciation of Antarctica induced by declining atmospheric $\mathrm{CO}_{2}$. Nature, 421: 245-249.

Deer, W. A., Howie, R. A. and Zussman, J. (1997). Zircon. In: Deer, W. A., Howie, R. A. and Zussman, J. (eds.) An Introduction to the Rock-Forming Minerals, Longman Group UK Limited, Essex, pp 22-26.

DeGraaf-Surpless, K., Mahoney, J. B., Wooden, J. L. and McWilliams, M. O. (2003). Lithofacies control in detrital zircon provenance studies: Insights from the Cretaceous Mathow Basin, southern Canadian Cordillera. GSA Bulletin, 118: 899-915.

Delmonte, B., Petit, J. R., Basile-Doelsch, I. and Lipenkov, D. (2004). First characterization and dating of East Antarctic bedrock inclusions from subglacial Lake Vostok accreted ice. Environmental Chemistry, I: 90-94.

Denton, G. H. and Hughes, T. J. (2002). Reconstructing the Antarctic Ice Sheet at the Last Glacial Maximum. Quaternary Science Reviews, 21: 193-202.

Dickin, A. P. (2003). Mass Spectrometry. In: Dickin, A. P. (ed.) Radiogenic Isotope Geology, Cambridge University Press, Cambridge, 32 pp.

Dodson, M. H., Compston, W., Williams, I. S. and Wilson, J. F. (1988). A search for ancient detrital zircons in Zimbabwean sediments. Journal of the Geological Society, London, 14: 977-983.

Dunbar, G. B., Naish, T. R., Barrett, P. J., Fielding, C. R. and Powell, R. D. (2008). Constraining the amplitude of Late Oligocene bathymetric changes in Western Ross Sea during orbitally-induced oscillations in the East Antarctic Ice Sheet: (1) Implications for glacimarine sequence stratigraphic models. Paleogeography, Paleoclimatology, Paleoecology, 260: 50-65.

Edwards, A. R. and Waghorn, D. B. (1989). Calcareous nannofossils. DSIR Bulletin, 245: $145-150$. 
Ehrmann, W. (1998). Implications of Late Eocene to Early Miocene clay mineral assemblages in McMurdo Sound (Ross Sea, Antarctica) on paleoclimate and ice dynamics. Paleogeography, Paleoclimatology, Paleoecology, 139: 213-231.

Elliot, D. H. and Fanning, C. M. (2008). Detrital zircons from Upper Permian and Lower Triassic Victoria Group sandstones, Shackelton Glacier Region, Antarctica: Evidence for multiple sources along the Gondwana plate margin. Gondwana Research, 13: 259-274.

Elliot, D. H. and. Fleming, T. H. (2008). Physical volcanology and geological relationships of the Jurassic Ferrar Large Igneous Province, Antarctica. Journal of Volcanology and Geothermal Research, 172: 20-37.

Encarnación, J., Fleming, T. H., Elliot, D. H. and Eales, J. V. (1996). Synchronous emplacement of Ferrar and Karoo Dolerites and the early breakup of Gondwana. Geology, 24: 535-538

Evitt, W. R. and Pierce, S. T. (1975). Early Tertiary ages from the coastal belt of the Franciscan Comples, northern California. Geology, 3: 433-436.

Fedo, C. M., Sircombe, K. N. and Rainbird, R. H. (2003). Detrital zircon analysis of the sedimentary record. Reviews in Mineralogy and Geochemistry, 53: 277-303.

Fielding, C. R., Woolfe, K. J., Purdon, R. G., Lavelle, M. and Howe, J. A. (1997). Sedimentological and stratigraphical re-evaluation of the CIROS-1 core, McMurdo Sound, Antarctica. Terra Antarctica, 4: 149-160.

Fielding, C.R., Naish T. R. and Woolfe, K. J. (2001). Facies architecture of the CRP3 drill hole, Victoria Land Basin, Antarctica. Terra Antartica, 8: 317-224.

Fielding, C. R., Henrys, S. A. and Wilson, T. J. (2006). Rift history of the western Victoria Land Basin: A new perspective based on integration of cores with seismic reflection data. In: Futterer, D. K., Damaske, D., Kleinschmidt, G., Miller, H., Tessensohn, F. (eds.) Antarctica: Contributions to Global Earth Sciences. Springer-Verlag, Berlin, pp 309-318.

Fielding, C., Whittaker, J., Henrys S., Wilson, T. and Naish, T. (2008). Seismic facies and stratigraphy of the Cenozoic succession in McMurdo Sound, Antarctica: Implications for tectonic, climatic and glacial history. Paleogeography, Paleoclimatology, Paleoecology, 260: 8-29.

Finch, R. J. and Hanchar, J. M. (2003). Structure and chemistry of zircon and zircongroup minerals. Reviews in Mineralogy and Geochemistry, 53: 1-25.

Findley, R. H., Skinner, D. N. and Craw, D. (1984). Lithostratigraphy and structure of the Koettlitz Group, McMurdo Sound, Antarctica. New Zealand Journal of Geology and Geophysics, 27: 512-536.

Fitzgerald, P. (2002). Tectonics and landscape evolution of the Antarctic Plate since the breakup of Gondwana, with an emphasis on the West Antarctic Rift System, and the Trans-Antarctic Mountains. Royal Society of New Zealand Bulletin, 35: 453-469. 
Fitzsimons, I. C. W. (2000). A review of tectonic events in the East Antarctic Shield and their implications for Gondwana and earlier supercontinents. Journal of African Earth Sciences, 31: 3-23.

Fleming, T. H., Heimann, A., Foland, K. A. and Elliot, D. H. (1997). ${ }^{40} \mathrm{Ar} /{ }^{39} \mathrm{Ar}$ geochronology of Ferrar Dolerite sills from the Trans-Antarctic Mmountains, Antarctica: Implications for the age and origin of the Ferrar magmatic province. Geological Society of America Bulletin, 109: 533-546.

Fu, B., Page, F. Z., Cavosie, A. J., Fournelle, J., Kita, N. T., Lackey, J. S., Wilde, S. A. and Valley, J. W. (2008). Ti-in-zircon thermometry: Applications and limitations. Contributions to Mineralogy and Petrology, 156: 197-215.

Gagnevin, D., Daly J. S. and Kronz, A. (2010). Zircon texture and chemical composition as a guide to magmatic processes and mixing in a granitic environment and coeval volcanic system. Contributions to Mineralogy and Petrology, 159: 579-596.

Geisler, T., Schaltegger, U. and Tomaschek, F. (2007). Re-equilibration of zircon in aqueous fluids and melts. Elements, 3: 43-50.

George, A. (1989). Sand provenance. DSIR Bulletin, 245: 159-168.

Glass, B. P. and Lui, L. (2001). Discovery of high-pressure $\mathrm{ZrSiO}_{4}$ polymorphs in naturally occurring shock-metamorphosed zircons. Geology, 29: 371-373.

Glass, B. P., Lui, L. and Leavens, P. B. (2002). Reidite: An impact-produced highpressure polymorph of zircon found in marine sediments. American Mineralogist, 87: 562-565.

Goodge, J. W. and Fanning, C. M. (1999). 2.5 b.y. of punctuated Earth history as recorded in a single rock. Geology, 27: 1007-1010.

Goodge, J. W., Fanning, C. M. and Bennett, V. C. (2001). U-Pb evidence of $\sim 1.7$ Ga crustal tectonism during the Nimrod Orogeny in the Trans-Antarctic Mountains, Antarctica: Implications for Proterozoic plate reconstructions. Precambrian Research, 112: 261-288.

Goodge, J. W., Myrow, P., Williams, I. S. and Bowring, S. A. (2002). Age and provenance of the Beardmore Group, Antarctica: Constraints on Rodinia Supercontinent breakup. Journal of Geology, 110: 393-406.

Goodge, J. W., Vervoort, J. D., Fanning, C. M., Brecke, D. M., Farmer, G. L., Williams, I. S., Myrow, P. M. and DePaolo, D. J. (2008). A positive test of East Antarctica-Laurentia juxtaposition within the Rodinia Supercontinent. Science, 321: 235-240.

Gradstein, F. M., Ogg, J. G. and Smith, A. G. (2004). A Geological Time Scale, Cambridge University Press, New York, 589 pp.

Grimes, C. B., John, B. E., Kelemen, P. B., Mazdab, F. K., Wooden, J. L., Cheadle, M. J., Hanghoj, K and Schwartz, J. J. (2007). Trace element chemistry of zircons from oceanic crust: A method for distinguishing detrital zircon provenance. Geology, 35: 643-646. 
Grimes, C. B., John, B. E., Cheadle, M. J., Mazdab, F. K., Wooden, J. L., Swapp, S. and Schwartz, J. J. (2009). On the occurrence, trace element geochemistry, and crystallization history of zircon from in situ ocean lithosphere. Contributions to Mineralogy and Petrology, 158: 757-783.

Grindely, B. M. and Warren, G. (1964). Stratigraphic nomenclature and correlation in the western part of the Ross Sea. In: Adie, R. J. (ed.) Antarctic Geology, North Holland Publishing Co., Amsterdam, pp 313-333.

Grindely, G. W. and McDougall, I. (1969). Age and correlation of the Nimrod Group and other Precambrian rocks of the central Trans-Antarctic Mountains, Antarctica. New Zealand Journal of Geology and Geophysics, 12: 391411.

Gulson, B. L. (1969). Electron microprobe determination of $\mathrm{Zr} / \mathrm{Hf}$ ratios in zircons from the Yeoval Diorite Complex, N.S.W., Australia. Lithos, 3: 17-23.

Hambrey, M. J., Barrett, P. J. and Robinson, P. (1989). Stratigraphy of the CIROS-1 drill core. DSIR Bulletin, 245: 23-48.

Hannah, M. J. (1994). Eocene dinoflagellates from the CIROS-1 drill hole, McMurdo Sound, Antarctica. Terra Antarctica, 1: 371-372.

Hannah, M. J., Cita, M. B., Coccioni, R. and Monechi, S. (1997). The Eocene/Oligocene boundary at $70^{\circ}$ south, McMurdo Sounds, Antarctica. Terra Antarctica, 4: 79-88.

Hanchar, J. M. and van Westrenen, W. (2007). Rare earth element behaviour in zircon-melt systems. Elements, 3: 37-42.

Harley, S. L. (2003). Archaean-Cambrian crustal development of East Antarctica: Metamorphic characteristics and tectonic implications. Geological Society, London, Special Publications, 206: 203-230.

Harwood, D. M. (1989). Siliceous microfossils. DSIR Bulletin, 245: 67-98.

Harwood, D. M. and Maruyama, T. (1992). Middle Eocene to Pleistocene diatom biostratigraphy of Southern Ocean sediments from the Kerguelen Plateau, Leg 120. In: Wise, S. W., Schlich, R. et al. (eds.) Proceedings of the Ocean Drilling Project, Scientific Results, 120, pp 683-734.

Harwood, D. M., Florindo, F., Levy, R., Fielding, C. R., Pekar. S. F., and a. S. S. Team (2008). ANDRILL Southern McMurdo Sound Project Scientific Prospectus, ANDRILL Scientific Prospectus Report, pp 1-29.

Hecht, L., Vigneresse, J. L. and Morteani, G. (1997). Constraints on the origin of zonation of the granite complexes in the Fichtelgebirge (Germany and Czech Republic): Evidence from a gravity and geochemical study. Geology Rundsch, 86(supplement): S93-S109.

Hill, R. S. (1989). Fossil leaf. DSIR Bulletin, 245: 143-144. 
Hirata, T. and Nesbitt, R. W. (1995). U-Pb isotope geochronology of zircon: Valuation of the laser probe-inductively coupled plasma mass spectrometry technique. Geochemica et Cosmochemica Acta, 59: 2491-2500.

Hoskin, P. W. O. (2004). Trace element composition of hydrothermal zircon and the alteration of Hadean zircon from Jack Hills, Australia. Geochemica et Cosmochemica Acta, 69: 637-648.

Hoskin, P. W. O. and Schaltegger, U. (2003). The composition of zircon and igneous and metamorphic petrogenesis. Reviews in Mineralogy and Geochemistry, 53: 2762.

Huybrechts, P. (2002). Sea level changes at the LGM from ice-dynamic reconstructions of the Greenland and Antarctic ice sheets during the glacial cycles. Quaternary Science Reviews, 21: 203-231.

IPCC. (2007). Climate Change 2007: The Physical Science Basis. Contribution of Working Group I to the Fourth Assessment Report of the Intergovernmental Panel on Climate Change. Cambridge University Press, Cambridge, 989 pp.

Jaffey, A. H., Flynn, K. F., Glendenin, L. E., Bentley W. C. and Essling, A. M. (1971). Precision measurement of half-lives and specific activities of ${ }^{235} \mathrm{U}$ and ${ }^{238}$ U. Physical Reviews, 4: 1889-1906.

Kennett, J. P. (1982). Marine Geology. Prentice Hall, Englewood Cliffs, 813 pp.

Kennett, J. P., Houtz, R. E., Andrews, P.V., Edwards, A.R., Gostin, V.A., Hajos, N. Hampton, M., Jenkins, D.G., Margolis, S.V., Ovenshine, A.T. and PerchNielsen, K. (1975). Initial Reports of the Deep Sea Drilling Project, 29, US Government Printing Office, Washington, DC, 1197 pp.

Kitajima, K., Hirata, T., Maruyama, S., Yamanashi, T., Sano, Y. and Liou, J. G. (2008). U-Pb zircon geochronology using LA-ICP-MS in the North Pole Dome, Pilbara Craton, Western Australia: A new tectonic growth model for the Archaean Chert/Greenstone succession. International Geology Review, 50: 1-15.

Kŏsler, J. and Sylvester, P. J. (2003). Present trends and the future of zircon in geochronology: Laser ablation ICP-MS. Reviews in Mineralogy and Geochemistry, 53: 243-275.

Krissek, L. A., Browne, G., Carter, L., Cowan, E., Dunbar, G., McKay, R., Naish, T., Powell, R., Reed, J., Wilch, T. and the ANDRILL-MIS Science Team (2007). Sedimentology and stratigraphy of the ANDRILL McMurdo Ice Shelf (AND-1B) core. Geological Survey and the National Academies, USGS OF-2007-1047 (Extended Abstract 148).

Laird, M. G. (1991). The Late Proterozoic-Middle Paleozoic rocks of Antarctica. In: Tingey, R. J. (ed.) Monographs on Geology and Geophysics, Clarendon Press, Oxford, pp 75-119.

Lewis, A. R., Marchant, D. R., Ashworth, A. C., Hemming, S. R. and Machlus, M. L. (2007). Major Middle Miocene global climate change: Evidence from East 
Antarctica and the Trans-Antarctic Mountains. GSA Bulletin, 119: 1449_ 1461.

Licht, K. J., Lederer, J. R. and Swope, R. J. (2005). Provenance of LGM glacial till (sand fraction) across the Ross Embayment, Antarctica. Quaternary Science Reviews, 24: 1499-1520.

Ludwig, K. R. (2003). User's manual for Isoplot/Ex, Version 3.0, a geochronological toolkit for Microsoft Excel. Berkeley Geochronology Centre Special Publication, 4, $71 \mathrm{pp}$.

McClintock, M. K. (2001). Phreatomagmatism at Coombs Hills, Antarctica: Magma-water Super-Volcanism in a Wet Failed Rift. [Unpublished MSc thesis] University of Otago, Dunedin, 141 pp.

McDonough, W. F. (2000). Chapter 1. In: Teisseyre, R. and Majewski, E. (eds.) Earthquake Thermodynamics and Phase Transformations in the Earth's Interior, pp $1-25$.

McKay, R. (2008). Late Cenozoic (13-0 Myr) Glacimarine Sedimentology, Facies Analysis, and Sequence Stratigraphy from the Western Ross Embayment, Antarctica: Implications for the Variability of the West Antarctic Ice Sheet. [Unpublished PhD thesis] Victoria University of Wellington, Wellington, $262 \mathrm{pp}$.

McKay, R., Browne, G., Carter, L., Cowan, E., Dunbar, G., Krissek, L., Naish, T., Powell, R., Reed, J., Talarico F. and Wilch, T. (2009). The stratigraphic signature of the Late Cenozoic Antarctic Ice Sheets in the Ross Embayment. Geological Society of America Bulletin, 121: 1537-1561.

Martin, A. P. (2009). Mt. Morning, Antarctica: Geochemistry, Geochronology, Petrology, Volcanology, and Oxygen Fugacity of the Rifted Antarctic Lithosphere. [Unpublished PhD thesis] University of Otago, Dunedin, 826 pp.

Martin, L. A. J., Duchene, S., Deloule, E. and Vanderhaeghe, O. (2008). Mobility of trace elements and oxygen in zircon during metamorphism: Consequences for geochemical tracing. Earth and Planetary Science Letters, 267: 161-174.

Maslin, M. A., Li, Z., Loutre, M. F. and Berger, A. (1999). The contribution of orbital forcing to the progressive intensification of Northern Hemisphere glaciation. Quaternary Science Reviews, 17: 411-426.

Mattinson, J. M. (1987) U-Pb ages of zircons: A basic examination of error propagation. Chemical Geology (Isotope Geoscience Section), 66: 151-162.

Mildenhall, D. C. (1989). Terrestrial palynology. DSIR Bulletin, 245: 119-128.

Mohr, B. A. R. (1990). Eocene and Oligocene sporomorphis and dinoflagellate cysts from Leg 113 drill sites, Weddell Sea, Antarctica. In: Barker, P. F., Kennett, J. P. et al, (eds.) Proceedings of the Ocean Drilling Program, Scientific results, College Station, Texas (Ocean Drilling Program), 113, pp 595-612.

Monechi, S. and Reale, V. (1997). Calcareous nannofossil assemblages of the CIROS-1 Core (Ross Sea): Further assessment of age. Terra Antarctica, 4: 89-102. 
Naish, T., Woolfe, K. J., Barrett, P. J., Wilson, G., Atkins, C., Bohaty, S. M., Claps, M., Davey, F. J., Dunbar, G., Dunn, A., Fielding, C., Florindo, F., Hannah, M., Harwood, D., Henrys, S., Krissek, L., Lavelle, M., van der Meer, J., McIntosh, W., Niessen, F., Passchier, S., Powell, R., Roberts, A., Sagnotti, L., Scherer, R., Strong, C., Talarico, C., Verosub, K., Villa, G., Watkins, D., Webb, P. and Wonik, T. (2001a). Orbitally induced oscillations in the East Antarctic Ice Sheet at the Oligocene/Miocene boundary. Nature, 413: 719723.

Naish, T. R., Barrett, P. J., Dunbar, G. B., Woolfe, K. J., Dunn, A. G., Henrys, S. A., Claps, M., Powell, R. D. and Fielding, C. R. (2001b). Sedimentary cyclicity in CRP drill core, Victoria Land Basin, Antarctica. Terra Antarctica, 8: 225244.

Naish, T. R., Levy, R. H., Powell, R. D. and MIS Science and Operations Team Members (2006). Scientific logistics implementation plan for the ANDRILL McMurdo Ice Shelf Project. ANDRILL Contribution 7, University of Nebraska-Lincoln, Lincoln, 117 pp.

Naish, T. R., Wilson, G. S., Dunbar, G. B. and Barrett, P. J. (2008a). Constraining the amplitude of Late Oligocene bathymetric changes in western Ross Sea during orbitally-induced oscillations in the East Antarctic Ice Sheet: (2) Implications for global sea level change. Paleogeography, Paleoclimatology, Paleoecology, 260: 66-76.

Naish, T. R., Powell, R. D., Barrett, P. J., Levy, R. H., Henrys, S., Wilson, G. S., Krissek, L. A., Niessen, F., Pompilio, M., Ross, J., Scherer, R., Talarico, F., Pyne, A. and the ANDRILL-MIS Science team (2008b). Late Cenozoic climate history of the Ross Embayment from the AND-1B drill hole: Culmination of three decades of Antarctic margin drilling. In: Cooper, A. K., Barrett, P. J., Stagg, H., Storey, B., Stump, E., Wise, W. and the 10th ISAES editorial team (eds.) Antarctica: A Keystone in a Changing World. Proceedings of the 10th International Symposium on Antarctic Earth Sciences, The National Academies Press, Washington, DC, pp 71-82.

Naish’ T., Powell, R., Levy, R., Wilson, G., Scherer, R., Talarico, F., Krissek, L., Niessen, F., Pompilio, M., Wilson, T., Carter, L., DeConto, R., Huybers, P., McKay, R., Pollard, D., Ross, J., Winter, D., Barrett, P., Browne, G., Cody, R., Cowan, E., Crampton, J., Dunbar, G., Dunbar, N., Florindo, F., Gebhardt, C., Graham, I., Hannah, M., Hansaraj, D., Harwood, D., Helling, D., Henrys, S., Hinnov, L., Kuhn, G., Kyle, P., Läufer, A., Maffioli, P., Magens, D., Mandernack, K., McIntosh, W., Millan, C., Morin, R., Ohneiser, C., Paulsen, T., Persico, D., Raine, I., Reed, J., Riesselman, C., Sagnotti, L., Schmitt, D., Sjunneskog, C., Strong, P., Taviani., M., Vogel, S., Wilch, T. and Williams, T. (2009). Obliquity-paced Pliocene West Antarctic ice sheet oscillations. Nature, 458; 322-328.

Neir, A. O., Thompson, R. W. and Murphey, B. F. (1941). The isotopic constitution of lead and the measurement of geological time III. Physical Review, 60: 112116. 
Pagani, M., Zachos, J., Freeman, K. H., Tippli, B. and Bohaty, S. M. (2005). Marked decline in atmospheric carbon dioxide concentrations in the Paleogene. Science, 309: 600-603.

Pälike, H., Norris, R. D., Herrle, J. O., Wilson, P. A., Coxall, H. K., Lear, C. H., Shackleton, N. J., Tripati, A. K. and Wade B. S. (2006) The heartbeat of the Oligocene climate system. Science, 314: 1894 - 1898.

Palmer, E. F. (2008). Rock, Till and Ice: A Provenance Study of the Byrd Glacier and the Central and Western Ross Sea, Antarctica. [Unpublished MSc thesis] Indiana University, $191 \mathrm{pp}$.

Pekar, S. F. and DeConto, R. M. (2006). High-resolution ice volume estimates for the Early Miocene: Evidence for a dynamic ice sheet in Antarctica. Paleogeography, Paleoclimatology, Paleoecology, 231: 101-109.

Pekar, S. F. and Christie-Blick, N. (2008). Resolving apparent conflicts between oceanographic and Antarctic climate records and evidence for a decrease in $p \mathrm{CO}_{2}$ during the Oligocene through Early Miocene (34-16 Ma). Paleogeography, Paleoclimatology, Paleoecology, 260: 41-49.

Pekar, S. F., Christie-Blick, N., Cominz, M. A. and Miller, K. G. (2002). Calibrating eustasy to oxygen isotopes for the early icehouse world of the Oligocene. Paleogeography, Paleoclimatology, Paleoecology, 260: 41-49.

Pekar, S. F., DeConto, R. M. and Harwood, D. M. (2006). Resolving a Late Oligocene conundrum: Deep-sea warming and Antarctic glaciation. Paleogeography, Paleoclimatology, Paleoecology, 231: 29-40.

Pelleter, E., Cheilletz, A., Gasquet, D., Mouttaqi, A., Annich, M., El Hakour, A., Deloule, E. and Féraud, G. (2007). Hydrothermal zircons: A tool for ion microprobe U-Pb dating of gold mineralization (Mamlalt-Menhouhou gold deposit-Morocco). Chemical Geology, 245: 135-161.

Pettke, T., Audetat, A., Schaltegger, U. and Heinrich, C. A. (2005). Magmatic-tohydrothermal crystallization in the W-Sn mineralized Mole Granite (NSW, Australia) part II: Evolving zircon and thorite trace element chemistry. Chemical Geology, 220: 191-213.

Pyne, A. R., Robinson, P. H. and Barrett, P. J. (1985). Corelog, description and photographs, CIROS-1, Ferrar Fjord, Antarctica. Antarctic Data Series no. 11, Victoria University of Wellington, $80 \mathrm{pp}$.

Raymond, K. P. (1976). Geology, Mineralogy and Geochemistry of the Late Cenozoic McMurdo Volcanic Group, Victoria Land, Antarctica. [Unpublished PhD thesis] Victoria University of Wellington, Wellington, $372 \mathrm{pp}$.

Reiners, P. W., Campbell, I. H., Nicolescu, S., Allen, C. M., Houragan, J. K., Garver, J. I., Mattinson, J. M. and Cowan, D. S. (2005). (U-Th)/(He-Pb) double dating of detrital zircons. American Journal of Science, 305: 259-311.

Rieck, H. J. (1989). Paleomagnetic stratigraphy. DSIR Bulletin, 245: 153-158. 
Roberts, A.P., Wilson, G. S., Harwood, D. M. and Verosub, K. L. (2003). Glaciation across the Oligocene-Miocene boundary in the southern McMurdo Sound, Antarctica: New chronology from the CIROS-1 drill hole. Paleogeography, Paleoclimatology, Paleoecology, 198: 113-130.

Roser, B. P. and Pyne, A. R. (1989). Wholerock geochemistry, DSIR Bulletin, 245: 175-184.

Ross, P., White, J. D. L. and McClintock, M. (2008). Geological evolution of the Coombs-Allan Hills area, Ferrar Large Igneous Province, Antarctica: Debris avalanches, mafic pyroclastic density currents, phreatocauldrons. Journal of Volcanology and Geothermal Research, 172: 38-60.

Rowell, A. J., van Schus, W. R., Storey, B. C., Fetter, A. H. and Evans, K. R. (2001). Latest Neoproterozoic to Mid-Cambrian age for the main deformational phases of the Trans-Antarctic Mountains: New stratigraphic and isotopic constraints from the Pensacola Mountains, Antarctica. Journal of the Geological Society, London, 158: 295-308.

Rubatto, D. and Hermann, J. (2003). Zircon formation during fluid circulation in eclogites (Monviso, Western Alps): Implications for $\mathrm{Zr}$ and $\mathrm{Hf}$ budget in subduction zones. Geochemica et Cosmochemica Acta, 67: 2173-2187.

Rubatto, D. and Hermann, J. (2007). Zircon behaviour in deeply subducted rocks. Elements, 3: 31-35.

Savage, J. E. (2005). Provenance analysis of the Sperm Bluff Formation, southern Victoria Land, Antarctica. [Unpublished MSc thesis] University of Canterbury, Christchurch, 206 pp.

Schaltegger, U. (2007). Hydrothermal zircon. Elements, 3: 51-52.

Scherer, R. P., Bohaty, S. M. and Harwood, D. M. (2000). Oligocene and Lower Miocene siliceous microfossil biostratigraphy of Cape Roberts Project Core CRP-2/2A, Victoria Land Basin, Antarctica. Terra Antarctica, 7: 417-442.

Scherer, R., Winter, D., Sjunneskog, C., Maffioli, P. and the ANDRILL-MIS Science team. (2007). The diatom record of the ANDRILL - McMurdo Ice Shelf project drill core. U.S. Geological Survey and the National Academies, USGS, OF-2007-1047 (Extended Abstract 171).

Schulz, B., Klemd, R. and Bratz, H. (2006). Host rock compositional controls on zircon trace element signatures in metabasites from the Austroalpine basement. Geochimica et Cosmochimica Acta, 70: 697-710.

Shackelton, N. J. and Kennett, J. P. (1974). Paleotemperature history of the Cenozoic and the initiation of Antarctic glaciation: Oxygen and carbon isotope analyses in DSDP Sites 277, 279 and 281. In: Kennett, J. P. and Houtz. R. E. (eds.) Initial Reports of the Deep Sea Drilling Project, 29, U.S. Government Printing Offices, Washington, D.C, pp 743-756. 
Schmidberger, S. S., Heaman, L. M., Simonetti, A., Creaser, R. A. and Cookenboo, H. O. (2005). Formation of Paleoproterozoic eclogitic mantle, Slave Province (Canada): Insights from in situ $\mathrm{Hf}$ and $\mathrm{U}-\mathrm{Pb}$ isotopic analysis of mantle zircons. Earth and Planetary Science Letters, 240: 621-633.

Siddoway, C. S. and Fanning, C. M. (2009). Paleozoic tectonism on the East Gondwana margin: Evidence from SHRIMP U-PB zircon geochronology of a migmatite-granite complex in West Antarctica. Tectonophysics, 130: 1-22.

Siebel, W., Schmitt, A. K., Danisik, M., Chen F., Meier, S., Weib, S. and Eroğlu, S. (2009). Prolonged mantle residence of zircon xenocrysts from the western Eger Rift. Nature Geoscience, 2: 886-890.

Smillie, R. W. (1992). Suite subdivision and petrological evolution of granitoids from the Taylor Valley and Ferrar Glacier region, South Victoria Land. Antarctic Science, 4: 71-87.

Speer, J. A. (1982a). Zircon. Reviews in Mineralogy and Geochemistry, 5: 67-112.

Stern, R. A. and Amelin, Y. (2003). Assessment of errors in SIMS zircon U-Pb geochronology using a natural zircon standard and NIST SRM 610 glass. Chemical Geology, 197: 111-142.

Stern, T. A., Baxter, A. K. and Barrett, P. J. (2005). Isostatic rebound due to glacial erosion within the Trans-Antarctic Mountains. Geology, 33: 221-224.

Stover, L. E. and Williams, G. L. (1995). A revision of the Paleogene dinoflagellate genera Areosphaeridium (Eaton, 1975) and Eatonicysia (Stover and Evit, 1978). Micropaleontology, 41: 97-141.

Talarico, F. M., McKay, R. M., Powell, R. D., Sandroni, S. and Naish, T. (2009). Late Cenozoic oscillations of Antarctic ice sheets revealed by provenance of basement clasts and grain detrital modes in ANDRILL core AND-1B. Global and Planetary Change (In Press).

Tingey, R. J. (1991). The regional geology of Archaean and Proterozoic rocks in Antarctica. In: Tingey, R. J. (ed.) The Geology of Antarctica, Clarendon Press, Oxford, pp 1-73.

Ushikubo, T., Kita, N. T., Cavosie, A. J., Wilde, S. A., Rudnick, R. L. and Valley, J. W. (2008). Lithium in Jack Hills zircon: Evidence for extensive weathering of the Earth's earliest crust. Earth and Planetary Science Letters, 272: 666-676.

Van Lichtervelde, M., Melcher, F. and Wirth, R. (2009). Magmatic vs. hydrothermal origins for zircon associated with tantalum mineralization in the Tanco Pegmatite, Manitoba, Canada. American Mineralogist, 94: 439-450.

Veevers, J. J., Saeed, A. and O'Brien, P. E. (2008). Provenance of the Gamburtsev Subglacial Mountains from U-Pb and $\mathrm{Hf}$ analysis of detrital zircons in Cretaceous to Quaternary sediments in Prydz Bay and beneath the Amery Ice Shelf. Sedimentary Geology, 211: 12-32.

Warney, S., Askin, R., Hannah, M. J., Mohr, B. A. R., Raine, J. I., Harwood, D. M., Florindo, F. and the SMS Science Team (2009). Palynomorphs from a 
sediment core reveal a sudden remarkably warm Antarctica during the Middle Miocene. Geology, 37: 955-958.

Watkins, D. K. (2007). Quantitative analysis of the calcareous nannofossil assemblages from CIROS-1, Victoria Land Basin, Antarctica. Journal of Nannoplankton Research, 29: 130-137.

Watson, E. B. and Harrison, T. M. (2005). Zircon thermometer reveals minimum melting conditions on earliest Earth. Science, 308, 841-844.

Watson, E. B., Wark, D. A. and Thomas, J. B. (2006). Crystallization thermometers for zircon and rutile. Contributions to Mineralogy and Petrology, 151: 413-433.

Webb, P. N. (1989). Benthic foraminifera. DSIR Bulletin, 245: 99-118.

Wendlandt, R. F. (1982). Sulfide saturation of basalt and andesite melts at high pressures and temperatures. American Mineralogist, 67: 877-885.

Wei, W. (1992). Updated nannofossil stratigraphy of the CIROS-1 Core from McMurdo Sound (Ross Sea). In: Wise, S.W., Schlich, R. et al. (eds.) Proceedings of the Ocean Drilling Program, Scientific Results, 120, College Station, Texas, pp 1105-1117.

Whitehouse, M. J. (2003). Rare earth elements in zircon: a review of applications and case studies from the Outer Hebridean Lewisian Complex, NW Scotland. Geological Society, London, Special Publications, 220: 49-64.

Wilson, G. J. (1967). Some new species of Lower Tertiary dinoflagellates from McMurdo Sound, Antarctica. New Zealand Journal of Botany, 5: 57-83.

Wilson, G. J. (1989). Marine palynology. DSIR Bulletin, 245: 129-134.

Wilson, G. S., Roberts, A. P., Verosub, K. L., Florindo, F. and Sagnotti, L. (1998). Magnetobiostratigrapic chronology of the Eocene-Oligocene transition in the CIROS-1 core, Victoria Land Margin, Antarctica: Implications for Antarctic glacial history. GS A Bulletin, 110: 35-47.

Wilson, G. S., Lavelle, M., McIntosh, W. C., Roberts, A. P., Harwood, D. M., Watkins, D. K., Villa, G., Bohaty, S. M., Fielding, C. R., Florindo, F., Sagnotti, L., Naish, T. R., Scherer, R. P. and Verosub, K. L. (2002). Integrated chronostratigraphic calibration of the Oligocene-Miocene boundary at $24.0 \pm 0.1 \mathrm{Ma}$ from the CRP2/2A drill core, Ross Sea, Antarctica. Geology, 30: 1043-1046.

Winberry, J. P. and Anandakrishnan, S. (2004). The crustal structure of the West Antarctic Rift System and Marie Byrd Land hotspot. Geology, 32: 977-980.

Zachos, J. C., Flower, B. P. and Paul, H. (1997). Orbitally paced climate oscillations across the Oligocene/Miocene boundary. Nature, 388: 567-570.

Zachos, J. C., Pagani, M., Sloan, L., Thomas, E. and Billups, K. (2001a). Trends, rhythms, and aberrations in global climate $65 \mathrm{Ma}$ to present. Science, 292: 686-693. 
Zachos, J. C., Shackleton, N. J., Revenaugh, J. S., Pälike, H. and Flower, B. P. (2001b). Climate response to orbital forcing across the Oligocene-Miocene boundary. Science, 292: 274-278. 


\section{Appendix 1: Sample descriptions}

\section{Sample 28-21}

Location: 28.3 mbsf.

Depositional age: Early Miocene.

Source unit: Poorly sorted coarse/very coarse sandstone.

Sedimentology: coarse sandstone, yellow brown with grey to medium-dark brown grains, poorly sorted (medium to coarse sandstone), lithified and friable in places

Clasts: $<5 \%$ clasts, poorly sorted $(\sim 1-7 \mathrm{~mm})$, light-dark grey, rounded-angular, lithologies include granite.

Sedimentary features: broad and irregular bedding of hard lithified sections and friable, coarse grained and better sorted sections.

Fossils: no fossils visible.

\section{Sample 78-18}

Location: 78.9 mbsf.

Depositional age: Early Miocene.

Source unit: fine sandstone/mudstone.

Sedimentology: fine sandstone, light yellow brown, poorly sorted (mud- medium sandstone, very hard and lithified, not friable.

Clasts: $<1 \%$ clasts, well sorted $(\sim 5 \mathrm{~mm})$, light to medium grey, angular, unknown

lithology.

Sedimentary features: massive sandstone, some vertical fractures present.

Fossils: no fossils visible.

\section{Sample 91-17}

Location: 91.8 mbsf.

Depositional Age: Early Miocene.

Source unit: sandstone matrix of a diamict.

Sedimentology: medium sandstone, medium yellow brown, poorly sorted (mud-medium sandstone), hard and non friable.

Clasts: $\sim 15 \%$ clasts, very poorly sorted $(\sim 1-30 \mathrm{~mm})$, variable colours include white, light and dark red browns and medium to dark greys, angular-subrounded, Lithologies

include: granite, granodiorite.

Sedimentary features: massive.

Fossils: no fossils visible.

\section{Sample 148-16}

Location: 148.3 mbsf.

Depositional age: Early Miocene.

Source unit: medium/coarse sandstone.

Sedimentology: medium-coarse sandstone, yellow brown, poorly sorted, hard, not friable. Clasts: $<5 \%$ clasts, medium sorted $(\sim 2-5 \mathrm{~mm})$, light-dark grey, angular-rounded, lithologies include granite.

Sedimentary features: massive.

Fossils: no fossils visible. 


\section{Sample 205-15}

Location: 205.8 mbsf.

Depositional age: late Oligocene.

Source unit: medium sandstone.

Sedimentology: medium-coarse sandstone, light brown grey, poorly sorted, hard and friable in paces.

Clasts: $\sim 15 \%$ clasts, very poorly sorted $(\sim 1-15 \mathrm{~mm})$, light-dark grey, angular to rounded, light-dark grey, lithologies include, granite and a number of dark unknown lithologies. Sedimentary structures: vague and irregular bedding between friable, coarser units and diner grains hard massive units.

Fossils: no fossils visible.

\section{Sample 249-14}

Location: 249.0 mbsf.

Depositional age: Late Oligocene.

Source unit: sandstone matrix of a diamict.

Sedimentology: fine-medium sandstone, medium grey brown, poorly sorted, unlithified and very friable

Clasts: $<1 \%$ clasts, medium sorted $(\sim 2-4 \mathrm{~mm})$, white to dark grey, angular, unknown lithologies.

Sedimentary structures: none seen.

Fossils: no fossils visible.

\section{Sample 292-13}

Location: 292.2 mbsf.

Depositional age: Late Oligocene.

Source unit: fine sandstone/mudstone.

Sedimentology: fine sandstone/mudstone, medium grey, poorly sorted, lithified, hard and not friable.

Clasts: $<5 \%$ clasts, poorly sorted $(\sim 1-8 \mathrm{~mm})$, light-dark grey and medium brown, subrounded-angular, granite and unknown lithologies.

Sedimentary structures: massive.

Fossils: no fossils visible.

\section{Sample 295-12}

Location: 295.7 mbsf.

Depositional age: Late Oligocene.

Source unit: fine/medium sandstone.

Sedimentology: coarse sandstone, medium-well sorted, light yellow grey, very friable both soft and hard.

Clasts: $\sim 5 \%$ clasts, medium sorted $(\sim 2-6 \mathrm{~mm})$, light-medium grey, subrounded-angular, unknown lithologies.

Sedimentary structures: none seen.

Fossils: no fossils visible. 


\section{Sample 362-11}

Location: 362.8 mbsf.

Depositional age: Late Oligocene.

Source unit: coarse sandstone.

Sedimentology: coarse-very coarse sand stone, very poorly sorted, medium/light brown, hard and very friable.

Clasts: $\sim 20 \%$ clasts, poorly sorted $(\sim 1-10 \mathrm{~mm})$, dominantly dark grey; $<1 \%$ light grey, unknown lithology.

Sedimentary features: none seen.

Fossils: no fossils visible.

\section{Sample 403-10}

Location: 403.6 mbsf.

Depositional age: Late Oligocene-Late Eocene?

Source unit: medium/coarse bedded sandstone.

Sedimentology: very fine sandstone/mudstone, light grey, hard and friable.

Clasts: $<1 \%$ clasts, well sorted $(\sim 1-2 \mathrm{~mm})$, dark grey, unknown lithologies.

Sedimentary features: massive.

Fossils: no fossils visible.

\section{Sample 462-7}

Location: 462.8 mbsf.

Depositional age: Late Oligocene-Late Eocene?

Source unit: medium/coarse sandstone.

Sedimentology: fine-medium sandstone, light brown (incl. white and dark pink, shiny grains $\sim 0.5 \mathrm{~mm}$, may be micas?), poorly sorted (incl. silt component), hard and friable. Clasts: $\sim 5 \%$ clasts, medium sorted $(\sim 1-5 \mathrm{~mm})$, light-dark grey, angular, includes granite? and unidentified lithologies.

Sedimentary structures: massive.

Fossils: no fossils seen.

\section{Sample 465-8}

Location: 465.7 mbsf.

Depositional age: Late Oligocene-Late Eocene?

Source unit: medium/coarse sandstone.

Sedimentology: fine sandstone/mudstone, light grey brown (incl. shiny white and black grains $\sim 0.5 \mathrm{~mm}$ ), poorly sorted, hard and not friable.

Clasts: $<1 \%$ clasts, well sorted $(\sim 1-2 \mathrm{~mm})$, light grey, angular-sub rounded, granite?

Sedimentary structures: massive.

Fossils: no fossils visible. 


\section{Sample 507-6}

Location: 507.4 mbsf.

Depositional age: Late Oligocene-Late Eocene?

Source unit: medium/coarse sandstone.

Sedimentology: medium sandstone, medium yellow brown (incl. $1-5 \%$ white, shiny clasts), poorly sorted (incl. silt component), hard and moderately friable.

Clasts: $<5 \%$ clasts, white-dark grey, poorly sorted $(\sim 1-6 \mathrm{~mm})$, angular, unidentified

lithologies.

Sedimentary structures: none seen.

Fossils: no fossils visible.

\section{Sample 560-5}

Location: 507.0 mbsf.

Depositional age: Late Eocene.

Source unit: medium sandstone.

Sedimentology: medium to coarse sandstone, yellow brown, poorly sorted (incl. silt component), soft and very friable.

Clasts: $<1 \%$ clasts, medium-dark grey, well sorted $(\sim 1-3 \mathrm{~mm})$, subangular, unidentified lithologies.

Sedimentary structures: none seen.

Fossils: no fossils visible.

\section{Sample 610-4}

Location: 610.4 mbsf.

Depositional age: Late Eocene.

Source unit: medium sandstone.

Sedimentology: fine sandstone, medium grey brown ( $\sim 5 \%$ back, shiny clasts), moderately sorted (incl. $\sim 10 \%$ silt component), very hard and not friable.

Clasts: no clasts visible.

Sedimentary structures: vague fine scale bedding $(\sim 1-2 \mathrm{~mm})$ between medium brown and medium grey sands, no grain size change.

Fossils: $10-15 \mathrm{~mm}$, curved, white shell fossils, bivalves?

\section{Sample 652-3}

Location: 652.5 mbsf.

Depositional age: Late Eocene.

Source unit: medium sandstone.

Sedimentology: fine-medium sandstone, medium brown grey $(<5 \%$ black shiny grains (biotite?), $\sim 5 \%$ white shiny clasts (incl. muscovite??)), hard and moderately friable.

Clasts: $\sim 5-10 \%$ clasts, white-dark grey, very poorly sorted $(\sim 1-17 \mathrm{~mm})$, angularrounded, includes granite.

Sedimentary structures: none visible, massive.

Fossils: one white shell fragment, $3 \mathrm{~mm}$, unknown origin. One white, poorly preserved bivalve fossil, $22 \mathrm{~mm}$ long, $>19 \mathrm{~mm}$ wide. 


\section{Sample 687-1}

Location: 687.0 mbsf.

Depositional age: Late Eocene.

Source unit: sandstone matrix of a conglomerate.

Sedimentology: medium-coarse grained sandstone, light yellow brown $(\sim 5 \%$ grains dark grey and $\sim 1 \%$ orange brown), medium sorting, soft and very friable.

Clasts: $<1 \%$ clasts, medium grey, well sorted $(\sim 2 \mathrm{~mm})$, subrounded, unknown origin.

Sedimentary structures: none seen.

Fossils: none present.

\section{Sample 693-2}

Location: 693.4 mbsf.

Depositional age: Late Eocene.

Source unit: sandstone matrix of a conglomerate.

Sedimentology: very coarse sandstone, light grey brown $(\sim 15 \%$ white shiny grains (muscovite?), $\sim 50 \%$ very light brown, not shiny grains with concoidal fractures (Quartz?), 35\% medium-dark brown and grey grains), hard and not friable. Clasts: none visible.

Sedimentary features: none visible. Fossils: no fossils visible. 
Sample 28-21 Page 1

\begin{tabular}{|c|c|c|c|c|c|c|c|c|c|c|c|c|c|c|c|c|c|}
\hline \multirow[b]{3}{*}{ Zircon } & \multirow[b]{3}{*}{$\mathrm{U}(\mathrm{ppm})$} & \multirow[b]{3}{*}{ Th (ppm) } & \multirow[b]{3}{*}{$\mathrm{U} / \mathrm{Th}$} & \multicolumn{7}{|c|}{ Isotopic ratios } & \multicolumn{4}{|c|}{ Apparent ages (Ma) } & \multirow[b]{3}{*}{$\pm \mathrm{Ma}$} & \multirow[b]{3}{*}{ Concordia } & \multirow[b]{3}{*}{$\pm \mathrm{Ma}$} \\
\hline & & & & \multicolumn{2}{|l|}{${ }^{207} \mathrm{~Pb}$} & ${ }^{238} \mathrm{U}$ & & ${ }^{235} \mathrm{U}$ & & ${ }^{207} \mathrm{~Pb}$ & & ${ }^{206} \mathrm{~Pb}$ & & ${ }^{207} \mathrm{~Pb}$ & & & \\
\hline & & & & ${ }^{206} \mathrm{~Pb}$ & $\pm(2 \sigma)$ & ${ }^{206} \mathrm{~Pb}$ & $\pm(2 \sigma)$ & ${ }^{207} \mathrm{~Pb}$ & $\pm(2 \sigma)$ & ${ }^{206} \mathrm{~Pb}$ & $\pm \mathrm{Ma}$ & ${ }^{238} \mathrm{U}$ & $\pm \mathrm{Ma}$ & ${ }^{235} \mathrm{U}$ & & & \\
\hline 52 & 1965 & 702 & 2.8 & 0.059 & 0.001 & 11.437 & 0.198 & 1.370 & 0.026 & 576 & 24 & 541 & 9 & 557 & 8 & 549 & 130 \\
\hline 50 & 282 & 125 & 2.3 & 0.061 & 0.002 & 11.366 & 0.296 & 1.495 & 0.068 & 627 & 56 & 544 & 13 & 520 & 18 & 535 & 150 \\
\hline 49 & 191 & 100 & 1.9 & 0.060 & 0.002 & 12.393 & 0.411 & 1.675 & 0.101 & 612 & 67 & 500 & 15 & 476 & 22 & 492 & 13 \\
\hline 48 & 814 & 224 & 3.6 & 0.057 & 0.001 & 12.376 & 0.351 & 1.590 & 0.056 & 510 & 35 & 501 & 13 & 496 & 13 & 498 & 10 \\
\hline 47 & 281 & 152 & 1.9 & 0.058 & 0.002 & 11.831 & 0.372 & 1.618 & 0.074 & 529 & 60 & 523 & 15 & 489 & 17 & 508 & 220 \\
\hline 46 & 5680 & 6927 & 0.8 & 0.057 & 0.001 & 8.858 & 0.224 & 1.130 & 0.024 & 503 & 22 & 690 & 16 & 644 & 10 & discordant & \\
\hline 45 & 289 & 175 & 1.6 & 0.059 & 0.002 & 12.438 & 0.365 & 1.644 & 0.075 & 581 & 59 & 499 & 14 & 483 & 17 & 492 & 11 \\
\hline 43 & 972 & 170 & 5.7 & 0.057 & 0.001 & 11.933 & 0.255 & 1.540 & 0.047 & 505 & 33 & 519 & 10 & 509 & 12 & 514 & 9 \\
\hline 42 & 121 & 220 & 0.5 & 0.175 & 0.002 & 2.057 & 0.052 & 0.086 & 0.002 & 2608 & 22 & 2555 & 52 & 2575 & 22 & 2571 & 22 \\
\hline 41 & 174 & 47 & 3.7 & 0.059 & 0.002 & 12.598 & 0.538 & 2.243 & 0.485 & 557 & 74 & 493 & 19 & 375 & 57 & discordant & \\
\hline 40 & 714 & 336 & 2.1 & 0.058 & 0.001 & 12.109 & 0.265 & 1.559 & 0.046 & 549 & 40 & 512 & 11 & 504 & 12 & 508 & 1 \\
\hline 39 & 1625 & 889 & 1.8 & 0.060 & 0.001 & 12.228 & 0.307 & 1.499 & 0.040 & 608 & 28 & 507 & 12 & 519 & 11 & 514 & 3 \\
\hline 38 & 1257 & 201 & 6.3 & 0.060 & 0.001 & 11.968 & 0.293 & 1.464 & 0.041 & 601 & 29 & 518 & 12 & 529 & 11 & 523 & 9 \\
\hline 37 & 188 & 88 & 2.1 & 0.059 & 0.002 & 12.579 & 0.509 & 1.772 & 0.130 & 584 & 79 & 493 & 18 & 455 & 25 & 480 & 250 \\
\hline 36 & 1784 & 552 & 3.2 & 0.057 & 0.001 & 11.972 & 0.283 & 1.534 & 0.040 & 504 & 26 & 517 & 11 & 510 & 10 & 513 & 9 \\
\hline 35 & 1793 & 285 & 6.3 & 0.058 & 0.001 & 12.024 & 0.274 & 1.523 & 0.037 & 545 & 26 & 515 & 11 & 513 & 9 & 514 & 9 \\
\hline 34 & 300 & 135 & 2.2 & 0.058 & 0.002 & 12.469 & 0.539 & 1.631 & 0.087 & 545 & 60 & 497 & 20 & 486 & 20 & 491 & 15 \\
\hline 33 & 3682 & 2061 & 1.8 & 0.057 & 0.001 & 13.558 & 0.408 & 1.709 & 0.049 & 503 & 27 & 459 & 13 & 468 & 10 & 465 & 10 \\
\hline 32 & 173 & 132 & 1.3 & 0.060 & 0.002 & 12.790 & 0.763 & 1.793 & 0.170 & 617 & 86 & 485 & 26 & 450 & 32 & 471 & 22 \\
\hline 31 & 1855 & 552 & 3.4 & 0.058 & 0.001 & 12.248 & 0.600 & 1.557 & 0.069 & 512 & 32 & 506 & 23 & 504 & 17 & 504 & 17 \\
\hline 29 RIM & 592 & 267 & 2.2 & 0.057 & 0.001 & 11.968 & 0.324 & 1.579 & 0.055 & 509 & 41 & 518 & 13 & 498 & 13 & 508 & 140 \\
\hline 28 & 1161 & 744 & 1.6 & 0.059 & 0.001 & 11.215 & 0.436 & 1.385 & 0.051 & 583 & 30 & 551 & 20 & 552 & 15 & 552 & 14 \\
\hline 26A CORE & 446 & 256 & 1.7 & 0.058 & 0.001 & 12.061 & 0.587 & 1.562 & 0.074 & 535 & 53 & 514 & 23 & 503 & 18 & 506 & 16 \\
\hline 26 & 1434 & 221 & 6.5 & 0.057 & 0.001 & 12.310 & 0.282 & 1.596 & 0.052 & 504 & 31 & 504 & 11 & 494 & 13 & 500 & 9 \\
\hline 29 core & 891 & 387 & 2.3 & 0.060 & 0.001 & 12.816 & 0.442 & 1.568 & 0.060 & 611 & 39 & 485 & 16 & 501 & 15 & 493 & 13 \\
\hline 26A RIM & 230 & 69 & 3.3 & 0.062 & 0.002 & 12.601 & 0.692 & 1.632 & 0.118 & 710 & 56 & 492 & 25 & 486 & 26 & 489 & 20 \\
\hline 30 & 1078 & 502 & 2.1 & 0.061 & 0.001 & 12.316 & 0.450 & 1.494 & 0.053 & 644 & 41 & 503 & 17 & 521 & 14 & 514 & 13 \\
\hline $25 \mathrm{CORE}$ & 3060 & 1158 & 2.6 & 0.064 & 0.003 & 12.014 & 0.877 & 1.479 & 0.104 & 741 & 103 & 516 & 34 & 525 & 27 & 521 & 26 \\
\hline 25 RIM & 1412 & 525 & 2.7 & 0.065 & 0.002 & 13.052 & 1.497 & 1.461 & 0.158 & 781 & 79 & 476 & 47 & 530 & 41 & 508 & 38 \\
\hline
\end{tabular}


Sample 28-21 Page 2

\begin{tabular}{|c|c|c|c|c|c|c|c|c|c|c|c|c|c|c|c|c|c|}
\hline \multirow[b]{3}{*}{ Zircon } & \multirow[b]{3}{*}{$\mathrm{U}(\mathrm{ppm})$} & \multirow[b]{3}{*}{ Th (ppm) } & \multirow[b]{3}{*}{$\mathrm{U} / \mathrm{Th}$} & \multicolumn{6}{|c|}{ Isotopic ratios } & \multicolumn{5}{|c|}{ Apparent ages $(\mathrm{Ma})$} & \multirow[b]{3}{*}{$\pm \mathrm{Ma}$} & \multirow[b]{3}{*}{ Concordia } & \multirow[b]{3}{*}{$\pm \mathrm{Ma}$} \\
\hline & & & & \multicolumn{2}{|l|}{${ }^{207} \mathrm{~Pb}$} & ${ }^{238} \mathrm{U}$ & & ${ }^{235} \mathrm{U}$ & & ${ }^{207} \mathrm{~Pb}$ & & ${ }^{206} \mathrm{~Pb}$ & & ${ }^{207} \mathrm{~Pb}$ & & & \\
\hline & & & & $\overline{{ }^{206} \mathrm{~Pb}}$ & $\pm(2 \sigma)$ & ${ }^{206} \mathrm{~Pb}$ & $\pm(2 \sigma)$ & ${ }^{207} \mathrm{~Pb}$ & $\pm(2 \sigma)$ & ${ }^{206} \mathrm{~Pb}$ & $\pm \mathrm{Ma}$ & ${ }^{238} \mathrm{U}$ & $\pm \mathrm{Ma}$ & ${ }^{235} \mathrm{U}$ & & & \\
\hline $24 \mathrm{CORE}$ & 3641 & 4172 & 0.9 & 0.060 & 0.002 & 10.901 & 0.891 & 1.314 & 0.094 & 620 & 51 & 566 & 41 & 575 & 30 & 575 & 32 \\
\hline 24 RIM & 3040 & 844 & 3.6 & 0.061 & 0.002 & 13.487 & 1.336 & 1.581 & 0.135 & 646 & 64 & 461 & 40 & 498 & 31 & 484 & 27 \\
\hline 23 CORE & 962 & 325 & 3.0 & 0.064 & 0.002 & 13.009 & 1.400 & 1.439 & 0.138 & 758 & 61 & 478 & 45 & 536 & 37 & 521 & 730 \\
\hline 23 RIM & 1318 & 198 & 6.7 & 0.059 & 0.001 & 13.440 & 1.274 & 1.598 & 0.137 & 560 & 51 & 463 & 39 & 494 & 31 & 485 & 32 \\
\hline 22 RIM & 53 & 23 & 2.3 & 0.088 & 0.008 & 13.774 & 2.285 & 1.367 & 0.176 & 1375 & 168 & 452 & 62 & 558 & 50 & 519 & 770 \\
\hline 21 & 240 & 146 & 1.6 & 0.060 & 0.002 & 12.630 & 0.987 & 1.635 & 0.142 & 607 & 69 & 491 & 34 & 485 & 31 & 487 & 28 \\
\hline 12 rim & 198 & 102 & 1.9 & 0.063 & 0.002 & 12.916 & 0.477 & 1.855 & 0.150 & 699 & 79 & 481 & 17 & 438 & 27 & 469 & 250 \\
\hline 12 core & 319 & 233 & 1.4 & 0.060 & 0.002 & 12.757 & 0.420 & 1.682 & 0.082 & 567 & 104 & 487 & 15 & 474 & 18 & 481 & 12 \\
\hline 11 & 130 & 90 & 1.4 & 0.059 & 0.003 & 12.623 & 0.580 & 1.878 & 0.152 & 577 & 123 & 492 & 21 & 434 & 27 & 470 & 360 \\
\hline $10 \mathrm{rim}$ & 174 & 75 & 2.3 & 0.061 & 0.002 & 13.088 & 0.515 & 1.831 & 0.153 & 657 & 82 & 475 & 17 & 443 & 28 & 466 & 15 \\
\hline 10core & 282 & 194 & 1.5 & 0.058 & 0.002 & 12.796 & 0.393 & 1.793 & 0.094 & 514 & 69 & 485 & 14 & 450 & 18 & 472 & 230 \\
\hline 9 core & 586 & 483 & 1.2 & 0.057 & 0.001 & 12.608 & 0.457 & 1.660 & 0.072 & 510 & 56 & 492 & 17 & 479 & 16 & 485 & 14 \\
\hline 9 & 271 & 179 & 1.5 & 0.059 & 0.002 & 12.848 & 0.502 & 1.775 & 0.130 & 552 & 61 & 483 & 18 & 454 & 25 & 474 & 15 \\
\hline 8 core & 825 & 451 & 1.8 & 0.061 & 0.001 & 11.479 & 0.523 & 1.398 & 0.054 & 631 & 41 & 539 & 23 & 548 & 16 & 546 & 16 \\
\hline 7 core & 764 & 473 & 1.6 & 0.061 & 0.002 & 13.305 & 1.040 & 1.600 & 0.107 & 647 & 73 & 467 & 33 & 493 & 25 & 488 & 25 \\
\hline 7rim & 712 & 365 & 1.9 & 0.060 & 0.002 & 13.369 & 0.973 & 1.628 & 0.099 & 607 & 60 & 465 & 31 & 487 & 23 & 481 & 23 \\
\hline 6rim & 164 & 118 & 1.4 & 0.061 & 0.003 & 12.984 & 0.997 & 1.831 & 0.156 & 623 & 94 & 478 & 33 & 443 & 29 & 457 & 25 \\
\hline 6core & 1213 & 367 & 3.3 & 0.058 & 0.001 & 12.368 & 0.251 & 1.574 & 0.038 & 535 & 20 & 501 & 10 & 500 & 9 & 500 & 7 \\
\hline 5 core & 2588 & 1204 & 2.1 & 0.059 & 0.001 & 11.428 & 0.281 & 1.403 & 0.032 & 564 & 38 & 541 & 12 & 547 & 10 & 545 & 9 \\
\hline 5 coreish & 1734 & 672 & 2.6 & 0.059 & 0.001 & 11.539 & 0.275 & 1.417 & 0.036 & 571 & 32 & 536 & 12 & 543 & 10 & 540 & 9 \\
\hline 4 core & 231 & 113 & 2.0 & 0.060 & 0.002 & 12.662 & 0.421 & 1.688 & 0.092 & 603 & 79 & 490 & 15 & 473 & 20 & 484 & 13 \\
\hline 4rim & 190 & 89 & 2.1 & 0.059 & 0.002 & 13.084 & 0.483 & 1.855 & 0.146 & 550 & 89 & 475 & 16 & 438 & 26 & 465 & 210 \\
\hline 3 & 867 & 565 & 1.5 & 0.058 & 0.001 & 11.462 & 0.241 & 1.429 & 0.036 & 542 & 32 & 539 & 11 & 539 & 10 & 539 & 8 \\
\hline 2 & 808 & 236 & 3.4 & 0.060 & 0.001 & 11.322 & 0.231 & 1.410 & 0.041 & 594 & 36 & 546 & 10 & 545 & 12 & 545 & 8 \\
\hline 1core & 626 & 375 & 1.7 & 0.060 & 0.001 & 12.770 & 0.264 & 1.613 & 0.049 & 609 & 41 & 486 & 9 & 490 & 11 & 488 & 8 \\
\hline 1 rima & 980 & 302 & 3.2 & 0.057 & 0.001 & 12.146 & 0.227 & 1.540 & 0.039 & 508 & 32 & 510 & 9 & 509 & 10 & 510 & 7 \\
\hline 51core & 1992 & 993 & 2.0 & 0.060 & 0.001 & 16.853 & 0.288 & 2.022 & 0.043 & 606 & 29 & 372 & 6 & 408 & 7 & discordant & \\
\hline $51 \mathrm{rim}$ & 404 & 101 & 4.0 & 0.058 & 0.001 & 12.220 & 0.282 & 1.563 & 0.058 & 543 & 50 & 507 & 11 & 502 & 14 & 505 & 9 \\
\hline
\end{tabular}


Sample 28-21 Page 3

\begin{tabular}{|c|c|c|c|c|c|c|c|c|c|c|c|c|c|c|c|c|c|}
\hline \multirow[b]{3}{*}{ Zircon } & \multirow[b]{3}{*}{$\mathrm{U}(\mathrm{ppm})$} & \multirow[b]{3}{*}{ Th (ppm) } & \multirow[b]{3}{*}{$\mathrm{U} / \mathrm{Th}$} & \multicolumn{7}{|c|}{ Isotopic ratios } & \multicolumn{3}{|c|}{ Apparent ages $(\mathrm{Ma})$} & \multirow[b]{2}{*}{${ }^{207} \mathrm{~Pb}$} & \multirow[b]{3}{*}{$\pm \mathrm{Ma}$} & \multirow[b]{3}{*}{ Concordia } & \multirow[b]{3}{*}{$\pm \mathrm{Ma}$} \\
\hline & & & & ${ }^{207} \mathrm{~Pb}$ & & ${ }^{238} \mathrm{U}$ & & ${ }^{235} \mathrm{U}$ & & ${ }^{207} \mathrm{~Pb}$ & & ${ }^{206} \mathrm{~Pb}$ & & & & & \\
\hline & & & & $\overline{{ }^{206} \mathrm{~Pb}}$ & $\pm(2 \sigma)$ & ${ }^{206} \mathrm{~Pb}$ & $\pm(2 \sigma)$ & ${ }^{207} \mathrm{~Pb}$ & $\pm(2 \sigma)$ & ${ }^{206} \mathrm{~Pb}$ & $\pm \mathrm{Ma}$ & ${ }^{238} \mathrm{U}$ & $\pm \mathrm{Ma}$ & $\overline{{ }^{235} \mathrm{U}}$ & & & \\
\hline 1 rimb & 746 & 322 & 2.3 & 0.057 & 0.001 & 11.924 & 0.230 & 1.521 & 0.042 & 500 & 40 & 519 & 9 & 514 & 11 & 517 & 7 \\
\hline 57 & 179 & 106 & 1.7 & 0.061 & 0.002 & 13.856 & 0.588 & 1.808 & 0.104 & 656 & 75 & 449 & 18 & 447 & 20 & 448 & 14 \\
\hline 56 & 88 & 68 & 1.3 & 0.069 & 0.005 & 14.171 & 0.838 & 2.006 & 0.179 & 899 & 130 & 440 & 24 & 411 & 28 & 428 & 19 \\
\hline 55 & 134 & 78 & 1.7 & 0.060 & 0.003 & 12.996 & 0.446 & 1.849 & 0.131 & 617 & 96 & 478 & 15 & 439 & 24 & 467 & 230 \\
\hline 55ACORE & 391 & 51 & 7.6 & 0.072 & 0.002 & 7.550 & 0.125 & 0.807 & 0.020 & 976 & 45 & 802 & 12 & 819 & 14 & 809 & 10 \\
\hline 55ARIM & 326 & 71 & 4.6 & 0.080 & 0.001 & 5.525 & 0.098 & 0.503 & 0.010 & 1204 & 30 & 1073 & 17 & 1112 & 13 & discordant & \\
\hline 20 & 743 & 20 & 37.5 & 0.103 & 0.001 & 3.469 & 0.133 & 0.240 & 0.008 & 1677 & 22 & 1633 & 53 & 1667 & 26 & 1668 & 26 \\
\hline 19 & 113 & 49 & 2.3 & 0.091 & 0.002 & 4.201 & 0.336 & 0.348 & 0.028 & 1440 & 50 & 1377 & 92 & 1376 & 58 & 1375 & 50 \\
\hline 42(repeat) & 107 & 241 & 0.4 & 0.175 & 0.003 & 2.142 & 0.055 & 0.088 & 0.002 & 2603 & 23 & 2470 & 52 & 2555 & 25 & 2542 & 480 \\
\hline 18 & 193 & 82 & 2.4 & 0.059 & 0.002 & 13.164 & 1.026 & 1.822 & 0.163 & 566 & 89 & 472 & 33 & 444 & 30 & 456 & 29 \\
\hline 17 & 194 & 75 & 2.6 & 0.057 & 0.002 & 12.952 & 0.529 & 1.868 & 0.148 & 499 & 72 & 480 & 18 & 436 & 26 & 465 & 260 \\
\hline $16 \mathrm{c}$ & 211 & 105 & 2.0 & 0.058 & 0.002 & 13.401 & 0.896 & 1.920 & 0.164 & 527 & 82 & 464 & 28 & 426 & 28 & 444 & 290 \\
\hline $16 \mathrm{r}$ & 201 & 87 & 2.3 & 0.056 & 0.002 & 12.607 & 0.658 & 1.883 & 0.164 & 456 & 78 & 492 & 24 & 433 & 29 & 468 & 400 \\
\hline $15 \mathrm{a}$ & 195 & 125 & 1.6 & 0.059 & 0.002 & 12.562 & 0.406 & 1.775 & 0.122 & 559 & 78 & 494 & 15 & 454 & 24 & 483 & 230 \\
\hline $15 b$ & 119 & 39 & 3.1 & 0.063 & 0.003 & 13.737 & 0.815 & 1.888 & 0.194 & 715 & 96 & 453 & 25 & 432 & 33 & 446 & 22 \\
\hline $14 \mathrm{c}$ & 2331 & 729 & 3.2 & 0.057 & 0.001 & 12.095 & 0.206 & 1.526 & 0.030 & 508 & 25 & 512 & 8 & 512 & 8 & 512 & 6 \\
\hline $14 \mathrm{r}$ & 2436 & 888 & 2.7 & 0.057 & 0.001 & 12.658 & 0.196 & 1.596 & 0.026 & 487 & 18 & 490 & 7 & 494 & 6 & 492 & 5 \\
\hline 13 & 127 & 72 & 1.8 & 0.058 & 0.003 & 12.884 & 0.541 & 1.930 & 0.157 & 539 & 95 & 482 & 19 & 424 & 26 & discordant & \\
\hline 46 (repeat) & 1049 & 771 & 1.4 & 0.057 & 0.001 & 12.068 & 0.215 & 1.539 & 0.039 & 490 & 29 & 513 & 9 & 509 & 10 & 511 & 7 \\
\hline 45 (repeat) & 90 & 42 & 2.1 & 0.059 & 0.002 & 13.556 & 0.717 & 2.098 & 0.217 & 591 & 38 & 459 & 22 & 396 & 31 & 437 & 386 \\
\hline 17 (repeat) & 1318 & 1314 & 1.0 & 0.062 & 0.002 & 13.911 & 0.707 & 1.693 & 0.087 & 689 & 78 & 448 & 21 & 472 & 19 & 462 & 240 \\
\hline 18 (repeat) & 84 & 96 & 0.9 & 0.061 & 0.003 & 14.480 & 0.975 & 2.053 & 0.224 & 646 & 94 & 431 & 26 & 403 & 33 & 420 & 22 \\
\hline 20 (repeat) & 2292 & 2872 & 0.8 & 0.107 & 0.002 & 14.601 & 0.262 & 1.780 & 0.041 & 1757 & 33 & 427 & 7 & 453 & 8 & discordant & \\
\hline 21 (repeat) & 3970 & 9487 & 0.4 & 0.061 & 0.003 & 11.194 & 0.265 & 1.413 & 0.032 & 635 & 94 & 552 & 12 & 544 & 9 & 545 & 9 \\
\hline 52 (repeat) & 273 & 263 & 1.0 & 0.057 & 0.001 & 12.971 & 0.414 & 1.738 & 0.095 & 510 & 30 & 479 & 14 & 462 & 20 & 473 & 12 \\
\hline 41 (repeat) & 187 & 155 & 1.2 & 0.066 & 0.004 & 13.137 & 0.547 & 1.797 & 0.116 & 811 & 134 & 473 & 18 & 450 & 22 & 463 & 15 \\
\hline 39 (repeat) & 142 & 130 & 1.1 & 0.059 & 0.001 & 14.045 & 0.667 & 1.849 & 0.142 & 585 & 46 & 444 & 19 & 439 & 26 & 442 & 16 \\
\hline 37 (repeat) & 144 & 122 & 1.2 & 0.068 & 0.005 & 3.640 & 0.103 & 0.251 & 0.008 & 870 & 141 & 1565 & 38 & 1631 & 27 & 1609 & 440 \\
\hline 32 (repeat) & 121 & 179 & 0.7 & 0.059 & 0.001 & 13.086 & 0.557 & 1.863 & 0.146 & 560 & 28 & 475 & 19 & 437 & 26 & 462 & 230 \\
\hline
\end{tabular}


Sample 78-18 Page 1

\begin{tabular}{|c|c|c|c|c|c|c|c|c|c|c|c|c|c|c|c|c|c|}
\hline \multirow[b]{3}{*}{ Zircon } & \multirow[b]{3}{*}{$\mathrm{U}(\mathrm{ppm})$} & \multirow[b]{3}{*}{ Th (ppm) } & \multirow[b]{3}{*}{$\mathrm{U} / \mathrm{Th}$} & \multicolumn{7}{|c|}{ Isotopic ratios } & \multicolumn{4}{|c|}{ Apparent ages $(\mathrm{Ma})$} & \multirow[b]{3}{*}{$\pm \mathrm{Ma}$} & \multirow[b]{3}{*}{ Concordia } & \multirow[b]{3}{*}{$\pm \mathrm{Ma}$} \\
\hline & & & & ${ }^{207} \mathrm{~Pb}$ & & ${ }^{238} \mathrm{U}$ & & ${ }^{235} \mathrm{U}$ & & ${ }^{207} \mathrm{~Pb}$ & & ${ }^{206} \mathrm{~Pb}$ & & ${ }^{207} \mathrm{~Pb}$ & & & \\
\hline & & & & $\overline{{ }^{206} \mathrm{~Pb}}$ & $\pm(2 \sigma)$ & ${ }^{206} \mathrm{~Pb}$ & $\pm(2 \sigma)$ & ${ }^{207} \mathrm{~Pb}$ & $\pm(2 \sigma)$ & ${ }^{206} \mathrm{~Pb}$ & $\pm \mathrm{Ma}$ & ${ }^{238} \mathrm{U}$ & $\pm \mathrm{Ma}$ & ${ }^{235} \mathrm{U}$ & & & \\
\hline $33 c$ & 645 & 588 & 1.1 & 0.059 & 0.002 & 13.886 & 1.276 & 1.742 & 0.141 & 586 & 79 & 448 & 37 & 461 & 28 & 458 & 29 \\
\hline 34 & 1661 & 609 & 2.7 & 0.062 & 0.001 & 12.328 & 0.682 & 1.521 & 0.083 & 669 & 41 & 503 & 25 & 513 & 21 & 510 & 21 \\
\hline 35 & 192 & 52 & 3.7 & 0.074 & 0.002 & 5.505 & 0.296 & 0.551 & 0.032 & 1046 & 48 & 1076 & 51 & 1051 & 36 & 1058 & 34 \\
\hline 36 & 183 & 161 & 1.1 & 0.107 & 0.002 & 3.116 & 0.080 & 0.217 & 0.006 & 1743 & 30 & 1795 & 39 & 1753 & 24 & 1763 & 20 \\
\hline $32 \mathrm{c}$ & 170 & 63 & 2.7 & 0.064 & 0.003 & 13.235 & 1.114 & 1.857 & 0.270 & 750 & 86 & 470 & 35 & 438 & 46 & 459 & 33 \\
\hline 38 & 1220 & 612 & 2.0 & 0.073 & 0.001 & 7.915 & 0.192 & 0.819 & 0.020 & 1020 & 41 & 767 & 17 & 811 & 13 & discordant & \\
\hline 39 & 505 & 123 & 4.1 & 0.063 & 0.001 & 11.979 & 0.388 & 1.553 & 0.064 & 711 & 49 & 517 & 16 & 505 & 16 & 511 & 12 \\
\hline 40 & 1345 & 647 & 2.1 & 0.060 & 0.003 & 12.427 & 0.456 & 1.584 & 0.054 & 608 & 99 & 499 & 17 & 497 & 13 & 498 & 12 \\
\hline 41 & 547 & 172 & 3.2 & 0.059 & 0.001 & 12.609 & 0.556 & 1.553 & 0.069 & 578 & 47 & 492 & 20 & 505 & 17 & 500 & 15 \\
\hline $41 \mathrm{r}$ & 387 & 143 & 2.7 & 0.060 & 0.002 & 12.252 & 0.617 & 1.542 & 0.078 & 595 & 60 & 506 & 23 & 508 & 19 & 507 & 17 \\
\hline 42 & 2389 & 380 & 6.3 & 0.065 & 0.001 & 28.476 & 0.950 & 3.192 & 0.110 & 777 & 36 & 223 & 7 & 277 & 8 & discordant & \\
\hline 43 & 82 & 15 & 5.3 & 0.102 & 0.008 & 14.092 & 1.212 & 1.372 & 0.160 & 1659 & 144 & 442 & 34 & 556 & 46 & discordant & \\
\hline 44 & 89 & 168 & 0.5 & 0.109 & 0.006 & 12.614 & 0.745 & 1.016 & 0.092 & 1780 & 98 & 492 & 26 & 696 & 43 & discordant & \\
\hline 45 & 3092 & 1165 & 2.7 & 0.066 & 0.001 & 22.356 & 0.871 & 2.477 & 0.088 & 814 & 33 & 282 & 10 & 345 & 10 & discordant & \\
\hline 46 & 95 & 27 & 3.5 & 0.073 & 0.004 & 8.415 & 0.517 & 0.986 & 0.085 & 1025 & 104 & 724 & 40 & 712 & 41 & 718 & 32 \\
\hline $47 c$ & 230 & 118 & 2.0 & 0.059 & 0.002 & 12.508 & 0.846 & 1.664 & 0.124 & 575 & 75 & 496 & 30 & 478 & 27 & 485 & 22 \\
\hline $47 \mathrm{r}$ & 509 & 364 & 1.4 & 0.058 & 0.002 & 12.760 & 0.788 & 1.663 & 0.097 & 537 & 62 & 487 & 27 & 478 & 21 & 481 & 20 \\
\hline 48 & 777 & 364 & 2.1 & 0.061 & 0.002 & 12.592 & 0.864 & 1.539 & 0.084 & 640 & 56 & 493 & 31 & 509 & 21 & 506 & 22 \\
\hline $50 \mathrm{r}$ & 2028 & 584 & 3.5 & 0.059 & 0.001 & 13.758 & 0.711 & 1.680 & 0.074 & 569 & 40 & 452 & 22 & 475 & 16 & 470 & 240 \\
\hline $51 \mathrm{c}$ & 385 & 110 & 3.5 & 0.061 & 0.002 & 12.919 & 1.106 & 1.645 & 0.123 & 626 & 77 & 481 & 37 & 482 & 27 & 482 & 28 \\
\hline 49 & 1515 & 1442 & 1.1 & 0.072 & 0.002 & 15.979 & 1.187 & 1.722 & 0.110 & 992 & 52 & 391 & 26 & 465 & 23 & discordant & \\
\hline $51 \mathrm{r}$ & 122 & 72 & 1.7 & 0.063 & 0.007 & 12.685 & 1.425 & 1.755 & 0.237 & 700 & 209 & 489 & 48 & 458 & 45 & 472 & 39 \\
\hline 1 & 254 & 106 & 2.4 & 0.056 & 0.002 & 11.345 & 0.755 & 1.544 & 0.136 & 450 & 80 & 545 & 33 & 507 & 33 & 526 & 29 \\
\hline 2 & 1531 & 595 & 2.6 & 0.061 & 0.002 & 13.860 & 0.761 & 1.644 & 0.081 & 641 & 55 & 449 & 23 & 483 & 18 & 473 & 360 \\
\hline 3 & 122 & 43 & 2.8 & 0.073 & 0.003 & 6.406 & 0.487 & 0.649 & 0.041 & 1016 & 74 & 935 & 62 & 947 & 38 & 945 & 38 \\
\hline $4 c$ & 850 & 864 & 1.0 & 0.061 & 0.002 & 13.441 & 0.782 & 1.651 & 0.077 & 650 & 62 & 463 & 25 & 481 & 17 & 479 & 18 \\
\hline $4 \mathrm{r}$ & 1312 & 348 & 3.8 & 0.062 & 0.002 & 13.507 & 0.679 & 1.611 & 0.073 & 689 & 61 & 461 & 21 & 491 & 17 & 481 & 280 \\
\hline 5 & 3914 & 4172 & 0.9 & 0.083 & 0.002 & 21.684 & 1.348 & 1.838 & 0.090 & 1270 & 40 & 291 & 17 & 441 & 17 & discordant & \\
\hline
\end{tabular}


Sample 78-18 Page 2

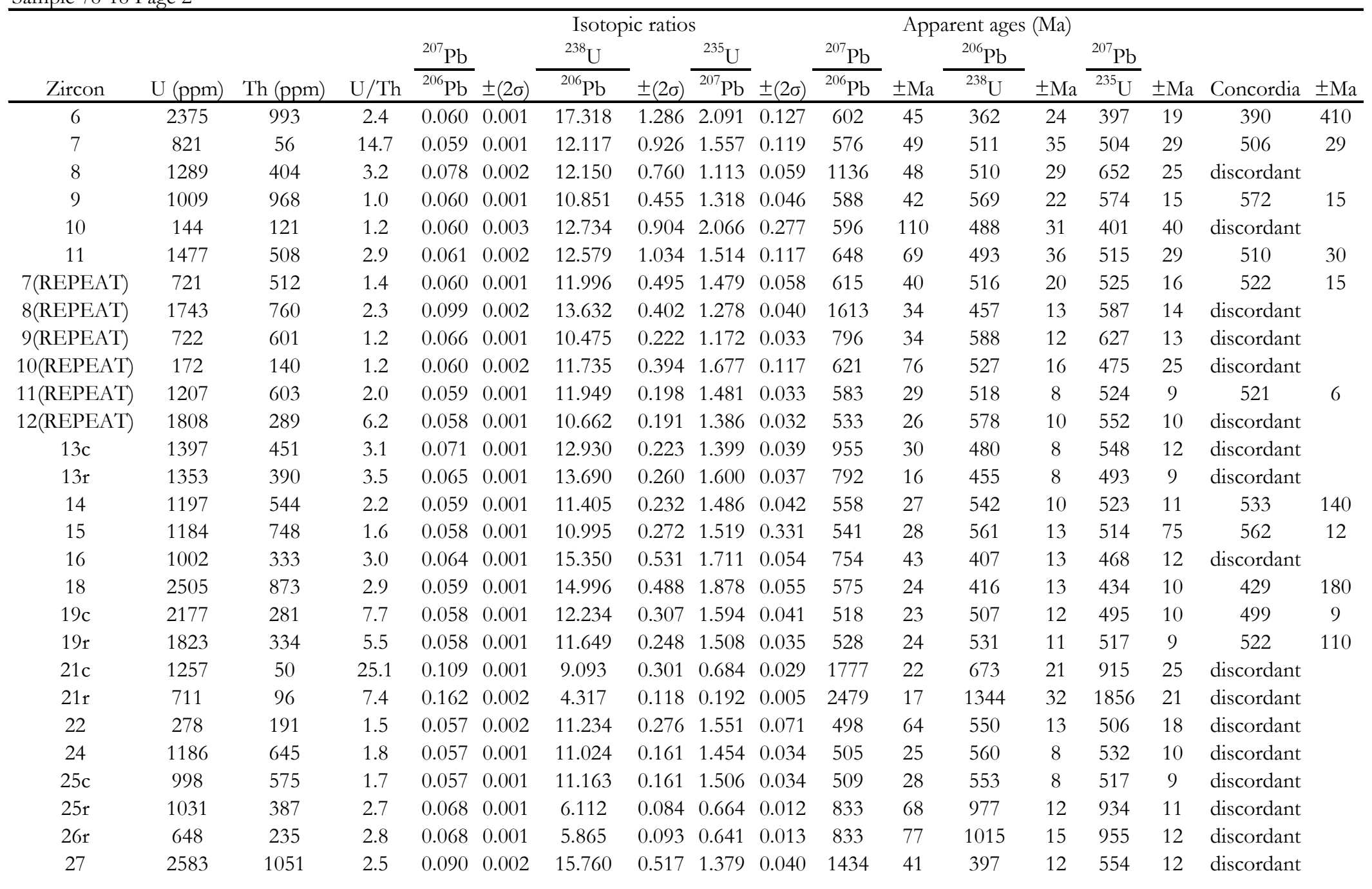


Sample 78-18 Page 3

\begin{tabular}{|c|c|c|c|c|c|c|c|c|c|c|c|c|c|c|c|c|c|}
\hline \multirow[b]{3}{*}{ Zircon } & \multirow[b]{3}{*}{$\mathrm{U}(\mathrm{ppm})$} & \multirow[b]{3}{*}{ Th (ppm) } & \multirow[b]{3}{*}{$\mathrm{U} / \mathrm{Th}$} & \multicolumn{7}{|c|}{ Isotopic ratios } & \multicolumn{3}{|c|}{ Apparent ages $(\mathrm{Ma})$} & \multirow[b]{2}{*}{${ }^{207} \mathrm{~Pb}$} & \multirow[b]{3}{*}{$\pm \mathrm{Ma}$} & \multirow[b]{3}{*}{ Concordia } & \multirow[b]{3}{*}{$\pm \mathrm{Ma}$} \\
\hline & & & & ${ }^{207} \mathrm{~Pb}$ & & ${ }^{238} \mathrm{U}$ & & ${ }^{235} \mathrm{U}$ & & ${ }^{207} \mathrm{~Pb}$ & & ${ }^{206} \mathrm{~Pb}$ & & & & & \\
\hline & & & & $\overline{{ }^{206} \mathrm{~Pb}}$ & $\pm(2 \sigma)$ & ${ }^{206} \mathrm{~Pb}$ & $\pm(2 \sigma)$ & ${ }^{207} \mathrm{~Pb}$ & $\pm(2 \sigma)$ & ${ }^{206} \mathrm{~Pb}$ & $\pm \mathrm{Ma}$ & ${ }^{238} \mathrm{U}$ & $\pm \mathrm{Ma}$ & ${ }^{235} \mathrm{U}$ & & & \\
\hline $28 \mathrm{c}$ & 1665 & 905 & 1.8 & 0.079 & 0.001 & 17.352 & 0.362 & 1.885 & 0.044 & 1171 & 33 & 361 & 7 & 432 & 8 & discordant & \\
\hline $28 \mathrm{r}$ & 1774 & 540 & 3.3 & 0.066 & 0.001 & 15.876 & 0.240 & 1.836 & 0.037 & 817 & 32 & 394 & 6 & 442 & 7 & discordant & \\
\hline $30 c$ & 170 & 107 & 1.6 & 0.091 & 0.001 & 3.940 & 0.082 & 0.331 & 0.009 & 1445 & 30 & 1458 & 27 & 1415 & 20 & 1428 & 300 \\
\hline $30 \mathrm{r}$ & 213 & 138 & 1.5 & 0.091 & 0.001 & 3.935 & 0.074 & 0.325 & 0.008 & 1452 & 28 & 1460 & 24 & 1429 & 18 & 1435 & 210 \\
\hline $32 r$ (repeat) & 369 & 135 & 2.7 & 0.058 & 0.001 & 11.465 & 0.309 & 1.574 & 0.069 & 546 & 49 & 539 & 14 & 500 & 17 & discordant & \\
\hline 36 (repeat) & 243 & 210 & 1.2 & 0.105 & 0.001 & 3.050 & 0.050 & 0.221 & 0.004 & 1707 & 26 & 1829 & 26 & 1737 & 16 & discordant & \\
\hline 41 (repeat) & 502 & 193 & 2.6 & 0.057 & 0.001 & 12.332 & 0.259 & 1.680 & 0.056 & 483 & 50 & 503 & 10 & 475 & 12 & discordant & \\
\hline 46 (repeat) & 234 & 41 & 5.7 & 0.068 & 0.002 & 6.899 & 0.164 & 0.802 & 0.029 & 857 & 63 & 873 & 19 & 823 & 20 & discordant & \\
\hline 48 (repeat) & 894 & 379 & 2.4 & 0.058 & 0.001 & 11.888 & 0.229 & 1.553 & 0.042 & 531 & 37 & 521 & 9 & 505 & 11 & 514 & 100 \\
\hline 51 (repeat) & 395 & 91 & 4.3 & 0.060 & 0.002 & 11.204 & 0.216 & 1.483 & 0.044 & 595 & 65 & 551 & 10 & 524 & 12 & discordant & \\
\hline
\end{tabular}

Sample 91-17 Page 1

\begin{tabular}{|c|c|c|c|c|c|c|c|c|c|c|c|c|c|c|c|c|c|}
\hline \multirow[b]{3}{*}{ Zircon } & \multirow[b]{3}{*}{$\mathrm{U}(\mathrm{ppm})$} & \multirow[b]{3}{*}{ Th (ppm) } & \multirow[b]{3}{*}{$\mathrm{U} / \mathrm{Th}$} & \multicolumn{7}{|c|}{ Isotopic ratios } & \multicolumn{4}{|c|}{ Apparent ages $(\mathrm{Ma})$} & \multirow[b]{3}{*}{$\pm \mathrm{Ma}$} & \multirow[b]{3}{*}{ Concordia } & \multirow[b]{3}{*}{$\pm \mathrm{Ma}$} \\
\hline & & & & ${ }^{207} \mathrm{~Pb}$ & & ${ }^{238} \mathrm{U}$ & & ${ }^{235} \mathrm{U}$ & & ${ }^{207} \mathrm{~Pb}$ & & ${ }^{206} \mathrm{~Pb}$ & & ${ }^{207} \mathrm{~Pb}$ & & & \\
\hline & & & & ${ }^{206} \mathrm{~Pb}$ & $\pm(2 \sigma)$ & ${ }^{206} \mathrm{~Pb}$ & $\pm(2 \sigma)$ & $\overline{207} \mathrm{~Pb}$ & $\pm(2 \sigma)$ & ${ }^{206} \mathrm{~Pb}$ & $\pm \mathrm{Ma}$ & ${ }^{238} \mathrm{U}$ & $\pm \mathrm{Ma}$ & $\overline{{ }^{235} \mathrm{U}}$ & & & \\
\hline $18 \mathrm{c}$ & 596 & 268 & 2.2 & 0.058 & 0.001 & 12.580 & 0.308 & 1.633 & 0.062 & 528 & 40 & 493 & 11 & 485 & 14 & 490 & 10 \\
\hline $18 \mathrm{r}$ & 691 & 311 & 2.2 & 0.065 & 0.001 & 12.298 & 0.261 & 1.542 & 0.049 & 781 & 42 & 504 & 10 & 508 & 12 & 503 & 8 \\
\hline 20 & 998 & 612 & 1.6 & 0.097 & 0.001 & 3.931 & 0.054 & 0.288 & 0.004 & 1561 & 13 & 1462 & 18 & 1522 & 11 & discordant & \\
\hline 21 & 1698 & 632 & 2.7 & 0.081 & 0.001 & 12.770 & 0.166 & 1.157 & 0.019 & 1228 & 24 & 486 & 6 & 633 & 8 & discordant & \\
\hline 22 & 3808 & 859 & 4.4 & 0.111 & 0.001 & 24.596 & 0.304 & 1.499 & 0.018 & 1823 & 11 & 257 & 3 & 519 & 5 & discordant & \\
\hline 9 & 4292 & 926 & 4.6 & 0.059 & 0.000 & 11.478 & 0.154 & 1.421 & 0.020 & 566 & 17 & 539 & 7 & 541 & 6 & 540 & 5 \\
\hline 8 & 4303 & 642 & 6.7 & 0.058 & 0.001 & 19.505 & 0.620 & 2.537 & 0.130 & 517 & 22 & 322 & 10 & 338 & 14 & 324 & 150 \\
\hline $6 r$ & 1577 & 553 & 2.9 & 0.061 & 0.001 & 13.242 & 0.226 & 1.580 & 0.034 & 635 & 24 & 469 & 8 & 498 & 8 & discordant & \\
\hline $6 \mathrm{c}$ & 1185 & 316 & 3.7 & 0.061 & 0.001 & 12.364 & 0.209 & 1.420 & 0.030 & 642 & 28 & 502 & 8 & 542 & 9 & discordant & \\
\hline 5 & 659 & 282 & 2.3 & 0.058 & 0.001 & 12.097 & 0.272 & 1.585 & 0.051 & 516 & 39 & 512 & 11 & 497 & 12 & 506 & 9 \\
\hline $2 \mathrm{c}$ & 1410 & 891 & 1.6 & 0.066 & 0.001 & 13.006 & 0.327 & 1.435 & 0.036 & 822 & 31 & 478 & 11 & 537 & 10 & discordant & \\
\hline
\end{tabular}


Sample 91-17 Page 2

\begin{tabular}{|c|c|c|c|c|c|c|c|c|c|c|c|c|c|c|c|c|c|}
\hline \multirow[b]{3}{*}{ Zircon } & \multirow[b]{3}{*}{$\mathrm{U}(\mathrm{ppm})$} & \multirow[b]{3}{*}{ Th (ppm) } & \multirow[b]{3}{*}{$\mathrm{U} / \mathrm{Th}$} & \multicolumn{7}{|c|}{ Isotopic ratios } & \multicolumn{3}{|c|}{ Apparent ages (Ma) } & \multirow[b]{2}{*}{${ }^{207} \mathrm{~Pb}$} & \multirow[b]{3}{*}{$\pm \mathrm{Ma}$} & \multirow[b]{3}{*}{ Concordia } & \multirow[b]{3}{*}{$\pm \mathrm{Ma}$} \\
\hline & & & & ${ }^{207} \mathrm{~Pb}$ & & ${ }^{238} \mathrm{U}$ & & ${ }^{235} \mathrm{U}$ & & ${ }^{207} \mathrm{~Pb}$ & & ${ }^{206} \mathrm{~Pb}$ & & & & & \\
\hline & & & & ${ }^{206} \mathrm{~Pb}$ & $\pm(2 \sigma)$ & ${ }^{206} \mathrm{~Pb}$ & $\pm(2 \sigma)$ & ${ }^{207} \mathrm{~Pb}$ & $\pm(2 \sigma)$ & ${ }^{206} \mathrm{~Pb}$ & $\pm \mathrm{Ma}$ & ${ }^{238} \mathrm{U}$ & $\pm \mathrm{Ma}$ & $\overline{{ }^{235} \mathrm{U}}$ & & & \\
\hline $1 \mathrm{c}$ & 138 & 50 & 2.8 & 0.154 & 0.005 & 9.696 & 0.346 & 0.468 & 0.024 & 2392 & 59 & 633 & 21 & 1162 & 34 & discordant & \\
\hline 1 (repeat) & 205 & 63 & 3.2 & 0.059 & 0.002 & 12.193 & 0.412 & 1.673 & 0.109 & 580 & 71 & 508 & 16 & 476 & 24 & 498 & 200 \\
\hline 4 & 652 & 268 & 2.4 & 0.060 & 0.001 & 10.566 & 0.268 & 1.331 & 0.041 & 586 & 40 & 583 & 14 & 569 & 13 & 575 & 11 \\
\hline 7 & 921 & 411 & 2.2 & 0.060 & 0.001 & 12.558 & 0.199 & 1.537 & 0.036 & 595 & 32 & 494 & 7 & 509 & 9 & 500 & 96 \\
\hline 10 & 704 & 328 & 2.1 & 0.061 & 0.001 & 11.572 & 0.193 & 1.400 & 0.038 & 635 & 38 & 534 & 8 & 548 & 11 & 539 & 7 \\
\hline $12 r$ & 726 & 245 & 3.0 & 0.059 & 0.001 & 12.384 & 0.205 & 1.542 & 0.041 & 577 & 36 & 501 & 8 & 508 & 10 & 503 & 6 \\
\hline $12 \mathrm{c}$ & 299 & 143 & 2.1 & 0.059 & 0.002 & 12.041 & 0.283 & 1.587 & 0.064 & 571 & 59 & 514 & 11 & 497 & 15 & 508 & 10 \\
\hline 13 & 167 & 86 & 1.9 & 0.061 & 0.002 & 12.898 & 0.462 & 1.862 & 0.136 & 622 & 86 & 482 & 16 & 437 & 24 & 468 & 260 \\
\hline 13(repeat) & 194 & 82 & 2.4 & 0.060 & 0.002 & 12.593 & 0.369 & 1.760 & 0.125 & 619 & 75 & 493 & 14 & 457 & 25 & 485 & 190 \\
\hline $14 \mathrm{c}$ & 718 & 446 & 1.6 & 0.060 & 0.001 & 10.878 & 0.220 & 1.329 & 0.038 & 587 & 33 & 567 & 11 & 570 & 12 & 568 & 9 \\
\hline $15 c$ & 273 & 52 & 5.2 & 0.071 & 0.001 & 6.717 & 0.178 & 0.692 & 0.024 & 963 & 39 & 895 & 22 & 908 & 20 & 902 & 17 \\
\hline $15 r$ & 227 & 49 & 4.6 & 0.075 & 0.001 & 5.560 & 0.144 & 0.546 & 0.017 & 1074 & 36 & 1067 & 25 & 1057 & 20 & 1060 & 16 \\
\hline 8 & 512 & 103 & 5.0 & 0.059 & 0.001 & 10.260 & 0.277 & 1.274 & 0.045 & 551 & 44 & 600 & 15 & 589 & 15 & 694 & 12 \\
\hline 8(repeat) & 978 & 223 & 4.4 & 0.059 & 0.001 & 10.244 & 0.253 & 1.299 & 0.038 & 560 & 34 & 601 & 14 & 580 & 13 & 589 & 170 \\
\hline $6 \mathrm{c}$ & 170 & 65 & 2.6 & 0.070 & 0.002 & 6.739 & 0.190 & 0.736 & 0.030 & 926 & 53 & 892 & 23 & 872 & 23 & 882 & 17 \\
\hline 6r & 208 & 84 & 2.5 & 0.070 & 0.002 & 7.179 & 0.247 & 0.772 & 0.038 & 927 & 51 & 841 & 26 & 844 & 27 & 842 & 21 \\
\hline $7 \mathrm{c}$ & 380 & 253 & 1.5 & 0.059 & 0.001 & 10.115 & 0.301 & 1.292 & 0.048 & 582 & 47 & 608 & 17 & 582 & 16 & 594 & 190 \\
\hline $7 \mathrm{r}$ & 484 & 384 & 1.3 & 0.063 & 0.001 & 10.039 & 0.306 & 1.233 & 0.045 & 703 & 43 & 612 & 17 & 603 & 16 & 607 & 13 \\
\hline $9 \mathrm{c}$ & 461 & 331 & 1.4 & 0.062 & 0.002 & 13.250 & 0.425 & 1.798 & 0.087 & 681 & 71 & 469 & 14 & 449 & 17 & 461 & 11 \\
\hline $9 \mathrm{r}$ & 366 & 260 & 1.4 & 0.060 & 0.001 & 12.353 & 0.377 & 1.427 & 0.090 & 614 & 50 & 502 & 14 & 540 & 25 & 510 & 210 \\
\hline $1 \mathrm{c}$ & 691 & 331 & 2.1 & 0.057 & 0.001 & 10.244 & 0.179 & 1.302 & 0.034 & 505 & 35 & 601 & 10 & 579 & 11 & 591 & 150 \\
\hline 2 & 275 & 159 & 1.7 & 0.092 & 0.001 & 3.793 & 0.074 & 0.302 & 0.007 & 1467 & 25 & 1509 & 26 & 1486 & 18 & 1492 & 16 \\
\hline 3 & 1004 & 726 & 1.4 & 0.097 & 0.001 & 12.533 & 0.245 & 0.970 & 0.031 & 1562 & 26 & 495 & 9 & 720 & 16 & discordant & \\
\hline $4 c$ & 730 & 1125 & 0.6 & 0.161 & 0.003 & 15.721 & 0.234 & 0.727 & 0.018 & 2467 & 35 & 398 & 6 & 879 & 15 & discordant & \\
\hline
\end{tabular}


Sample 148-16 Page 1

\begin{tabular}{|c|c|c|c|c|c|c|c|c|c|c|c|c|c|c|c|c|c|}
\hline \multirow[b]{3}{*}{ Zircon } & \multirow[b]{3}{*}{$\mathrm{U}$ (ppm) } & \multirow[b]{3}{*}{ Th (ppm) } & \multirow[b]{3}{*}{$\mathrm{U} / \mathrm{Th}$} & \multicolumn{7}{|c|}{ Isotopic ratios } & \multicolumn{3}{|c|}{ Apparent ages $(\mathrm{Ma})$} & \multirow[b]{2}{*}{${ }^{207} \mathrm{~Pb}$} & \multirow[b]{3}{*}{$\pm \mathrm{Ma}$} & \multirow[b]{3}{*}{ Concordia } & \multirow[b]{3}{*}{$\pm \mathrm{Ma}$} \\
\hline & & & & \multicolumn{2}{|l|}{${ }^{207} \mathrm{~Pb}$} & ${ }^{238} \mathrm{U}$ & & ${ }^{235} \mathrm{U}$ & & ${ }^{207} \mathrm{~Pb}$ & & ${ }^{206} \mathrm{~Pb}$ & & & & & \\
\hline & & & & ${ }^{206} \mathrm{~Pb}$ & $\pm(2 \sigma)$ & ${ }^{206} \mathrm{~Pb}$ & $\pm(2 \sigma)$ & ${ }^{207} \mathrm{~Pb}$ & $\pm(2 \sigma)$ & ${ }^{206} \mathrm{~Pb}$ & $\pm \mathrm{Ma}$ & ${ }^{238} \mathrm{U}$ & $\pm \mathrm{Ma}$ & $\overline{{ }^{235} \mathrm{U}}$ & & & \\
\hline 12 & 1671 & 417 & 4.0 & 0.058 & 0.001 & 11.071 & 0.194 & 1.401 & 0.030 & 537 & 35 & 558 & 9 & 548 & 9 & 552 & 7 \\
\hline 11 & 127 & 58 & 2.2 & 0.067 & 0.004 & 13.269 & 0.744 & 1.861 & 0.177 & 835 & 114 & 469 & 24 & 437 & 31 & 457 & 21 \\
\hline 9 & 393 & 179 & 2.2 & 0.067 & 0.001 & 7.747 & 0.156 & 0.860 & 0.025 & 837 & 35 & 783 & 15 & 784 & 16 & 783 & 11 \\
\hline 8 & 288 & 124 & 2.3 & 0.057 & 0.002 & 11.152 & 0.344 & 1.575 & 0.104 & 479 & 60 & 554 & 16 & 499 & 25 & discordant & \\
\hline 10 & 1109 & 740 & 1.5 & 0.058 & 0.001 & 11.559 & 0.179 & 1.472 & 0.036 & 511 & 29 & 535 & 8 & 527 & 10 & 532 & 6 \\
\hline 13 & 254 & 95 & 2.7 & 0.059 & 0.002 & 10.985 & 0.260 & 1.531 & 0.091 & 551 & 79 & 562 & 12 & 511 & 23 & discordant & \\
\hline 14 & 1412 & 282 & 5.0 & 0.059 & 0.001 & 10.947 & 0.142 & 1.327 & 0.025 & 561 & 25 & 564 & 7 & 571 & 8 & 566 & 5 \\
\hline $15 \mathrm{c}$ & 369 & 144 & 2.6 & 0.061 & 0.001 & 10.894 & 0.293 & 1.334 & 0.048 & 644 & 47 & 566 & 14 & 569 & 15 & 567 & 11 \\
\hline $15 r$ & 920 & 188 & 4.9 & 0.058 & 0.001 & 10.828 & 0.245 & 1.355 & 0.033 & 541 & 32 & 570 & 12 & 562 & 10 & 565 & 8 \\
\hline 17 & 191 & 171 & 1.1 & 0.159 & 0.002 & 2.811 & 0.072 & 0.129 & 0.003 & 2446 & 21 & 1963 & 43 & 2207 & 22 & discordant & \\
\hline 16 & 446 & 55 & 8.2 & 0.071 & 0.002 & 5.886 & 0.163 & 0.615 & 0.021 & 959 & 47 & 1012 & 25 & 981 & 21 & 992 & 250 \\
\hline 4 & 146 & 68 & 2.1 & 0.063 & 0.003 & 10.554 & 0.374 & 1.523 & 0.212 & 716 & 104 & 584 & 19 & 513 & 50 & 575 & 290 \\
\hline 5 & 249 & 86 & 2.9 & 0.060 & 0.002 & 10.320 & 0.274 & 1.367 & 0.066 & 617 & 59 & 596 & 15 & 558 & 20 & 582 & 240 \\
\hline 6 & 436 & 263 & 1.7 & 0.062 & 0.002 & 11.343 & 0.269 & 1.371 & 0.052 & 673 & 51 & 545 & 12 & 557 & 16 & 549 & 10 \\
\hline 7 & 190 & 112 & 1.7 & 0.062 & 0.002 & 12.170 & 0.668 & 1.672 & 0.149 & 666 & 74 & 509 & 26 & 476 & 32 & 496 & 22 \\
\hline $2 \mathrm{a}$ & 253 & 145 & 1.7 & 0.085 & 0.003 & 12.752 & 0.363 & 1.176 & 0.045 & 1311 & 68 & 487 & 13 & 625 & 17 & discordant & \\
\hline $4 a$ & 160 & 84 & 1.9 & 0.121 & 0.007 & 11.642 & 0.405 & 0.854 & 0.059 & 1978 & 96 & 531 & 17 & 788 & 36 & discordant & \\
\hline $5 a$ & 155 & 292 & 0.5 & 0.127 & 0.005 & 13.057 & 0.537 & 0.748 & 0.040 & 2063 & 62 & 476 & 18 & 862 & 30 & discordant & \\
\hline $6 a$ & 552 & 238 & 2.3 & 0.054 & 0.010 & 12.409 & 0.221 & 1.580 & 0.049 & 361 & 376 & 500 & 8 & 498 & 12 & 499 & 7 \\
\hline $7 a$ & 135 & 530 & 0.3 & 0.104 & 0.005 & 12.646 & 0.512 & 1.001 & 0.073 & 1689 & 94 & 491 & 18 & 704 & 35 & discordant & \\
\hline
\end{tabular}


Sample 205-15 Page 1

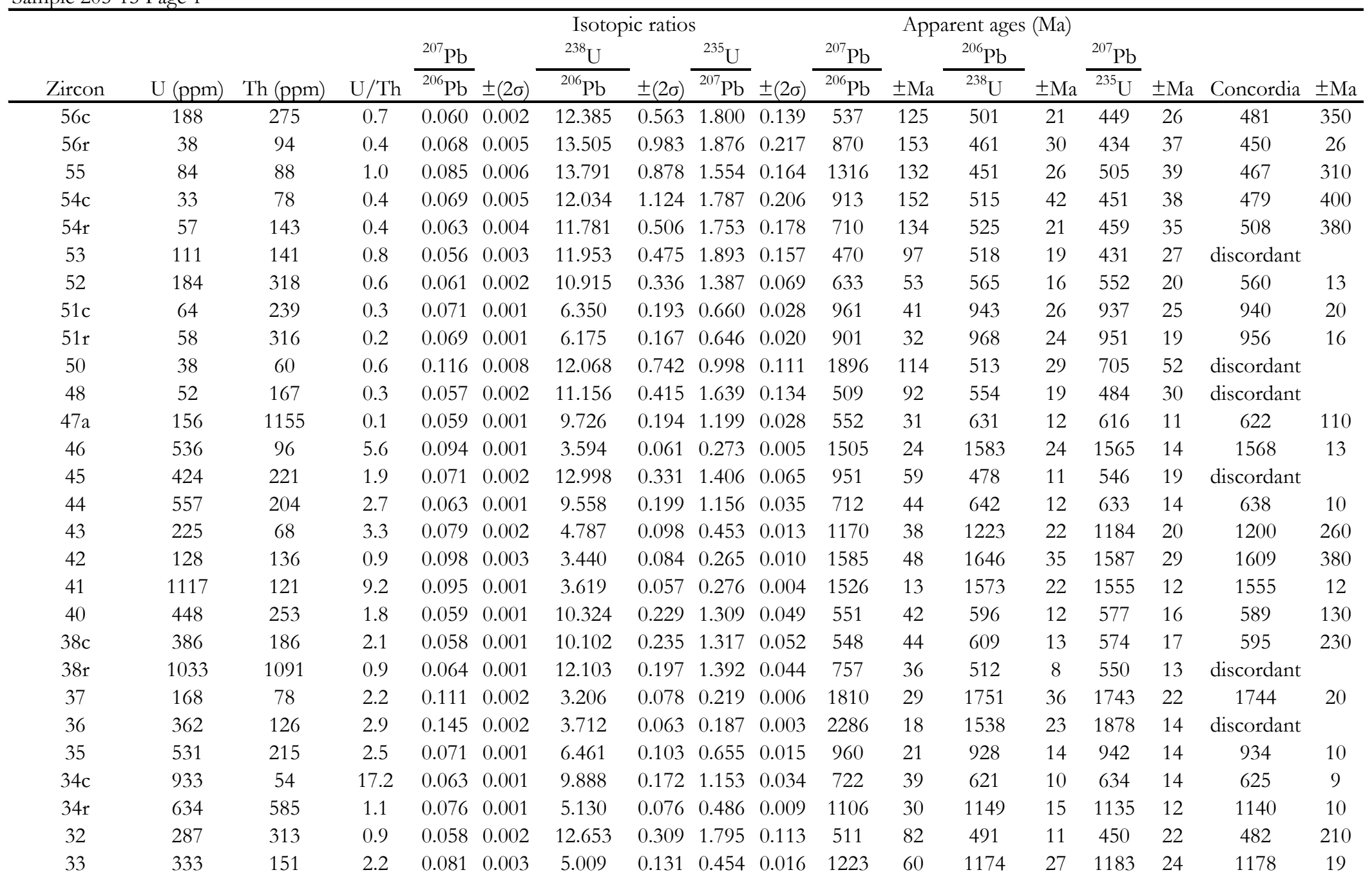


Sample 205-15 Page 2

\begin{tabular}{|c|c|c|c|c|c|c|c|c|c|c|c|c|c|c|c|c|c|}
\hline \multirow[b]{3}{*}{ Zircon } & \multirow[b]{3}{*}{$\mathrm{U}(\mathrm{ppm})$} & \multirow[b]{3}{*}{ Th (ppm) } & \multirow[b]{3}{*}{$\mathrm{U} / \mathrm{Th}$} & \multicolumn{7}{|c|}{ Isotopic ratios } & \multicolumn{4}{|c|}{ Apparent ages $(\mathrm{Ma})$} & \multirow[b]{3}{*}{$\pm \mathrm{Ma}$} & \multirow[b]{3}{*}{ Concordia } & \multirow[b]{3}{*}{$\pm \mathrm{Ma}$} \\
\hline & & & & \multicolumn{2}{|l|}{${ }^{207} \mathrm{~Pb}$} & ${ }^{238} \mathrm{U}$ & & ${ }^{235} \mathrm{U}$ & & ${ }^{207} \mathrm{~Pb}$ & & ${ }^{206} \mathrm{~Pb}$ & & ${ }^{207} \mathrm{~Pb}$ & & & \\
\hline & & & & $\overline{{ }^{206} \mathrm{~Pb}}$ & $\pm(2 \sigma)$ & ${ }^{206} \mathrm{~Pb}$ & $\pm(2 \sigma)$ & ${ }^{207} \mathrm{~Pb}$ & $\pm(2 \sigma)$ & ${ }^{206} \mathrm{~Pb}$ & $\pm \mathrm{Ma}$ & ${ }^{238} \mathrm{U}$ & $\pm \mathrm{Ma}$ & ${ }^{235} \mathrm{U}$ & & & \\
\hline $31 \mathrm{c}$ & 362 & 121 & 3.0 & 0.080 & 0.001 & 4.659 & 0.130 & 0.431 & 0.013 & 1190 & 29 & 1254 & 31 & 1220 & 21 & 1227 & 270 \\
\hline $31 \mathrm{r}$ & 255 & 90 & 2.8 & 0.059 & 0.002 & 10.707 & 0.466 & 1.412 & 0.086 & 573 & 56 & 576 & 23 & 544 & 24 & 561 & 18 \\
\hline 30 & 220 & 119 & 1.8 & 0.160 & 0.002 & 2.407 & 0.088 & 0.108 & 0.003 & 2453 & 23 & 2241 & 67 & 2363 & 28 & discordant & \\
\hline $29 c$ & 195 & 71 & 2.8 & 0.161 & 0.002 & 2.153 & 0.059 & 0.098 & 0.003 & 2469 & 21 & 2460 & 55 & 2457 & 27 & 2456 & 28 \\
\hline $29 \mathrm{r}$ & 556 & 84 & 6.7 & 0.077 & 0.001 & 5.048 & 0.167 & 0.482 & 0.015 & 1121 & 32 & 1166 & 34 & 1141 & 21 & 1142 & 21 \\
\hline 28 & 743 & 208 & 3.6 & 0.059 & 0.001 & 9.875 & 0.277 & 1.205 & 0.037 & 583 & 33 & 622 & 16 & 614 & 14 & 617 & 11 \\
\hline 27 & 254 & 130 & 2.0 & 0.091 & 0.001 & 3.571 & 0.073 & 0.289 & 0.007 & 1440 & 30 & 1592 & 28 & 1520 & 19 & discordant & \\
\hline $25 r$ & 340 & 159 & 2.1 & 0.091 & 0.001 & 3.776 & 0.085 & 0.302 & 0.007 & 1449 & 23 & 1515 & 30 & 1484 & 17 & 1489 & 210 \\
\hline $25 \mathrm{c}$ & 673 & 371 & 1.8 & 0.055 & 0.001 & 16.197 & 0.399 & 2.227 & 0.089 & 409 & 53 & 386 & 9 & 377 & 12 & 383 & 8 \\
\hline 24 & 96 & 41 & 2.4 & 0.070 & 0.003 & 7.632 & 0.319 & 0.919 & 0.077 & 927 & 81 & 794 & 30 & 748 & 42 & 778 & 25 \\
\hline $23 c$ & 224 & 95 & 2.4 & 0.065 & 0.002 & 8.102 & 0.222 & 0.971 & 0.045 & 787 & 56 & 751 & 19 & 719 & 23 & 738 & 210 \\
\hline $23 r$ & 82 & 43 & 1.9 & 0.087 & 0.004 & 5.884 & 0.234 & 0.576 & 0.051 & 1370 & 83 & 1012 & 36 & 1023 & 54 & 1015 & 32 \\
\hline $22 c$ & 722 & 117 & 6.2 & 0.059 & 0.001 & 11.056 & 0.417 & 1.392 & 0.054 & 556 & 39 & 558 & 19 & 550 & 16 & 553 & 14 \\
\hline 21 & 168 & 42 & 4.0 & 0.075 & 0.002 & 5.708 & 0.188 & 0.562 & 0.024 & 1058 & 47 & 1041 & 31 & 1038 & 27 & 1039 & 22 \\
\hline 21 (repeat) & 407 & 123 & 3.3 & 0.109 & 0.001 & 2.986 & 0.088 & 0.202 & 0.006 & 1790 & 21 & 1863 & 46 & 1813 & 25 & 1812 & 410 \\
\hline $18 \mathrm{c}$ & 290 & 110 & 2.6 & 0.112 & 0.001 & 2.897 & 0.073 & 0.188 & 0.005 & 1838 & 22 & 1912 & 41 & 1873 & 21 & 1873 & 280 \\
\hline $18 \mathrm{r}$ & 166 & 33 & 5.0 & 0.060 & 0.003 & 11.609 & 0.451 & 1.641 & 0.125 & 612 & 89 & 533 & 19 & 484 & 28 & 517 & 300 \\
\hline $17 \mathrm{c}$ & 367 & 127 & 2.9 & 0.059 & 0.002 & 11.402 & 0.494 & 1.491 & 0.082 & 556 & 55 & 542 & 22 & 521 & 21 & 531 & 17 \\
\hline $17 \mathrm{r}$ & 187 & 85 & 2.2 & 0.064 & 0.003 & 11.181 & 0.536 & 1.448 & 0.110 & 749 & 83 & 552 & 24 & 534 & 30 & 545 & 21 \\
\hline 16 & 356 & 313 & 1.1 & 0.058 & 0.001 & 9.853 & 0.407 & 1.285 & 0.067 & 532 & 49 & 623 & 24 & 585 & 22 & 602 & 290 \\
\hline 16(repeat) & 431 & 243 & 1.8 & 0.063 & 0.001 & 9.782 & 0.328 & 1.180 & 0.052 & 693 & 50 & 628 & 19 & 624 & 20 & 625 & 15 \\
\hline 14 & 338 & 134 & 2.5 & 0.072 & 0.002 & 6.785 & 0.188 & 0.715 & 0.025 & 990 & 37 & 887 & 22 & 889 & 20 & 887 & 16 \\
\hline $13 c$ & 140 & 81 & 1.7 & 0.063 & 0.003 & 12.464 & 0.604 & 1.700 & 0.149 & 710 & 88 & 498 & 22 & 470 & 31 & 488 & 19 \\
\hline $13 r$ & 264 & 201 & 1.3 & 0.060 & 0.002 & 12.327 & 0.395 & 1.590 & 0.081 & 614 & 79 & 503 & 15 & 496 & 19 & 500 & 12 \\
\hline 12 & 170 & 110 & 1.6 & 0.063 & 0.002 & 11.414 & 0.353 & 1.452 & 0.106 & 711 & 69 & 542 & 16 & 532 & 29 & 539 & 14 \\
\hline 10 & 52 & 46 & 1.1 & 0.076 & 0.004 & 5.908 & 0.309 & 0.762 & 0.084 & 1088 & 96 & 1008 & 47 & 852 & 59 & discordant & \\
\hline 9 & 244 & 156 & 1.6 & 0.073 & 0.001 & 6.099 & 0.135 & 0.625 & 0.023 & 1012 & 37 & 979 & 20 & 971 & 23 & 975 & 15 \\
\hline $8 c$ & 215 & 246 & 0.9 & 0.076 & 0.002 & 5.329 & 0.120 & 0.524 & 0.016 & 1103 & 41 & 1109 & 23 & 1085 & 20 & 1095 & 15 \\
\hline
\end{tabular}


Sample 205-15 Page 3

\begin{tabular}{|c|c|c|c|c|c|c|c|c|c|c|c|c|c|c|c|c|c|}
\hline \multirow[b]{3}{*}{ Zircon } & \multirow[b]{3}{*}{$\mathrm{U}(\mathrm{ppm})$} & \multirow[b]{3}{*}{ Th (ppm) } & \multirow[b]{3}{*}{$\mathrm{U} / \mathrm{Th}$} & \multicolumn{7}{|c|}{ Isotopic ratios } & \multicolumn{3}{|c|}{ Apparent ages $(\mathrm{Ma})$} & \multirow[b]{2}{*}{${ }^{207} \mathrm{~Pb}$} & \multirow[b]{3}{*}{$\pm \mathrm{Ma}$} & \multirow[b]{3}{*}{ Concordia } & \multirow[b]{3}{*}{$\pm \mathrm{Ma}$} \\
\hline & & & & ${ }^{207} \mathrm{~Pb}$ & & ${ }^{238} \mathrm{U}$ & & ${ }^{235} \mathrm{U}$ & & ${ }^{207} \mathrm{~Pb}$ & & ${ }^{206} \mathrm{~Pb}$ & & & & & \\
\hline & & & & ${ }^{206} \mathrm{~Pb}$ & $\pm(2 \sigma)$ & ${ }^{206} \mathrm{~Pb}$ & $\pm(2 \sigma)$ & ${ }^{207} \mathrm{~Pb}$ & $\pm(2 \sigma)$ & ${ }^{206} \mathrm{~Pb}$ & $\pm \mathrm{Ma}$ & ${ }^{238} \mathrm{U}$ & $\pm \mathrm{Ma}$ & ${ }^{235} \mathrm{U}$ & & & \\
\hline $7 \mathrm{c}$ & 119 & 61 & 2.0 & 0.066 & 0.003 & 13.054 & 0.601 & 1.836 & 0.198 & 777 & 115 & 476 & 20 & 442 & 36 & 468 & 19 \\
\hline $7 \mathrm{r}$ & 96 & 47 & 2.1 & 0.068 & 0.004 & 13.105 & 0.622 & 1.864 & 0.197 & 857 & 114 & 474 & 21 & 436 & 35 & 464 & 19 \\
\hline $6 c$ & 531 & 187 & 2.8 & 0.057 & 0.001 & 11.971 & 0.256 & 1.598 & 0.053 & 498 & 51 & 517 & 10 & 494 & 13 & 508 & 15 \\
\hline 6r & 632 & 214 & 2.9 & 0.055 & 0.001 & 12.735 & 0.252 & 1.743 & 0.065 & 427 & 43 & 487 & 9 & 461 & 13 & discordant & \\
\hline $5 c$ & 227 & 141 & 1.6 & 0.214 & 0.002 & 1.711 & 0.028 & 0.058 & 0.001 & 2934 & 14 & 2968 & 39 & 2946 & 14 & 1946 & 13 \\
\hline $4 c$ & 188 & 101 & 1.9 & 0.217 & 0.002 & 1.743 & 0.030 & 0.059 & 0.001 & 2963 & 9 & 2925 & 40 & 2937 & 16 & 2936 & 16 \\
\hline $4 \mathrm{r}$ & 191 & 28 & 6.8 & 0.076 & 0.002 & 5.478 & 0.152 & 0.548 & 0.021 & 1088 & 42 & 1081 & 27 & 1055 & 24 & 1065 & 22 \\
\hline 3 & 268 & 191 & 1.4 & 0.077 & 0.002 & 5.654 & 0.139 & 0.554 & 0.018 & 1115 & 40 & 1050 & 23 & 1048 & 21 & 1048 & 16 \\
\hline $2 c$ & 713 & 357 & 2.0 & 0.073 & 0.001 & 6.350 & 0.152 & 0.632 & 0.015 & 1010 & 27 & 943 & 20 & 964 & 14 & 957 & 13 \\
\hline $2 \mathrm{r}$ & 108 & 86 & 1.3 & 0.083 & 0.002 & 4.721 & 0.151 & 0.449 & 0.027 & 1261 & 49 & 1239 & 35 & 1191 & 40 & 1218 & 430 \\
\hline $1 \mathrm{c}$ & 482 & 80 & 6.0 & 0.076 & 0.001 & 6.954 & 0.190 & 0.676 & 0.021 & 1106 & 34 & 866 & 22 & 923 & 19 & discordant & \\
\hline $1 \mathrm{r}$ & 745 & 34 & 22.1 & 0.097 & 0.001 & 3.756 & 0.088 & 0.282 & 0.006 & 1561 & 16 & 1522 & 31 & 1538 & 16 & 1535 & 16 \\
\hline
\end{tabular}

Sample 249-14 Page 1

\begin{tabular}{|c|c|c|c|c|c|c|c|c|c|c|c|c|c|c|c|c|c|}
\hline \multirow[b]{3}{*}{ Zircon } & \multirow[b]{3}{*}{$\mathrm{U}(\mathrm{ppm})$} & \multirow[b]{3}{*}{ Th (ppm) } & \multirow[b]{3}{*}{$\mathrm{U} / \mathrm{Th}$} & \multicolumn{6}{|c|}{ Isotopic ratios } & \multicolumn{5}{|c|}{ Apparent ages $(\mathrm{Ma})$} & \multirow[b]{3}{*}{$\pm \mathrm{Ma}$} & \multirow[b]{3}{*}{ Concordia } & \multirow[b]{3}{*}{$\pm \mathrm{Ma}$} \\
\hline & & & & ${ }^{207} \mathrm{~Pb}$ & & ${ }^{238} \mathrm{U}$ & & ${ }^{235} \mathrm{U}$ & & ${ }^{207} \mathrm{~Pb}$ & & ${ }^{206} \mathrm{~Pb}$ & & ${ }^{207} \mathrm{~Pb}$ & & & \\
\hline & & & & ${ }^{206} \mathrm{~Pb}$ & $\pm(2 \sigma)$ & ${ }^{206} \mathrm{~Pb}$ & $\pm(2 \sigma)$ & ${ }^{207} \mathrm{~Pb}$ & $\pm(2 \sigma)$ & ${ }^{206} \mathrm{~Pb}$ & $\pm \mathrm{Ma}$ & ${ }^{238} \mathrm{U}$ & $\pm \mathrm{Ma}$ & ${ }^{235} \mathrm{U}$ & & & \\
\hline $70 \mathrm{c}$ & 614 & 223 & 2.7 & 0.074 & 0.001 & 6.967 & 0.120 & 0.709 & 0.017 & 1033 & 27 & 865 & 14 & 894 & 14 & 878 & 190 \\
\hline $70 \mathrm{r}$ & 963 & 265 & 3.6 & 0.059 & 0.001 & 12.477 & 0.229 & 1.573 & 0.038 & 550 & 33 & 497 & 9 & 500 & 9 & 498 & 7 \\
\hline 69 & 203 & 83 & 2.5 & 0.072 & 0.002 & 6.957 & 0.193 & 0.735 & 0.030 & 975 & 50 & 866 & 22 & 873 & 23 & 869 & 17 \\
\hline 71 & 470 & 235 & 2.0 & 0.092 & 0.001 & 4.840 & 0.165 & 0.385 & 0.011 & 1463 & 26 & 1211 & 36 & 1301 & 20 & discordant & \\
\hline 72 & 273 & 299 & 0.9 & 0.059 & 0.002 & 11.744 & 0.427 & 1.530 & 0.083 & 557 & 59 & 527 & 18 & 511 & 21 & 520 & 15 \\
\hline 68 & 107 & 75 & 1.4 & 0.094 & 0.002 & 3.902 & 0.121 & 0.311 & 0.011 & 1503 & 38 & 1471 & 40 & 1462 & 28 & 1464 & 24 \\
\hline 73 & 91 & 46 & 2.0 & 0.066 & 0.004 & 11.831 & 0.822 & 1.698 & 0.160 & 798 & 123 & 523 & 33 & 470 & 33 & 496 & 340 \\
\hline $67(b)$ & 475 & 78 & 6.1 & 0.146 & 0.001 & 2.437 & 0.055 & 0.120 & 0.002 & 2303 & 17 & 2218 & 41 & 2272 & 17 & 2274 & 320 \\
\hline 75 & 104 & 54 & 1.9 & 0.282 & 0.003 & 1.556 & 0.043 & 0.040 & 0.001 & 3374 & 16 & 3201 & 69 & 3303 & 22 & 3304 & 440 \\
\hline
\end{tabular}


Sample 249-14 Page 2

\begin{tabular}{|c|c|c|c|c|c|c|c|c|c|c|c|c|c|c|c|c|c|}
\hline \multirow[b]{3}{*}{ Zircon } & \multirow[b]{3}{*}{$\mathrm{U}(\mathrm{ppm})$} & \multirow[b]{3}{*}{ Th (ppm) } & \multirow[b]{3}{*}{$\mathrm{U} / \mathrm{Th}$} & \multicolumn{7}{|c|}{ Isotopic ratios } & \multicolumn{3}{|c|}{ Apparent ages $(\mathrm{Ma})$} & \multirow[b]{2}{*}{${ }^{207} \mathrm{~Pb}$} & \multirow[b]{3}{*}{$\pm \mathrm{Ma}$} & \multirow[b]{3}{*}{ Concordia } & \multirow[b]{3}{*}{$\pm \mathrm{Ma}$} \\
\hline & & & & \multicolumn{2}{|l|}{${ }^{207} \mathrm{~Pb}$} & ${ }^{238} \mathrm{U}$ & & ${ }^{235} \mathrm{U}$ & & ${ }^{207} \mathrm{~Pb}$ & & ${ }^{206} \mathrm{~Pb}$ & & & & & \\
\hline & & & & $\overline{{ }^{206} \mathrm{~Pb}}$ & $\pm(2 \sigma)$ & ${ }^{206} \mathrm{~Pb}$ & $\pm(2 \sigma)$ & ${ }^{207} \mathrm{~Pb}$ & $\pm(2 \sigma)$ & ${ }^{206} \mathrm{~Pb}$ & $\pm \mathrm{Ma}$ & ${ }^{238} \mathrm{U}$ & $\pm \mathrm{Ma}$ & ${ }^{235} \mathrm{U}$ & & & \\
\hline 67 & 204 & 92 & 2.2 & 0.070 & 0.001 & 6.509 & 0.381 & 0.696 & 0.040 & 934 & 42 & 922 & 48 & 905 & 33 & 909 & 31 \\
\hline 66 & 142 & 121 & 1.2 & 0.061 & 0.002 & 12.189 & 0.378 & 1.742 & 0.125 & 631 & 76 & 508 & 15 & 461 & 25 & 496 & 270 \\
\hline 65 & 181 & 101 & 1.8 & 0.061 & 0.002 & 11.037 & 0.306 & 1.488 & 0.096 & 637 & 71 & 559 & 14 & 522 & 25 & 550 & 200 \\
\hline 64 & 660 & 316 & 2.1 & 0.060 & 0.003 & 11.039 & 0.212 & 1.372 & 0.037 & 614 & 98 & 559 & 10 & 556 & 11 & 558 & 8 \\
\hline 63 & 234 & 118 & 2.0 & 0.076 & 0.001 & 5.526 & 0.113 & 0.539 & 0.017 & 1084 & 33 & 1073 & 20 & 1066 & 20 & 1069 & 15 \\
\hline 62 & 829 & 357 & 2.3 & 0.072 & 0.001 & 9.644 & 0.253 & 0.994 & 0.025 & 997 & 30 & 636 & 15 & 707 & 13 & discordant & \\
\hline 61 & 441 & 272 & 1.6 & 0.073 & 0.001 & 6.371 & 0.189 & 0.637 & 0.018 & 1014 & 28 & 940 & 25 & 959 & 17 & 954 & 16 \\
\hline 59 & 148 & 54 & 2.8 & 0.186 & 0.002 & 2.020 & 0.055 & 0.077 & 0.002 & 2707 & 17 & 2594 & 57 & 2686 & 21 & discordant & \\
\hline 58 & 305 & 126 & 2.4 & 0.076 & 0.001 & 6.114 & 0.173 & 0.592 & 0.020 & 1096 & 39 & 977 & 25 & 1005 & 21 & 993 & 17 \\
\hline 57 & 237 & 99 & 2.4 & 0.065 & 0.002 & 11.446 & 0.360 & 1.464 & 0.088 & 781 & 54 & 540 & 16 & 529 & 24 & 537 & 14 \\
\hline 56 & 762 & 395 & 1.9 & 0.180 & 0.002 & 2.050 & 0.053 & 0.080 & 0.001 & 2648 & 16 & 2563 & 53 & 2650 & 17 & discordant & \\
\hline 55 & 139 & 23 & 6.1 & 0.068 & 0.002 & 6.140 & 0.220 & 0.641 & 0.030 & 858 & 59 & 973 & 31 & 955 & 29 & 962 & 24 \\
\hline 54 & 731 & 187 & 3.9 & 0.060 & 0.001 & 10.691 & 0.222 & 1.311 & 0.032 & 597 & 30 & 577 & 11 & 576 & 10 & 576 & 9 \\
\hline 53 & 130 & 180 & 0.7 & 0.098 & 0.002 & 3.713 & 0.078 & 0.280 & 0.007 & 1589 & 31 & 1538 & 28 & 1544 & 21 & 1541 & 18 \\
\hline 52 & 1461 & 419 & 3.5 & 0.059 & 0.001 & 11.425 & 0.204 & 1.432 & 0.030 & 552 & 27 & 541 & 9 & 538 & 9 & 539 & 7 \\
\hline 51 & 335 & 201 & 1.7 & 0.071 & 0.001 & 6.851 & 0.167 & 0.725 & 0.021 & 944 & 37 & 879 & 20 & 880 & 17 & 879 & 14 \\
\hline 50 & 241 & 1 & 162.5 & 0.062 & 0.002 & 9.590 & 0.243 & 1.221 & 0.060 & 682 & 58 & 640 & 15 & 608 & 22 & 629 & 190 \\
\hline 49 & 267 & 131 & 2.0 & 0.092 & 0.001 & 4.303 & 0.077 & 0.347 & 0.008 & 1459 & 28 & 1348 & 21 & 1378 & 16 & 1367 & 200 \\
\hline 48 & 191 & 115 & 1.7 & 0.059 & 0.002 & 11.475 & 0.350 & 1.567 & 0.097 & 584 & 67 & 539 & 15 & 502 & 23 & 527 & 220 \\
\hline 47 & 276 & 45 & 6.1 & 0.060 & 0.002 & 11.498 & 0.289 & 1.560 & 0.075 & 599 & 63 & 538 & 13 & 503 & 18 & 526 & 210 \\
\hline 46 & 139 & 107 & 1.3 & 0.063 & 0.002 & 12.926 & 0.539 & 1.701 & 0.114 & 706 & 76 & 481 & 19 & 470 & 24 & 476 & 15 \\
\hline 45 & 212 & 108 & 2.0 & 0.060 & 0.002 & 11.810 & 0.329 & 1.550 & 0.077 & 612 & 77 & 524 & 14 & 506 & 19 & 518 & 11 \\
\hline 42 & 99 & 166 & 0.6 & 0.159 & 0.002 & 2.191 & 0.048 & 0.099 & 0.002 & 2447 & 24 & 2424 & 43 & 2444 & 20 & 2440 & 20 \\
\hline 41 & 370 & 218 & 1.7 & 0.225 & 0.002 & 1.859 & 0.042 & 0.059 & 0.001 & 3016 & 14 & 2776 & 50 & 2929 & 16 & discordant & \\
\hline 40 & 328 & 193 & 1.7 & 0.102 & 0.001 & 3.731 & 0.078 & 0.270 & 0.006 & 1662 & 21 & 1531 & 28 & 1573 & 17 & 1565 & 330 \\
\hline 39 & 515 & 271 & 1.9 & 0.059 & 0.001 & 11.939 & 0.233 & 1.517 & 0.050 & 555 & 47 & 519 & 10 & 514 & 13 & 517 & 8 \\
\hline 38 & 747 & 281 & 2.7 & 0.060 & 0.001 & 12.096 & 0.240 & 1.480 & 0.036 & 595 & 35 & 512 & 10 & 525 & 10 & 518 & 7 \\
\hline 37 & 307 & 119 & 2.6 & 0.111 & 0.001 & 3.145 & 0.057 & 0.209 & 0.004 & 1812 & 17 & 1780 & 28 & 1785 & 15 & 1783 & 15 \\
\hline
\end{tabular}


Sample 249-14 Page 3

\begin{tabular}{|c|c|c|c|c|c|c|c|c|c|c|c|c|c|c|c|c|c|}
\hline \multirow[b]{3}{*}{ Zircon } & \multirow[b]{3}{*}{$\mathrm{U}(\mathrm{ppm})$} & \multirow[b]{3}{*}{ Th (ppm) } & \multirow[b]{3}{*}{$\mathrm{U} / \mathrm{Th}$} & \multicolumn{7}{|c|}{ Isotopic ratios } & \multicolumn{4}{|c|}{ Apparent ages $(\mathrm{Ma})$} & \multirow[b]{3}{*}{$\pm \mathrm{Ma}$} & \multirow[b]{3}{*}{ Concordia } & \multirow[b]{3}{*}{$\pm \mathrm{Ma}$} \\
\hline & & & & \multicolumn{2}{|l|}{${ }^{207} \mathrm{~Pb}$} & ${ }^{238} \mathrm{U}$ & & ${ }^{235} \mathrm{U}$ & & ${ }^{207} \mathrm{~Pb}$ & & ${ }^{206} \mathrm{~Pb}$ & & ${ }^{207} \mathrm{~Pb}$ & & & \\
\hline & & & & $\overline{{ }^{206} \mathrm{~Pb}}$ & $\pm(2 \sigma)$ & ${ }^{206} \mathrm{~Pb}$ & $\pm(2 \sigma)$ & ${ }^{207} \mathrm{~Pb}$ & $\pm(2 \sigma)$ & ${ }^{206} \mathrm{~Pb}$ & $\pm \mathrm{Ma}$ & ${ }^{238} \mathrm{U}$ & $\pm \mathrm{Ma}$ & ${ }^{235} \mathrm{U}$ & & & \\
\hline 36 & 237 & 153 & 1.5 & 0.061 & 0.002 & 10.997 & 0.288 & 1.398 & 0.067 & 625 & 56 & 561 & 14 & 548 & 19 & 557 & 12 \\
\hline 35 & 72 & 39 & 1.9 & 0.066 & 0.004 & 11.586 & 0.505 & 1.815 & 0.194 & 793 & 116 & 534 & 21 & 446 & 35 & discordant & \\
\hline 34 & 159 & 90 & 1.8 & 0.074 & 0.002 & 6.574 & 0.165 & 0.683 & 0.028 & 1037 & 46 & 913 & 21 & 916 & 24 & 914 & 16 \\
\hline 33 & 35 & 27 & 1.3 & 0.103 & 0.005 & 4.036 & 0.164 & 0.341 & 0.022 & 1675 & 82 & 1427 & 50 & 1392 & 47 & 1407 & 36 \\
\hline 32 & 69 & 58 & 1.2 & 0.094 & 0.002 & 3.937 & 0.118 & 0.331 & 0.013 & 1499 & 48 & 1460 & 38 & 1415 & 28 & 1429 & 23 \\
\hline 31 & 192 & 181 & 1.1 & 0.180 & 0.002 & 2.280 & 0.042 & 0.091 & 0.002 & 2657 & 17 & 2346 & 36 & 2519 & 16 & discordant & \\
\hline 30 & 264 & 160 & 1.6 & 0.120 & 0.002 & 3.062 & 0.074 & 0.186 & 0.005 & 1950 & 23 & 1822 & 38 & 1882 & 20 & 1847 & 430 \\
\hline 29 & 396 & 109 & 3.6 & 0.124 & 0.001 & 3.571 & 0.064 & 0.212 & 0.003 & 2015 & 18 & 1592 & 25 & 1773 & 14 & discordant & \\
\hline 28 & 131 & 103 & 1.3 & 0.093 & 0.002 & 3.998 & 0.095 & 0.322 & 0.011 & 1491 & 38 & 1440 & 30 & 1435 & 26 & 1436 & 20 \\
\hline 27 & 249 & 109 & 2.3 & 0.124 & 0.001 & 2.742 & 0.048 & 0.161 & 0.003 & 2016 & 20 & 2005 & 30 & 2006 & 14 & 2004 & 14 \\
\hline 26 & 85 & 59 & 1.4 & 0.112 & 0.004 & 3.085 & 0.090 & 0.207 & 0.007 & 1833 & 59 & 1811 & 45 & 1793 & 28 & 1797 & 25 \\
\hline 25 & 95 & 68 & 1.4 & 0.080 & 0.002 & 5.114 & 0.136 & 0.514 & 0.024 & 1189 & 54 & 1152 & 27 & 1098 & 31 & 1127 & 340 \\
\hline 24 & 754 & 120 & 6.3 & 0.059 & 0.001 & 10.496 & 0.171 & 1.316 & 0.031 & 567 & 31 & 587 & 9 & 574 & 10 & 581 & 7 \\
\hline 23 & 793 & 201 & 3.9 & 0.060 & 0.001 & 10.547 & 0.170 & 1.308 & 0.030 & 601 & 29 & 584 & 9 & 577 & 10 & 581 & 7 \\
\hline 22 & 1888 & 821 & 2.3 & 0.072 & 0.001 & 28.645 & 0.657 & 2.909 & 0.082 & 973 & 32 & 221 & 5 & 300 & 7 & discordant & \\
\hline 21 & 214 & 79 & 2.7 & 0.095 & 0.001 & 4.011 & 0.071 & 0.313 & 0.007 & 1519 & 25 & 1435 & 22 & 1457 & 16 & 1449 & 14 \\
\hline 20 & 215 & 136 & 1.6 & 0.071 & 0.001 & 6.419 & 0.149 & 0.683 & 0.023 & 948 & 42 & 934 & 20 & 916 & 20 & 924 & 14 \\
\hline 19 & 40 & 109 & 0.4 & 0.066 & 0.003 & 12.339 & 0.441 & 1.668 & 0.157 & 819 & 94 & 503 & 17 & 477 & 33 & 497 & 16 \\
\hline 18 & 247 & 281 & 0.9 & 0.081 & 0.001 & 4.892 & 0.128 & 0.445 & 0.014 & 1223 & 34 & 1199 & 28 & 1196 & 21 & 1196 & 18 \\
\hline 17 & 806 & 814 & 1.0 & 0.070 & 0.003 & 20.551 & 1.232 & 2.084 & 0.126 & 838 & 175 & 306 & 17 & 398 & 19 & discordant & \\
\hline 16 & 148 & 445 & 0.3 & 0.075 & 0.001 & 5.857 & 0.215 & 0.564 & 0.018 & 1072 & 36 & 1017 & 33 & 1036 & 20 & 1033 & 20 \\
\hline 15 & 40 & 88 & 0.5 & 0.081 & 0.003 & 5.863 & 0.304 & 0.580 & 0.043 & 1233 & 59 & 1016 & 46 & 1018 & 45 & 1016 & 38 \\
\hline 14 & 209 & 679 & 0.3 & 0.063 & 0.002 & 13.616 & 0.789 & 1.609 & 0.075 & 711 & 64 & 457 & 24 & 491 & 17 & 483 & 320 \\
\hline 13 & 476 & 1155 & 0.4 & 0.064 & 0.001 & 14.363 & 0.361 & 1.589 & 0.043 & 731 & 26 & 434 & 10 & 496 & 10 & discordant & \\
\hline 12 & 108 & 218 & 0.5 & 0.076 & 0.001 & 5.862 & 0.116 & 0.603 & 0.021 & 1089 & 34 & 1016 & 18 & 994 & 21 & 1006 & 15 \\
\hline 11 & 139 & 324 & 0.4 & 0.059 & 0.001 & 11.437 & 0.253 & 1.529 & 0.064 & 574 & 53 & 541 & 11 & 511 & 16 & 531 & 170 \\
\hline 10 & 324 & 1181 & 0.3 & 0.150 & 0.002 & 3.253 & 0.075 & 0.157 & 0.004 & 2348 & 21 & 1729 & 34 & 2029 & 19 & discordant & \\
\hline 9 & 124 & 291 & 0.4 & 0.117 & 0.002 & 3.373 & 0.052 & 0.208 & 0.004 & 1906 & 33 & 1674 & 22 & 1788 & 15 & discordant & \\
\hline
\end{tabular}


Sample 249-14 Page 4

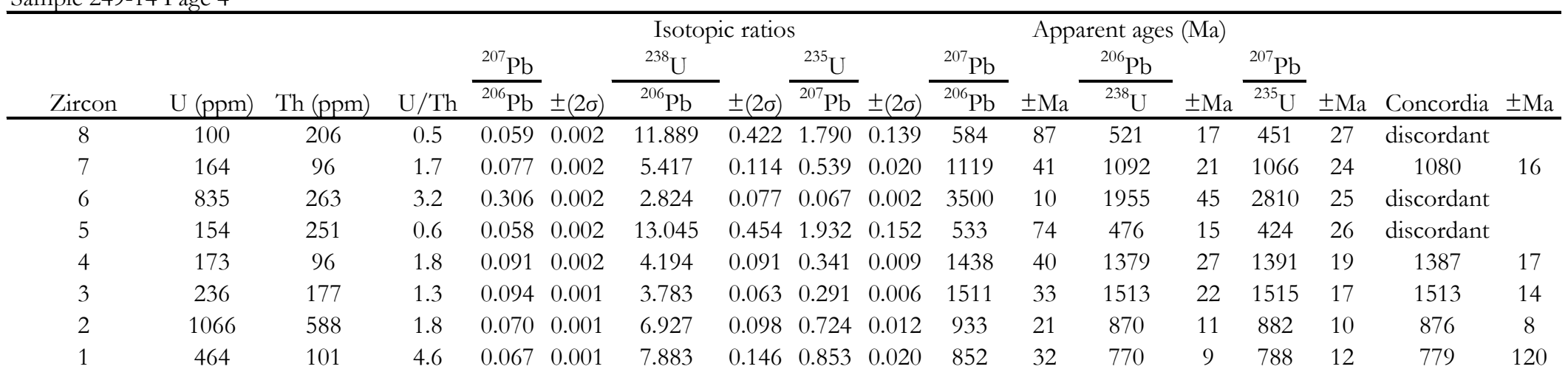

Sample 292-13 Page 1

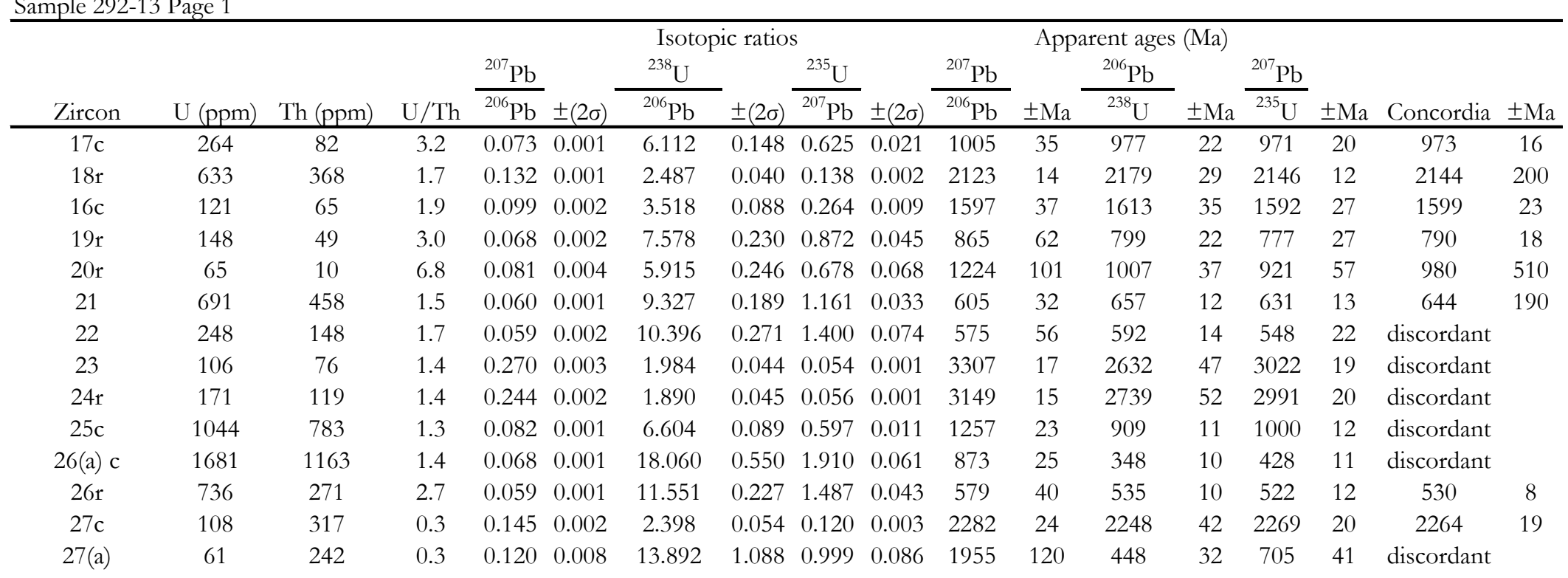


Sample 292-13 Page 2

\begin{tabular}{|c|c|c|c|c|c|c|c|c|c|c|c|c|c|c|c|c|c|}
\hline \multirow[b]{3}{*}{ Zircon } & \multirow[b]{3}{*}{$\mathrm{U}(\mathrm{ppm})$} & \multirow[b]{3}{*}{ Th (ppm) } & \multirow[b]{3}{*}{$\mathrm{U} / \mathrm{Th}$} & \multicolumn{7}{|c|}{ Isotopic ratios } & \multicolumn{4}{|c|}{ Apparent ages $(\mathrm{Ma})$} & \multirow[b]{3}{*}{$\pm \mathrm{Ma}$} & \multirow[b]{3}{*}{ Concordia } & \multirow[b]{3}{*}{$\pm \mathrm{Ma}$} \\
\hline & & & & \multicolumn{2}{|l|}{${ }^{207} \mathrm{~Pb}$} & ${ }^{238} \mathrm{U}$ & & ${ }^{235} \mathrm{U}$ & & ${ }^{207} \mathrm{~Pb}$ & & ${ }^{206} \mathrm{~Pb}$ & & ${ }^{207} \mathrm{~Pb}$ & & & \\
\hline & & & & $\overline{{ }^{206} \mathrm{~Pb}}$ & $\pm(2 \sigma)$ & ${ }^{206} \mathrm{~Pb}$ & $\pm(2 \sigma)$ & ${ }^{207} \mathrm{~Pb}$ & $\pm(2 \sigma)$ & ${ }^{206} \mathrm{~Pb}$ & $\pm \mathrm{Ma}$ & ${ }^{238} \mathrm{U}$ & $\pm \mathrm{Ma}$ & ${ }^{235} \mathrm{U}$ & & & \\
\hline $27(\mathrm{~b})$ & 186 & 30 & 6.1 & 0.099 & 0.003 & 12.666 & 0.456 & 0.972 & 0.048 & 1605 & 54 & 490 & 16 & 719 & 24 & discordant & \\
\hline 28 & 115 & 87 & 1.3 & 0.134 & 0.002 & 2.665 & 0.065 & 0.144 & 0.004 & 2151 & 26 & 2055 & 42 & 2108 & 24 & 2095 & 320 \\
\hline 29 & 515 & 85 & 6.1 & 0.072 & 0.001 & 5.690 & 0.100 & 0.568 & 0.012 & 988 & 29 & 1044 & 17 & 1032 & 14 & 1036 & 11 \\
\hline 30 & 300 & 161 & 1.9 & 0.092 & 0.001 & 4.063 & 0.066 & 0.319 & 0.007 & 1462 & 25 & 1419 & 20 & 1443 & 17 & 1432 & 14 \\
\hline $30(a)$ & 105 & 63 & 1.7 & 0.060 & 0.003 & 12.654 & 0.708 & 1.879 & 0.205 & 612 & 92 & 491 & 25 & 434 & 35 & 471 & 340 \\
\hline $30(\mathrm{~b})$ & 540 & 347 & 1.6 & 0.058 & 0.001 & 11.736 & 0.287 & 1.494 & 0.054 & 518 & 39 & 527 & 12 & 521 & 14 & 524 & 10 \\
\hline $30(\mathrm{~d})$ & 168 & 26 & 6.4 & 0.138 & 0.004 & 11.314 & 0.337 & 0.684 & 0.027 & 2208 & 47 & 546 & 15 & 915 & 23 & discordant & \\
\hline 31 & 1494 & 1129 & 1.3 & 0.082 & 0.001 & 12.719 & 0.172 & 1.128 & 0.022 & 1240 & 20 & 488 & 6 & 645 & 9 & discordant & \\
\hline $34 \mathrm{c}$ & 703 & 217 & 3.2 & 0.059 & 0.001 & 10.729 & 0.219 & 1.340 & 0.041 & 595 & 6 & 575 & 11 & 567 & 13 & 571 & 9 \\
\hline 35 & 394 & 52 & 7.6 & 0.076 & 0.001 & 4.970 & 0.094 & 0.471 & 0.012 & 1108 & 30 & 1182 & 20 & 1157 & 17 & 1167 & 170 \\
\hline 36 & 369 & 285 & 1.3 & 0.075 & 0.001 & 5.154 & 0.190 & 0.500 & 0.018 & 1062 & 33 & 1143 & 37 & 1116 & 24 & 1120 & 24 \\
\hline 37 & 161 & 165 & 1.0 & 0.062 & 0.002 & 11.677 & 0.493 & 1.627 & 0.134 & 674 & 82 & 530 & 21 & 487 & 30 & 516 & 260 \\
\hline 38 & 259 & 113 & 2.3 & 0.108 & 0.001 & 3.199 & 0.101 & 0.215 & 0.006 & 1758 & 24 & 1754 & 47 & 1760 & 23 & 1758 & 23 \\
\hline 39 & 423 & 179 & 2.4 & 0.069 & 0.001 & 6.635 & 0.162 & 0.730 & 0.020 & 893 & 41 & 905 & 20 & 877 & 16 & 886 & 200 \\
\hline 40 & 2201 & 913 & 2.4 & 0.070 & 0.001 & 17.386 & 0.477 & 1.791 & 0.044 & 929 & 26 & 361 & 9 & 451 & 9 & discordant & \\
\hline 75 & 196 & 134 & 1.5 & 0.063 & 0.002 & 9.460 & 0.326 & 1.209 & 0.084 & 684 & 73 & 648 & 21 & 612 & 30 & 637 & 18 \\
\hline $74(a)$ & 103 & 55 & 1.9 & 0.075 & 0.002 & 6.677 & 0.240 & 0.725 & 0.050 & 1075 & 65 & 900 & 29 & 881 & 39 & 893 & 25 \\
\hline 74(b) & 71 & 560 & 0.1 & 0.175 & 0.007 & 11.287 & 0.686 & 0.468 & 0.051 & 2609 & 69 & 547 & 30 & 1162 & 70 & discordant & \\
\hline 73 & 1405 & 474 & 3.0 & 0.061 & 0.001 & 12.993 & 0.320 & 1.565 & 0.044 & 637 & 28 & 478 & 11 & 502 & 11 & discordant & \\
\hline $72 \mathrm{c}$ & 183 & 71 & 2.6 & 0.236 & 0.002 & 1.588 & 0.035 & 0.047 & 0.001 & 3094 & 16 & 3150 & 54 & 3149 & 19 & 3147 & 19 \\
\hline 71 & 314 & 97 & 3.2 & 0.061 & 0.002 & 10.699 & 0.329 & 1.338 & 0.055 & 649 & 53 & 576 & 16 & 567 & 17 & 572 & 13 \\
\hline 69 & 436 & 135 & 3.2 & 0.058 & 0.001 & 10.314 & 0.241 & 1.337 & 0.054 & 533 & 48 & 597 & 13 & 567 & 17 & 586 & 200 \\
\hline 68 & 648 & 433 & 1.5 & 0.057 & 0.001 & 11.950 & 0.280 & 1.574 & 0.058 & 506 & 37 & 518 & 11 & 500 & 14 & 511 & 140 \\
\hline $67 c$ & 141 & 66 & 2.1 & 0.200 & 0.002 & 1.933 & 0.046 & 0.071 & 0.002 & 2822 & 17 & 2689 & 52 & 2760 & 22 & 2757 & 410 \\
\hline 66 & 216 & 128 & 1.7 & 0.078 & 0.002 & 7.662 & 0.218 & 0.791 & 0.040 & 1139 & 58 & 791 & 21 & 830 & 28 & 804 & 250 \\
\hline 64 & 151 & 104 & 1.5 & 0.118 & 0.002 & 2.976 & 0.073 & 0.184 & 0.005 & 1928 & 26 & 1868 & 39 & 1890 & 24 & 1883 & 22 \\
\hline 65 & 658 & 252 & 2.6 & 0.061 & 0.001 & 9.837 & 0.189 & 1.185 & 0.035 & 635 & 37 & 624 & 11 & 622 & 13 & 623 & 9 \\
\hline 63 & 806 & 354 & 2.3 & 0.059 & 0.001 & 10.797 & 0.237 & 1.348 & 0.035 & 555 & 34 & 571 & 12 & 564 & 11 & 567 & 9 \\
\hline
\end{tabular}


Sample 292-13 Page 3

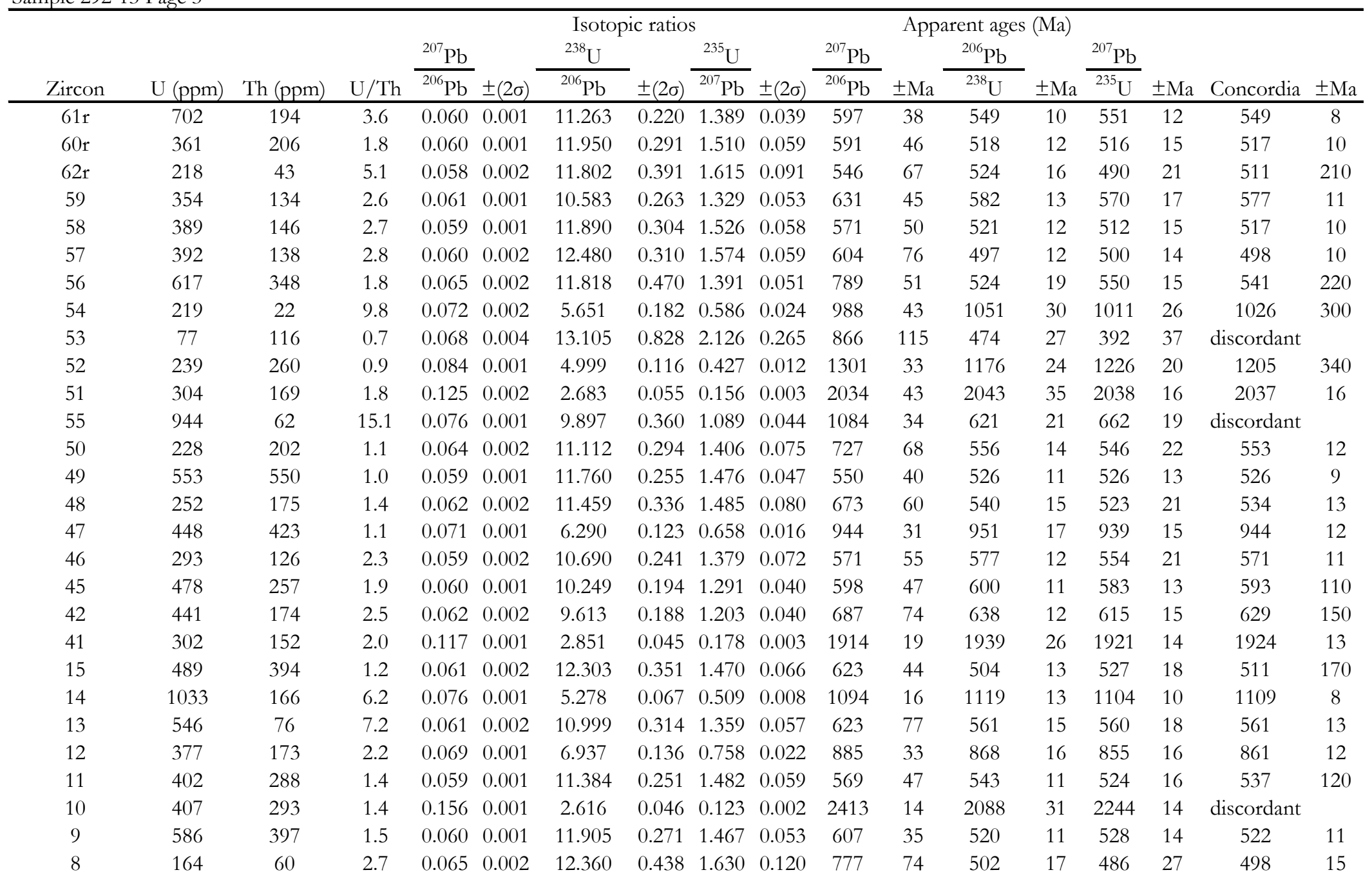


Sample 292-13 Page 4

\begin{tabular}{|c|c|c|c|c|c|c|c|c|c|c|c|c|c|c|c|c|c|}
\hline \multirow[b]{3}{*}{ Zircon } & \multirow[b]{3}{*}{$\mathrm{U}(\mathrm{ppm})$} & \multirow[b]{3}{*}{ Th (ppm) } & \multirow[b]{3}{*}{$\mathrm{U} / \mathrm{Th}$} & \multicolumn{7}{|c|}{ Isotopic ratios } & \multicolumn{3}{|c|}{ Apparent ages $(\mathrm{Ma})$} & \multirow[b]{2}{*}{${ }^{207} \mathrm{~Pb}$} & \multirow[b]{3}{*}{$\pm \mathrm{Ma}$} & \multirow[b]{3}{*}{ Concordia } & \multirow[b]{3}{*}{$\pm \mathrm{Ma}$} \\
\hline & & & & ${ }^{207} \mathrm{~Pb}$ & & ${ }^{238} \mathrm{U}$ & & ${ }^{235} \mathrm{U}$ & & ${ }^{207} \mathrm{~Pb}$ & & ${ }^{206} \mathrm{~Pb}$ & & & & & \\
\hline & & & & ${ }^{206} \mathrm{~Pb}$ & $\pm(2 \sigma)$ & ${ }^{206} \mathrm{~Pb}$ & $\pm(2 \sigma)$ & ${ }^{207} \mathrm{~Pb}$ & $\pm(2 \sigma)$ & ${ }^{206} \mathrm{~Pb}$ & $\pm \mathrm{Ma}$ & ${ }^{238} \mathrm{U}$ & $\pm \mathrm{Ma}$ & ${ }^{235} \mathrm{U}$ & & & \\
\hline 44 & 406 & 205 & 2.0 & 0.060 & 0.001 & 10.944 & 0.244 & 1.389 & 0.047 & 594 & 44 & 564 & 12 & 551 & 14 & 558 & 9 \\
\hline 43 & 362 & 105 & 3.4 & 0.060 & 0.001 & 10.094 & 0.242 & 1.277 & 0.049 & 614 & 47 & 609 & 14 & 588 & 17 & 601 & 150 \\
\hline 7 & 385 & 340 & 1.1 & 0.059 & 0.002 & 28.278 & 1.400 & 3.850 & 0.227 & 570 & 83 & 224 & 10 & 235 & 12 & 229 & 9 \\
\hline 6 & 96 & 37 & 2.6 & 0.069 & 0.003 & 8.926 & 0.446 & 1.088 & 0.097 & 894 & 75 & 685 & 31 & 663 & 41 & 679 & 26 \\
\hline 5 & 511 & 132 & 3.9 & 0.059 & 0.001 & 10.526 & 0.338 & 1.324 & 0.047 & 580 & 49 & 585 & 17 & 572 & 15 & 577 & 12 \\
\hline 4 & 1225 & 457 & 2.7 & 0.060 & 0.001 & 12.922 & 0.346 & 1.617 & 0.049 & 588 & 31 & 481 & 12 & 489 & 12 & 485 & 140 \\
\hline 3 & 456 & 115 & 4.0 & 0.072 & 0.001 & 9.448 & 0.311 & 1.040 & 0.045 & 991 & 36 & 649 & 20 & 685 & 21 & 665 & 280 \\
\hline 2 & 338 & 116 & 2.9 & 0.075 & 0.001 & 5.900 & 0.130 & 0.582 & 0.017 & 1061 & 31 & 1010 & 20 & 1016 & 18 & 1013 & 17 \\
\hline 1 & 69 & 59 & 1.2 & 0.071 & 0.005 & 13.423 & 0.843 & 1.834 & 0.208 & 954 & 133 & 463 & 26 & 442 & 37 & 457 & 24 \\
\hline
\end{tabular}

Sample 295-12- Round 1, Page 1

\begin{tabular}{|c|c|c|c|c|c|c|c|c|c|c|c|c|c|c|c|c|c|}
\hline \multirow[b]{3}{*}{ Zircon } & \multirow[b]{3}{*}{$\mathrm{U}(\mathrm{ppm})$} & \multirow[b]{3}{*}{ Th (ppm) } & \multirow[b]{3}{*}{$\mathrm{U} / \mathrm{Th}$} & \multicolumn{7}{|c|}{ Isotopic ratios } & \multicolumn{4}{|c|}{ Apparent ages $(\mathrm{Ma})$} & \multirow[b]{3}{*}{$\pm \mathrm{Ma}$} & \multirow[b]{3}{*}{ Concordia } & \multirow[b]{3}{*}{$\pm \mathrm{Ma}$} \\
\hline & & & & ${ }^{207} \mathrm{~Pb}$ & & ${ }^{238} \mathrm{U}$ & & ${ }^{235} \mathrm{U}$ & & ${ }^{207} \mathrm{~Pb}$ & & ${ }^{206} \mathrm{~Pb}$ & & ${ }^{207} \mathrm{~Pb}$ & & & \\
\hline & & & & ${ }^{206} \mathrm{~Pb}$ & $\pm(2 \sigma)$ & ${ }^{206} \mathrm{~Pb}$ & $\pm(2 \sigma)$ & ${ }^{207} \mathrm{~Pb}$ & $\pm(2 \sigma)$ & ${ }^{206} \mathrm{~Pb}$ & $\pm \mathrm{Ma}$ & ${ }^{238} \mathrm{U}$ & $\pm \mathrm{Ma}$ & ${ }^{235} \mathrm{U}$ & & & \\
\hline 1 & 370 & 156 & 2.4 & 0.060 & 0.001 & 11.185 & 0.323 & 1.516 & 0.071 & 615 & 47 & 552 & 15 & 515 & 18 & discordant & \\
\hline 2 & 323 & 164 & 2.0 & 0.060 & 0.001 & 11.357 & 0.382 & 1.474 & 0.063 & 612 & 50 & 544 & 17 & 526 & 17 & 535 & 13 \\
\hline 3 & 222 & 170 & 1.3 & 0.082 & 0.001 & 4.631 & 0.126 & 0.417 & 0.012 & 1240 & 34 & 1261 & 30 & 1243 & 21 & 1247 & 19 \\
\hline $4 c$ & 695 & 45 & 15.5 & 0.191 & 0.002 & 2.751 & 0.065 & 0.105 & 0.002 & 2751 & 14 & 2000 & 40 & 2393 & 18 & discordant & \\
\hline 5 & 145 & 195 & 0.7 & 0.084 & 0.002 & 4.534 & 0.148 & 0.415 & 0.015 & 1284 & 39 & 1285 & 37 & 1246 & 26 & 1257 & 23 \\
\hline 7 & 402 & 274 & 1.5 & 0.059 & 0.001 & 10.833 & 0.335 & 1.421 & 0.059 & 585 & 48 & 569 & 16 & 541 & 17 & 555 & 210 \\
\hline 6 & 453 & 305 & 1.5 & 0.057 & 0.001 & 11.632 & 0.323 & 1.573 & 0.056 & 504 & 43 & 532 & 14 & 500 & 14 & discordant & \\
\hline 31 & 90 & 39 & 2.3 & 0.065 & 0.004 & 12.438 & 0.656 & 1.896 & 0.184 & 785 & 115 & 499 & 24 & 430 & 31 & 437 & 420 \\
\hline 32 & 193 & 92 & 2.1 & 0.058 & 0.002 & 12.112 & 0.448 & 1.787 & 0.139 & 524 & 82 & 512 & 18 & 452 & 27 & discordant & \\
\hline 33 & 373 & 80 & 4.7 & 0.218 & 0.002 & 1.566 & 0.041 & 0.047 & 0.001 & 2968 & 16 & 3184 & 64 & 3145 & 19 & 3139 & 19 \\
\hline $34 \mathrm{a}$ & 124 & 63 & 2.0 & 0.262 & 0.003 & 1.569 & 0.040 & 0.044 & 0.001 & 3256 & 22 & 3180 & 63 & 3228 & 20 & 3229 & 20 \\
\hline 34 & 302 & 112 & 2.7 & 0.059 & 0.001 & 10.131 & 0.260 & 1.500 & 0.046 & 555 & 54 & 607 & 15 & 519 & 12 & discordant & \\
\hline
\end{tabular}


Sample 295-12- Round 1, Page 2

\begin{tabular}{|c|c|c|c|c|c|c|c|c|c|c|c|c|c|c|c|c|c|}
\hline \multirow[b]{3}{*}{ Zircon } & \multirow[b]{3}{*}{$\mathrm{U}(\mathrm{ppm})$} & \multirow[b]{3}{*}{ Th (ppm) } & \multirow[b]{3}{*}{$\mathrm{U} / \mathrm{Th}$} & \multicolumn{6}{|c|}{ Isotopic ratios } & \multicolumn{5}{|c|}{ Apparent ages (Ma) } & \multirow[b]{3}{*}{$\pm \mathrm{Ma}$} & \multirow[b]{3}{*}{ Concordia } & \multirow[b]{3}{*}{$\pm \mathrm{Ma}$} \\
\hline & & & & ${ }^{207} \mathrm{~Pb}$ & & ${ }^{238} \mathrm{U}$ & & ${ }^{235} \mathrm{U}$ & & ${ }^{207} \mathrm{~Pb}$ & & ${ }^{206} \mathrm{~Pb}$ & & ${ }^{207} \mathrm{~Pb}$ & & & \\
\hline & & & & ${ }^{206} \mathrm{~Pb}$ & $\pm(2 \sigma)$ & ${ }^{206} \mathrm{~Pb}$ & $\pm(2 \sigma)$ & ${ }^{207} \mathrm{~Pb}$ & $\pm(2 \sigma)$ & ${ }^{206} \mathrm{~Pb}$ & $\pm \mathrm{Ma}$ & ${ }^{238} \mathrm{U}$ & $\pm \mathrm{Ma}$ & ${ }^{235} \mathrm{U}$ & & & \\
\hline 33 & 906 & 280 & 3.2 & 0.057 & 0.001 & 11.412 & 0.225 & 1.489 & 0.033 & 502 & 36 & 542 & 10 & 522 & 9 & discordant & \\
\hline 35 & 99 & 43 & 2.3 & 0.095 & 0.002 & 3.611 & 0.081 & 0.296 & 0.012 & 1525 & 40 & 1576 & 31 & 1501 & 31 & discordant & \\
\hline 36 & 326 & 38 & 8.6 & 0.075 & 0.001 & 5.415 & 0.094 & 0.543 & 0.011 & 1059 & 32 & 1093 & 17 & 1061 & 13 & 1071 & 250 \\
\hline 37 & 253 & 166 & 1.5 & 0.095 & 0.001 & 3.604 & 0.061 & 0.283 & 0.005 & 1529 & 27 & 1579 & 23 & 1536 & 15 & discordant & \\
\hline 38 & 453 & 167 & 2.7 & 0.070 & 0.001 & 6.621 & 0.111 & 0.709 & 0.014 & 923 & 32 & 907 & 14 & 894 & 11 & 898 & 10 \\
\hline 40 & 1248 & 319 & 3.9 & 0.060 & 0.001 & 11.121 & 0.158 & 1.362 & 0.025 & 615 & 29 & 555 & 7 & 559 & 8 & 557 & 6 \\
\hline 41 & 159 & 103 & 1.5 & 0.072 & 0.002 & 12.932 & 0.329 & 1.565 & 0.079 & 981 & 69 & 480 & 11 & 502 & 19 & 485 & 10 \\
\hline 42 & 182 & 208 & 0.9 & 0.143 & 0.002 & 2.140 & 0.034 & 0.110 & 0.002 & 2262 & 21 & 2473 & 32 & 2345 & 15 & discordant & \\
\hline 43 & 699 & 129 & 5.4 & 0.059 & 0.001 & 9.726 & 0.165 & 1.230 & 0.024 & 565 & 31 & 631 & 10 & 604 & 9 & discordant & \\
\hline 44 & 245 & 270 & 0.9 & 0.061 & 0.002 & 9.707 & 0.203 & 1.265 & 0.039 & 633 & 57 & 632 & 12 & 592 & 13 & discordant & \\
\hline $45 c$ & 209 & 145 & 1.4 & 0.062 & 0.003 & 13.692 & 0.966 & 1.778 & 0.140 & 684 & 87 & 455 & 29 & 453 & 27 & 454 & 24 \\
\hline $45 r$ & 386 & 313 & 1.2 & 0.062 & 0.003 & 14.453 & 1.293 & 1.872 & 0.178 & 681 & 90 & 431 & 34 & 435 & 31 & 433 & 31 \\
\hline 46 & 282 & 113 & 2.5 & 0.060 & 0.002 & 12.317 & 0.391 & 1.620 & 0.084 & 588 & 71 & 503 & 15 & 488 & 19 & 498 & 13 \\
\hline 47 & 181 & 83 & 2.2 & 0.111 & 0.002 & 3.189 & 0.072 & 0.211 & 0.006 & 1815 & 27 & 1759 & 34 & 1774 & 23 & 1769 & 22 \\
\hline 48 & 299 & 158 & 1.9 & 0.065 & 0.002 & 10.425 & 0.371 & 1.223 & 0.056 & 778 & 52 & 591 & 19 & 607 & 20 & 598 & 16 \\
\hline 49 & 198 & 112 & 1.8 & 0.200 & 0.002 & 1.875 & 0.033 & 0.067 & 0.001 & 2829 & 20 & 2756 & 39 & 2808 & 15 & 2809 & 280 \\
\hline 51 & 700 & 65 & 10.7 & 0.059 & 0.001 & 10.903 & 0.199 & 1.387 & 0.035 & 571 & 34 & 566 & 10 & 551 & 11 & 559 & 110 \\
\hline 50 & 119 & 195 & 0.6 & 0.065 & 0.003 & 10.940 & 0.433 & 1.469 & 0.113 & 783 & 91 & 564 & 21 & 528 & 30 & 552 & 18 \\
\hline 52 & 262 & 148 & 1.8 & 0.072 & 0.002 & 6.643 & 0.232 & 0.684 & 0.027 & 980 & 46 & 904 & 29 & 915 & 23 & 911 & 20 \\
\hline 53 & 236 & 88 & 2.7 & 0.194 & 0.002 & 2.008 & 0.060 & 0.075 & 0.002 & 2778 & 16 & 2606 & 63 & 2702 & 23 & discordant & \\
\hline 55 & 141 & 100 & 1.4 & 0.067 & 0.002 & 8.964 & 0.374 & 1.097 & 0.069 & 835 & 64 & 682 & 26 & 658 & 29 & 671 & 21 \\
\hline 54 & 37 & 33 & 1.1 & 0.083 & 0.004 & 5.730 & 0.326 & 0.612 & 0.058 & 1263 & 82 & 1037 & 52 & 984 & 57 & 1013 & 41 \\
\hline 30 & 156 & 80 & 1.9 & 0.182 & 0.002 & 3.485 & 0.069 & 0.146 & 0.003 & 2671 & 20 & 1627 & 28 & 2094 & 17 & discordant & \\
\hline 29 & 417 & 241 & 1.7 & 0.058 & 0.001 & 11.377 & 0.238 & 1.500 & 0.059 & 533 & 48 & 543 & 11 & 519 & 16 & 536 & 160 \\
\hline 28 & 627 & 281 & 2.2 & 0.060 & 0.001 & 13.053 & 0.441 & 1.625 & 0.063 & 612 & 47 & 476 & 15 & 487 & 14 & 482 & 12 \\
\hline $27 \mathrm{c}$ & 212 & 129 & 1.6 & 0.100 & 0.002 & 4.310 & 0.170 & 0.300 & 0.012 & 1623 & 40 & 1345 & 46 & 1490 & 30 & discordant & \\
\hline $27 \mathrm{r}$ & 197 & 134 & 1.5 & 0.098 & 0.003 & 4.298 & 0.188 & 0.322 & 0.013 & 1577 & 49 & 1349 & 51 & 1435 & 30 & 1417 & 570 \\
\hline 26 & 1717 & 544 & 3.2 & 0.063 & 0.002 & 16.723 & 1.377 & 1.948 & 0.150 & 708 & 61 & 375 & 28 & 421 & 25 & discordant & \\
\hline
\end{tabular}


Sample 295-12- Round 1, Page 3

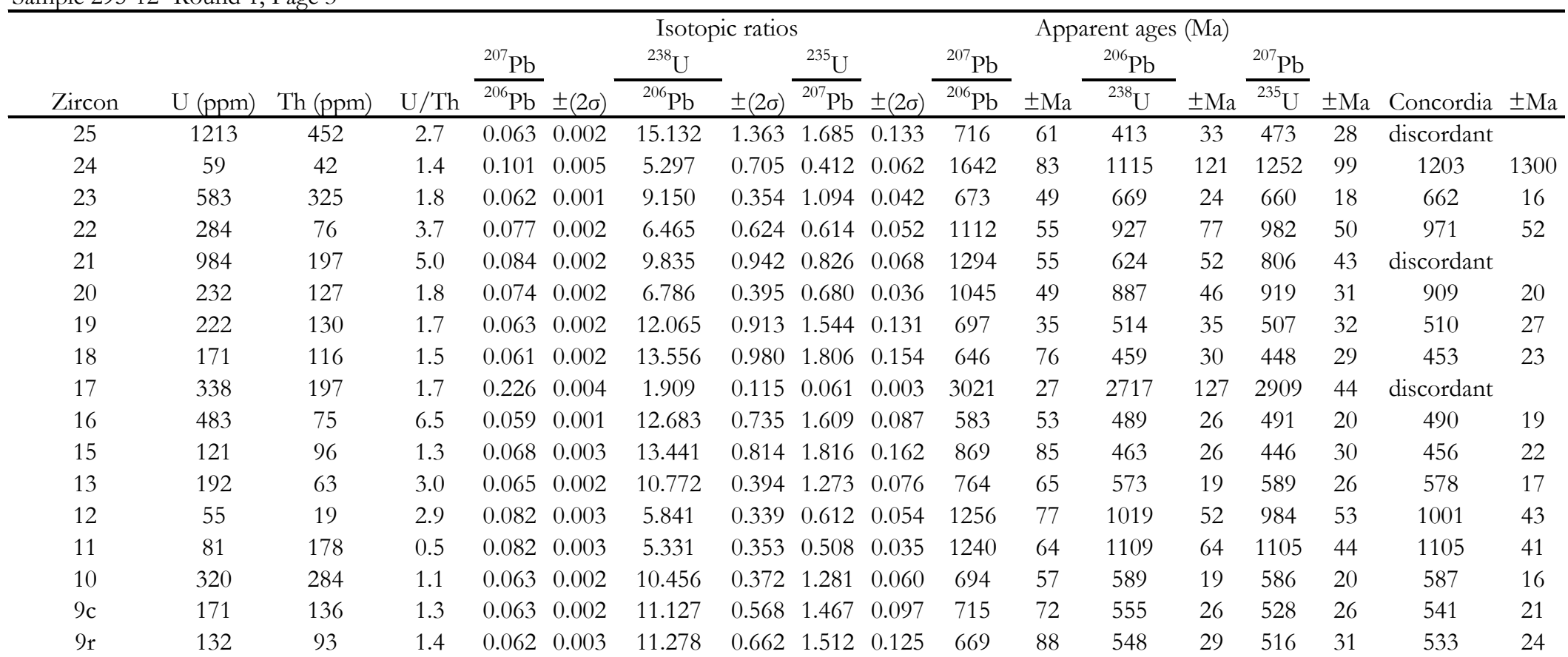


Sample 295-12- Round 2, Page 1

\begin{tabular}{|c|c|c|c|c|c|c|c|c|c|c|c|c|c|c|c|c|c|}
\hline \multirow[b]{3}{*}{ Zircon } & \multirow[b]{3}{*}{$\mathrm{U}(\mathrm{ppm})$} & \multirow[b]{3}{*}{ Th (ppm) } & \multirow[b]{3}{*}{$\mathrm{U} / \mathrm{Th}$} & \multicolumn{7}{|c|}{ Isotopic ratios } & \multicolumn{3}{|c|}{ Apparent ages (Ma) } & \multirow[b]{2}{*}{${ }^{207} \mathrm{~Pb}$} & \multirow[b]{3}{*}{$\pm \mathrm{Ma}$} & \multirow[b]{3}{*}{ Concordia } & \multirow[b]{3}{*}{$\pm \mathrm{Ma}$} \\
\hline & & & & \multicolumn{2}{|l|}{${ }^{207} \mathrm{~Pb}$} & ${ }^{238} \mathrm{U}$ & & ${ }^{235} \mathrm{U}$ & & ${ }^{207} \mathrm{~Pb}$ & & ${ }^{206} \mathrm{~Pb}$ & & & & & \\
\hline & & & & ${ }^{206} \mathrm{~Pb}$ & $\pm(2 \sigma)$ & ${ }^{206} \mathrm{~Pb}$ & $\pm(2 \sigma)$ & ${ }^{207} \mathrm{~Pb}$ & $\pm(2 \sigma)$ & ${ }^{206} \mathrm{~Pb}$ & $\pm \mathrm{Ma}$ & ${ }^{238} \mathrm{U}$ & $\pm \mathrm{Ma}$ & $\overline{{ }^{235} \mathrm{U}}$ & & & \\
\hline 1 & 370 & 156 & 2.4 & 0.097 & 0.009 & 4.391 & 0.135 & 0.375 & 0.018 & 1572 & 168 & 1323 & 36 & 1321 & 34 & 1321 & 26 \\
\hline 2 & 323 & 164 & 2.0 & 0.071 & 0.002 & 7.933 & 0.147 & 0.838 & 0.019 & 960 & 52 & 766 & 13 & 798 & 13 & discordant & \\
\hline 3 & 222 & 170 & 1.3 & 0.063 & 0.001 & 14.097 & 0.276 & 1.738 & 0.052 & 714 & 29 & 442 & 8 & 462 & 11 & 449 & 130 \\
\hline 4 & 695 & 45 & 15.5 & 0.059 & 0.002 & 13.364 & 0.319 & 1.839 & 0.088 & 577 & 57 & 465 & 10 & 441 & 17 & 459 & 140 \\
\hline 5 & 145 & 195 & 0.7 & 0.058 & 0.002 & 12.775 & 0.222 & 1.681 & 0.046 & 532 & 60 & 486 & 8 & 474 & 10 & 481 & 6 \\
\hline 6 & 402 & 274 & 1.5 & 0.075 & 0.001 & 18.002 & 0.265 & 1.988 & 0.041 & 1081 & 31 & 349 & 5 & 414 & 7 & discordant & \\
\hline 7 & 453 & 305 & 1.5 & 0.061 & 0.003 & 13.233 & 0.386 & 1.786 & 0.102 & 653 & 85 & 470 & 13 & 452 & 20 & 464 & 11 \\
\hline 8 & 90 & 39 & 2.3 & 0.060 & 0.001 & 12.947 & 0.301 & 1.668 & 0.068 & 601 & 49 & 480 & 11 & 477 & 15 & 479 & 9 \\
\hline 9 & 193 & 92 & 2.1 & 0.062 & 0.001 & 14.272 & 0.268 & 1.737 & 0.046 & 679 & 27 & 437 & 8 & 462 & 10 & discordant & \\
\hline 10 & 373 & 80 & 4.7 & 0.052 & 0.009 & 15.267 & 0.635 & 2.165 & 0.145 & 283 & 368 & 409 & 16 & 386 & 20 & 400 & 13 \\
\hline 11 & 124 & 63 & 2.0 & 0.059 & 0.001 & 14.524 & 0.250 & 1.831 & 0.045 & 558 & 28 & 429 & 7 & 443 & 9 & 438 & 83 \\
\hline 12 & 302 & 112 & 2.7 & 0.066 & 0.001 & 15.890 & 0.221 & 1.822 & 0.035 & 805 & 31 & 394 & 5 & 445 & 7 & discordant & \\
\hline 13 & 906 & 280 & 3.2 & 0.112 & 0.003 & 8.886 & 0.310 & 0.602 & 0.028 & 1825 & 47 & 688 & 22 & 994 & 29 & discordant & \\
\hline 14 & 99 & 43 & 2.3 & 0.191 & 0.002 & 2.240 & 0.040 & 0.084 & 0.001 & 2752 & 15 & 2380 & 35 & 2598 & 14 & discordant & \\
\hline 15 & 326 & 38 & 8.6 & 0.075 & 0.001 & 5.658 & 0.090 & 0.551 & 0.013 & 1077 & 37 & 1050 & 15 & 1051 & 16 & 1050 & 11 \\
\hline 16 & 253 & 166 & 1.5 & 0.057 & 0.001 & 12.803 & 0.190 & 1.636 & 0.038 & 507 & 28 & 485 & 7 & 485 & 9 & 485 & 6 \\
\hline 17 & 453 & 167 & 2.7 & 0.058 & 0.001 & 12.156 & 0.183 & 1.530 & 0.037 & 542 & 44 & 510 & 7 & 511 & 10 & 510 & 6 \\
\hline 18 & 1248 & 319 & 3.9 & 0.091 & 0.001 & 4.077 & 0.065 & 0.321 & 0.006 & 1431 & 36 & 1414 & 20 & 1438 & 14 & 1430 & 170 \\
\hline 19 & 159 & 103 & 1.5 & 0.069 & 0.002 & 7.166 & 0.236 & 0.755 & 0.041 & 910 & 60 & 842 & 25 & 857 & 30 & 848 & 21 \\
\hline 20 & 182 & 208 & 0.9 & 0.098 & 0.001 & 3.672 & 0.066 & 0.269 & 0.005 & 1586 & 21 & 1553 & 25 & 1576 & 16 & 1570 & 15 \\
\hline 21 & 699 & 129 & 5.4 & 0.058 & 0.001 & 12.467 & 0.179 & 1.531 & 0.031 & 547 & 24 & 498 & 7 & 511 & 8 & 503 & 87 \\
\hline 22 & 245 & 270 & 0.9 & 0.071 & 0.002 & 6.575 & 0.158 & 0.704 & 0.027 & 952 & 42 & 913 & 20 & 898 & 22 & 906 & 15 \\
\hline 23 & 209 & 145 & 1.4 & 0.059 & 0.002 & 11.302 & 0.221 & 1.427 & 0.043 & 554 & 57 & 547 & 10 & 540 & 12 & 544 & 8 \\
\hline 24 & 386 & 313 & 1.2 & 0.067 & 0.001 & 8.033 & 0.306 & 0.903 & 0.040 & 833 & 44 & 757 & 26 & 757 & 23 & 757 & 20 \\
\hline 25 & 282 & 113 & 2.5 & 0.073 & 0.002 & 6.843 & 0.218 & 0.769 & 0.050 & 1003 & 62 & 880 & 25 & 847 & 36 & 868 & 21 \\
\hline 26 & 181 & 83 & 2.2 & 0.058 & 0.001 & 12.117 & 0.259 & 1.588 & 0.060 & 515 & 45 & 511 & 10 & 496 & 14 & 506 & 9 \\
\hline 27 & 299 & 158 & 1.9 & 0.072 & 0.004 & 9.688 & 0.563 & 1.196 & 0.115 & 975 & 106 & 633 & 33 & 617 & 42 & 627 & 28 \\
\hline 29 & 198 & 112 & 1.8 & 0.066 & 0.001 & 25.689 & 1.234 & 3.456 & 0.094 & 792 & 18 & 246 & 11 & 258 & 6 & 257 & 90 \\
\hline
\end{tabular}


Sample 295-12- Round 2, Page 2

\begin{tabular}{|c|c|c|c|c|c|c|c|c|c|c|c|c|c|c|c|c|c|}
\hline \multirow[b]{3}{*}{ Zircon } & \multirow[b]{3}{*}{$\mathrm{U}(\mathrm{ppm})$} & \multirow[b]{3}{*}{ Th (ppm) } & \multirow[b]{3}{*}{$\mathrm{U} / \mathrm{Th}$} & \multicolumn{7}{|c|}{ Isotopic ratios } & \multicolumn{4}{|c|}{ Apparent ages $(\mathrm{Ma})$} & \multirow[b]{3}{*}{$\pm \mathrm{Ma}$} & \multirow[b]{3}{*}{ Concordia } & \multirow[b]{3}{*}{$\pm \mathrm{Ma}$} \\
\hline & & & & ${ }^{207} \mathrm{~Pb}$ & & ${ }^{238} \mathrm{U}$ & & ${ }^{235} \mathrm{U}$ & & ${ }^{207} \mathrm{~Pb}$ & & ${ }^{206} \mathrm{~Pb}$ & & ${ }^{207} \mathrm{~Pb}$ & & & \\
\hline & & & & ${ }^{206} \mathrm{~Pb}$ & $\pm(2 \sigma)$ & ${ }^{206} \mathrm{~Pb}$ & $\pm(2 \sigma)$ & ${ }^{207} \mathrm{~Pb}$ & $\pm(2 \sigma)$ & ${ }^{206} \mathrm{~Pb}$ & $\pm \mathrm{Ma}$ & ${ }^{238} \mathrm{U}$ & $\pm \mathrm{Ma}$ & ${ }^{235} \mathrm{U}$ & & & \\
\hline 30 & 700 & 65 & 10.7 & 0.067 & 0.001 & 8.212 & 0.161 & 0.910 & 0.030 & 833 & 35 & 741 & 13 & 753 & 17 & 745 & 11 \\
\hline 31 & 119 & 195 & 0.6 & 0.064 & 0.013 & 12.201 & 0.357 & 1.663 & 0.105 & 748 & 389 & 508 & 14 & 478 & 23 & 501 & 180 \\
\hline 32 & 262 & 148 & 1.8 & 0.063 & 0.006 & 12.127 & 0.417 & 2.358 & 1.436 & 720 & 194 & 511 & 16 & 359 & 122 & 514 & 17 \\
\hline 33 & 236 & 88 & 2.7 & 0.086 & 0.003 & 5.593 & 0.227 & 0.593 & 0.050 & 1339 & 73 & 1061 & 38 & 1004 & 51 & 1040 & 33 \\
\hline 34 & 141 & 100 & 1.4 & 0.059 & 0.001 & 12.563 & 0.217 & 1.612 & 0.046 & 559 & 43 & 494 & 8 & 490 & 11 & 492 & 7 \\
\hline
\end{tabular}

Sample 362-11 Page 1

\begin{tabular}{|c|c|c|c|c|c|c|c|c|c|c|c|c|c|c|c|c|c|}
\hline \multirow[b]{3}{*}{ Zircon } & \multirow[b]{3}{*}{$\mathrm{U}(\mathrm{ppm})$} & \multirow[b]{3}{*}{ Th (ppm) } & \multirow[b]{3}{*}{$\mathrm{U} / \mathrm{Th}$} & \multicolumn{7}{|c|}{ Isotopic ratios } & \multicolumn{4}{|c|}{ Apparent ages $(\mathrm{Ma})$} & \multirow[b]{3}{*}{$\pm \mathrm{Ma}$} & \multirow[b]{3}{*}{ Concordia } & \multirow[b]{3}{*}{$\pm \mathrm{Ma}$} \\
\hline & & & & ${ }^{207} \mathrm{~Pb}$ & & ${ }^{238} \mathrm{U}$ & & ${ }^{235} \mathrm{U}$ & & ${ }^{207} \mathrm{~Pb}$ & & ${ }^{206} \mathrm{~Pb}$ & & ${ }^{207} \mathrm{~Pb}$ & & & \\
\hline & & & & ${ }^{206} \mathrm{~Pb}$ & $\pm(2 \sigma)$ & ${ }^{206} \mathrm{~Pb}$ & $\pm(2 \sigma)$ & ${ }^{207} \mathrm{~Pb}$ & $\pm(2 \sigma)$ & ${ }^{206} \mathrm{~Pb}$ & $\pm \mathrm{Ma}$ & ${ }^{238} \mathrm{U}$ & $\pm \mathrm{Ma}$ & ${ }^{235} \mathrm{U}$ & & & \\
\hline 1 & 127 & 66 & 1.9 & 0.078 & 0.002 & 5.720 & 0.185 & 0.545 & 0.022 & 1146 & 49 & 1039 & 30 & 1058 & 26 & 1050 & 22 \\
\hline 2 & 59 & 59 & 1.0 & 0.099 & 0.003 & 4.052 & 0.164 & 0.317 & 0.016 & 1613 & 55 & 1422 & 50 & 1446 & 39 & 1437 & 34 \\
\hline $3(\mathrm{a})$ & 292 & 208 & 1.4 & 0.058 & 0.002 & 12.255 & 0.321 & 1.634 & 0.082 & 536 & 55 & 506 & 12 & 485 & 19 & 500 & 11 \\
\hline 4 & 430 & 129 & 3.3 & 0.081 & 0.001 & 4.856 & 0.085 & 0.435 & 0.009 & 1215 & 25 & 1207 & 19 & 1213 & 15 & 1211 & 13 \\
\hline 5 & 132 & 129 & 1.0 & 0.065 & 0.003 & 12.152 & 0.445 & 1.607 & 0.133 & 776 & 88 & 510 & 17 & 492 & 30 & 505 & 16 \\
\hline 6 & 334 & 203 & 1.6 & 0.060 & 0.001 & 12.149 & 0.283 & 1.553 & 0.073 & 589 & 53 & 510 & 11 & 505 & 18 & 509 & 10 \\
\hline 9 & 196 & 109 & 1.8 & 0.059 & 0.002 & 11.973 & 0.438 & 1.692 & 0.114 & 556 & 73 & 517 & 18 & 472 & 24 & 501 & 270 \\
\hline 10 & 1192 & 49 & 24.2 & 0.061 & 0.001 & 10.467 & 0.181 & 1.264 & 0.029 & 655 & 30 & 588 & 10 & 592 & 10 & 599 & 8 \\
\hline 11 & 138 & 334 & 0.4 & 0.059 & 0.002 & 10.902 & 0.417 & 1.469 & 0.093 & 583 & 79 & 566 & 20 & 528 & 25 & 551 & 250 \\
\hline 12 & 295 & 106 & 2.8 & 0.061 & 0.001 & 10.594 & 0.261 & 1.312 & 0.056 & 641 & 49 & 582 & 13 & 576 & 18 & 579 & 11 \\
\hline 13 & 553 & 356 & 1.6 & 0.058 & 0.001 & 12.605 & 0.254 & 1.611 & 0.052 & 511 & 40 & 492 & 9 & 491 & 12 & 491 & 8 \\
\hline $13(\mathrm{a})$ & 516 & 286 & 1.8 & 0.057 & 0.001 & 12.034 & 0.246 & 1.596 & 0.053 & 475 & 44 & 515 & 10 & 494 & 13 & 507 & 130 \\
\hline 14 & 487 & 268 & 1.8 & 0.074 & 0.001 & 5.589 & 0.095 & 0.546 & 0.012 & 1041 & 27 & 1061 & 16 & 1058 & 14 & 1059 & 12 \\
\hline 15 & 237 & 110 & 2.2 & 0.077 & 0.001 & 5.256 & 0.108 & 0.510 & 0.015 & 1118 & 36 & 1123 & 21 & 1103 & 20 & 1112 & 15 \\
\hline 16 & 591 & 248 & 2.4 & 0.076 & 0.001 & 5.303 & 0.092 & 0.509 & 0.010 & 1091 & 24 & 1114 & 17 & 1104 & 13 & 1106 & 11 \\
\hline 19 & 123 & 58 & 2.1 & 0.069 & 0.003 & 8.594 & 0.274 & 1.018 & 0.054 & 910 & 92 & 710 & 21 & 695 & 26 & 704 & 17 \\
\hline
\end{tabular}


Sample 362-11 Page 2

\begin{tabular}{|c|c|c|c|c|c|c|c|c|c|c|c|c|c|c|c|c|c|}
\hline \multirow[b]{3}{*}{ Zircon } & \multirow[b]{3}{*}{$\mathrm{U}(\mathrm{ppm})$} & \multirow[b]{3}{*}{ Th (ppm) } & \multirow[b]{3}{*}{$\mathrm{U} / \mathrm{Th}$} & \multicolumn{6}{|c|}{ Isotopic ratios } & \multicolumn{5}{|c|}{ Apparent ages $(\mathrm{Ma})$} & \multirow[b]{3}{*}{$\pm \mathrm{Ma}$} & \multirow[b]{3}{*}{ Concordia } & \multirow[b]{3}{*}{$\pm \mathrm{Ma}$} \\
\hline & & & & ${ }^{207} \mathrm{~Pb}$ & & ${ }^{238} \mathrm{U}$ & & ${ }^{235} \mathrm{U}$ & & ${ }^{207} \mathrm{~Pb}$ & & ${ }^{206} \mathrm{~Pb}$ & & ${ }^{207} \mathrm{~Pb}$ & & & \\
\hline & & & & ${ }^{206} \mathrm{~Pb}$ & $\pm(2 \sigma)$ & ${ }^{206} \mathrm{~Pb}$ & $\pm(2 \sigma)$ & ${ }^{207} \mathrm{~Pb}$ & $\pm(2 \sigma)$ & ${ }^{206} \mathrm{~Pb}$ & $\pm \mathrm{Ma}$ & ${ }^{238} \mathrm{U}$ & $\pm \mathrm{Ma}$ & $\frac{{ }^{235} \mathrm{U}}{{ }^{235}}$ & & & \\
\hline 17 & 130 & 75 & 1.7 & 0.155 & 0.002 & 2.552 & 0.070 & 0.119 & 0.003 & 2405 & 22 & 2132 & 48 & 2279 & 23 & discordant & \\
\hline 20 & 353 & 156 & 2.3 & 0.059 & 0.001 & 11.755 & 0.279 & 1.522 & 0.063 & 553 & 49 & 526 & 12 & 513 & 16 & 522 & 10 \\
\hline $20(a)$ & 678 & 33 & 20.4 & 0.061 & 0.001 & 10.384 & 0.263 & 1.257 & 0.038 & 638 & 36 & 593 & 14 & 595 & 13 & 593 & 10 \\
\hline 21 & 71 & 35 & 2.0 & 0.067 & 0.004 & 13.275 & 0.794 & 2.143 & 0.252 & 843 & 116 & 468 & 26 & 389 & 35 & discordant & \\
\hline 22 & 834 & 143 & 5.8 & 0.059 & 0.001 & 11.454 & 0.372 & 1.409 & 0.047 & 562 & 35 & 540 & 16 & 545 & 14 & 543 & 12 \\
\hline 23 & 485 & 192 & 2.5 & 0.062 & 0.001 & 9.443 & 0.285 & 1.141 & 0.043 & 659 & 37 & 649 & 18 & 640 & 17 & 644 & 14 \\
\hline 24 & 1536 & 764 & 2.0 & 0.059 & 0.001 & 10.813 & 0.293 & 1.320 & 0.033 & 557 & 30 & 570 & 14 & 573 & 11 & 572 & 10 \\
\hline 25 & 408 & 222 & 1.8 & 0.057 & 0.001 & 12.261 & 0.299 & 1.588 & 0.058 & 497 & 53 & 506 & 12 & 496 & 14 & 502 & 9 \\
\hline 26 & 230 & 258 & 0.9 & 0.056 & 0.002 & 12.061 & 0.442 & 1.733 & 0.097 & 465 & 67 & 514 & 17 & 463 & 20 & discordant & \\
\hline 27 & 528 & 213 & 2.5 & 0.077 & 0.001 & 5.510 & 0.145 & 0.524 & 0.013 & 1120 & 26 & 1076 & 25 & 1085 & 17 & 1082 & 16 \\
\hline 28 & 250 & 69 & 3.6 & 0.092 & 0.003 & 12.145 & 0.400 & 1.173 & 0.063 & 1464 & 55 & 510 & 16 & 627 & 24 & discordant & \\
\hline 30 & 152 & 72 & 2.1 & 0.145 & 0.002 & 3.823 & 0.142 & 0.196 & 0.007 & 2286 & 29 & 1499 & 48 & 1839 & 31 & discordant & \\
\hline $30(a)$ & 255 & 228 & 1.1 & 0.060 & 0.002 & 11.183 & 0.468 & 1.464 & 0.086 & 619 & 58 & 552 & 21 & 529 & 23 & 541 & 17 \\
\hline 31 & 234 & 138 & 1.7 & 0.100 & 0.001 & 3.528 & 0.118 & 0.257 & 0.008 & 1628 & 26 & 1609 & 46 & 1612 & 24 & 1610 & 24 \\
\hline $30(\mathrm{~b})$ & 437 & 279 & 1.6 & 0.081 & 0.002 & 12.785 & 0.392 & 1.192 & 0.041 & 1218 & 54 & 486 & 14 & 619 & 15 & discordant & \\
\hline 34 & 1140 & 165 & 6.9 & 0.059 & 0.001 & 11.035 & 0.326 & 1.362 & 0.043 & 584 & 30 & 559 & 15 & 560 & 13 & 559 & 12 \\
\hline 37 & 101 & 82 & 1.2 & 0.069 & 0.005 & 13.157 & 0.639 & 1.981 & 0.190 & 898 & 138 & 472 & 21 & 415 & 30 & 545 & 350 \\
\hline 36 & 3593 & 60 & 60.2 & 0.061 & 0.001 & 16.034 & 0.406 & 1.931 & 0.044 & 629 & 21 & 390 & 9 & 424 & 8 & discordant & \\
\hline 38 & 253 & 72 & 3.5 & 0.062 & 0.002 & 11.965 & 0.429 & 1.584 & 0.095 & 681 & 61 & 518 & 17 & 497 & 22 & 510 & 15 \\
\hline 39 & 521 & 79 & 6.6 & 0.057 & 0.001 & 11.937 & 0.311 & 1.518 & 0.054 & 509 & 44 & 519 & 13 & 514 & 14 & 517 & 10 \\
\hline 40 & 102 & 78 & 1.3 & 0.089 & 0.002 & 3.931 & 0.104 & 0.336 & 0.013 & 1404 & 36 & 1462 & 34 & 1403 & 29 & 1425 & 400 \\
\hline 41 & 153 & 54 & 2.8 & 0.098 & 0.002 & 4.166 & 0.113 & 0.308 & 0.009 & 1592 & 39 & 1388 & 33 & 1468 & 23 & discordant & \\
\hline 42 & 1143 & 299 & 3.8 & 0.060 & 0.001 & 11.131 & 0.237 & 1.357 & 0.032 & 587 & 32 & 555 & 11 & 561 & 10 & 558 & 9 \\
\hline 43 & 88 & 58 & 1.5 & 0.067 & 0.003 & 9.683 & 0.404 & 1.403 & 0.138 & 833 & 95 & 634 & 24 & 547 & 39 & discordant & \\
\hline 44(a) & 275 & 113 & 2.4 & 0.070 & 0.002 & 9.346 & 0.257 & 1.105 & 0.043 & 938 & 51 & 656 & 17 & 655 & 18 & 655 & 13 \\
\hline 44 & 171 & 138 & 1.2 & 0.066 & 0.003 & 12.639 & 0.468 & 1.570 & 0.086 & 792 & 81 & 491 & 17 & 501 & 21 & 495 & 14 \\
\hline 45 & 160 & 225 & 0.7 & 0.113 & 0.002 & 3.043 & 0.082 & 0.197 & 0.005 & 1846 & 26 & 1832 & 42 & 1833 & 23 & 1831 & 22 \\
\hline 46 & 744 & 46 & 16.3 & 0.060 & 0.001 & 10.200 & 0.265 & 1.254 & 0.033 & 594 & 33 & 603 & 15 & 596 & 12 & 598 & 10 \\
\hline
\end{tabular}


Sample 362-11 Page 3

\begin{tabular}{|c|c|c|c|c|c|c|c|c|c|c|c|c|c|c|c|c|c|}
\hline \multirow[b]{3}{*}{ Zircon } & \multirow[b]{3}{*}{$\mathrm{U}(\mathrm{ppm})$} & \multirow[b]{3}{*}{ Th (ppm) } & \multirow[b]{3}{*}{$\mathrm{U} / \mathrm{Th}$} & \multicolumn{7}{|c|}{ Isotopic ratios } & \multicolumn{3}{|c|}{ Apparent ages $(\mathrm{Ma})$} & \multirow[b]{2}{*}{${ }^{207} \mathrm{~Pb}$} & \multirow[b]{3}{*}{$\pm \mathrm{Ma}$} & \multirow[b]{3}{*}{ Concordia } & \multirow[b]{3}{*}{$\pm \mathrm{Ma}$} \\
\hline & & & & ${ }^{207} \mathrm{~Pb}$ & & ${ }^{238} \mathrm{U}$ & & ${ }^{235} \mathrm{U}$ & & ${ }^{207} \mathrm{~Pb}$ & & ${ }^{206} \mathrm{~Pb}$ & & & & & \\
\hline & & & & ${ }^{206} \mathrm{~Pb}$ & $\pm(2 \sigma)$ & ${ }^{206} \mathrm{~Pb}$ & $\pm(2 \sigma)$ & ${ }^{207} \mathrm{~Pb}$ & $\pm(2 \sigma)$ & ${ }^{206} \mathrm{~Pb}$ & $\pm \mathrm{Ma}$ & ${ }^{238} \mathrm{U}$ & $\pm \mathrm{Ma}$ & ${ }^{235} \mathrm{U}$ & & & \\
\hline 47 & 306 & 96 & 3.2 & 0.136 & 0.002 & 3.888 & 0.093 & 0.202 & 0.004 & 2179 & 24 & 1476 & 31 & 1813 & 18 & discordant & \\
\hline 48 & 118 & 67 & 1.8 & 0.062 & 0.002 & 13.001 & 0.603 & 1.847 & 0.165 & 690 & 79 & 478 & 20 & 440 & 30 & 466 & 230 \\
\hline 49 & 571 & 468 & 1.2 & 0.059 & 0.001 & 10.707 & 0.276 & 1.322 & 0.042 & 595 & 33 & 576 & 14 & 572 & 14 & 574 & 11 \\
\hline 50 & 1389 & 499 & 2.8 & 0.061 & 0.001 & 12.144 & 0.256 & 1.425 & 0.032 & 639 & 29 & 510 & 10 & 540 & 9 & discordant & \\
\hline 51 & 357 & 203 & 1.8 & 0.093 & 0.001 & 3.969 & 0.088 & 0.310 & 0.007 & 1483 & 24 & 1449 & 28 & 1464 & 17 & 1460 & 17 \\
\hline 52 & 484 & 303 & 1.6 & 0.058 & 0.001 & 12.126 & 0.290 & 1.605 & 0.058 & 540 & 44 & 511 & 11 & 492 & 14 & 503 & 130 \\
\hline 52 (repeat) & 311 & 160 & 1.9 & 0.057 & 0.001 & 12.153 & 0.317 & 1.624 & 0.069 & 506 & 54 & 510 & 12 & 488 & 16 & 501 & 150 \\
\hline $52(\mathrm{a})$ & 213 & 160 & 1.3 & 0.075 & 0.001 & 6.035 & 0.147 & 0.610 & 0.020 & 1062 & 39 & 989 & 22 & 986 & 20 & 987 & 10 \\
\hline $48(a)$ & 223 & 68 & 3.3 & 0.062 & 0.002 & 10.254 & 0.281 & 1.349 & 0.075 & 676 & 57 & 600 & 15 & 564 & 23 & 589 & 220 \\
\hline 53 & 68 & 54 & 1.3 & 0.072 & 0.004 & 10.641 & 0.584 & 1.498 & 0.185 & 980 & 102 & 579 & 29 & 520 & 46 & 562 & 340 \\
\hline $53(\mathrm{a})$ & 447 & 263 & 1.7 & 0.061 & 0.001 & 11.498 & 0.282 & 1.472 & 0.050 & 640 & 42 & 538 & 12 & 527 & 14 & 533 & 10 \\
\hline 54 & 575 & 163 & 3.5 & 0.059 & 0.001 & 10.966 & 0.236 & 1.374 & 0.043 & 595 & 28 & 563 & 11 & 556 & 13 & 560 & 9 \\
\hline 55 & 628 & 229 & 2.7 & 0.059 & 0.001 & 10.895 & 0.263 & 1.354 & 0.040 & 571 & 38 & 566 & 13 & 562 & 12 & 564 & 10 \\
\hline
\end{tabular}

Sample 403-10 Page 1

\begin{tabular}{|c|c|c|c|c|c|c|c|c|c|c|c|c|c|c|c|c|c|}
\hline \multirow[b]{3}{*}{ Zircon } & \multirow[b]{3}{*}{$\mathrm{U}(\mathrm{ppm})$} & \multirow[b]{3}{*}{ Th (ppm) } & \multirow[b]{3}{*}{$\mathrm{U} / \mathrm{Th}$} & \multicolumn{7}{|c|}{ Isotopic ratios } & \multicolumn{4}{|c|}{ Apparent ages $(\mathrm{Ma})$} & \multirow[b]{3}{*}{$\pm \mathrm{Ma}$} & \multirow[b]{3}{*}{ Concordia } & \multirow[b]{3}{*}{$\pm \mathrm{Ma}$} \\
\hline & & & & ${ }^{207} \mathrm{~Pb}$ & & ${ }^{238} \mathrm{U}$ & & ${ }^{235} \mathrm{U}$ & & ${ }^{207} \mathrm{~Pb}$ & & ${ }^{206} \mathrm{~Pb}$ & & ${ }^{207} \mathrm{~Pb}$ & & & \\
\hline & & & & ${ }^{206} \mathrm{~Pb}$ & $\pm(2 \sigma)$ & ${ }^{206} \mathrm{~Pb}$ & $\pm(2 \sigma)$ & ${ }^{207} \mathrm{~Pb}$ & $\pm(2 \sigma)$ & ${ }^{206} \mathrm{~Pb}$ & $\pm \mathrm{Ma}$ & ${ }^{238} \mathrm{U}$ & $\pm \mathrm{Ma}$ & ${ }^{235} \mathrm{U}$ & & & \\
\hline 2 & 238 & 32 & 7.5 & 0.209 & 0.002 & 2.165 & 0.065 & 0.075 & 0.002 & 2897 & 15 & 2449 & 60 & 2711 & 25 & discordant & \\
\hline 1 & 479 & 288 & 1.7 & 0.059 & 0.001 & 12.049 & 0.455 & 1.501 & 0.064 & 560 & 46 & 514 & 18 & 519 & 17 & 516 & 14 \\
\hline 3 & 257 & 110 & 2.3 & 0.078 & 0.002 & 10.825 & 0.431 & 1.241 & 0.077 & 1167 & 31 & 570 & 21 & 600 & 27 & 580 & 18 \\
\hline 4 & 574 & 234 & 2.5 & 0.066 & 0.001 & 12.193 & 0.350 & 1.392 & 0.045 & 794 & 44 & 508 & 14 & 550 & 13 & discordant & \\
\hline 5 & 420 & 63 & 6.7 & 0.059 & 0.001 & 11.231 & 0.344 & 1.420 & 0.052 & 558 & 50 & 550 & 16 & 542 & 15 & 545 & 11 \\
\hline 5(repeat) & 133 & 84 & 1.6 & 0.061 & 0.003 & 11.729 & 0.496 & 1.752 & 0.194 & 643 & 88 & 528 & 21 & 459 & 38 & 512 & 370 \\
\hline 6 & 502 & 226 & 2.2 & 0.122 & 0.001 & 2.887 & 0.072 & 0.170 & 0.004 & 1992 & 19 & 1918 & 40 & 1961 & 20 & 1957 & 280 \\
\hline 11 & 537 & 268 & 2.0 & 0.121 & 0.001 & 3.335 & 0.073 & 0.199 & 0.004 & 1975 & 18 & 1691 & 32 & 1823 & 17 & discordant & \\
\hline
\end{tabular}


Sample 403-10 Page 2

\begin{tabular}{|c|c|c|c|c|c|c|c|c|c|c|c|c|c|c|c|c|c|}
\hline \multirow[b]{3}{*}{ Zircon } & \multirow[b]{3}{*}{$\mathrm{U}(\mathrm{ppm})$} & \multirow[b]{3}{*}{ Th (ppm) } & \multirow[b]{3}{*}{$\mathrm{U} / \mathrm{Th}$} & \multicolumn{7}{|c|}{ Isotopic ratios } & \multicolumn{4}{|c|}{ Apparent ages $(\mathrm{Ma})$} & \multirow[b]{3}{*}{$\pm \mathrm{Ma}$} & \multirow[b]{3}{*}{ Concordia } & \multirow[b]{3}{*}{$\pm \mathrm{Ma}$} \\
\hline & & & & \multicolumn{2}{|l|}{${ }^{207} \mathrm{~Pb}$} & ${ }^{238} \mathrm{U}$ & & ${ }^{235} \mathrm{U}$ & & ${ }^{207} \mathrm{~Pb}$ & & ${ }^{206} \mathrm{~Pb}$ & & ${ }^{207} \mathrm{~Pb}$ & & & \\
\hline & & & & $\overline{{ }^{206} \mathrm{~Pb}}$ & $\pm(2 \sigma)$ & ${ }^{206} \mathrm{~Pb}$ & $\pm(2 \sigma)$ & ${ }^{207} \mathrm{~Pb}$ & $\pm(2 \sigma)$ & ${ }^{206} \mathrm{~Pb}$ & $\pm \mathrm{Ma}$ & ${ }^{238} \mathrm{U}$ & $\pm \mathrm{Ma}$ & ${ }^{235} \mathrm{U}$ & & & \\
\hline 12 & 376 & 86 & 4.4 & 0.102 & 0.001 & 3.516 & 0.085 & 0.249 & 0.005 & 1659 & 21 & 1614 & 34 & 1639 & 16 & 1636 & 16 \\
\hline 13 & 513 & 167 & 3.1 & 0.084 & 0.001 & 4.485 & 0.109 & 0.390 & 0.009 & 1303 & 23 & 1298 & 28 & 1291 & 16 & 1291 & 16 \\
\hline 14 & 498 & 69 & 7.2 & 0.067 & 0.001 & 11.826 & 0.325 & 1.286 & 0.044 & 824 & 39 & 523 & 13 & 585 & 15 & discordant & \\
\hline 15 & 179 & 72 & 2.5 & 0.086 & 0.002 & 4.428 & 0.120 & 0.381 & 0.014 & 1344 & 35 & 1313 & 32 & 1308 & 26 & 1309 & 22 \\
\hline 23 & 173 & 77 & 2.3 & 0.061 & 0.002 & 10.877 & 0.369 & 1.480 & 0.106 & 628 & 67 & 567 & 18 & 524 & 28 & 555 & 260 \\
\hline 24 & 258 & 139 & 1.9 & 0.099 & 0.001 & 3.594 & 0.080 & 0.261 & 0.006 & 1610 & 28 & 1583 & 31 & 1601 & 19 & 1596 & 18 \\
\hline 25 & 305 & 43 & 7.1 & 0.237 & 0.002 & 2.080 & 0.046 & 0.064 & 0.001 & 3099 & 16 & 2532 & 45 & 2858 & 16 & discordant & \\
\hline 26 & 159 & 98 & 1.6 & 0.061 & 0.003 & 12.705 & 0.522 & 1.718 & 0.116 & 626 & 90 & 489 & 19 & 466 & 24 & 480 & 15 \\
\hline 27 & 26 & 39 & 0.7 & 0.106 & 0.005 & 4.350 & 0.268 & 0.367 & 0.031 & 1727 & 86 & 1334 & 70 & 1337 & 60 & 1335 & 48 \\
\hline 28 & 656 & 563 & 1.2 & 0.074 & 0.002 & 12.378 & 0.302 & 1.386 & 0.048 & 1051 & 42 & 501 & 11 & 552 & 14 & discordant & \\
\hline $29 \mathrm{c}$ & 273 & 79 & 3.5 & 0.205 & 0.003 & 4.342 & 0.107 & 0.167 & 0.004 & 2864 & 20 & 1337 & 29 & 1975 & 21 & discordant & \\
\hline 31 & 134 & 141 & 0.9 & 0.059 & 0.002 & 11.994 & 0.457 & 1.690 & 0.135 & 582 & 81 & 516 & 18 & 472 & 28 & 504 & 260 \\
\hline 39 & 155 & 63 & 2.4 & 0.059 & 0.003 & 12.823 & 0.655 & 1.881 & 0.155 & 567 & 91 & 484 & 23 & 433 & 27 & 463 & 350 \\
\hline 32 & 183 & 76 & 2.4 & 0.058 & 0.002 & 11.144 & 0.379 & 1.569 & 0.100 & 514 & 71 & 554 & 18 & 501 & 24 & discordant & \\
\hline 34 & 97 & 209 & 0.5 & 0.063 & 0.003 & 11.958 & 0.534 & 1.957 & 0.360 & 694 & 99 & 518 & 21 & 419 & 55 & 506 & 400 \\
\hline 33 & 163 & 126 & 1.3 & 0.060 & 0.002 & 11.671 & 0.407 & 1.646 & 0.119 & 604 & 83 & 530 & 17 & 482 & 26 & 516 & 290 \\
\hline 35 & 455 & 117 & 3.9 & 0.104 & 0.001 & 3.411 & 0.074 & 0.237 & 0.005 & 1690 & 22 & 1658 & 31 & 1680 & 19 & 1676 & 19 \\
\hline 36 & 699 & 417 & 1.7 & 0.065 & 0.001 & 12.078 & 0.349 & 1.492 & 0.049 & 793 & 36 & 513 & 14 & 521 & 13 & 517 & 11 \\
\hline 37 & 514 & 37 & 13.8 & 0.093 & 0.001 & 4.795 & 0.104 & 0.368 & 0.008 & 1490 & 29 & 1221 & 24 & 1333 & 16 & discordant & \\
\hline 38 & 274 & 85 & 3.2 & 0.061 & 0.002 & 12.231 & 0.400 & 1.562 & 0.079 & 650 & 65 & 507 & 15 & 503 & 19 & 505 & 13 \\
\hline $38(a)$ & 179 & 161 & 1.1 & 0.087 & 0.003 & 12.586 & 0.548 & 1.111 & 0.060 & 1355 & 64 & 493 & 20 & 652 & 25 & discordant & \\
\hline $22(a)$ & 173 & 295 & 0.6 & 0.088 & 0.003 & 12.658 & 0.694 & 1.105 & 0.071 & 1390 & 72 & 490 & 25 & 655 & 29 & discordant & \\
\hline 22 & 1376 & 545 & 2.5 & 0.067 & 0.001 & 13.820 & 0.426 & 1.401 & 0.039 & 832 & 33 & 451 & 13 & 547 & 11 & discordant & \\
\hline 21 & 1352 & 771 & 1.8 & 0.072 & 0.002 & 16.357 & 0.659 & 1.501 & 0.047 & 989 & 43 & 383 & 14 & 519 & 12 & discordant & \\
\hline 20 & 166 & 38 & 4.4 & 0.069 & 0.002 & 8.363 & 0.297 & 0.932 & 0.048 & 831 & 121 & 728 & 24 & 741 & 26 & 733 & 19 \\
\hline 18 & 377 & 135 & 2.8 & 0.066 & 0.002 & 11.709 & 0.326 & 1.309 & 0.077 & 806 & 48 & 529 & 14 & 577 & 25 & discordant & \\
\hline 17 & 703 & 15 & 46.4 & 0.058 & 0.001 & 11.200 & 0.380 & 1.461 & 0.056 & 545 & 42 & 552 & 17 & 530 & 15 & 538 & 180 \\
\hline 16 & 384 & 232 & 1.7 & 0.060 & 0.002 & 11.451 & 0.401 & 1.533 & 0.088 & 605 & 54 & 540 & 18 & 510 & 22 & 528 & 190 \\
\hline
\end{tabular}


Sample 403-10 Page 3

\begin{tabular}{|c|c|c|c|c|c|c|c|c|c|c|c|c|c|c|c|c|c|}
\hline \multirow[b]{3}{*}{ Zircon } & \multirow[b]{3}{*}{$\mathrm{U}(\mathrm{ppm})$} & \multirow[b]{3}{*}{ Th (ppm) } & \multirow[b]{3}{*}{$\mathrm{U} / \mathrm{Th}$} & \multicolumn{7}{|c|}{ Isotopic ratios } & \multicolumn{4}{|c|}{ Apparent ages $(\mathrm{Ma})$} & \multirow[b]{3}{*}{$\pm \mathrm{Ma}$} & \multirow[b]{3}{*}{ Concordia } & \multirow[b]{3}{*}{$\pm \mathrm{Ma}$} \\
\hline & & & & \multicolumn{2}{|l|}{${ }^{207} \mathrm{~Pb}$} & ${ }^{238} \mathrm{U}$ & & ${ }^{235} \mathrm{U}$ & & ${ }^{207} \mathrm{~Pb}$ & & ${ }^{206} \mathrm{~Pb}$ & & ${ }^{207} \mathrm{~Pb}$ & & & \\
\hline & & & & $\overline{{ }^{206} \mathrm{~Pb}}$ & $\pm(2 \sigma)$ & ${ }^{206} \mathrm{~Pb}$ & $\pm(2 \sigma)$ & ${ }^{207} \mathrm{~Pb}$ & $\pm(2 \sigma)$ & ${ }^{206} \mathrm{~Pb}$ & $\pm \mathrm{Ma}$ & ${ }^{238} \mathrm{U}$ & $\pm \mathrm{Ma}$ & ${ }^{235} \mathrm{U}$ & & & \\
\hline 10 & 461 & 220 & 2.1 & 0.093 & 0.001 & 3.833 & 0.119 & 0.294 & 0.008 & 1498 & 25 & 1495 & 40 & 1506 & 21 & 1504 & 21 \\
\hline 9 & 769 & 297 & 2.6 & 0.073 & 0.001 & 6.190 & 0.164 & 0.617 & 0.016 & 1017 & 33 & 966 & 23 & 979 & 16 & 975 & 15 \\
\hline 8 & 340 & 93 & 3.7 & 0.060 & 0.002 & 11.529 & 0.432 & 1.486 & 0.071 & 590 & 56 & 536 & 19 & 523 & 19 & 529 & 14 \\
\hline 7 & 326 & 287 & 1.1 & 0.096 & 0.002 & 6.144 & 0.221 & 0.464 & 0.016 & 1549 & 34 & 972 & 31 & 1168 & 23 & discordant & \\
\hline 17 & 129 & 59 & 2.2 & 0.077 & 0.002 & 4.267 & 0.139 & 0.425 & 0.021 & 1107 & 52 & 1358 & 39 & 1229 & 34 & discordant & \\
\hline 16 & 502 & 156 & 3.2 & 0.076 & 0.002 & 4.856 & 0.301 & 0.461 & 0.026 & 1088 & 51 & 1207 & 65 & 1172 & 37 & 1177 & 37 \\
\hline 15 & 304 & 127 & 2.4 & 0.060 & 0.002 & 10.738 & 0.891 & 1.403 & 0.126 & 602 & 75 & 574 & 42 & 547 & 35 & 557 & 33 \\
\hline 14 & 852 & 5 & 159.2 & 0.154 & 0.005 & 2.105 & 0.207 & 0.096 & 0.009 & 2391 & 55 & 2506 & 189 & 2470 & 84 & 2465 & 87 \\
\hline 13 & 291 & 76 & 3.8 & 0.058 & 0.002 & 10.936 & 0.790 & 1.398 & 0.103 & 518 & 75 & 564 & 37 & 548 & 30 & 554 & 25 \\
\hline 12 & 85 & 84 & 1.0 & 0.079 & 0.005 & 7.175 & 0.637 & 0.823 & 0.085 & 1183 & 129 & 841 & 65 & 808 & 54 & 820 & 49 \\
\hline 11 & 56 & 59 & 1.0 & 0.090 & 0.003 & 3.631 & 0.210 & 0.340 & 0.044 & 1428 & 65 & 1569 & 77 & 1394 & 91 & 1491 & 1200 \\
\hline 10 & 384 & 246 & 1.6 & 0.058 & 0.001 & 10.001 & 0.259 & 1.348 & 0.064 & 539 & 52 & 615 & 15 & 564 & 20 & discordant & \\
\hline 9 & 230 & 133 & 1.7 & 0.059 & 0.003 & 9.644 & 0.312 & 1.302 & 0.085 & 560 & 112 & 636 & 19 & 579 & 27 & discordant & \\
\hline 8 & 507 & 177 & 2.9 & 0.056 & 0.001 & 9.584 & 0.223 & 1.254 & 0.048 & 471 & 45 & 640 & 14 & 596 & 17 & discordant & \\
\hline 7 & 129 & 399 & 0.3 & 0.058 & 0.002 & 9.574 & 0.421 & 1.314 & 0.098 & 533 & 94 & 641 & 26 & 575 & 31 & 613 & 410 \\
\hline 6 & 440 & 16 & 28.1 & 0.073 & 0.001 & 4.534 & 0.121 & 0.446 & 0.013 & 1007 & 38 & 1285 & 30 & 1195 & 20 & discordant & \\
\hline 5 & 171 & 75 & 2.3 & 0.061 & 0.002 & 11.346 & 0.363 & 1.556 & 0.111 & 641 & 68 & 545 & 16 & 504 & 27 & 534 & 230 \\
\hline 4 & 210 & 127 & 1.7 & 0.092 & 0.001 & 3.823 & 0.075 & 0.302 & 0.009 & 1476 & 28 & 1499 & 26 & 1484 & 22 & 1489 & 18 \\
\hline 3 & 301 & 109 & 2.7 & 0.096 & 0.002 & 11.236 & 0.302 & 0.857 & 0.027 & 1548 & 42 & 550 & 14 & 786 & 17 & discordant & \\
\hline 2 & 52 & 91 & 0.6 & 0.070 & 0.005 & 11.161 & 0.649 & 2.136 & 0.586 & 917 & 143 & 553 & 29 & 390 & 72 & discordant & \\
\hline 1 & 103 & 85 & 1.2 & 0.185 & 0.003 & 2.184 & 0.043 & 0.087 & 0.002 & 2699 & 23 & 2431 & 40 & 2566 & 20 & discordant & \\
\hline 1 (repeat) & 97 & 100 & 1.0 & 0.186 & 0.003 & 1.931 & 0.037 & 0.076 & 0.001 & 2710 & 22 & 2692 & 41 & 2695 & 18 & 2693 & 18 \\
\hline
\end{tabular}


Sample 462-7 Page 1

\begin{tabular}{|c|c|c|c|c|c|c|c|c|c|c|c|c|c|c|c|c|c|}
\hline \multirow[b]{3}{*}{ Zircon } & \multirow[b]{3}{*}{$\mathrm{U}(\mathrm{ppm})$} & \multirow[b]{3}{*}{ Th (ppm) } & \multirow[b]{3}{*}{$\mathrm{U} / \mathrm{Th}$} & \multicolumn{7}{|c|}{ Isotopic ratios } & \multicolumn{3}{|c|}{ Apparent ages $(\mathrm{Ma})$} & \multirow[b]{2}{*}{${ }^{207} \mathrm{~Pb}$} & \multirow[b]{3}{*}{$\pm \mathrm{Ma}$} & \multirow[b]{3}{*}{ Concordia } & \multirow[b]{3}{*}{$\pm \mathrm{Ma}$} \\
\hline & & & & \multicolumn{2}{|l|}{${ }^{207} \mathrm{~Pb}$} & ${ }^{238} \mathrm{U}$ & & ${ }^{235} \mathrm{U}$ & & ${ }^{207} \mathrm{~Pb}$ & & ${ }^{206} \mathrm{~Pb}$ & & & & & \\
\hline & & & & $\overline{{ }^{206} \mathrm{~Pb}}$ & $\pm(2 \sigma)$ & ${ }^{206} \mathrm{~Pb}$ & $\pm(2 \sigma)$ & ${ }^{207} \mathrm{~Pb}$ & $\pm(2 \sigma)$ & ${ }^{206} \mathrm{~Pb}$ & $\pm \mathrm{Ma}$ & ${ }^{238} \mathrm{U}$ & $\pm \mathrm{Ma}$ & ${ }^{235} \mathrm{U}$ & & & \\
\hline 5 & 134 & 114 & 1.2 & 0.236 & 0.002 & 1.543 & 0.034 & 0.047 & 0.001 & 3094 & 15 & 3223 & 55 & 3146 & 18 & 3146 & 320 \\
\hline 6 & 200 & 249 & 0.8 & 0.098 & 0.001 & 3.575 & 0.078 & 0.266 & 0.006 & 1585 & 27 & 1591 & 30 & 1586 & 19 & 1586 & 17 \\
\hline 7 & 68 & 29 & 2.3 & 0.068 & 0.005 & 10.685 & 0.637 & 1.457 & 0.137 & 854 & 133 & 577 & 31 & 531 & 36 & 557 & 25 \\
\hline 8 & 176 & 82 & 2.1 & 0.194 & 0.002 & 1.859 & 0.034 & 0.070 & 0.001 & 2780 & 16 & 2776 & 41 & 2777 & 19 & 2775 & 18 \\
\hline 9 & 68 & 69 & 1.0 & 0.245 & 0.003 & 1.609 & 0.049 & 0.048 & 0.001 & 3154 & 22 & 3117 & 73 & 3135 & 27 & 3131 & 26 \\
\hline 10 & 177 & 299 & 0.6 & 0.054 & 0.002 & 10.877 & 0.412 & 1.583 & 0.109 & 359 & 81 & 567 & 20 & 498 & 26 & discordant & \\
\hline 11 & 337 & 259 & 1.3 & 0.068 & 0.002 & 12.315 & 0.356 & 1.415 & 0.057 & 871 & 85 & 503 & 14 & 543 & 16 & discordant & \\
\hline 12 & 469 & 92 & 5.1 & 0.063 & 0.001 & 9.970 & 0.210 & 1.169 & 0.036 & 711 & 37 & 616 & 12 & 628 & 14 & 621 & 10 \\
\hline 13 & 164 & 96 & 1.7 & 0.076 & 0.003 & 11.234 & 0.431 & 1.024 & 0.056 & 1092 & 68 & 550 & 19 & 693 & 26 & discordant & \\
\hline 14 & 302 & 141 & 2.1 & 0.067 & 0.002 & 12.416 & 0.426 & 1.443 & 0.068 & 846 & 75 & 500 & 16 & 535 & 19 & 514 & 220 \\
\hline 15 & 143 & 50 & 2.9 & 0.066 & 0.002 & 7.568 & 0.219 & 0.911 & 0.045 & 808 & 63 & 800 & 21 & 753 & 25 & 780 & 320 \\
\hline 16 & 271 & 17 & 15.7 & 0.072 & 0.001 & 6.571 & 0.136 & 0.673 & 0.020 & 994 & 38 & 913 & 17 & 925 & 18 & 919 & 13 \\
\hline 17 & 1377 & 98 & 14.0 & 0.073 & 0.001 & 8.401 & 0.137 & 0.809 & 0.015 & 1020 & 24 & 725 & 11 & 818 & 10 & discordant & \\
\hline $18 \mathrm{c}$ & 307 & 405 & 0.8 & 0.080 & 0.001 & 5.341 & 0.138 & 0.473 & 0.015 & 1191 & 33 & 1107 & 26 & 1155 & 21 & 1135 & 330 \\
\hline $18 \mathrm{r}$ & 728 & 77 & 9.5 & 0.075 & 0.001 & 5.459 & 0.107 & 0.517 & 0.010 & 1080 & 24 & 1085 & 19 & 1094 & 13 & 1090 & 11 \\
\hline $18(a)$ & 50 & 174 & 0.3 & 0.154 & 0.011 & 14.530 & 1.257 & 0.822 & 0.093 & 2387 & 114 & 429 & 33 & 809 & 59 & discordant & \\
\hline 19 & 62 & 108 & 0.6 & 0.065 & 0.004 & 12.017 & 0.996 & 1.912 & 0.243 & 770 & 135 & 515 & 38 & 428 & 40 & 473 & 550 \\
\hline 23 & 349 & 89 & 3.9 & 0.069 & 0.001 & 7.890 & 0.243 & 0.830 & 0.034 & 889 & 43 & 770 & 22 & 803 & 22 & 785 & 240 \\
\hline 24 & 506 & 211 & 2.4 & 0.063 & 0.002 & 11.417 & 0.401 & 1.393 & 0.103 & 723 & 51 & 541 & 18 & 550 & 30 & 543 & 16 \\
\hline 25 & 334 & 197 & 1.7 & 0.076 & 0.001 & 5.136 & 0.124 & 0.493 & 0.015 & 1094 & 30 & 1147 & 25 & 1126 & 20 & 1133 & 17 \\
\hline 26 & 131 & 126 & 1.0 & 0.091 & 0.002 & 3.904 & 0.123 & 0.315 & 0.013 & 1443 & 48 & 1470 & 40 & 1453 & 31 & 1458 & 27 \\
\hline 27 & 279 & 132 & 2.1 & 0.060 & 0.002 & 10.546 & 0.243 & 1.304 & 0.046 & 618 & 55 & 584 & 13 & 578 & 15 & 582 & 10 \\
\hline 20 & 905 & 229 & 4.0 & 0.061 & 0.001 & 10.304 & 0.170 & 1.211 & 0.023 & 628 & 28 & 597 & 9 & 612 & 9 & 605 & 110 \\
\hline 28 & 133 & 298 & 0.4 & 0.059 & 0.002 & 10.438 & 0.358 & 1.343 & 0.077 & 579 & 79 & 590 & 19 & 566 & 24 & 580 & 15 \\
\hline 29 & 282 & 346 & 0.8 & 0.092 & 0.001 & 3.790 & 0.108 & 0.296 & 0.008 & 1464 & 29 & 1510 & 38 & 1500 & 21 & 1501 & 20 \\
\hline 30 & 348 & 697 & 0.5 & 0.060 & 0.002 & 10.647 & 0.330 & 1.421 & 0.102 & 588 & 57 & 579 & 17 & 541 & 28 & 569 & 210 \\
\hline 33 & 256 & 101 & 2.5 & 0.062 & 0.002 & 11.123 & 0.482 & 1.333 & 0.063 & 672 & 68 & 555 & 22 & 569 & 20 & 562 & 16 \\
\hline 34 & 152 & 186 & 0.8 & 0.063 & 0.003 & 10.623 & 0.502 & 1.383 & 0.085 & 723 & 83 & 580 & 25 & 553 & 25 & 566 & 19 \\
\hline
\end{tabular}


Sample 462-7 Page 2

\begin{tabular}{|c|c|c|c|c|c|c|c|c|c|c|c|c|c|c|c|c|c|}
\hline \multirow[b]{3}{*}{ Zircon } & \multirow[b]{3}{*}{$\mathrm{U}(\mathrm{ppm})$} & \multirow[b]{3}{*}{ Th (ppm) } & \multirow[b]{3}{*}{$\mathrm{U} / \mathrm{Th}$} & \multicolumn{7}{|c|}{ Isotopic ratios } & \multicolumn{4}{|c|}{ Apparent ages $(\mathrm{Ma})$} & \multirow[b]{3}{*}{$\pm \mathrm{Ma}$} & \multirow[b]{3}{*}{ Concordia } & \multirow[b]{3}{*}{$\pm \mathrm{Ma}$} \\
\hline & & & & \multicolumn{2}{|l|}{${ }^{207} \mathrm{~Pb}$} & ${ }^{238} \mathrm{U}$ & & ${ }^{235} \mathrm{U}$ & & ${ }^{207} \mathrm{~Pb}$ & & ${ }^{206} \mathrm{~Pb}$ & & ${ }^{207} \mathrm{~Pb}$ & & & \\
\hline & & & & $\overline{{ }^{206} \mathrm{~Pb}}$ & $\pm(2 \sigma)$ & ${ }^{206} \mathrm{~Pb}$ & $\pm(2 \sigma)$ & ${ }^{207} \mathrm{~Pb}$ & $\pm(2 \sigma)$ & ${ }^{206} \mathrm{~Pb}$ & $\pm \mathrm{Ma}$ & ${ }^{238} \mathrm{U}$ & $\pm \mathrm{Ma}$ & ${ }^{235} \mathrm{U}$ & & & \\
\hline 35 & 497 & 440 & 1.1 & 0.085 & 0.002 & 4.625 & 0.151 & 0.388 & 0.011 & 1316 & 35 & 1262 & 36 & 1295 & 20 & 1292 & 20 \\
\hline 36 & 666 & 173 & 3.8 & 0.119 & 0.002 & 2.941 & 0.077 & 0.175 & 0.004 & 1945 & 22 & 1888 & 42 & 1934 & 20 & 1931 & 300 \\
\hline 37 & 222 & 238 & 0.9 & 0.058 & 0.002 & 11.966 & 0.506 & 1.625 & 0.086 & 546 & 73 & 518 & 20 & 487 & 20 & 502 & 220 \\
\hline 38 & 165 & 66 & 2.5 & 0.074 & 0.002 & 6.392 & 0.188 & 0.625 & 0.026 & 1051 & 45 & 937 & 25 & 971 & 25 & 953 & 19 \\
\hline 39 & 59 & 95 & 0.6 & 0.071 & 0.004 & 6.555 & 0.294 & 0.804 & 0.073 & 957 & 110 & 916 & 37 & 821 & 48 & 879 & 590 \\
\hline 40 & 243 & 101 & 2.4 & 0.078 & 0.001 & 4.735 & 0.106 & 0.442 & 0.012 & 1154 & 36 & 1236 & 25 & 1201 & 19 & 1212 & 230 \\
\hline 41 & 331 & 101 & 3.3 & 0.073 & 0.001 & 7.753 & 0.152 & 0.782 & 0.022 & 1017 & 41 & 782 & 14 & 837 & 16 & discordant & \\
\hline 42 & 307 & 142 & 2.2 & 0.059 & 0.002 & 11.130 & 0.291 & 1.430 & 0.062 & 569 & 57 & 555 & 14 & 539 & 18 & 549 & 11 \\
\hline 43 & 374 & 217 & 1.7 & 0.071 & 0.002 & 12.036 & 0.307 & 1.385 & 0.053 & 961 & 49 & 515 & 12 & 552 & 16 & discordant & \\
\hline 44 & 530 & 204 & 2.6 & 0.059 & 0.001 & 10.526 & 0.243 & 1.327 & 0.044 & 559 & 47 & 585 & 13 & 571 & 14 & 579 & 10 \\
\hline 45 & 170 & 83 & 2.1 & 0.065 & 0.003 & 11.507 & 0.657 & 1.431 & 0.105 & 760 & 88 & 537 & 28 & 538 & 29 & 538 & 22 \\
\hline 46 & 330 & 149 & 2.2 & 0.059 & 0.002 & 11.942 & 0.528 & 1.575 & 0.103 & 557 & 63 & 519 & 21 & 500 & 25 & 510 & 17 \\
\hline 47 & 928 & 188 & 4.9 & 0.063 & 0.001 & 9.603 & 0.232 & 1.150 & 0.041 & 696 & 33 & 639 & 14 & 636 & 16 & 637 & 12 \\
\hline 49 & 132 & 48 & 2.7 & 0.073 & 0.004 & 13.299 & 0.870 & 1.799 & 0.214 & 1017 & 102 & 468 & 28 & 449 & 39 & 461 & 24 \\
\hline 50 & 510 & 283 & 1.8 & 0.085 & 0.002 & 14.768 & 0.537 & 1.254 & 0.045 & 1324 & 41 & 423 & 14 & 596 & 16 & discordant & \\
\hline 51 & 309 & 49 & 6.3 & 0.096 & 0.002 & 3.507 & 0.087 & 0.267 & 0.007 & 1543 & 32 & 1618 & 35 & 1583 & 22 & 1588 & 270 \\
\hline 52 & 342 & 65 & 5.2 & 0.105 & 0.001 & 3.713 & 0.077 & 0.256 & 0.006 & 1722 & 23 & 1538 & 28 & 1617 & 19 & discordant & \\
\hline 53 & 317 & 44 & 7.2 & 0.057 & 0.002 & 12.203 & 0.347 & 1.662 & 0.126 & 491 & 70 & 508 & 14 & 479 & 27 & 502 & 12 \\
\hline 54 & 174 & 72 & 2.4 & 0.061 & 0.002 & 11.315 & 0.534 & 1.537 & 0.109 & 640 & 74 & 546 & 24 & 509 & 27 & 530 & 230 \\
\hline 55 & 271 & 141 & 1.9 & 0.076 & 0.001 & 5.451 & 0.141 & 0.517 & 0.017 & 1099 & 33 & 1086 & 25 & 1094 & 21 & 1090 & 18 \\
\hline 56 & 342 & 259 & 1.3 & 0.089 & 0.002 & 5.651 & 0.148 & 0.491 & 0.014 & 1401 & 28 & 1051 & 25 & 1129 & 20 & discordant & \\
\hline 57 & 404 & 293 & 1.4 & 0.079 & 0.001 & 4.971 & 0.119 & 0.451 & 0.012 & 1177 & 25 & 1182 & 25 & 1187 & 18 & 1185 & 16 \\
\hline 69 & 282 & 167 & 1.7 & 0.061 & 0.002 & 11.604 & 0.355 & 1.496 & 0.069 & 651 & 59 & 533 & 15 & 520 & 18 & 527 & 12 \\
\hline 67 & 265 & 238 & 1.1 & 0.059 & 0.002 & 11.463 & 0.353 & 1.488 & 0.079 & 581 & 63 & 539 & 15 & 522 & 21 & 533 & 14 \\
\hline 66 & 138 & 49 & 2.8 & 0.111 & 0.002 & 5.427 & 0.319 & 0.335 & 0.020 & 1820 & 40 & 1091 & 56 & 1406 & 44 & discordant & \\
\hline 65 & 405 & 8 & 48.3 & 0.059 & 0.001 & 11.365 & 0.287 & 1.462 & 0.057 & 555 & 42 & 544 & 13 & 529 & 16 & 538 & 11 \\
\hline 64 & 86 & 42 & 2.1 & 0.180 & 0.003 & 2.461 & 0.075 & 0.097 & 0.003 & 2651 & 26 & 2199 & 56 & 2466 & 30 & discordant & \\
\hline 63 & 660 & 265 & 2.5 & 0.059 & 0.001 & 12.666 & 0.332 & 1.586 & 0.054 & 551 & 48 & 490 & 12 & 497 & 13 & 493 & 9 \\
\hline
\end{tabular}


Sample 462-7 Page 3

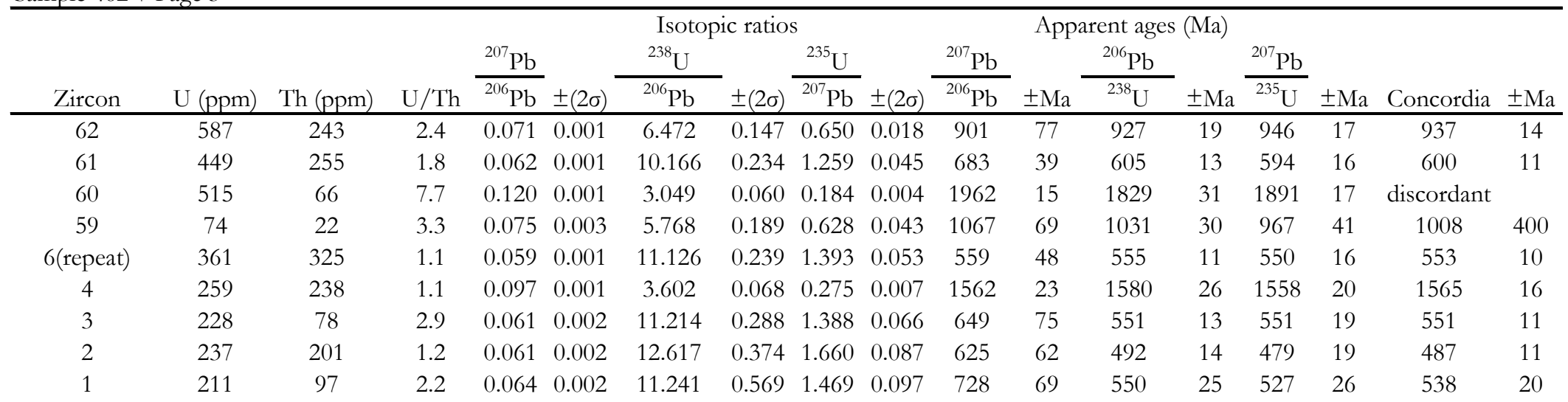

Sample 465-8 Page 1

\begin{tabular}{|c|c|c|c|c|c|c|c|c|c|c|c|c|c|c|c|c|c|}
\hline \multirow[b]{3}{*}{ Zircon } & \multirow[b]{3}{*}{$\mathrm{U}(\mathrm{ppm})$} & \multirow[b]{3}{*}{ Th (ppm) } & \multirow[b]{3}{*}{$\mathrm{U} / \mathrm{Th}$} & \multicolumn{7}{|c|}{ Isotopic ratios } & \multicolumn{3}{|c|}{ Apparent ages $(\mathrm{Ma})$} & \multirow[b]{2}{*}{${ }^{207} \mathrm{~Pb}$} & \multirow[b]{3}{*}{$\pm \mathrm{Ma}$} & \multirow[b]{3}{*}{ Concordia } & \multirow[b]{3}{*}{$\pm \mathrm{Ma}$} \\
\hline & & & & \multicolumn{2}{|l|}{${ }^{207} \mathrm{~Pb}$} & ${ }^{238} \mathrm{U}$ & & ${ }^{235} \mathrm{U}$ & & ${ }^{207} \mathrm{~Pb}$ & & ${ }^{206} \mathrm{~Pb}$ & & & & & \\
\hline & & & & $\overline{{ }^{206} \mathrm{~Pb}}$ & $\pm(2 \sigma)$ & ${ }^{206} \mathrm{~Pb}$ & $\pm(2 \sigma)$ & ${ }^{207} \mathrm{~Pb}$ & $\pm(2 \sigma)$ & ${ }^{206} \mathrm{~Pb}$ & $\pm \mathrm{Ma}$ & ${ }^{238} \mathrm{U}$ & $\pm \mathrm{Ma}$ & $\overline{{ }^{235} \mathrm{U}}$ & & & \\
\hline 13 & 379 & 264 & 1.4 & 0.059 & 0.001 & 10.991 & 0.210 & 1.410 & 0.048 & 566 & 47 & 562 & 10 & 545 & 14 & 556 & 110 \\
\hline 11 & 221 & 149 & 1.5 & 0.082 & 0.001 & 4.405 & 0.084 & 0.402 & 0.010 & 1252 & 34 & 1319 & 22 & 1270 & 18 & discordant & \\
\hline 10 & 242 & 142 & 1.7 & 0.060 & 0.002 & 12.526 & 0.339 & 1.633 & 0.087 & 608 & 69 & 495 & 13 & 485 & 20 & 492 & 11 \\
\hline 9 & 156 & 73 & 2.1 & 0.081 & 0.002 & 4.793 & 0.112 & 0.448 & 0.016 & 1210 & 38 & 1222 & 25 & 1192 & 25 & 1206 & 18 \\
\hline 8 & 325 & 115 & 2.8 & 0.073 & 0.001 & 5.882 & 0.106 & 0.589 & 0.014 & 1010 & 36 & 1013 & 17 & 1008 & 15 & 1010 & 11 \\
\hline 7 & 67 & 19 & 3.5 & 0.063 & 0.003 & 11.648 & 0.621 & 1.561 & 0.132 & 700 & 111 & 531 & 26 & 503 & 32 & 520 & 21 \\
\hline 3 & 305 & 158 & 1.9 & 0.061 & 0.001 & 10.511 & 0.247 & 1.292 & 0.059 & 632 & 53 & 586 & 13 & 583 & 20 & 585 & 11 \\
\hline 4 & 409 & 209 & 2.0 & 0.061 & 0.001 & 12.020 & 0.322 & 1.535 & 0.084 & 652 & 45 & 515 & 13 & 510 & 21 & 514 & 12 \\
\hline 6 & 461 & 348 & 1.3 & 0.061 & 0.001 & 11.738 & 0.247 & 1.394 & 0.040 & 646 & 43 & 527 & 10 & 549 & 12 & 536 & 140 \\
\hline 5 & 261 & 75 & 3.5 & 0.110 & 0.002 & 2.966 & 0.052 & 0.195 & 0.004 & 1801 & 27 & 1874 & 28 & 1843 & 16 & 1849 & 14 \\
\hline 2 & 306 & 248 & 1.2 & 0.078 & 0.001 & 5.166 & 0.111 & 0.485 & 0.012 & 1137 & 34 & 1141 & 22 & 1137 & 17 & 1138 & 14 \\
\hline 1 & 211 & 113 & 1.9 & 0.059 & 0.002 & 11.230 & 0.320 & 1.571 & 0.119 & 564 & 67 & 550 & 15 & 500 & 28 & 539 & 260 \\
\hline
\end{tabular}


$\underline{\text { Sample 465-8 Page } 2}$

\begin{tabular}{|c|c|c|c|c|c|c|c|c|c|c|c|c|c|c|c|c|c|}
\hline \multirow[b]{3}{*}{ Zircon } & \multirow[b]{3}{*}{$\mathrm{U}(\mathrm{ppm})$} & \multirow[b]{3}{*}{ Th (ppm) } & \multirow[b]{3}{*}{$\mathrm{U} / \mathrm{Th}$} & \multicolumn{7}{|c|}{ Isotopic ratios } & \multicolumn{4}{|c|}{ Apparent ages $(\mathrm{Ma})$} & \multirow[b]{3}{*}{$\pm \mathrm{Ma}$} & \multirow[b]{3}{*}{ Concordia } & \multirow[b]{3}{*}{$\pm \mathrm{Ma}$} \\
\hline & & & & \multicolumn{2}{|l|}{${ }^{207} \mathrm{~Pb}$} & ${ }^{238} \mathrm{U}$ & & ${ }^{235} \mathrm{U}$ & & ${ }^{207} \mathrm{~Pb}$ & & ${ }^{206} \mathrm{~Pb}$ & & ${ }^{207} \mathrm{~Pb}$ & & & \\
\hline & & & & $\overline{{ }^{206} \mathrm{~Pb}}$ & $\pm(2 \sigma)$ & ${ }^{206} \mathrm{~Pb}$ & $\pm(2 \sigma)$ & ${ }^{207} \mathrm{~Pb}$ & $\pm(2 \sigma)$ & ${ }^{206} \mathrm{~Pb}$ & $\pm \mathrm{Ma}$ & ${ }^{238} \mathrm{U}$ & $\pm \mathrm{Ma}$ & ${ }^{235} \mathrm{U}$ & & & \\
\hline 12 & 300 & 119 & 2.5 & 0.077 & 0.001 & 5.641 & 0.108 & 0.514 & 0.013 & 1126 & 31 & 1053 & 18 & 1097 & 17 & discordant & \\
\hline 1 & 601 & 124 & 4.8 & 0.070 & 0.001 & 11.583 & 0.210 & 1.229 & 0.039 & 941 & 34 & 534 & 9 & 605 & 14 & discordant & \\
\hline 2 & 207 & 100 & 2.1 & 0.101 & 0.001 & 3.254 & 0.062 & 0.234 & 0.005 & 1635 & 26 & 1728 & 28 & 1689 & 17 & 1697 & 240 \\
\hline 3 & 203 & 124 & 1.6 & 0.063 & 0.002 & 10.885 & 0.342 & 1.449 & 0.084 & 713 & 67 & 567 & 17 & 533 & 23 & 555 & 210 \\
\hline 4 & 898 & 842 & 1.1 & 0.183 & 0.001 & 3.564 & 0.059 & 0.143 & 0.002 & 2683 & 14 & 1595 & 23 & 2114 & 12 & discordant & \\
\hline 5 & 463 & 228 & 2.0 & 0.059 & 0.001 & 11.074 & 0.287 & 1.384 & 0.052 & 571 & 45 & 558 & 14 & 552 & 15 & 555 & 10 \\
\hline $6 a$ & 222 & 119 & 1.9 & 0.059 & 0.002 & 12.687 & 0.403 & 1.796 & 0.143 & 574 & 72 & 489 & 15 & 450 & 27 & 481 & 210 \\
\hline 6 & 411 & 211 & 1.9 & 0.060 & 0.001 & 11.200 & 0.235 & 1.423 & 0.055 & 613 & 48 & 552 & 11 & 541 & 16 & 548 & 9 \\
\hline 7 & 137 & 74 & 1.9 & 0.061 & 0.004 & 11.216 & 0.320 & 1.609 & 0.097 & 634 & 145 & 551 & 15 & 491 & 22 & discordant & \\
\hline 10 & 957 & 1107 & 0.9 & 0.106 & 0.002 & 14.916 & 0.247 & 0.928 & 0.025 & 1728 & 34 & 418 & 7 & 743 & 14 & discordant & \\
\hline 11 & 435 & 189 & 2.3 & 0.059 & 0.002 & 10.948 & 0.226 & 1.391 & 0.054 & 575 & 56 & 564 & 11 & 550 & 16 & 559 & 9 \\
\hline 12 & 122 & 63 & 1.9 & 0.173 & 0.002 & 2.099 & 0.040 & 0.087 & 0.002 & 2588 & 17 & 2513 & 39 & 2562 & 19 & 2560 & 350 \\
\hline 13 & 193 & 65 & 3.0 & 0.078 & 0.003 & 11.248 & 0.282 & 1.019 & 0.038 & 1150 & 62 & 549 & 13 & 695 & 18 & discordant & \\
\hline 15 & 436 & 291 & 1.5 & 0.060 & 0.001 & 11.881 & 0.287 & 1.534 & 0.064 & 591 & 46 & 521 & 12 & 510 & 16 & 517 & 10 \\
\hline 17 & 179 & 60 & 3.0 & 0.113 & 0.003 & 3.480 & 0.295 & 0.217 & 0.016 & 1856 & 40 & 1629 & 113 & 1752 & 58 & 1764 & 960 \\
\hline 18 & 85 & 62 & 1.4 & 0.101 & 0.004 & 5.428 & 0.675 & 0.364 & 0.038 & 1650 & 71 & 1090 & 112 & 1343 & 73 & discordant & \\
\hline 19 & 88 & 65 & 1.3 & 0.067 & 0.004 & 13.162 & 1.285 & 1.759 & 0.218 & 834 & 124 & 472 & 41 & 457 & 41 & 465 & 34 \\
\hline 20 & 365 & 94 & 3.9 & 0.073 & 0.001 & 6.525 & 0.227 & 0.662 & 0.026 & 1016 & 37 & 920 & 29 & 935 & 23 & 928 & 19 \\
\hline 16 & 234 & 67 & 3.5 & 0.081 & 0.002 & 5.723 & 0.484 & 0.486 & 0.038 & 1227 & 46 & 1039 & 75 & 1136 & 51 & 1109 & 710 \\
\hline 21 & 435 & 187 & 2.3 & 0.060 & 0.001 & 10.402 & 0.281 & 1.276 & 0.044 & 595 & 40 & 592 & 15 & 588 & 15 & 590 & 12 \\
\hline 22 & 233 & 5 & 44.8 & 0.092 & 0.003 & 6.211 & 0.226 & 0.348 & 0.019 & 1475 & 65 & 963 & 31 & 1377 & 40 & discordant & \\
\hline 23 & 349 & 190 & 1.8 & 0.071 & 0.002 & 11.029 & 0.235 & 1.113 & 0.055 & 960 & 61 & 560 & 11 & 651 & 23 & discordant & \\
\hline 24 & 84 & 61 & 1.4 & 0.184 & 0.003 & 2.050 & 0.049 & 0.081 & 0.002 & 2691 & 31 & 2563 & 50 & 2637 & 20 & 2630 & 380 \\
\hline 25 & 292 & 132 & 2.2 & 0.058 & 0.002 & 11.515 & 0.308 & 1.516 & 0.070 & 526 & 59 & 537 & 13 & 515 & 18 & 529 & 140 \\
\hline 26 & 187 & 48 & 3.8 & 0.060 & 0.002 & 11.216 & 0.354 & 1.514 & 0.087 & 605 & 22 & 551 & 16 & 515 & 22 & 538 & 220 \\
\hline 27 & 168 & 142 & 1.2 & 0.081 & 0.002 & 5.329 & 0.190 & 0.476 & 0.022 & 1224 & 43 & 1109 & 35 & 1150 & 31 & 1132 & 25 \\
\hline 28 & 505 & 217 & 2.3 & 0.074 & 0.002 & 12.478 & 0.314 & 1.315 & 0.044 & 1046 & 45 & 497 & 12 & 575 & 14 & discordant & \\
\hline 29 & 774 & 204 & 3.8 & 0.076 & 0.001 & 5.314 & 0.112 & 0.505 & 0.011 & 1084 & 32 & 1112 & 21 & 1110 & 14 & 1110 & 13 \\
\hline
\end{tabular}


Sample 465-8 Page 3

\begin{tabular}{|c|c|c|c|c|c|c|c|c|c|c|c|c|c|c|c|c|c|}
\hline \multirow[b]{3}{*}{ Zircon } & \multirow[b]{3}{*}{$\mathrm{U}(\mathrm{ppm})$} & \multirow[b]{3}{*}{ Th (ppm) } & \multirow[b]{3}{*}{$\mathrm{U} / \mathrm{Th}$} & \multicolumn{7}{|c|}{ Isotopic ratios } & \multicolumn{4}{|c|}{ Apparent ages $(\mathrm{Ma})$} & \multirow[b]{3}{*}{$\pm \mathrm{Ma}$} & \multirow[b]{3}{*}{ Concordia } & \multirow[b]{3}{*}{$\pm \mathrm{Ma}$} \\
\hline & & & & \multicolumn{2}{|l|}{${ }^{207} \mathrm{~Pb}$} & ${ }^{238} \mathrm{U}$ & & ${ }^{235} \mathrm{U}$ & & ${ }^{207} \mathrm{~Pb}$ & & ${ }^{206} \mathrm{~Pb}$ & & ${ }^{207} \mathrm{~Pb}$ & & & \\
\hline & & & & ${ }^{206} \mathrm{~Pb}$ & $\pm(2 \sigma)$ & ${ }^{206} \mathrm{~Pb}$ & $\pm(2 \sigma)$ & ${ }^{207} \mathrm{~Pb}$ & $\pm(2 \sigma)$ & ${ }^{206} \mathrm{~Pb}$ & $\pm \mathrm{Ma}$ & ${ }^{238} \mathrm{U}$ & $\pm \mathrm{Ma}$ & ${ }^{235} \mathrm{U}$ & & & \\
\hline 30 & 136 & 83 & 1.6 & 0.076 & 0.002 & 5.590 & 0.174 & 0.551 & 0.024 & 1103 & 49 & 1061 & 30 & 1051 & 28 & 1055 & 22 \\
\hline 31 & 163 & 149 & 1.1 & 0.077 & 0.002 & 5.496 & 0.154 & 0.534 & 0.021 & 1130 & 45 & 1078 & 27 & 1073 & 26 & 1075 & 19 \\
\hline 32 & 504 & 188 & 2.7 & 0.067 & 0.002 & 11.071 & 0.277 & 1.445 & 0.066 & 837 & 50 & 558 & 13 & 534 & 18 & 550 & 140 \\
\hline 33 & 155 & 48 & 3.2 & 0.060 & 0.002 & 11.475 & 0.407 & 1.680 & 0.155 & 603 & 78 & 539 & 18 & 475 & 32 & discordant & \\
\hline 35 & 418 & 283 & 1.5 & 0.093 & 0.002 & 5.611 & 0.152 & 0.384 & 0.011 & 1486 & 34 & 1058 & 26 & 1302 & 21 & $\mathrm{~d}$ & 0 \\
\hline 34 & 391 & 49 & 8.0 & 0.062 & 0.001 & 8.975 & 0.841 & 1.091 & 0.099 & 685 & 44 & 681 & 56 & 661 & 41 & 667 & 38 \\
\hline 36 & 346 & 65 & 5.3 & 0.059 & 0.002 & 11.501 & 0.387 & 1.500 & 0.081 & 576 & 68 & 538 & 17 & 519 & 21 & 530 & 14 \\
\hline 37 & 232 & 44 & 5.3 & 0.069 & 0.002 & 7.362 & 0.210 & 0.802 & 0.033 & 894 & 48 & 821 & 21 & 823 & 22 & 822 & 16 \\
\hline 38 & 277 & 189 & 1.5 & 0.062 & 0.002 & 11.184 & 0.320 & 1.394 & 0.052 & 691 & 70 & 552 & 15 & 549 & 15 & 551 & 11 \\
\hline
\end{tabular}

Sample 507-6 Page 1

\begin{tabular}{|c|c|c|c|c|c|c|c|c|c|c|c|c|c|c|c|c|c|}
\hline \multirow[b]{3}{*}{ Zircon } & \multirow[b]{3}{*}{$\mathrm{U}(\mathrm{ppm})$} & \multirow[b]{3}{*}{ Th (ppm) } & \multirow[b]{3}{*}{$\mathrm{U} / \mathrm{Th}$} & \multicolumn{7}{|c|}{ Isotopic ratios } & \multicolumn{3}{|c|}{ Apparent ages $(\mathrm{Ma})$} & \multirow[b]{2}{*}{${ }^{207} \mathrm{~Pb}$} & \multirow[b]{3}{*}{$\pm \mathrm{Ma}$} & \multirow[b]{3}{*}{ Concordia } & \multirow[b]{3}{*}{$\pm \mathrm{Ma}$} \\
\hline & & & & ${ }^{207} \mathrm{~Pb}$ & & ${ }^{238} \mathrm{U}$ & & ${ }^{235} \mathrm{U}$ & & ${ }^{207} \mathrm{~Pb}$ & & ${ }^{206} \mathrm{~Pb}$ & & & & & \\
\hline & & & & ${ }^{206} \mathrm{~Pb}$ & $\pm(2 \sigma)$ & ${ }^{206} \mathrm{~Pb}$ & $\pm(2 \sigma)$ & ${ }^{207} \mathrm{~Pb}$ & $\pm(2 \sigma)$ & ${ }^{206} \mathrm{~Pb}$ & $\pm \mathrm{Ma}$ & ${ }^{238} \mathrm{U}$ & $\pm \mathrm{Ma}$ & ${ }^{235} \mathrm{U}$ & & & \\
\hline 1 & 603 & 125 & 0.2 & 0.071 & 0.002 & 6.230 & 0.160 & 0.651 & 0.026 & 962 & 45 & 960 & 22 & 946 & 24 & 953 & 17 \\
\hline 3 & 898 & 1107 & 1.2 & 0.155 & 0.002 & 2.143 & 0.039 & 0.100 & 0.002 & 2402 & 16 & 2470 & 37 & 2441 & 17 & 2442 & 16 \\
\hline 8 & 88 & 174 & 2.0 & 0.060 & 0.003 & 12.826 & 0.511 & 1.909 & 0.168 & 601 & 103 & 484 & 18 & 428 & 29 & 468 & 320 \\
\hline 10 & 84 & 137 & 1.6 & 0.310 & 0.028 & 15.016 & 2.030 & 0.507 & 0.061 & 3522 & 132 & 416 & 48 & 1107 & 75 & discordant & \\
\hline 9 & 85 & 180 & 2.1 & 0.116 & 0.001 & 3.297 & 0.063 & 0.206 & 0.004 & 1898 & 23 & 1708 & 28 & 1795 & 17 & discordant & \\
\hline 12 & 436 & 842 & 1.9 & 0.071 & 0.002 & 7.494 & 0.204 & 0.812 & 0.038 & 965 & 46 & 808 & 20 & 815 & 25 & 810 & 17 \\
\hline 15 & 203 & 156 & 0.8 & 0.093 & 0.004 & 12.016 & 0.580 & 1.077 & 0.087 & 1480 & 89 & 516 & 23 & 667 & 37 & discordant & \\
\hline 16 & 349 & 83 & 0.2 & 0.070 & 0.001 & 6.087 & 0.117 & 0.640 & 0.017 & 926 & 33 & 981 & 17 & 957 & 16 & 967 & 180 \\
\hline 17 & 137 & 65 & 0.5 & 0.065 & 0.002 & 12.225 & 0.395 & 1.452 & 0.072 & 775 & 60 & 507 & 15 & 532 & 20 & 516 & 170 \\
\hline 18 & 222 & 61 & 0.3 & 0.197 & 0.014 & 12.004 & 0.781 & 0.573 & 0.041 & 2798 & 108 & 516 & 30 & 1026 & 44 & discordant & \\
\hline 21 & 122 & 62 & 0.5 & 0.073 & 0.001 & 7.103 & 0.191 & 0.753 & 0.032 & 1013 & 38 & 849 & 21 & 859 & 24 & 853 & 16 \\
\hline 25 & 411 & 291 & 0.7 & 0.077 & 0.002 & 5.540 & 0.212 & 0.566 & 0.030 & 1129 & 54 & 1070 & 36 & 1034 & 33 & 1049 & 26 \\
\hline
\end{tabular}


Sample 507-6 Page 2

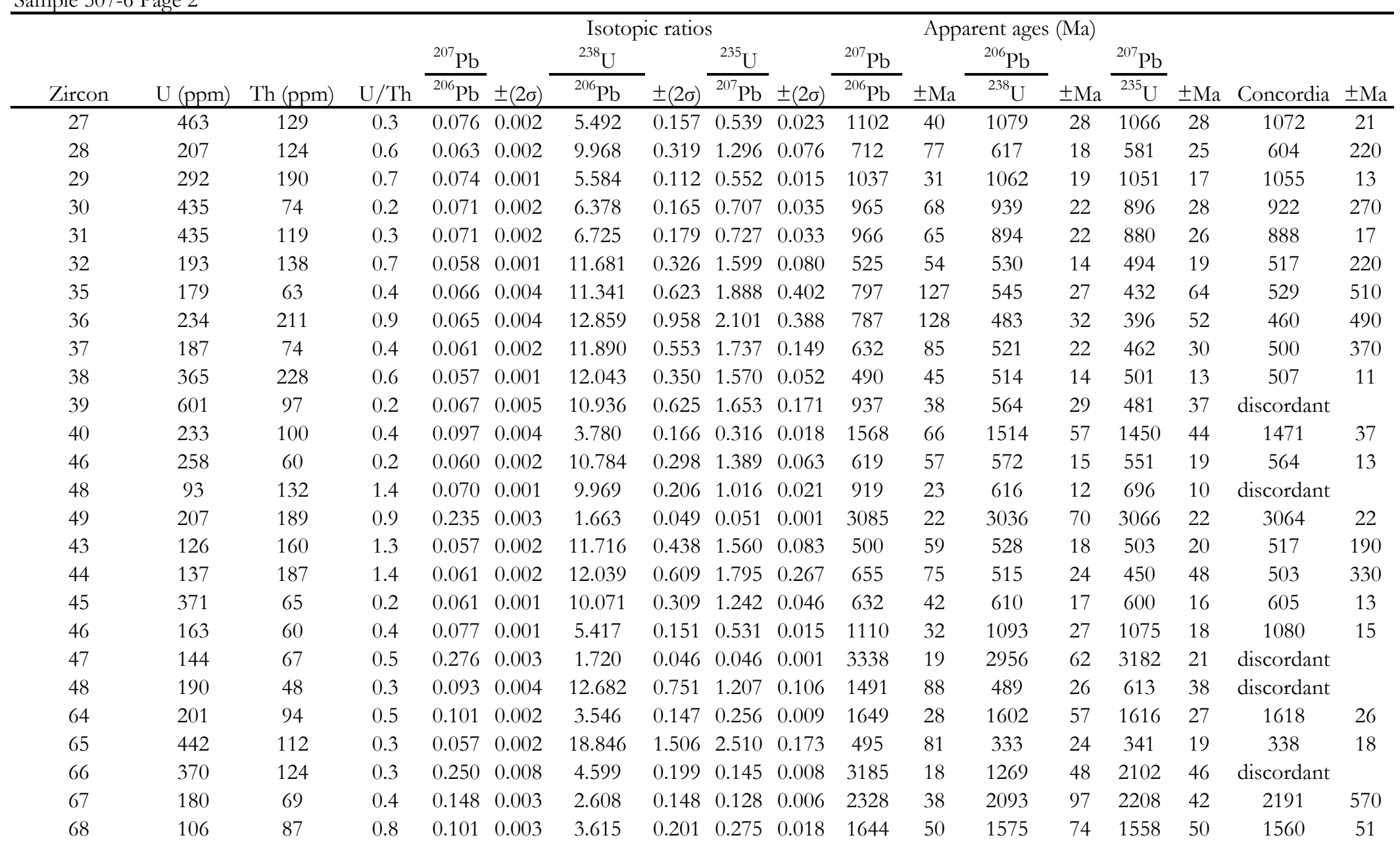


Sample 560-5 Page 1

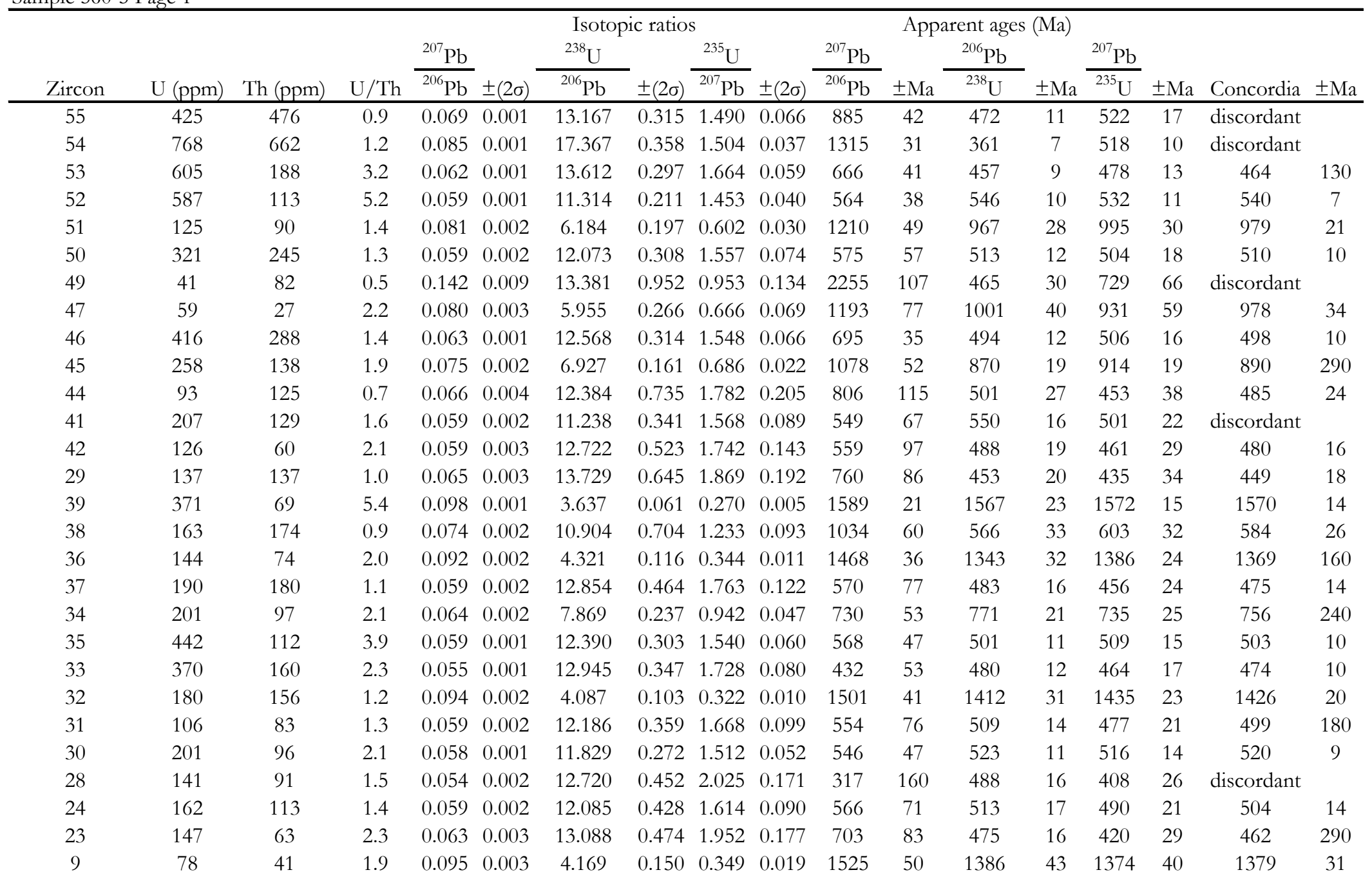


Sample 560-5 Page 2

\begin{tabular}{|c|c|c|c|c|c|c|c|c|c|c|c|c|c|c|c|c|c|}
\hline \multirow[b]{3}{*}{ Zircon } & \multirow[b]{3}{*}{$\mathrm{U}(\mathrm{ppm})$} & \multirow[b]{3}{*}{ Th (ppm) } & \multirow[b]{3}{*}{$\mathrm{U} / \mathrm{Th}$} & \multicolumn{7}{|c|}{ Isotopic ratios } & \multicolumn{3}{|c|}{ Apparent ages $(\mathrm{Ma})$} & \multirow[b]{2}{*}{${ }^{207} \mathrm{~Pb}$} & \multirow[b]{3}{*}{$\pm \mathrm{Ma}$} & \multirow[b]{3}{*}{ Concordia } & \multirow[b]{3}{*}{$\pm \mathrm{Ma}$} \\
\hline & & & & \multicolumn{2}{|l|}{${ }^{207} \mathrm{~Pb}$} & ${ }^{238} \mathrm{U}$ & & ${ }^{235} \mathrm{U}$ & & ${ }^{207} \mathrm{~Pb}$ & & ${ }^{206} \mathrm{~Pb}$ & & & & & \\
\hline & & & & ${ }^{206} \mathrm{~Pb}$ & $\pm(2 \sigma)$ & ${ }^{206} \mathrm{~Pb}$ & $\pm(2 \sigma)$ & ${ }^{207} \mathrm{~Pb}$ & $\pm(2 \sigma)$ & ${ }^{206} \mathrm{~Pb}$ & $\pm \mathrm{Ma}$ & ${ }^{238} \mathrm{U}$ & $\pm \mathrm{Ma}$ & ${ }^{235} \mathrm{U}$ & & & \\
\hline 20 & 200 & 110 & 1.8 & 0.070 & 0.002 & 7.140 & 0.211 & 0.792 & 0.036 & 921 & 47 & 845 & 23 & 830 & 25 & 838 & 17 \\
\hline 19 & 224 & 96 & 2.3 & 0.067 & 0.002 & 8.762 & 0.237 & 1.037 & 0.043 & 823 & 55 & 697 & 17 & 686 & 20 & 692 & 14 \\
\hline 18 & 396 & 197 & 2.0 & 0.058 & 0.001 & 11.630 & 0.340 & 1.526 & 0.070 & 546 & 47 & 532 & 15 & 512 & 18 & 524 & 12 \\
\hline 16 & 247 & 126 & 2.0 & 0.072 & 0.008 & 6.005 & 0.137 & 0.613 & 0.018 & 996 & 211 & 993 & 21 & 983 & 18 & 987 & 15 \\
\hline 17 & 76 & 23 & 3.2 & 0.094 & 0.003 & 4.050 & 0.114 & 0.333 & 0.013 & 1507 & 50 & 1423 & 35 & 1410 & 30 & 1414 & 24 \\
\hline 14 & 385 & 124 & 3.1 & 0.174 & 0.002 & 2.227 & 0.052 & 0.093 & 0.002 & 2596 & 20 & 2392 & 45 & 2508 & 16 & discordant & \\
\hline 13 & 358 & 21 & 16.8 & 0.072 & 0.001 & 6.353 & 0.193 & 0.649 & 0.020 & 986 & 38 & 943 & 26 & 948 & 18 & 946 & 17 \\
\hline 11 & 187 & 109 & 1.7 & 0.076 & 0.002 & 5.903 & 0.177 & 0.598 & 0.023 & 1082 & 41 & 1009 & 27 & 998 & 24 & 1002 & 19 \\
\hline 8 & 147 & 59 & 2.5 & 0.074 & 0.002 & 5.934 & 0.145 & 0.608 & 0.025 & 1033 & 46 & 1004 & 22 & 988 & 25 & 997 & 18 \\
\hline 7 & 667 & 194 & 3.4 & 0.060 & 0.001 & 10.756 & 0.248 & 1.326 & 0.038 & 618 & 23 & 573 & 12 & 571 & 12 & 572 & 10 \\
\hline 6 & 71 & 34 & 2.1 & 0.065 & 0.004 & 12.862 & 0.745 & 1.704 & 0.152 & 784 & 132 & 483 & 26 & 469 & 31 & 477 & 21 \\
\hline 5 & 594 & 107 & 5.6 & 0.059 & 0.001 & 11.787 & 0.274 & 1.490 & 0.046 & 585 & 42 & 525 & 11 & 522 & 12 & 523 & 9 \\
\hline 4 & 141 & 70 & 2.0 & 0.064 & 0.003 & 12.185 & 0.504 & 1.676 & 0.151 & 736 & 82 & 509 & 19 & 475 & 32 & 500 & 17 \\
\hline 3 & 314 & 220 & 1.4 & 0.061 & 0.002 & 10.305 & 0.315 & 1.267 & 0.046 & 648 & 54 & 597 & 17 & 591 & 16 & 594 & 12 \\
\hline 1(a) & 344 & 466 & 0.7 & 0.080 & 0.001 & 7.074 & 0.284 & 0.694 & 0.027 & 1199 & 32 & 853 & 31 & 907 & 23 & 890 & 460 \\
\hline 1 & 1010 & 276 & 3.7 & 0.908 & 0.004 & 3.982 & 0.042 & 0.032 & 0.000 & 1442 & 9 & 1445 & 14 & 3539 & 8 & discordant & \\
\hline
\end{tabular}

Sample 610-4 Page 1

\begin{tabular}{|c|c|c|c|c|c|c|c|c|c|c|c|c|c|c|c|c|c|}
\hline \multirow[b]{3}{*}{ Zircon } & \multirow[b]{3}{*}{$\mathrm{U}(\mathrm{ppm})$} & \multirow[b]{3}{*}{ Th (ppm) } & \multirow[b]{3}{*}{$\mathrm{U} / \mathrm{Th}$} & \multicolumn{7}{|c|}{ Isotopic ratios } & \multicolumn{4}{|c|}{ Apparent ages $(\mathrm{Ma})$} & \multirow[b]{3}{*}{$\pm \mathrm{Ma}$} & \multirow[b]{3}{*}{ Concordia } & \multirow[b]{3}{*}{$\pm \mathrm{Ma}$} \\
\hline & & & & ${ }^{207} \mathrm{~Pb}$ & & ${ }^{238} \mathrm{U}$ & & ${ }^{235} \mathrm{U}$ & & ${ }^{207} \mathrm{~Pb}$ & & ${ }^{206} \mathrm{~Pb}$ & & ${ }^{207} \mathrm{~Pb}$ & & & \\
\hline & & & & $\overline{{ }^{206} \mathrm{~Pb}}$ & $\pm(2 \sigma)$ & ${ }^{206} \mathrm{~Pb}$ & $\pm(2 \sigma)$ & ${ }^{207} \mathrm{~Pb}$ & $\pm(2 \sigma)$ & ${ }^{206} \mathrm{~Pb}$ & $\pm \mathrm{Ma}$ & ${ }^{238} \mathrm{U}$ & $\pm \mathrm{Ma}$ & $\overline{{ }^{235} \mathrm{U}}$ & & & \\
\hline 1 & 981 & 259 & 3.8 & 0.060 & 0.001 & 11.496 & 0.177 & 1.363 & 0.029 & 616 & 27 & 538 & 8 & 559 & 9 & discordant & \\
\hline 2 & 231 & 135 & 1.7 & 0.090 & 0.001 & 4.529 & 0.078 & 0.371 & 0.009 & 1418 & 29 & 1287 & 20 & 1328 & 18 & 1308 & 270 \\
\hline 3 & 241 & 159 & 1.5 & 0.070 & 0.002 & 11.956 & 0.325 & 1.137 & 0.056 & 922 & 62 & 518 & 13 & 641 & 23 & discordant & \\
\hline 4 & 837 & 331 & 2.5 & 0.087 & 0.001 & 4.413 & 0.072 & 0.354 & 0.006 & 1366 & 18 & 1317 & 19 & 1362 & 12 & $\mathrm{~d}$ & 0 \\
\hline 5 & 476 & 254 & 1.9 & 0.060 & 0.001 & 11.559 & 0.263 & 1.487 & 0.060 & 602 & 41 & 535 & 11 & 523 & 16 & 531 & 20 \\
\hline
\end{tabular}


Sample 610-4 Page 2

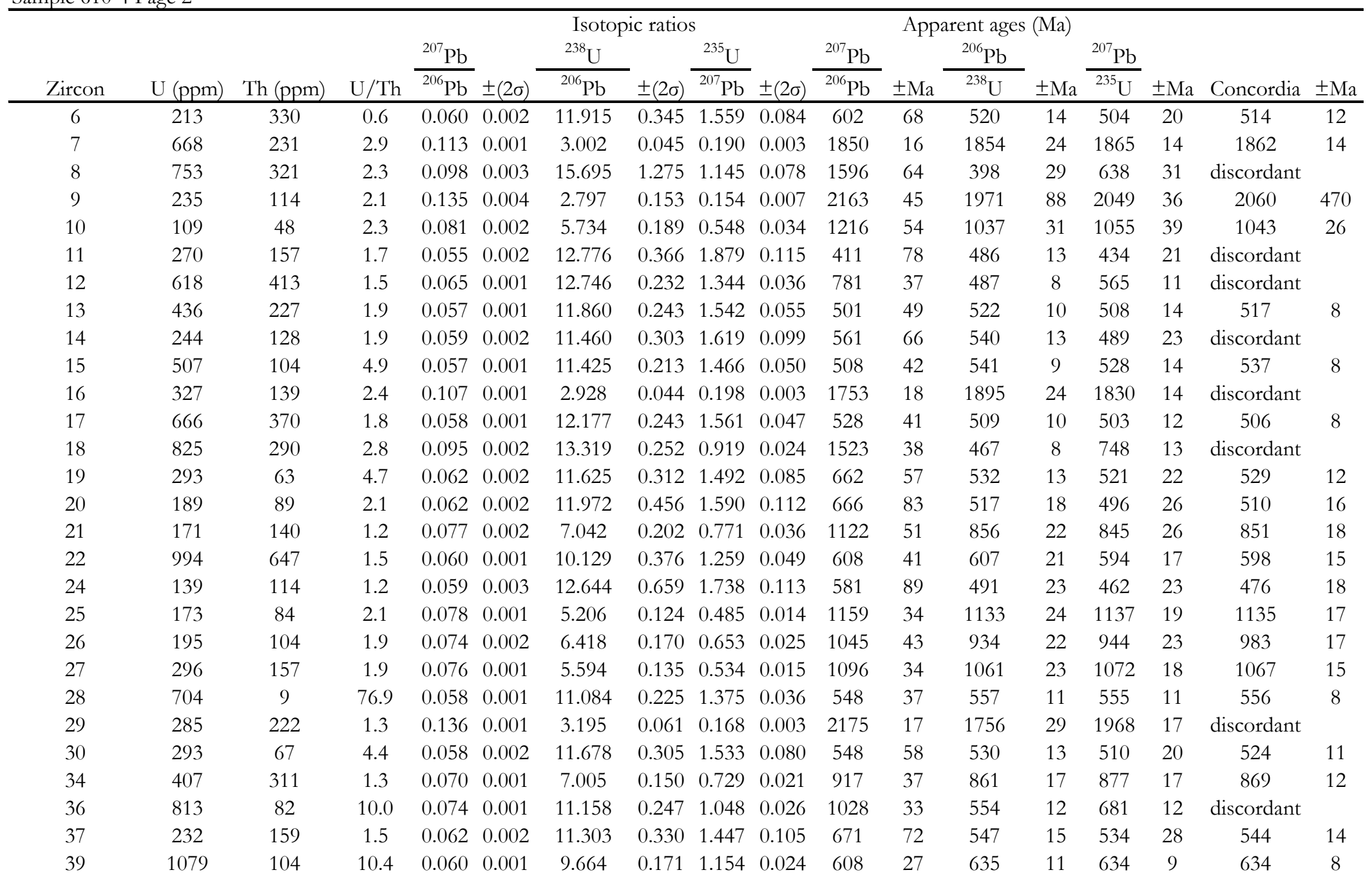


Sample 610-4 Page 3

\begin{tabular}{|c|c|c|c|c|c|c|c|c|c|c|c|c|c|c|c|c|c|}
\hline \multirow[b]{3}{*}{ Zircon } & \multirow[b]{3}{*}{$\mathrm{U}(\mathrm{ppm})$} & \multirow[b]{3}{*}{ Th (ppm) } & \multirow[b]{3}{*}{$\mathrm{U} / \mathrm{Th}$} & \multicolumn{7}{|c|}{ Isotopic ratios } & \multicolumn{3}{|c|}{ Apparent ages (Ma) } & \multirow[b]{2}{*}{${ }^{207} \mathrm{~Pb}$} & \multirow[b]{3}{*}{$\pm \mathrm{Ma}$} & \multirow[b]{3}{*}{ Concordia } & \multirow[b]{3}{*}{$\pm \mathrm{Ma}$} \\
\hline & & & & \multicolumn{2}{|l|}{${ }^{207} \mathrm{~Pb}$} & ${ }^{238} \mathrm{U}$ & & ${ }^{235} \mathrm{U}$ & & ${ }^{207} \mathrm{~Pb}$ & & ${ }^{206} \mathrm{~Pb}$ & & & & & \\
\hline & & & & $\overline{{ }^{206} \mathrm{~Pb}}$ & $\pm(2 \sigma)$ & ${ }^{206} \mathrm{~Pb}$ & $\pm(2 \sigma)$ & ${ }^{207} \mathrm{~Pb}$ & $\pm(2 \sigma)$ & ${ }^{206} \mathrm{~Pb}$ & $\pm \mathrm{Ma}$ & ${ }^{238} \mathrm{U}$ & $\pm \mathrm{Ma}$ & ${ }^{235} \mathrm{U}$ & & & \\
\hline 40 & 122 & 159 & 0.8 & 0.080 & 0.002 & 4.901 & 0.141 & 0.460 & $\overline{0.018}$ & 1191 & 48 & 1198 & 31 & 1173 & 27 & 1183 & 21 \\
\hline 41 & 193 & 69 & 2.8 & 0.063 & 0.002 & 11.214 & 0.304 & 1.432 & 0.094 & 710 & 82 & 551 & 14 & 538 & 26 & 548 & 13 \\
\hline 42 & 347 & 125 & 2.8 & 0.093 & 0.001 & 4.319 & 0.083 & 0.336 & 0.007 & 1492 & 25 & 1343 & 23 & 1403 & 16 & discordant & \\
\hline 43 & 1545 & 767 & 2.0 & 0.078 & 0.001 & 13.273 & 0.238 & 1.224 & 0.027 & 1151 & 26 & 468 & 8 & 607 & 10 & discordant & \\
\hline 44 & 636 & 147 & 4.3 & 0.080 & 0.002 & 13.032 & 0.285 & 0.992 & 0.028 & 1198 & 44 & 477 & 10 & 709 & 14 & discordant & \\
\hline 45 & 432 & 84 & 5.2 & 0.061 & 0.001 & 11.773 & 0.331 & 1.444 & 0.057 & 642 & 46 & 526 & 14 & 535 & 16 & 529 & 11 \\
\hline 46 & 623 & 326 & 1.9 & 0.067 & 0.001 & 11.916 & 0.245 & 1.265 & 0.038 & 851 & 37 & 520 & 10 & 592 & 13 & discordant & \\
\hline 47 & 1186 & 126 & 9.4 & 0.080 & 0.001 & 6.241 & 0.122 & 0.552 & 0.012 & 1195 & 24 & 958 & 17 & 1051 & 14 & discordant & \\
\hline 48 & 273 & 108 & 2.5 & 0.060 & 0.002 & 12.108 & 0.431 & 1.598 & 0.091 & 598 & 65 & 512 & 17 & 494 & 21 & 505 & 14 \\
\hline 49 & 734 & 171 & 4.3 & 0.070 & 0.001 & 13.089 & 0.392 & 1.391 & 0.042 & 942 & 39 & 475 & 13 & 550 & 13 & discordant & \\
\hline 50 & 738 & 165 & 4.5 & 0.065 & 0.001 & 9.905 & 0.241 & 1.106 & 0.032 & 779 & 30 & 620 & 14 & 655 & 14 & $\mathrm{~d}$ & 0 \\
\hline 51 & 269 & 66 & 4.1 & 0.070 & 0.001 & 6.630 & 0.181 & 0.700 & 0.028 & 932 & 39 & 906 & 23 & 902 & 23 & 904 & 18 \\
\hline 52 & 536 & 177 & 3.0 & 0.062 & 0.001 & 12.032 & 0.296 & 1.504 & 0.048 & 668 & 44 & 515 & 12 & 518 & 13 & 516 & 9 \\
\hline 53 & 219 & 58 & 3.8 & 0.059 & 0.002 & 12.827 & 0.580 & 1.737 & 0.124 & 585 & 67 & 484 & 20 & 462 & 25 & 475 & 17 \\
\hline 54 & 1603 & 511 & 3.1 & 0.075 & 0.001 & 13.242 & 0.378 & 1.285 & 0.038 & 1062 & 29 & 469 & 13 & 585 & 13 & discordant & \\
\hline 55 & 262 & 193 & 1.4 & 0.077 & 0.002 & 6.206 & 0.238 & 0.594 & 0.025 & 1109 & 40 & 963 & 33 & 1004 & 26 & 989 & 320 \\
\hline 56 & 353 & 220 & 1.6 & 0.060 & 0.002 & 12.433 & 0.613 & 1.572 & 0.093 & 598 & 56 & 499 & 23 & 500 & 22 & 499 & 18 \\
\hline $57(\mathrm{a})$ & 303 & 112 & 2.7 & 0.059 & 0.002 & 11.182 & 0.362 & 1.506 & 0.080 & 556 & 57 & 552 & 17 & 518 & 21 & 539 & 240 \\
\hline 58 & 218 & 78 & 2.8 & 0.253 & 0.002 & 1.993 & 0.043 & 0.056 & 0.001 & 3204 & 15 & 2623 & 45 & 2986 & 18 & discordant & \\
\hline $58(\mathrm{a})$ & 642 & 492 & 1.3 & 0.124 & 0.001 & 3.855 & 0.074 & 0.221 & 0.004 & 2016 & 16 & 1487 & 25 & 1736 & 15 & $\mathrm{~d}$ & 0 \\
\hline 60 & 136 & 65 & 2.1 & 0.062 & 0.003 & 13.657 & 0.664 & 1.946 & 0.178 & 663 & 90 & 456 & 20 & 421 & 29 & 445 & 18 \\
\hline 61 & 816 & 552 & 1.5 & 0.069 & 0.001 & 12.854 & 0.273 & 1.356 & 0.036 & 896 & 33 & 483 & 10 & 561 & 11 & discordant & \\
\hline 62 & 155 & 66 & 2.3 & 0.059 & 0.002 & 12.042 & 0.532 & 1.745 & 0.139 & 561 & 78 & 514 & 21 & 460 & 28 & 494 & 330 \\
\hline 64 & 366 & 169 & 2.2 & 0.060 & 0.001 & 11.643 & 0.293 & 1.468 & 0.056 & 592 & 50 & 531 & 13 & 528 & 15 & 530 & 10 \\
\hline 65 & 218 & 148 & 1.5 & 0.062 & 0.002 & 12.266 & 0.358 & 1.497 & 0.079 & 681 & 72 & 505 & 14 & 520 & 21 & 509 & 12 \\
\hline 66 & 936 & 207 & 4.5 & 0.059 & 0.001 & 12.074 & 0.458 & 1.477 & 0.051 & 559 & 45 & 513 & 18 & 525 & 14 & 521 & 12 \\
\hline 67 & 457 & 159 & 2.9 & 0.066 & 0.002 & 11.836 & 0.522 & 1.416 & 0.070 & 791 & 58 & 523 & 21 & 543 & 20 & 533 & 17 \\
\hline 68 & 195 & 106 & 1.8 & 0.172 & 0.003 & 2.393 & 0.036 & 0.099 & 0.001 & 2580 & 30 & 2252 & 28 & 2442 & 13 & discordant & \\
\hline
\end{tabular}


Sample 610-4 Page 4

\begin{tabular}{|c|c|c|c|c|c|c|c|c|c|c|c|c|c|c|c|c|c|}
\hline \multirow[b]{3}{*}{ Zircon } & \multirow[b]{3}{*}{$\mathrm{U}(\mathrm{ppm})$} & \multirow[b]{3}{*}{ Th (ppm) } & \multirow[b]{3}{*}{$\mathrm{U} / \mathrm{Th}$} & \multicolumn{7}{|c|}{ Isotopic ratios } & \multicolumn{3}{|c|}{ Apparent ages $(\mathrm{Ma})$} & \multirow[b]{2}{*}{${ }^{207} \mathrm{~Pb}$} & \multirow[b]{3}{*}{$\pm \mathrm{Ma}$} & \multirow[b]{3}{*}{ Concordia } & \multirow[b]{3}{*}{$\pm \mathrm{Ma}$} \\
\hline & & & & ${ }^{207} \mathrm{~Pb}$ & & ${ }^{238} \mathrm{U}$ & & ${ }^{235} \mathrm{U}$ & & ${ }^{207} \mathrm{~Pb}$ & & ${ }^{206} \mathrm{~Pb}$ & & & & & \\
\hline & & & & $\overline{{ }^{206} \mathrm{~Pb}}$ & $\pm(2 \sigma)$ & ${ }^{206} \mathrm{~Pb}$ & $\pm(2 \sigma)$ & ${ }^{207} \mathrm{~Pb}$ & $\pm(2 \sigma)$ & ${ }^{206} \mathrm{~Pb}$ & $\pm \mathrm{Ma}$ & ${ }^{238} \mathrm{U}$ & $\pm \mathrm{Ma}$ & ${ }^{235} \mathrm{U}$ & & & \\
\hline 69 & 800 & 380 & 2.1 & 0.187 & 0.001 & 2.456 & 0.035 & 0.096 & 0.001 & 2714 & 9 & 2203 & 26 & 2476 & 13 & discordant & \\
\hline 70 & 378 & 221 & 1.7 & 0.059 & 0.001 & 11.811 & 0.311 & 1.524 & 0.062 & 568 & 48 & 524 & 13 & 513 & 16 & 519 & 10 \\
\hline 71 & 933 & 270 & 3.5 & 0.059 & 0.001 & 10.411 & 0.151 & 1.289 & 0.028 & 585 & 28 & 591 & 8 & 584 & 9 & 588 & 7 \\
\hline 72 & 132 & 1 & 140.1 & 0.063 & 0.003 & 9.676 & 0.288 & 1.283 & 0.078 & 715 & 108 & 634 & 18 & 585 & 26 & 618 & 290 \\
\hline 73 & 894 & 206 & 4.3 & 0.098 & 0.001 & 4.306 & 0.058 & 0.318 & 0.005 & 1578 & 17 & 1347 & 16 & 1445 & 12 & discordant & \\
\hline 74 & 454 & 379 & 1.2 & 0.064 & 0.001 & 11.571 & 0.237 & 1.257 & 0.046 & 744 & 43 & 535 & 10 & 595 & 16 & discordant & \\
\hline 75 & 702 & 357 & 2.0 & 0.097 & 0.001 & 5.729 & 0.083 & 0.432 & 0.007 & 1571 & 20 & 1037 & 14 & 1218 & 11 & discordant & \\
\hline
\end{tabular}

Sample 652-3 Page 1

\begin{tabular}{|c|c|c|c|c|c|c|c|c|c|c|c|c|c|c|c|c|c|}
\hline \multirow[b]{3}{*}{ Zircon } & \multirow[b]{3}{*}{$\mathrm{U}(\mathrm{ppm})$} & \multirow[b]{3}{*}{ Th (ppm) } & \multirow[b]{3}{*}{$\mathrm{U} / \mathrm{Th}$} & \multicolumn{6}{|c|}{ Isotopic ratios } & \multicolumn{5}{|c|}{ Apparent ages $(\mathrm{Ma})$} & \multirow[b]{3}{*}{$\pm \mathrm{Ma}$} & \multirow[b]{3}{*}{ Concordia } & \multirow[b]{3}{*}{$\pm \mathrm{Ma}$} \\
\hline & & & & \multicolumn{2}{|l|}{${ }^{207} \mathrm{~Pb}$} & ${ }^{238} \mathrm{U}$ & & ${ }^{235} \mathrm{U}$ & & ${ }^{207} \mathrm{~Pb}$ & & ${ }^{206} \mathrm{~Pb}$ & & ${ }^{207} \mathrm{~Pb}$ & & & \\
\hline & & & & $\overline{{ }^{206} \mathrm{~Pb}}$ & $\pm(2 \sigma)$ & ${ }^{206} \mathrm{~Pb}$ & $\pm(2 \sigma)$ & ${ }^{207} \mathrm{~Pb}$ & $\pm(2 \sigma)$ & ${ }^{206} \mathrm{~Pb}$ & $\pm \mathrm{Ma}$ & ${ }^{238} \mathrm{U}$ & $\pm \mathrm{Ma}$ & $\overline{{ }^{235} \mathrm{U}}$ & & & \\
\hline 1 & 169 & 52 & 3.3 & 0.096 & 0.004 & 7.202 & 0.726 & 0.707 & 0.065 & 1541 & 77 & 838 & 72 & 896 & 51 & 883 & 53 \\
\hline 2 & 959 & 576 & 1.7 & 0.059 & 0.001 & 13.127 & 1.072 & 1.605 & 0.122 & 576 & 43 & 473 & 35 & 492 & 28 & 486 & 28 \\
\hline 3 & 128 & 65 & 2.0 & 0.066 & 0.003 & 12.807 & 1.538 & 1.544 & 0.171 & 819 & 94 & 485 & 50 & 507 & 41 & 499 & 39 \\
\hline 4 & 253 & 67 & 3.8 & 0.061 & 0.002 & 14.181 & 1.406 & 1.742 & 0.141 & 653 & 80 & 439 & 38 & 461 & 28 & 455 & 28 \\
\hline 5 & 1041 & 211 & 4.9 & 0.076 & 0.002 & 14.338 & 1.770 & 1.355 & 0.144 & 1107 & 72 & 435 & 46 & 561 & 42 & discordant & \\
\hline 6 & 238 & 215 & 1.1 & 0.069 & 0.003 & 10.622 & 1.282 & 1.124 & 0.122 & 900 & 83 & 580 & 60 & 647 & 48 & 625 & 610 \\
\hline 7 & 2305 & 1402 & 1.6 & 0.137 & 0.006 & 7.311 & 0.949 & 0.373 & 0.045 & 2187 & 72 & 827 & 90 & 1325 & 83 & discordant & \\
\hline 9 & 469 & 311 & 1.5 & 0.116 & 0.004 & 3.872 & 0.450 & 0.238 & 0.029 & 1895 & 62 & 1481 & 139 & 1674 & 94 & 1629 & 1700 \\
\hline 8 & 182 & 116 & 1.6 & 0.065 & 0.003 & 13.695 & 2.030 & 1.709 & 0.325 & 782 & 90 & 454 & 57 & 468 & 62 & 460 & 54 \\
\hline 10 & 260 & 260 & 1.0 & 0.063 & 0.002 & 12.781 & 1.117 & 1.585 & 0.178 & 699 & 76 & 486 & 38 & 497 & 40 & 490 & 34 \\
\hline 11 & 166 & 110 & 1.5 & 0.108 & 0.003 & 3.716 & 0.170 & 0.249 & 0.010 & 1773 & 45 & 1537 & 60 & 1638 & 33 & discordant & \\
\hline 12 & 403 & 100 & 4.1 & 0.148 & 0.003 & 2.640 & 0.204 & 0.126 & 0.009 & 2320 & 30 & 2072 & 129 & 2225 & 64 & 2233 & 1100 \\
\hline 13 & 649 & 250 & 2.6 & 0.060 & 0.001 & 12.021 & 0.301 & 1.482 & 0.049 & 610 & 39 & 515 & 12 & 524 & 13 & 519 & 10 \\
\hline 14 & 1023 & 200 & 5.1 & 0.061 & 0.001 & 9.751 & 0.226 & 1.170 & 0.030 & 638 & 28 & 630 & 14 & 628 & 12 & 628 & 10 \\
\hline
\end{tabular}


Sample 652-3 Page 2

\begin{tabular}{|c|c|c|c|c|c|c|c|c|c|c|c|c|c|c|c|c|c|}
\hline \multirow[b]{3}{*}{ Zircon } & \multirow[b]{3}{*}{$\mathrm{U}(\mathrm{ppm})$} & \multirow[b]{3}{*}{ Th (ppm) } & \multirow[b]{3}{*}{$\mathrm{U} / \mathrm{Th}$} & \multicolumn{7}{|c|}{ Isotopic ratios } & \multicolumn{4}{|c|}{ Apparent ages $(\mathrm{Ma})$} & \multirow[b]{3}{*}{$\pm \mathrm{Ma}$} & \multirow[b]{3}{*}{ Concordia } & \multirow[b]{3}{*}{$\pm \mathrm{Ma}$} \\
\hline & & & & \multicolumn{2}{|l|}{${ }^{207} \mathrm{~Pb}$} & ${ }^{238} \mathrm{U}$ & & ${ }^{235} \mathrm{U}$ & & ${ }^{207} \mathrm{~Pb}$ & & ${ }^{206} \mathrm{~Pb}$ & & ${ }^{207} \mathrm{~Pb}$ & & & \\
\hline & & & & $\overline{{ }^{206} \mathrm{~Pb}}$ & $\pm(2 \sigma)$ & ${ }^{206} \mathrm{~Pb}$ & $\pm(2 \sigma)$ & ${ }^{207} \mathrm{~Pb}$ & $\pm(2 \sigma)$ & ${ }^{206} \mathrm{~Pb}$ & $\pm \mathrm{Ma}$ & ${ }^{238} \mathrm{U}$ & $\pm \mathrm{Ma}$ & ${ }^{235} \mathrm{U}$ & & & \\
\hline 24 & 1562 & 380 & 4.1 & 0.060 & 0.001 & 11.620 & 0.549 & 1.371 & 0.058 & 618 & 34 & 532 & 23 & 557 & 18 & 552 & 270 \\
\hline 15 & 268 & 205 & 1.3 & 0.058 & 0.002 & 12.431 & 0.473 & 1.619 & 0.092 & 539 & 63 & 499 & 18 & 489 & 21 & 495 & 15 \\
\hline 17 & 773 & 181 & 4.3 & 0.099 & 0.001 & 4.057 & 0.140 & 0.293 & 0.009 & 1600 & 25 & 1421 & 43 & 1509 & 23 & discordant & \\
\hline 19 & 190 & 61 & 3.1 & 0.060 & 0.002 & 12.368 & 0.715 & 1.677 & 0.160 & 586 & 85 & 501 & 26 & 475 & 34 & 492 & 23 \\
\hline 16 & 1331 & 489 & 2.7 & 0.061 & 0.001 & 11.634 & 0.496 & 1.328 & 0.052 & 638 & 34 & 532 & 21 & 570 & 17 & discordant & \\
\hline 18 & 420 & 216 & 1.9 & 0.062 & 0.002 & 12.120 & 0.584 & 1.442 & 0.067 & 677 & 57 & 511 & 23 & 535 & 19 & 526 & 17 \\
\hline 20 & 129 & 116 & 1.1 & 0.098 & 0.003 & 4.340 & 0.263 & 0.335 & 0.018 & 1594 & 51 & 1337 & 69 & 1405 & 40 & 1400 & 550 \\
\hline 21 & 1567 & 74 & 21.2 & 0.091 & 0.001 & 5.130 & 0.251 & 0.390 & 0.017 & 1454 & 29 & 1148 & 49 & 1292 & 32 & discordant & \\
\hline 22 & 322 & 197 & 1.6 & 0.059 & 0.002 & 12.672 & 0.546 & 1.553 & 0.070 & 556 & 56 & 490 & 20 & 505 & 17 & 499 & 16 \\
\hline 23 & 311 & 206 & 1.5 & 0.061 & 0.001 & 12.990 & 0.601 & 1.634 & 0.075 & 651 & 49 & 478 & 20 & 485 & 17 & 482 & 16 \\
\hline 25 & 43 & 26 & 1.7 & 0.278 & 0.005 & 1.599 & 0.048 & 0.041 & 0.001 & 3350 & 27 & 3133 & 72 & 3279 & 23 & discordant & \\
\hline 26 & 131 & 65 & 2.0 & 0.057 & 0.003 & 19.113 & 1.313 & 2.742 & 0.227 & 499 & 113 & 329 & 21 & 316 & 21 & 322 & 16 \\
\hline $26 a$ & 70 & 101 & 0.7 & 0.157 & 0.008 & 13.917 & 0.963 & 0.719 & 0.078 & 2419 & 82 & 447 & 28 & 886 & 59 & discordant & \\
\hline 4 & 142 & 59 & 2.4 & 0.064 & 0.003 & 11.496 & 0.421 & 1.604 & 0.215 & 755 & 80 & 538 & 18 & 492 & 47 & 532 & 18 \\
\hline 5 & 793 & 106 & 7.5 & 0.147 & 0.001 & 2.721 & 0.037 & 0.135 & 0.002 & 2317 & 11 & 2018 & 23 & 2166 & 11 & discordant & \\
\hline 6 & 195 & 115 & 1.7 & 0.074 & 0.002 & 6.620 & 0.191 & 0.680 & 0.027 & 1029 & 60 & 907 & 24 & 919 & 24 & 913 & 18 \\
\hline 7 & 495 & 237 & 2.1 & 0.053 & 0.002 & 27.522 & 0.834 & 4.410 & 0.566 & 325 & 77 & 230 & 7 & 208 & 22 & 229 & 7 \\
\hline 8 & 211 & 207 & 1.0 & 0.062 & 0.002 & 10.627 & 0.413 & 1.358 & 0.086 & 671 & 65 & 580 & 21 & 561 & 26 & 572 & 17 \\
\hline 9 & 355 & 218 & 1.6 & 0.061 & 0.002 & 11.737 & 0.366 & 1.476 & 0.065 & 656 & 62 & 527 & 15 & 526 & 17 & 526 & 12 \\
\hline 10 & 211 & 165 & 1.3 & 0.063 & 0.002 & 10.000 & 0.343 & 1.290 & 0.111 & 709 & 78 & 615 & 19 & 583 & 36 & 608 & 18 \\
\hline 11 & 662 & 175 & 3.8 & 0.127 & 0.001 & 4.202 & 0.066 & 0.242 & 0.004 & 2057 & 18 & 1377 & 19 & 1663 & 12 & discordant & \\
\hline 12 & 75 & 44 & 1.7 & 0.064 & 0.004 & 13.554 & 0.737 & 1.884 & 0.177 & 745 & 127 & 459 & 23 & 433 & 31 & 450 & 19 \\
\hline 13 & 693 & 231 & 3.0 & 0.069 & 0.001 & 12.086 & 0.309 & 1.209 & 0.032 & 900 & 34 & 513 & 12 & 613 & 12 & discordant & \\
\hline 14 & 170 & 96 & 1.8 & 0.077 & 0.002 & 5.350 & 0.133 & 0.523 & 0.019 & 1116 & 47 & 1105 & 25 & 1087 & 23 & 1094 & 18 \\
\hline 15 & 220 & 63 & 3.5 & 0.075 & 0.002 & 5.583 & 0.162 & 0.558 & 0.019 & 1064 & 41 & 1063 & 28 & 1043 & 22 & 1050 & 18 \\
\hline 18 & 179 & 60 & 3.0 & 0.061 & 0.002 & 11.223 & 0.399 & 1.513 & 0.099 & 637 & 70 & 550 & 18 & 516 & 25 & 538 & 210 \\
\hline 19 & 984 & 80 & 12.3 & 0.061 & 0.001 & 9.848 & 0.217 & 1.190 & 0.029 & 634 & 30 & 624 & 13 & 620 & 11 & 621 & 9 \\
\hline 20 & 374 & 256 & 1.5 & 0.064 & 0.002 & 11.989 & 0.329 & 1.446 & 0.064 & 752 & 73 & 517 & 13 & 534 & 18 & 523 & 11 \\
\hline
\end{tabular}


Sample 652-3 Page 3

\begin{tabular}{|c|c|c|c|c|c|c|c|c|c|c|c|c|c|c|c|c|c|}
\hline \multirow[b]{3}{*}{ Zircon } & \multirow[b]{3}{*}{$\mathrm{U}(\mathrm{ppm})$} & \multirow[b]{3}{*}{ Th (ppm) } & \multirow[b]{3}{*}{$\mathrm{U} / \mathrm{Th}$} & \multicolumn{7}{|c|}{ Isotopic ratios } & \multicolumn{4}{|c|}{ Apparent ages $(\mathrm{Ma})$} & \multirow[b]{3}{*}{$\pm \mathrm{Ma}$} & \multirow[b]{3}{*}{ Concordia } & \multirow[b]{3}{*}{$\pm \mathrm{Ma}$} \\
\hline & & & & ${ }^{207} \mathrm{~Pb}$ & & ${ }^{238} \mathrm{U}$ & & ${ }^{235} \mathrm{U}$ & & ${ }^{207} \mathrm{~Pb}$ & & ${ }^{206} \mathrm{~Pb}$ & & ${ }^{207} \mathrm{~Pb}$ & & & \\
\hline & & & & ${ }^{206} \mathrm{~Pb}$ & $\pm(2 \sigma)$ & ${ }^{206} \mathrm{~Pb}$ & $\pm(2 \sigma)$ & ${ }^{207} \mathrm{~Pb}$ & $\pm(2 \sigma)$ & ${ }^{206} \mathrm{~Pb}$ & $\pm \mathrm{Ma}$ & ${ }^{238} \mathrm{U}$ & $\pm \mathrm{Ma}$ & ${ }^{235} \mathrm{U}$ & & & \\
\hline 23 & 684 & 374 & 1.8 & 0.060 & 0.001 & 11.561 & 0.264 & 1.406 & 0.049 & 612 & 40 & 535 & 11 & 546 & 14 & 539 & 10 \\
\hline 24 & 434 & 234 & 1.9 & 0.059 & 0.001 & 11.512 & 0.264 & 1.489 & 0.052 & 556 & 45 & 537 & 12 & 522 & 14 & 531 & 10 \\
\hline 25 & 854 & 317 & 2.7 & 0.099 & 0.001 & 3.677 & 0.061 & 0.267 & 0.004 & 1607 & 17 & 1551 & 23 & 1583 & 13 & 1574 & 170 \\
\hline 22 & 421 & 286 & 1.5 & 0.059 & 0.001 & 12.617 & 0.334 & 1.628 & 0.069 & 552 & 54 & 492 & 12 & 487 & 16 & 490 & 10 \\
\hline 21 & 325 & 170 & 1.9 & 0.059 & 0.002 & 12.268 & 0.340 & 1.639 & 0.086 & 554 & 62 & 505 & 13 & 484 & 19 & 499 & 11 \\
\hline 17 & 397 & 269 & 1.5 & 0.059 & 0.001 & 11.858 & 0.284 & 1.544 & 0.063 & 553 & 48 & 522 & 12 & 507 & 16 & 517 & 10 \\
\hline 16 & 317 & 113 & 2.8 & 0.061 & 0.001 & 11.289 & 0.274 & 1.410 & 0.056 & 623 & 52 & 547 & 12 & 545 & 16 & 546 & 10 \\
\hline
\end{tabular}

Sample 687-1 Page 1

\begin{tabular}{|c|c|c|c|c|c|c|c|c|c|c|c|c|c|c|c|c|c|}
\hline \multirow[b]{3}{*}{ Zircon } & \multirow[b]{3}{*}{$\mathrm{U}(\mathrm{ppm})$} & \multirow[b]{3}{*}{ Th (ppm) } & \multirow[b]{3}{*}{$\mathrm{U} / \mathrm{Th}$} & \multicolumn{6}{|c|}{ Isotopic ratios } & \multicolumn{5}{|c|}{ Apparent ages $(\mathrm{Ma})$} & \multirow[b]{3}{*}{$\pm \mathrm{Ma}$} & \multirow[b]{3}{*}{ Concordia } & \multirow[b]{3}{*}{$\pm \mathrm{Ma}$} \\
\hline & & & & ${ }^{207} \mathrm{~Pb}$ & & ${ }^{238} \mathrm{U}$ & & ${ }^{235} \mathrm{U}$ & & ${ }^{207} \mathrm{~Pb}$ & & ${ }^{206} \mathrm{~Pb}$ & & ${ }^{207} \mathrm{~Pb}$ & & & \\
\hline & & & & ${ }^{206} \mathrm{~Pb}$ & $\pm(2 \sigma)$ & ${ }^{206} \mathrm{~Pb}$ & $\pm(2 \sigma)$ & ${ }^{207} \mathrm{~Pb}$ & $\pm(2 \sigma)$ & ${ }^{206} \mathrm{~Pb}$ & $\pm \mathrm{Ma}$ & ${ }^{238} \mathrm{U}$ & $\pm \mathrm{Ma}$ & $\overline{{ }^{235} \mathrm{U}}$ & & & \\
\hline 1 & 328 & 205 & 1.6 & 0.058 & 0.002 & 11.966 & 0.315 & 1.562 & 0.070 & 517 & 57 & 518 & 13 & 503 & 17 & 512 & 11 \\
\hline 2 & 311 & 100 & 3.1 & 0.076 & 0.001 & 5.551 & 0.186 & 0.525 & 0.020 & 1096 & 35 & 1068 & 32 & 1084 & 24 & 1078 & 23 \\
\hline 3 & 1040 & 595 & 1.7 & 0.071 & 0.001 & 10.115 & 0.494 & 1.071 & 0.049 & 968 & 39 & 608 & 27 & 670 & 22 & discordant & \\
\hline 4 & 1015 & 247 & 4.1 & 0.061 & 0.001 & 11.817 & 0.572 & 1.417 & 0.057 & 625 & 43 & 524 & 23 & 543 & 16 & 539 & 16 \\
\hline 5 & 440 & 280 & 1.6 & 0.064 & 0.002 & 12.238 & 0.835 & 1.469 & 0.092 & 738 & 57 & 507 & 31 & 528 & 25 & 520 & 22 \\
\hline 6 & 224 & 61 & 3.7 & 0.155 & 0.008 & 12.450 & 0.819 & 0.612 & 0.043 & 2396 & 87 & 498 & 30 & 985 & 42 & discordant & \\
\hline 7 & 615 & 619 & 1.0 & 0.058 & 0.001 & 13.027 & 0.620 & 1.619 & 0.076 & 541 & 46 & 477 & 21 & 489 & 18 & 484 & 16 \\
\hline 8 & 608 & 279 & 2.2 & 0.059 & 0.001 & 12.123 & 0.591 & 1.521 & 0.074 & 554 & 47 & 511 & 23 & 513 & 19 & 512 & 18 \\
\hline 9 & 181 & 84 & 2.2 & 0.073 & 0.018 & 7.146 & 0.340 & 0.764 & 0.045 & 1005 & 430 & 845 & 36 & 851 & 33 & 848 & 29 \\
\hline 10 & 687 & 214 & 3.2 & 0.059 & 0.001 & 12.011 & 0.628 & 1.483 & 0.075 & 559 & 46 & 516 & 25 & 524 & 20 & 521 & 19 \\
\hline 11 & 488 & 280 & 1.7 & 0.073 & 0.002 & 12.963 & 0.660 & 1.471 & 0.071 & 1006 & 65 & 479 & 22 & 527 & 19 & discordant & \\
\hline 12 & 330 & 168 & 2.0 & 0.061 & 0.002 & 11.694 & 0.570 & 1.476 & 0.080 & 640 & 61 & 529 & 24 & 526 & 21 & 527 & 18 \\
\hline 13 & 779 & 365 & 2.1 & 0.059 & 0.001 & 11.919 & 0.457 & 1.497 & 0.059 & 583 & 45 & 520 & 18 & 520 & 16 & 519 & 14 \\
\hline 14 & 967 & 714 & 1.4 & 0.063 & 0.003 & 11.778 & 0.707 & 1.344 & 0.070 & 730 & 76 & 526 & 29 & 565 & 22 & 553 & 350 \\
\hline
\end{tabular}


Sample 687-1 Page 2

\begin{tabular}{|c|c|c|c|c|c|c|c|c|c|c|c|c|c|c|c|c|c|}
\hline \multirow[b]{3}{*}{ Zircon } & \multirow[b]{3}{*}{$\mathrm{U}(\mathrm{ppm})$} & \multirow[b]{3}{*}{ Th (ppm) } & \multirow[b]{3}{*}{$\mathrm{U} / \mathrm{Th}$} & \multicolumn{7}{|c|}{ Isotopic ratios } & \multicolumn{3}{|c|}{ Apparent ages $(\mathrm{Ma})$} & \multirow[b]{2}{*}{${ }^{207} \mathrm{~Pb}$} & \multirow[b]{3}{*}{$\pm \mathrm{Ma}$} & \multirow[b]{3}{*}{ Concordia } & \multirow[b]{3}{*}{$\pm \mathrm{Ma}$} \\
\hline & & & & ${ }^{207} \mathrm{~Pb}$ & & ${ }^{238} \mathrm{U}$ & & ${ }^{235} \mathrm{U}$ & & ${ }^{207} \mathrm{~Pb}$ & & ${ }^{206} \mathrm{~Pb}$ & & & & & \\
\hline & & & & ${ }^{206} \mathrm{~Pb}$ & $\pm(2 \sigma)$ & ${ }^{206} \mathrm{~Pb}$ & $\pm(2 \sigma)$ & ${ }^{207} \mathrm{~Pb}$ & $\pm(2 \sigma)$ & ${ }^{206} \mathrm{~Pb}$ & $\pm \mathrm{Ma}$ & ${ }^{238} \mathrm{U}$ & $\pm \mathrm{Ma}$ & ${ }^{235} \mathrm{U}$ & & & \\
\hline 15 & 227 & 125 & 1.8 & 0.058 & 0.002 & 12.161 & 0.438 & 1.657 & 0.117 & 524 & 67 & 510 & 17 & 480 & 26 & 501 & 15 \\
\hline 16 & 113 & 122 & 0.9 & 0.180 & 0.003 & 2.025 & 0.081 & 0.082 & 0.003 & 2649 & 29 & 2588 & 82 & 2621 & 30 & 2622 & 29 \\
\hline 17 & 134 & 74 & 1.8 & 0.064 & 0.003 & 12.073 & 0.739 & 1.612 & 0.175 & 736 & 86 & 513 & 29 & 490 & 39 & 505 & 25 \\
\hline 18 & 1601 & 100 & 16.0 & 0.141 & 0.003 & 6.600 & 0.427 & 0.312 & 0.017 & 2245 & 30 & 910 & 52 & 1459 & 40 & discordant & \\
\hline
\end{tabular}

$\underline{\text { Sample 693-2 Page } 1}$

\begin{tabular}{|c|c|c|c|c|c|c|c|c|c|c|c|c|c|c|c|c|c|}
\hline \multirow[b]{3}{*}{ Zircon } & \multirow[b]{3}{*}{$\mathrm{U}(\mathrm{ppm})$} & \multirow[b]{3}{*}{ Th (ppm) } & \multirow[b]{3}{*}{$\mathrm{U} / \mathrm{Th}$} & \multicolumn{7}{|c|}{ Isotopic ratios } & \multicolumn{3}{|c|}{ Apparent ages $(\mathrm{Ma})$} & \multirow[b]{2}{*}{${ }^{207} \mathrm{~Pb}$} & \multirow[b]{3}{*}{$\pm \mathrm{Ma}$} & \multirow[b]{3}{*}{ Concordia } & \multirow[b]{3}{*}{$\pm \mathrm{Ma}$} \\
\hline & & & & ${ }^{207} \mathrm{~Pb}$ & & ${ }^{238} \mathrm{U}$ & & ${ }^{235} \mathrm{U}$ & & ${ }^{207} \mathrm{~Pb}$ & & ${ }^{206} \mathrm{~Pb}$ & & & & & \\
\hline & & & & ${ }^{206} \mathrm{~Pb}$ & $\pm(2 \sigma)$ & ${ }^{206} \mathrm{~Pb}$ & $\pm(2 \sigma)$ & ${ }^{207} \mathrm{~Pb}$ & $\pm(2 \sigma)$ & ${ }^{206} \mathrm{~Pb}$ & $\pm \mathrm{Ma}$ & ${ }^{238} \mathrm{U}$ & $\pm \mathrm{Ma}$ & ${ }^{235} \mathrm{U}$ & & & \\
\hline 27 & 100 & 37 & 2.7 & 0.063 & 0.003 & 12.302 & 0.549 & 1.743 & 0.262 & 714 & 93 & 504 & 21 & 461 & 50 & 450 & 17 \\
\hline 26 & 289 & 137 & 2.1 & 0.059 & 0.002 & 11.517 & 0.318 & 1.539 & 0.122 & 561 & 55 & 537 & 14 & 509 & 30 & 483 & 11 \\
\hline 25 & 358 & 210 & 1.7 & 0.060 & 0.004 & 11.520 & 0.265 & 1.536 & 0.074 & 591 & 123 & 537 & 12 & 509 & 18 & 475 & 280 \\
\hline 24 & 244 & 72 & 3.4 & 0.124 & 0.001 & 2.636 & 0.041 & 0.152 & 0.003 & 2021 & 20 & 2074 & 27 & 2060 & 15 & discordant & \\
\hline 23 & 810 & 222 & 3.6 & 0.062 & 0.001 & 14.193 & 0.285 & 1.652 & 0.049 & 662 & 39 & 439 & 8 & 481 & 11 & discordant & \\
\hline 22 & 400 & 132 & 3.0 & 0.056 & 0.002 & 10.310 & 0.309 & 1.400 & 0.072 & 464 & 92 & 597 & 17 & 548 & 21 & discordant & \\
\hline 21 & 359 & 54 & 6.6 & 0.060 & 0.002 & 11.795 & 0.383 & 1.672 & 0.106 & 586 & 77 & 525 & 16 & 476 & 23 & discordant & \\
\hline 20 & 244 & 163 & 1.5 & 0.050 & 0.002 & 11.267 & 0.317 & 1.463 & 0.082 & 196 & 91 & 548 & 14 & 529 & 22 & 493 & 12 \\
\hline 19 & 800 & 550 & 1.5 & 0.075 & 0.002 & 8.809 & 0.260 & 0.908 & 0.033 & 1054 & 47 & 693 & 19 & 755 & 19 & discordant & \\
\hline 18 & 601 & 425 & 1.4 & 0.060 & 0.001 & 11.458 & 0.222 & 1.399 & 0.043 & 589 & 39 & 540 & 10 & 548 & 13 & 490 & 110 \\
\hline 17 & 256 & 118 & 2.2 & 0.068 & 0.002 & 7.883 & 0.183 & 0.881 & 0.032 & 863 & 51 & 770 & 17 & 771 & 19 & 701 & 12 \\
\hline 16 & 142 & 66 & 2.2 & 0.060 & 0.002 & 11.763 & 0.462 & 1.705 & 0.170 & 604 & 85 & 526 & 19 & 469 & 35 & 467 & 300 \\
\hline 15 & 250 & 196 & 1.3 & 0.059 & 0.002 & 13.205 & 0.379 & 1.736 & 0.082 & 584 & 64 & 471 & 13 & 462 & 17 & 423 & 9 \\
\hline 14 & 159 & 140 & 1.1 & 0.081 & 0.002 & 5.176 & 0.140 & 0.483 & 0.017 & 1212 & 44 & 1139 & 28 & 1141 & 23 & 1049 & 16 \\
\hline 13 & 526 & 124 & 4.2 & 0.075 & 0.001 & 5.553 & 0.134 & 0.532 & 0.013 & 1067 & 28 & 1068 & 23 & 1075 & 15 & 990 & 210 \\
\hline 12 & 646 & 203 & 3.2 & 0.055 & 0.001 & 17.265 & 0.376 & 2.348 & 0.091 & 398 & 46 & 363 & 8 & 361 & 11 & 327 & 5 \\
\hline 11 & 244 & 105 & 2.3 & 0.059 & 0.002 & 12.828 & 0.365 & 1.675 & 0.082 & 567 & 75 & 484 & 13 & 476 & 18 & 435 & 9 \\
\hline
\end{tabular}


Sample 693-2 Page 2

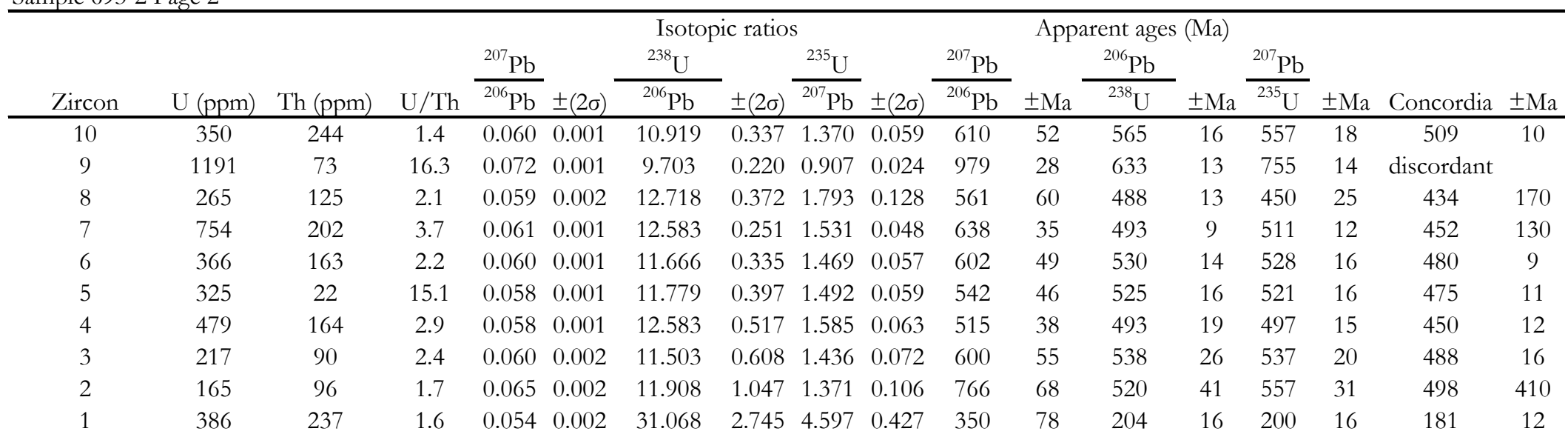


Trace Element Data Sorted by Zircon Age Page 1

\begin{tabular}{|c|c|c|c|c|c|c|c|c|c|c|c|c|c|c|c|c|c|c|c|c|c|c|c|c|c|c|c|c|c|c|}
\hline Sample & Zircon & $\begin{array}{l}\text { Age } \\
(\mathrm{Ma})\end{array}$ & $\begin{array}{r}\text { Error } \\
(2 \sigma)\end{array}$ & \begin{tabular}{|c|} 
TE \\
Group
\end{tabular} & $\mathrm{Eu} / \mathrm{Eu}^{*}$ & $\mathrm{Ce} / \mathrm{Ce}^{*}$ & $\mathrm{Nd} / \mathrm{Yb}$ & $\overline{\mathrm{Lu} / \mathrm{Gd}}$ & $\begin{array}{c}\mathrm{U} \\
(\mathrm{ppm})\end{array}$ & $\begin{array}{c}\text { Th } \\
(\mathrm{ppm})\end{array}$ & $\mathrm{Th} / \mathrm{U}$ & $\mathrm{Zr} / \mathrm{Hf}$ & $\begin{array}{c}\mathrm{Ti} \\
(\mathrm{ppm})\end{array}$ & $\begin{array}{c}\text { Ti temp } \\
\left({ }^{\circ} \mathrm{C}\right)\end{array}$ & $\begin{array}{c}\mathrm{Li} \\
(\mathrm{ppm})\end{array}$ & $\begin{array}{c}\Sigma \text { REE } \\
(\mathrm{ppm})\end{array}$ & $\begin{array}{c}\mathrm{La} \\
(\mathrm{ppm})\end{array}$ & $\begin{array}{c}\mathrm{Ce} \\
(\mathrm{ppm})\end{array}$ & $\begin{array}{c}\mathrm{Pr} \\
(\mathrm{ppm})\end{array}$ & $\begin{array}{c}\mathrm{Nd} \\
(\mathrm{ppm})\end{array}$ & $\begin{array}{c}\mathrm{Sm} \\
(\mathrm{ppm})\end{array}$ & $\begin{array}{c}\mathrm{Eu} \\
(\mathrm{ppm})\end{array}$ & $\begin{array}{c}\mathrm{Gd} \\
(\mathrm{ppm})\end{array}$ & $\begin{array}{c}\mathrm{Tb} \\
(\mathrm{ppm})\end{array}$ & $\begin{array}{c}\text { Dy } \\
(\mathrm{ppm})\end{array}$ & $\begin{array}{l}\text { Ho } \\
(\mathrm{ppm})\end{array}$ & $\begin{array}{c}\mathrm{Er} \\
(\mathrm{ppm})\end{array}$ & $\begin{array}{l}\mathrm{Tm} \\
(\mathrm{ppm})\end{array}$ & $\begin{array}{c}\mathrm{Yb} \\
(\mathrm{ppm})\end{array}$ & $\begin{array}{c}\mathrm{Lu} \\
(\mathrm{ppm})\end{array}$ \\
\hline 652 & 7 & 230 & 7 & 1 & 0.01 & 44 & 115 & 1.87 & 394 & 265 & 0.67 & 40 & 3.95 & 665 & \begin{tabular}{|l|}
0.13 \\
\end{tabular} & 518 & 0.09 & 24.3 & 0.03 & 0.54 & 1.78 & 0.43 & 10.4 & 3.73 & 48.5 & 19.5 & 99.6 & 23.3 & 235 & 50.9 \\
\hline 652 & z 26 & 329 & 21 & 1 & 0.18 & 171 & 236 & 2.51 & 102 & 54 & 0.52 & 46 & 14.2 & 773 & 0.39 & 437 & 0.03 & 3.08 & 0.01 & 0.77 & 2.65 & 0.35 & 13.5 & 4.95 & 60.3 & 22.0 & 95.0 & 19.5 & 180 & 33.9 \\
\hline 205 & 24 & 386 & 9 & 1 & 0.12 & 57 & 561 & 3.06 & 673 & 371 & 0.55 & 52 & 4.63 & 677 & 1.46 & 1313 & 0.02 & 6.19 & 0.04 & 1.09 & 3.55 & 0.40 & 29.6 & 12.0 & 157.74 & 62.4 & 275 & 62.5 & 613 & 90.4 \\
\hline 652 & z4 & 439 & 38 & 4 & 0.46 & 154 & 229 & 6.23 & 211 & 72 & 0.34 & 46 & 0.47 & 528 & 1.19 & 240 & 0.00 & 1.62 & 0.03 & 0.51 & 1.46 & 0.39 & 4.56 & 1.64 & 20.5 & 8.71 & 44.0 & 11.0 & 117 & 28.4 \\
\hline 652 & z8 & 454 & 57 & 1 & 0.13 & 191 & 31 & 0.64 & 415 & 202 & 0.49 & 39 & 12.9 & 764 & 2.89 & 116 & 0.01 & 3.78 & 0.06 & 1.03 & 2.00 & 0.19 & 9.54 & 2.45 & 23.4 & 6.71 & 25.2 & 4.03 & 31.77 & 6.08 \\
\hline 652 & 12 & 459 & 23 & 4 & 0.28 & 162 & 56 & 2.10 & 41 & 24 & 0.58 & 60 & 8.39 & 726 & 0.88 & 223 & 0.01 & 3.79 & 0.07 & 1.56 & 2.01 & 0.39 & 9.34 & 2.66 & 30.1 & 10.6 & 45.8 & 9.38 & 87.84 & 19.7 \\
\hline 652 & z2 & 473 & 35 & 1 & 0.62 & 577 & 324 & 6.54 & 362 & 220 & 0.61 & 41 & 0.63 & 545 & 0.72 & 470 & 0.04 & 29.3 & 0.07 & 0.70 & 1.47 & 0.70 & 8.10 & 2.96 & 35.0 & 14.9 & 77.3 & 19.2 & 227 & 53.0 \\
\hline 205 & 16 & 475 & 14 & 1 & 0.14 & 450 & 105 & 1.63 & 107 & 54 & 0.50 & 44 & 13.5 & 768 & 0.18 & 319 & 0.00 & 5.81 & 0.08 & 1.29 & 2.76 & 0.26 & 12.0 & 3.78 & 44.7 & 15.1 & 63.3 & 13.9 & 137 & 19.5 \\
\hline 652 & z 23 & 478 & 20 & 1 & 0.30 & 240 & 307 & 4.31 & 311 & 206 & 0.66 & 43 & 8.05 & 722 & 0.38 & 1198 & 0.05 & 17.1 & 0.10 & 1.81 & 3.98 & 0.99 & 24.7 & 9.41 & 125 & 51.9 & 244 & 55.3 & 557 & 106 \\
\hline 652 & z22 & 490 & 20 & 1 & 0.21 & 403 & 274 & 4.08 & 374 & 223 & 0.60 & 40 & 5.27 & 687 & 2.59 & 692 & 0.05 & 17.1 & 0.03 & 1.16 & 2.63 & 0.43 & 15.3 & 5.59 & 69.1 & 28.8 & 139 & 31.9 & 318 & 62 \\
\hline 462 & 63 & 490 & 12 & 1 & 0.21 & 85 & 193 & 2.50 & 301 & 121 & 0.40 & 41 & 5.15 & 686 & 2.64 & 453 & 0.02 & 12.3 & 0.05 & 0.99 & 2.22 & 0.39 & 13.8 & 4.72 & 56.2 & 20.9 & 93.7 & 20.3 & 192 & 34.4 \\
\hline 205 & 33 & 491 & 11 & 1 & 0.12 & 4 & 132 & 1.59 & 287 & 313 & 1.09 & 38 & 7.68 & 718 & 4.34 & 680 & 0.23 & 3.36 & 0.22 & 2.14 & 4.21 & 0.40 & 26.4 & 10.38 & 112 & 34.3 & 134 & 28.9 & 283 & 42.0 \\
\hline 652 & 22 & 492 & 12 & 1 & 0.16 & 31 & 75 & 2.47 & 324 & 229 & 0.71 & 42 & 6.83 & 708 & 0.02 & 857 & 0.87 & 22.0 & 0.59 & 4.59 & 6.17 & 0.67 & 26.8 & 9.61 & 113 & 41.7 & 184 & 37.7 & 342 & 66.3 \\
\hline 205 & 9 & 498 & 22 & 1 & 0.15 & 103 & 136 & 1.96 & 140 & 81 & 0.58 & 59 & 3.98 & 666 & 0.03 & 612 & 0.07 & 7.76 & 0.09 & 2.03 & 4.90 & 0.49 & 20.5 & 6.97 & 79.9 & 28.2 & 119 & 26.5 & 275 & 40.2 \\
\hline 652 & z15 & 499 & 18 & 1 & 0.63 & 330 & 79 & 4.06 & 195 & 160 & 0.82 & 43 & 2.30 & 626 & 0.70 & 316 & 0.00 & 7.31 & 0.19 & 1.84 & 2.79 & 0.98 & 8.25 & 2.67 & 31.1 & 11.6 & 57.5 & 13.5 & 145 & 33.5 \\
\hline 652 & z19 & 501 & 26 & 1 & 0.12 & 39 & 270 & 3.13 & 91 & 48 & 0.53 & 47 & 33.9 & 861 & 3.54 & 347 & 0.07 & 2.45 & 0.06 & 0.56 & 1.65 & 0.15 & 9.37 & 3.42 & 41.2 & 16.6 & 75.9 & 16.3 & 150 & 29.3 \\
\hline 652 & 21 & 505 & 13 & 1 & 0.17 & 52 & 180 & 2.66 & 287 & 208 & 0.73 & 40 & 2.19 & 623 & 0.30 & 856 & 0.45 & 16.5 & 0.23 & 1.98 & 3.61 & 0.53 & 23.7 & 8.97 & 112 & 41.7 & 187 & 38.4 & 357 & 63.1 \\
\hline 462 & 53 & 508 & 14 & 1 & 0.24 & 45 & 483 & 2.94 & 352 & 134 & 0.38 & 45 & 2.10 & 620 & 0.20 & 690 & 0.00 & 12.2 & 0.02 & 0.63 & 2.33 & 0.51 & 17.6 & 6.70 & 82.3 & 32.9 & 145 & 32.7 & 305 & 51.8 \\
\hline 652 & z18 & 511 & 23 & 3 & 0.76 & 12 & 31 & 1.67 & 620 & 352 & 0.57 & 42 & 32.8 & 857 & 2.07 & 1801 & 1.87 & 27.2 & 2.84 & 22.8 & 25.5 & 11.0 & 76.2 & 22.9 & 249 & 86.9 & 375 & 77.8 & 694 & 127 \\
\hline 462 & 37 & 518 & 20 & 1 & 0.09 & 164 & 88 & 1.21 & 170 & 187 & 1.10 & 49 & 10.3 & 743 & 0.29 & 404 & 0.01 & 19.1 & 0.10 & 1.85 & 3.60 & 0.24 & 17.6 & 5.29 & 59.3 & 19.4 & 77.0 & 16.8 & 162 & 21.4 \\
\hline 462 & 46 & 519 & 21 & 1 & 0.07 & 35 & 279 & 3.21 & 462 & 212 & 0.46 & 51 & 27.1 & 837 & 2.05 & 877 & 0.15 & 17.0 & 0.09 & 1.42 & 3.11 & 0.18 & 20.0 & 7.96 & 102 & 40.4 & 183 & 41.8 & 396 & 64.1 \\
\hline 205 & 54 & 520 & 22 & 1 & 0.17 & 96 & 179 & 2.02 & 45 & 110 & 2.46 & 45 & 289 & 1158 & 0.96 & 478 & 0.00 & 10.5 & 0.12 & 1.14 & 2.71 & 0.35 & 15.7 & 5.45 & 65.9 & 22.8 & 96.0 & 21.4 & 205 & 31.6 \\
\hline 652 & 17 & 522 & 12 & 3 & 0.57 & 40 & 9 & 0.35 & 295 & 324 & 1.10 & 65 & 9.31 & 735 & 2.40 & 1588 & 0.32 & 35.2 & 2.54 & 39.3 & 51.7 & 17.9 & 178 & 41.9 & 341 & 91.6 & 317 & 44.9 & 364 & 62.6 \\
\hline 652 & 9 & 527 & 15 & 1 & 0.21 & 33 & 113 & 2.68 & 109 & 66 & 0.61 & 47 & 4.32 & 672 & 1.27 & 502 & 0.31 & 9.30 & 0.26 & 1.81 & 2.67 & 0.43 & 14.7 & 5.41 & 64.1 & 25.1 & 111 & 23.1 & 204 & 39.3 \\
\hline 652 & z24 & 532 & 23 & 1 & 0.32 & 27 & 13 & 0.57 & 112 & 72 & 0.65 & 46 & 11.1 & 750 & 0.75 & 289 & 0.30 & 10.1 & 0.49 & 6.35 & 8.63 & 1.49 & 23.8 & 6.22 & 56.1 & 15.8 & 53.8 & 9.89 & 82 & 13.5 \\
\hline 205 & $5 c$ & 533 & 19 & 1 & 0.83 & 16 & 147 & 5.29 & 166 & 33 & 0.20 & 72 & 3.94 & 665 & 0.00 & 293 & 0.02 & 3.33 & 0.11 & 1.04 & 1.46 & 0.75 & 5.18 & 2.14 & 25.2 & 10.2 & 50.9 & 13.0 & 152 & 27.4 \\
\hline 462 & 69 & 533 & 15 & 1 & 0.08 & 18 & 113 & 1.78 & 357 & 266 & 0.75 & 43 & 9.01 & 732 & 8.97 & 1245 & 0.00 & 6.59 & 0.25 & 4.45 & 8.69 & 0.55 & 47.5 & 15.3 & 181 & 65.3 & 270 & 56.9 & 503 & 84.6 \\
\hline 652 & 23 & 535 & 11 & 1 & 0.09 & 15 & 51 & 2.50 & 406 & 319 & 0.79 & 44 & 4.80 & 680 & 3.80 & 1149 & 3.69 & 34.0 & 1.37 & 9.02 & 8.06 & 0.51 & 34.3 & 12.3 & 14 & 55.0 & 245 & 51.3 & 462 & 86.0 \\
\hline 652 & 24 & 537 & 12 & 1 & 0.05 & 61 & 590 & 5.19 & 387 & 98 & 0.25 & 33 & 6.64 & 706 & 25.1 & 2124 & 0.03 & 3.16 & 0.11 & 1.64 & 5.27 & 0.21 & 34.9 & 17.3 & 23 & 99.0 & 476 & 110 & 965 & 181 \\
\hline 462 & 45 & 537 & 28 & 1 & 0.19 & 75 & 48 & 0.97 & 167 & 100 & 0.60 & 56 & 14.5 & 77 & 2.19 & 198 & 0.01 & 11.8 & 0.11 & 1.48 & 2.94 & 0.34 & 11.0 & 3.01 & 30. & 9.46 & 37.7 & 7.61 & 71.5 & 10.7 \\
\hline 652 & 4 & 538 & 18 & 1 & 0.10 & 249 & 211 & 2.49 & 95 & 59 & 0.62 & 52 & 7.11 & 712 & 0.21 & 572 & 0.00 & 3.61 & 0.06 & 1.11 & 2.97 & 0.25 & 18.7 & 6.08 & 74.5 & 29.1 & 128 & 25.9 & 235 & 46.6 \\
\hline 462 & 67 & 539 & 15 & 1 & 0.26 & 58 & 40 & 1.28 & 245 & 266 & 1.09 & 41 & 9.92 & 740 & 0.59 & 468 & 0.08 & 33.0 & 0.24 & 4.25 & 6.12 & 0.99 & 22.8 & 6.35 & 65.0 & 21.9 & 89.0 & 19.2 & 170 & 29.1 \\
\hline 205 & 12 & 542 & 16 & 1 & 0.23 & 7 & 132 & 1.9 & 170 & 110 & 0.65 & 36 & 5.45 & 69 & 0.56 & 557 & 0.00 & 6.99 & 0.00 & 1.89 & 3.48 & 0.61 & 18 & 5.86 & 73.7 & 26.4 & 111 & 24.2 & 249 & 35.6 \\
\hline 462 & 65 & 544 & 13 & 1 & 0.60 & 13 & 45 & 1.12 & 1209 & 371 & 0.31 & 46 & 4.66 & 678 & 16.9 & 750 & 0.13 & 12.5 & 0.40 & 6.13 & 10.0 & 4.08 & 43.7 & 11.9 & 118 & 37.5 & 149 & 29.7 & 277 & 49.0 \\
\hline 205 & 6 & 547 & 16 & 1 & 0.11 & 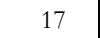 & 340 & 2.49 & 277 & 106 & 0.38 & 47 & 7.36 & 715 & 0.58 & 660 & 0.00 & 6.02 & 0.00 & 0.89 & 2.53 & 0.23 & 17.4 & 6.09 & 82.6 & 30.7 & 140 & 31.3 & 301 & 43.3 \\
\hline 652 & 18 & 550 & 18 & 1 & 0.24 & 238 & 2129 & 4.50 & 88 & 39 & 0.44 & 44 & 3.03 & 646 & 0.91 & 230 & 0.00 & 7.41 & 0.04 & 0.05 & 0.45 & 0.12 & 4.91 & 2.05 & 24.4 & 9.56 & 44.9 & 10.6 & 103 & 22.1 \\
\hline 462 & 42 & 555 & 14 & 1 & 0.25 & 12 & 209 & 3.37 & 279 & 190 & 0.68 & 57 & 3.21 & 650 & 11.3 & 1310 & 0.15 & 8.48 & 0.20 & 2.76 & 5.45 & 1.12 & 33.4 & 12.2 & 153 & 61.2 & 281 & 62.6 & 575 & 113 \\
\hline 462 & $6 r$ & 555 & 11 & 1 & 0.06 & 34 & 186 & 2.59 & 172 & 148 & 0.86 & 38 & 12.3 & 760 & 0.37 & 651 & 0.00 & 10.2 & 0.10 & 1.46 & 3.39 & 0.16 & 18.3 & 6.97 & 87.2 & 32.9 & 142 & 30.2 & 271 & 47.4 \\
\hline 462 & 33 & 555 & 22 & 1 & 0.13 & 3 & 74 & 2.74 & 181 & 79 & 0.44 & 51 & 5.33 & 688 & 0.32 & 597 & 0.84 & 7.03 & 0.51 & 3.81 & 2.98 & 0.28 & 14.8 & 5.43 & 69.2 & 26.4 & 116 & 27.5 & 281 & 40.6 \\
\hline
\end{tabular}


Trace Element Data Sorted by Zircon Age Page 2

\begin{tabular}{|c|c|c|c|c|c|c|c|c|c|c|c|c|c|c|c|c|c|c|c|c|c|c|c|c|c|c|c|c|c|c|}
\hline Sample & Zircon & $\begin{array}{l}\text { Age } \\
(\mathrm{Ma})\end{array}$ & $\begin{array}{c}\text { Error } \\
(2 \sigma)\end{array}$ & \begin{tabular}{|c|} 
TE \\
Group
\end{tabular} & $\mathrm{Eu} / \mathrm{Eu}^{*}$ & $\mathrm{Ce} / \mathrm{Ce} *$ & $\mathrm{Nd} / \mathrm{Yb}$ & $\mathrm{Lu} / \mathrm{Gd}$ & $\begin{array}{c}\mathrm{U} \\
(\mathrm{ppm})\end{array}$ & $\begin{array}{l}\text { Th } \\
\text { (ppm) }\end{array}$ & $\mathrm{Th} / \mathrm{U}$ & $\mathrm{Zr} / \mathrm{Hf}$ & $\begin{array}{c}\mathrm{Ti} \\
(\mathrm{ppm})\end{array}$ & $\begin{array}{c}\text { Ti temp } \\
\left({ }^{\circ} \mathrm{C}\right)\end{array}$ & \begin{tabular}{|c|}
$\mathrm{Li}$ \\
$(\mathrm{ppm})$
\end{tabular} & $\begin{array}{c}\mathrm{REE} \\
(\mathrm{ppm})\end{array}$ & $\begin{array}{c}\mathrm{La} \\
(\mathrm{ppm})\end{array}$ & $\begin{array}{c}\mathrm{Ce} \\
(\mathrm{ppm})\end{array}$ & $\begin{array}{c}\mathrm{Pr} \\
(\mathrm{ppm})\end{array}$ & $\begin{array}{c}\mathrm{Nd} \\
(\mathrm{ppm})\end{array}$ & $\begin{array}{c}\mathrm{Sm} \\
(\mathrm{ppm})\end{array}$ & $\begin{array}{c}\mathrm{Eu} \\
(\mathrm{ppm})\end{array}$ & $\begin{array}{c}\mathrm{Gd} \\
(\mathrm{ppm})\end{array}$ & $\begin{array}{l}\mathrm{Tb} \\
(\mathrm{ppm})\end{array}$ & $\begin{array}{c}\text { Dy } \\
(\mathrm{ppm})\end{array}$ & $\begin{array}{l}\mathrm{Ho} \\
(\mathrm{ppm})\end{array}$ & $\begin{array}{c}\mathrm{Er} \\
(\mathrm{ppm})\end{array}$ & $\begin{array}{l}\mathrm{Tm} \\
(\mathrm{ppm})\end{array}$ & $\begin{array}{c}\mathrm{Yb} \\
(\mathrm{ppm})\end{array}$ & $\begin{array}{c}\mathrm{Lu} \\
(\mathrm{ppm})\end{array}$ \\
\hline 205 & 3 & 558 & 19 & 1 & 0.18 & 3 & 70 & 3.93 & 722 & 117 & 0.16 & 48 & 5.98 & 698 & 10.6 & 568 & 0.51 & 7.15 & 0.52 & 4.30 & 4.02 & 0.42 & 12.2 & 3.54 & 45.0 & 18.2 & 93.9 & 28.7 & 302 & 47.8 \\
\hline 205 & 52 & 565 & 16 & 1 & 19 & 74 & 59 & 0.94 & 184 & 318 & 1.72 & 44 & 5.0 & 937 & 1.82 & 352 & 0.03 & 16.6 & 0.11 & 2.15 & 4.46 & 0.57 & 20.0 & 5.67 & 56.1 & 17.7 & 67.8 & 14.1 & 128 & 18.7 \\
\hline 205 & 30 & 576 & 23 & 1 & 16 & 3 & 49 & 2.24 & 255 & 90 & 0.36 & 50 & 8.91 & 731 & 9.83 & 872 & 0.88 & 12.0 & 0.92 & 8.21 & 8.88 & 0.83 & 26.9 & 8.98 & 102 & 37.7 & 162 & 39.8 & 402 & 60.3 \\
\hline 462 & 30 & 579 & 17 & 3 & 0.79 & 37 & 10 & 0.45 & 323 & 429 & 1.33 & 48 & 16.3 & 785 & 0.57 & 927 & 0.24 & 99.0 & 1.82 & 26.1 & 30.3 & 12.0 & 72.6 & 16.6 & 148 & 40.6 & 144 & 29.9 & 274 & 32.7 \\
\hline 652 & 8 & 580 & 21 & 1 & 0.12 & 134 & 20 & 0.80 & 136 & 188 & 1.38 & 48 & 14.3 & 774 & 1.64 & 384 & 0.02 & 11.1 & 0.38 & 6.13 & 9.79 & 0.63 & 27.2 & 7.13 & 67.8 & 20.2 & 77.0 & 14.1 & 121 & 21.8 \\
\hline 462 & 34 & 580.2 & 25 & 3 & 0.47 & 7 & 10.58 & 0.55 & 133 & 354 & 2.66 & 58 & 21.1 & 811 & 0.08 & 658 & 5.75 & 92.9 & 2.10 & 18.5 & 17.0 & 4.23 & 45.4 & 10.4 & 94.0 & 27.3 & 99.3 & 20.9 & 195 & 25.0 \\
\hline 462 & 44 & 585.3 & 13 & 1 & 0.27 & 861 & 970.3 & 4.28 & 546 & 204 & 0.37 & 47 & 2.26 & 625 & 19.7 & 1242 & 0.02 & 49.0 & 0.01 & 0.61 & 2.56 & 0.65 & 21.3 & 8.97 & 127 & 50.9 & 239 & 58.3 & 592 & 91.1 \\
\hline 462 & 28 & 590 & 19 & 1 & 0.50 & 70 & 12 & 0.48 & 128 & 282 & 2.20 & 54 & 26.8 & 836 & 0.56 & 235 & 0.15 & 64.2 & 0.33 & 4.70 & 5.96 & 1.58 & 15.7 & 3.56 & 28.6 & 8.14 & 30.3 & 6.08 & 57.6 & 7.59 \\
\hline 205 & 38 & 602 & 9 & 1 & 0.03 & 87 & 185 & 1.83 & 417 & 219 & 0.53 & 42 & 6.66 & 706 & 0.47 & 1110 & 0.00 & 14.3 & 0.09 & 2.58 & 7.71 & 0.17 & 38.7 & 13.3 & 152 & 54.5 & 226 & 50.4 & 479 & 70.7 \\
\hline 462 & 61 & 605 & 13 & 1 & 05 & 393 & 16 & 0.24 & 577 & 208 & 0.36 & 38 & 3.10 & 647 & 13.9 & 130 & 0.00 & 11.3 & 0.10 & 1.69 & 3.93 & 0.13 & 15.2 & 4.02 & 30.93 & 7.33 & 21.65 & 3.53 & 26.23 & 3.69 \\
\hline 652 & 10 & 615 & 19 & 1 & 0.04 & 276 & 103 & 1.38 & 326 & 95 & 0.29 & 38 & 3.59 & 658 & 4.70 & 322 & 0.00 & 3.16 & 0.03 & 1.12 & 3.18 & 0.10 & 16.3 & 5.47 & 54.5 & 17.2 & 69.9 & 3.2 & 16 & 22.4 \\
\hline 462 & 12 & 616 & 12 & 1 & 0.11 & 43 & 286 & 1.91 & 291 & 94 & 0.32 & 40 & 13.2 & 766 & 1.49 & 551 & 0.08 & 13.0 & 0.07 & 0.83 & 1.94 & 0.22 & 18.9 & 6.83 & 75.5 & 25.1 & 109 & 25.0 & 238 & 36.2 \\
\hline 205 & $34 \mathrm{R}$ & 621 & 10 & 1 & 0.17 & 60 & 308 & 2.24 & 933 & 54 & 0.06 & 42 & 7.83 & 720 & 0.45 & 604 & 0.03 & 9.69 & 0.05 & 0.87 & 2.50 & 0.37 & 17.3 & 6.35 & 78.1 & 29.1 & 126 & 28.2 & 267 & 38.7 \\
\hline 205 & 27 & 622 & 16 & 1 & 0.14 & 39 & 163 & 1.86 & 743 & 208 & 0.28 & 45 & 6.88 & 709 & 1.58 & 358 & 0.03 & 7.39 & 0.08 & 0.97 & 1.95 & 0.22 & 12.0 & 3.95 & 46.5 & 16.9 & 72.3 & 15.9 & 58 & 22.2 \\
\hline 652 & 19 & 624 & 13 & 2 & 0.01 & 48 & 23 & 0.06 & 969 & 95 & 0.10 & 25 & 7.71 & 718 & 8.78 & 375 & 0.02 & 1.65 & 0.05 & 1.32 & 7.44 & 0.10 & 69.7 & 20.4 & 159 & 23.0 & 53.1 & 4.89 & 30.3 & 4.32 \\
\hline 205 & 7 & 626 & 15 & 3 & 0.47 & 23 & 22 & 0.77 & 394 & 278 & 0.71 & 58 & 14.3 & 773 & 0.00 & 881 & 2.53 & 41.5 & 1.38 & 13.9 & 16.8 & 4.81 & 57.9 & 14.6 & 142 & 42.6 & 161 & 34.4 & 304 & 44.3 \\
\hline 652 & z14 & 630 & 14 & 1 & 0.08 & 40 & 108 & 1.47 & 623 & 160 & 0.26 & 45 & 4.32 & 672 & 5.56 & 975 & 0.14 & 5.62 & 0.15 & 3.29 & 5.81 & 0.41 & 44.2 & 14.5 & 163 & 54.9 & 219 & 43.6 & 356 & 64.8 \\
\hline 205 & 46 & 631 & 12 & 1 & 0.12 & 30 & 110 & 1.17 & 156 & 1155 & 7.41 & 43 & 6.05 & 699 & 1.54 & 341 & 0.02 & 4.48 & 0.07 & 1.22 & 2.93 & 0.29 & 17.0 & 6.01 & 57.9 & 17.5 & 65.7 & 14.3 & 134 & 20.0 \\
\hline 462 & 47 & 639 & 14 & 1 & 0.18 & 105 & 313 & 2.83 & 145 & 69 & 0.48 & 52 & 18.7 & 799 & 1.21 & 357 & 0.02 & 10.72 & 0.03 & 0.50 & 1.53 & 0.23 & 9.31 & 3.49 & 42.3 & 16.7 & 72.5 & 16.7 & 156 & 26.4 \\
\hline 205 & 43 & 642 & 12 & 1 & 0. & 4 & 100 & 1.72 & 557 & 204 & 0.37 & 55 & 21.5 & 81 & 1.47 & 887 & 0.21 & 4.36 & 0.32 & 3.83 & 6.87 & 0.55 & 34.2 & 10.8 & 123 & 43.2 & 179 & 40.6 & 381 & 58.8 \\
\hline 205 & $1 \mathrm{r}$ & 751 & 19 & 1 & 0.10 & 45 & 200 & 2.43 & 224 & 95 & 0.42 & 60 & 5.62 & 693 & 0.52 & 418 & 0.00 & 4.44 & 0.05 & 1.00 & 2.16 & 0.16 & 11.3 & 4.17 & 51.7 & 18.5 & 77.6 & 19.5 & 200 & 27.3 \\
\hline 462 & 15 & 808 & 63 & 1 & 0.01 & 42 & 442 & 2.71 & 213 & 88 & 0.41 & 41 & 15.3 & 780 & 0.21 & 927 & 0.00 & 3.64 & 0.04 & 0.93 & 3.59 & 0.03 & 24.4 & 9.15 & 116 & 44. & 203 & 43.9 & 413 & 66.0 \\
\hline 652 & z3 & 819 & 94 & 3 & 0.46 & 76 & 17 & 0. & 107 & 81 & 0.75 & 55 & 19.4 & 802 & 0.62 & 387 & 0.06 & 12.7 & 0.45 & 6.91 & 8.00 & 2.34 & 29.5 & 7.56 & 68.1 & 20. & 76.1 & 4.2 & 118 & 22.0 \\
\hline 462 & 7 & 854 & 133 & 1 & 0.20 & 33 & 48 & 0.94 & 137 & 85 & 0.62 & 43 & 14.2 & 772 & 0.00 & 559 & 0.03 & 12.1 & 0.24 & 4.06 & 8.25 & 1.11 & 33.7 & 9.67 & 98.5 & 30.5 & 114 & 22.6 & 194 & 31.6 \\
\hline 652 & z6 & 900 & 83 & 1 & 0.08 & 29 & 30.66 & 1.14 & 158 & 174 & 1.10 & 55 & 24.4 & 826 & 0.44 & 1303 & 0.18 & 12.1 & 0.99 & 14.8 & 19.4 & 0.98 & 71.8 & 21.8 & 219 & 74.2 & 278 & 54.3 & 454 & 81.6 \\
\hline 462 & 62 & 901 & 77 & 1 & 0.33 & 48 & 186.2 & 3.06 & 339 & 139 & 0.41 & 45 & 4.68 & 678 & 3.14 & 540 & 0.06 & 14.1 & 0.08 & 1.33 & 2.68 & 0.68 & 14.7 & 4.93 & 58.5 & 22.3 & 104 & 24.3 & 247 & 45.1 \\
\hline 205 & 51 & 931 & 26 & 1 & 0.01 & 16 & 721.82 & 4.27 & 61 & 278 & 4.52 & 37 & 23.4 & 822 & 4.71 & 1005 & 0.02 & 1.26 & 0.02 & 0.67 & 2.15 & 0.02 & 16.7 & 7.95 & 1 & 45.5 & 214 & 0.3 & 482 & 71.4 \\
\hline 462 & 39 & 957 & 110 & 3 & 0.28 & 6 & 28.11 & 1.01 & 67 & 155 & 2.30 & 52 & 12.0 & 757 & 1.29 & 1114 & 1.95 & 42.2 & 1.72 & 15.2 & 15.2 & 2.62 & 55.8 & 15.7 & 169 & 54 & 210 & .3 & 8 & 56.4 \\
\hline 462 & 43 & 961 & 49 & 1 & & 107 & 807.2 & 6.72 & 416 & 173 & 0.42 & 44 & 5.44 & 690 & 2.10 & 295 & 0.02 & 11.0 & 0.03 & 0.19 & 0.87 & 0.28 & 4. & $1 .($ & 22.4 & 8. & 48.9 & .5 & 52 & 30.1 \\
\hline 205 & $8 c$ & 990 & 37 & 1 & & 16 & 101.9 & 2.6 & 338 & 134 & 0.40 & 44 & 6.63 & 70 & 22 & 857 & 0.42 & 6.92 & 0.4 & 3.85 & 4.79 & 0.66 & 22.4 & 8.3 & 10 & 39 & 172 & 40.0 & 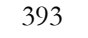 & 59.3 \\
\hline 462 & 16 & 994 & 38 & 2 & 0.0 & 5 & 11 & 0.09 & 336 & 17 & 0.05 & 34 & 7.21 & 71 & 12 & 145 & 0.03 & 0.93 & 0.07 & 1.08 & 2.34 & 0.08 & 19.2 & 7.5 & 75.3 & 7.0 & 14.8 & 1.62 & 12.8 & 1.72 \\
\hline 205 & $22 c$ & 1010 & 27 & 1 & & 72 & 217.9 & 3.35 & 713 & 35 & 0.5 & 63 & 9.14 & 73 & 16 & 739 & 0.11 & 7.47 & 0.10 & 1.70 & 2.85 & 1.18 & 18.0 & 5.7 & 73.3 & 28. & 135 & 4 & 3 & 60.1 \\
\hline 462 & 41 & 1017 & 41 & 3 & 0. & 2 & 96 & 3.4 & 431 & 101 & 0.2 & 47 & 18.4 & 79 & 5.02 & 1452 & 1.54 & 12.5 & 1.17 & 7.39 & 6.77 & 2.22 & 28.8 & 12.0 & 156 & 60.3 & 282 & 68.9 & 713 & 99.4 \\
\hline 462 & 49 & 1017 & 102 & 1 & 0. & 3 & 83.35 & 2.55 & 341 & 161 & 0.2 & 53 & 4.25 & 67 & 1. & 674 & 1.55 & 10.4 & 0.50 & 3.49 & 3.68 & 0.12 & 18.6 & 6.66 & 85.5 & 32.3 & 142 & 31.1 & 291 & 47.3 \\
\hline 462 & 17 & 1020 & 24 & 1 & $0 .{ }^{2}$ & 78 & 76.11 & 2.32 & 92 & 83 & 0. & 47 & 3.98 & 666 & 2. & 350 & 0.00 & 24.5 & 0.13 & 1.95 & 3.05 & 0.95 & 12.7 & 3.50 & 36.6 & 13.3 & 60.8 & 14.5 & 148 & 29.6 \\
\hline 652 & 6 & 1029 & 60 & 1 & 0.17 & 146 & 54.4 & 1.51 & 265 & 192 & 0.72 & 49 & 6.76 & 708 & 0.37 & 715 & 0.03 & 12.8 & 0.30 & 4.81 & 7.54 & 0.87 & 32.7 & 9.98 & 10 & 37.8 & 158 & 30.5 & 262 & 49.5 \\
\hline 05 & 13 & 1050 & 47 & 1 & 0.01 & 12 & 7.1 & 01 & 148 & 101 & 0.68 & 42 & 12.4 & 760 & .64 & 336 & 0.00 & 1.75 & .08 & 1.85 & 1.86 & .06 & 32.0 & 1.1 & 139 & 0.8 & 224 & 48.3 & 457 & (14. \\
\hline
\end{tabular}


Trace Element Data Sorted by Zircon Age Page 3

\begin{tabular}{|c|c|c|c|c|c|c|c|c|c|c|c|c|c|c|c|c|c|c|c|c|c|c|c|c|c|c|c|c|c|c|}
\hline Sample & Zircon & $\begin{array}{l}\text { Age } \\
(\mathrm{Ma})\end{array}$ & $\begin{array}{l}\text { Error } \\
(2 \sigma)\end{array}$ & \begin{tabular}{|c|}
$\mathrm{TE}$ \\
Group
\end{tabular} & $\mathrm{Eu} / \mathrm{Eu}^{*}$ & $\mathrm{Ce} / \mathrm{Ce} *$ & $\mathrm{Nd} / \mathrm{Yb}$ & $\mathrm{Lu} / \mathrm{Gd}$ & $\begin{array}{c}\mathrm{U} \\
(\mathrm{ppm})\end{array}$ & $\begin{array}{c}\text { Th } \\
\text { (ppm) }\end{array}$ & $\mathrm{Th} / \mathrm{U}$ & $\mathrm{Zr} / \mathrm{Hf}$ & $\begin{array}{c}\mathrm{Ti} \\
(\mathrm{ppm})\end{array}$ & $\begin{array}{c}\text { Ti temp } \\
\left({ }^{\circ} \mathrm{C}\right)\end{array}$ & \begin{tabular}{|c|}
$\mathrm{Li}$ \\
$(\mathrm{ppm})$
\end{tabular} & $\begin{array}{l}\mathrm{REE} \\
(\mathrm{ppm})\end{array}$ & $\begin{array}{c}\mathrm{La} \\
(\mathrm{ppm})\end{array}$ & $\begin{array}{c}\mathrm{Ce} \\
(\mathrm{ppm})\end{array}$ & $\begin{array}{c}\mathrm{Pr} \\
(\mathrm{ppm})\end{array}$ & $\begin{array}{c}\mathrm{Nd} \\
(\mathrm{ppm})\end{array}$ & $\begin{array}{c}\mathrm{Sm} \\
(\mathrm{ppm})\end{array}$ & $\begin{array}{c}\mathrm{Eu} \\
(\mathrm{ppm})\end{array}$ & $\begin{array}{c}\mathrm{Gd} \\
(\mathrm{ppm})\end{array}$ & $\begin{array}{c}\mathrm{Tb} \\
(\mathrm{ppm})\end{array}$ & $\begin{array}{c}\text { Dy } \\
\text { (ppm) }\end{array}$ & $\begin{array}{c}\text { Ho } \\
\text { (ppm) }\end{array}$ & $\begin{array}{c}\mathrm{Er} \\
(\mathrm{ppm})\end{array}$ & $\begin{array}{l}\mathrm{Tm} \\
(\mathrm{ppm})\end{array}$ & $\begin{array}{c}\mathrm{Yb} \\
(\mathrm{ppm})\end{array}$ & $\begin{array}{c}\mathrm{Lu} \\
(\mathrm{ppm})\end{array}$ \\
\hline 205 & $2 \mathrm{r}$ & 1058 & 47 & $\overline{1}$ & 0.19 & 17 & 90.14 & 1.32 & 168 & 42 & 0.25 & 66 & 5.23 & 687 & 2.58 & 629 & 0.02 & 3.52 & 0.15 & 3.00 & 6.12 & 0.82 & 27.6 & 8.88 & 93.6 & 30.8 & 121 & 27.2 & 270 & 36.3 \\
\hline 652 & 15 & 1064 & 41 & 1 & 01 & 76 & 366.3 & 3.53 & 192 & 88 & 0.46 & 35 & 11.3 & 752 & 7.83 & 1705 & 0.00 & 2.03 & 0.12 & 2.00 & 5.88 & 0.05 & 39.1 & 16.0 & 208 & 84.8 & 396 & 81.1 & 732 & 138 \\
\hline 462 & 59 & 1067 & 69 & 1 & 38 & 87 & 1205 & 5.36 & 48 & 17 & 0.36 & 43 & 4.78 & 680 & 0.48 & 513 & 0.00 & 5.13 & 0.01 & 0.20 & 1.21 & 0.41 & 9.02 & 3.60 & 50.0 & 21.3 & 103 & 24.6 & 247 & 48.4 \\
\hline 462 & 13 & 1092 & 68 & 1 & 23 & 3 & 64.88 & 2.42 & 342 & 281 & 0.82 & 44 & 7.88 & 720 & 0.91 & 1576 & 4.04 & 30.0 & 1.46 & 10.7 & 9.57 & 1.55 & 46.2 & 16.2 & 190 & 71.9 & 317 & 71.7 & 694 & 112 \\
\hline 462 & 55 & 1099 & 33 & 1 & 0.07 & 22 & 49.25 & 1.04 & 391 & 232 & 0.59 & 45 & 2.93 & 643 & 0.32 & 1169 & 0.05 & 14.7 & 0.51 & 8.39 & 14.6 & 0.73 & 64.9 & 19.1 & 198 & 65.5 & 252 & 49.5 & 413 & 67.3 \\
\hline 205 & 21 & 1102 & 29 & 1 & 0.03 & 54 & 573.4 & 2.93 & 230 & 109 & 0.48 & 42 & 35.2 & 865 & 3.03 & 1144 & 0.00 & 0.65 & 0.04 & 0.93 & 3.34 & 0.08 & 25.9 & 10.6 & 138 & 54.3 & 244 & 54.5 & 536 & 75.8 \\
\hline 205 & 14 & 1103 & 41 & 1 & 0.39 & 99 & 85.53 & 2.32 & 215 & 246 & 1.14 & 46 & 10.2 & 743 & 0.06 & 940 & 0.20 & 25.4 & 0.34 & 4.79 & 6.88 & 1.81 & 29.3 & 9.68 & 112 & 42.0 & 188 & 41.7 & 410 & 68.1 \\
\hline 205 & 32 & 1106 & 30 & 1 & 0.05 & 10 & 608.3 & 3.93 & 634 & 585 & 0.92 & 37 & 4.04 & 667 & 1.00 & 1678 & 0.02 & 1.45 & 0.08 & 1.32 & 4.23 & 0.18 & 31.9 & 13.4 & 188 & 76.0 & 349 & 82.2 & 805 & 125 \\
\hline 205 & $23 r$ & 1106 & 34 & 1 & 0.39 & 15 & 95.16 & 2.89 & 482 & 80 & 0.17 & 41 & 5.32 & 688 & 1.72 & 273 & 0.21 & 3.00 & 0.20 & 1.35 & 1.76 & 0.44 & 6.63 & 2.74 & 34.2 & 12.2 & 50.5 & 12.9 & 128 & 19.1 \\
\hline 652 & 14 & 1116 & 47 & 1 & 0.27 & 1066 & 148.9 & 2.57 & 128 & 71 & 0.56 & 52 & 10.1 & 742 & 1.12 & 388 & 0.00 & 9.85 & 0.05 & 1.10 & 2.26 & 0.47 & 12.8 & 4.07 & 48.5 & 18.2 & 75.7 & 17.8 & 164 & 33.0 \\
\hline 205 & 28 & 1121 & 32 & 1 & 0.07 & 4 & 202 & 1.90 & 556 & 84 & 0.15 & 49 & 2060 & 1611 & 33.1 & 1751 & 0.26 & 4.43 & 0.31 & 3.70 & 8.42 & 0.53 & 56.2 & 21.2 & 257 & 91.2 & 373 & 81.0 & 747 & 107 \\
\hline 462 & 40 & 1154 & 36 & 1 & 0.14 & 67 & 245.7 & 2.36 & 92 & 54 & 0.59 & 48 & 12.1 & 758 & 0.80 & 400 & 0.01 & 6.92 & 0.04 & 0.77 & 1.99 & 0.21 & 10.9 & 3.92 & 47.8 & 17.9 & 75.6 & 18.2 & 190 & 25.7 \\
\hline 205 & 42 & 1170 & 38 & 1 & 0.10 & 64 & 336.7 & 2.67 & 225 & 68 & 0.30 & 48 & 9.01 & 732 & 21.9 & 1008 & 0.06 & 5.21 & 0.07 & 1.41 & 4.15 & 0.34 & 26.2 & 9.58 & 120 & 46.2 & 203 & 48.5 & 474 & 69.9 \\
\hline 462 & 57 & 1177 & 25 & 1 & 0.05 & 145 & 239.9 & 3.63 & 396 & 304 & 0.77 & 36 & 17.1 & 790 & 20.1 & 393 & 0.01 & 10.8 & 0.04 & 0.74 & 1.80 & 0.07 & 8.76 & 3.46 & 44.3 & 16.6 & 77.5 & 18.8 & 178 & 31.8 \\
\hline 205 & 31 & 1207 & 31 & 1 & 0.02 & 7 & 340.6 & 2.16 & 348 & 136 & 0.39 & 52 & 5.35 & 689 & 0.00 & 557 & 0.00 & 8.78 & 0.00 & 0.73 & 2.51 & 0.00 & 16.0 & 5.70 & 73.9 & 26.8 & 115 & 25.2 & 249 & 34.7 \\
\hline 462 & 35 & 1316 & 35 & 1 & 0.43 & 5 & 95.064 & 1.35 & 427 & 385 & 0.90 & 60 & 11.0 & 749 & $\mid 1.71$ & 2013 & 0.35 & 10.9 & 0.68 & 8.78 & 15.6 & 5.07 & 83.0 & 26.9 & 300 & 104 & 422 & 88.7 & 834 & 112 \\
\hline 462 & 56 & 1401 & 28 & 1 & 0.36 & 41 & 171.29 & 3.27 & 209 & 156 & 0.74 & 37 & 3.91 & 665 & 1.33 & 690 & 0.04 & 12.3 & 0.15 & 1.85 & 3.05 & 0.87 & 17.9 & 5.90 & 74.91 & 28.93 & 137 & 32.3 & 317 & 58.7 \\
\hline 205 & 25 & 1445 & 19 & 1 & 0.13 & 53 & 462.3 & 2.54 & 297 & 145 & 0.49 & 59 & 6.83 & 708 & 0.12 & 518 & 0.00 & 7.22 & 0.03 & 0.53 & 1.45 & 0.19 & 14.6 & 4.95 & 59.3 & 22.6 & 101 & 24.2 & 245 & 37.0 \\
\hline 462 & 29 & 1464 & 29 & 1 & 0.62 & 44 & 71.02 & 1.64 & 311 & 414 & 1.33 & 46 & 89.2 & 978 & 8.12 & 1064 & 0.10 & 42.5 & 0.57 & 6.67 & 10.12 & 4.07 & 39.8 & 12.2 & 134 & 44.4 & $18 /$ & 44.1 & 474 & 65.2 \\
\hline 205 & 45 & 1505 & 24 & 1 & 0.05 & 10 & 608.3 & 3.93 & 536 & 96 & 0.18 & 37 & 4.04 & 667 & 1.00 & 1678 & 0.02 & 1.45 & 0.08 & 1.32 & 4.23 & 0.18 & 31.9 & 13.4 & 188 & 76.0 & 349 & 82.2 & 805 & 125 \\
\hline 205 & 40 & 1526 & 13 & 1 & 0.13 & 3 & 370.1 & 4.91 & 1117 & 121 & 0.11 & 42 & 32.8 & 857 & 37.0 & 1890 & 0.31 & 3.27 & 0.24 & 2.58 & 4.88 & 0.51 & 29.3 & 13.6 & 189 & 77.6 & 377 & 92.9 & 955 & 144 \\
\hline 652 & z1 & 1541 & 77 & 1 & 0. & 21 & 77.78 & 1.37 & 206 & 155 & 0.75 & 46 & 2.67 & 637 & 0.30 & 1212 & 0.00 & 8.46 & 0.29 & 5.60 & 11.4 & 1.23 & 57.5 & 17.9 & 192 & 69.6 & 28 & 53.0 & 436 & 78.8 \\
\hline 462 & 51 & 1543 & 32 & 1 & 0.67 & 3 & 114.5 & 1.88 & 501 & 97 & 0.19 & 46 & 14.7 & 776 & 5.75 & 1394 & 0.94 & 8.10 & 0.6 & 5.45 & 10.5 & 5.39 & 58.1 & 17.5 & 185 & 57.9 & 251 & 60.5 & 624 & 109 \\
\hline 205 & $47 a$ & 1561 & 16 & 1 & 0. & 5 & 153.6 & 4.41 & 745 & 34 & 0.05 & 37 & 11.2 & 751 & 0.59 & 1607 & 0.27 & 8.68 & 0.62 & 5.16 & 5.72 & 0.40 & 27.2 & 11.1 & 170 & 67.2 & 318 & 8.9 & 193 & 120 \\
\hline 205 & 41 & 1585 & 48 & 1 & 0. & 240 & 374 & 5.23 & 128 & 136 & 1.06 & 60 & 7.51 & 716 & 8.52 & 2053 & 0.06 & 92.9 & 0.14 & 2.64 & 5.27 & 1.40 & 33.2 & 12.6 & 175 & 3.2 & 394 & 97.0 & 987 & 173 \\
\hline 652 & z20 & 1594 & 51 & 1 & 0.29 & 1711 & 196.7 & 3.01 & 88 & 85 & 0.96 & 45 & 17.4 & 792 & 22.6 & 681 & 0.01 & 27.8 & 0.05 & 1.48 & 3.01 & 0.70 & 18.3 & 6.52 & 81.5 & 31 & 1. & 30.4 & 291 & 54.9 \\
\hline 652 & 25 & 1607 & 17 & 1 & 0. & 1 & 86.62 & 3.01 & 163 & 90 & 0.55 & 36 & 5.70 & 694 & 0.37 & 534 & 1.04 & 10.8 & 0.39 & 2.69 & 2.30 & 0.18 & 13.7 & 4.85 & 59.7 & 26 & 11 & 24.7 & 233 & 41.2 \\
\hline 462 & 52 & 1722 & 23 & 1 & & 40 & 757.8 & 7.51 & 233 & 77 & 0.33 & 46 & 121 & 1020 & 1.75 & 1544 & 0.08 & 12.0 & 0.07 & 1.05 & 2.66 & 0.60 & 18.9 & 8.51 & 132 & 58 & 2 & 76.8 & 793 & 142 \\
\hline 652 & z11 & 1773 & 45 & 1 & 0.38 & 2636 & 221.7 & 3.79 & 137 & 52 & 0.38 & 41 & 8.07 & 722 & 5.31 & 428 & 0.00 & 15.0 & 0.09 & 0.86 & 1.63 & 0.50 & 9.71 & 3.49 & 46.9 & 18 & 84.9 & 19.2 & 190 & 36.8 \\
\hline 205 & 4 & 1814 & 48 & 1 & 0.14 & 7 & 1653 & 10.29 & 349 & 117 & 0.33 & 45 & 5.70 & 694 & 34.9 & 761 & 0.01 & 3.08 & 0.01 & 0.28 & 0.76 & 0.11 & 7.34 & 2.80 & 45.3 & 20 & 114 & 35.7 & 457 & 75.5 \\
\hline 462 & 36 & 1945 & 22 & 1 & 0.03 & 19 & 734.1 & 3.47 & 721 & 110 & 0.15 & 40 & 7.25 & 713 & 13.2 & 1426 & 0.02 & 2.31 & 0.05 & 0.94 & 3.68 & 0.11 & 26.8 & 12.2 & 17 & 66. & 291 & 68.8 & 689 & 93.1 \\
\hline 462 & 60 & 1962 & 15 & 2 & 0 & 4 & 2.137 & 0.05 & 505 & 65 & 0.13 & 33 & 11.9 & 756 & 1.28 & 52 & 0.13 & 1.81 & 0.12 & 2.03 & 5.34 & 0.11 & 15.8 & 2.55 & 12.2 & 1.80 & 3.90 & 0.61 & 4.33 & 0.79 \\
\hline 652 & 11 & 2057 & 18 & 1 & 0. & 40 & 87.65 & 2.21 & 449 & 212 & 0.47 & 39 & 5.82 & 695 & 25.8 & 1114 & 0.17 & 8.77 & 0.30 & 5.18 & 8.96 & 2.21 & 41.4 & 12.8 & 148 & 55.1 & 236 & 48.8 & 454 & 91.7 \\
\hline 205 & 35 & 2286 & 18 & 1 & 0.06 & 8 & 138.3 & 1.79 & 362 & 126 & 0.35 & 45 & 11.1 & 750 & 10.9 & 668 & 0.04 & 2.37 & 0.13 & 2.16 & 4.34 & 0.19 & 23.1 & 7.67 & 89.8 & 32.6 & 135 & 30.7 & 299 & 41.2 \\
\hline 652 & 5 & 2317 & 11 & 1 & 0.05 & 708 & 333.3 & 3.33 & 243 & 84 & 0.35 & 44 & 19.0 & 800 & 4.14 & 782 & 0.00 & 3.81 & 0.04 & 1.01 & 3.00 & 0.12 & 19.6 & 7.25 & 94.5 & 37.4 & 175 & 36.7 & 338 & 65.2 \\
\hline 652 & z12 & 2320 & 30 & 1 & 0.17 & 10 & 53.87 & 1.39 & 375 & 81 & 0.22 & 36 & 4.57 & 676 & 1.56 & 556 & 0.26 & 2.97 & 0.35 & 3.81 & 5.99 & 0.70 & 27.3 & 8.40 & 91.8 & 29.9 & 119 & 22.9 & 205 & 38.0 \\
\hline 205 & 29 & 2461 & 16 & 1 & 0.43 & 153 & 189.1 & 3.15 & 207 & 95 & 0.46 & 68 & 6.60 & 706 & 0.08 & 480 & 0.00 & 7.16 & 0.04 & 1.23 & 2.73 & 0.81 & 12.0 & 4.41 & 51.8 & 19.3 & 89.1 & 22.2 & 232 & 37.9 \\
\hline 462 & 64 & 2651 & 26 & 1 & 0.47 & 12 & 76.11 & 2.32 & 92 & 83 & 0.90 & 47 & 3.98 & 666 & 2.25 & 350 & 0.00 & 24.5 & 0.13 & 1.95 & 3.05 & 0.95 & 12.7 & 3.50 & 36.6 & 13.3 & 60.8 & 14.5 & 148 & 29.6 \\
\hline 462 & 8 & 2780 & 16 & 3 & 1.02 & 4 & 17.28 & 0.50 & 195 & 89 & 0.46 & 41 & 6.25 & 701 & 0.00 & 1107 & 0.93 & 17.8 & 1.61 & 18.77 & 31.0 & 19.0 & 104 & 25.8 & 211 & 58.7 & 203 & 38.5 & 324 & 52.1 \\
\hline 205 & 18 & 2949 & 8 & 1 & 0.11 & 10 & 52.25 & 2.05 & 208 & 121 & 0.58 & 41 & 3.73 & 661 & 3.01 & 560 & 1.73 & 10.6 & 0.67 & 4.62 & 3.32 & 0.27 & 18.1 & 5.69 & 70.7 & 26.4 & 113 & 25.8 & 242 & 37.1 \\
\hline 462 & 5 & 3094 & 15 & 1 & 0.37 & 420 & 97.19 & 2.17 & 223 & 375 & 1.68 & 44 & 5.95 & 697 & 1.26 & 792 & 0.01 & 63.8 & 0.20 & 3.23 & 5.61 & 1.48 & 26.9 & 8.14 & 93.3 & 33.9 & 151 & 33.2 & 314 & 58.2 \\
\hline 462 & 9 & 3154 & 22 & 1 & 0.28 & 183 & 196.9 & 2.02 & 92 & 82 & 0.88 & 46 & 5.56 & 692 & 1.60 & 573 & 0.01 & 18.6 & 0.06 & 1.21 & 3.55 & 0.76 & 20.1 & 6.56 & 74.5 & 27.5 & 116 & 25.0 & 238 & 40.8 \\
\hline 652 & z 25 & 3350 & 27 & 1 & 0.53 & 1254 & 141.1 & 3.05 & 57 & 17 & 0.30 & 47 & 5.67 & 693 & 0.13 & 334 & 0.00 & 7.44 & 0.06 & 1.03 & 2.25 & 0.82 & 9.94 & 3.25 & 38.1 & 14.6 & 66.2 & 14.9 & 146 & 30.3 \\
\hline
\end{tabular}




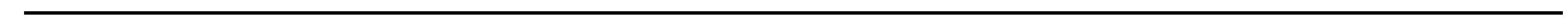






$$
\longrightarrow
$$

